UNIVERSIDAD NACIONAL DE LA PLATA

FACULTAD DE CIENCIAS EXACTAS

DEPARTAMENTO DE CIENCIAS BIOLÓGICAS

\title{
PESQUISA NEONATAL DE \\ ENFERMEDADES CONGÉNITAS
}

TESIS DOCTORAL

GUSTAVO JC BORRAJO 



\section{PESQUISA NEONATAL DE ENFERMEDADES CONGÉNITAS}

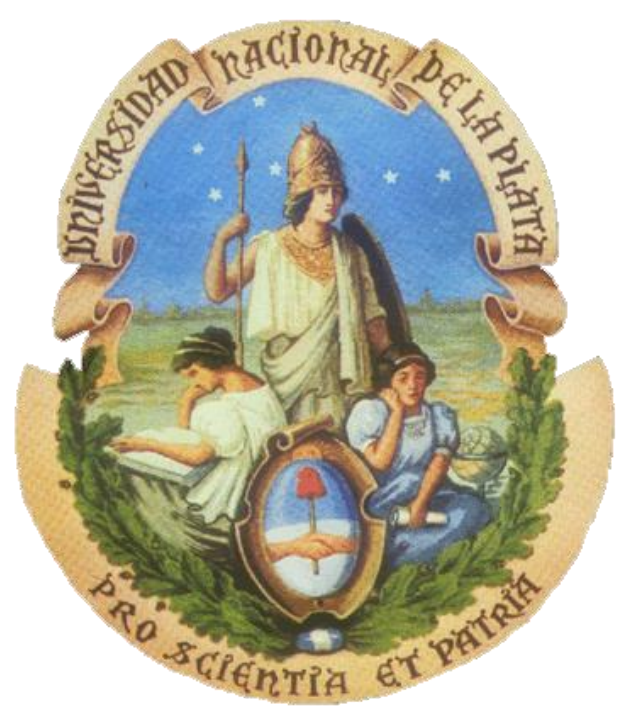

GUSTAVO JC BORRAJO

2011

UNIVERSIDAD NACIONAL DE LA PLATA

FACULTAD DE CIENCIAS EXACTAS

DEPARTAMENTO DE CIENCIAS BIOLÓGICAS 
El presente trabajo de tesis para optar al grado de Doctor en Ciencias Bioquímicas de la Facultad de Ciencias Exactas, fue realizado en la Cátedra de Bioquímica Patológica del Departamento de Ciencias Biológicas de la Facultad de Ciencias Exactas de la Universidad Nacional de La Plata y en el Laboratorio de Detección de Errores Congénitos de la Fundación Bioquímica Argentina, bajo la dirección de la Prof. Dra. Susana B. Etcheverry.

Mayo de 2011. 
A Griselda,

por tanto sacrificio silencioso

sin el cual nunca hubiera podido

lograr mi desarrollo y crecimiento

profesional. 


\section{AGRADECIMIENTOS}

- A mi directora, Prof. Dra. Susana B. Etcheverry,

por su apoyo, respaldo y soporte incondicional sin los cuales no hubiera podido dar mis primeros pasos experimentales en la Cátedra de Bioquímica Patológica e iniciarme en la Pesquisa Neonatal,

por haber entendido, y fundamentalmente respetado, mis tiempos, obligaciones y necesidades familiares y laborales pero sin desistir en su convencimiento de que este emprendimiento podía y debía concretarse en una realidad,

por enseñarme a valorar la importancia y magnitud de mi trabajo, y por alentarme aún desde su silencio para continuar adelante con este proyecto,

por brindarme su confianza y amistad permanente, y por tener siempre un consejo y una palabra justa y objetiva para cada situación de la vida.

- Al Dr. Helvio L. Galdeano (ex-Profesor Titular de la Cátedra de Bioquímica Patológica),

por haberme transmitido su interés por la Pesquisa Neonatal de Fenilcetonuria en tiempos en que en nuestro país era un área casi inexplorada,

por haberme brindado los medios para comenzar a trabajar en este tema abriéndome las puertas de la Cátedra de Bioquímica Patológica cuando apenas tenía algunos días de recibido,

por ser el responsable de que la Pesquisa Neonatal sea mi especialidad profesional.

- A Norberto V. Cabutti (ex-Presidente de la Federación Bioquímica de la Provincia de Buenos Aires y ex-Presidente de la Fundación Bioquímica Argentina),

por su visión de la salud pública mucho más allá de lo que muchos podían ver, y por haber apostado a la Pesquisa Neonatal aún cuando en nuestro país las políticas de salud fijaban otro tipo de prioridades,

por haber confiado y creído que un Bioquímico joven con una corta trayectoria pero con muchas ganas, 
empeño y dedicación podía llevar a cabo la implementación de la Pesquisa Neonatal desde un ámbito estrictamente bioquímico, apostando a su crecimiento, expansión e integración con todo el equipo de salud,

por haberme con-

fiado la responsabilidad de ser la cabeza del proyecto.

- A la Facultad de Ciencias Exactas de la UNLP,

por enseñarme a pensar y a razonar, por inculcarme la necesidad de una superación permanente, y por brindarme la posibilidad de tener una formación profesional y científica con un enorme bagaje de herramientas y potencialidades, a las cuales pude explotar y utilizar a medida que fui alcanzando mi madurez profesional,

por permitirme desarrollar mi tesis doctoral desde un lugar muy poco habitual como lo es el de la ciencia aplicada.

- A la Fundación Bioquímica Argentina,

por haberme brindado el ámbito apropiado y los medios necesarios para desarrollar mi tarea sin restricciones ni limitaciones cuando de evolución, crecimiento, calidad y excelencia se tratara,

por haberme dado la libertad de decidir y de fijar mis propios horizontes de trabajo confiando en todo aquello que yo mismo pudiera decidir a través del dictado de mi propio criterio,

por haberme permitido lograr mi crecimiento y proyección profesional.

- A Guillermo B. Bilder (Vice-Presidente de la Fundación Bioquímica Argentina), por haber sido un facilitador de mi tarea durante los años más importantes del proceso de expansión inicial del Laboratorio de la Fundación Bioquímica Argentina al haber confiado en mi conocimiento y criterio personal para la adquisición de tecnología e instrumental, dándome la posibilidad de disponer además de una libertad absoluta en la toma de decisiones, no sólo en lo que respecta a los aspectos técnicos sino también en la elección de los recursos humanos que conformarían mi equipo de trabajo. 
- A Fabián R. Gómez (Bioquímico y Coordinador de Area del Laboratorio de Detección de Errores Congénitos),

por su generosidad para hacerse partícipe activo del proyecto de Pesquisa Neonatal a través de su conocimiento y criterio, por sus dotes de “artesano del laboratorio” puestas al servicio de la resolución de problemas, y por su enorme creatividad para idear alternativas más eficientes de trabajo.

- A Luis G. Pistaccio (ex-Bioquímico y ex-Coordinador de Area del Laboratorio de Detección de Errores Congénitos),

por la importancia que tuvo su actividad de acompañamiento durante los años en que fue parte de este proyecto en lo que respecta a la actualización y búsqueda de nuevos conocimientos, y por estar siempre dispuesto a involucrarse activamente en cuanto nuevo proyecto de trabajo fuera propuesto.

- A Marcelo, Patricia y Mariela, Bioquímicos del Laboratorio de Detección de Errores Congénitos, por acompañarme desde hace muchos años con su disposición y dedicación desde la ardua labor del trabajo diario.

- A Delia, Natalia y Marcela, Secretarias del Laboratorio de Detección de Errores Congénitos, por el soporte administrativo tan necesario para el correcto funcionamiento del Laboratorio.

- A Norma, Jorgelina, Zulma y Perla, miembros de la Comisión Coordinadora del Prodytec, por tantos años de lucha compartida en pos de poder contar con un Programa de Pesquisa Neonatal con todas las letras tal como desde hace muchos años lo es el Prodytec.

- A Ana, Renata, Ana Laura y Juan Manuel, por el aguante que me hacen desde la Cátedra de Bioquímica Patológica.

- A la Dra. Nilda Fink, por haberme alentado a proseguir con mi trabajo de Tesis en momentos en los cuales todo parecía mostrar un panorama muy complicado.

- A Paula, Agus, Pachu, Fede y Vicky (mis hijos), por todo el tiempo que dejé de dedicarles en pos de realizar mis actividades profesionales. 
- A Nina y a Juan (mis viejos), quienes dieron todo para que pudiera alcanzar mi título de Bioquímico, y quienes seguramente, de haber estado presentes, estarían sumamente orgullosos de que haya concretado este logro. 
- INTRODUCCIÓN. . . . . . . . . . . . . . . . . . . . . . . . . . . . . 1

- Pesquisa Neonatal. ...................................... 3

- Definición y objetivos................................ 3

- Organización, estructura y componentes .................... 4

- Criterios de selección de enfermedades congénitas a pesquisar . . . . . .6 6

- Historia de la Pesquisa Neonatal. ........................... 9

- Cronología....................................... 10

- Nuevos criterios de selección de enfermedades a pesquisar .......... 15

- Futuro de la Pesquisa Neonatal . . . . . . . . . . . . . . . . . . . . . . . . . . 19

- Pesquisa Neonatal de Inmunodeficiencia Combinada Severa ...........19

- Pesquisa Neonatal de Enfermedades de Almacenamiento Lisosomal . . . 20

- Pesquisa Neonatal de Enfermedad Cardíaca Congénita Cianótica Crítica 24

- Pesquisa Genética empleando Microarreglos de ADN o "Biochips". . . . . 25

- Bibliografía.......................................27

- OBJETIVOS........................................ 37

- Objetivo General ...................................... 39

- Objetivos Específicos................................... 39

\section{SECCIÓN I: ASPECTOS GENERALES DE LA PESQUISA NEONATAL}

- CAPÍtUlO 1: Organización de un Programa de Pesquisa Neonatal. ...... 43

- Diagnóstico de situación. ................................. 45

- Introducción. .................................... 45

- Aspectos a considerar en la definición del diagnóstico de situación . . . 46

$\checkmark$ Legislación .................................... 46

$\checkmark$ Recursos humanos ................................47 47

$\checkmark$ Educación y difusión ........................... 48

$\checkmark$ Efectores para la recolección de muestras de sangre. .......... 49 
$\checkmark$ Características de las muestras de sangre. . . . . . . . . . . . . . 50

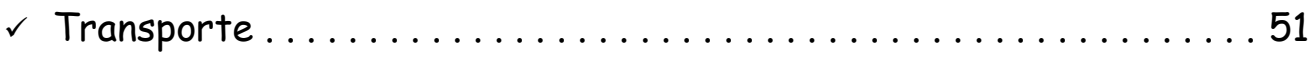

$\checkmark$ Laboratorios de pesquisa y confirmación. . . . . . . . . . . . 52

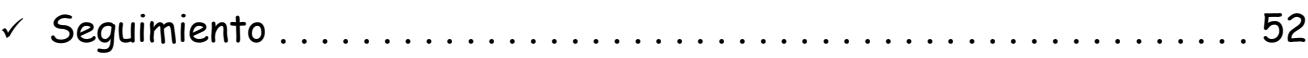

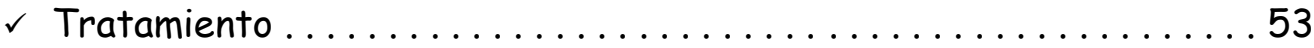

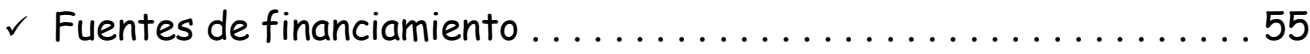

$\checkmark$ Expansión potencial. . . ...................... 57

- Organización del Programa de Diagnóstico y Tratamiento de Enfermedades Congénitas del Ministerio de Salud de la Provincia de Buenos Aires. . 58 - Introducción. . . . . . . . . . . . . . . . . . . . . . . 58

- Planificación e implementación . . . . . . . . . . . . . . . . . . . . 59

$\checkmark$ Acciones de implementación .......................59

$\checkmark$ Estructura funcional del Prodytec. . . . . . . . . . . . . . . . .60

$\checkmark$ Equipo interdisciplinario de salud. . . . . . . . . . . 62

$\checkmark$ Normas y pautas de funcionamiento . . . . . . . . . . . . 63

$\checkmark$ Estrategia de implementación. ....................64

- Alcance y resultados . . . . . . . . . . . . . . . . . . . . . . . . . 69

- Bibliografía ................................... 75

- CAPÍTULO 2: Organización y Funcionamiento de un Laboratorio de

Pesquisa Neonatal . . . . . . . . . . . . . . . 79

- Introducción.................................. 81

- Recursos humanos............................ 82

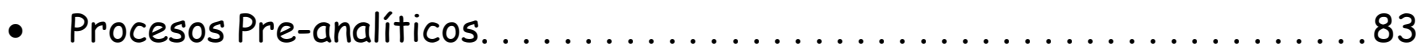

- Procesos Analíticos . . . . . . . . . . . . . . . . . . . . 84

- Muestras de sangre. . . . . . . . . . . . . . . . . . . . . . . . 85

$\checkmark$ Tipos de muestras de sangre. . . . . . . . . . . . . . 85

$\checkmark$ Sistemas de recolección de muestras de sangre . . . . . . . . . . . 87

$\checkmark$ Soportes de recolección de muestras. . . . . . . . . . . . 88

$\checkmark$ Tiempo de recolección de muestras. . . . . . . . . . . . . . . . . . 90

$\checkmark$ Información requerida del recién nacido ................ 98 
$\checkmark$ Técnica de recolección de muestras . . . . . . . . . . . . . . . . . . . . . 100

$\checkmark$ Condiciones de secado de muestras . . . . . . . . . . . . . . . . . 104

$\checkmark$ Condiciones de envío y almacenamiento de muestras. . . . . . . . . . 106

$\checkmark$ Muestras satisfactorias e insatisfactorias. . . . . . . . . . . . . 107

- Métodos. . . . . . . . . . . . . . . . . . . . . . . . . . . . . . . . . . . 110

- Valores de corte. . . ......................... 112

$\checkmark$ Criterios de definición de valores de corte . . . . . . . . . . . . . 113

$\checkmark$ Influencia de la imprecisión y de la inexactitud de los métodos de medida sobre los valores de corte . . . . . . . . . . . . . . . . 116

$\checkmark$ Premisas para la definición de los valores de corte . . . . . . . . . . 119

- Control de Calidad. . . . . . . . . . . . . . . . . . . . . . . . . . . . . . . 121

- Procesos Post-analíticos. . . . . . . . . . . . . . . . . . . . . . . . 121

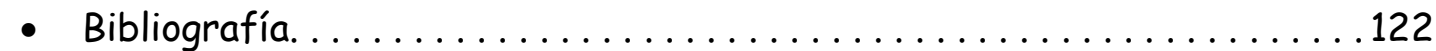

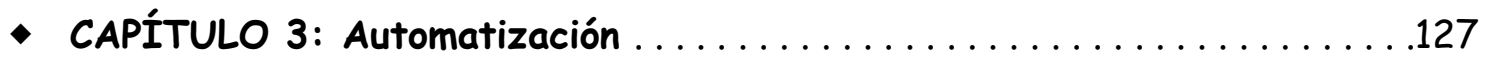

- Introducción. . . . . . . . . . . . . . . . . . . . . . . . . . . . . . . . . . 129

- Objetivos y beneficios. . . . . . . . . . . . . . . . . . . . . . . . 129

- Experiencia en la Fundación Bioquímica Argentina . . . . . . . . . . . . . . . 130

- Introducción. ................................. 130

- Procesos Pre-analíticos. . . . . . . . . . . . . . . . . . . . . . . . . . . . 131

- Procesos Analíticos. . . . . . . . . . . . . . . . . . . . . . . 147

- Procesos Post-analíticos . . . . . . . . . . . . . . . . . . . . . . . . 163

- Bibliografía................................. 178

- CAPÍtUlo 4: Validación de Métodos ........................ . 179

- Introducción. . . . . . . . . . . . . . . . . . . . . . . . . . . . 181

- Validación de métodos. . . . . . . . . . . . . . . . . . . . . . . . . . 181

- Parámetros analíticos ... . . . . . . . . . . . . . . . . . . . 183

- Efecto de la exactitud y la precisión sobre los resultados de las mediciones. . . . . . . . . . . . . . . . . . . . . . . . . . . . . . 187

- Parámetros diagnósticos . . . . . . . . . . . . . . . . . . . . . . . 192 
- Parámetros operativos. ... . . . . . . . . . . . . . . . . . . . . 194

- Parámetros de diseño . . . . . . . . . . . . . . . . . . . . . . . . . 196

- Parámetros de costos . . . . . . . . . . . . . . . . . . . . . . . . . . . . . . . . 199

- Herramientas para la validación de métodos. . . . . . . . . . . . . . . . . 198

- Herramientas para la validación de parámetros analíticos. . . . . . . . . 198

- Herramientas para la validación de parámetros diagnósticos . . . . . . . 202

- Problemas detectados a través del procedimiento de Validación de

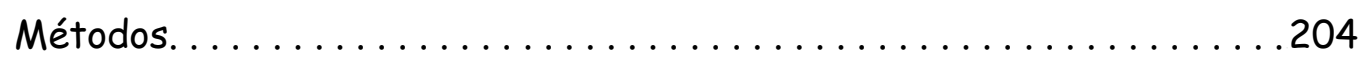

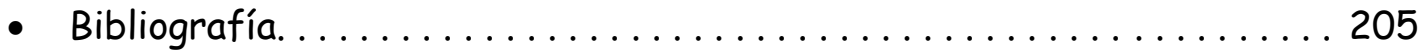

\section{- CAPÍTULO 5: Control de Calidad Interno y Evaluación Externa de Cali-} dad Aplicados a Pesquisa Neonatal ... . . . . . . . . . 209

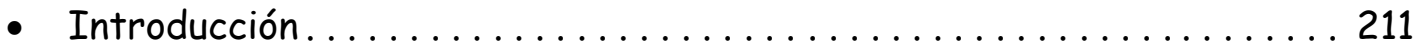

- Variables propias y específicas de los Laboratorios de Pesquisa

Neonatal. . . . . . . . . . . . . . . . . . . . . . . . . .212

- Matriz y soporte de las muestras. . . . . . . . . . . . . . . . . . . 212

- Técnica, tiempos y condiciones de recolección de muestras . . . . . . . 214

- Condiciones de secado, transporte y conservación de muestras . . . . . . 214

- Características intrínsecas de las muestras . . . . . . . . . . . . . 2214

- Zona de corte o "puncheo" ...........................218

- Elusión de las muestras . . . . . . . . . . . . . . . . . . . . . . . . . 2221

- Mayor imprecisión relativa en los métodos de medida . . . . . . . . . . . 2222

- Limitada disponibilidad de materiales de control . . . . . . . . . . . . 222

- Características de los materiales de control empleados en la EEC. . . . 222

- Control de Calidad Interno . . . . . . . . . . . . . . . . . . . . . . 223

- Introducción. ... . . . . . . . . . . . . . . . . . . . . . . . . . . 2223

- Implementación de un sistema de Control de Calidad Interno en el Laboratorio de Pesquisa Neonatal . . . . . . . . . . . . . . . . . . . . . . . 2224

$\checkmark$ Fuentes de materiales de control ...................224

$\checkmark$ Características de los materiales de control. . . . . . . . . . . . . . 225

$\checkmark$ Niveles de los analitos. . . . . . . . . . . . . . . . . 226 


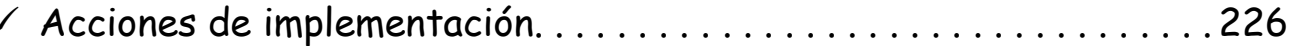

$\checkmark$ Seguimiento diario del control de calidad interno. . . . . . . . . 227

- Evaluación Externa de Calidad. . . . . . . . . . . . . . . . . . 232

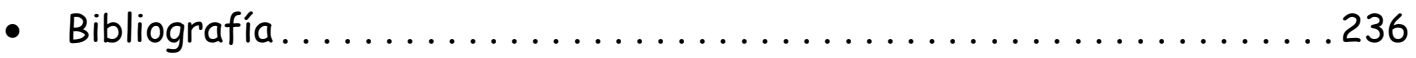

- CAPÍTULO 6: Desarrollo e Implementación de un Programa de Evaluación Externa de Calidad para Pesquisa Neonatal en Latinoamérica ........................... 241

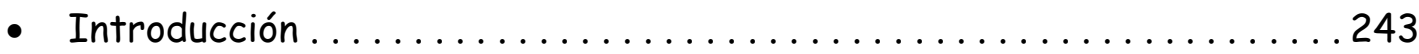

- Organización, características y estrategia de implementación. . . . . . . 244

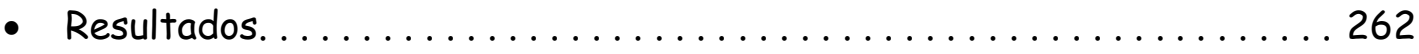

- Laboratorios inscriptos y participación. . . . . . . . . . . . . . . 263

- Distribución de Laboratorios según el analito . . . . . . . . . . . . 268

- Distribución de Laboratorios por métodos. . . . . . . . . . . . . . . . . . . 270

- Aceptabilidad Clínica ............................. 272

- Falsos resultados . . . . . . . . . . . . . . . . . . . . . . . . . . . . . 275

- Conclusiones .................................. 291

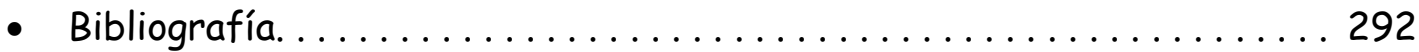

- Anexo 1: Preparación de materiales de control de sangre entera impregnada en papel de filtro (DBS) . . . . . . . . . . . . . 293

- Materiales necesarios......................... 293

- Procedimiento de preparación ................... 295

- Comentarios acerca de la preparación. . . . . . . . . . . . . 299

- CAPÍtUlO 7: Desarrollo de un Sistema Integral de Control de Calidad para un Programa de Pesquisa Neonatal. . . . . . . . . . . 301

- Introducción. .............................. 303

- Elementos a considerar en el diseño de un Sistema Integral de Control de Calidad para PN . . . . . . . . . . . . . . . . . . . . 305

- Efectores del Sistema de Pesquisa Neonatal . . . . . . . . . . . . . . . 305

- Indices o indicadores de desempeño . . . . . . . . . . . . . . . . . . 309 
- Planificación y desarrollo de un Sistema Integral de Control de Calidad para el Programa de Detección de Errores Congénitos de la Fundación Bioquímica Argentina . . . . . . . . . . . . . . . . . . . . . . . . . 313

- Bibliografía

\section{SECCIÓN II: RESULTADOS DE LA IMPLEMENTACIÓN DE LA PESQUISA NEONATAL DE ENFERMEDADES CONGÉNITAS.}

- CAPÍTULO 8: Pesquisa Neonatal de Fenilcetonuria.

- Introducción. . . . . . . . . . . . . . . . . . . . . . . . . . . . . . . 329

- Pesquisa Neonatal. .............................. 332

- Métodos .................................... 332

- Condiciones para la recolección de muestras . . . . . . . . . . . . . . 336

- Control de calidad. . . . . . . . . . . . . . . . . . . . . . . . 336

- Valores de corte . . . . . . . . . . . . . . . . . . . . . . 337

- Algoritmo de trabajo ........................... 338

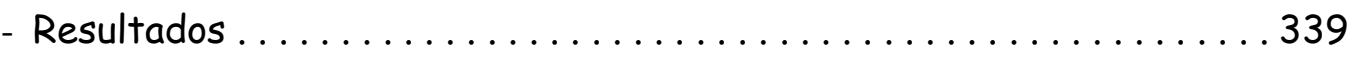

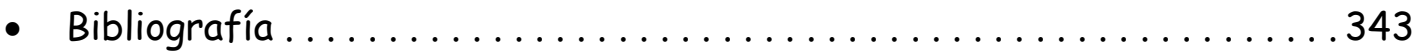

- Anexo 2: Método de Inhibición Bacteriana de Guthrie para la medida de

Fenilalanina en DBS, de desarrollo propio. . . . . . . . . 345

- Preparación de reactivos . . . . . . . . . . . . . . . 345

- Protocolo de ensayo para placas de Petri . . . . . . . . . . 345

- Protocolo de ensayo para placas de $24 \mathrm{~cm} \times 24 \mathrm{~cm} \ldots \ldots . .346$

- Anexo 3: Método Fluorométrico para la medida de Fenilalanina en DBS,

de desarrollo propio . . . . . . . . . . . . . . . . . 349

- Preparación de reactivos . . . . . . . . . . . . . . . . . . . . 349

- Protocolo de ensayo ....................... 349

- CAPÍtUlo 9: Pesquisa Neonatal de Hipotiroidismo Congénito . . . . . . . . 351

- Introducción. .................................... 353 
- Pesquisa Neonatal. . . . . . . . . . . . . . . . . . . . . . . . . . . 356

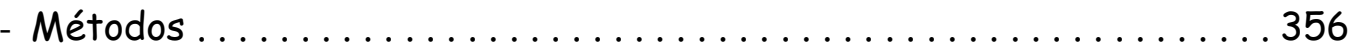

- Condiciones para la recolección de muestras . . . . . . . . . . . . . . . . 359

- Control de calidad. . . . . . . . . . . . . . . . . . . . . . . 359

- Valores de corte ... . . . . . . . . . . . . . . . . . . . . . . . . . . . 360

- Algoritmo de trabajo ......................... 362

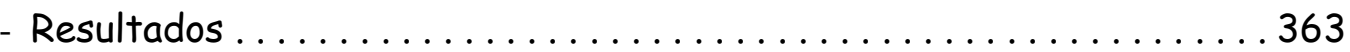

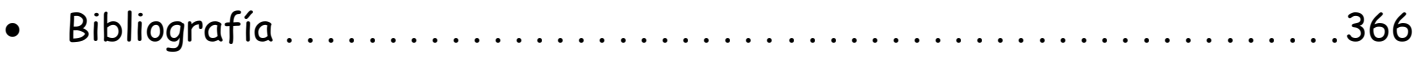

- CAPÍtUlO 10: Pesquisa Neonatal de Fibrosis Quística . . . . . . . . . . . . 369

- Introducción. . . . . . . . . . . . . . . . . . . . . . . . . 371

- Pesquisa Neonatal. . . . . . . . . . . . . . . . . . . . . . . . . . . . . . 374

- Estrategia de trabajo. . . . . . . . . . . . . . . . . . . . 374

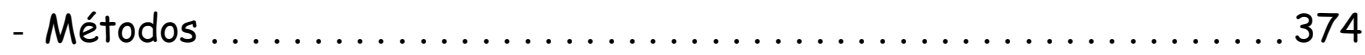

- Condiciones para la recolección de muestras . . . . . . . . . . . . . . 376

- Control de calidad. . . . . . . . . . . . . . . . . . . . . . 376

- Valores de corte . . . . . . . . . . . . . . . . . . . . . . . . . . . . . . . 377

- Algoritmo de trabajo . . . . . . . . . . . . . . . . . . . . . . . 379

- Resultados ... . . . . . . . . . . . . . . . . . . . . . . . . . . . . . . . . . 379

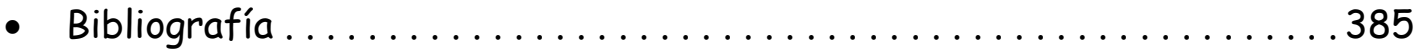

- CAPÍtUlo 11: Pesquisa Neonatal de Galactosemia . . . . . . . . . . . . . . . 387

- Introducción. . . . . . . . . . . . . . . . . . . . . . . . . . . . . . 389

- Pesquisa Neonatal. . . . . . . . . . . . . . . . . . . . . . . . . . . . . . . . 392

- Métodos ....................................... 392

- Condiciones para la recolección de muestras . . . . . . . . . . . . . . . . . 394

- Control de calidad. . . . . . . . . . . . . . . . . . . . . . . . . . 394

- Valores de corte ... . . . . . . . . . . . . . . . . . . . . . . 395

- Algoritmo de trabajo ........................... 396

- Resultados ............. . . . . . . . . . . . . . . . . . . . . 397

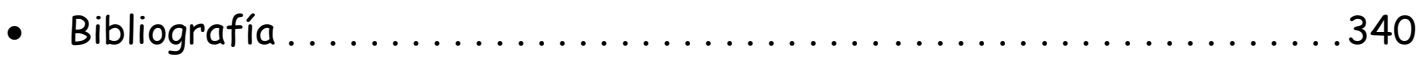


- Anexo 4: Método Enzimático - Fluorométrico para la medida de Galactosa en DBS, de desarrollo propio . . . . . . . . . . . 405 - Preparación de reactivos . . . . . . . . . . . . . . . . . 405

- Protocolo de ensayo. . . . . . . . . . . . . . . . . . . 4407

- CAPÍtUlO 12: Pesquisa Neonatal de Hiperplasia Suprarrenal Congénita 409

- Introducción. .............................. 411

- Pesquisa Neonatal. . . . . . . . . . . . . . . . . . . . . . . . . . . . . 414

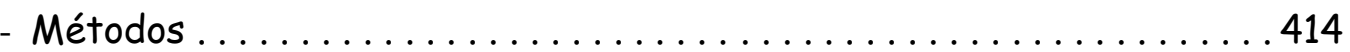

- Condiciones para la recolección de muestras . . . . . . . . . . . . . 415

- Control de calidad. . . . . . . . . . . . . . . . . . . . . . 416

- Valores de corte . . . . . . . . . . . . . . . . . . . . . . . . 416

- Algoritmo de trabajo . . . . . . . . . . . . . . . . . . . . 422

- Resultados .................................. 423

- Bibliografía .................................4428

- CAPÍtUlO 13: Pesquisa Neonatal de Deficiencia de Biotinidasa . . . . . . 431

- Introducción. . . . . . . . . . . . . . . . . . . . . . . . . . . 433

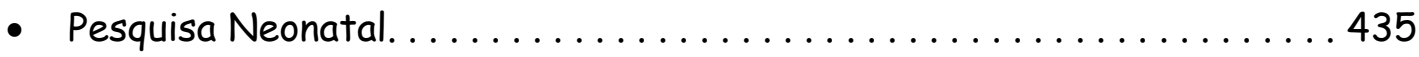

- Métodos ..................................... 435

- Condiciones para la recolección de muestras . . . . . . . . . . . . . 438

- Control de calidad. . . . . . . . . . . . . . . . . . . . . . . . 438

- Valores de corte . . . . . . . . . . . . . . . . . . . . . . . . 438

- Algoritmo de trabajo . . . . . . . . . . . . . . . . . . . . . . . . . . 439

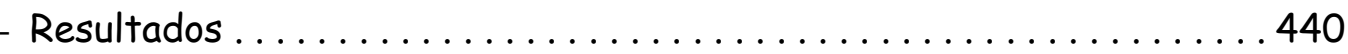

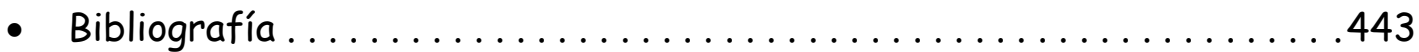

- Anexo 5: Método Colorimétrico - Cuantitativo para la medida de Biotinidasa en DBS de desarrollo propio, empleando calibradores líquidos. . ....................... 445 - Preparación de reactivos . . . . . . . . . . . . . . . . . 4445

- Protocolo de ensayo . . . . . . . . . . . . . . . . . . 446 
- Anexo 6: Método Colorimétrico - Cuantitativo para la medida de Biotinidasa en DBS de desarrollo propio, empleando calibradores en DBS.

- Preparación de reactivos.

- Protocolo de ensayo

- Anexo 7: Calibradores de Biotinidasa en sangre entera, impregnados en papel de filtro ..................... 451

- Preparación de reactivos . . . . . . . . . . . . . . . . 451

- Protocolo de ensayo . . . . . . . . . . . . . . . . . . . . . 452

- CAPÍtUlO 14: Pesquisa Neonatal de Enfermedad de Orina de Jarabe de Arce

- Introducción.

- Pesquisa Neonatal. 460

- Métodos 460

- Condiciones para la recolección de muestras .461

- Control de calidad. 462

- Valores de corte. 462

- Algoritmo de trabajo 463

- Resultados 463

- Bibliografía .468

- Anexo 8: Método Enzimático - Fluorométrico para la medida de BCAA en DBS, de desarrollo propio 469

- Preparación de reactivos 469

- Protocolo de ensayo. .470

- CONCLUSIONES.

- Conclusiones. 
INTRODUCCIÓN 



\section{- PESQUisa NEONATAL}

\section{Definición y objetivos}

La Pesquisa Neonatal (PN), conocida también como screening, tamizaje, cribado, triagem o dépistage, es un sistema interdisciplinario de la Salud Pública diseñado para llevar a cabo la búsqueda masiva y universal, y el posterior tratamiento precoz de una serie de enfermedades congénitas potencialmente catastróficas y difíciles de reconocer clínicamente sobre la población neonatal (1-3). Dicha pesquisa está dirigida fundamentalmente a aquellas enfermedades que carecen de síntomas en el período neonatal, que producen daño neurológico severo e irreversible o, eventualmente la muerte del recién nacido (RN) durante los primeros días de vida, y que poseen un tratamiento efectivo cuando el mismo es implementado en forma precoz (1).

La ausencia de manifestaciones clínicas durante el período neonatal impide que el pediatra o neonatólogo que asiste al RN pueda establecer un diagnóstico en base a los síntomas, razón por la cual necesariamente debe recurrirse a la determinación de marcadores bioquímicos en sangre a efectos de hacer posible la detección precoz y, de este modo, implementar el tratamiento adecuado en forma oportuna. En consecuencia, el objetivo de la PN consiste en identificar y tratar un grupo de enfermedades congénitas seleccionadas a efectos de reducir o eliminar la morbilidad, mortalidad $y / 0$ discapacidad asociadas con los desórdenes investigados (3), motivo por el cual es considerada uno de los avances más importantes de la medicina preventiva moderna (1).

Dentro de este contexto, el Laboratorio de Pesquisa desempeña un rol fundamental puesto que es el responsable de tamizar a toda la población de RN a efectos de separar a los neonatos normales de aquellos presuntamente afectados (4). Sin embargo, se debe destacar que la PN no consiste simplemente en efectuar una prueba de Laboratorio en forma aislada y que un resultado anormal en una prueba de pesquisa no es equivalente a diagnóstico $(2,4,5)$. De hecho, ha sido claramente establecido que la PN no tiene por objetivo implementar acciones terapéuticas sobre la simple base de un resultado positivo en una prueba de pesquisa (6), razón por la cual todo RN con un resultado anormal deberá ser sometido a una secuencia de acciones diagnósticas en concordancia con los algoritmos de trabajo establecidos en cada 
Programa, a través de las cuales será posible confirmar o descartar la patología $(2,4)$.

\section{Organización, estructura y componentes}

En virtud de lo antes expuesto, y con la finalidad de asegurar el éxito de la PN, la misma debe ejecutarse bajo la forma de Programas organizados, geográficamente regionalizados y funcionalmente centralizados $(2,7,8)$. Esto significa que las distintas actividades del sistema de PN deberán estar perfectamente definidas, planificadas y sistematizadas como parte de un Programa de Atención Preventiva, el cual presentará un alcance regional -ya sea un país, una provincia o bien un conjunto de provincias o ciudades-, que funcionará en forma centralizada en la mayor parte de las actividades específicas que conforman la estructura del Programa, y cuyos límites de acción quedarán definidos en base al número anual de RN de dicha región, a la superficie que comprenda la misma, a sus características geográficas, al grado de urbanización, a las políticas de salud vigentes y al presupuesto con que se cuente para su ejecución.

En cuanto a la estructura del Programa, la misma debe planificarse sobre la base de los seis componentes esenciales de la PN (3) que son presentados en la Tabla 1, y su conformación debe ser tal que permita lograr una integración coordinada y dinámica entre sus distintos niveles de ejecución, con lo cual será posible asegurar que los mismos sean ejecutados en forma oportuna y apropiada por parte de efectores específicos.

Tabla 1. Componentes del Sistema de Pesquisa Neonatal

- Educación: personal de salud, padres, población en general y políticos.

- Pesquisa: recolección, transporte y análisis de las muestras de sangre

- Seguimiento: localización inmediata, seguimiento y derivación a centros especializados de aquellos RN con pruebas de pesquisa positivas.

- Diagnóstico: evaluación clínica y bioquímica de RN con pruebas positivas a efectos de realizar un diagnóstico definitivo o de descartar el mismo.

- Tratamiento: planificación inmediata en el corto plazo e implementación de la terapia a largo plazo.

- Evaluación: validación de los procedimientos de análisis, evaluación de la eficiencia del seguimiento, de las intervenciones terapéuticas y del beneficio recibido por el paciente, la familia y la sociedad. 
Un concepto importante para destacar es que estos componentes no constituyen compartimientos estancos e independientes, sino que en la práctica están fuertemente vinculados unos con otros (Figura 1), observándose inclusive un cierto grado de simultaneidad de ocurrencia entre los mismos, lo cual determina que en los hechos exista una superposición temporal entre las acciones de uno y otro (3).

Por otra parte, y si bien en la Figura 1 no ha sido representado, la Educación resulta ser un componente de características aún más abarcativas que la Evaluación, englobando de manera completa al resto de los componentes (9).

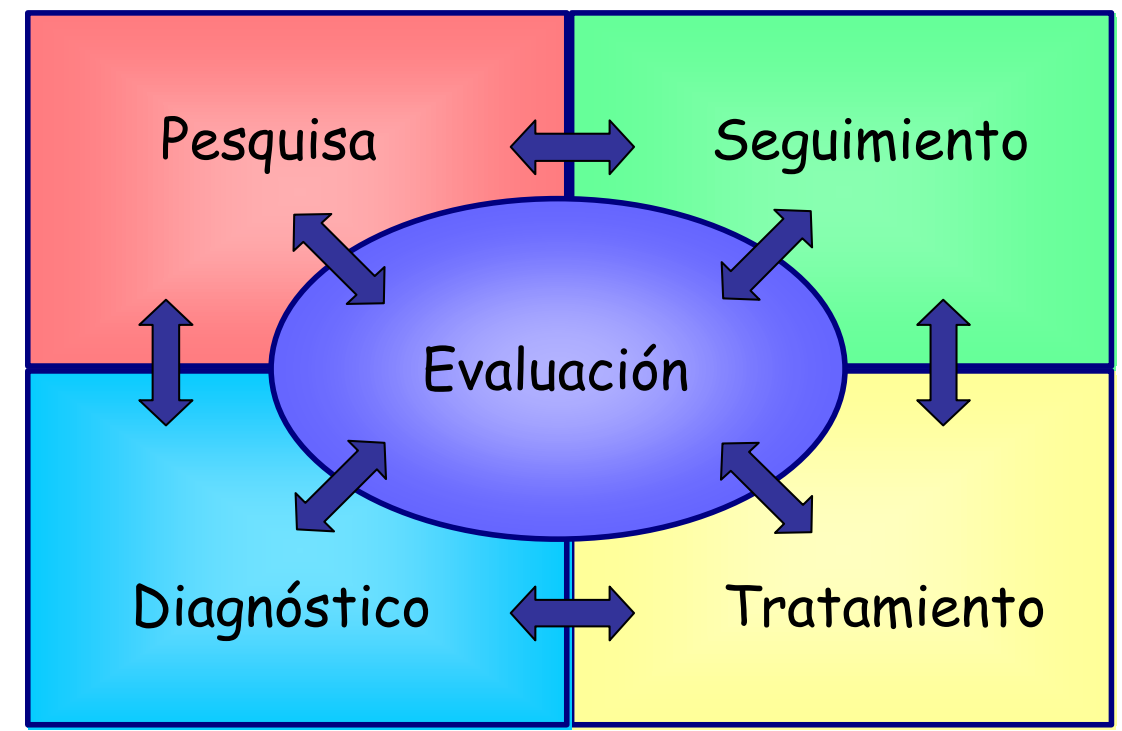

Figura 1. Interrelación entre los componentes del Sistema de Pesquisa Neonatal.

Con respecto a los niveles de ejecución, los mismos pueden ser definidos como las unidades funcionales de los componentes antes mencionados. Dichos niveles de ejecución corresponden a cada una de las tareas específicas del Programa de PN y, tal como se visualiza en la Figura 2, pueden ser presentados como los eslabones de una cadena o secuencia de acciones.

Por último, se debe mencionar que por definición la PN forma parte de la Atención Primaria de la Salud Pública (2) y por lo tanto el acceso a este tipo de sistemas de detección es un derecho de todos los RN del mismo modo que ocurre, por ejemplo, con otros Programas de Acciones Preventivas como son los planes 
de vacunación. Por los motivos antes expuestos, es una obligación del Estado asegurar la implementación y el funcionamiento continuo y sistemático de los mismos bajo la forma de programas centralizados y regionalizados, lo cual permitirá alcanzar un máximo rendimiento y eficiencia, una adecuada optimización y aprovechamiento de los recursos humanos y económicos, y una significativa reducción en los costos $(2,8)$.

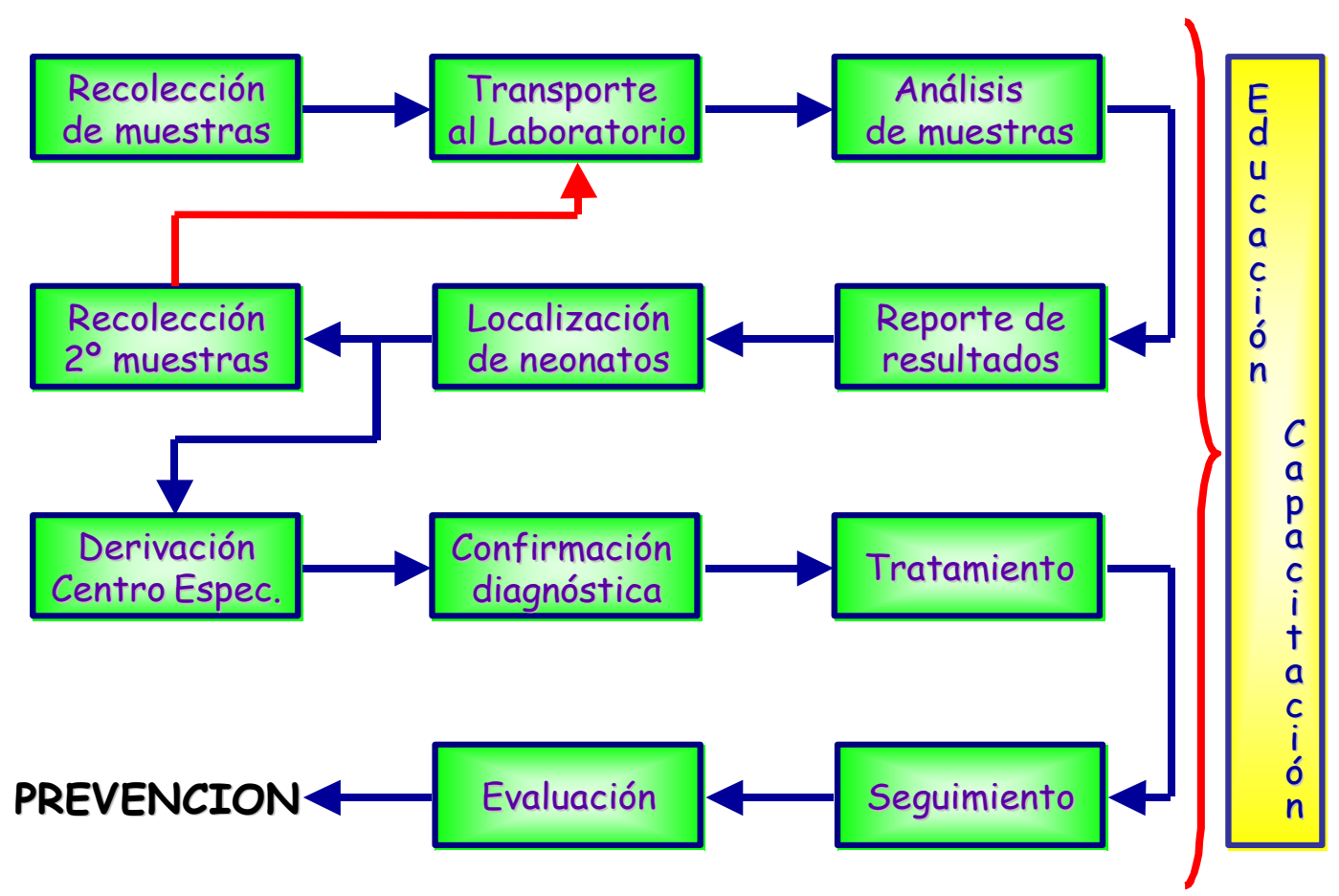

Figura 2. Niveles de ejecución de la Pesquisa Neonatal.

\section{Criterios de selección de enfermedades congénitas a pesquisar}

Un aspecto sumamente importante a tomar en consideración en los Programas de PN son los criterios utilizados para la selección de las enfermedades congénitas a pesquisar, puesto que la incorporación de una patología determinada a un Programa siempre debe estar sustentada por una relación costo/beneficio favorable que permita justificar la realización de la misma.

Con esta finalidad, Wilson y Jungner establecieron 10 criterios de selección (10) (Tabla 2), los cuales fueron adoptados en 1968 por la Organización Mundial de la Salud como criterios de aplicación universal. 
Tabla 2. Criterios de Wilson y Jungner para la selección de Enfermedades Congénitas a pesquisar

1. La enfermedad debe ser un importante problema de salud: debe causar daño grave e irreversible y presentar una incidencia significativa.

2. Debe existir un tratamiento aceptado para los pacientes con enfermedad reconocida, el cual debe ser efectivo ante su implementación precoz.

3. Debe disponerse de medios y recursos para el diagnóstico y el tratamiento.

4. Debe existir un estadío latente o sintomático temprano reconocible.

5. Deben existir exámenes o pruebas de pesquisa adecuados.

6. Los exámenes o pruebas deben ser aceptables para la población neonatal: inocuas, simples y no invasivas.

7. Debe existir un adecuado conocimiento de la historia natural de la enfermedad (curso clínico), incluyendo la transición desde el estadío de enfermedad latente al de enfermedad clínicamente declarada.

8. Deben existir políticas definidas acerca de quienes deben ser tratados como pacientes.

9. Los costos de detección, diagnóstico y tratamiento deben estar económicamente balanceados con respecto a los posibles costos de la atención médica completa.

10. La detección de casos debe ser un proceso continuo.

A partir de dichos criterios y con el transcurrir de los años, se fue experimentando la incorporación progresiva de nuevos desórdenes congénitos al grupo de patologías pesquisables, habiendo alcanzado en la actualidad más de 30 enfermedades que pueden ser agrupadas en dos categorías principales: el Panel Básico y el Panel Ampliado de PN.

Dentro del Panel Básico se incluyen aquellas enfermedades que pueden ser pesquisadas utilizando métodos clásicos de Laboratorio, entre los que se pueden citar los métodos bacteriológicos, químicos, enzimáticos o inmunológicos (RIA-IRMA, EIA, FEIA, DELFIA), y cuya pesquisa está ampliamente difundida a lo largo de todo el mundo desde hace alrededor de 2 décadas o más (Tabla 3); mientras que dentro del Panel Ampliado se incluye una gran variedad de enfermedades 
congénitas entre las cuales se puede citar a aquellas patologías en las que su investigación está indicada dependiendo expresamente de la composición étnica de la población en estudio -como por ejemplo en individuos de una etnia particular-, aquellas cuya incorporación a los Programas de PN se ha producido mucho más recientemente y que requieren la utilización de métodos altamente sofisticados y costosos como la Espectrometría de Masa en Tándem (EMT) o cuya detección no se realiza a través de la determinación de parámetros bioquímicos sino que se efectúa empleando otro tipo de marcadores como por ejemplo a través de la medida de potenciales evocados auditivos, y finalmente aquellas enfermedades que aún no han experimentado una implementación generalizada debido a que todavía existen cuestionamientos acerca de la efectividad y los beneficios de su detección y tratamiento precoz (Tabla 4).

\section{Tabla 3. Panel Básico de Pesquisa Neonatal}

- Hipotiroidismo Congénito $(H C)$.

- Fenilcetonuria (PKU).

- Galactosemia.

- Hiperplasia Suprarrenal Congénita (HSC).

- Deficiencia de Biotinidasa.

- Enfermedad de Orina de Jarabe de Arce (MSUD).

- Fibrosis Quística (FQ).

\section{Tabla 4. Panel Ampliado de Pesquisa Neonatal}

- Hemoglobinopatías (Hbpatías).

- Deficiencia de Glucosa 6 P-Deshidrogenasa (DG6PD).

- Otras Aminoacidopatías.

- Defectos de la Oxidación de Ácidos Grasos.

- Acidurias Orgánicas.

- Defectos de la Audición.

- Inmunodeficiencia Combinada Severa (SCID).

- Enfermedades de Almacenamiento Lisosomal.

- HIV, Toxoplasmosis, Chagas. 


\section{- Historia de la PESQUisa neONATAL}

La PN reconoce su origen en los EE.UU. a comienzos de la década del '60, cuando Robert Guthrie (Figura 3) materializó su genial idea de recolectar las muestras de sangre de RN en tarjetas de papel de filtro (DBS) y puso en práctica el Método de Inhibición Bacteriana (BIA) que él mismo desarrollara (11), para la detección neonatal de PKU empleando muestras de sangre seca. Estos avances introducidos por Robert Guthrie no solamente permitieron abrir una puerta de acceso al diagnóstico precoz, sino que también introdujeron una posibilidad inédita de prevenir el daño neurológico causado por la enfermedad, puesto que algunos años antes, Hoerst Bickel (Figura 4) en Alemania, había demostrado que la implementación precoz de una restricción dietaria de Phe era capaz de atenuar la expresión del cuadro clínico de la enfermedad en individuos no tratados $(12,13)$.

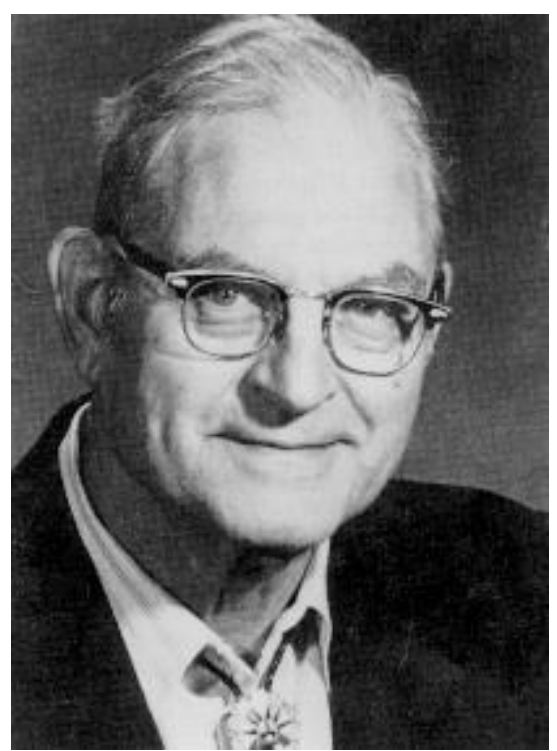

Figura 3. Robert Guthrie

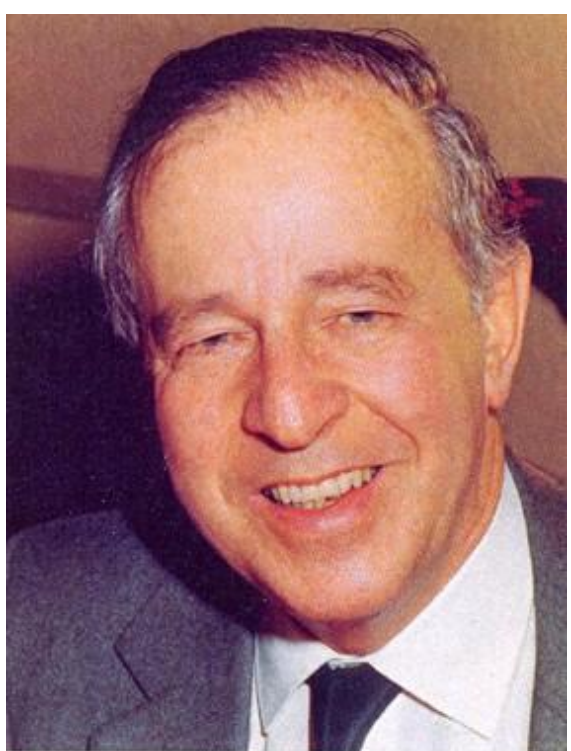

Figura 4. Hoerst Bickel

El hecho de que la PN surgiera estrechamente ligada a la PKU, un Error Congénito del Metabolismo (ECM) de Fenilalanina (Phe), sumado a la incorporación en años inmediatos posteriores de otros ECM al grupo de enfermedades pesquisadas, determinaron que en los inicios se hablara exclusivamente en términos de PN de ERRORES CONGENITOS DEL METABOLISMO, es decir de un sistema de prevención dirigido exclusivamente a la detección y tratamiento precoz de enfermedades congé- 
nitas genéticamente determinadas. Este concepto se modificó espontáneamente a mediados de la década del '70 a partir de la inclusión de la PN del HC, patología en la cual solamente el $5 \%$ de los casos reconoce una etiología relacionada con defectos metabólicos genéticamente determinados. Por esta razón, y a pesar de que la mayor parte de las enfermedades pesquisadas son precisamente ECM, de allí en más la PN comenzó a referirse como PN de ENFERMEDADES CONGENITAS. Adicionalmente, la inclusión en la década del '90 de algunas enfermedades infecciosas como parte de los paneles de pesquisa, fortaleció los argumentos de esta nueva denominación.

\section{Cronología de la Pesquisa Neonatal}

A continuación se describen cronológicamente los principales hechos ocurridos a lo largo de la historia de la PN:

\section{- 1960's:}

- A partir del desarrollo del sistema de recolección de muestras en papel de filtro y del método BIA para la medida de Phe (11) por parte de Robert Guthrie, se dio comienzo a la PN de ECM, específicamente de PKU.

- En las instancias iniciales, esta pesquisa se ejecutó en forma fragmentada, es decir que la misma se realizaba en cada Hospital para los RN de cada institución, y también en algunos Laboratorios privados en forma aislada. Sin embargo, a poco tiempo de iniciada la misma, comenzó a ponerse énfasis en la importancia de la centralización basándose en la observación de 3 hechos:

a) la estabilidad de la Phe en las muestras de sangre colectadas en papel de filtro, lo cual permitía el envío de las muestras por correo.

b) la hipótesis de que el desempeño de los laboratorios sería mejor cuando los casos fueran detectados en períodos de tiempo razonablemente cortos, dado que en caso contrario, la baja prevalencia de la enfermedad determinaría que dicha detección resultara extremadamente esporádica.

c) la comprobación de que la eficiencia del sistema de PN era mayor cuando se integraban las pruebas de pesquisa junto con el seguimiento, la confirmación y el tratamiento a largo plazo, a través de un sistema 
centralizado (14).

- Una vez consolidada la PN de PKU, el mismo Robert Guthrie introdujo otros métodos bacteriológicos, en este caso para la medida de Leucina (Leu), Metionina (Met), Tirosina (Tyr) y Galactosa (Gal), permitiendo así la implementación de la PN de MSUD, Homocistinuria, Tirosinemia y Galactosemia $(7,8,15)$.

- Al mismo tiempo que se concretó el desarrollo de estos nuevos ensayos, se comenzó a incursionar en el proceso de automatización con la finalidad de que, a través del mismo, fuera posible trabajar simultáneamente y de manera sencilla con dichos ensayos, promoviendo así la centralización y regionalización de los Laboratorios de pesquisa. En tal sentido, el primer paso fue dado a partir de la creación del primer Puncher automático -denominado Punch Indexer-por parte de Robert Phillips con el asesoramiento de Robert Guthrie $(7,8,15,16)$ (Figura 5).

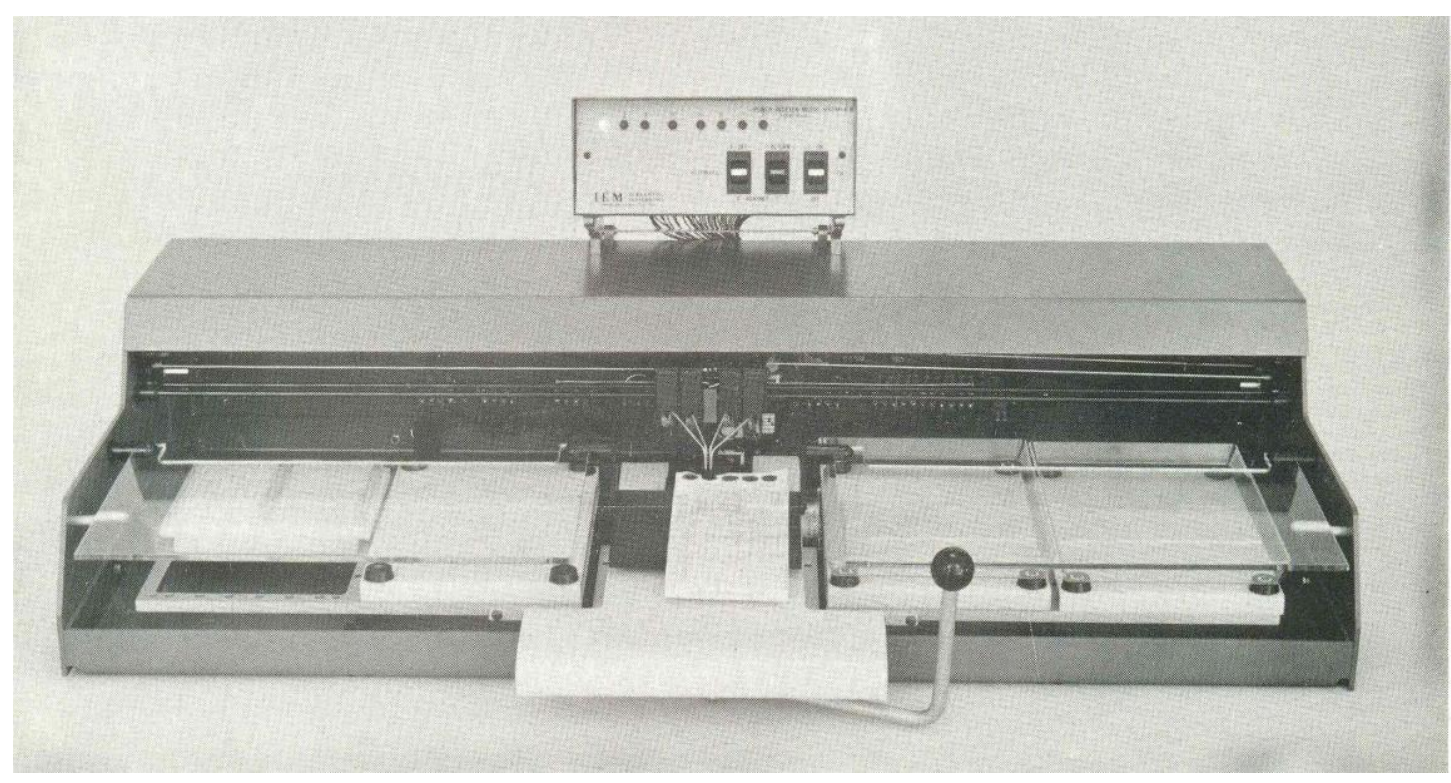

Figura 5. Puncher Automático Punch Indexer (Punch-Index Machine).

La utilización de este equipo automatizado hizo una muy importante contribución a la expansión de los Programas de PN por el hecho de que el mismo era capaz de cortar simultáneamente 4 discos a partir de una misma mancha de sangre y distribuirlos en las correspondientes placas de ensayo.

- Finalmente, durante los últimos años de esta década, en diferentes estados de 
los EE.UU., se trabajó intensamente en la formulación de proyectos de ley tendientes a definir la obligatoriedad de la realización de estas pruebas, lo cual resultó ser también un factor determinante por su contribución tanto a la expansión como al incremento en la cobertura experimentada por parte de los Programas de PN $(7,15)$.

\section{- 1970's:}

- Se desarrollaron nuevos métodos de pesquisa para utilizar sobre DBS basados en otras tecnologías como Fluorometría, Cromatografía en Capa Fina (TLC), RIA y EIA. Tanto la implementación de estas nuevas tecnologías en el Laboratorio de PN como la interpretación de sus resultados no significaron un problema operativo importante ni tampoco requirieron un entrenamiento especial del personal técnico, puesto que, en su gran mayoría, se trataba de tecnologías con las cuales dicho personal ya estaba familiarizado (14).

- Se mejoraron las tecnologías existentes, fundamentalmente en lo que respecta a su automatización, con lo cual los Laboratorios centralizados adquirieron la capacidad de analizar un gran número de muestras para diferentes analitos, realizando así una muy importante contribución a la expansión de los Programas de PN.

- A partir de las experiencias realizadas por Jean Dussault (Figura 6) en Québec - Canadá, se implementó la $P N$ de $H C$, un desorden al menos cinco veces más frecuente que la PKU, y capaz de causar retraso mental severo en ausencia de tratamiento. No obstante esto, previamente a la consolidación y aceptación definitiva de esta pesquisa se requirió la realización de pruebas piloto que demostraran fehacientemente su utilidad y que, además, se mejorara la sensibilidad y especifici-

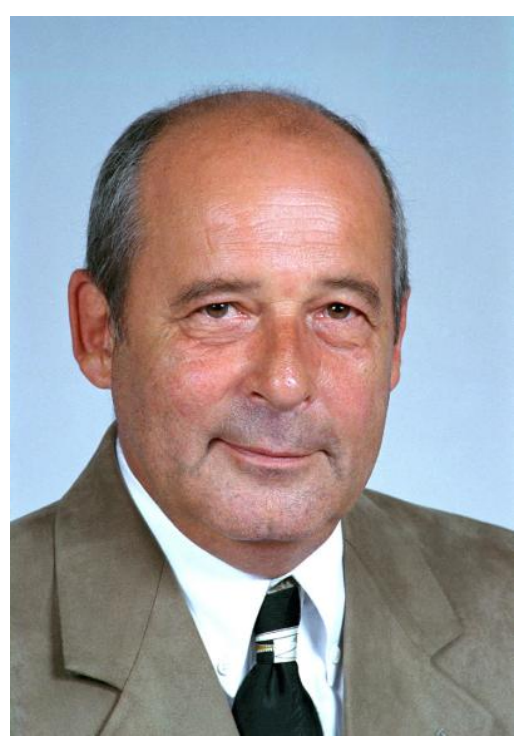

Figura 6. Jean Dussault dad de los sistemas de detección utilizados, a costos apropiados $(14,17-20)$. 
- Por último, en esta década se produjo también la expansión de la PN a otras enfermedades capaces de conducir a la muerte del RN como la Galactosemia, aunque ahora empleando un método Fluorométrico capaz de medir la actividad de una de las enzimas afectadas (21), la HSC (22) y las Hbpatías (23).

\section{- 1980's:}

- Se continuó con el proceso de automatización de los Laboratorios y se inició el proceso de informatización de los Programas de PN.

- Se demostró que el ADN presente en DBS era estable (24) y que, empleando técnicas de Biología Molecular, dicho ADN podía ser amplificado para la caracterización de algunos defectos moleculares (14).

- Se produjo la "universalización" de los Programas de PN de PKU e HC en países desarrollados, alcanzando coberturas cercanas al $100 \%$ de los RN.

\section{- 1990's:}

- Se produjo la incorporación del estudio de mutaciones específicas al algoritmo de pesquisa de algunas enfermedades como la FQ $(25,26)$, las Hbpatías $(26,27)$, la HSC (26) y la Deficiencia de Acil CoA Deshidrogenasa de Cadena Media (MCAD) (28), empleando para esto técnicas de Biología Molecular y DBS.

- Se incorporaron algunas enfermedades infecciosas como el HIV (29) y la Toxoplasmosis $(30,31)$, reafirmando el concepto de PN de ENFERMEDADES CONGÉNITAS.

- Se introdujo la EMT por parte de David Millington y Donald Chace $(32,33)$, permitiendo así la incorporación de los Defectos de Oxidación de Ácidos Grasos, Acidurias Orgánicas y algunas Aminoacidopatías a los paneles de PN.

La implementación de esta tecnología marcó un nuevo hito en la historia de la PN porque a través de la misma se hizo posible la incorporación de un grupo de ECM que hasta ese momento nunca habían podido ser abordados por parte de este tipo de Programas, introduciendo además el concepto de sistemas multiplex, es decir de sistemas de detección de múltiples desórdenes a partir de un único ensayo, en el cual se lleva a cabo la medida simultánea de aminoáci- 
dos y acilcarnitinas (34-38).

A diferencia de lo experimentado en décadas anteriores con otras tecnologías convencionales, la incorporación de la EMT al laboratorio de pesquisa no resultó ser un proceso sencillo, por un lado porque esta tecnología requiere la utilización de instrumental muy costoso, lo cual ha determinado que su implementación haya quedado espontáneamente restringida a Programas que cuentan con una sólida plataforma de recursos económicos, y por el otro, porque el personal de laboratorio no cuenta ni con el entrenamiento necesario para el uso del mismo, ni con la experiencia requerida para una correcta interpretación de sus resultados (14).

- Por último, se planteó la necesidad de establecer políticas claras en relación con las acciones futuras que puedan realizarse con las muestras de sangre residuales de los RN (39).

\section{- 2000's:}

- Se produjo la expansión y "universalización" de la PN por EMT en países desarrollados, especialmente en EE.UU., Australia y algunos países de Europa.

- Se incorporó la PN de Defectos de la Audición a través de la realización de medidas funcionales (potenciales evocados auditivos) (40), constituyéndose de este modo en el primer grupo de patologías que no requiere la realización de pruebas bioquímicas para llevar a cabo su detección precoz, independientemente de que en la instancia de confirmación se requiera la realización de ensayos bioquímicos moleculares $(26,41)$.

- Finalmente se afianzó la tendencia puesta de manifiesto en la segunda mitad de la década del '90 de sustituir los sistemas clásicos de PN basados en "1 test : 1 desorden" por sistemas más modernos del tipo del introducido por la EMT de "1 test : múltiples desórdenes". Este afianzamiento se produjo a expensas no sólo de la universalización de la EMT, sino también del desarrollo y evaluación exitosa en fase preliminar de un nuevo principio analítico como la tecnología Multiplex (Luminex $\left.{ }^{\circledR}\right)$, con la cual es posible la detección simultánea de varias de las enfermedades que forman parte del Panel Básico de PN $(42,43)$. 


\section{- NUEVOS CRITERIOS DE SELECCIÓN DE ENFERMEDADES}

Tal como se puede inferir a partir de la cronología presentada anteriormente, la PN se ha caracterizado por ser un sistema extremadamente dinámico, en el cual en el transcurso de 40 años se evolucionó desde realizar la pesquisa de una enfermedad aislada como la PKU a pesquisar actualmente para más de 30 desórdenes; desde testear a los RN con tecnologías relativamente simples como los ensayos bacteriológicos de lectura visual a realizarlos con metodologías más complejas que requieren instrumental sofisticado, informatización y personal altamente entrenado como la EMT y las técnicas genético-moleculares (14); y finalmente desde utilizar formatos de ensayo del tipo "1 test : 1 patología detectada" a emplear plataformas de ensayo del tipo multiplex en las cuales a partir de 1 prueba se pueden detectar múltiples enfermedades (44).

Sin embargo, este proceso evolutivo no sólo estuvo determinado por el avance en las técnicas de pesquisa, sino que también han intervenido otros factores como son el surgimiento de nuevas alternativas para el diagnóstico y el manejo terapéutico de los casos detectados, y la potencialidad actual que ofrece la terapia génica.

En contraposición con esta evolución, los criterios de Wilson y Jungner para la selección de enfermedades congénitas a pesquisar se han mantenido prácticamente inalterados a lo largo del tiempo, lo cual motivó que en los últimos 10 a 15 años hayan surgido numerosas publicaciones que cuestionan a dichos criterios basándose en que los mismos requieren una modernización y flexibilización acorde con los avances tecnológicos y terapéuticos observados $(9,44-50)$, y en el hecho de que los mismos están formulados en términos cualitativos y sin un punto final claro, lo cual limita su aplicabilidad como herramienta de decisión (51-54).

En consonancia con dichos cuestionamientos, y con la finalidad de definir un panel uniforme de PN para todos los estados de los EE.UU., el American College of Medical Genetics ( $A C M G$ ) ha realizado y publicado recientemente uno de los trabajos más importantes en este sentido (53-54). En dicho documento se establece que los criterios de Wilson y Jungner son difíciles de cuantificar, que no permiten establecer un ranking de prioridades entre las diferentes enfermedades en forma 
comparativa, y que además son inadecuados para evaluar enfermedades que presentan marcadores similares o superpuestos, o que pueden ser detectadas utilizando tecnologías del tipo multiplex, pero que a su vez pueden variar en sus rasgos analíticos y clínicos.

La modalidad seguida en dicho trabajo consistió en definir inicialmente 11 principios básicos de la PN y 19 criterios de evaluación clínicos, analíticos y de diagnóstico, tratamiento y seguimiento, a cada uno de los cuales les fue asignado un puntaje. Posteriormente, se estableció un ranking de puntuación sobre un grupo de 84 enfermedades congénitas previamente seleccionadas y de etiología diversa de acuerdo con las calificaciones asignadas a cada patología por parte de un grupo de 289 expertos, quienes calificaron a las mismas haciendo uso de los criterios de evaluación antes mencionados. Por último, se reevaluó cada patología en base a las evidencias científicas y bibliográficas disponibles con la finalidad de que, en caso de no encontrarse una correspondencia absoluta entre el puntaje asignado inicialmente $y$ dichas evidencias, se efectuara una re-categorización de las mismas.

Los resultados finales de la evaluación determinaron que las más altas puntuaciones correspondieran a la MCAD, el HC y la PKU seguidos por la Deficiencia de Biotinidasa, la Anemia Falciforme y la HSC. De éste modo, fueron definidos 4 grupos o categorías (53-54):

a) Un Panel Central de 29 enfermedades consideradas aptas para la PN Y recomendadas como de realización obligatoria (Tabla 5).

b) Un Panel Secundario constituido por 25 enfermedades cuya detección se produce como parte del diagnóstico diferencial de alguna de las enfermedades del Panel Central, y que deberían reportarse al médico y a la familia cuando las mismas son detectadas (Tabla 6).

c) Un grupo constituido por otras 27 enfermedades identificadas como no aptas para la realización de la $\mathrm{PN}$, ya sea por la ausencia de pruebas de pesquisa o porque reúnen muy pocos de los criterios de evaluación definidos.

d) Otras 3 enfermedades cuya evaluación fue diferida por no contarse con especialistas específicos dentro del grupo de expertos consultados (HIV, 
Toxoplasmosis y Citomegalovirosis).

Tabla 5. Panel central recomendado por el ACMG de EE.UU.

\begin{tabular}{|c|c|}
\hline Acidurias Orgánicas & Def. de la Oxidación de Ácidos Grasos \\
\hline $\begin{array}{l}\text { 1. Acidemia Metilmalónica (Deficiencia } \\
\text { de Mutasa) }\end{array}$ & $\begin{array}{l}\text { 1. Deficiencia de Acil CoA Deshidrogenasa } \\
\text { de Cadena Media (MCAD) }\end{array}$ \\
\hline $\begin{array}{l}\text { 2. Acidemia Metilmalónica (Deficiencia } \\
\text { de Cb1 } A, B \text { ) }\end{array}$ & $\begin{array}{l}\text { 2. Deficiencia de Acil CoA Deshidrogenasa } \\
\text { de Cadena Muy Larga (VLCAD) }\end{array}$ \\
\hline $\begin{array}{l}\text { 3. Deficiencia de 3-Metilcrotonil CoA } \\
\text { Carboxilasa }\end{array}$ & $\begin{array}{l}\text { 3. Deficiencia de } 3 O H-A c i l \text { CoA Deshidro- } \\
\text { genasa de Cadena Larga (LCHAD) }\end{array}$ \\
\hline 4. Acidemia Isovalérica & 4. Deficiencia de Proteína Trifuncional \\
\hline 5. Acidemia Glutárica Tipo I & 5. Defecto de Captura de Carnitina \\
\hline 6. Aciduria 3-OH 3-Metil Glutárica & Hemoglobinopatías \\
\hline 7. Deficiencia Múltiple de Carboxilasas & 1. Anemia Falciforme \\
\hline 8. Acidemia Propiónica & 2. Anemia Falciforme/ $\beta$ Talasemia \\
\hline 9. Deficiencia de $\beta$-Ceto Tiolasa & 3. Anemia Falciforme/Enfermedad $\mathrm{Hb} C$ \\
\hline Aminoacidopatías & Otras enfermedades \\
\hline 1. Fenilcetonuria & 1. Hipotiroidismo Congénito \\
\hline 2. Enferm. de Orina de Jarabe de Arce & 2. Deficiencia de Biotinidasa \\
\hline 3. Homocistinuria & 3. Hiperplasia Suprarrenal Congénita \\
\hline 4. Citrulinemia & 4. Galactosemia Clásica (Def. GAL-T) \\
\hline 5. Acidemia Arginino-Succínica & 5. Defectos de la Audición \\
\hline 6. Tirosinemia Tipo I & 6. Fibrosis Quística \\
\hline
\end{tabular}

Con respecto al grupo de enfermedades que fueron incluidas dentro del Panel Central recomendado por el ACMG, todas cumplen con los siguientes 3 criterios (52):

a) pueden ser detectadas en una fase en la cual no es posible el diagnóstico clínico,

b) existe disponibilidad de una prueba de detección con apropiada sensibilidad y especificidad, $y$

c) existen beneficios demostrados de la detección temprana, intervención oportuna y eficacia del tratamiento.

Por otra parte es importante mencionar que 20 de estas 29 enfermedades pueden ser detectadas empleando una tecnología de tipo multiplex como lo es la EMT, 
lo cual es, además, un claro indicador del cambio trascendente que ha experimentado el rumbo de la PN en los últimos años.

Tabla 6. Panel Secundario recomendado por el ACMG de EE.UU.

\begin{tabular}{|c|c|}
\hline Acidurias Orgánicas & Def. de la Oxidación de Ácidos Grasos \\
\hline $\begin{array}{l}\text { 1. Acidemia Metilmalónica (Deficiencia } \\
\text { de } C b 1 C, D)\end{array}$ & $\begin{array}{l}\text { 1. Deficiencia de Acil CoA Deshidrogenasa } \\
\text { de Cadena Corta (SCAD) }\end{array}$ \\
\hline 2. Acidemia Malónica & 2. Acidemia Glutárica Tipo II \\
\hline $\begin{array}{l}\text { 3. Deficiencia de Isobutiril CoA Deshi- } \\
\text { drogenasa }\end{array}$ & $\begin{array}{l}\text { 3. Def. de } 3 O H \text {-Acil CoA Deshidrogenasa } \\
\text { de Cadena Media y Corta (M/SCHAD) }\end{array}$ \\
\hline 4. Aciduria 2-Metil 3-OH Butírica & 4. Deficiencia de Ceto Acil CoA Tiolasa de \\
\hline 5. Deficiencia de 2-Metilbutiril CoA & Cadena Media (MCKAT) \\
\hline Deshidrogenasa & 5. Deficiencia de Carnitina Palmitoil \\
\hline 6. Aciduria 3 Metil Glutacónica & Transferasa II (CPT2) \\
\hline Aminoacidopatías & 6. Deficiencia de Dienoil CoA Reductasa \\
\hline 1. Hiperfenilalaninemias Persistentes & 7. Deficiencia de Carnitina : Acilcarnitina \\
\hline 2. Deficiencia de Biopterinas & Translocasa \\
\hline (biosíntesis) & 8. Deficiencia de Carnitina Palmitoil \\
\hline 3. Deficiencia de Biopterinas & Transferasa I (CPT1) (Hígado) \\
\hline (reciclado) & Hemoglobinopatías \\
\hline 4. Hipermetioninemia & 1. Variantes de Hemoglobinas anormales \\
\hline 5. Argininemia & (incluyendo $\mathrm{Hb} \mathrm{E}$ ) \\
\hline 6. Tirosinemia Tipo II & Otras enfermedades \\
\hline 7. Tirosinemia Tipo III & 1. Deficiencia de Galactokinasa \\
\hline 8. Citrulinemia Tipo II & 2. Deficiencia de UDP-Gal 4 Epimerasa \\
\hline
\end{tabular}

Por último, y si bien resulta claro que los criterios empleados por el ACMG pueden presentar algunos aspectos subjetivos, éste es el primer intento de una evaluación comparativa y "cuantitativa" que se realiza de las diferentes enfermedades congénitas potencialmente pesquisables para una población determinada, en la cual, inclusive, se recomienda la PN obligatoria de algunas enfermedades cuya inclusión en los paneles de pesquisa estaría contraindicada en caso de que la selección se hubiera llevado a cabo empleando exclusivamente los criterios de Wilson y Jungner. 


\section{- futuro de la pesquisa neonatal}

La evaluación retrospectiva de los diferentes factores que han influenciado el rumbo de la PN a lo largo de su historia sugiere que el surgimiento de nuevas formas de diagnóstico, ya sea tanto a través del desarrollo de nuevas tecnologías como del hallazgo de nuevos marcadores bioquímicos o moleculares, sumado al descubrimiento de nuevas alternativas de tratamiento y de nuevas medidas preventivas, serán las variables que determinarán si una enfermedad resulta apropiada para considerar su inclusión en un Programa de PN (55), y por lo tanto estas mismas variables serán las que determinarán la dirección que la pesquisa ha de tomar en el futuro.

De acuerdo a este panorama, es posible presuponer que en los próximos años se experimentará una expansión en el espectro de enfermedades a pesquisar, el cual potencialmente podrá alcanzar un número significativo de enfermedades congénitas severas que actualmente no tienen acceso a los beneficios de la misma. No obstante esto, no se debe perder de vista el objetivo real de la PN y se debe evitar abordar aspectos no previstos como puede ser la detección de desórdenes con poca o ninguna significación clínica, la búsqueda neonatal de enfermedades de presentación en la edad adulta, o la detección de factores de susceptibilidad para padecer una enfermedad determinada como podría ser por ejemplo el caso de la Diabetes tipo I (55).

Adicionalmente debe tomarse en cuenta que la expansión de la PN necesariamente requiere una reconsideración de su infraestructura ya sea tanto para la ejecución de las pruebas de pesquisa como para el diagnóstico, educación, consejo genético, tratamiento y seguimiento de los casos detectados, lo cual sin lugar a dudas determina que los aspectos económicos puedan resultar un factor limitante en dicho proceso de expansión y que por lo tanto los mismos no deban ser ignorados (56).

\section{Pesquisa Neonatal de Inmunodeficiencia Combinada Severa}

La Inmunodeficiencia Combinada Severa (SCID), una Deficiencia Primaria del Sistema Inmune que se presenta con una incidencia del orden de $1: 50.000$ nacidos vivos, constituye el ejemplo más claro y reciente de expansión de los paneles de enfermedades a pesquisar. Su pesquisa fue definida como obligatoria para todos los 
estados de los EE.UU. a mediados de 2010, constituyéndose de esta forma en la primera enfermedad que se agrega al Panel Central recomendado por el $A C M G$ en el año 2006.

La SCID es una patología que comprende al menos 15 condiciones genéticas independientes que se caracterizan por presentar una ausencia completa, o al menos un nivel extremadamente bajo, de células $T$ funcionales, dando lugar así a un defecto severo tanto en la inmunidad celular como en la inmunidad humoral. Clínicamente esta característica se traduce en una incrementada susceptibilidad a infecciones severas y oportunistas las que habitualmente causan la muerte de los individuos afectados, en promedio, dentro del primer año de vida (57). No obstante esto, el transplante precoz de células madre hematopoyéticas ofrece una oportunidad concreta de cura de la enfermedad, constituyéndose así en la primera patología detectada por PN en la cual es posible realizar una prevención primaria.

Para su detección se requiere el empleo de un ensayo molecular como método de screening primario, a través del cual se lleva a cabo la cuantificación de un círculo de ADN extracromosómico no replicante denominado Círculo de Escisión del Receptor de Células T (TREC), el cual es un indicador de la presencia de células T autólogas generadas recientemente (57).

\section{Pesquisa Neonatal de Enfermedades de Almacenamiento Lisosomal}

Sin lugar a dudas, y a pesar de que en 2006 las Enfermedades de Almacenamiento Lisosomal (LSD) no reunían algunos de los criterios establecidos para su inclusión en el Panel de pesquisa recomendado por el $A C M G$, básicamente debido a que por aquel entonces aún no se disponía de pruebas adecuadas y de alto rendimiento para realizar la pesquisa $(53,54)$, las LSD representan el grupo de enfermedades con mayores chances de inclusión inminente, razón por la cual en los últimos años las mismas han concentrado en mayor medida la atención de los expertos $(45,55,58)$.

Las LSD son un grupo heterogéneo de más de 50 enfermedades severas que se presentan con una incidencia conjunta de $1: 7.000$ a $1: 8.000$ nacidos vivos (59-61), entre las cuales se incluyen las Mucopolisacaridosis (MPS), Esfingolipidosis, Oligosa- 
caridosis, Mucolipidosis y Glucogenosis Tipo II. Estas enfermedades presentan un mecanismo patogénico común caracterizado por un defecto genético que puede dar lugar tanto a la ausencia de una enzima lisosomal determinada como a la formación de un producto inactivo $(60,61)$, conduciendo de este modo a la acumulación de sustratos específicos en el interior de los lisosomas y a un deterioro de la función celular y tisular cuya severidad es función del tipo y cantidad de sustrato acumulado $(59,61)$.

La mayoría de los individuos afectados por estas enfermedades son aparentemente normales al nacimiento, pero desarrollan un cuadro severo $y$ progresivo que resulta evidente en los primeros años de vida. Los síntomas típicos incluyen retraso mental, disostosis múltiples, patología articular con movilidad reducida, hepatoesplenomegalia, patología respiratoria, enfermedad cardiovascular y daño renal. En ausencia de tratamiento los pacientes severamente afectados frecuentemente mueren durante el transcurso de la adolescencia (60).

Desde el punto de vista del tratamiento, las opciones disponibles hasta hace algo más de 10 años eran solamente de carácter paliativo o de alto riesgo, como es el caso del trasplante de médula ósea. Sin embargo, esta situación cambió sustancialmente con la implementación de la terapia de reemplazo enzimático con enzimas recombinantes, la cual fue aprobada en 1991 por la Food and Drug Administration (FDA) de los EE.UU. para la Enfermedad de Gaucher $(58,60-62)$ y más recientemente para la Enfermedad de Fabry, MPS I, MPS II, MPS VI y Enfermedad de Pompe $(58,61)$, encontrándose en fase de estudios clínicos para Niemann-Pick $B(58,61)$ y de estudios preclínicos para otro numeroso grupo de LSD $(60,61,63)$.

Sumado a esto, también se deben considerar otras terapias específicas que se encuentran en fase de desarrollo como son el transplante con sangre de cordón $(58,64)$, la terapia génica y la terapia con pequeñas moléculas $(58,60,61,65)$, las cuales podrían mejorar aún más las expectativas de éxito terapéutico.

En cuanto a las pruebas de pesquisa, la no disponibilidad de métodos para trabajar sobre DBS determinó que hasta hace algunos años la búsqueda masiva de las LSD en RN fuera no solamente inaccesible desde el punto de vista práctico sino también una alternativa racionalmente impensada. Recién en 2001 se produjo un 
cambio trascendente en el panorama diagnóstico cuando Néstor Chamoles en nuestro país demostró que las enzimas lisosomales permanecían activas durante mucho tiempo en DBS (64), e ideó una metodología fluorométrica sumamente simple y de bajo costo que permite determinar separadamente la actividad de 15 enzimas lisosomales diferentes (66-71), dando lugar así a lo que probablemente pueda significar un nuevo hito en la historia de la PN. Este importante avance no sólo fue innovador en sí mismo, sino que además desencadenó un efecto multiplicador que motivó la puesta en marcha de nuevas líneas de investigación tanto para el desarrollo y mejoramiento de nuevos métodos de pesquisa, como para la búsqueda de nuevas alternativas terapéuticas.

De este modo, y además de los métodos fluorométricos antes mencionados, también se desarrollaron un método de inmunocaptura para determinar específicamente la actividad de la enzima $\alpha$-Glucosidasa a través de una medida fluorométrica (72), y un ensayo multiplex de inmunocuantificación fluorométrica para 11 marcadores lisosomales en el cual se utilizan microesferas recubiertas con anticuerpos específicos de captura (60) que permiten determinar ciertas proteínas específicas como son la Proteína de Membrana Asociada a Lisosomas (LAMP-1) y la Saposina C (73), en combinación con 9 enzimas lisosomales que reflejan las deficiencias propias de las correspondientes LSD (60).

No obstante esto, la metodología que mayor impulso le ha proporcionado a la PN de LSD es un ensayo multiplex en el cual se analizan por EMT los productos resultantes de la acción de un grupo seleccionado de enzimas lisosomales sobre sus propios sustratos naturales específicos $(64,74)$. Esta tecnología, resulta analíticamente ventajosa con respecto a los métodos fluorométricos porque ofrece la posibilidad de realizar una cuantificación específica de la actividad enzimática, porque no requiere el empleo de sustratos artificiales, y porque puede ser utilizada en una plataforma multiplex para el dosaje simultáneo de varias enzimas, dejando abierta la posibilidad a una potencial incorporación de otras nuevas enzimas dependiendo de si la relación masa/carga de los analitos detectados y sus fragmentos de disociación permiten que los mismos puedan ser identificados específicamente (74). En tal sentido, resulta oportuno mencionar que si bien esta metodología se describe como una plataforma 
multiplex, éste formato solo afecta a las etapas de elución de muestras y de análisis combinado de los productos de reacción por EMT, siendo necesario realizar ensayos separados para permitir que cada enzima pueda ejercer su acción sobre los sustratos específicos correspondientes $(61,64,74)$.

De este modo, y empleando estas tecnologías se han realizado diversas experiencias a modo de prueba piloto en las que se determina la actividad de las enzimas $\alpha$-Galactosidasa, $\beta$-Glucosidasa, $\beta$-Galactosidasa, Esfingomielinasa, $\alpha$-Glucosidasa y $\alpha$-Iduronidasa, permitiendo de este modo la detección de Enfermedad de Fabry $(58,64,74)$, Gaucher $(58,64,74)$, Krabbe $(58,64,74-76)$, Niemann-Pick A/B $(58,64,74)$, Pompe $(58,64,74,77)$ y MPS I $(58,64,75,78)$ respectivamente. Sumado a esto, y haciendo una contribución para la validación y posterior expansión de la PN de LSD, a través del Newborn Screening Translation Research Initiative at the Centers for Disease Control and Prevention de EE.UU., actualmente es posible acceder en forma gratuita a reactivos registrados por la FDA para llevar a cabo el dosaje por EMT de las 6 enzimas lisosomales antes mencionadas $(79,80)$. Estos reactivos ya han sido distribuidos a la fecha a más de 70 laboratorios en todo el mundo incluyendo varios Programas de PN, como así también laboratorios involucrados en estudios piloto (58).

Por último, y para concluir con la PN de LSD, es importante dejar en claro que aún existen numerosos interrogantes, dilemas y controversias por resolver en relación a la potencial implementación sistemática y masiva de la misma, situación que ha dado lugar a que en los últimos años se plantee un verdadero debate ético y científico -y porqué no también desde el punto de vista de las familias afectadas, de la comunidad y de los equipos médicos (63)-, en torno a si se debería realizar la pesquisa en forma masiva, a la forma en que debería realizarse la misma, a si todos los neonatos que se podrían detectar realmente corresponderán a casos clínicos verdaderos, a quienes de aquellos neonatos potencialmente detectados se debería poner bajo tratamiento, y también en cuanto al momento en que debería instaurarse la terapéutica requerida en aquellas formas de presentación tardía o de la edad adulta $(58,61,63)$. Por todas estas razones, aún resta un camino extenso por recorrer antes de que se llegue a recomendar taxativamente la PN sistemática de LSD, no obstante lo cual todo lleva a 
pensar que esta definición se alcanzará en el transcurso de los próximos años, planteando al mismo tiempo un nuevo desafío científico y financiero para el sistema de salud (45).

\section{Pesquisa Neonatal de Enfermedad Cardíaca Congénita Cianótica Crítica}

Muy probablemente la enfermedad que más recientemente ha sido puesta a consideración por parte de los especialistas para su inclusión en los Programas de PN sea la Enfermedad Cardíaca Congénita Cianótica Crítica (ECCCC), la cual de hecho representa la segunda enfermedad que podría ser agregada al Panel Central recomendado por el ACMG de los EE.UU. en 2006 (58).

Los Defectos Cardíacos Congénitos constituyen los defectos más prevalentes al nacimiento afectando a aproximadamente 1 de cada 100 nacidos vivos. De todas las causas posibles que pueden dar lugar a este cuadro, aproximadamente un $25 \%$ de ellas son causadas precisamente por la ECCCC, una patología inaparente y sin síntomas reconocibles en el período neonatal que requiere intervención quirúrgica o cateterismo dentro del primer año de vida.

Hablando específicamente desde el punto de vista de la PN, la misma se realiza empleando un Oxímetro de pulso, un procedimiento simple y no invasivo que permite determinar el contenido de oxígeno en la sangre, posibilitando así la detección del defecto antes del alta de la maternidad y la implementación del tratamiento oportuno que ha de permitir evitar la insuficiencia cardíaca, el potencial daño neurológico, el retraso del desarrollo, la insuficiencia de órganos y la muerte asociados a la misma.

Las características de la estrategia de pesquisa a utilizar determinan que la ECCCC sea junto a los Defectos de la Audición una de las dos únicas enfermedades no metabólicas en las cuales la detección neonatal se realiza en la propia maternidad antes del alta del RN, y empleando dispositivos que no requieren el análisis de DBS en el Laboratorio (58).

Los principales cuestionamientos en torno a la inclusión de esta patología en el panel de enfermedades a pesquisar pasan por saber quién será el responsable de aportar los recursos económicos necesarios para solventar los procedimientos 
requeridos como parte del tratamiento, los cuales de por sí resultan sumamente costosos, planteando de este modo el principal obstáculo a resolver.

\section{Pesquisa Genética empleando Microarreglos de ADN o "Biochips"}

Entre las nuevas tecnologías que se han desarrollado y mejorado en los últimos años -fundamentalmente a expensas del Proyecto del Genoma Humano-, y que a futuro ofrece una enorme potencialidad de aplicación en PN, sin lugar a dudas se debe incluir al uso de Microarreglos de ADN o "Biochips" $(44,45,51)$. Sin embargo, y a pesar de que virtualmente el uso de los mismos permitiría la detección de un ilimitado número de enfermedades hereditarias, esta tecnología se halla sujeta a diversas limitaciones como lo son la enorme cantidad de mutaciones que pueden dar lugar a las enfermedades en cuestión, el costo elevado de las pruebas, su complejidad operativa (45), y los riesgos de incluir desórdenes que no reúnen los criterios tradicionales de selección de enfermedades a pesquisar como pueden ser la búsqueda de factores de susceptibilidad o riesgo y la detección de portadores, hechos que indudablemente conllevan el riesgo de cambiar el paradigma de la PN desde el concepto de la "medicina preventiva" al de la "medicina predictiva" (51).

Tradicionalmente, la tecnología de Microarreglos de ADN o "DNA Microarrays" fue utilizada en forma casi exclusiva en investigación y en algunos diagnósticos clínicos de muy alto costo, y recién a fines de la década del '90 la misma comenzó a ser considerada como una herramienta factible de ser utilizada en PN como prueba de screening primario. Este cambio se produjo a consecuencia de la ocurrencia de ciertos hechos entre los que se puede citar la dilucidación por parte de la Genética Humana de numerosos defectos moleculares causantes de enfermedades metabólicas heredables, la reducción experimentada en los costos de los reactivos necesarios para la realización de las pruebas, y también la posibilidad de incrementar significativamente el rendimiento del sistema a través de la automatización completa de los procesos de extracción y amplificación del ADN, y de detección de los híbridos $(81,82)$.

En cuanto a las características de esta tecnología, la misma hace uso de una de 
las propiedades de las DBS de ser un material apropiado para la conservación y obtención de ADN de alta calidad, haciendo factible la búsqueda de mutaciones causantes de diferentes enfermedades genéticamente determinadas a través del uso de la Reacción en Cadena de la Polimerasa (PCR) en un sistema multiplex $(44,81)$. De este modo, trabajando en un ensayo simple, es posible llevar a cabo, por un lado, la coamplificación de diferentes genes empleando una PCR, y por el otro, la posterior codetección de diferentes productos de amplificación que presentan implicancias diagnósticas para varias enfermedades genéticas, procediéndose a identificar las potenciales mutaciones presentes en las muestras a través de un proceso automatizado de análisis (44).

En la práctica, esta tecnología requiere la utilización de microarreglos de ADN en los cuales se disponen 60.000 o más amplicones diagnósticos en placas microscópicas de 100-110 $\mu \mathrm{m}$, y sondas de oligonucleótidos con marcación fluorescente que permiten la asignación del genotipo (82) (Figura 7).

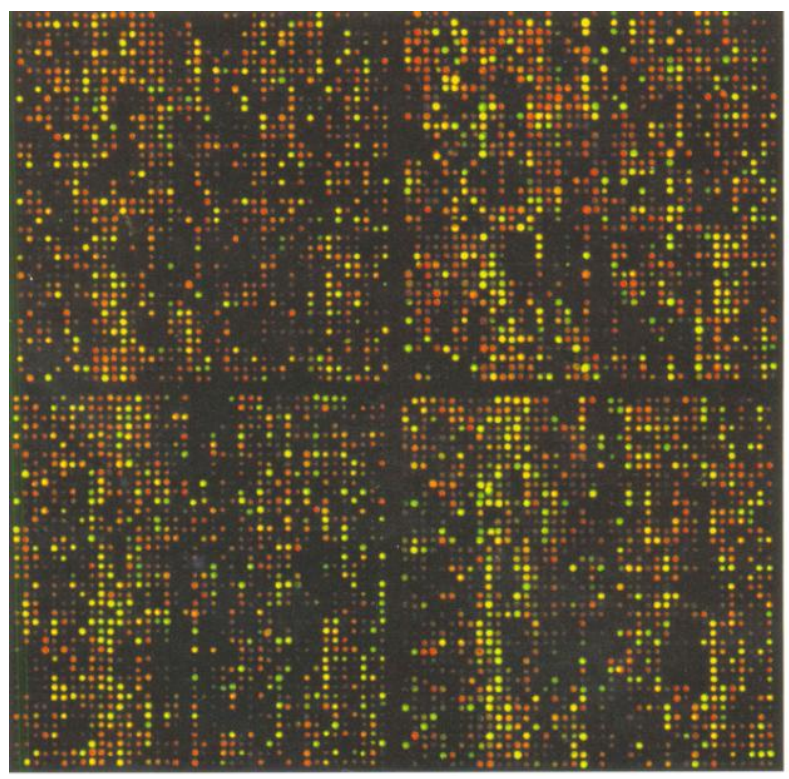

Figura 7. Tecnología de Microarreglos de ADN.

Finalmente, y desde el punto de vista de su aplicabilidad, se debe tener en cuenta que una de las condiciones exigibles para que una enfermedad determinada pueda ser detectada mediante un sistema de pesquisa molecular en un paso, es que la misma tenga una etiología genética simple. Así se ha establecido que esta tecnología 
posee el potencial necesario para pesquisar ciertos desórdenes genético-metabólicos -especialmente aquellos asociados con retardo mental o con enfermedades neurovegetativas-, distrofias musculares, inmunodeficiencias, FQ, Hbpatías, coagulopatías y síndromes genéticos causantes de sordera (44), y se ha sugerido un grupo preliminar de enfermedades tratables $(81,82)$, al cual se detalla en la Tabla $7, y$ que actualmente ya podrían ser pesquisadas empleando la tecnología de microarreglos de ADN.

Tabla 7. Enfermedades propuestas para Pesquisa Molecular por Microarreglos de ADN

Anemia Falciforme
Deficiencia de $\alpha 1$-antitripsina
Factor V Leiden
Hemocromatosis
Síndrome MERRF
Síndrome MELAS
Defectos de la Audición

\section{BIBLIOGRAFIA}

1. Bickel H. "Rationale of Neonatal Screening in Inborn Errors of Metabolism" en "Neonatal Screening for Inborn Errors of Metabolism". Bickel H, Guthrie R and Hammersen G Eds, Springer-Verlag, Berlin-Heidelberg-New York, 1-6, 1980.

2. Therrell BL, Panny SR, Davidson A, Eckman J, Hannon WH, Henson MA, Hillard M, Kling S, Levy HL, Meaney FJ, McCabe ERB, Mordaunt V, Pass K, Shapira E and Tuerck J. "U.S. Newborn Screening System Guidelines: Statement of the Council of Regional Networks for Genetic Services". Screening 1, 135-47, 1992.

3. Pass KA, Lane PA, Fernhoff PM, Hinton CF, Panny SR, Parks JS, Pelias MZ, Rhead WJ, Ross SI, Wethers DL and Elsas LJ; "U.S. Newborn Screening System Guidelines II: Follow-up of Children, Diagnosis, Management, and Evaluation Statement of the Council of Regional Networks for Genetic Services (CORN)". Journal of Pediatrics 137, S1-S46, 2000.

4. Slazyk WE and Hannon WH; "Quality Assurance in the Newborn Screening 
Laboratory" en "Laboratory Methods for Neonatal Screening". Therrell BL Ed, American Public Health Association, Washington, 23-46, 1993.

5. Committee on Genetics - American Academy of Pediatrics; "Issues in Newborn Screening". Pediatrics, 89, 345-349, 1992.

6. Cuckle HS and Wald N. "Tests Using Single Markers" en "Antenatal and Neonatal Screening". Wald N and Leck I Eds, Second Edition, Oxford University Press, Oxford New York, 1-22, 2000.

7. Guthrie R; "Organization of a Regional Newborn Screening Laboratory" en "Neonatal Screening for Inborn Errors of Metabolism". Bickel H, Guthrie R and Hammersen G Eds, Springer-Verlag, Berlin Heidelberg New York, 259-270, 1980.

8. Guthrie R. "Mass Screening for Genetic Disease". Hospital Practice, 7, 93-100, 1972.

9. Therrell BL. "U.S. Newborn Screening Policy Dilemmas for the Twenty-First Century". Molecular Genetics and Metabolism, 74, 64-74, 2001.

10. Wilson JM and Jungner G. "Principles and Practice of Screening Disease". Public Health Papers No 34. Geneva: World Health Organization, 26-39, 1968.

11. Guthrie R and Susi A. "A Simple Phenylalanine Method for Detecting Phenylketonuria in Large Populations of Newborn Infants". Pediatrics 32, 338-43, 1963.

12. Bickel H, Gerrard $J$ and Hickmans EM. "Influence of Phenylalanine Intake on Phenylketonuria". Lancet 2, 812-3, 1953.

13. Bickel H, Gerrard $J$ and Hickmans EM. "The Influence of Phenylalanine Intake on the Chemistry and Behaviour of a Phenylketonuria Child". Acta Paeditr 43, 64-71, 1954.

14. McCabe L, Therrell B and McCabe E. "Newborn Screening: Rationale for a Comprehensive, Fully Integrated Public Health System". Molecular Genetics and Metabolism 77, 267-73, 2002.

15. Guthrie R, "The Origin of Newborn Screening". Screening 1, 5-15,1992.

16. Therrell B, "Automation and Computarization in Newborn Screening" en "Laboratory Methods for Neonatal Screening". Therrell BL Ed, American Public 
Health Association, Washington, 1-21, 1993.

17. Dussault $J$ and Laberge C. "Thyroxine (T4) Determinations in Dried Blood by Radioimmunoassay. A Screening Method for Neonatal Hypothyroidism". Union Med Can 102, 2062-4, 1973.

18. Dussault J, Coulombe P and Laberge C. "Preliminary Report on a Mass Screening Program for Neonatal Hypothyroidism". J Pediatr 86, 620-4, 1974.

19. Dussault J, Parlow A, Letarte J, Guyda H and Laberge C. "TSH Measurement from Blood Spots on Filter Paper. A Confirmatory Screening Test for Neonatal Hypothyroidism". J Pediatr 89, 550-2, 1976.

20. Foley T, Klein A and Agustin A. "Adaptation of TSH Filter Paper Method for Regionalized Screening for Congenital Hypothyroidism". J Lab Clin Med, 90, 11-7, 1977.

21. Beutler E and Baluda M. "A Simple Spot Screening Test for Galactosemia". J Lab Clin Med 68, 137-41, 1966.

22. Pang S, Hotchkiss J, Drash A, Levine L and New M. "Microfilter Paper Method for 17a-Hydroxyprogesterone Radioimmunoassay: Its Application for Rapid Screening for Congenital Adrenal Hyperplasia". J Clin Endocrinol Metab 45, 1003-8, 1977.

23. Garrick M, Dembure $P$ and Guthrie R. "Sickle-Cell Anemia and Other Hemoglobinopathies - Procedures and Strategy for Screening Employing Spots of Blood on Filter Paper as Specimens". N Engl J Med 288, 1265-8, 1973.

24. McCabe E, Huang S, Seltzer W and Law M. "DNA Microextraction from Dried Blood Spots on Filter Paper Blotters: Potential application to Newborn Screening". Hum Genet 75, 213-6, 1987.

25. Ranieri E, Ryall RG, Phillip Morris C, Nelson PV, Carey WF, Pollard AC and Robertson EF. "Neonatal Screening Strategy for Cystic Fibrosis Using Immunoreactive Trypsinogen and Direct Gene Analysis". Br Med J, 302, 1237-40, 1991.

26. McCabe $E$ and McCabe L. "State-of-the-Art for DNA Technology in Newborn Screening". Acta Paediatr Suppl 432, 58-60, 1999.

27. Zhang Y, McCabe L, Wilborn M, Therrell B and McCabe E. "Application of 
Molecular Genetics in Public Health: Improved Follow-up in a Neonatal Hemoglobinopathy Screening Program". Biochem Med Metab Biol 52, 27-35, 1994. 28. Gregersen N, Andresen B, Bross P, Winter V, Rudiger N, Engst S et al. "Molecular Characterization of MCAD Deficiency: Identification of a Lys329 to Glu Mutation in the MCAD Gene and Expression of Inactive Mutant Enzyme in E. Coli". Hum Genet 86, 545-51, 1991.

29. Bellisario R, Colinas R and Pass K. "Simultaneous Measurement of Antibodies to Three HIV-1 Antigens in Newborn Dried Blood-Spot Specimens Using a Multiplexed Microsphere-Based Immunoassay". Early Human Development 64, 215, 2001.

30. Eaton $R$, Petersen E, Seppänen $H$ and Tuuminen T. "Multicenter Evaluation of a Fluorometric Enzyme Immunocapture Assay to Detect Toxoplasma-Specific Immunoglobulin M in Dried Blood Filter Paper Specimens from Newborns". J Clin Microbiol 34, 3147-50, 1996.

31. Petersen E and Eaton R. "Control of Congenital Infection with Toxoplasma gondii by Neonatal Screening Based on Detection of Specific Immunoglobulin $M$ Antibodies Eluted from Phenylketonuria Filter-Paper Blood-Spot Samples". Acta Paediatr Suppl 432, 36-9, 1999.

32. Millington DS, Kodo N, Norwood DL and Roe CR. "Tandem Mass Spectrometry: a New Method for Acylcarnitine Profiling with Potential for Neonatal Screening for Inborn Errors of Metabolism". J Inherit Metab Dis, 13, 321-4, 1990.

33. Chace D, Millington D, Terada N, Kahler S, Roe C and Hofman L. "Rapid Diagnosis of Phenylketonuria by Quantitative Analysis for Phenylketonuria and Tyrosine in Neonatal Blood Spots by Tandem Mass Spectrometry". Clin Chem 39, 66-71, 1993. 34.Levy $H$. "Newborn Screening by Tandem Mass Spectrometry: A New Era (Editorial)". Clin Chem 44, 2401-2, 1998.

35. Rashed MS, Ozand PT Bucknall MP and Little D. "Diagnosis of Inborn Errors of Metabolism by Electrospray from Blood Spots by Acilcarnitines and Amino Acids Profiling Using Automated Electrospray Tandem Mass Spectrometry". Pediatr Res 38, 324-31, 1995. 
36.Rashed M, Bucknall M, Little D, Awad A, Jacob M, Alamoudi M, Alwattar M and Ozand P. "Screening Blood Spots for Inborn Errors of Metabolism by Electrospray Tandem Mass Spectrometry with a Microplate Batch Process and a Computer Algorithm for Automated Flagging of Abnormal Profiles". Clin Chem 43, 1129-41, 1997.

37. Centers for Disease Control and Prevention. "Using Tandem Mass Spectrometry for Metabolic Disease Screening Among Newborns: A Report of a Work Group". MMWR 50, No RR-3, 1-34, 2001.

38. Chace $D$ and Kalas T. "A Biochemical Perspective on the Use of Tandem Mass Spectrometry for Newborn Screening and Clinical Testing". Clin Biochem 38, 296$309,2005$.

39. Therrell B, Hannon W, Pass K, Lorey F, Brokopp C, Eckman J, Glass M, Heidenreich R, Kinney S, Kling S, Landenburger G, Meaney F, McCabe E, Panny S, Schwartz M and Shapira E. "Guidelines for the Retention, Storage and Use of Residual Dried Blood Spot Samples After Newborn Screening Analysis: Statement of the Council of Regional Networks for Genetic Services". Biochem Mol Med 57, 116-24, 1996.

40.Kennedy C. "Controlled Trial of Universal Neonatal Screening for Early Identification of Permanent Childhood Hearing Impairment: Coverage, Positive Predictive Value, Effect on Mothers and Incremental Yield". Acta Paediatr Suppl $432,73-5,1999$.

41. Milunsky J, Maher T, Yosunkaya B and Vohr B. "Connexin-26 Gene Analysis in Hearing-Impaired Newborns". Genet Testing 4, 345-9, 2000.

42. Bellisario R, Colinas R and Pass K. "Simultaneous Measurement of Thyroxine and Thyrotropin from Newborn Dried Blood-Spot Specimens Using a Multiplexed Fluorescent Microsphere Immunoassay". Clin Chem 46, 1422-4, 2000.

43.Dunbar $S$ and Jacobson J. "Rapid Screening for 31 Mutations and Polymorphisms in the Cystic Fibrosis Transmembrane Conductance Regulator Gene by Luminex xMAP Suspension Array". Methods Mol Med 114, 147-71, 2005.

44.Duane $A$ and van Dyck P. "A Vision of the Future of Newborn Screening". 
Pediatrics 117, S350-S354, 2006.

45.Pollit RJ. "Introducing New Screens: Why are we all doing different things?". J Inherit Metab Dis, 30, 423-9, 2007.

46.Levy HL. "Dilemmas in Newborn Screening". Southeast Asian J Trop Med Public Health, 30 [Suppl 2], 11-13, 1999.

47.Farriaux JP. "Les critères de Wilson en...l'an 2000. Editorial. La Depeche, 28, 1998.

48. Howse JL and Katz M. "The Importance of the Newborn Screening". Pediatrics, $106,595,2000$.

49. Cunningham $G$. "The Science and Politics of Screening Newborns". Editorial. $N$ Engl J Med, 346, 1084-1085, 2002.

50.Pollit RJ, Green A, Mc Cabe CJ, Booth A, Cooper NJ, Leonard JV et al. "Neonatal Screening for Inborn Errors of Metabolism: Cost, Yield and Outcome". Health Technol Assess, 1, 137-140, 1997.

51. Dhondt JL. "Neonatal Screening: from the 'Guthrie age' to the 'Genetic Age' ". J Inherit Metab Dis, 30, 418-22, 2007.

52.Pollit RJ. "International Perspectives on Newborn Screening". J Inherit Metab Dis, 29, 390-6, 2006.

53. American College of Medical Genetics, "Newborn Screening: Toward a Uniform Screening Panel and System". Genet Med 8 (Supplement 1), S1-S252, 2006.

54.American College of Medical Genetics, "Newborn Screening: Toward a Uniform Screening Panel and System - Executive Summary". Pediatrics 117, S296-S307, 2006.

55. Wilcken B. "Recent Advances in Newborn Screening". J Inherit Metab Dis, 30, 129-33, 2007.

56.Dhondt JL. "Expanded Newborn Screening: Social and Ethical Issues". J Inherit Metab Dis, 33 (Suppl 2), S211-S217, 2010.

57.Comeau AM, Hale JE, Pai S-Y, Bonilla FA, Notarangelo LD, Pasternack MS, Meissner $\mathrm{HC}$ et al. "Guidelines for Implementation of Population-Based Newborn Screening for Severe Combined Immunodeficiency". J Inherit Metab Dis, 33 
(Suppl 2), S273-S281, 2010.

58.Zhou H, Fernhoff $P$ and Vogt RF. "Newborn Bloodspot Screening for Lysosomal Storage Disorders". J Pediatr, 2011. En prensa.

59. Wilcox W. "Lysosomal Storage Disorders: The Need for Better Pediatric Recognition and Comprehensive Care". J Pediatr 144, S3-S14, 2004.

60.Meikle PJ, Grasby DJ, Dean CJ, Lang DL, Bockmann M, Whittle AM, Fietz MJ et al. "Newborn Screening for Lysosomal Storage Disorders". Mol Genet Metab 88, 307-14, 2006.

61. Marsden D and Levy H. "Newborn Screening of Lysosomal Storage Disorders". Clin Chem 56, 1071-9, 2010.

62.Grabowsky G. "Gaucher Disease: Lessons From a Decade of Therapy". J Pediatr 144, S15-S19, 2004.

63.Fletcher JM. "Screening for Lysosomal Storage Disorders - A Clinical Perspective". J Inherit Metab Dis, 29, 405-8, 2006.

64.Gelb MH, Turecek F, Scott CR and Chamoles NA. "Direct Multiplex Assay of Enzymes in Dried Blood Spots by Tandem Mass Spectrometry for the Newborn Screening of Lysosomal Storage Disorders". J Inherit Metab Dis 29, 397-40, 2006.

65.Grabowsky G (Ed.). "Introduction" en "Symposium on Lysosomal Storage Disorders". J Pediatr 144, S1, 2004.

66.Chamoles N, Blanco M, Gaggioli D. "Diagnosis of Alpha-L-Iduronidasa Deficiency in Dried Blood Spots on Filter Paper: the Possibility of Newborn Diagnosis". Clin Chem 47, 780-1, 2001. (Erratum in Clin Chem 47, 2192, 2001).

67.Chamoles N, Blanco $M$ and Gaggioli D. "Fabry Disease: Enzymatic Diagnosis in Dried Blood Spots on Filter Paper". Clin Chim Acta 308, 195-6, 2001.

68.Chamoles N, Blanco M, Gaggioli D and Casentini C. "Hurler-Like Phenotype: Enzymatic Diagnosis in Dried Blood Spots on Filter Paper". Clin Chem 47, 2098102.

69. Chamoles N, Blanco M, Gaggioli D and Casentini C. "Gaucher and Niemann-Pick Diseases - Enzymatic Diagnosis in Dried Blood Spots on Filter Paper: 
Retrospective Diagnoses in Newborn Screening Cards". Clin Chim Acta 317, 191-7, 2002.

70.Chamoles N, Blanco M, Gaggioli D and Casentini C. "Tay-Sachs and Sandhoff Diseases: Enzymatic Diagnosis in Dried Blood Spots on Filter Paper: Retrospective Diagnoses in Newborn Screening Cards". Clin Chim Acta 318, 133-7, 2002.

71. Chamoles N, Niizawa G, Blanco M, Gaggioli D and Casentini C. "Glycogen Storage Disease Type II: Enzymatic Screening in Dried Blood Spots on Filter Paper". Clin Chim Acta 347, 97-102, 2004.

72. Umapathysivam K, Hopwood J and Meikle P. "Determination of Acid a-Glucosidase Activity in Blood Spots as a Diagnostic for Pompe Disease". Clin Chem 47, 137883, 2001.

73.Li Y, Scott C, Chamoles N, Ghavami A, Pinto B, Turecek, F and Gelb M. "Direct Multiplex Assay of Lysosomal Enzymes in Dried Blood Spots for Newborn Screening". Clin Chem 50, 1785-96, 2004.

74.Li Y, Brockman K, Turecek F, Scott $C$ and Gelb M. "Tandem Mass Spectrometry for the Direct Assay of Enzymes in Dried Blood Spots: Application to Newborn Screening for Krabbe Disease". Clin Chem 50, 638-40, 2004.

75. Wang D, Eadala B, Sadilek M, Chamoles N, Turecek F, Scott $C$ and Gelb $M$. "Tandem Mass Spectrometric Analysis of Dried Blood Spots for Screening of Mucopolysaccharidosis I in Newborns". Clin Chem 51, 898-900, 2005.

76. Orsini JJ, Morrisey NA, Slavin LN, Wojcik M, Biski C, Martin M et al. "Implementation of Newborn Screening for Krabbe Disease: Population Study and Cutoff Determination". Clin Biochem 42, 877-84, 2009.

77.Dajnoki A, Muhl A, Fekete G, Keutzer J, Orsini J, De Jesus V et al. "Newborn Screening for Pompe Disease by Mesuring Acid a-Glucosidase Activity Using Tandem Mass Spectrometry". Clin Chem 54, 1624-9, 2008.

78. Meikle P, Ranieri E, Simonsen H, Rozaklis T, Ramsay S, Whitfield P, Fuller $M$, Christensen E, Skovby F and Hopwood J. "Newborn Screening for Lysosomal Storage Disorders: Clinical Evaluation of a Two-Tier Strategy". Pediatrics 114, 909-16, 2004. 
79.Zhang XK, Elbin CS, Turecek F, Scott R, Chuang WL, Keutzer JM, et al. Multiplex lysosomal enzyme activity assay on dried blood spots using tandem mass spectrometry. Methods Mol Biol 603, 339-50, 2010.

80.De Jesus VR, Zhang XK, Keutzer J, Bodamer OA, Muhl A, Orsini JJ, et al. Development and evaluation of quality control dried blood spot materials in newborn screening for lysosomal storage disorders. Clin Chem 55, 158-64, 2009.

81. Dobrowolski S, Banas R, Naylor E, Powdrill T and Thakkar D. "DNA Microarray Technology for Neonatal Screening". Acta Paediatr Suppl 432, 61-4, 1999.

82.Dobrowolski S, Lin Z, Suzow J, Banas R and Naylor E. "Utilizing Molecular Genetic Analysis in Primary Newborn Screening: The Microarray Platform and Applications". Proceedings of 5th Meeting of the International Society for Neonatal Screening: "Neonatal Screening from the Spot to Diagnosis and Treatment", Genova-Italy, 33-34, 2002. 
OBJETIVOS 



\section{- OBJETIVO gENERAL}

Implementar las etapas necesarias para la conformación de un Programa de Detección Neonatal de Enfermedades Congénitas en nuestro medio, y en particular en la Provincia de Buenos Aires, a fin de hacer una contribución al mejor desarrollo y bienestar de la población como parte de las acciones de un Programa de Atención Preventiva de la Salud Pública.

\section{- OBJETIVOS ESPECIFICOS}

A fin de cumplimentar el Objetivo General antes descripto se planteó trabajar en forma particular sobre los siguientes Objetivos Específicos:

1. Organización de un Programa de Pesquisa Neonatal.

2. Organización y Funcionamiento de un Laboratorio de Pesquisa Neonatal.

3. Automatización del Laboratorio de Pesquisa Neonatal.

4. Desarrollo de métodos de pesquisa para utilizar en Programas de Pesquisa Neonatal.

5. Validación de los Métodos de Pesquisa.

6. Implementación de un Sistema de Control de Calidad Interno y participación en Programas de Evaluación Externa de Calidad.

7. Desarrollo e implementación de un Programa de Evaluación Externa de Calidad para Pesquisa Neonatal en Latinoamérica.

8. Análisis específico de los resultados de la implementación de la Pesquisa Neonatal de las enfermedades congénitas que se listan a continuación, poniendo especial énfasis en los métodos de análisis utilizados, en el control de calidad de los mismos, en las condiciones de recolección de muestras exigidas, en los valores de corte empleados, en los algoritmos de decisión, en la forma de 
implementación de la pesquisa, en los resultados obtenidos, casos detectados e incidencias, y en los parámetros de desempeño de cada una de ellas:

a. Fenilcetonuria.

b. Hipotiroidismo Congénito.

c. Fibrosis Quística.

d. Galactosemia.

e. Hiperplasia Suprarrenal Congénita.

f. Deficiencia de Biotinidasa.

9. Enfermedad de orina de Jarabe de Arce. 


\section{SECCIÓN I}

ASPECTOS GENERALES

$\triangle E L A$

PESQUISA NEONATAL 



\section{CAPÍTULO 1}

ORGANIZACIÓN DE UN

PROGRAMA DE

PESQUISA NEONATAL 


$$
\text { - }
$$




\section{- DIAGNÓSTICO DE SITUACION}

\section{Introducción}

Las tareas de organización e implementación de un Programa de PN requieren que previamente a la puesta en marcha del mismo se realice un profundo y detallado análisis de todos aquellos aspectos que han de incidir sobre las mencionadas actividades a efectos de poder determinar con precisión cuales son las fortalezas y debilidades existentes en la región en la cual tendrá definido su alcance, y de posibilitar de esta forma el acceso a un correcto diagnóstico de situación.

A lo largo de todo el proceso de planificación siempre se debe tomar en consideración que las estrategias de implementación y funcionamiento de un Programa de PN presentan una muy fuerte dependencia de factores geográficos, políticos y económicos (1). Los factores geográficos juegan un rol crítico a nivel logístico, es decir en lo que respecta a las comunicaciones, transporte de muestras, localización y derivación de RN puesto que cada una de estas actividades resulta influenciada en forma directa por los accidentes geográficos, por la disponibilidad de vías de comunicación adecuadas y por la amplitud de la región; en tanto que los factores políticos y económicos son determinantes en lo que se refiere a la definición del número y tipo de patologías a incluir, en la definición de las estrategias de pesquisa a utilizar $y$, fundamentalmente, en el establecimiento de las fuentes de financiamiento del Programa.

La realización de un apropiado diagnóstico de situación previo a la implementación de un Programa permitirá efectuar no solamente una planificación adecuada del mismo sino también una correcta asignación tanto de los recursos humanos como económicos, y fundamentalmente, encontrar soluciones apropiadas y acordes a las necesidades existentes.

No obstante estos conceptos, resulta importante dejar en claro que en la actualidad no hace falta "inventar nuevamente la rueda", y que por lo tanto el desarrollo de un Programa de PN debe ser construido sobre la base y experiencia de casi cinco décadas de organización exitosa de diferentes sistemas de PN a lo largo de todo el mundo. Esto significa que, a pesar de que la experiencia demuestra que los 
obstáculos y desafíos que deben enfrentar los Programas de PN en vías de implementación siguen existiendo, los errores cometidos previamente por otros no deben ser repetidos y debe aprovecharse la experiencia de quienes han transitado y allanado el camino con anterioridad (2).

Para lograr esto resulta esencial que no se realicen esfuerzos aislados y que se establezcan colaboraciones entre Programas ya desarrollados y en vías de organización, de forma tal de poder tener acceso al aprendizaje necesario para desarrollar estrategias exitosas de implementación, y de esta forma evitar un gasto infructuoso de tiempo, recursos y energía.

\section{Aspectos a considerar en la definición del diagnóstico de situación}

- Legislación: se deberá contemplar si existe legislación vigente a nivel nacional, estatal o provincial referida a la realización de las pruebas de pesquisa o a la ejecución de los Programas de PN, a partir de lo cual pueden presentarse diferentes situaciones.

- Si al momento de organizar el Programa ya existe alguna ley referida a la PN, se contará con un elemento importante en favor de una rápida implementación del mismo. En estos casos deberán analizarse cuales son los contenidos de dicha ley y si existe una reglamentación de la misma.

- En algunos casos existen leyes que sólo contemplan la obligatoriedad de la realización de las pruebas de PN para determinadas patologías pero sin contemplar otros aspectos de la misma. En estos casos, la legislación hará una contribución significativa para poder alcanzar una mayor cobertura en menor período de tiempo, pero, indudablemente, quedarán descubiertos aspectos relacionados con la confirmación, tratamiento y seguimiento de los casos detectados, lo cual a la larga redundará en una menor eficiencia del Programa en su conjunto.

- La mayor utilidad de las leyes vinculadas con la PN se presenta cuando las mismas no sólo contemplan la obligatoriedad de la realización de las pruebas de laboratorio, sino que también prevén la confirmación, tratamiento y seguimiento 
de los casos detectados, y el origen de los recursos financieros que serán utilizados para solventar el funcionamiento global del Programa a lo largo del tiempo.

- Otro punto importante a tomar en consideración es que estas leyes pueden estar definidas solamente para dar cobertura a algunas patologías sin posibilidad de inclusión de otras nuevas, o bien puede darse una situación menos rígida como la que se presenta en aquellos casos en los que la lista de enfermedades a pesquisar queda abierta a una potencial ampliación posterior.

- En aquellos casos en los que no existe legislación se deberá tomar en consideración que si se va a trabajar sobre un Proyecto de Ley para un Programa de PN, las implicancias de las leyes a formular deberán ser tales que, por un lado, ofrezcan la mayor cantidad de beneficios en cuanto a las posibilidades de implementación y desarrollo del Programa, pero por el otro, que el alcance de las mismas no sea excesivamente ambicioso al punto de que la oligatoriedad definida exceda o comprometa las posibilidades reales del Programa.

- Recursos humanos: se deberá prever cuales serán los recursos humanos que estarán afectados a las tareas del Programa.

- En general, cuando se lleva a cabo la implementación de un Programa de PN son muy pocos los recursos humanos genuinos que se designan, y en la mayor parte de los casos se procede efectuando una asignación de tareas y responsabilidades a personal previamente designado en hospitales públicos y maternidades o laboratorios del sector privado.

- En vista de la aseveración anterior y de que la PN requiere la participación de un equipo multidisciplinario de salud, se deberá evaluar si se cuenta con el personal apropiado para poder llevar a cabo las tareas específicas en los distintos niveles de ejecución, y establecer además una escala de responsabilidades según las tareas asignadas a cada uno de ellos (1). 
- Educación y difusión: se deberá evaluar si existe una estrategia definida para llevar a cabo la educación y difusión del Programa, y si se cuenta además con los elementos y el financiamiento necesarios para la ejecución de la misma.

- El proceso educativo deberá estar dirigido al personal de Salud afectado a cada una de las tareas del Programa y deberá incluir tanto la capacitación como la formación del mismo. Su planificación deberá efectuarse de manera tal que dicho personal tenga acceso a un conocimiento detallado de todas las actividades y procedimientos del Programa, las responsabilidades que les competen y los tiempos óptimos de ejecución de cada tarea.

La educación deberá ser un proceso prioritario, sistemático y continuo, para cuya ejecución podrán emplearse distintas estrategias que incluyen charlas, videos, cursos, seminarios y simposios de entrenamiento y concientización (2). Estas actividades deberán complementarse además con manuales de procedimientos escritos que sean suficientemente claros y concisos a fin de facilitar su comprensión y aplicación.

En el caso del personal de salud que tiene a su cargo las tareas específicas correspondientes al Laboratorio de pesquisa y al Centro de Atención Especializada encargado de la confirmación diagnóstica, el tratamiento y el seguimiento de los casos detectados, resulta recomendable la planificación de rotaciones o pasantías en Programas de PN afianzados y reconocidos por su trayectoria, y también la convocatoria de expertos externos a efectos de que, a través de visitas científicas periódicas, brinden su asesoramiento y asistencia técnica $(2,3)$.

Adicionalmente, el proceso educativo también deberá estar dirigido a políticos y responsables de la toma de decisiones políticas en Salud Pública, los cuales pueden resultar sumamente importantes para asegurar la sustentabilidad del Programa. En estos casos, y a efectos de evitar una interpretación errónea que pueda conducir a pensar que la PN se trata solamente de una prueba de laboratorio, la educación deberá enfocarse poniendo el mayor énfasis posible en asegurar que se realice una transmisión apropiada del concepto de PN y de sus 
objetivos. Por otra parte, la misma deberá complementarse con documentación que ponga en evidencia en forma contundente los resultados y beneficios obtenidos por otros Programas ya implementados previamente, los propios resultados que pudieran haberse obtenido en una experiencia piloto previa, las consecuencias de una enfermedad congénita no tratada, los beneficios resultantes de la detección y tratamiento precoz ilustradas de una manera gráfica y simple, y finalmente, los costos estimativos del Programa desarrollados en forma concisa y preferentemente desde el punto de vista del costo beneficio resultante.

En esta última tarea puede resultar de vital importancia la asistencia de expertos externos ya sea tanto a través de visitas personales como del envío de documentos escritos, y también la participación de diferentes grupos de padres sensibilizados con la detección de enfermedades congénitas (4).

- En cuanto a la difusión, el Programa de PN debe ser promovido y difundido en forma continua a nivel de la comunidad pública, antes de su implementación y una vez que el mismo ya ha sido puesto en funcionamiento, para lo cual es indispensable la correcta información y concientización de la población en general acerca de los objetivos y beneficios reales del Programa.

Las estrategias a utilizar para ejecutar esta tarea incluyen la entrega de folletos explicativos a padres y madres -tanto durante los cursos de preparto como también inmediatamente después de haberse producido el nacimiento del niño-, la presentación de charlas y videos, y la colocación de posters o afiches en lugares públicos, maternidades, laboratorios y centros asistenciales (2,4-5).

Por otra parte, y en caso de que se pretenda lograr una difusión de acceso masivo puede recurrirse a campañas a través de medios de difusión pública como diarios, revistas de actualidad, radio y televisión, y también a través de la emisión periódica de comunicados de prensa $(2,5)$.

- Efectores para la recolección de muestras de sangre: se deberá determinar si existe personal capacitado para llevar a cabo la recolección de las muestras de 
sangre de los RN.

- Se deberá definir claramente quienes son los responsables de la recolección de dichas muestras en cada maternidad, ya sea tanto del ámbito público como del ámbito privado, e inclusive también en aquellos casos en los que el parto se produzca en forma domiciliaria o fuera de algunos de los establecimientos antes mencionados.

- En general se establece que la responsabilidad de la toma de muestras recae sobre el personal de salud que se encuentra en el entorno del RN en el momento del nacimiento, y se define una escala de responsabilidades de acuerdo a las funciones desempeñadas.

De este modo, y dependiendo de la organización interna de cada institución, la responsabilidad puede recaer sobre Obstetras, Parteras, Enfermeras, Técnicos de Laboratorio y de Hemoterapia, Bioquímicos, Médicos Residentes, Neonatólogos, Pediatras o Jefes de Servicio.

- En el caso de que se produzcan partos domiciliarios se define que la responsabilidad de la toma de muestras recaerá sobre las parteras, padres y/o tutores.

- Características de las muestras de sangre: se deberá evaluar si existe una definición conceptual clara acerca del tipo de muestras de sangre a utilizar, los requisitos que deben cumplir las mismas, y los tiempos óptimos de recolección y envío al laboratorio de pesquisa.

- El tipo y condiciones de muestras de sangre a utilizar dependerá fundamentalmente de las patologías que hayan sido seleccionadas para pesquisar y de las estrategias de pesquisa definidas por el propio Programa, siendo las muestras de sangre entera impregnadas en papel de filtro (DBS) obtenidas por punción de talón las que se utilizan en la mayor parte de los mismos. A pesar de esto, se debe mencionar que existen algunos ejemplos de Programas que utilizan otras materiales biológicos como por ejemplo sangre entera de cordón impregnada en papel de filtro.

- Con respecto a las características de las muestras de sangre, existen normas 
específicas publicadas por el Instituto de Estándares Clínicos y de Laboratorio de los EE.UU. (CLSI, ex-NCCLS) (6) en las cuales se establecen las condiciones necesarias para una correcta recolección de muestras. Estas características, al igual que otros aspectos relacionados con las muestras de sangre serán descriptos en detalle en el Capítulo 2.

- En cuanto a los tiempos de recolección de muestras, y tal como ocurre con el tipo de muestras de sangre a utilizar, los mismos deberán ser establecidos en cada Programa de acuerdo a las patologías a pesquisar y a las estrategias de trabajo definidas, en tanto que la frecuencia de envío de las mismas al laboratorio deberá establecerse de manera tal de asegurar que las muestras lleguen rápidamente y que, en consecuencia, esta etapa no resulte un factor determinante como una potencial causa de retraso en la confirmación diagnóstica e inicio del tratamiento.

- Transporte: se deberán evaluar las alternativas disponibles para llevar a cabo el transporte de las muestras de sangre de los RN al laboratorio de pesquisa en tiempo y forma.

- Dado que la logística es un punto crítico en relación a la eficiencia que ha de alcanzar un Programa de PN, antes del lanzamiento del mismo se deberá definir cuál es el sistema de transporte de muestras a utilizar que permitirá asegurar un traslado seguro y eficiente de las mismas, a un costo razonable.

- En el caso de las instituciones públicas se podrá establecer la utilización de algún sistema de transporte oficial, o bien el uso de las propias ambulancias de los hospitales, mientras que en el caso de las instituciones o laboratorios del sector privado se podrá recurrir a servicios de correo privado o a comisionistas.

- Un punto importante a tomar en consideración es la posibilidad de gestionar un acuerdo de franqueo especial -o en el mejor de los casos de un franqueo exento de pago-, para el envío de las muestras de sangre de RN a través de algún sistema de servicio postal o courier de alcance nacional que asuma la responsabilidad de brindar apoyo logístico al Programa de PN (2). 
- Laboratorios de pesquisa y confirmación: se deberá evaluar si se cuenta con un Laboratorio de pesquisa centralizado, capacitado para analizar eficiente y oportunamente un elevado número de muestras a diario, con métodos de análisis y equipamiento apropiados, y dotado de un estricto sistema de control de calidad interno y externo; y por otra parte si existe disponibilidad de un Laboratorio de confirmación capaz de responder en tiempo y forma a la demanda resultante del panel de pruebas requeridas a efectos de poder establecer un diagnóstico definitivo de certeza o de descartar una patología, respaldado por un sistema de calidad apropiado, acorde a las implicancias de las tareas que le competen (2).

En lo que se refiere al Laboratorio de pesquisa, los requisitos y condiciones que debe cumplir el mismo serán discutidos en detalle en el Capítulo 2.

- Seguimiento: se deberá definir un Sistema de Seguimiento que asegure la continuidad del proceso de PN más allá de lo que implican las pruebas de pesquisa en sí mismas.

- La definición del Sistema de Seguimiento del Programa requiere que se determine quienes serán los responsables de llevar a cabo la localización de aquellos neonatos que asi lo requieran, la recolección de nuevas muestras de sangre, el envío de las mismas al laboratorio de pesquisa, la derivación de los RN al Centro de Atención Especializada para su confirmación diagnóstica, y la localización de aquellos niños con diagnóstico ya confirmado y que por alguna razón no estén cumpliendo con las pautas de seguimiento de tratamiento previamente establecidas.

- En general, este Sistema de Seguimiento debe estar conformado por un equipo de Asistentes Sociales, de los cuales un número mínimo debe desempeñar sus funciones a nivel central, es decir coordinando las acciones desde el Centro de Atención Especializada, mientras que el resto debe realizar sus tareas distribuido a lo largo de toda el área de alcance del Programa.

- Adicionalmente debe tomarse en consideración que este Sistema de Seguimiento también será el responsable de monitorear que todas las 
acciones desencadenadas como parte del algoritmo de trabajo a partir de una muestra mal colectada o de un resultado anormal en una prueba de pesquisa sean cumplimentadas en tiempo y forma. En general, esta tarea no es ejecutada por el equipo de Asistentes Sociales sino que, en razón de la disponibilidad de la información necesaria para tal fin, es ejecutada por el propio Laboratorio de pesquisa.

- Tratamiento: se deberá evaluar la disponibilidad de Centros de Atención Especializada, que cuenten con recursos humanos e infraestructura de diagnóstico y tratamiento apropiados para llevar a cabo dichas tareas.

- Los principios generales de la PN establecen que para alcanzar una máxima eficiencia en las instancias de confirmación, tratamiento y seguimiento de los casos detectados, es necesario que las mismas sean ejecutadas en forma centralizada a través de Centros de Atención Especializada.

- La conformación de un equipo de médicos especialistas es uno de los elementos clave a considerar para asegurar el correcto funcionamiento de dichos Centros. El mencionado equipo médico deberá incluir endocrinólogos especializados en pediatría, neurólogos especializados en el manejo de enfermedades neurometabólicas, genetistas, nutricionistas, neumonólogos, kinesiólogos y psicólogos, y eventualmente infectólogos dependiendo esto del grupo de enfermedades que hayan sido seleccionadas para pesquisar.

- Por otra parte, los Centros de Atención Especializada deberán contar con infraestructura y herramientas diagnósticas apropiadas de manera tal que les sea posible definir el diagnóstico en forma rápida y eficiente, lo cual en la mayor parte de los casos implicará la realización de pruebas de laboratorio.

No obstante esto, debe tenerse en cuenta que en algunos casos se requerirá también la realización de otro tipo de pruebas, como por ejemplo estudios de diagnósticos por imágenes (rayos $X$, centellografías) o de ultrasonido (ecografías).

- Un concepto sumamente importante para destacar con referencia al manejo del 
tratamiento es que no se recomienda bajo ninguna circunstancia que el mismo sea llevado a cabo por médicos clínicos generalistas, por médicos especializados en el manejo de algunas de estas enfermedades pero de presentación en la edad adulta, o en forma aislada en consultorios médicos que no forman parte de la estructura de un Programa, puesto que cualquiera de estas circunstancias puede afectar significativamente la eficiencia de dicho tratamiento.

- En cuanto a los tiempos de inicio del tratamiento, los mismos deben ser definidos durante la planificación del Programa de PN, para lo cual se debe partir de la premisa de que cuanto más precozmente sea implementado el mismo mayor será su efectividad.

Habitualmente se define como tiempo óptimo de inicio del tratamiento antes de los 15 días de vida. Sin embargo, debe contemplarse que algunas patologías requieren ser tratadas aún más precozmente, puesto que en caso contrario, puede producirse la muerte del RN por una crisis metabólica aguda o bien instalarse algún tipo de alteración neurológica a consecuencia de la existencia de una ventana de vulnerabilidad que se pone de manifiesto durante los primeros días de vida.

- Otro elemento a considerar es que el Programa debe asegurar la disponibilidad de una fuente confiable para la provisión continua tanto de los medicamentos necesarios para el tratamiento, como de los productos y alimentos especiales utilizados para el manejo terapéutico de muchas de las enfermedades metabólicas pesquisadas.

- La centralización del seguimiento del tratamiento a largo plazo y su evaluación periódica, son una condición fundamental para asegurar el éxito del Programa, puesto que de este modo se puede contar con los datos y elementos necesarios para realizar una valoración objetiva de los pro y contras del tratamiento, desarrollar e implementar nuevas alternativas terapéuticas, y contar con una cantidad de casos detectados significativos desde el punto de vista epidemiológico.

- La planificación del tratamiento también debe considerar que el manejo de los 
casos detectados es un proceso acumulativo, por lo cual se deberá contemplar la incorporación progresiva de recursos humanos y también la factibilidad de una descentralización en etapas avanzadas del seguimiento.

- La transferencia del seguimiento clínico general de los casos detectados a los pediatras de cabecera es un procedimiento que debe ser considerado como una norma a fin de descomprimir la carga de trabajo en el Centro de Atención Especializada.

- Fuentes de financiamiento: se deberá evaluar si existe una partida presupuestaria asignada al Programa, por ejemplo a través de la legislación vigente, o bien una fuente de financiamiento estable que permita solventar no solamente las pruebas de pesquisa, sino también el tratamiento y el seguimiento de los casos detectados, la educación del personal, la difusión del Programa, y la provisión de los recursos humanos necesarios.

- Sin lugar a dudas, el financiamiento es el problema más dificultoso que deben enfrentar los Programas de PN, no sólo en lo referente a la fuente de financiamiento en sí misma sino también en lo que respecta al potencial alcance del Programa y a los métodos de reembolso a utilizar (1).

- En vista de lo expresado anteriormente, el primer punto a definir es quién será el responsable del financiamiento del mismo. Por definición, y por tratarse de un Programa de Atención Primaria de la Salud Pública, es el Estado quién debería hacerse cargo de crear y proveer el presupuesto necesario para su funcionamiento.

Sin embargo, este financiamiento no necesariamente debe limitarse a los ingresos públicos del estado (1), razón por la cual no es infrecuente encontrar situaciones en las cuales es el sector privado quien financia a los Programas, por ejemplo a través de Organizaciones no Gubernamentales (ONG), 0 , inclusive, situaciones en las cuales el Estado se hace cargo de organizar y coordinar todas las actividades, pero a través de terceros pagadores de dichas prestaciones.

- Hablar de financiamiento no solamente implica crear el presupuesto para las 
pruebas de pesquisa, sino también para cubrir la educación, difusión, y el tratamiento y seguimiento de los casos detectados, especialmente en aquellas enfermedades en las que el mismo implica un costo muy elevado, como es el caso por ejemplo de los ECM que requieren un tratamiento dietario con alimentos y/o productos especiales.

- También deberá contemplarse el alcance que tendrá el financiamiento del tratamiento y seguimiento en cuanto al tipo de medicamentos, alimentos $y / 0$ productos especiales a proveer, a la posible cobertura por parte de las obras sociales o la seguridad social, y al límite de edad hasta el cual se extenderá la provisión de los mismos.

- Al presupuestar un Programa de PN se debe tomar en consideración que una vez que el Programa está instalado y funcionando correctamente, cuanto mayor sea la cantidad de patologías pesquisadas menor será el costo relativo del mismo.

Esta afirmación se basa en el hecho de que la incorporación de una nueva práctica al panel de pesquisa implicará principalmente la utilización del mismo sistema de comunicaciones, equipamiento, personal e infraestructura, y los únicos costos adicionales que se agregarán serán aquellos que corresponden a los reactivos empleados para la realización de las pruebas de Laboratorio (pesquisa y diagnóstico) y al tratamiento requerido para los casos detectados con la enfermedad en cuestión.

- Además, se debe tener en cuenta que la centralización de los Programas de PN no sólo se basa en un principio de eficiencia sino también en un principio de economía, puesto que cuanto mayor sea la cantidad de muestras analizadas por un Laboratorio de Pesquisa, entonces mayor será el rendimiento de los reactivos utilizados y menores serán sus costos.

De este modo se ha determinado que el número mínimo de muestras que deberían procesarse para lograr reducir los costos de un Programa está en el orden de las 50.000 muestras al año, es decir aproximadamente un mínimo de 200-300 muestras diarias $(1,5,7)$. 
- Expansión potencial: se deberán prever los criterios a utilizar para llevar a cabo la selección e inclusión racional y sistemática de nuevas patologías al Programa de PN.

- La selección de las patologías que se han de incluir en el Programa de PN se deberá realizar tomando como base los criterios de selección de Wilson y Jungner antes descriptos o eventualmente los criterios definidos por el propio Programa o recomendados por organismos competentes.

Sin embargo, la decisión de incorporar definitivamente una nueva patología al panel de pesquisa dependerá de la incidencia de la misma -la cual debería ser determinada preferentemente en una prueba piloto previa-, de la composición étnica de la población y de la estimación del costo/beneficio establecido en base a los resultados preliminares de la prueba piloto y a las experiencias previamente publicadas.

- La estimación del costo/beneficio es un procedimiento que en algunos casos particulares, muy especialmente en países subdesarrollados o en vías de desarrollo, es muy difícil de realizar en la práctica, fundamentalmente por 3 razones:

a) porque en numerosas ocasiones no existen valoraciones de los costos reales que implican la educación diferencial especializada que requiere un individuo discapacitado mental y la atención médica y hospitalizaciones requeridas por individuos detectados tardíamente.

b) porque en otros casos el Estado realiza inversiones mínimas en este tipo de educación, razón por la cual prevenir la discapacidad no se traduce en un ahorro concreto.

c) porque no existen modelos que permitan realizar una valoración del costo social que implica el hecho de tener un individuo discapacitado mental en el seno de una familia y de la pérdida de productividad ocasionada por la imposibilidad de inserción de dicho individuo en la sociedad. 
- ORganización del pROGRAMa de diagnóstico y tRataMIENTO DE ENFERMEDADES CONGÉNITAS DEL MINISTERIO DE SALUD DE LA PROVINCIA DE BUENOS AIRES ${ }^{(\#)}$

\section{Introducción}

El Programa de Diagnóstico y Tratamiento de Enfermedades Congénitas (Prodytec) del Ministerio de Salud de la Provincia de Buenos Aires es un Programa Preventivo diseñado con el objetivo de llevar a cabo la detección, tratamiento y seguimiento de Fenilcetonuria (PKU) e Hipotiroidismo Congénito $(H C)$ en todos los RN del territorio de la Provincia de Buenos Aires. Dicho Programa, declarado de interés provincial en Octubre de 1995 mediante Resolución Ministerial 2760/95 (8), se inició en Abril de ese mismo año constituyéndose de este modo en el primer Programa de PN organizado y regionalizado que se implementó en la Argentina, hecho que se concretó sustentándose en 3 elementos principales:

1. La existencia de la Ley Provincial 10.429, sancionada y promulgada en 1986, en la cual "se declara obligatoria en todo el territorio de la Provincia de Buenos Aires, la investigación masiva con la finalidad del diagnóstico precoz de todo tipo de anomalías para el desarrollo del sistema nervioso de los niños RN y el consecuente tratamiento de los enfermos detectados por esa pesquisa", incluyéndose al HC y a la PKU a los fines de la aplicación de la mencionada Ley.

2. La conformación en Abril de 1994 por Resolución Ministerial 1819/94 (9), de una Comisión Coordinadora integrada por representantes del Ministerio de Salud de la Provincia de Buenos Aires, de la Fundación Bioquímica Argentina (FBA), y del Hospital Interzonal de Agudos Especializado en Pediatría "Sor María Ludovica" de La Plata (HIAEP SML).

3. La firma de un Convenio entre el Ministerio de Salud de la Provincia y la FBA en Febrero de 1995, por medio del cual esta última Institución se comprometió

(\#) Las actividades de organización e implementación del Prodytec fueron llevadas a cabo por las Dras. Norma Spécola, Zulma Santucci y Jorgelina Pattin del HIAEP Sor María Ludovica de La Plata junto con el autor de esta Tesis, todos miembros de la Comisión Coordinadora del mencionado Programa. 
a realizar en forma gratuita las pruebas de pesquisa de PKU e HC en todos los RN de maternidades de Hospitales Provinciales. El mencionado Convenio, aún vigente hasta Dic/2009, fue refrendado por Resolución Ministerial 705/95 (10) y ha sido el verdadero motor impulsor del Prodytec desde el origen del mismo.

\section{Planificación e implementación}

- Acciones de implementación. En la Tabla 8 se presentan las acciones que se llevaron a cabo en la planificación e implementación del Prodytec:

Tabla 8. Acciones de implementación del Prodytec

- Conformación de la Comisión Coordinadora

- Definición de las normas y pautas de funcionamiento

- Constitución de un equipo multidisciplinario de salud

- Diseño de las estrategias de formación y capacitación del personal de salud

- Diseño de la estrategias de difusión e información de la población general

- Definición de las estrategias de implementación del Programa

En relación a la Comisión Coordinadora, y a pesar de que con anterioridad al lanzamiento del Programa ya se contaba con una Comisión oficialmente designada por Resolución Ministerial (9), en cuyo seno se contemplaba la participación tanto de miembros de carácter político como de carácter técnico, una de las primeras acciones de implementación del Prodytec consistió en la materialización de dicha Comisión a través de la conformación del grupo de profesionales con funciones estrictamente técnicas que se haría cargo del diseño del Programa, incluyendo su planificación e implementación y también el desarrollo de las diversas actividades que le competerían en el futuro.

Este hecho quedó plasmado oficialmente en Diciembre de 1995 por Resolución Ministerial 6898/95 (11), a través de la cual la mencionada Comisión quedó conformada por cuatro profesionales médicos y bioquímicos del HIAEP SML y de la FBA, bajo la tutela del Director de Salud Mental del Ministerio de Salud de la Provincia de Buenos Aires. En la Tabla 9 se describen las funciones de la mencionada Comisión. 
Tabla 9. Funciones de la Comisión Coordinadora del Prodytec

- Definir las patologías a pesquisar (de acuerdo a la ley vigente)

- Definir los diferentes niveles de ejecución:

- Centros de recolección de muestras

- Sistema de transporte de muestras

- Laboratorios de pesquisa

- Centros Atención Especializada para el diagnóstico, tratamiento y seguimiento.

- Definir las normas y pautas de funcionamiento:

- Condiciones y tiempos de recolección de muestras

- Condiciones y frecuencia de envío de muestras al laboratorio

- Tiempos de análisis

- Criterios de interpretación de resultados

- Sistemas de seguimiento para localización de los RN

- Tiempos de inicio de tratamiento

- Coordinar las acciones entre los distintos niveles de ejecución

- Definir las estrategias de difusión y educación

- Definir las estrategias de implementación del Programa

- Evaluar los resultados en forma sistemática

- Conformar un registro epidemiológico

- Modificar las normas de funcionamiento cuando se requiera y corresponda

- Trabajar en la reglamentación de la Ley 10.429/86

- Estructura funcional. El Prodytec es un Programa cuyo funcionamiento se sustenta desde sus orígenes, en tres pilares principales:

1. Los Centros Asistenciales de toda la Provincia entre los que se incluye a Hospitales públicos provinciales y municipales, a Clínicas y Sanatorios Privados, y a Laboratorios de Análisis Clínicos. Los mismos son los responsables de llevar a cabo la recolección de las muestras de sangre de los RN, de enviar las mismas al Laboratorio de Pesquisa, de entregar los informes de resultados a los padres o tutores, y de proceder a la localización de los RN ya sea para efectuar la recolección de una segunda muestra o para realizar su derivación al Centro de Atención Especializada según corresponda, de acuerdo a la indicación recibida desde el Laboratorio de Pesquisa. 
2. El Laboratorio de Pesquisa -representado por el Laboratorio de Detección de Errores Congénitos de la FBA-, responsable de proveer las tarjetas de recolección de muestras, de efectuar el análisis de las mismas, de informar los resultados de las pruebas, de validar los métodos de análisis, de definir los valores de corte a utilizar, de comunicar a los Centros Asistenciales cuales RN requerirán su localización y las acciones a seguir con los mismos, y de comunicar al Centro de Atención Especializada la información de aquellos RN que fueron derivados para su confirmación, a fin de que éste último coordine las acciones de localización que corresponda realizar.

3. El Centro de Atención Especializada-representado por el HIAEP SML de La Plata a través del Servicio Social, el Laboratorio de Bioquímica Especializada del Laboratorio Central, la Sala de Endocrinología y Crecimiento, y la Sala de Neurología-, responsable de realizar la evaluación clínica y las pruebas diagnósticas de laboratorio o de la índole que corresponda en aquellos RN con pruebas de pesquisa anormales, de confirmar o descartar el diagnóstico, de implementar el tratamiento y el seguimiento a largo plazo de los casos confirmados, y de comunicar la información final del diagnóstico al Centro Asistencial de origen y al médico pediatra a cargo del paciente.

Por otra parte, además de los tres pilares principales antes mencionados, también se debe destacar la participación de un cuarto componente que ha desempeñado un rol fundamental para asegurar el correcto funcionamiento del Programa, representado por el Sistema Oficial de Distribución de Información Clasificada (SODIC) dependiente del Ministerio de Gobierno de la Provincia de Buenos Aires, el cual es el responsable de efectuar el transporte de las muestras de sangre de los RN desde los Hospitales públicos provinciales y municipales al Laboratorio de la FBA, y también de los informes de resultados y el material necesario para la recolección de muestras desde la FBA hacia los mencionados Hospitales.

En la Figura 8 se presenta el organigrama que define la estructura funcional actual del Prodytec. 


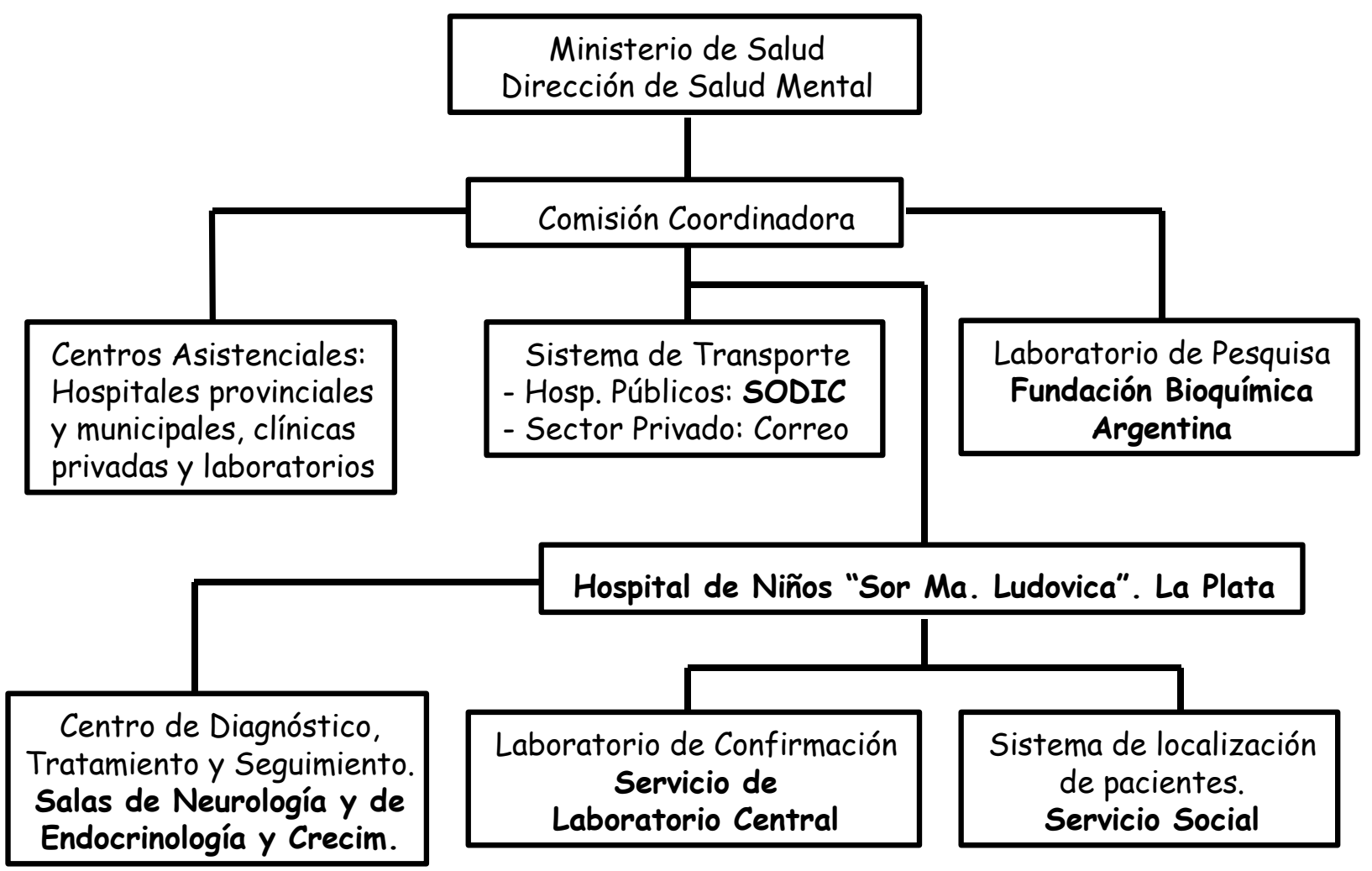

Figura 8. Estructura funcional del Prodytec

- Equipo interdisciplinario de salud. Se constituyó un equipo interdisciplinario al cual se dividió en 2 niveles de acuerdo a las funciones asignadas a cada uno de ellos:

- Nivel general: comprende a todo el personal de salud que se desempeña en los Centros Asistenciales y que tiene a su cargo la ejecución de las actividades asignadas a los mismos en relación al Programa de PN. En el mismo se incluye a Neonatólogos, Pediatras, Obstetras, Parteras, Personal de Enfermería, Técnicos de Laboratorio y Hemoterapia, Bioquímicos, Asistentes Sociales y Personal Administrativo.

- Nivel especializado: comprende a todo el personal afectado al Laboratorio de Pesquisa y al Centro de Atención Especializada, y que tiene a su cargo la ejecución de las actividades asignadas a los mismos. En dicho nivel se incluye a Bioquímicos, Técnicos de Laboratorio, Endocrinólogos especializados en Pediatría, Neurólogos especializados en enfermedades neurometabólicas, Nutricionistas, Genetistas, Psicólogos, Asistentes Sociales y Personal Administrativo. 
- Normas y pautas de funcionamiento. Las normas y pautas de funcionamiento del Prodytec han sido descriptas en detalle en el texto de la Reglamentación de la Ley 10.429/86 de la Provincia de Buenos Aires (12-14). Las mismas son presentadas a continuación en forma resumida:

- Responsables de la recolección de muestras: se asignó esta responsabilidad a los Jefes de Servicio, Médicos Obstetras, Médicos que actúen en la atención del RN, Parteras y personal a cargo de la atención del RN, habiéndose establecido que en el caso de partos domiciliarios los responsables de asegurar que se efectúe la toma de muestra son los padres, tutores, curadores o guardadores.

- Condiciones de recolección de muestras: se definió que las pruebas de pesquisa deben ser realizadas sobre muestras de sangre entera colectadas en tarjetas de papel de filtro de uso diagnóstico provistas por el Laboratorio de la FBA, empleando para ello la técnica de recolección recomendada en la normas del CLSI (ver Capítulo 2).

- Tiempos de recolección de muestras: se estableció que para la pesquisa de PKU e HC las muestras deben ser colectadas entre las 24 horas y el $7^{\circ}$ día de vida, aunque preferentemente entre las 48 horas y el $5^{\circ}$ día de vida.

Para el caso de las altas precoces de las maternidades, producidas antes de las 24 horas de vida, se estableció que las muestras deben recolectarse indefectiblemente antes del alta y que se debe tomar una segunda muestra antes de los 7 días de vida.

- Condiciones y frecuencia de envío: se estableció que las muestras de sangre deben ser remitidas al Laboratorio de Pesquisa dentro de los 3 días de efectuada la extracción, asegurando su entrega antes de las 72 horas a contar a partir del momento de la realización del envío.

En relación al procedimiento de transporte de las muestras al laboratorio, el mismo debe realizarse colocando las muestras en sobres de papel, asegurando condiciones tales que las mismas no resulten expuestas al calor, sol, humedad, líquidos o cualquier otro tipo de material o sustancia que pueda 
alterar o dañar las mismas. En el caso de los Hospitales públicos, para los cuales se cuenta con un sistema de transporte específico, se estableció que los sobres conteniendo las muestras de sangre deben colocarse a su vez en cajas plásticas con tapa para ser transportadas.

- Tiempos de análisis: se estableció que las pruebas de pesquisa deben realizarse en el Laboratorio con una frecuencia no inferior a 3 veces por semana.

- Criterios de interpretación de resultados: se estableció que los resultados de las pruebas de pesquisa serían clasificados en 3 categorías según los valores de corte definidos por el propio Laboratorio de Pesquisa:

- Resultados normales: no requieren implementar ninguna acción posterior al análisis.

- Resultados dudosos: requieren la recolección de una segunda muestra colectada en papel de filtro.

- Resultados patológicos: requieren la inmediata derivación del RN al Centro de Atención Especializada para la confirmación del diagnóstico.

- Sistemas de comunicación y seguimiento para la localización de los RN: se estableció que el Laboratorio de Pesquisa debe ser el disparador de las acciones de localización y que estas acciones deben ser ejecutadas por los Centros Asistenciales de origen, bajo la coordinación central del Servicio Social del HIAEP SML de La Plata.

Por otra parte, se estableció que en el caso de aquellos RN en los que no sea posible obtener una respuesta a la citación, se debe proceder a comunicar la situación al Juez de Menores de turno de la jurisdicción correspondiente, de acuerdo a lo establecido por la Procuración General de la Suprema Corte de Justicia de la Provincia de Buenos Aires.

- Tiempos de inicio de tratamiento: se estableció que el tiempo óptimo para el inicio del tratamiento debe estar comprendido dentro de los primeros 21 días de vida.

- Estrategia de implementación. Si bien actualmente el Prodytec tiene alcance en todo el ámbito de la Provincia de Buenos Aires independientemente de si el 
nacimiento del RN ocurre en el sector público provincial o municipal o en el sector privado, cuando se dio inicio al mencionado Programa en 1995, su alcance estaba limitado exclusivamente a los Hospitales provinciales dependientes del Ministerio de Salud, puesto que la Ley 10.429/86 aún no había sido reglamentada.

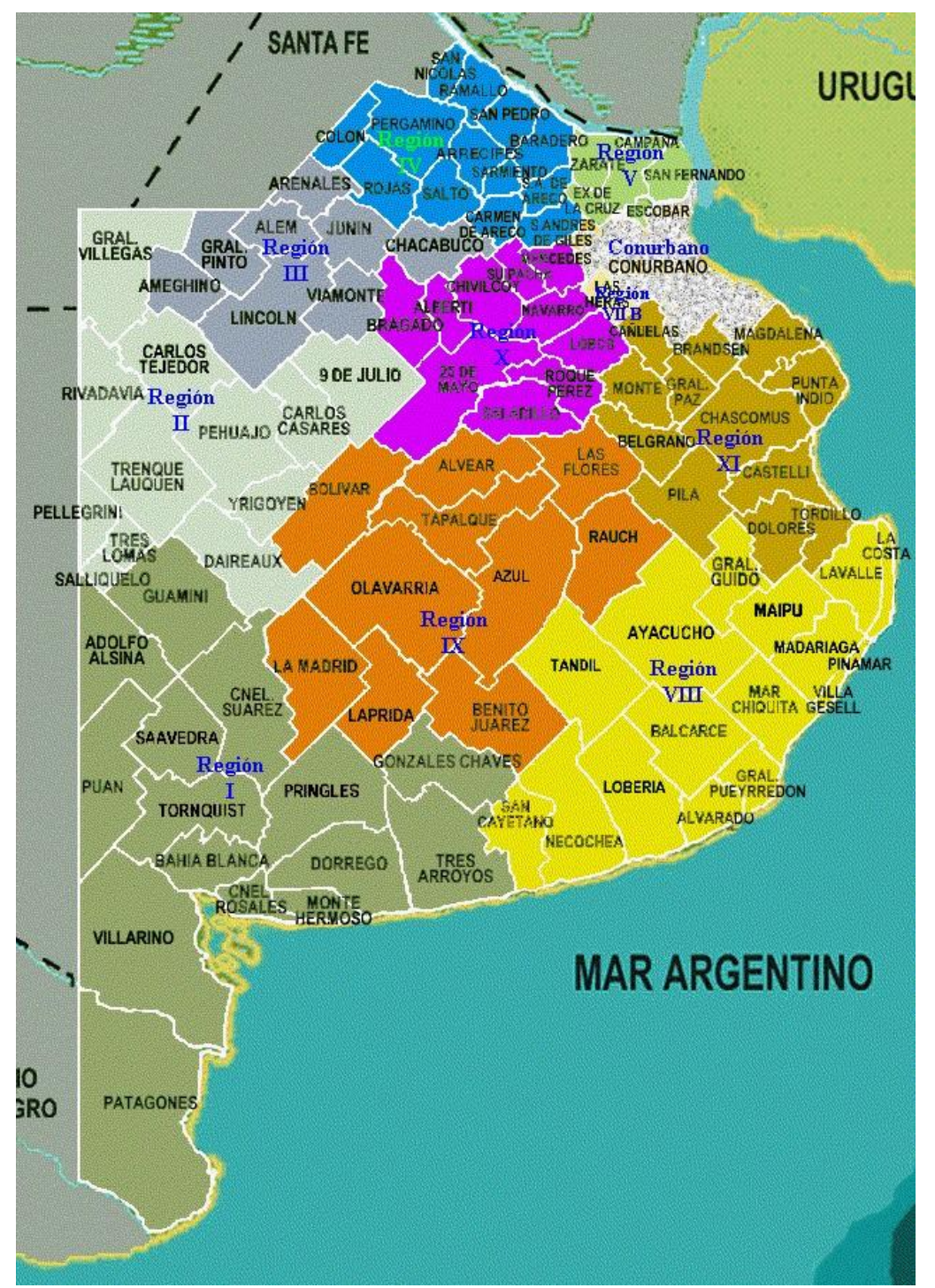

Figura 9. Regiones Sanitarias de la Provincia de Buenos Aires.

En función de esto, y habiendo realizado un análisis exhaustivo de los diferentes factores geográficos y poblacionales característicos de la región que podrían incidir en el funcionamiento del Programa, como son la superficie total de la Provincia (307.571 $\mathrm{km}^{2}$ ), la distribución geográfica de las 12 Regiones Sanitarias en las que se halla organizada la misma (Figuras 9 y 10), las distancias máximas a cubrir desde el punto previsto de centralización hasta las localidades más 
distantes (en promedio 550 a $600 \mathrm{~km}$, y aproximadamente $800 \mathrm{Km}$ al punto más distante ubicado en Carmen de Patagones), el número de nacidos vivos estimado para ese año en todo el territorio provincial (220.000 RN), las características de los 41 Hospitales provinciales que en aquel momento contaban con maternidad, y el número de nacimientos anuales ocurridos en cada uno de ellos individualmente y en su conjunto (aproximadamente 75.000 RN/año para el total de hospitales), se decidió plantear una estrategia de implementación progresiva del Programa por Regiones Sanitarias.

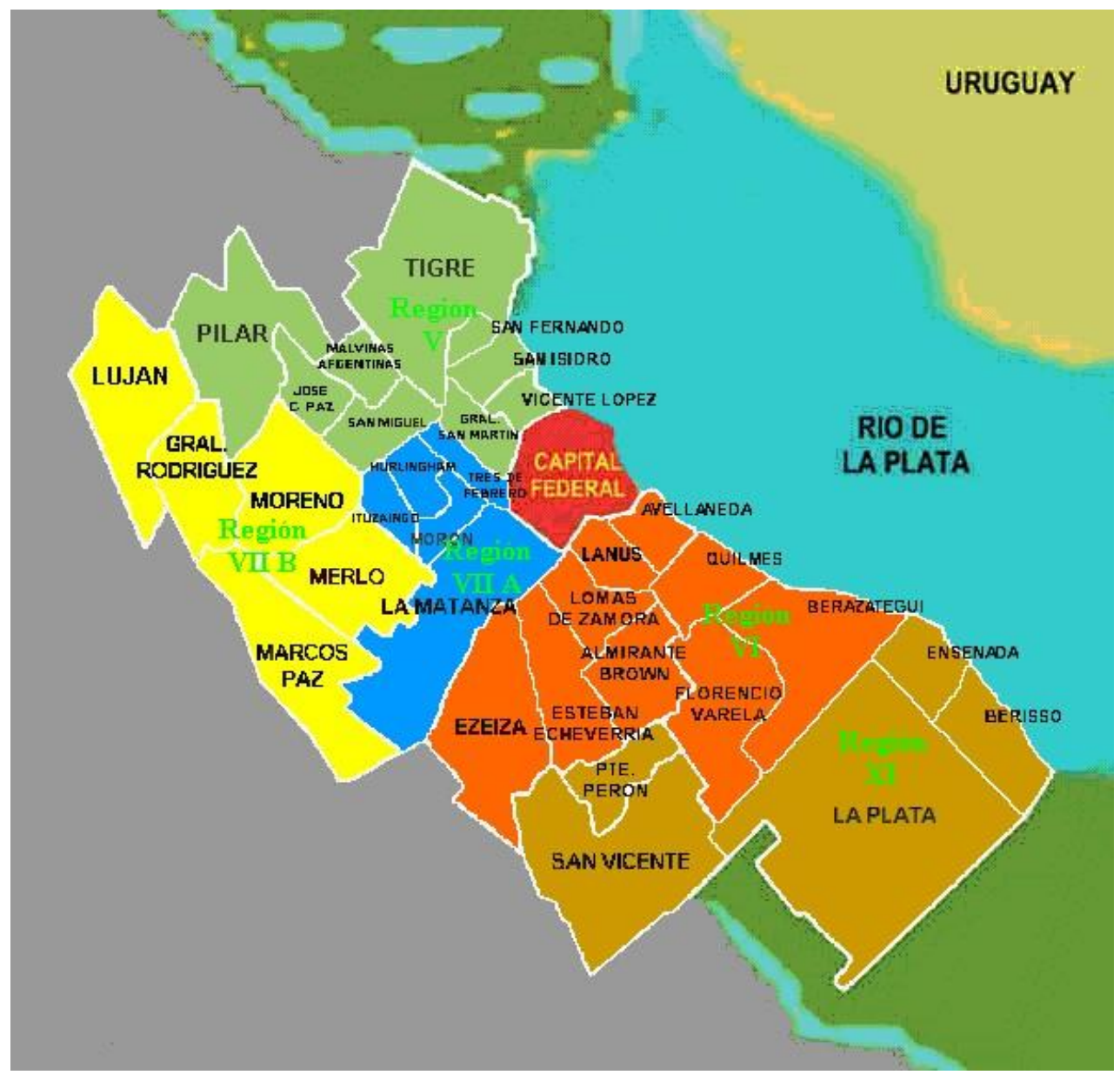

Figura 10. Regiones Sanitarias del Conurbano Bonaerense.

De esta forma, y en vista de que la centralización de las actividades del Prodytec se llevaría a cabo en la ciudad de La Plata, se seleccionó a la Regiones Sanitarias XI y VI, con cabeceras en La Plata y Lomas de Zamora respectivamente, para efectuar allí el lanzamiento del Programa y para realizar una experiencia de 6 meses de duración a contar a partir de Abril de 1995, a modo de prueba piloto. 
La selección de estas 2 regiones se realizó con la finalidad de contar con datos objetivos y concretos acerca del desempeño general del Programa trabajando con un grupo de Hospitales ubicados a distancias no superiores a los $150 \mathrm{~km}$ desde el punto de centralización, y con indicadores que permitieran evaluar su capacidad para responder eficientemente a la demanda generada por Hospitales que contaban con un número significativo de nacimientos mensuales, como era el caso de aquellos localizados principalmente en el área del Conurbano Bonaerense.

En función de esta selección, se trabajaría con un total de 8 hospitales de la Región Sanitaria XI (2 de ellos Hospitales pediátricos sin maternidad) y 11 hospitales de la Región Sanitaria VI, dando cobertura a un número potencial de 17.500 RN a lo largo de los primeros 6 meses de trabajo. En la Tabla 10 se presenta un listado de los hospitales incorporados en esta primera fase del Programa.

Tabla 10. Hospitales incluidos en la fase inicial del Prodytec

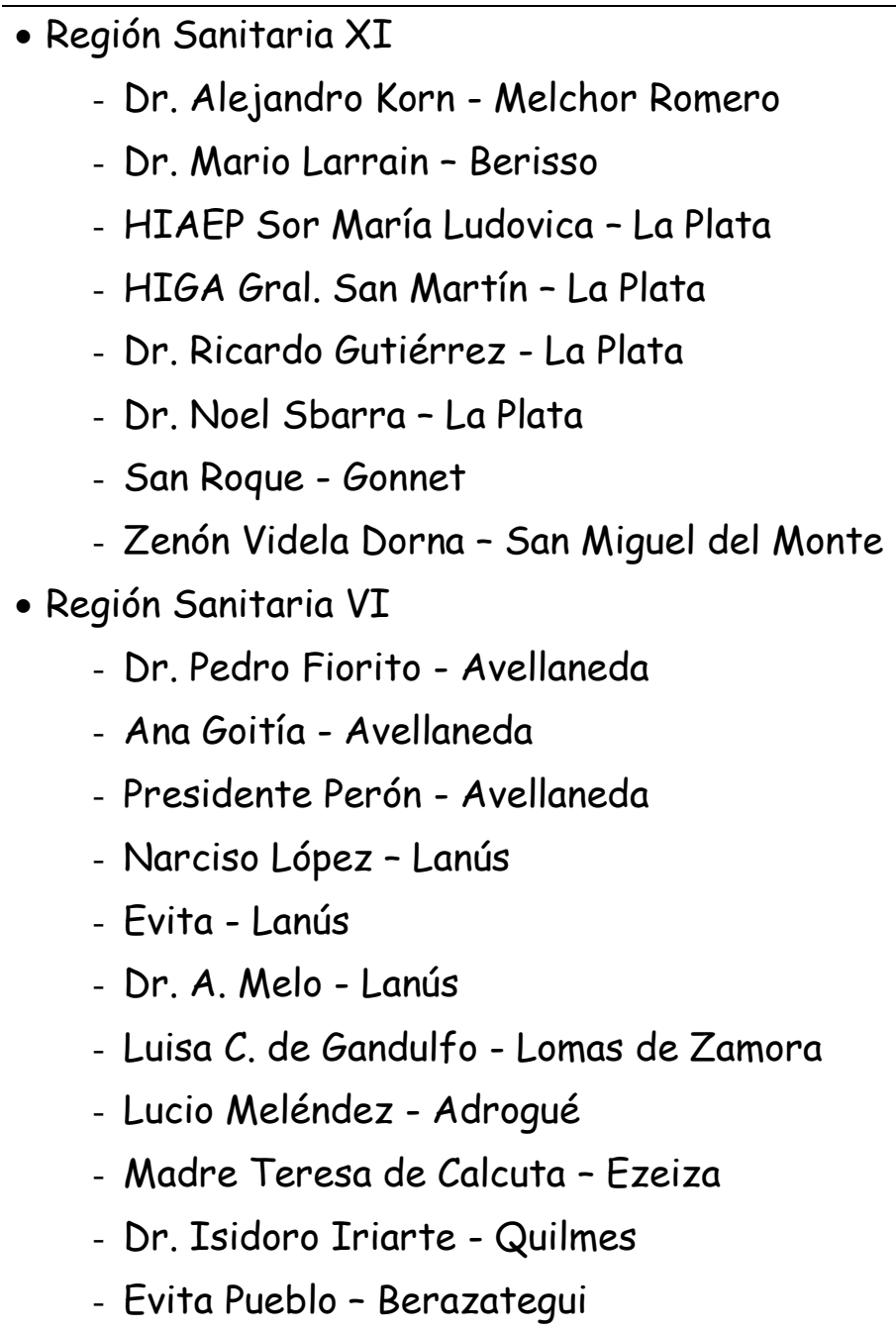


En cuanto a la estrategia de implementación propiamente dicha, el primer paso de la misma consistió en la realización de visitas personalizadas por parte de los integrantes de la Comisión Coordinadora a cada uno de los 18 Hospitales antes mencionados, tarea que se planificó de forma tal de lograr la incorporación progresiva de los mismos en un plazo estimado de 2 meses. En dichas visitas, y a través de charlas dirigidas a todo el personal que estaría afectado a las tareas del Programa, se procedió a comunicar las normas y pautas de funcionamiento del Prodytec, a capacitar al personal acerca de los aspectos técnicos de la recolección, conservación y envío de las muestras, y a entregar los procedimientos escritos a los cuales cada Hospital debería ajustarse de allí en más (13).

Una vez concluida dicha etapa piloto, y habiendo efectuado una revisión detallada del funcionamiento del Programa según las pautas establecidas en el diseño del mismo y también las modificaciones correspondientes en aquellos aspectos que no funcionaron de acuerdo a lo previsto -como ocurrió por ejemplo con el sistema de transporte utilizado para el traslado de las muestras de sangre desde los Hospitales al Laboratorio de Pesquisa (*)-, se procedió a continuar con la implementación del Prodytec a lo largo del resto de la Provincia.

Para cumplimentar esta segunda etapa se propuso un mecanismo de expansión "en mancha de aceite", de forma tal de concretar la incorporación progresiva de los Hospitales pertenecientes a 2 o 3 Regiones Sanitarias por mes a lo largo del período comprendido entre Octubre y Diciembre de 1995. Para tal fin, y de igual modo a lo realizado durante la fase piloto, la Comisión Coordinadora procedió a realizar visitas personalizadas a cada uno de los Hospitales a incorporar, con el objeto de informar y capacitar al personal de salud afectado a las tareas del Programa.

De esta forma, hacia fines de 1995 se había logrado la incorporación de 37 Hospitales provinciales sobre un total de 41 posibles, completándose la incorporación de los 4 Hospitales restantes en el transcurso de los primeros meses de 1996.

$\left.{ }^{*}\right)$ inicialmente el transporte de las muestras se realizó empleando los vehículos del Plan VIDA del Programa Materno Infantil del Ministerio de Salud, pero dado que dicho sistema de transporte no funcionó eficientemente, el mismo fue reemplazado por los servicios del SODIC. 
A lo largo del segundo año de trabajo del Prodytec, las actividades realizadas por la Comisión Coordinadora fueron tareas de carácter preponderantemente educativo y de afianzamiento del Programa, habiéndose alcanzado un objetivo de enorme trascendencia para su funcionamiento como fue haber logrado la Reglamentación de la ley 10.429/86 en Marzo de 1996, mediante Resolución Ministerial 1343/96 (12). Este hecho determinó que la exigencia de obligatoriedad de realización de las pruebas de pesquisa definidas por la Ley en cuestión dejara de ser exclusividad de los Hospitales Provinciales, extendiéndose su alcance a partir de ese momento también a los Hospitales de dependencia municipal y al sector privado.

Consecuentemente, durante el transcurso del año 1996, los representantes de la Comisión Coordinadora visitaron las cabeceras de cada una de las 12 Regiones Sanitarias con la finalidad de reunirse allí con los referentes/responsables del Prodytec de cada uno de los Hospitales provinciales ya incorporados, a efectos de intercambiar ideas e información, y de revisar en forma crítica y constructiva las acciones desarrolladas hasta ese momento. Adicionalmente, estas reuniones también contaron con la participación de distintos representantes del equipo de salud pertenecientes a los diferentes Hospitales municipales de cada región, los cuales podrían tomar a futuro la responsabilidad de la implementación del mencionado Programa en cada uno de ellos.

Sumado a estas tareas, hacia fines de ese mismo año también se concretó la incorporación de otros 4 nuevos Hospitales Provinciales, los cuales fueron inaugurados y puestos en funcionamiento por parte del Gobierno Provincial.

\section{Alcance y resultados}

En la actualidad, el Prodytec es el Programa más importante de la Argentina, no sólo por sus características en cuanto a organización, amplitud de su área geográfica de acción y trayectoria de más de 15 años de experiencia, sino también por la contribución que el mismo realiza a la tasa de cobertura nacional, por tratarse del Programa que anualmente pesquisa la mayor cantidad de niños para PKU e $\mathrm{HC}$ a nivel 
país (181.953 RN en el año 2009), y por contar con el mayor número absoluto de RN pesquisados para estas dos patologías (2.243.430 niños hasta Diciembre de 2009).

En la Tabla 11 se presenta un detalle del número anual de nacidos vivos de la Provincia de Buenos Aires, del número anual de nacidos vivos que corresponden específicamente al sector de hospitales públicos, del número de RN pesquisados y de la cobertura alcanzada año a año para el período 1995-2009 (14), mientras que en la Figura 11 se presenta gráficamente la evolución del mencionado Programa a lo largo del mismo período, incluyendo también la contribución realizada al total de RN evaluados por parte de los sectores público provincial, público municipal y privado.

Tabla 11. Prodytec: Evolución 1995 - 2009

\begin{tabular}{|c|c|c|c|c|}
\hline Año & $\begin{array}{c}\text { Nacidos vivos } \\
\text { Total }\end{array}$ & $\begin{array}{l}\text { Nacidos vivos } \\
\text { Sector público }\end{array}$ & $\begin{array}{c}\text { RN } \\
\text { Pesquisados }\end{array}$ & $\begin{array}{c}\text { Cobertura } \\
(\%)\end{array}$ \\
\hline 1995 & 219.045 & nd & 48.612 & $22.2(73.2)$ \\
\hline 1996 & 229.640 & nd & 108.669 & $47.3(85.7)$ \\
\hline 1997 & 235.273 & nd & 135.339 & $57.5(96.0)$ \\
\hline 1998 & 235.989 & $142.974(60.6)$ & 156.398 & $66.3(97.3)$ \\
\hline 1999 & 244.644 & $142.867(58.4)$ & 152.196 & $62.2(96.7)$ \\
\hline 2000 & 248.838 & $148.627(59.7)$ & 158.071 & $63.5(97.2)$ \\
\hline 2001 & 243.720 & $143.013(58.7)$ & 158.336 & $65.0(98.3)$ \\
\hline 2002 & 247.738 & $150.346(60.7)$ & 157.927 & $63.7(98.2)$ \\
\hline 2003 & 249.915 & $148.077(59.3)$ & 158.834 & $63.6(99.2)$ \\
\hline 2004 & 268.281 & $147.142(54.8)$ & 162.684 & $60.6(97.2)$ \\
\hline 2005 & 262.786 & 139.107 (52.9) & 162.975 & $62.0(97.1)$ \\
\hline 2006 & 261.941 & $134.908(51.5)$ & 162.242 & 61.9 (96.9) \\
\hline 2007 & 263.343 & $132.416(50.3)$ & 163.760 & $62.2(96.3)$ \\
\hline 2008 & 280.318 & $133.550(47.6)$ & 175.434 & $62.6(97.5)$ \\
\hline 2009 & 279.941 & $133.843(47.8)$ & 181.953 & $65.0(98.6)$ \\
\hline
\end{tabular}

NOTA 1: El dato de RN pesquisados correspondiente al año 1995 comprende exclusivamente el período Abril-Diciembre.

NOTA 2: El dato indicado entre paréntesis en la columna Nacidos vivos - Sector Público, corresponde a la contribución porcentual de este sector respecto del Total de Nacidos vivos.

NOTA 3: El dato indicado entre paréntesis en la columna Cobertura, corresponde a la cobertura alcanzada exclusivamente en el sector de Hospitales Provinciales.

Con respecto a la cobertura alcanzada, los datos presentados en la Tabla anterior ponen en evidencia un comportamiento muy diferente dependiendo de si el análisis se realiza en forma general para el total de la Provincia de Buenos Aires o en 
forma particular para aquellos niños que nacieron específicamente en el sector de Hospitales Provinciales. De este modo, es posible observar que la cobertura en el primero de estos casos alcanzó un valor máximo del 66.3 \% en 1998, y que a partir de alli hasta 2009 se mantuvo oscilando dentro de un rango comprendido entre el 60.0 y el $65.0 \%$, con la particularidad de que el último año repuntó precisamente hasta éste último valor. En contraposición, la cobertura lograda en el sector de Hospitales Provinciales alcanzó valores óptimos muy rápidamente ( 96.0 \% en 1997), y de allí en más se mantuvo en promedio en el orden del $97.5 \%$.

Estas diferencias en la tasa de cobertura dependiendo del sector al cual se haga referencia pueden ser explicadas sobre la base de diversos factores, entre los cuales el más importante es un factor de índole económico, relacionado con el hecho de que los Hospitales Provinciales son los únicos que gozan de gratuidad absoluta para la realización de las pruebas de pesquisa a todos los RN, a expensas del Convenio firmado entre el Ministerio de Salud de la Provincia de Buenos Aires y la FBA, por el cual ésta última institución es quién se hace cargo de cubrir los costos de dichas pruebas. A diferencia de esto, en el caso del sector público municipal y del sector privado, los recursos financieros para cubrir dichos costos provienen en el primer caso del propio presupuesto de cada Municipio, mientras que en el segundo son el resultado de la cobertura ofrecida por la obras sociales y sistemas de medicina prepaga, o por los propios padres de los RN.

Adicionalmente también intervinieron otros 3 factores que ejercieron su influencia para que la cobertura provincial no se incrementara en la magnitud esperada:

a) En primer lugar el hecho de que 8 Hospitales Municipales y el único Hospital Nacional de la provincia, cuyos RN representan el $6 \%$ del total, resuelven las pruebas de pesquisa por su propia cuenta o derivando las muestras a instituciones de la Ciudad de Buenos Aires,

b) En segundo lugar el hecho de que estimativamente, entre un 15 y un $20 \%$ de los RN que nacen en maternidades del sector privado, acceden a las pruebas de PN a través de Laboratorios privados de la misma provincia, -aunque por fuera de la estructura del Prodytec-, o eventualmente lo hacen en la Ciudad de Buenos Aires. 
c) Por último, el hecho de que a lo largo de los últimos 12 años analizados el número de nacidos vivos en la provincia experimentó variaciones muy significativas, ya sea tanto en el número total como en su distribución por sectores, observándose un crecimiento de aproximadamente un 12.0 \% en el número total de nacidos vivos entre los períodos 1997-1998 y 2004-2007, y un 6 \% adicional en los dos últimos años evaluados, y con la particularidad de que la contribución del sector público - la cual en números absolutos alcanzó un máximo del orden de 148.000 nacidos vivos en el período 2002-2004 cayendo un 10 \% en el período 2006-2009 (135.000 nacidos vivos en promedio)-, disminuyó de manera significativa en términos porcentuales pasando de aportar el $60 \%$ del total de RN de la provincia en el período 1998-2003 a contribuir solamente con el 48 \% en 2008-2009.

De este modo, y a pesar del incremento significativo experimentado por el Prodytec en el número de RN pesquisados en 2008-2009, el porcentaje de cobertura se mantuvo prácticamente invariable con respecto a años anteriores.

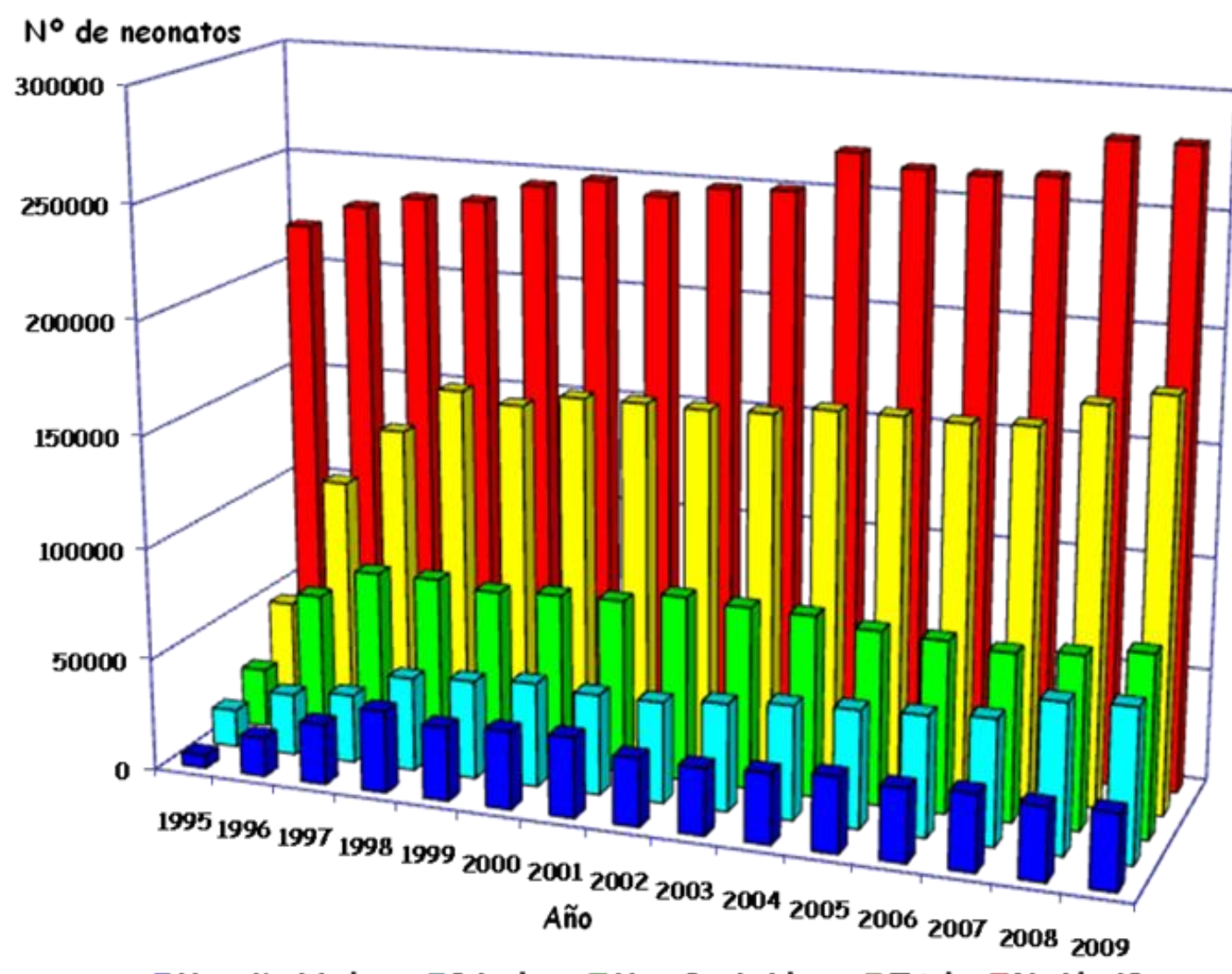

- Hosp. Muricipales $\square$ Privados $\square$ Hosp. Provinciales $\square$ Total $\square$ Nacidos Vivos

Figura 11. Distribución anual de neonatos pesquisados según jurisdicción y número de nacidos vivos. Período 1995-2009. 
Otro dato para comentar en relación a la evolución del Prodytec es la contribución realizada por cada sector al número total de RN pesquisados. Como se puede visualizar en la Figura 11, históricamente, la mayor contribución ha sido realizada por el sector de Hospitales Provinciales, a la cual le corresponde en promedio un $49.3 \%$ del total de RN pesquisados. Sin embargo, desde 2002 en adelante su contribución porcentual ha ido experimentando una disminución progresiva desde el 52.4 al $44.0 \%$ en 2008-2009, acompañada por un crecimiento concomitante en la contribución del sector privado, el cual pasó del 28.5 al $37.5 \%$ en ese mismo período. A diferencia de esto, la contribución del sector municipal, la cual en el período 2002-2007 se mantuvo prácticamente invariable correspondiéndole en promedio un $20.0 \%$ del total de RN pesquisados, mostró una caída en 2008-2009 al 18.0\%.

Un análisis más detallado de éste último aspecto, más específicamente desde el punto de vista de la participación de los diferentes Hospitales públicos de la Provincia de Buenos Aires en el Prodytec, pone en evidencia una vez más que el factor económico al cual se hiciera referencia anteriormente -relacionado con el origen de los recursos económicos disponibles en cada sector para cubrir los costos de las pruebas de pesquisa-, también ha ejercido su influencia en lo que se refiere a la incorporación de dichos hospitales al mencionado Programa, dependiendo de la jurisdicción a la cual pertenece cada uno de ellos.

De este modo, el análisis cronológico pone en evidencia que apenas un año después de la implementación del Prodytec, ya se contaba con la participación activa del 100 \% de los Hospitales Provinciales que cuentan con maternidad. En contraposición, en el caso de los Hospitales Municipales se observó una situación muy diferente caracterizada por el hecho de que la adhesión de los mismos al Prodytec nunca logró superar el $60 \%$ del total, habiéndose observado inicialmente un incremento sustancial en el número de hospitales incorporados entre los años 1996 y 1997 -a expensas de la reglamentación de la Ley $10.429 / 86-$, pero seguido de un período posterior de crecimiento muy lento hasta 2001, y de una etapa prácticamente sin cambios hasta 2009.

A efectos de ilustrar la influencia que tiene la participación de los Hospitales pertenecientes a uno u otro sector sobre la tasa de cobertura provincial, en la Figura 
12 se presenta la distribución de los 41 Hospitales Municipales que no participaron del Prodytec a lo largo del año 2009, de los 79 Hospitales Municipales y 48 Hospitales Provinciales que si lo hicieron, y de los 9 Hospitales Municipales que realizaron la pesquisa por otra vía, con respecto al rango de nacimientos anuales correspondientes a cada uno de ellos para ese mismo año.

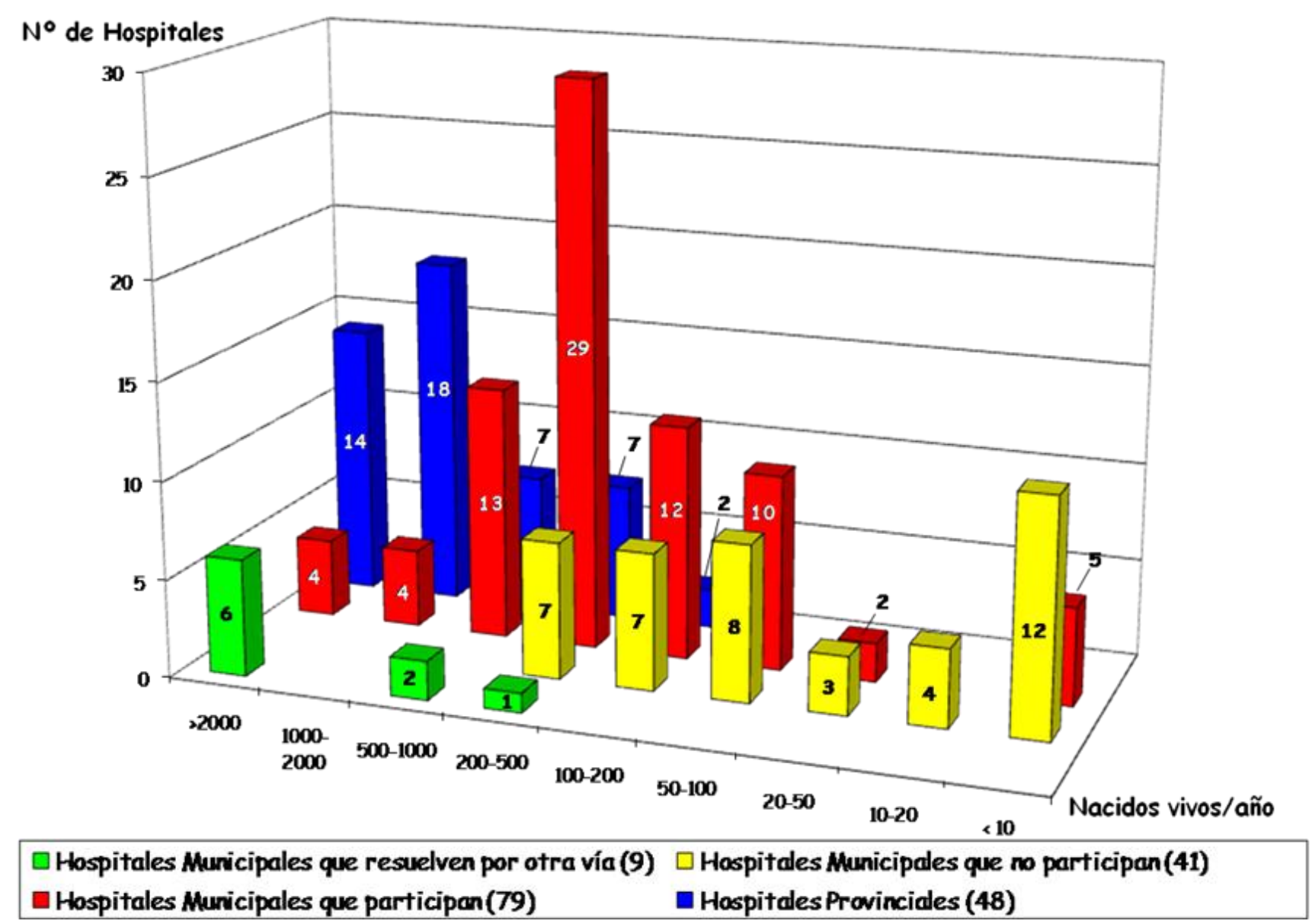

Figura 12. Distribución de Hospitales Provinciales y Municipales incorporados al Prodytec, y de Hospitales Municipales no incorporados al mismo, según el número anual de nacidos vivos correspondiente al año 2009.

NOTA 1: El grupo de 7 Hospitales Provinciales en el rango de 200-500 nacidos vivos/año, incluye 2 Hospitales Pediátricos sin maternidad.

NOTA 2: El grupo de 10 Hospitales Municipales incorporados al Prodytec, en el rango de 50-100 nacidos vivos/año, incluye 1 Hospital Pediátrico sin maternidad.

NOTA 3: El grupo de 6 Hospitales Municipales que resuelven la pesquisa por otra vía en el rango de más de 2000 nacidos vivos/año, incluye 1 Hospital Nacional.

NOTA 4: En el grupo de menos de 10 nacidos vivos/año correspondiente a Hospitales Municipales no incorporados al Prodytec, se deben incluir 11 Unidades Sanitarias y 3 Centros de Salud que no fueron contabilizados en la Figura 12, en los cuales durante el año 2009 se atendió un total de 53 partos. 
Como se puede inferir a partir de la Figura 12, y a pesar de que el número de 41 Hospitales Municipales no incorporados al Prodytec en sí mismo resulta realmente muy significativo, se debe destacar que el $83.5 \%$ del total de hospitales que cuentan con más de 100 nacimientos al año (71/85) participa activamente del Prodytec (72.9 $\%)$ o resuelve la pesquisa por otra vía (10.6 \%), mientras que el $33.3 \%$ de los hospitales que no participan (16/41) corresponden a hospitales que desde el punto de vista del número anual de nacimientos que presentan ( $<20$ nacidos vivos/año), tienen una influencia mínima sobre la cobertura general del Programa. No obstante esto, se debe poner un énfasis especial en asegurar la incorporación de la totalidad de los mismos, independientemente del número anual de nacidos vivos que le corresponda a cada uno de ellos.

Finalmente, y para concluir con esta somera descripción de las principales características del Prodytec, en la Tabla 12 se presentan el número de casos detectados a lo largo de los primeros 15 años de existencia del mismo y las incidencias resultantes para PKU, HPA persistente e HC en la Provincia de Buenos Aires.

Tabla 12. Prodytec: Casos detectados 1995 - 2009

\begin{tabular}{|c|c|c|}
\hline Patología & Casos detectados & Incidencia \\
\hline PKU & 78 & $1: 28.762$ \\
\hline HPA $A_{\text {persistente }}$ & 104 & $1: 21.571$ \\
\hline$H C$ & 983 & $1: 2.282$ \\
\hline
\end{tabular}

\section{BIBLIOGRAFIA}

1. Therrell BL, Panny SR, Davidson A, Eckman J, Hannon WH, Henson MA, Hillard M, Kling S, Levy HL, Meaney FJ, McCabe ERB, Mordaunt V, Pass K, Shapira E and Tuerck J. "U.S. Newborn Screening System Guidelines: Statement of the Council of Regional Networks for Genetic Services". Screening 1, 135-47, 1992.

2. International Atomic Energy Agency. "Implementing and Sustaining the Screening Programme" en "Screening of Newborns for Congenital Hypothyroidism. Guidance 
for Developing Programs". International Atomic Energy Agency Ed., Vienna, 67-88, 2005.

3. Webster D. "Quality Performance of Newborn Screening Systems: Strategies for Improvement". J Inherit Metab Dis 30, 576-84, 2007.

4. International Atomic Energy Agency. "Basic Aspects in the Screening of Newborns with Emphasis on the Detection of Hypothyroidism" en "Screening of Newborns for Congenital Hypothyroidism. Guidance for Developing Programs". International Atomic Energy Agency Ed., Vienna, 21-41, 2005.

5. Torresani T. "Quality Control Requirements in Neonatal Screening". Eur J Pediatr 162, S54-S56, 2003.

6. CLSI. "Blood Collection on Filter Paper for Neonatal Screening Programs". Approved Standard - Fifth Edition. CLSI Document LA4-A5, Vol 27 N²0, 2007.

7. Guthrie R; "Organization of a Regional Newborn Screening Laboratory" en "Neonatal Screening for Inborn Errors of Metabolism". Bickel H, Guthrie R and Hammersen G Eds, Springer-Verlag, Berlin Heidelberg New York, 259-270, 1980.

8. Resolución Ministerial 2760/95. Ministerio de Salud de la Provincia de Buenos Aires. "Declaración de Interés Provincial del Prodytec", 1995.

9. Resolución Ministerial 1819/94. Ministerio de Salud de la Provincia de Buenos Aires. "Designación Inicial de la Comisión Coordinadora del Prodytec", 1994.

10. Resolución Ministerial 705/95. Ministerio de Salud de la Provincia de Buenos Aires. "Firma del Convenio de Gratuidad para la Realización de las Pruebas de Pesquisa de $H C$ y PKU en Maternidades de Hospitales Provinciales, entre la Fundación Bioquímica Argentina y el Ministerio de Salud de la Provincia de Buenos Aires", 1995.

11. Resolución Ministerial 6898/95. Ministerio de Salud de la Provincia de Buenos Aires. "Modificación de la Conformación de la Comisión Coordinadora del Prodytec", 1995.

12. Resolución Ministerial 1343/96. Ministerio de Salud de la Provincia de Buenos Aires. "Reglamentación Ley 10.429/86", 1996. 
13. Santucci Z, Ansaldi M, Pattin J, Spécola N, Apezteguía M y Borrajo G. "Programa de Pesquisa Neonatal de Hipotiroidismo Congénito de la Provincia de Buenos Aires". Arch Arg Pediatr, 100, 456-67, 2002.

14.González V, Santucci Z, Pattin J, Apezteguía M y Borrajo G. "Programa de Pesquisa Neonatal de Hipotiroidismo Congénito de la Provincia de Buenos Aires: 1.377.455 Niños Evaluados en Diez Años de Experiencia". Arch Arg Pediatr, 105, 390-97, 2007. 


\section{CAPÍTULO 2}

ORGANIZACIÓN Y

FUNCIONAMIENTO DE

UN LABORATORIO DE

PESQUISA NEONATAL 



\section{- INTRODUCCIÓN}

La organización del Laboratorio de PN es sin lugar a dudas uno de los procesos de mayor importancia dentro del proceso global de organización de un Programa de pesquisa. Esta aseveración se sustenta en el hecho de que el Laboratorio tiene como función principal la identificación de RN presuntamente afectados dentro de un grupo de RN aparentemente sanos, lo cual a su vez determina que se trate del único efector centralizado que indefectiblemente va a tomar contacto con toda la población de RN.

Estas características le confieren al laboratorio un rol protagónico dentro del sistema y le exigen la responsabilidad de emitir resultados oportunos, confiables, seguros y de alta calidad analítica y diagnóstica, y de asegurar que todos sus procedimientos sean ejecutados teniendo presente que el objetivo de la PN va más allá de lo que implica la obtención de un simple resultado en una prueba de laboratorio.

En términos prácticos, la organización del Laboratorio de PN debe ser un fiel reflejo de la organización del Programa en su conjunto, es decir que el mismo debe estar funcionalmente centralizado y geográficamente regionalizado, con lo cual le será posible acceder a una serie de beneficios concretos los cuales se detallan en la Tabla 13.

Tabla 13. Beneficios de la centralización del Laboratorio de PN

- Máximo rendimiento, eficiencia y confiabilidad

- Óptimo aprovechamiento de recursos humanos

- Reducción significativa de costos (mayor rendimiento de reactivos)

- Procesamiento diario de muestras

- Utilización de equipamiento diseñado específicamente para pesquisa neonatal y eventual automatización

- Validación sistemática de los métodos analíticos utilizados

- Definición de valores de corte propios

- Implementación de un estricto sistema de control de calidad interno

- Participación en Programas de Evaluación Externa de Calidad

- Nivel controlado de falsos negativos y falsos positivos

- Mayor probabilidad de muestras con resultados anormales en períodos cortos de tiempo

- Número de casos confirmados epidemiológicamente significativos

- Facilidad para el manejo de datos y su posterior evaluación 
Sin embargo, y tal como ya ha sido demostrado en países desarrollados, se debe tomar en consideración que no cualquier condición de trabajo centralizada y regionalizada de un Laboratorio de PN le permite acceder a todos los beneficios antes mencionados, sino que por el contrario, y para que esto suceda, el mismo debe procesar un número mínimo de 50.000 muestras al año (1).

En cuanto al funcionamiento del Laboratorio, la planificación del mismo requiere considerar por un lado los recursos humanos responsables de la ejecución de las diferentes actividades que le competen, y por el otro los diferentes procesos que se llevan a cabo en el mismo. En la Figura 13 se presentan en forma esquemática los mencionados procesos y el flujo de tareas entre sus principales compartimientos.

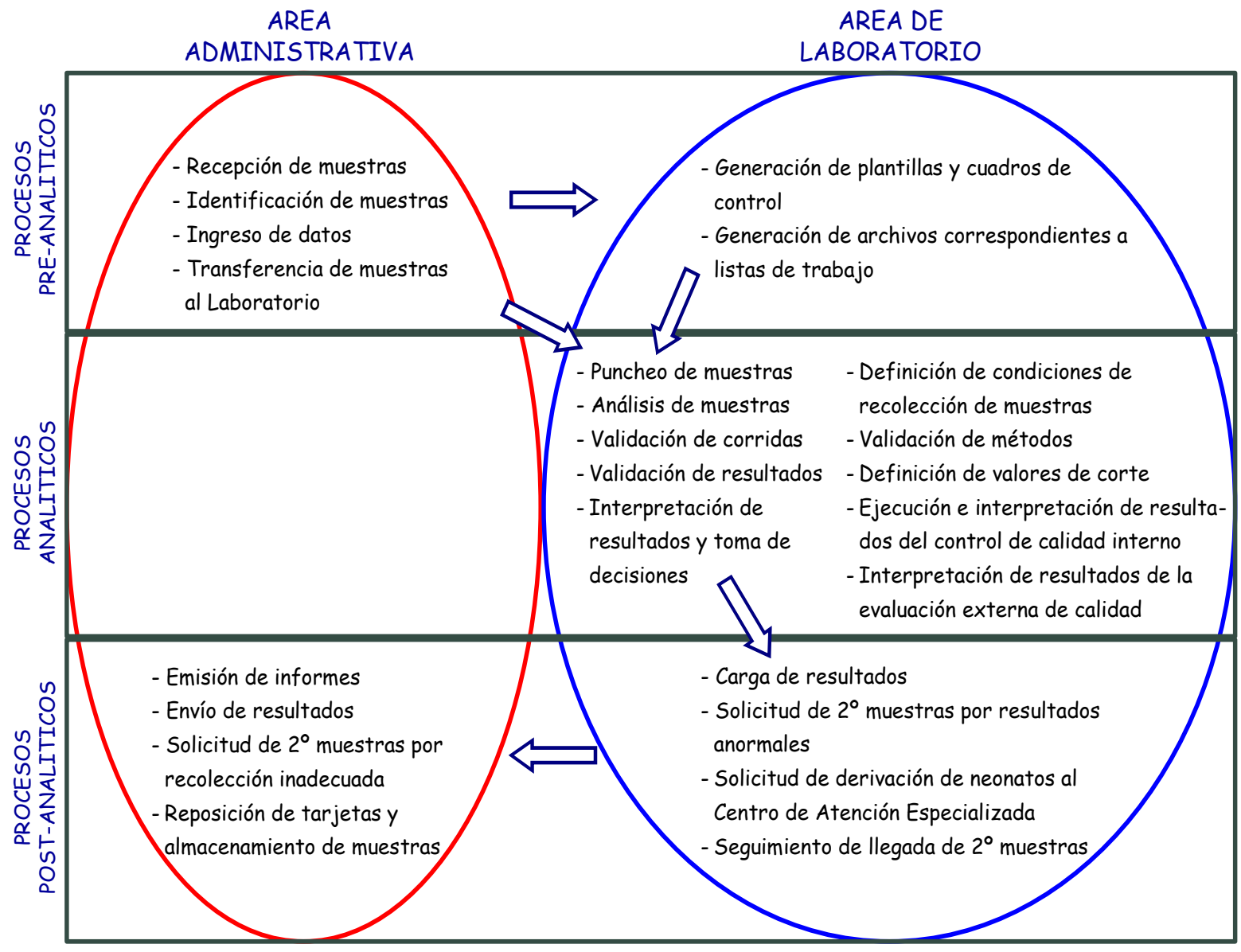

Figura 13. Procesos correspondientes al Laboratorio de pesquisa.

\section{- RECURSOS HUMANOS}

Las características tanto del personal profesional como del personal técnico auxiliar afectados a las tareas técnicas específicas del Laboratorio constituyen uno 
de los principales pilares sobre los que se sustenta el funcionamiento del mismo. Como norma general, se debe tratar de personal altamente motivado, idóneo y competente, con conocimiento de diversas áreas técnicas y entrenado en PN, conciente del impacto e importancia de su trabajo, y capacitado para llevar a cabo apropiadamente la validación de los métodos analíticos, la definición de los valores de corte, la interpretación del control de calidad, y fundamentalmente, para poder realizar una correcta interpretación de los resultados y una apropiada toma de decisiones. Este equipo debe estar acompañado además por un plantel de personal administrativo capacitado y comprometido con las tareas del Laboratorio y del Programa en su conjunto, las cuales por su propia naturaleza le exigen un alto rendimiento y eficiencia de trabajo.

\section{- PROCESOS PRE-ANALITICOS}

En la Tabla 14 se presentan los principales procesos Pre-analíticos a considerar en el Laboratorio de pesquisa.

Tabla 14. Procesos Pre-analíticos

- Recepción de muestras de sangre

- Ingreso y manejo de los datos demográficos correspondientes a los RN

- Ingreso y manejo de los datos correspondientes a los Laboratorios, Hospitales, Maternidades y/o Clínicas que deriven sus muestras al Programa de PN

- Identificación unívoca de muestras

- Manejo seguro y transferencia sin errores de muestras desde el sector administrativo al área analítica del Laboratorio

- Generación de los elementos de control (cuadros, plantillas, esquemas, etc.) y de las listas de trabajo necesarios para el manejo confiable y seguro de las muestras en el área analítica del Laboratorio

Idealmente cada uno de estos procesos requiere como condición necesaria el diseño de un apropiado Sistema Informatizado de Gestión de Muestras (SIGM) a efectos de simplificar su ejecución y de lograr una máxima eficiencia y confiabilidad, más allá de que en determinadas circunstancias, los mismos puedan ser ejecutados en 
forma manual. Por otra parte, y como se puede inferir del esquema presentado en la Figura 13, una parte de estos procesos afectan exclusivamente al personal administrativo, en tanto otros al personal responsable de la ejecución de las tareas de carácter técnico.

\section{- PROCESOS ANALÍtICOS}

Los procesos Analíticos abarcan más del $70 \%$ del total de actividades que se desarrollan en el Laboratorio de PN. Dichos procesos pueden dividirse en dos categorías dependiendo de si los mismos son ejecutados diariamente como parte del trabajo de rutina o si son de ejecución periódica, y de acuerdo con estos criterios son presentados en la Tabla 15.

Tabla 15. Procesos Analíticos

- De ejecución diaria

- Puncheo de muestras de sangre

- Análisis de muestras

- Validación de corridas analíticas

- Validación de resultados

- Interpretación de resultados y toma de decisiones

- Ejecución del control de calidad interno e interpretación de los resultados correspondientes

- De ejecución periódica

- Definición de condiciones de recolección de muestras

- Validación de métodos analíticos

- Definición y evaluación periódica de valores de corte

- Definición de criterios de interpretación de resultados

- Implementación de un sistema de control de calidad interno

- Interpretación de resultados de la evaluación externa de calidad

En relación a los mencionados procesos, y considerando que la mayor parte de ellos serán discutidos en forma pormenorizada en capítulos posteriores, este capítulo centralizará su atención en realizar una descripción detallada de las condiciones de recolección de muestras y de los criterios de definición de valores de corte, con una mínima mención acerca de los métodos de medida y el control de calidad. 


\section{Muestras de sangre}

Si bien la recolección de muestras de sangre es una tarea que debería incluirse dentro de los procesos Pre-analíticos del Programa de PN, el hecho de que el Laboratorio sea precisamente el responsable de definir las condiciones y recomendaciones para dicha recolección determina que, a los fines de su descripción, la discusión sea abordada dentro de los procesos Analíticos del Laboratorio de PN.

Entrando específicamente en el tema y tal como ya fuera mencionado en el Capítulo 1, existen normas específicas referidas a las condiciones requeridas para una correcta recolección de muestras, publicadas por el Comité Nacional de Estándares de Laboratorio Clínico (CLSI) de EE.UU. (2), en las cuales está basada la descripción que se presenta a continuación:

- Tipos de muestras de sangre: dependiendo de las patologías a investigar y de las estrategias de trabajo definidas en cada Programa es posible utilizar diferentes tipos de muestras de sangre obtenidas a partir de diferentes sitios de punción y con diferentes procedimientos, a las cuales se presenta en la Tabla 16.

Tabla 16. Tipos de muestras de sangre

- Sangre de cordón

- Sangre obtenida del RN

- Por punción del talón

- Impregnación directa del papel de filtro

- Recolección en capilares heparinizados y posterior impregnación.

- Por punción venosa

- De catéter umbilical (venoso o arterial)

- Sangre de cordón: la sangre de cordón presenta algunas ventajas con respecto a la sangre obtenida del RN como lo es la posibilidad de una rápida obtención, la simpleza del procedimiento de recolección y la disponibilidad de volúmenes significativos. Sin embargo, no resulta ser la fuente de elección para las pruebas de PN debido a que sólo posee valor diagnóstico para la detección de una muy limitada lista de enfermedades congénitas en las cuales la alteración 
bioquímica investigada ya está presente en la sangre al momento del nacimiento. Éste es el caso por ejemplo del HC, de la Galactosemia Clásica cuando su pesquisa se realiza dosando la enzima GAL-T, de la Deficiencia de Glucosa 6-P Deshidrogenasa o de las Hemoglobinopatías (2). En contraposición, las muestras de sangre de cordón carecen de valor diagnóstico, y por lo tanto no deben ser utilizadas, en las pruebas de PN de aquellas patologías que requieren que haya transcurrido un cierto período de tiempo para que se ponga de manifiesto bioquímicamente la acumulación de un metabolito determinado en la sangre del propio RN, situación que se presenta entre otros, en el caso de la PKU, MSUD o de la Galactosemia cuando la misma es pesquisada a través de la medida de Galactosa total.

Por otra parte, resulta importante mencionar que aquellos Programas de PN que utilizan muestras de sangre de cordón deben hacer frente a algunas dificultades operativas cuando toman la decisión de expandir la lista de enfermedades a pesquisar a otras que requieren sangre del RN a consecuencia de que, precisamente, la introducción de un cambio en el tipo de muestra de sangre empleado, les exige efectuar una serie de ajustes críticos en los procedimientos y condiciones de recolección de muestras, y también un re-entrenamiento del personal a cargo de esta tarea.

- Sangre obtenida por punción del talón: la sangre obtenida por punción del talón es la fuente de sangre recomendada para las pruebas de PN. Su procedimiento de recolección también ha sido normatizado y descripto en forma detallada por el CLSI en un documento específico en el cual se mencionan las diferentes técnicas de recolección de muestras de sangre por punción de piel (3).

Tal como se menciona en la Tabla 16, la impregnación del papel de filtro a partir de este tipo de muestras de sangre puede realizarse de dos formas diferentes, procedimientos que serán descriptos en detalle en la sección correspondiente a Técnica de Recolección de Muestras.

Con respecto al procedimiento de recolección en capilares heparinizados, 
debe tomarse en consideración que si bien la heparina no interfiere en las pruebas de pesquisa, la misma es un inhibidor de la PCR y por lo tanto puede interferir en las técnicas de biología molecular llevadas a cabo sobre muestras de sangre colectadas en papel de filtro.

- Sangre obtenida por punción venosa: si bien no existe una contraindicación explícita con respecto al uso de esta fuente alternativa, la misma debería limitarse exclusivamente a situaciones en las cuales exista una necesidad adicional de obtener volúmenes significativos de sangre para la realización simultánea de otro tipo de pruebas de laboratorio. Esta recomendación obedece al hecho de que, por un lado, la punción venosa resulta más invasiva que la punción del talón, y por el otro, a que las venas deberían preservarse para aquellos casos en los que se requiera la administración de líquidos por vía endovenosa (2).

Los sitios recomendados para dicha punción son las venas del dorso de la mano o eventualmente las venas del pliegue del codo, siendo necesario tomar siempre la precaución de que la misma no sea realizada sobre una extremidad en la cual se está o se estuvo infundiendo líquidos o sangre por vía endovenosa.

- Sangre obtenida a partir de un catéter umbilical: exclusivamente en el caso de ciertas situaciones especiales, como por ejemplo en neonatos críticamente enfermos o en RN de muy bajo peso, es aceptable que la recolección de muestras se realice a partir de un catéter umbilical venoso o arterial (2). Esta alternativa requiere tomar las precauciones necesarias a fin de evitar una dilución o contaminación de la sangre con otro tipo de líquidos o soluciones.

- Sistemas de recolección de muestras de sangre: El sistema de recolección de muestras de sangre recomendado para la realización de las pruebas de PN es aquel que fuera ideado por Robert Guthrie en los años '60 (4), basado en la utilización de muestras de sangre entera seca (DBS) impregnada en papel de filtro de uso diagnóstico.

Este tipo de sistemas de recolección admite trabajar tanto con sangre entera del RN como con sangre de cordón. Sin embargo, y en vista de la limitada 
aplicación diagnóstica que poseen las muestras de sangre de cordón, el sistema recomendado -y también más difundido y universalmente aceptado-, es el que utiliza sangre obtenida del RN por punción del talón impregnada en papel de filtro. En la Tabla 17 se presentan las principales ventajas que avalan el uso de DBS en las pruebas de $\mathrm{PN}$.

Tabla 17. Ventajas del uso de DBS

- Requerimiento de mínimos volúmenes de sangre

- Estabilidad de los analitos

- Simpleza para el transporte

- Facilidad para el manejo en el laboratorio

- Mínimo riesgo de transmisión de infecciones (Bioseguridad)

- Facilidad para el almacenamiento de muestras residuales

- Posibilidad de estudios retrospectivos

- Soporte de recolección de muestras: el tipo de papel de filtro que ha de ser utilizado como soporte para la recolección de muestras de sangre de RN debe cumplir con una serie de especificaciones que, en definitiva, son las que determinan que el mismo sea apto para su uso diagnóstico, razón por la cual dicho papel de filtro no puede ser sustituido por cualquier tipo de papel de filtro de uso corriente en el laboratorio.

Estas especificaciones deben ser respetadas en forma estricta puesto que las mismas inciden en forma directa tanto sobre la calidad final de las muestras como sobre el volumen de sangre absorbido por unidad de área de papel.

En la Tabla 18 se presentan algunas de las especificaciones más importantes que debe cumplir el papel de filtro para que pueda ser considerado como apto para su utilización en pruebas de PN (2).

Tabla 18. Especificaciones del papel de filtro

- Composición de las fibras: 100 \% fibras puras de algodón. Libre de aditivos que incrementen su resistencia al ser humedecido.

- Peso: $179 \mathrm{~g} / \mathrm{m}^{2} \pm 5 \%$

- $\mathrm{pH}: 5.7-7.5$

- Contenido de cenizas: menor de $0.1 \%$. 
Por otra parte, también han sido definidas una serie de características de performance (Tabla 19), las cuales deben ser validadas y garantizadas por parte del propio fabricante del papel de filtro previamente a la puesta en circulación de cada lote de producción (2).

\section{Tabla 19. Características de performance del papel de filtro}

- Capacidad de absorción:

- con glóbulos rojos intactos: $1.54 \pm 0.17 \mu \mathrm{L}$ suero/disco $3.2 \mathrm{~mm}$ diámetro

- con glóbulos rojos lisados: $1.30 \pm 0.19 \mu \mathrm{L}$ suero/disco $3.2 \mathrm{~mm}$ diámetro

- Homogeneidad

- Diámetro del círculo de la alícuota de sangre impregnada: $16 \pm 1 \mathrm{~mm}$.

- Tiempo de absorción de la alícuota de sangre: $12 \mathrm{seg}(5-30 \mathrm{seg}$ )

NOTA: todas las características de performance deben ser determinadas trabajando con alícuotas de $100 \mu \mathrm{L} /$ mancha de sangre entera, de hematocrito $55 \%$.

Con respecto a los diferentes tipos de papel de filtro disponibles en el mercado se debe mencionar que hacia fines de la década del '90 los más utilizados eran el Schleicher \& Schuell (S\&S) \# 903 de origen alemán -comercializado preferentemente en EE.UU., Australia, Nueva Zelanda y América Latina-; el S\&S \# 2992 -producido para su comercialización principalmente en Europa-; y en mucho menor proporción el Whatman BFC 180, de origen inglés.

Esta tendencia se fue modificando progresivamente en el siguiente lustro a partir de una propuesta realizada a fines de 1999 por parte de la comunidad internacional a la compañía S\&S, a través de la cual se le proponía sacar de circulación definitivamente al modelo \# 2992 (5), sustituyéndolo paulatinamente por el \# 903. De esta forma, y a través de esta estrategia se intentaba minimizar la diversidad de papeles de filtro disponibles en el mercado -fundamentalmente de aquellos producidos por una misma compañía-, realizando además un aporte a la armonización tanto en lo que respecta a la preparación de calibradores comerciales y materiales de control, como a la recolección de muestras de sangre de RN.

No obstante esto, hacia fines de 2005, cuando el papel de filtro S\&S \# 903 presentaba una preponderancia de uso muy significativa, se produjo un nuevo $e$ importante cambio a nivel de las principales compañías proveedoras de papel de 
filtro, puesto que S\&S fue adquirida por Whatman, determinando así que a partir de 2006 el papel S\&S \# 903 se comenzara a comercializar bajo la denominación de Whatman \# 903, y que se discontinuara definitivamente la producción del papel de filtro Whatman BFC 180 y del S\&S \# 2992. Y si bien en la actualidad el papel Whatman \# 903 continúa siendo el papel mayoritariamente utilizado en todo el mundo, en 2008 se introdujeron dos nuevos papeles de filtro en el mercado: Ahlstrom Grade 226 de origen Finlandés y Munktell Grade TFN de origen Alemán.

- Tiempo de recolección de muestras: La definición de los tiempos recomendados para la recolección de muestras de sangre por parte de un Programa de PN es una tarea que debe realizarse sobre la base del análisis de cuatro elementos esenciales:

a) cuáles son las enfermedades que forman parte del panel de pesquisa ofrecido,

b) cuáles son los analitos que se determinan como parte de las estrategias de detección utilizadas,

c) cuál es la ventana óptima de detección para cada una de las enfermedades que forman parte del mencionado panel en el período neonatal, que permite disponer de las mejores chances para el diagnóstico y tratamiento antes de que comiencen los síntomas o de que se instale el daño permanente, y

d) que las ventanas óptimas de detección de las distintas patologías a pesquisar no necesariamente son coincidentes entre sí, observándose que en algunos casos, como por ejemplo en la Galactosemia, HSC y MSUD, estas ventanas son extremadamente breves pudiendo aparecer los síntomas hacia el final de la primera semana de vida (6).

Tal como puede deducirse, este último hecho determina que, indefectiblemente, se deba establecer una situación de compromiso o equilibrio, de manera tal de lograr que los tiempos de recolección de muestras definidos permitan llevar a cabo una detección de todas las patologías con el máximo grado de confiabilidad, en el mínimo plazo de tiempo posible, y tomando la menor cantidad de muestras posibles a cada recién nacido. 
De este modo, los tiempos recomendados de recolección de muestras para el Panel Básico de PN descripto en la Introducción de esta Tesis (PKU, HC, FQ, Galactosemia a través de la medida de Galactosa Total, HSC, Deficiencia de Biotinidasa y MSUD), establecen que la misma debe llevarse a cabo después de que el RN haya cumplimentado 24 horas de ingesta de leche conteniendo lactosa -ya sea calostro, leche humana madura o leche maternizada-, y antes de superado el $5^{\circ}$ día de vida (6-8).

De este modo, la condición fijada para el tiempo mínimo de recolección de muestras permite minimizar la variabilidad biológica y reducir así a la mínima expresión posible el riesgo de resultados falsos negativos (FN) que pueden presentarse en la pesquisa de Galactosemia cuando el RN no ha alcanzado un mínimo de 24 horas de ingesta de leche, y el riesgo de resultados FN y falsos positivos (FP) que pueden presentarse en las pesquisas de PKU (9-11) y MSUD (12), y de HC (13) e HSC (14) respectivamente, cuando las muestras se colectan con anterioridad a las 24 horas de vida.

En este punto resulta oportuno mencionar que la exigencia de un mínimo de 24 horas de ingesta de leche previas a la toma de muestra tiene que ver directamente con la PN de Galactosemia, puesto que al no existir una fuente endógena de Galactosa de una magnitud significativa como para que espontáneamente se ponga de manifiesto el defecto metabólico en la sangre de los RN en las primeras horas de vida, resulta necesario asegurar un aporte exógeno suficiente de la misma a través de la leche o calostro. Por otra parte, el riesgo de resultados FN en la pesquisa de PKU y MSUD cuando las muestras se colectan antes de las 24 horas de vida se debe al hecho de que resulta necesario que transcurran como mínimo 24 horas para que el bloqueo metabólico causante de la enfermedad sea puesto de manifiesto a través de la acumulación endógena del metabolito investigado. Y finalmente, el riesgo de resultados FP en la pesquisas de $\mathrm{HC}$ e $\mathrm{HSC}$ tiene que ver expresamente con la situación de estrés que genera el nacimiento, hecho que desencadena un pico fisiológico de TSH que cae a valores normales a partir de las 12 horas de vida en el caso del HC, y la movilización transitoria de hormonas 
adrenales en el caso de la HSC.

Por otra parte, fijando el tiempo máximo de recolección de muestras en los 5 días de vida se evita que el procedimiento de recolección en sí mismo resulte un factor determinante de retraso en el inicio del tratamiento en aquellos casos en los que la patología resulte confirmada. Esta situación adquiere una vital importancia en aquellos RN afectados por las formas severas de HSC, Galactosemia y MSUD a efectos de minimizar el riesgo de expresión de los cuadros clínicos tempranos característicos de estas enfermedades, los cuales pueden causar daño severo e inclusive la muerte de esos niños durante las primeras dos semanas de vida (6).

Un aspecto que resulta interesante comentar, es que al efectuar una revisión de los tiempos recomendados para la recolección de muestras que se fueron sucediendo a lo largo de la historia de la PN, se pone de manifiesto que durante el transcurso de la misma se experimentó un proceso continuo de reducción en el tiempo mínimo de recolección, el cual pasó del requerimiento de 96 horas de ingesta de leche previas a la toma de muestras en la década del '80 (15), a las 24 horas de ingesta requeridas actualmente. Este cambio fue impulsado principalmente por el hecho de que las altas en las maternidades han mostrado una tendencia permanente y progresiva a lo largo del tiempo a producirse en forma cada vez más precoz $(8,16,17)$ dando lugar a que, indefectiblemente, las muestras de sangre debieran ser colectadas con anterioridad a los plazos recomendados o a que, eventualmente, los RN fueran dados de alta sin que se hubiera efectivizado el mencionado procedimiento de recolección de muestras. Esta tendencia es parte de un fenómeno que comenzó a experimentarse en el mundo hace algo más de 15 años atrás en respuesta a tres causas principales (9):

a) El incrementado interés por parte de las madres que recientemente han dado a luz, a ser dadas de alta de las maternidades y a retornar a sus hogares lo antes posible.

b) El interés por parte de las obras sociales y de los sistemas de medicina prepaga de que las madres y sus bebés sean dados de alta con la mayor 
celeridad posible a fin de reducir sus gastos $y$, por lo tanto, de aumentar sus ganancias.

c) Los problemas socio-económicos observados fundamentalmente en países subdesarrollados o en vías de desarrollo, en los cuales la incrementada demanda de atención en hospitales del sector público determina que las maternidades trabajen "a cama caliente", es decir en condiciones en las cuales una parturienta está esperando que una puérpera sea dada de alta para poder ser internada para tener a su hijo.

Más allá de este fenómeno de índole mayoritariamente social y económico, es importante destacar que los sucesivos cambios experimentados en los tiempos recomendados para la recolección de muestras solo pudieron materializarse en la práctica a expensas del surgimiento de métodos con mayor sensibilidad y capacidad para poder discernir claramente dentro de las primeras horas de vida entre aquellos individuos presuntamente afectados y los individuos normales.

No obstante esto, es posible presuponer de antemano que existe una limitación operativa en cuanto a futuras posibles reducciones en el tiempo mínimo de recolección de muestras -excepto para aquellas estrategias de pesquisa que puedan surgir a futuro y que utilicen a la biología molecular como método primario de screening (18)-, determinado por el hecho de que por debajo de las 24 horas de vida, y tal como fuera mencionado anteriormente, comienza a ejercer una influencia muy significativa la variabilidad biológica.

Finalmente, también resulta necesario dejar en claro que, a pesar de que la obtención de resultados confiables en las pruebas de pesquisa es función de que la recolección de muestras se realice respetando los tiempos óptimos recomendados, existen una serie de situaciones especiales que merecen ser analizadas en detalle.

- Situaciones especiales que requieren un doble muestreo: en todas las situaciones que se describirán a continuación se debe realizar la recolección de la muestra inicial de pesquisa según las recomendaciones generales y luego proceder a colectar una segunda muestra en un plazo de tiempo que dependerá de cada situación en particular: 
- RN cuyas altas de las maternidades se produzcan con anterioridad a cumplimentar las 24 horas de ingesta de leche conteniendo lactosa o con anterioridad a las 24 horas de vida del niño: Independientemente de las recomendaciones definidas anteriormente con respecto a los tiempos mínimos requeridos para la recolección de muestras, se establece que en aquellos casos en los que el niño sea dado de alta antes de cumplir el tiempo mínimo de ingesta de leche requerido o con anterioridad a las 24 hs de vida, se debe proceder a colectar la muestra inmediatamente antes del alta sin tener en cuenta su estado alimentario, y proceder posteriormente a colectar una segunda muestra una vez cumplimentadas las 24 horas de ingesta de leche conteniendo lactosa $(7,8)$.

En estos casos, y a pesar del conocimiento de que existe un riesgo potencial de falsos resultados, se indica igualmente la recolección de muestras con la finalidad de que el RN pase a formar parte de los registros del Programa, permitiendo así una localización dirigida en caso de que el mismo no haya acudido espontáneamente al Centro Asistencial para efectuar la recolección de la segunda muestra $(7,8)$. De esta forma, resulta posible mejorar la cobertura y eficiencia del sistema de pesquisa tal como reflejan de manera contundente los números de la práctica diaria que muestran que si el RN es dado de alta sin que previamente haya sido colectada la muestra de sangre, y se retira con la indicación de que debe retornar después de haber cumplimentado las 24 horas de ingesta de leche conteniendo lactosa, solo retorna alrededor del $20 \%$ de los mismos, y consecuentemente, el $80 \%$ restante se pierde.

- RN pretérmino de menos de 32 semanas de edad gestacional (EG): colectar una segunda muestra a los 21 días de vida, o una vez que el niño haya alcanzado una edad correspondiente a la $E G$ de un niño nacido a término, a efectos de evitar potenciales $F N$ en la pesquisa de $H C$ ocasionados por la inmadurez del eje hipotálamo-hipófisis-tiroides $(19,20)$. 
- RN mellizos monocigóticos: colectar una segunda muestra a los 14 días de vida, con la finalidad de evitar potenciales FN en la pesquisa de $H C$ debido a la compensación intrauterina en los niveles de hormonas tiroideas que puede producirse en aquellos casos en los cuales uno de los gemelares es hipotiroideo y el otro es normal $(20,21)$.

- RN tratados con corticoides: colectar una segunda muestra 2 semanas después de suspendida la administración del fármaco, a efectos de evitar potenciales $\mathrm{FN}$ en las pesquisas de $\mathrm{HC}$ e HSC que podrían producirse a consecuencia de la acción supresora de los corticoides tanto sobre la liberación de TSH como sobre la secreción de hormonas tiroideas y de $170 H P(6,20,21)$.

- RN cuyas madres recibieron tratamiento con corticoides en el último mes del embarazo: colectar una segunda muestra a los 14 días de vida, a efectos de evitar FN en las pesquisas de HC e HSC ocasionados por la acción supresora de los corticoides sobre la liberación de TSH y sobre la secreción de hormonas tiroideas y de 17OHP (6).

- RN recibiendo tratamiento con dopamina: colectar una segunda muestra una vez que la administración del fármaco haya sido suspendida, con la finalidad de evitar resultados FN en la pesquisa de $H C$ debido al efecto inhibitorio de la dopamina sobre la liberación de TSH $(6,19-21)$.

- RN ayunados: colectar una segunda muestra una vez cumplimentadas las 24 horas de ingesta de leche conteniendo lactosa, a efectos de evitar potenciales FN en la pesquisas de PKU, Galactosemia y MSUD (6).

- RN transfundidos o conectados a Dispositivos de Circulación Extracorpórea (DCE): en estos casos se recomienda recolectar la muestra inicial según las recomendaciones generales, pero antes de realizar cualquiera de estos dos procedimientos. Independientemente de esto, y en caso de que la recolección no se haya podido realizar de esta forma, se debe proceder a colectar una segunda muestra 72 horas después de haber concluido el 
procedimiento, a efectos de evitar potenciales FN en cualquiera de las 7 patologías en cuestión a consecuencia tanto del efecto dilucional y/o de lavado de la sangre, como del reemplazo de volumen producido por los procedimientos anteriores (6).

NOTA: LOS DCE son empleados en el tratamiento de niños afectados con una amplia variedad de condiciones tales como sepsis, neumonía, hernia diafragmática y aspiración de meconio, a fin de aportar circulación y oxigenación de la sangre, permitiendo al corazón y pulmones recuperarse de la injuria o inmadurez.

En este punto debe mencionarse que en aquellas estrategias de pesquisa que se basan en la medida de un analito localizado exclusivamente dentro de los glóbulos rojos como es el caso de la enzima GAL-T para la pesquisa de Galactosemia, o en la determinación de Hemoglobinas para la detección de Hemoglobinopatías, las pruebas quedan invalidadas durante un plazo de tiempo equivalente a la vida media de los glóbulos rojos del donante.

- RN críticamente enfermos: colectar una segunda muestra una vez que el niño haya superado su estado crítico de salud, a efectos de descartar disminuciones transitorias de $\mathrm{T}_{4}$ y $\mathrm{TSH}$ que habitualmente se presentan asociados a enfermedades no tiroideas $(20,21)$.

Como corolario del análisis realizado anteriormente, en la Tabla 20 se presenta un resumen de las situaciones que requieren la recolección de una segunda muestra, indicando el momento recomendado en que debe llevarse a cabo dicha recolección y los analitos que resultan afectados por cada situación y que, consecuentemente, deben repetirse en cada caso.

Finalmente, y a efectos de mejorar la eficiencia del sistema de seguimiento del Programa de PN, se recomienda que todos los procedimientos de recolección de segundas muestras que se deben llevar a cabo en aquellas situaciones que requieren un doble muestreo, sean programados y realizados en cada maternidad sin esperar que dicha recolección sea solicitada por parte del Laboratorio de Pesquisa. 


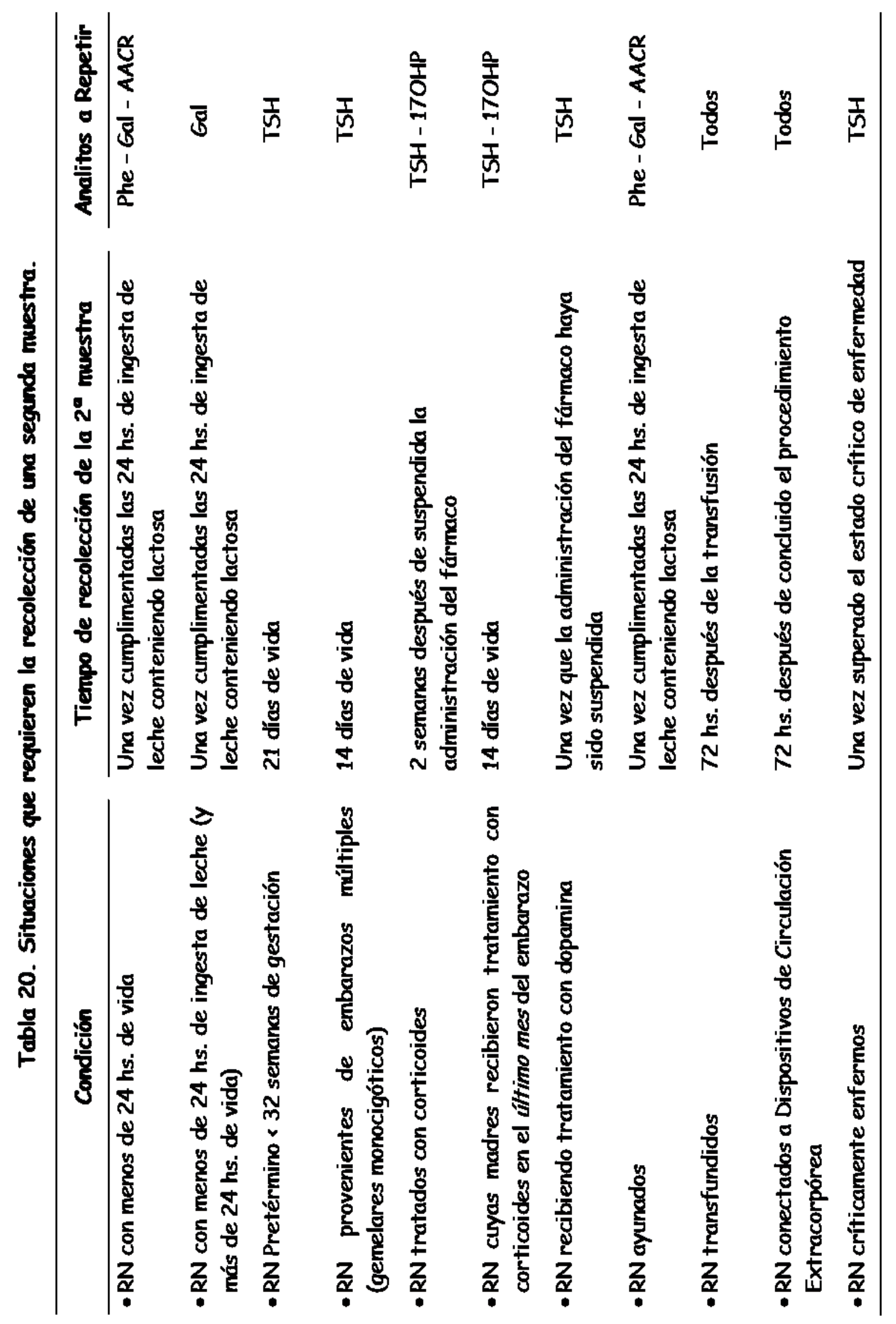


- RN mayores de 5 días de vida cuyas muestras de sangre no fueron colectadas dentro de los plazos generales recomendados: Una de las preguntas que suele presentarse en la práctica diaria es qué se debe hacer en aquellos casos en los cuales el RN tiene más de 5 días de vida y la toma de muestra aún no se llevó a cabo. Pues, en estos casos, no existe un argumento desde el punto de vista del valor diagnóstico de los resultados que impida que la muestra sea recolectada con posterioridad al $5^{\circ}$ día de vida, excepto en una situación particular como es el caso de la FQ. En esta patología se presenta una pérdida del valor diagnóstico de las pruebas cuando las muestras de sangre son colectadas después de los 30 días de vida, debido a que los individuos fibroquísticos sufren una sustitución del tejido pancreático funcional responsable de la producción de Tripsina Inmuno Reactiva (IRT) por tejido graso y fibroso, pudiendo presentar en consecuencia niveles normales de IRT que no permiten descartar taxativamente la presencia de la enfermedad. Por este motivo, la recolección de muestras para la $P N$ de $F Q$ debe efectuarse dentro de los plazos generales recomendados, y en caso de que haya sido sobrepasado el $5^{\circ}$ día de vida, la misma debe realizarse indefectiblemente antes de los 30 días de vida a efectos de que el resultado obtenido mantenga su valor diagnóstico (22).

Independientemente de lo expresado anteriormente, y más allá de que para muchas patologías es posible realizar la pesquisa con muestras colectadas con posterioridad al $5^{\circ}$ día de vida, siempre se debe recordar que la definición del tiempo máximo de recolección de muestras responde a razones de eficiencia, puesto que la PN es una carrera contra-reloj en la cual, cuanto más precoz sea el inicio del tratamiento, más efectivo será el mismo.

- Información requerida del RN: Existe una batería mínima de datos demográficos que deben ser solicitados a efectos de lograr una correcta identificación tanto del RN como de su madre, y una batería de datos adicionales que resultan necesarios para poder efectuar una correcta interpretación de los resultados. Dentro de este último grupo se encuentran algunos datos que son imprescindibles y que por lo tanto siempre deben estar presentes en el formulario de recolección de muestras, 
mientras que hay otros que pueden no ser solicitados de rutina en dicho formulario pero que, cuando corresponde, necesariamente deben ser informados.

Tabla 21. Información requerida en la tarjeta de recolección de muestras

- Información del RN:

- Nombre y apellido

- Sexo

- Fecha y hora de nacimiento

- Fecha y hora de primera ingesta de leche

- Fecha y hora de toma de muestra

- Peso al nacimiento

- Edad gestacional

$-1^{\circ}$ muestra/repetición

- Información de la madre:

- Nombre y apellido

- Domicilio

- Localidad

- Teléfono

- Información adicional

- Antecedentes de enfermedades tiroideas maternas y tratamiento

- Tratamiento del bebé con corticoides

- Tratamiento de la madre con corticoides en el último mes del embarazo

- Gemelares o mellizos $\left({ }^{\star 1}\right)$

- Administración de dopamina $\left({ }^{* 1}\right)$

- Ayunado (*1)

- Alimentación parenteral $\left.{ }^{\star 1}\right)$

- Transfusiones o conexión a DCE previos a la toma de muestras $\left({ }^{* 1}\right)$

- Internación en Unidad de Cuidados Intensivos Neonatales

- Ingesta de antibióticos por la mamá o el bebé $\left({ }^{\star 1,2}\right)$

- Uso de anticoagulantes complejantes del $\mathrm{Ca}^{+2}\left({ }^{\star 1,2}\right)$

- Información del remitente

- Nombre de la Institución y Sector o Departamento

- Nombre del responsable

- Domicilio

- Localidad

- Teléfono

$\left({ }^{\star 1}\right)$ información que habitualmente no se pide de rutina.

$\left({ }^{\star^{2}}\right)$ información que se solicita en algunos casos dependiendo de los métodos de medida que se estén utilizando. 
En la Tabla 21 se presenta un listado de los principales datos que deben ser incluidos en la tarjeta de recolección de muestras (2).

Adicionalmente todas las tarjetas de recolección de muestras deben incluir información acerca del tipo y lote de papel de filtro utilizado, y de la fecha de vencimiento de la misma (3 años a contar a partir de la fecha de su elaboración).

- Técnica de recolección de muestras: Considerando que las muestras de sangre obtenidas por punción del talón del RN e impregnadas directamente en el papel de filtro son el tipo de muestras de sangre recomendadas para las pruebas de PN (2), la descripción que se realizará a continuación está enfocada con mayor detalle precisamente en el procedimiento a seguir para la obtención de este último tipo de muestras.

- Recolección por punción del talón e impregnación directa del papel de filtro: La técnica de recolección correspondiente a este procedimiento se presenta a continuación en forma detallada, mediante una secuencia gráfica de 8 pasos confeccionada por la FBA en base a las normas del CLSI (2) (Figuras 14 a 21), junto a las cuales se mencionan las consideraciones más importantes a tener en cuenta en cada uno de ellos.

- Respetar Normas de Bioseguridad.

- Usar guantes libres de polvo (talco).

- Evitar el contacto de las áreas circulares con manos, guantes, líquidos o superficies.

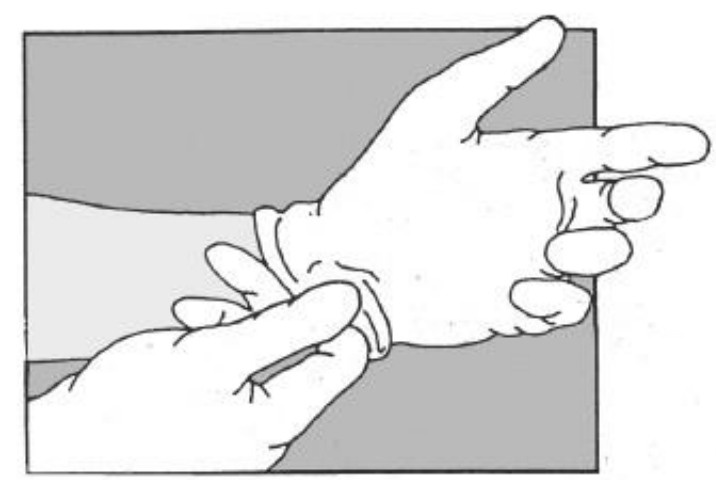

Se recomienda el uso de guantes para realizar este procedimiento. Evitar el contacto de las áreas circulares del papel con las manos, guantes, soluciones antisépticas, agua u otros materiales ya que pueden afectar la muestra y el diagnóstico.

Figura 14. Técnica de Recolección-1. 


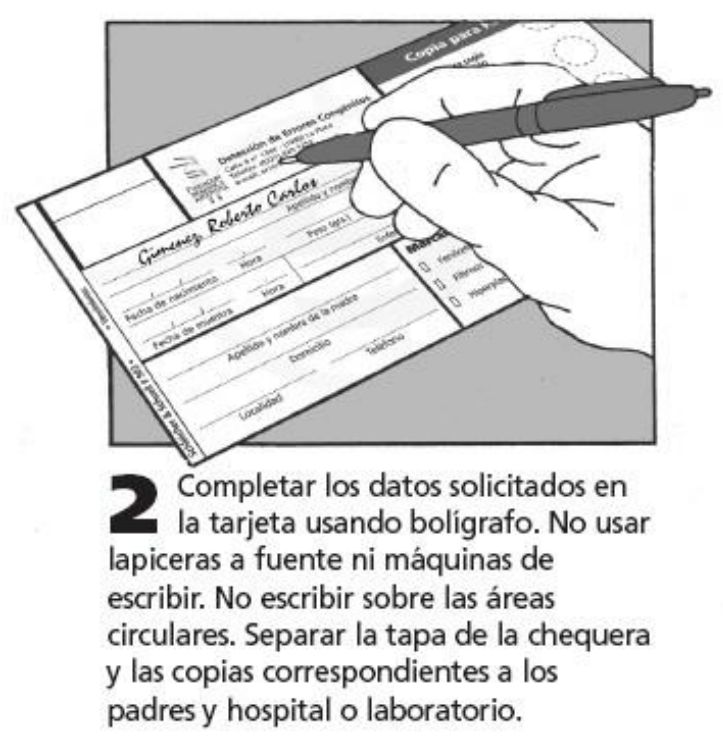

Figura 15. Técnica de Recolección-2.

- Calentar el talón del bebé con una gasa húmeda y tibia $\left(42^{\circ} \mathrm{C}\right.$ por 3 minutos).

- Colocar el pie del bebé por debajo del nivel del cuerpo.

- Seleccionar el área de punción.
- Confirmar la identidad del RN.

- Completar los datos requeridos en la tarjeta utilizando bolígrafo.

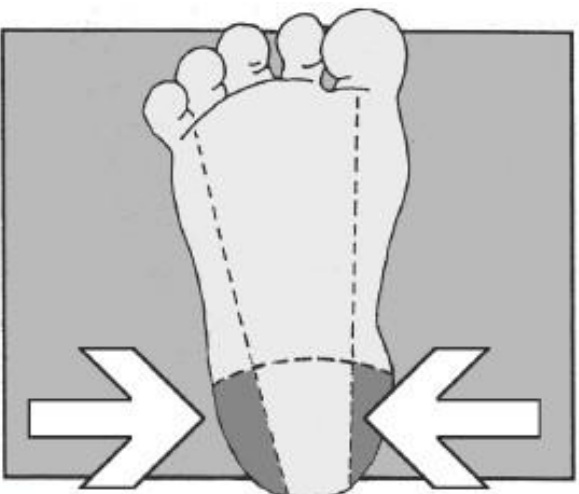

- Calentar el sitio de punción para aumentar el flujo sanguíneo. Colocar el pie del bebé en una posición tal de modo de incrementar la presión venosa.

Figura 16. Técnica de Recolección-3.

- Desinfectar el talón y eliminar el exceso de desinfectante.

- Realizar la punción con una lanceta descartable estéril (< 2,0 mm.).

- Desechar la primera gota de sangre.
Desinfectar la zona de punción con alcohol $70 \%$. Secar con una gasa estéril. Realizar la punción con una lanceta descartable estéril. Deshechar la primera gota de sangre.

Figura 17. Técnica de Recolección-4. 
- Hacer presión suave e intermitente en el talón ("no ordeñar ni exprimir").

- Impregnar cada círculo poniendo en contacto el papel de filtro con la gota de sangre formada.

- Colocar 1 gota de sangre por círculo.

- No superponer gotas.

- Asegurarse que ambas caras del papel se saturen completamente.

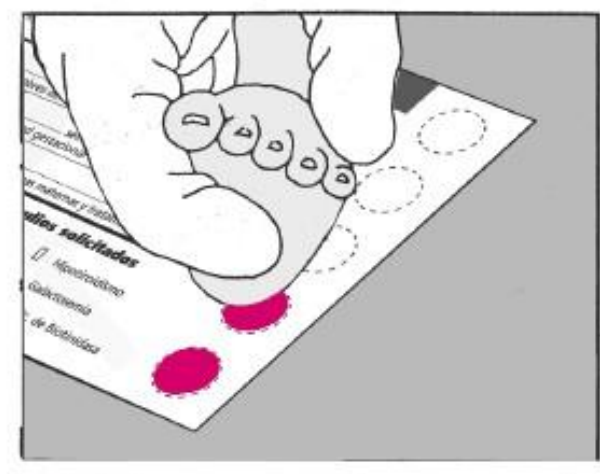

Colocar una gota de sangre en cada área circular de modo de impregnar completamente el círculo. Ambas caras del papel deben resultar saturadas con la sangre.

Figura 18. Técnica de Recolección-5.

- Verificar que las manchas de sangre en el papel de filtro tengan una calidad apropiada.

- Verificar que la sangre haya saturado ambas caras del papel en todas las manchas.

- Colocar la tarjeta en posición horizontal en un soporte apropiado.

- No colocar en posición vertical.

- Secar al aire durante 3 horas a temperatura ambiente.

- Evitar el contacto con superficies.

- No exponer al calor o a la luz solar directa.

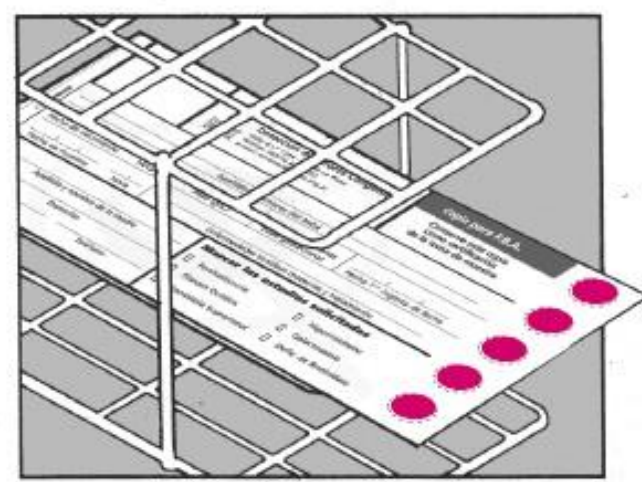

Dejar secar las muestras de sangre al aire durante 3 horas en posición horizontal y elevada, evitando el contacto con superficies, calor directo o luz solar.

Figura 20. Técnica de Recolección-7. 


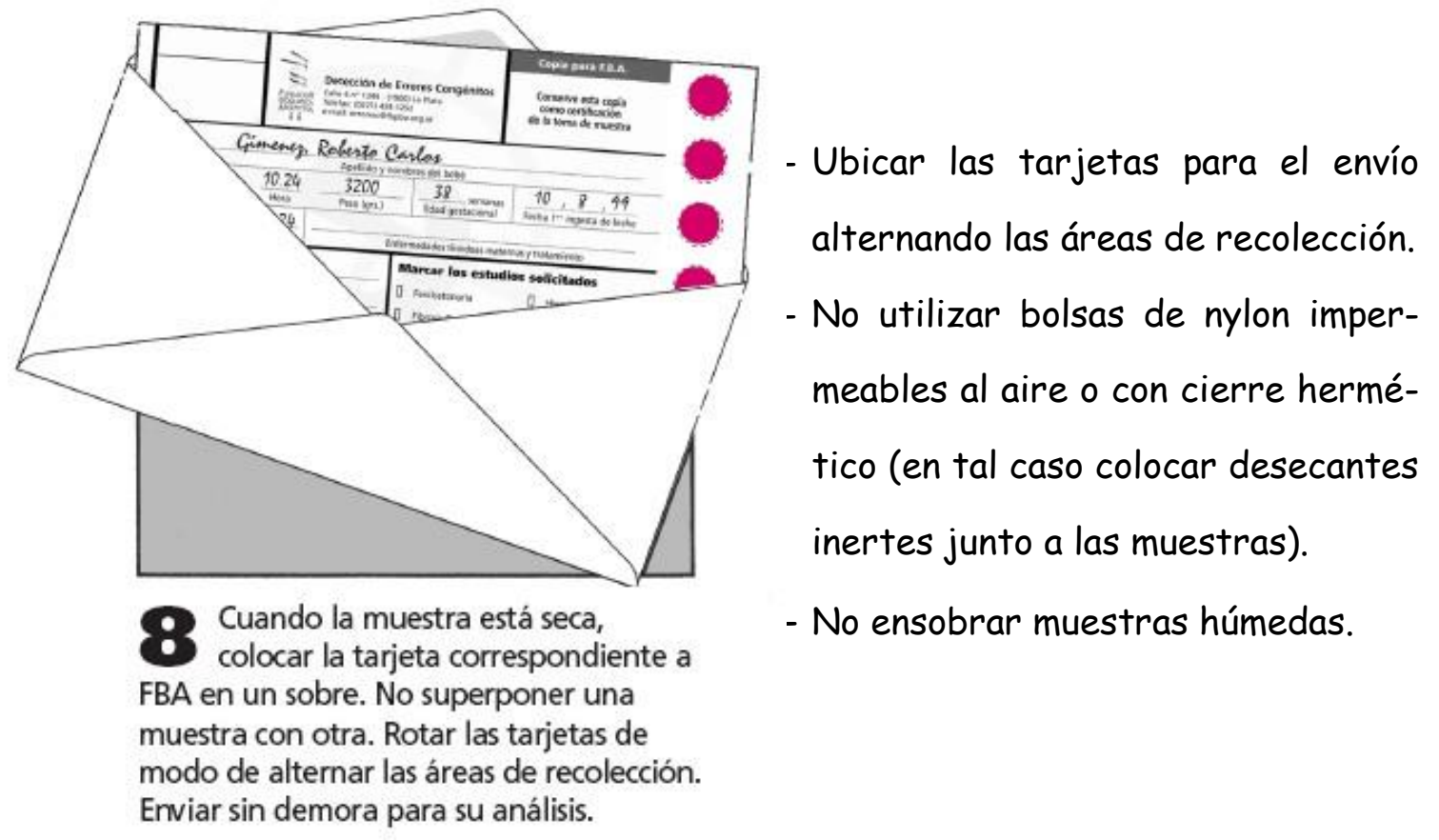

Figura 21. Técnica de Recolección-8.

- Recolección por punción del talón en capilares heparinizados: esta técnica alternativa comparte los primeros 4 pasos de la secuencia gráfica presentada en las Figuras 14 a 17, pero a partir de dicho punto -y a diferencia de la técnica anterior-, en lugar de proceder a impregnar directamente la sangre en el papel de filtro, la misma debe colectarse en capilares heparinizados, asegurando su correcta y completa anticoagulación.

Una vez culminada la extracción, y habiendo colectado un volumen suficiente de sangre en una cantidad apropiada de capilares (1 capilar por cada mancha), se debe proceder a impregnar inmediatamente el papel de filtro. Para esto, el capilar debe apoyarse suavemente en posición vertical en el centro de cada círculo preimpreso, dejando que la sangre fluya libremente por capilaridad hasta que el círculo esté completamente impregnado.

Es muy importante no dejar transcurrir un tiempo prolongado entre la extracción y la impregnación de la sangre en el papel de filtro, puesto que de ser así se producirá la sedimentación de los glóbulos rojos dando lugar a una muestra heterogénea $y$, probablemente, a la formación de anillos de suero (Figura 30 - Página 110).

En esta técnica alternativa de recolección de muestras está absolutamente 
contraindicado "pintar" el papel de filtro con la sangre desplazando el capilar sobre la superficie del mismo puesto que, cuando este tipo de papel de filtro se humedece, se torna sumamente friable y por lo tanto resulta susceptible de sufrir modificaciones tanto en su textura como en su espesor, pudiendo alterarse consecuentemente los resultados de las pruebas.

También está contraindicado realizar aplicaciones "puntiformes" con el capilar puesto que en este caso no sólo se modificará la textura del papel sino que además se correrá el riesgo de que, muy probablemente, el volumen de sangre impregnado por unidad de área de papel sea insuficiente.

- Recolección por punción venosa: esta alternativa adicional para la recolección de muestras requiere que la misma sea realizada preferentemente utilizando dispositivos especiales tipo "butterfly", y que la impregnación del papel de filtro sea efectuada directamente a partir de la guía de dicho dispositivo (2).

No se recomienda realizar la recolección de muestras empleando jeringas por existir un mayor riesgo de coagulación de la sangre y de sedimentación de las células, características que se asocian directamente con la obtención de especímenes de mala calidad desde el punto de vista de su homogeneidad. Por otra parte, y en caso de que igualmente se decida utilizar una jeringa para realizar la extracción, se debe tomar en consideración que no se recomienda obtener las manchas de sangre dejando caer las gotas directamente desde la jeringa porque las dimensiones de las mismas pueden ser exageradamente grandes, causando de este modo un efecto de sobresaturación del papel de filtro.

- Condiciones de secado: Tal como ya fuera mencionado en la información adjunta a la Figura 20, el secado de las muestras de sangre debe realizarse durante un tiempo mínimo de 3 horas, colocando a las mismas en posición horizontal, a temperatura ambiente, evitando la incidencia de la luz solar o el calor directo y el contacto con cualquier agente externo como superficies o líquidos que pudieran alterar sus propiedades.

Como norma de cumplimiento estricto, el procedimiento de secado de las 
muestras nunca debe efectuarse en posición vertical ("colgadas"), puesto que en tal caso se pone en juego un "efecto cromatográfico" desencadenado por la acción conjunta de la fuerza gravitacional y por la resistencia a la difusión de los glóbulos rojos en la matriz del papel de filtro. En términos prácticos, este efecto se traduce en un desplazamiento diferencial del plasma y los glóbulos rojos dentro de cada mancha, dando lugar en definitiva a una muestra de sangre heterogénea, caracterizada por presentar un gradiente decreciente de hematocrito entre la posición superior e inferior de cada mancha según el eje vertical en que fuera colocada la muestra para su secado.

En la práctica, y a fin de asegurar que el proceso de secado de muestras se realice efectivamente en posición horizontal, se utiliza un soporte de secado sumamente simple, al cual se presenta en la Figura 22.

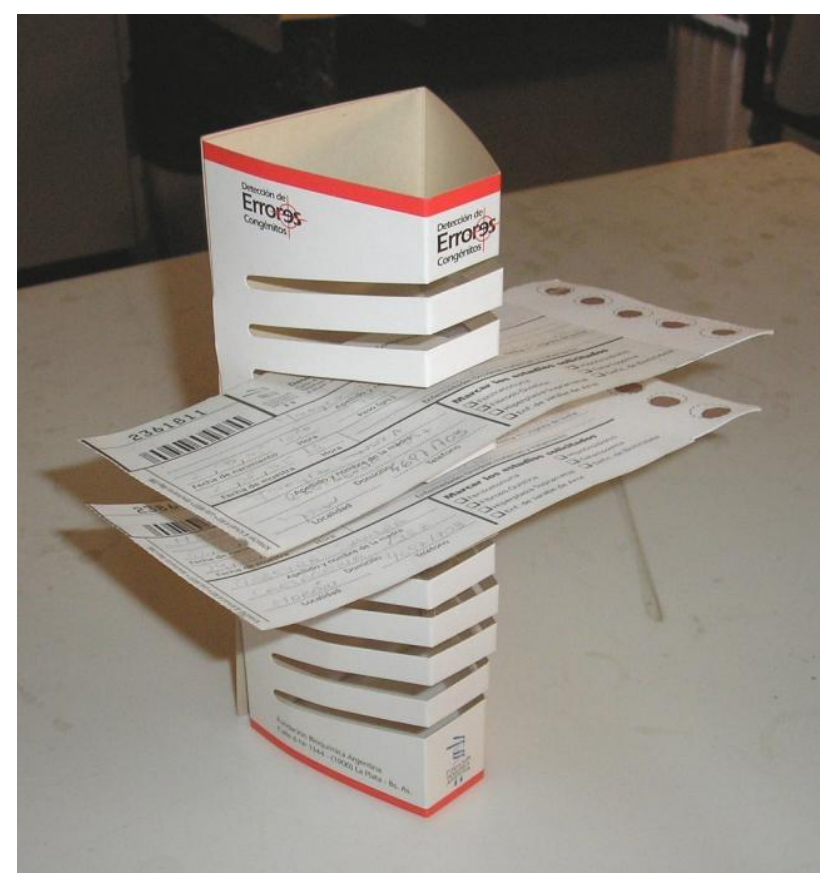

Figura 22. Soporte para el secado de muestras.

También es importante mencionar que las muestras nunca deben ser enviadas al laboratorio antes de que haya concluido el proceso de secado, puesto que la humedad es un factor tanto o más nocivo para la estabilidad de los analitos que la propia exposición al calor.

El secado incompleto de las muestras es un fenómeno fácilmente identificable 
en el Laboratorio en base al color rojo intenso de las manchas de sangre, las cuales toman un aspecto de sangre oxigenada (ver Figura 33 - Página 110). Sin embargo, es importante destacar que este color característico desaparece después de 1 o 2 horas de exposición de la muestra al ambiente, tornándolas así indistinguibles de una muestra correctamente secada. Este hecho amerita que el personal de laboratorio encargado de abrir los sobres que contienen las muestras de sangre registre inmediatamente esta particularidad toda vez que una muestra determinada se presenta con este tipo de características, en concordancia con los procedimientos establecidos en cada laboratorio.

\section{- Condiciones de envío y almacenamiento:}

- Envíos: El procedimiento de envío de muestras de sangre al Laboratorio de pesquisa debe ser realizado en sobres de papel o bolsas de nylon permeables al aire y abiertas, y asegurándose que al colocar las mismas en el interior de dichos sobres se alternen las áreas de recolección a efectos de evitar el contacto entre ellas (las muestras deben rotarse $180^{\circ}$ una respecto de la otra).

Las muestras nunca deben ser colocadas en bolsas impermeables y con cierre hermético puesto que al estar impedido el intercambio de aire se produce un aumento de la temperatura y acumulación de humedad en el interior de las bolsas, pudiendo resultar afectada la estabilidad de los analitos (2).

En el caso de que indefectiblemente se requiera el uso de este tipo de bolsas, por ejemplo por regulaciones inherentes al sistema de transporte de muestras, entonces necesariamente deberán colocarse desecantes en su interior a fin de evitar que las muestras resulten afectadas.

- Almacenamiento: En cuanto al procedimiento de almacenamiento de muestras, el mismo debe realizarse en ambientes secos y frescos, evitando la exposición de las mismas a cualquiera de los factores que ya fueran mencionados anteriormente (calor, luz solar directa, humedad) y que pueden afectar la estabilidad de los analitos.

En el caso de que el almacenamiento se realice en cámara refrigerada a $4^{\circ} \mathrm{C}$, las muestras deben ser colocadas en bolsas de plástico aluminizado de 
baja permeabilidad al aire, con cierre hermético, y adicionadas de desecantes e indicadores de humedad. En estas últimas condiciones es posible asegurar la integridad de las muestras por períodos de hasta 2 años, en tanto que si se requiere asegurar dicha integridad por períodos de tiempo superiores, entonces se recomienda el almacenamiento a $-20^{\circ} \mathrm{C}(2)$.

En cualquiera de las dos condiciones antes mencionadas, siempre se recomienda mantener la humedad por debajo del $30 \%$ a efectos de lograr una mejor conservación de las muestras.

- Muestras satisfactorias y muestras insatisfactorias: como corolario a las condiciones y recomendaciones antes descriptas para la recolección de muestras de sangre para las pruebas de PN, se debe mencionar que cada Programa debe tener claramente establecido y sin dejar lugar a ningún tipo de ambigüedades o de interpretaciones equívocas, acerca de que se entiende por muestra satisfactoria, adecuada, apropiada, válida o correctamente colectada.

Básicamente, con esta sinonimia o terminología equivalente se denomina a aquellas muestras que fueron recolectadas respetando todas las condiciones establecidas y recomendadas para la toma de muestras, poniendo un especial énfasis en que cada círculo preimpreso en el papel de filtro haya sido impregnado completamente a partir de una única gota de sangre, saturando igualmente ambas caras del papel, y que además el procedimiento de secado y posterior transporte de las muestras al laboratorio haya sido realizado en condiciones apropiadas.

Este hecho resulta de vital importancia para asegurar la eficiencia del Programa de PN por la sencilla razón de que la calidad del resultado de un análisis nunca puede ser superior a la calidad de la muestra analizada, aún en aquellas condiciones de trabajo en las que se cuente con tecnología de última generación, altamente automatizada y sometida a estrictos controles de calidad internos y externos.

Estas observaciones, que a priori pueden resultar casi una obviedad, tienen implicancias de un valor más que significativo puesto que una recolección inadecuada de las muestras puede dar lugar al retraso en la detección e inicio del 
tratamiento de casos positivos, a una potencial pérdida de casos, a la generación de un trauma innecesario al RN, a desencadenar una innecesaria carga de angustia $y$ ansiedad en los padres, y a ocasionar una sobrecarga de trabajo en el sistema de pesquisa en su conjunto (2). Por este motivo, resulta fundamental que el personal responsable de llevar a cabo la recolección de muestras esté capacitado como para poder discernir en qué casos la impregnación de la sangre en el papel de filtro ha sido correcta y en qué casos no, de manera tal de proceder a la toma de una nueva muestra de calidad satisfactoria inmediatamente antes de enviar la misma, evitando así que sea el Laboratorio de pesquisa quien deba notificar que corresponde la recolección de una segunda muestra.

Por último, en las Figuras 23 a 33 se ilustra desde el punto de vista de la calidad de impregnación de la sangre en el papel de filtro, la forma en que se visualizan las muestras correctamente colectadas y los diferentes tipos de muestras inadecuadas originadas ya sea tanto por una recolección deficiente como por un inapropiado procedimiento de secado, almacenamiento $y / 0$ transporte de las mismas:

- Muestra correctamente colectada:

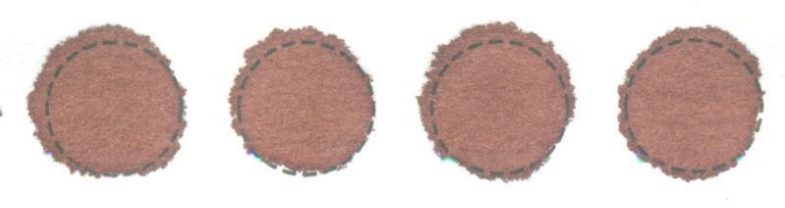

Figura 23. Muestra correctamente colectada.

- Muestras inadecuadas:
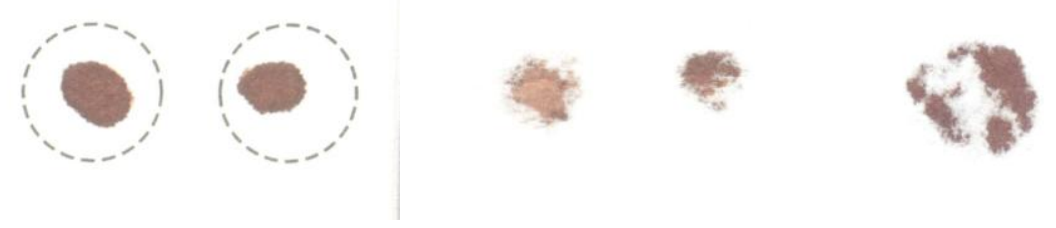

Figura 24. Volumen insuficiente. 


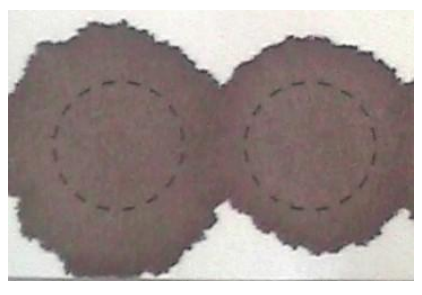

Figura 25. Muestra sobresaturada.

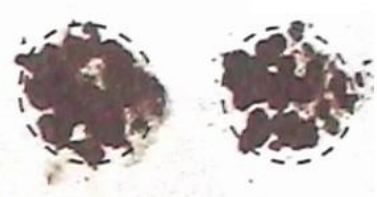

Figura 26. Recolección con capilares - Aplicaciones puntiformes.

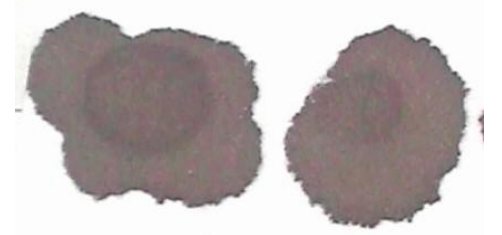

Figura 27. Superposición de gotas de sangre.
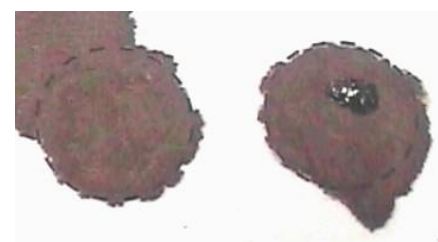

Figura 28. Presencia de coágulos.

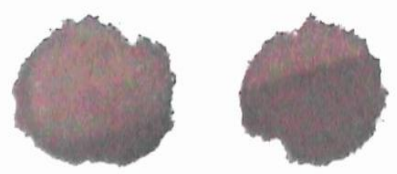

Figura 29. Contacto con superficies absorbentes. 

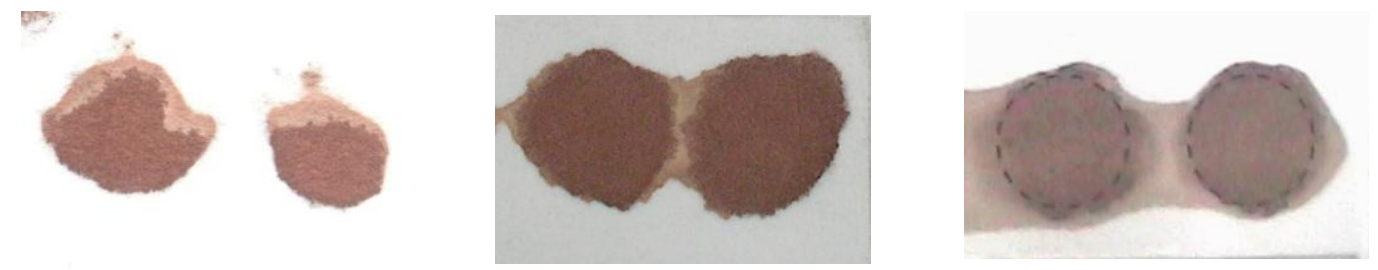

Figura 30. Anillos de suero o plasma.

NOTA: obsérvese en la imagen de la derecha el color más claro de la muestra, lo cual denota que se trata de una muestra diluida. En la práctica, esta situación se presenta preponderantemente como consecuencia de 3 hechos que confluyen: la recolección de la muestra con anticoagulante, el retraso en la impregnación de la misma en el papel (lo cual permite la sedimentación de las células sanguíneas) y la insuficiente homogeneización de la muestra previamente a la impregnación de la misma en el papel.
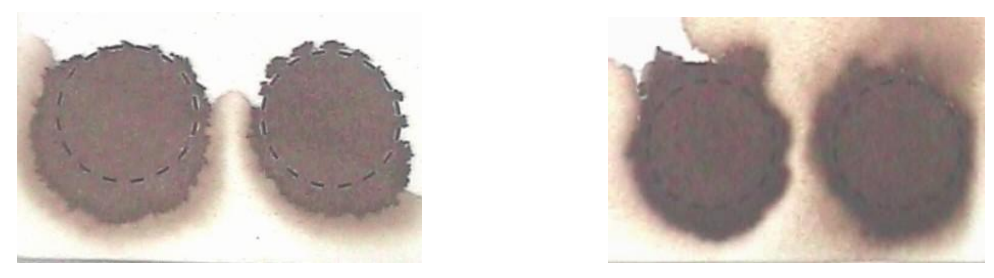

Figura 31. Contacto con líquidos (hemólisis).
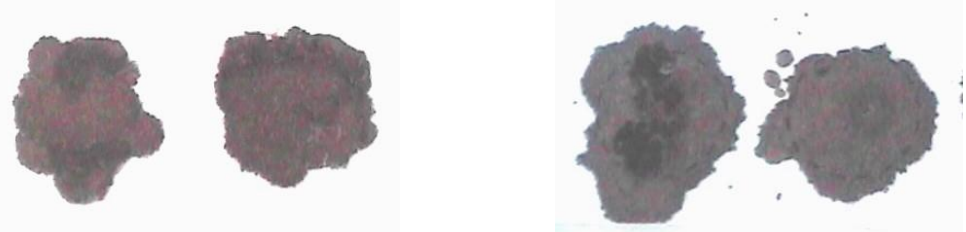

Figura 32. Textura del papel dañada.

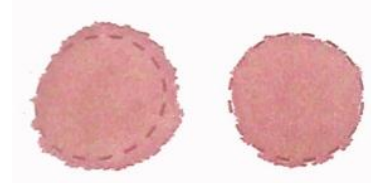

Figura 33. Secado incompleto de la muestra.

\section{Métodos}

De manera similar a lo que acontece en el caso de las pruebas analíticas utilizadas en los Laboratorios generales de análisis clínicos, los métodos empleados en 
las pruebas de PN deben cumplir con una serie de exigencias analíticas y diagnósticas que les permitan garantizar la obtención de resultados confiables.

Además de esto, en el caso particular de la PN, y más allá de la similitud antes mencionada con los métodos del Laboratorio general, resulta lógico esperar que el nivel de exigencia impuesto sea aún mayor en vista de que las implicancias de un resultado erróneo, y en particular de un resultado FN, darán lugar indefectiblemente a que un individuo afectado con alguna de estas enfermedades padezca una discapacidad física o neurológica de por vida o, eventualmente, a que muera en el período neonatal o durante su infancia temprana.

Hablando específicamente en términos de las características que deben presentar los métodos utilizados en PN, resulta una condición sine qua non que, previamente a la incorporación de un nuevo método a la rutina diaria, las mismas sean validadas a través de un procedimiento de Validación de Métodos -tema que será abordado en detalle en el Capítulo 4. Dichas características son presentadas en la Tabla 22 agrupadas en 5 categorías principales.

Tabla 22. Características de los métodos de pesquisa

\begin{tabular}{|c|c|}
\hline \multicolumn{2}{|c|}{ Analíticas } \\
\hline - Exactos & - Específicos \\
\hline - Precisos & - Robustos \\
\hline - Sensibles & \\
\hline \multicolumn{2}{|c|}{ Diagnósticas } \\
\hline - Sensibles & - Específicos \\
\hline \multicolumn{2}{|c|}{ Operativas } \\
\hline \multicolumn{2}{|l|}{ - Sencillos } \\
\hline \multicolumn{2}{|c|}{ - Eventualmente automatizados } \\
\hline \multicolumn{2}{|c|}{ De diseño } \\
\hline \multicolumn{2}{|c|}{ - Diseñados específicamente para PN } \\
\hline \multirow{3}{*}{\multicolumn{2}{|c|}{$\begin{array}{l}\text { - Provistos de calibradores y controles preparados } \\
\text { en una matriz idéntica a la de las muestras de RN } \\
\text { - Preferentemente cuantitativos }\end{array}$}} \\
\hline & \\
\hline & \\
\hline \multicolumn{2}{|c|}{ De costos } \\
\hline - Baratos & \\
\hline
\end{tabular}


Otro aspecto que debe mencionarse en relación a los métodos empleados en las pruebas de pesquisa es acerca de la evolución que los mismos han experimentado desde los orígenes de la PN hasta la actualidad, en sincronía con los avances tecnológicos puestos de manifiesto en las ciencias en general. Este hecho, el cual ya fue descripto en detalle en la Introducción de este trabajo, ha determinado que en los últimos años se haya impuesto una tendencia bien definida a sustituir las pruebas clásicas basadas en la realización de un test para detectar una patología determinada, por pruebas basadas en plataformas de tipo multiplex, en las cuales a partir de una única prueba es posible detectar múltiples patologías.

A efectos de ejemplificar esta evolución, en la Tabla 23 se presenta una lista de las diferentes metodologías empleadas en la PN, ordenadas según un orden cronológico aproximado de aparición de las mismas.

Tabla 23. Métodos empleados en PN

- Ensayos de Inhibición Bacteriana (BIA)

- Cromatografía en capa fina (TLC)

- Métodos Fluorométricos

- Radio Inmunoensayo (RIA)

- Inmunoensayos no isotópicos

- Enzimo inmunoensayo (EIA)

- Inmunoensayo Fluorométrico (FEIA)

- Fluorometría a Tiempo Resuelto (DELFIA)

- Métodos Enzimáticos Colorimétricos

- Cromatografía Líquida de Alta Performance (HPLC)

- Espectrometría de Masa en Tándem (EMT)

- Perfil de Múltiples Analitos (Luminex ${ }^{\circledR}$ )

\section{Valores de corte}

Los valores de corte (VC) constituyen una de las variables que mayor influencia ejerce sobre la exactitud diagnóstica del sistema de PN, razón por la cual resulta imprescindible que la definición de los mismos sea llevada a cabo trabajando sobre la base de una serie de criterios previamente establecidos. 
Esta modalidad racional de trabajo permitirá establecer VC apropiados y consecuentemente llevar a cabo una correcta identificación tanto de los individuos afectados como de los individuos normales.

En contraposición con esta aseveración, una inapropiada definición de los mismos podrá afectar de manera crítica y determinante tanto la sensibilidad como la especificidad diagnóstica del sistema y, en definitiva, la eficacia del mismo.

\section{- Criterios de definición de valores de corte:}

- Distribuciones normales o Gaussianas de individuos sanos: en aquellos casos en los que la distribución de los individuos sanos sea de tipo normal o Gaussiana, el criterio recomendado para la definición del $V C$ es $X \pm 2 D S$, donde $X$ es la media de la distribución y DS su desvío estándar. Empleando este criterio queda determinado que el 95.5 \% de la población de individuos sanos presentará resultados normales y el $4.5 \%$ resultado anormales (ver Figura 34 ).

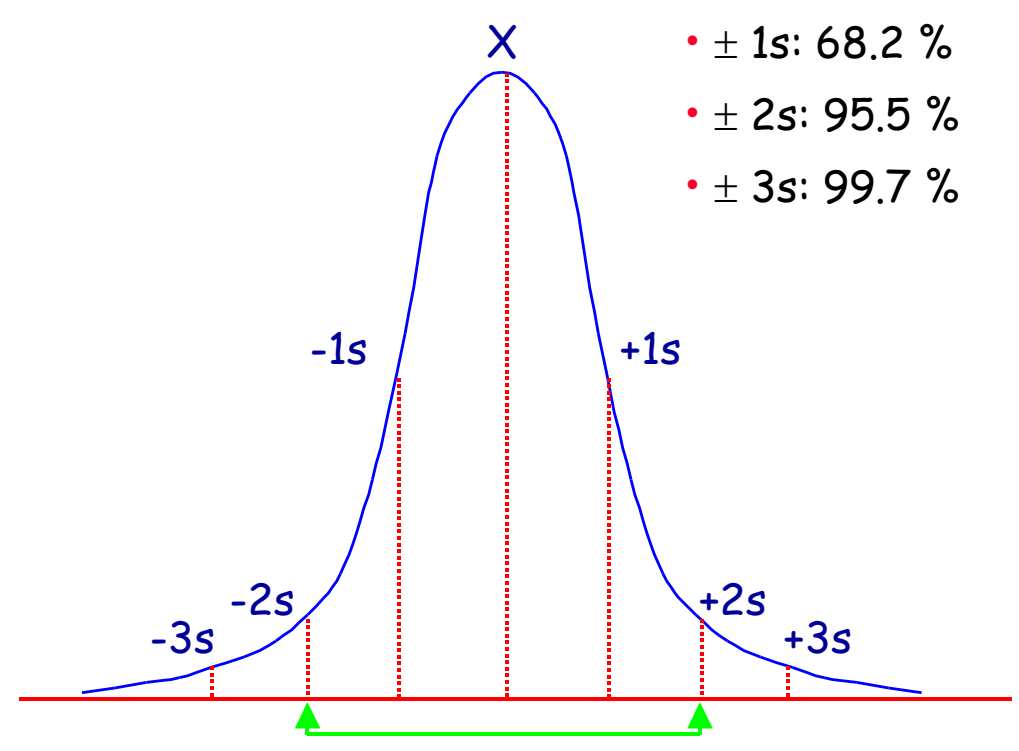

Figura 34. Distribución normal

Este criterio es el más frecuentemente utilizado en Química Clínica, sin embargo, en PN se utiliza en muy baja proporción porque en la mayor parte de los casos las distribuciones de RN sanos no se ajustan a curvas de tipo Gaussiana. 
Sumado a esto, debe tomarse en consideración que los resultados anormales en las pruebas de PN vienen determinados, en general, por valores aumentados o por valores disminuidos del analito en cuestión, pero muy rara vez por ambas situaciones en forma simultánea. En razón de esto, el VC debe ser fijado exclusivamente sobre una de las colas de la distribución según sea que la detección de los individuos afectados se realice midiendo la acumulación o la deficiencia de un analito determinado, siendo este un concepto que a su vez, puede extrapolarse también a distribuciones no normales.

- Distribuciones no Gaussianas de individuos sanos: en aquellos casos en los que la distribución de los individuos sanos sea no Gaussiana, el VC deberá establecerse mediante la definición de un percentilo o fractil seleccionado arbitrariamente $(23,24)$, tomando en consideración para esto 2 factores críticos: a) el grado de superposición o solapamiento esperado entre las distribuciones de individuos normales y de individuos afectados, y b) la situación de compromiso buscada entre sensibilidad y especificidad del sistema de detección, de manera tal de poder asegurar que los FN sean minimizados a un valor lo más próximo a cero posible, pero con una tasa de FP tal que sea manejable y que no genere una excesiva sobrecarga de trabajo en la instancia de seguimiento del Programa.

Esto significa que, utilizando este criterio y según sea el percentilo seleccionado, quedará definido de antemano el porcentaje de la población normal que presentará resultados anormales, o en otros términos el porcentaje de FP que presentará la estrategia de detección de una patología determinada.

A efectos de ejemplificar este concepto, si se define el VC en el percentilo $99.5 \%$ tal como se muestra en la Figura 35 , esto significa que la tasa de FP será del $0.5 \%$.

Este criterio de definición de VC empleando un percentilo determinado es el más frecuentemente utilizado en la pruebas de PN.

Como dato orientador, es recomendable que el porcentaje de FP en un Programa de PN sea siempre inferior al $1 \%$, con valores aceptables del orden 
del 0.3 al $0.5 \%$ y valores óptimos del $0.1 \%$ o menores.

Esta afirmación pone en evidencia que el criterio de la $X \pm 2 D S$ descripto para el caso de distribuciones normales excede largamente la tasa recomendada de FP para la PN, por lo cual en el caso de distribuciones normales también resulta apropiado definir el VC empleando una fórmula similar a la descripta anteriormente pero en la cual el factor que multiplica al DS sea de mayor magnitud (por ejemplo: $X \pm 3 D S$ ), o a través de la definición de un percentilo determinado en forma similar a lo descripto para distribuciones no Gaussianas $(23,24)$.

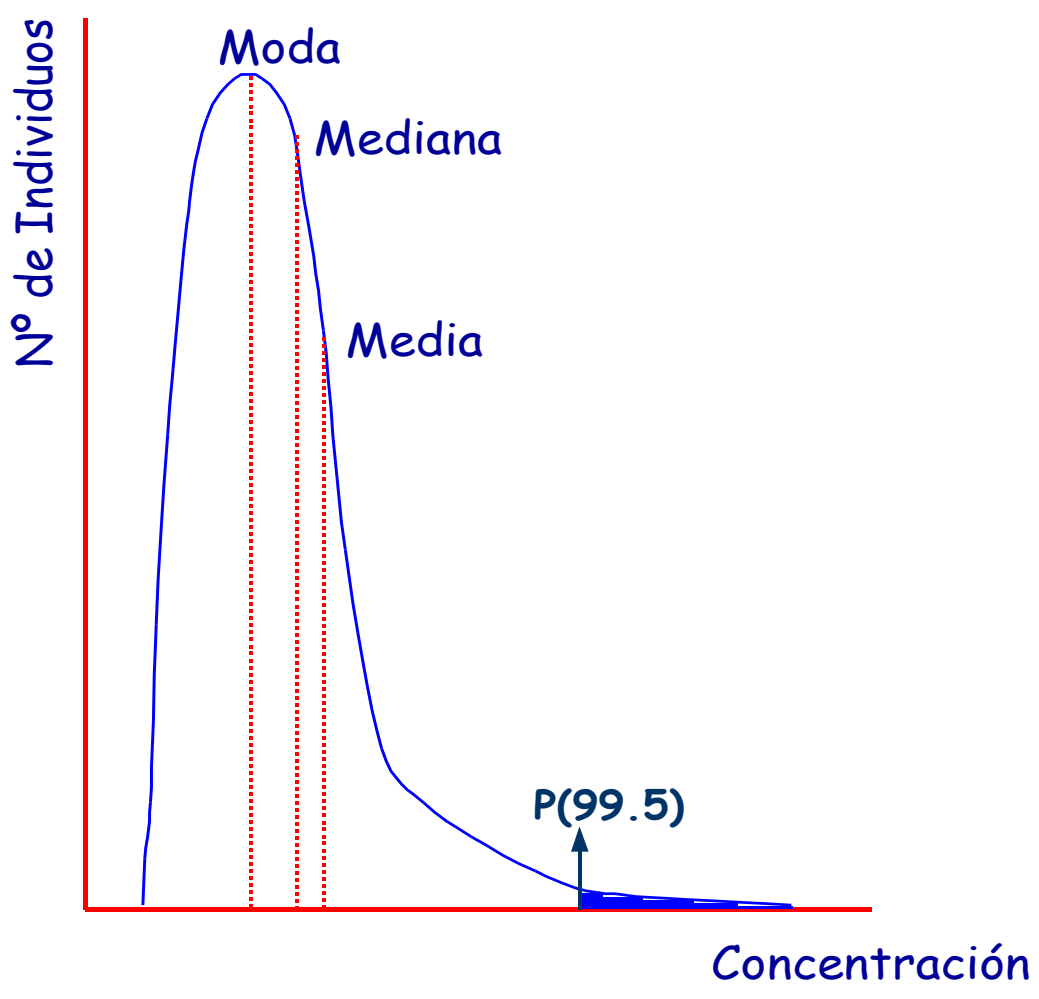

Figura 35. Distribución no normal

- Distribución de individuos afectados en condiciones ideales, el procedimiento a seguir para una óptima definición de los VC en el sentido estricto de la palabra requeriría trabajar no solamente con los datos de la distribución correspondiente a los individuos normales, sino también con los correspondientes a la distribución de los individuos afectados.

Este último hecho constituye una limitación práctica muy importante puesto que la prevalencia de estas enfermedades es usualmente muy baja y por 
lo tanto es casi imposible reunir una cantidad de datos estadísticamente significativa en un período de tiempo razonable, como para permitir efectuar una evaluación poblacional que sea representativa de la realidad.

En general, ningún Programa de PN en forma aislada cuenta con datos suficientes como para poder definir esta distribución de manera confiable, motivo por el cual la única alternativa posible para concretar este objetivo es a través de estudios colaborativos multicéntricos. No obstante esto, debe destacarse que dicha modalidad de trabajo sólo será válida y satisfactoria siempre y cuando los resultados obtenidos por los distintos centros involucrados en el mencionado estudio colaborativo al analizar cada muestra sean comparables, es decir cuando, en promedio, cada uno de ellos les asigne un valor similar (25).

\section{- Influencia de la imprecisión y la inexactitud de los métodos de medida sobre} los valores de corte: Otro aspecto muy importante a tener en cuenta en relación a los VC-y que habitualmente es considerado mínimamente-, es la influencia que la imprecisión y la inexactitud de los diferentes métodos de medida ejercen sobre los mismos, afectando tanto la sensibilidad como la especificidad diagnóstica del sistema de detección (26).

- Efecto de la imprecisión: tal como se describe en el Capítulo 4, un incremento en la imprecisión de un método determinado se traduce en una serie de modificaciones en la forma de la curva de distribución poblacional, la cual sufre un aplanamiento y un ensanchamiento debido a la mayor dispersión de los resultados y al consecuente incremento en el DS.

En función de este comportamiento, si experimentalmente se define el VC para un analito y una población determinados trabajando con 2 métodos que presentan distinta precisión -por ejemplo en el percentilo $99.5 \%$-, se observará que en el caso del método más impreciso el VC estará desplazado más significativamente hacia la zona de valores anormales que en el caso del método más preciso (25), dando lugar así a la situación que se presenta en la Figura 36, en la cual el efecto en estudio ha sido magnificado con la finalidad de facilitar la comprensión del mismo. 


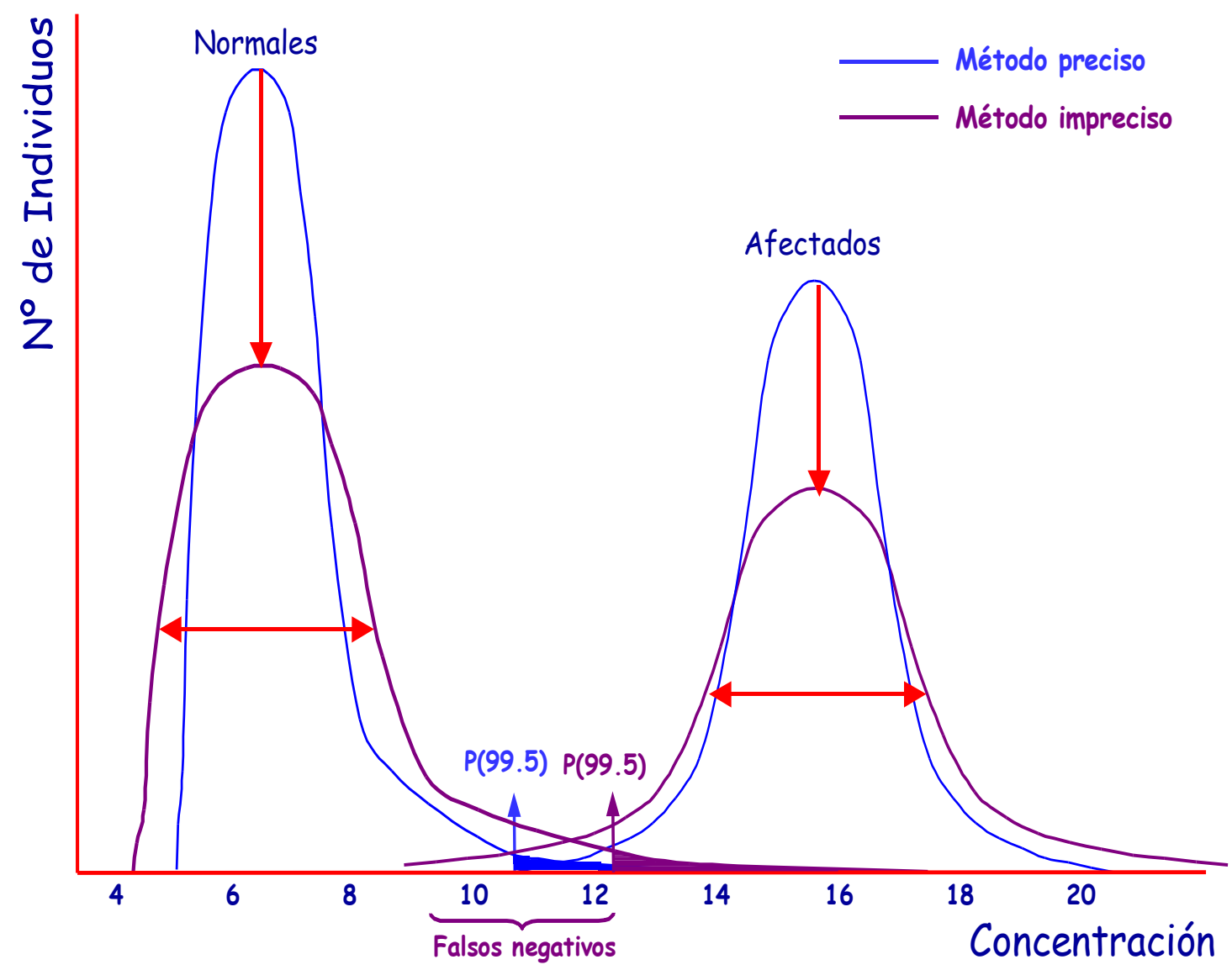

Figura 36. Efecto de la imprecisión sobre los valores de corte.

En la práctica este efecto implicará que ambos métodos de medida presentarán idéntica especificidad -determinada por el percentilo utilizado para definir el VC-, y diferente sensibilidad, correspondiéndole al método más impreciso una mayor probabilidad de presentar resultados FN (Figura 36). Adicionalmente los VC expresados en términos absolutos del analito a medir también serán diferentes para uno y otro caso.

Tal como puede inferirse de la discusión anterior, este fenómeno es con frecuencia el responsable tanto de la escasa comparabilidad observada entre los VC de diferentes laboratorios que utilizan el mismo percentilo para establecer sus propios VC, como de que los mismos presenten idéntica tasa de resultados FP y diferente tasa de resultados FN.

Otra situación que también puede observarse en la práctica y que es capaz de afectar la eficiencia diagnóstica del sistema de detección es la que se presenta cuando en determinadas circunstancias, un determinado método de 
medida en uso en la rutina diaria experimenta un incremento en su imprecisión. Si a pesar de este cambio, el laboratorio aún continúa trabajando con el VC definido en condiciones de precisión adecuadas, es decir conservando el VC originalmente definido, entonces el efecto se traducirá en una pérdida de sensibilidad -aunque de una magnitud mucho menos significativa que la observada en la situación antes descripta-, y también en una disminución en la especificidad, propiedad que no resultaba afectada en el caso anterior.

- Efecto de la inexactitud: a diferencia de lo descripto anteriormente en relación al efecto de la imprecisión sobre los métodos de medida, un incremento en la inexactitud de los mismos no da lugar a un cambio en la forma de la curva de distribución poblacional, sino que por el contrario se traduce en un desplazamiento de la misma hacia valores más altos o más bajos, dependiendo de si la inexactitud observada es positiva o negativa respectivamente (26) (Ver Capítulo 4).

De éste modo, si en la práctica se establece el VC para un analito determinado utilizando un método de medida que se encuentra funcionando dentro de un régimen de exactitud apropiada, y si en determinadas circunstancias de trabajo el mismo se torna más inexacto -por ejemplo por la utilización de un nuevo lote de calibradores cuyos valores han sido incorrectamente asignados-, y a pesar de este cambio en el desempeño del método se continúa utilizando el mismo VC originalmente definido, entonces el efecto resultante consistirá en un corrimiento de la curva de distribución poblacional a izquierda o a derecha con respecto a la disposición original de la misma, afectando de este modo en forma directa tanto la sensibilidad como la especificidad del método.

En el ejemplo de la Figura 37 se presenta la situación que se observa cuando el desplazamiento originado por la inexactitud del método se produce hacia la zona de valores normales (inexactitud negativa), lo cual consecuentemente dará lugar a la situación más grave que consiste precisamente, en un incremento en la tasa de FN asociado a una disminución en la tasa de FP (26). 


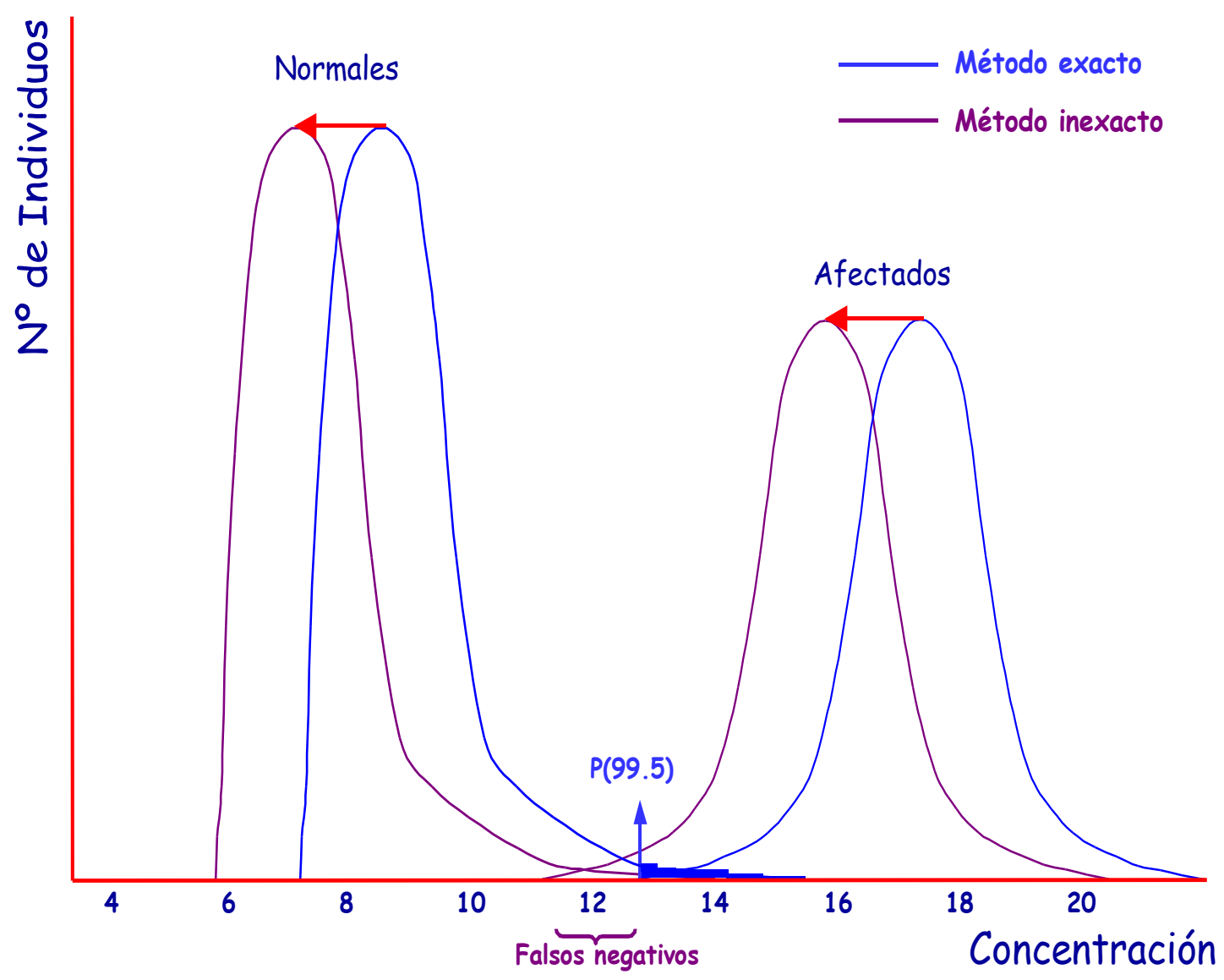

Figura 37. Efecto de la inexactitud sobre el valor de corte.

\section{- Premisas para la definición de valores de corte:}

- Los VC siempre deben ser establecidos previamente a la implementación de la pesquisa mediante un estudio poblacional realizado en prueba piloto sobre una población de al menos 500 RN.

- Los VC proporcionados en los insertos de los kits comerciales deben ser utilizados con precaución puesto que, en general, los mismos son establecidos sobre poblaciones muy reducidas de RN (del orden de 200 o menos), y cuya composición étnica puede distar diametralmente de la población target a la cual estará dirigida la pesquisa (23).

- Los VC proporcionados por la bibliografía deben ser utilizados sólo como orientación y referencia, y sin olvidar la influencia que ejercen sobre los mismos la imprecisión y la inexactitud de los métodos. Por otra parte, y al igual que en el caso de los VC proporcionados por los kits comerciales, se deberá prestar especial atención al hecho de que dichos VC pueden haber sido 
definidos sobre una población con una composición étnica absolutamente diferente de la que se está pesquisando o pretendiendo pesquisar (23).

- Adicionalmente, una alternativa válida que habilita a la utilización de VC bibliográficos, VC proporcionados por los fabricantes de reactivos o VC obtenidos en otros centros de pesquisa, evitando así la necesidad de definirlos en el propio laboratorio, es realizar una validación de los mismos empleando para ello protocolos de transferencia confeccionados específicamente para tal fin (23). Sin embargo, debe quedar en claro que estos protocolos no han sido diseñados pensando en pruebas de PN y que en principio no parecen ser fácilmente extrapolables a las mismas.

- Los VC a utilizar cuando se comienza con una pesquisa determinada deben ser VC conservadores, debiendo mantenerse sin cambios a lo largo del tiempo hasta tanto se amplíe el número de neonatos evaluados y los mismos puedan ser redefinidos sobre una población de RN que resulte estadísticamente más significativa.

- Los VC deben ser redefinidos o recalculados periódicamente a través de nuevos estudios poblacionales, muy especialmente toda vez que se introduce una modificación en los métodos de medida.

- Los VC podrán definirse siguiendo distintas modalidades según los analitos que se estén evaluando y las características analíticas y diagnósticas de los métodos de medida utilizados. De esta forma podrán definirse VC fijos -invariables corrida a corrida- como los utilizados por ejemplo en la medida de Phe o TSH; o VC fluctuantes -establecidos para cada corrida en forma particular utilizando un percentilo definido previamente-como los empleados en la medida de IRT o $T_{4}(27)$.

- Por otra parte, y dependiendo de la influencia ejercida por determinadas variables biológicas sobre los valores de referencia de ciertos analitos, como son por ejemplo la edad del RN al momento de la toma de muestras, la edad gestacional o el peso al nacimiento, podrán seleccionarse VC independientes de dichas variables -como los utilizados por ejemplo en la medida de Phe o TSH- o 
VC ajustados según algunas de esas variables -como por ejemplo los utilizados en la medida de $170 \mathrm{HP}$.

\section{Control de Calidad}

El Control de Calidad (CC) es otro de los pilares sobre los cuales debe sustentarse el Laboratorio de PN, puesto que a través de la implementación de un apropiado sistema de CC será posible llevar a cabo, por un lado, el monitoreo permanente del desempeño analítico de los métodos en uso y de los diferentes procedimientos que se ejecutan dentro del Laboratorio, y por el otro, la ejecución de todas las acciones correctivas que corresponda realizar antes de que la performance de dichos métodos resulte afectada.

Básicamente, el CC en el Laboratorio de pesquisa puede dividirse en 3 áreas, las cuales solamente serán mencionadas de manera suscinta en este capítulo, puesto que las mismas serán descriptas en detalle en los Capítulos 6 y 7:

- Implementación sistemática de un estricto sistema de CC Interno.

- Participación en al menos 2 Programas de Evaluación Externa de Calidad (EEC) para cada uno de los analitos evaluados.

- Implementación de un Sistema Integral de Control de Calidad en todos los procesos que se llevan a cabo en el Laboratorio, es decir que involucre también tanto a los procesos Pre-analíticos como a los Post-analíticos.

\section{- PROCESOS POST-ANALÍtICOS}

Con respecto a los procesos Post-analíticos, y al igual que lo que acontece en el caso de los procesos Pre-analíticos, los mismos requieren idealmente y como condición necesaria el empleo de un apropiado Sistema Informatizado de Gestión de Muestras (SIGM) a fin de lograr el manejo efectivo, seguro y confiable de los resultados, más allá de que en determinadas circunstancias los mismos podrían ser ejecutados en forma manual. En la Tabla 24 se presenta una lista que incluye los principales procesos Post-analíticos a considerar en el Laboratorio de pesquisa. 
Tabla 24. Procesos Post-analíticos

- Carga de resultados

- Emisión de informes de resultados

- Envío de informes de resultados

- Comunicación de solicitudes de $2^{\circ}$ muestras

- Por calidad inadecuada de la muestra

- Por incumplimiento de condiciones de recolección

- Por resultados anormales (dudosos)

- Comunicación de solicitudes de derivación de RN al Centro de Atención Especializada (resultados patológicos)

- Seguimiento de llegada de $2^{\circ}$ muestras solicitadas

- Seguimiento de concurrencia de neonatos derivados

- Apropiado almacenamiento de muestras de sangre residuales

- Apropiado almacenamiento de datos, resultados y documentación de valor legal del Programa

- Reposición de tarjetas de recolección de muestras

\section{BIBLIOGRAFIA}

1. Therrell BL, Panny SR, Davidson A, Eckman J, Hannon WH, Henson MA, Hillard M, Kling S, Levy HL, Meaney FJ, McCabe ERB, Mordaunt V, Pass K, Shapira E and Tuerck J. "U.S. Newborn Screening System Guidelines: Statement of the Council of Regional Networks for Genetic Services". Screening 1, 135-47, 1992.

2. CLSI. "Blood Collection on Filter Paper for Neonatal Screening Programs". Approved Standard - Fifth Edition. CLSI Document LA4-A5, Vol 27 № 20, 2007.

3. NCCLS. "Procedures and Devices for the Collection of Diagnostic Capillary Blood Specimens"; Approved Standard-Fifth Edition. NCCLS document H4-A5, Vol 24 $N^{0} 21,2004$.

4. Guthrie R and Susi A. "A Simple Phenylalanine Method for Detecting Phenylketonuria in Large Populations of Newborn Infants". Pediatrics 32, 338-43, 1963.

5. Webster D, Dhondt J-L, Hannon WH, Loeber $G$ and Torresani T. "Quality Assurance and Standardization: Summary of the Satellite Meeting, Turku, Finland, 11-12 June 1999". Acta Pediatr Suppl 432, 7-12, 1999. 
6. CLSI. "Newborn Screening for Preterm, Low Birth Weight, and Sick Newborns"; Approved Guideline. CLSI Document I/LA31-A. Vol 29 N 24, 2009.

7. Committee on Genetics - American Academy of Pediatrics; "Issues in Newborn Screening". Pediatrics, 89, 345-349, 1992.

8. Pass KA, Levy HL. "Statement of the Conference" en "Early Hospital Discharge: Impact on Newborn Screening". Pass KA and Levy HL Eds, CORN-Emory University School of Medicine, Atlanta, xiii-xvii, 1995.

9. Jew K, Kan K, Koch R, Cunningham GC. "Validity of Screening Early Collected Newborn Specimens for Phenylketonuria Using a Fluorometric Method". Screening 3, 1-9, 1994.

10. Jew K. "PKU - Review of Clinical Development \& Newborn Screening Aspects" en "Early Hospital Discharge: Impact on Newborn Screening". Pass KA and Levy HL Eds, CORN-Emory University School of Medicine, Atlanta, 113-25, 1995.

11. Levy HL. "Is Early Discharge a Problem for Newborn Screening?" en "Early Hospital Discharge: Impact on Newborn Screening". Pass KA and Levy HL Eds, CORN-Emory University School of Medicine, Atlanta, 23-30, 1995.

12. Naylor EW. "Impact of Early Hospital Discharge on Newborn Screening for Homocistinuria and Maple Syrup Urine Disease" en "Early Hospital Discharge: Impact on Newborn Screening". Pass KA and Levy HL Eds, CORN-Emory University School of Medicine, Atlanta, 126-32, 1995.

13. Foley TP, Torresani TE. "Congenital Hypothyroidism" en "Early Hospital Discharge: Impact on Newborn Screening". Pass KA and Levy HL Eds, CORN-Emory University School of Medicine, Atlanta, 133-54, 1995.

14. Gonzalez JL. "Newborn Screening for Congenital Adrenal Hyperplasia: The Texas Experience" en "Early Hospital Discharge: Impact on Newborn Screening". Pass KA and Levy HL Eds, CORN-Emory University School of Medicine, Atlanta, 155$66,1995$.

15. Bickel H. "Rationale of Neonatal Screening in Inborn Errors of Metabolism" en "Neonatal Screening for Inborn Errors of Metabolism". Bickel H, Guthrie R and Hammersen G Eds, Springer-Verlag, Berlin-Heidelberg-New York, 1-6, 1980. 
16. Pass K. "Introduction and Conference Overview" en "Early Hospital Discharge: Impact on Newborn Screening". Pass KA and Levy HL Eds, CORN-Emory University School of Medicine, Atlanta, 8-22, 1995.

17. Cunningham GC, Lorey F, Arnopp J, Patterson M, Currier R. "Early Discharge Trends and their Effect on PKU Screening" en "Early Hospital Discharge: Impact on Newborn Screening". Pass KA and Levy HL Eds, CORN-Emory University School of Medicine, Atlanta, 31-56, 1995.

18. Duane $A$ and van Dyck PC. "A Vision of the Future of Newborn Screening". Pediatrics 117, S350-S354, 2006.

19. Comité de Endocrinología. Sociedad Argentina de Pediatría. Recomendaciones para los Programas de Pesquisa Neonatal de Hipotiroidismo Congénito. Arch Argent Pediatr 98, 244-6, 2000.

20. Borrajo G, Fideleff G, Herzovich V, Testa G. "Hipotiroidismo Congénito: Pesquisa, Confirmación y Seguimiento". Tercer Consenso Argentino Sobre Patologías Endocrinológicas. Rev Argent Endocrinol Metab 46, 50-4, 2009.

21. American Academy of Pediatrics, Susan Rose, and the Section on Endocrinology and Committee on Genetics, American Thyroid Association, Rosalind Brown, and the Public Health Committee and Lawson Wilkins Pediatric Endocrine Society. "Update of Newborn Screening and Therapy for Congenital Hypothyroidism". Pediatr 117, 2290-2303, 2006.

22. Borrajo GJC. "Pesquisa Neonatal" en "Fibrosis Quística". Segal E, Fernández A y Rentería F Editores. $1^{a}$ Edición. Editorial Journal. Buenos Aires, 63-77, Cap. 15, 2003.

23. NCCLS. "How to Define and Determine Reference Intervals in the Clinical Laboratory": Approved Guideline-Second Edition. NCCLS document C28-A2, Vol $20 N^{\circ} 13,2000$.

24. Solberg HE. "Approved Recommendations (1987) on the Theory of Reference Values. Part 5. Statistical Treatment of Collected Reference Values. Determination of Reference Limits". J Clin Chem Clin Biochem 25, 645-56, 1987. 25. Cuckle HS and Wald N. "Tests Using Single Markers" en "Antenatal and Neonatal 
Screening". Wald N and Leck I Eds, Second Edition, Oxford University Press, Oxford-New York, 1-22, 2000.

26. Fraser CG. "Quality Specifications" en "Biological Variation: from Principles to Practice". Fraser CG Ed, First Edition, AACC Press, Washington, Chapter 2, 2966, 2001.

27. Slazyk WE and Hannon WH. "Quality Assurance in the Newborn Screening Laboratory" en "Laboratory Methods for Neonatal Screening", Therrell BL Ed, American Public Health Association, Washington, 23-46, 1993. 


\section{CAPÍTULO 3}

AUTOMATIZACIÓN 



\section{- INTRODUCCIÓN}

El contenido del presente Capítulo está basado en el modelo de automatización del Laboratorio de Detección de Errores Congénitos de la Fundación Bioquímica Argentina (FBA), y a través del mismo serán delineados los principales aspectos a considerar en el proceso de automatización del Laboratorio de PN.

\section{- OBJETIVOS Y BENEFICIOS}

La automatización es un proceso cuya finalidad consiste en incrementar la eficiencia y el rendimiento del Laboratorio con una concomitante disminución de los errores humanos, tiempos de operación y costos, a través de la estandarización y optimización de las diferentes tareas que se llevan a cabo en el mismo.

El diseño de un sistema automatizado de trabajo requiere como condiciones necesarias de cumplimiento estricto el acceso a la informatización y la disponibilidad del equipamiento de Laboratorio específico requerido para automatizar las diferentes tareas que le competen, incluyendo entre éstas tanto a los procesos Analíticos como a los Pre y Post-analíticos. En la Tabla 25 se presentan los beneficios a los cuales es posible acceder a partir de la implementación de un sistema automatizado de trabajo.

\section{Tabla 25. Beneficios de la automatización}

- Eliminación de errores de tipeo de números de identificación de muestras

- Procesamiento simultáneo de un número significativo de muestras por corrida

- Rápida disponibilidad de resultados

- Identificación segura de muestras en corridas según listas de trabajo

- Minimización de errores por transposición de muestras y por corrimiento del marco de lectura

- Acceso a lectura instrumental y a registros impresos de las mismas

- Eliminación de cálculos manuales y fácil manejo de bases de datos

- Eliminación de errores en la transcripción de resultados

- Eliminación de errores por omisión de resultados anormales

- Reducción en los tiempos de supervisión de resultados y procesos

- Reducción del tiempo-hombre de análisis y aumento en la capacidad de trabajo

- Mayor aprovechamiento de recursos humanos

- Optimización de los sistemas de seguimiento 


\section{- EXPERIENCIA EN LA FUNDACIÓN BIOQUÍMICA ARGENTINA}

\section{Introducción}

Antes de comenzar con la descripción detallada de la estrategia seguida en el Laboratorio de Detección de Errores Congénitos de la FBA a lo largo del proceso de automatización, y con la finalidad de lograr un mejor entendimiento de la modalidad de trabajo utilizada, es necesario mencionar que la forma en que se realiza la PN en dicho Laboratorio no se ajusta a las características de un sistema convencional. Este hecho determinó que el proceso de automatización no pudiera basarse estrictamente en modelos de automatización pre-existentes, sino que por el contrario requiriera una elaboración y diseño absolutamente personalizados.

Para clarificar los conceptos a los cuales se hace referencia cuando se habla de sistemas convencionales y no convencionales de trabajo, se debe mencionar que los sistemas convencionales son aquellos en los cuales todos los RN son pesquisados sistemáticamente para todas las patologías que forman parte del panel de enfermedades definidas por cada Programa, mientras que los sistemas no convencionales -como el de la FBA-son aquellos en los que el Programa ofrece un panel conformado por un número determinado de enfermedades a pesquisar, pero el cual no es realizado en forma sistemática a todos los RN sino que por el contrario, el hecho de que se efectúe la totalidad o sólo una parte de las pruebas ofrecidas, depende de una gran diversidad de factores. Entre éstos se puede citar por ejemplo si existe o no una obligatoriedad definida por ley con respecto a la realización de la pesquisa, a cuántas y cuáles pruebas está previsto dar cobertura por parte del centro asistencial en el cual nació el niño, si el médico que atiende al RN considera oportuno solicitar la realización de las mismas, si existe cobertura por parte de las obras sociales o de los sistemas de medicina prepaga, o eventualmente -en el caso de que no exista cobertura por parte de las anteriores ni tampoco por parte del Estado-, si los padres pueden hacerse cargo de los costos de las pruebas.

En consecuencia, y como puede inferirse a partir de lo expuesto anteriormente, en los sistemas no convencionales de trabajo las pruebas de PN son realizadas según la demanda existente. 
A efectos de ilustrar con datos concretos las características del sistema de trabajo de la FBA y de visualizar cómo influye la demanda antes mencionada sobre la solicitud de las diferentes pruebas ofrecidas, en la Tabla 26 se presenta el número promedio de RN pesquisados mensualmente para cada una de las 7 patologías que conforman el panel de pesquisa de la FBA según datos del año 2009.

Tabla 26. Número de neonatos pesquisados por mes en la FBA para cada patología

\begin{tabular}{lc}
\hline - Fenilcetonuria (PKU) & 17.500 \\
- Hipotiroidismo Congénito (HC) & 17.500 \\
- Fibrosis Quística (FQ) & 8.300 \\
- Galactosemia & 5.500 \\
- Hiperplasia Suprarrenal Congénita (HSC) & 5.500 \\
- Deficiencia de Biotinidasa & 5.000 \\
- Enf. de Orina de Jarabe de Arce (MSUD) & 2.000 \\
\hline NOTA: los datos presentados corresponden al promedio mensual del año 2009.
\end{tabular}

Por último, es importante destacar que la ejecución del proceso de automatización experimentado en el Laboratorio de la FBA se sustentó sobre 5 elementos principales que serán citados en reiteradas ocasiones a lo largo del desarrollo del presente Capítulo, y a los cuales se enumera a continuación:

1. Sistema Informatizado de Gestión de Muestras (SIGM) de desarrollo propio.

2. Software Multi-instrumento Multicalc (Wallac Oy, Turku - Finlandia).

3. Software BSD Worklist Translator - FBA (BSD Technologies International, Brisbane - Australia).

4. Instrumental de laboratorio modular automatizado y autoanalizadores, ambos de diversos orígenes, con características compatibles con el software Multicalc en aquellos casos en que corresponde.

5. Formato común de procesamiento para todos los analitos, representado por microplacas de 96 pocillos.

\section{Procesos Pre-analíticos}

La automatización de los procesos Pre-analíticos fue planificada con el objetivo de simplificar los procesos administrativos más complejos que, de alguna 
manera, dificultaban la interconexión fluida y dinámica entre el área administrativa y el área de laboratorio, y de minimizar o eliminar los errores que más frecuentemente fueron observados a lo largo del período previo a la implementación del sistema automatizado de trabajo motivo del presente Capítulo.

A continuación serán descriptas las diferentes herramientas y tareas que requirieron un desarrollo particular, y el equipamiento específico que debió incorporarse al Laboratorio para poder concretar la automatización de los diferentes procesos Pre-analíticos:

- Tarjeta de recolección de muestras: se sustituyó el modelo de tarjeta de recolección de muestras confeccionado íntegramente en papel de filtro que fuera provisto por la FBA hasta mediados de 1999 (Figura 38), por una chequera de recolección de muestras diseñada según normas internacionales (1), conformada por una tapa protectora de papel ilustración y tres hojas de papel químico autocopiativo, identificadas cada una de ellas con una numeración unívoca, propia de cada chequera, denominada Numeración Preimpresa (Figuras 39a, 39b, 40a, $40 b, 41 a$ y $41 b)$.

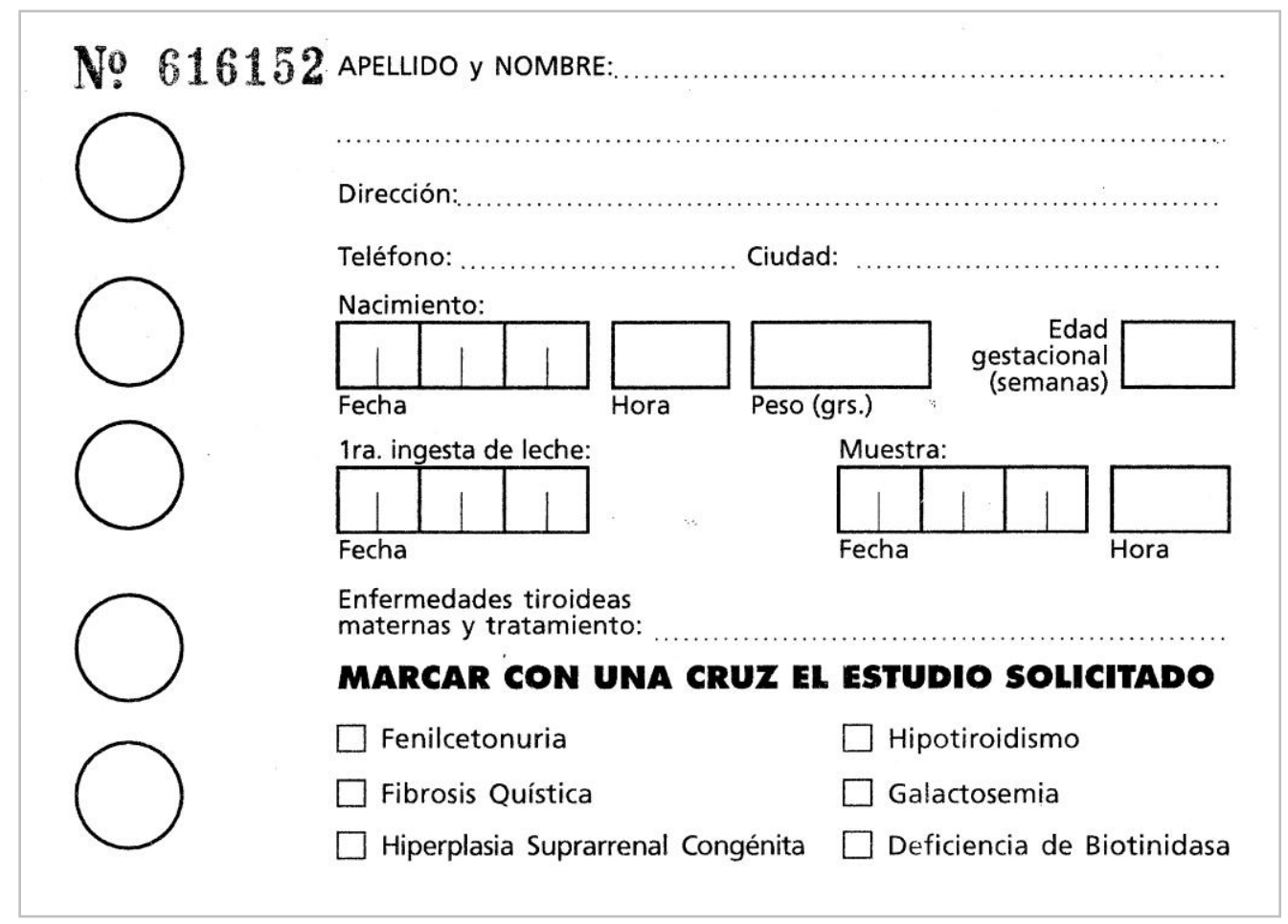

Figura 38. Tarjeta de recolección de muestras utilizada antes de la automatización. 
En cuanto al diseño de la nueva tarjeta de recolección de muestras, el mismo fue previsto de manera tal que la tapa no cumpliera solamente una función de protección del papel de filtro durante el período previo a la toma de la muestra, sino que además sirviera como un elemento para brindar información acerca de diferentes aspectos del Programa, como por ejemplo sus características, el marco legal dentro del cual se realizan las pruebas, los tiempos recomendados para la recolección de muestras, el procedimiento a seguir en caso de recolección anterior a las 24 horas de vida, los requerimientos especiales de recolección para la PN de Galactosemia y la técnica recomendada para la recolección de muestras.

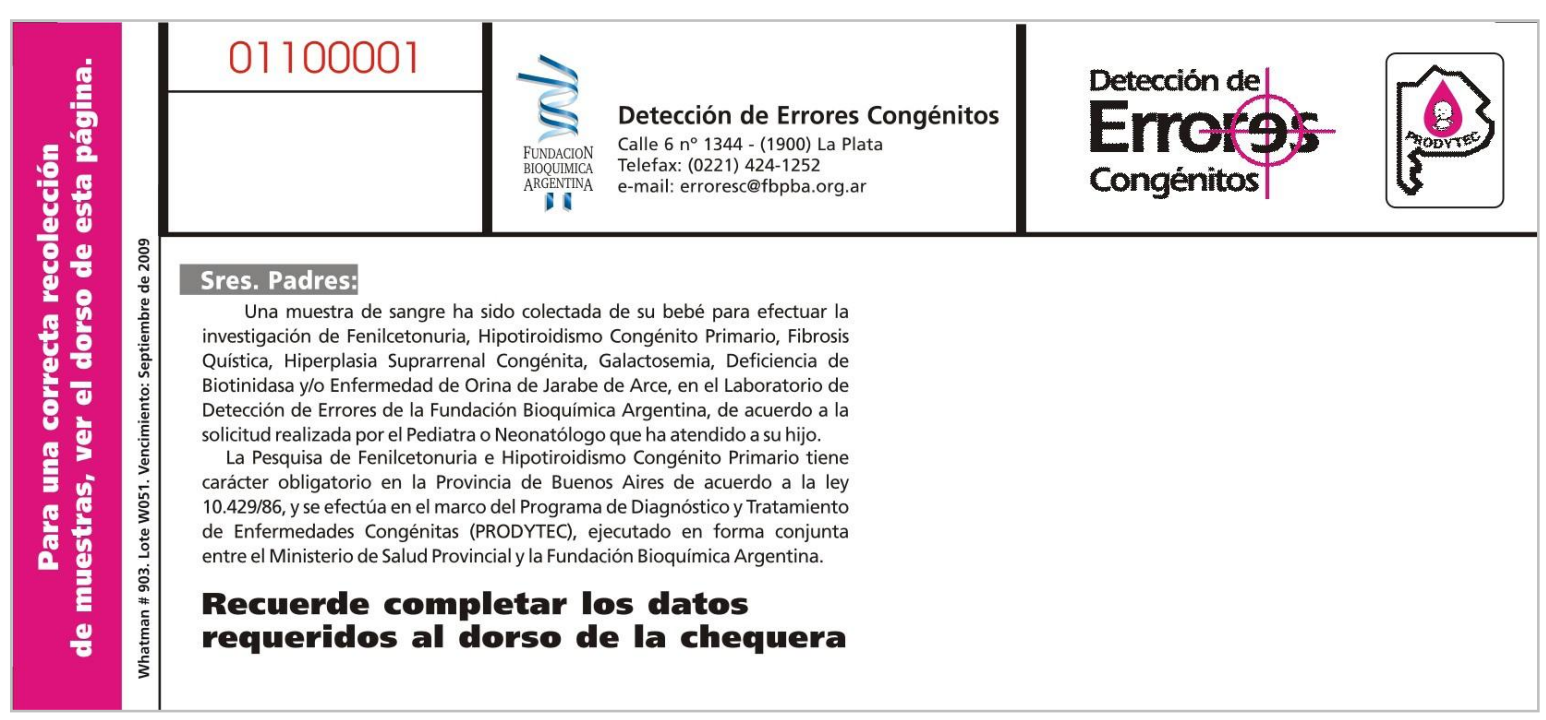

Figura 39a. Chequera de recolección de muestras (anverso tapa).

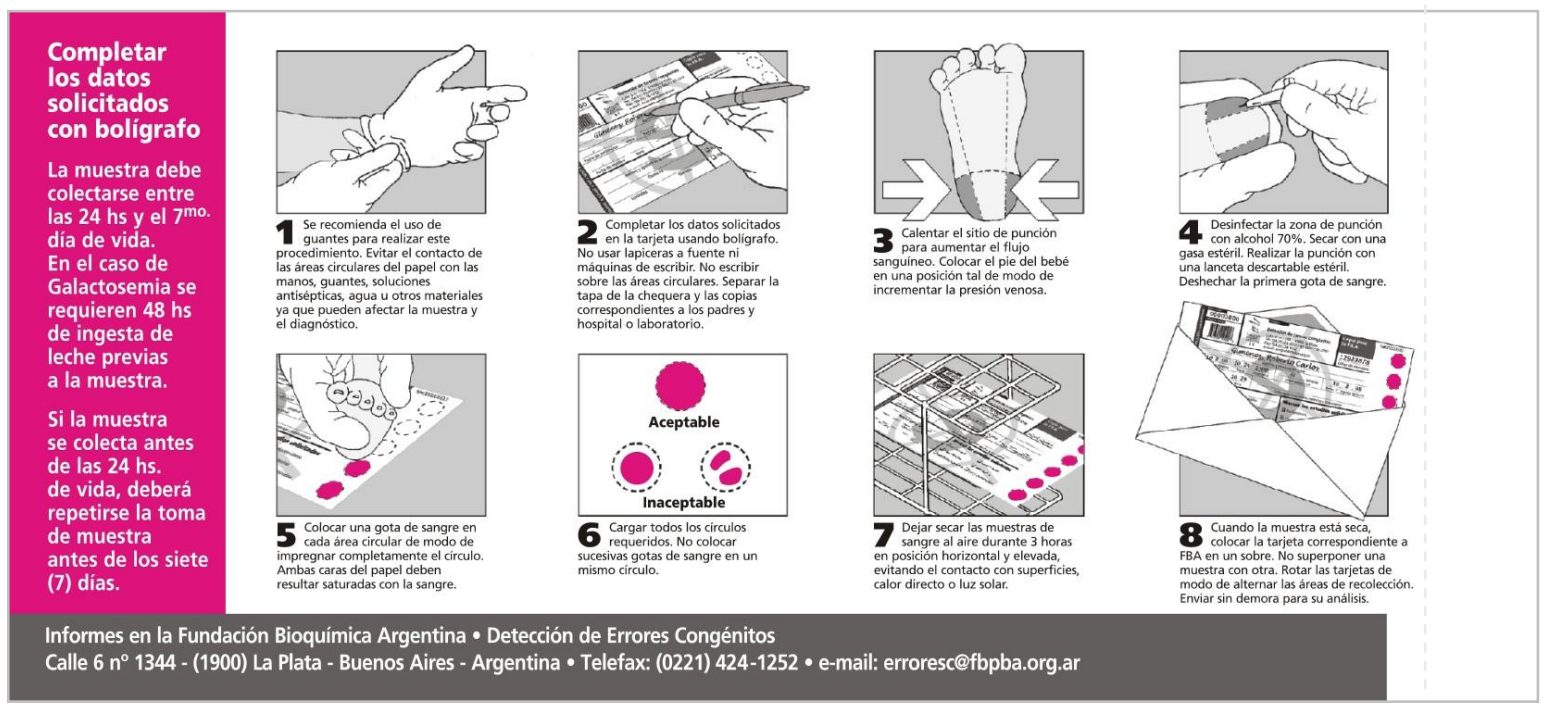

Figura 39b. Chequera de recolección de muestras (reverso tapa). 
Por otra parte, el diseño de las 3 hojas de papel químico fue previsto de forma tal que, haciendo uso de la capacidad de autocopiado de dicho papel, al completar la información del RN y de las pruebas solicitadas en la primera de estas tres hojas, la misma resultara automáticamente copiada en las dos restantes.

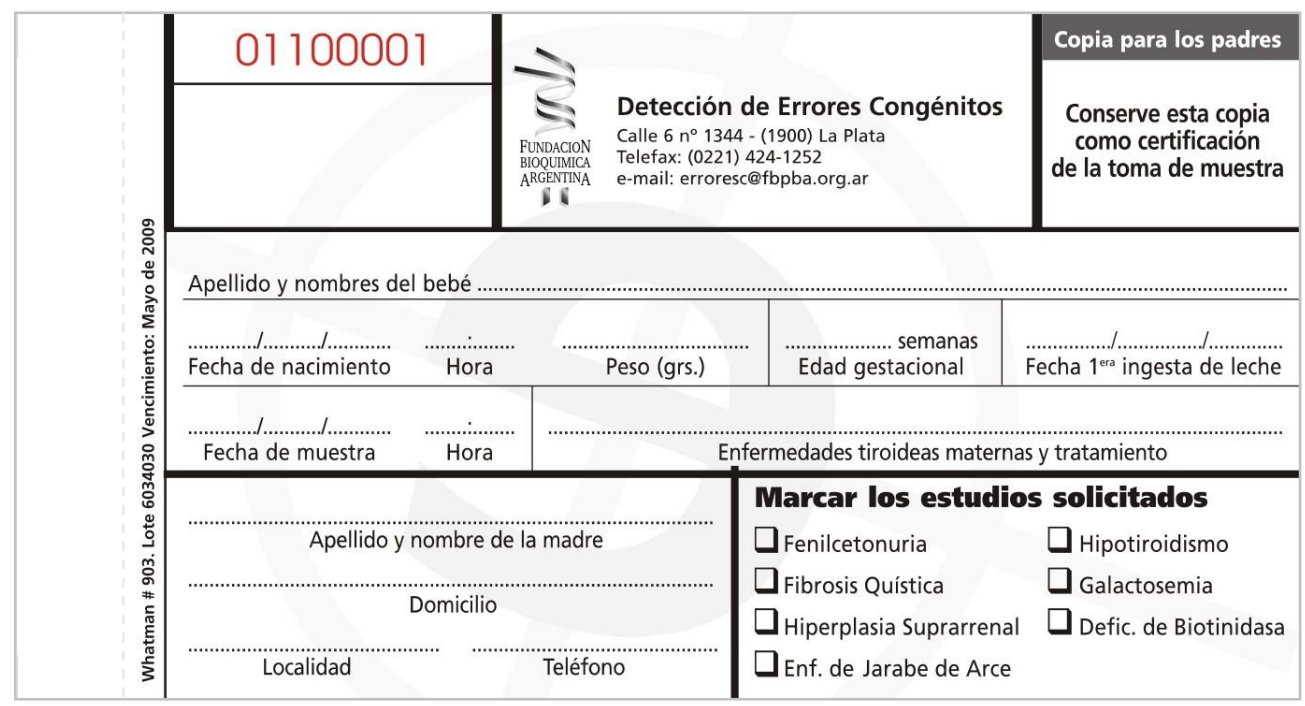

Figura 40a. Chequera de recolección de muestras ( $1^{\circ}$ hoja).

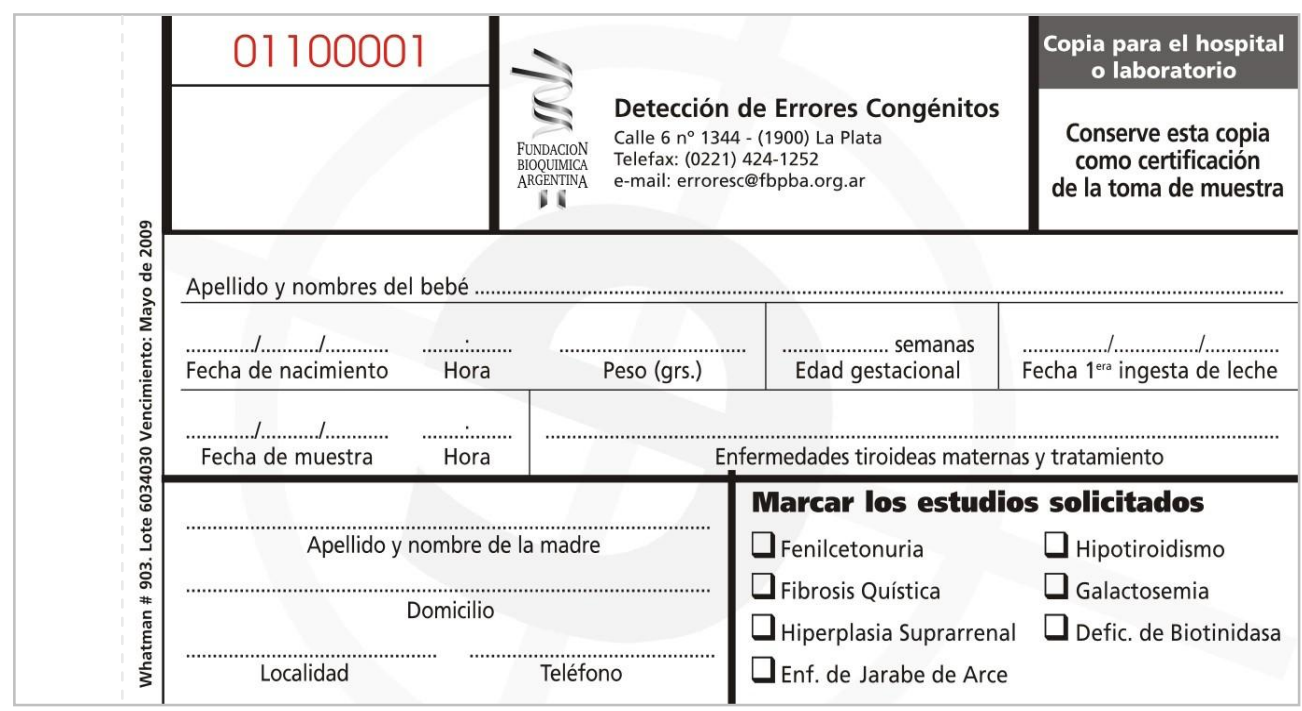

Figura $40 \mathrm{~b}$. Chequera de recolección de muestras $\left(2^{\circ}\right.$ hoja $)$.

Con respecto a la inclusión de las dos primeras hojas de papel químico en este nuevo modelo de tarjeta, la misma se realizó con la finalidad de que la primera de estas copias (Figura 40a) fuera entregada a los padres del RN como comprobante de la toma de muestras, mientras que la segunda (Figura 40b) fuera retenida en cada Centro Asistencial como una constancia de dicha recolección. 
Finalmente, en el caso de la tercera hoja de papel químico, y por tratarse de la copia destinada al Laboratorio de pesquisa, la misma fue diseñada con algunas características diferenciales con respecto a las dos hojas anteriores. Por un lado, en uno de sus laterales presenta adosado el papel de filtro en el cual se ha de impregnar la sangre del RN, y por el otro presenta: a) un código de barras que se corresponde con la Numeración Preimpresa de la tarjeta, b) un espacio destinado a colocar el Código de Identificación del Centro Asistencial que remite la muestra, y c) los espacios necesarios en el reverso de la misma, previstos para completar en forma detallada los datos del remitente (Figura 4la y 41b).

\begin{tabular}{|c|c|c|c|c|}
\hline &
\end{tabular}

Figura 41a. Chequera de recolección de muestras (anverso $3^{\circ}$ hoja).

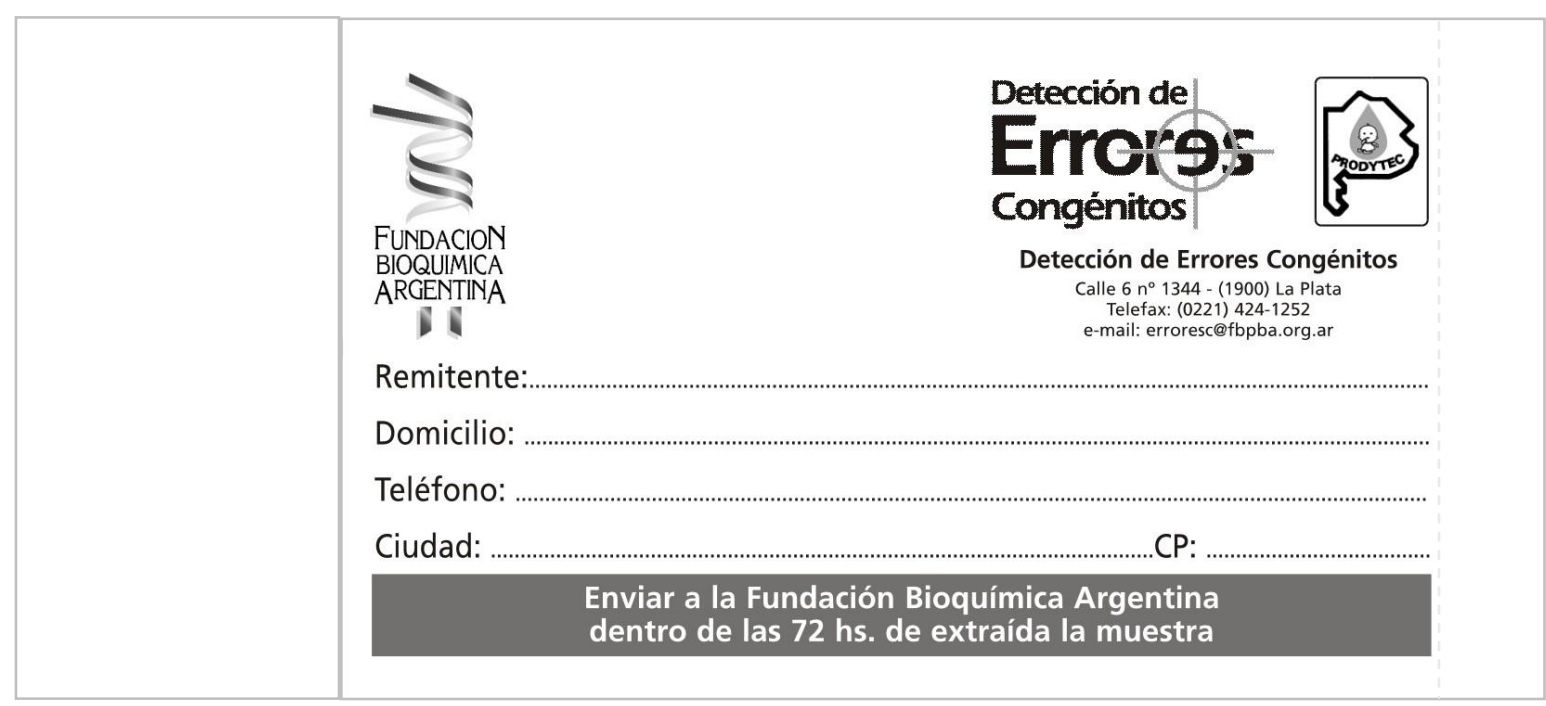

Figura 41b. Chequera de recolección de muestras (reverso $3^{\circ}$ hoja). 
- Códigos de barras correspondientes a la Numeración Preimpresa: tal como ya fuera mencionado anteriormente al realizar la descripción de la tarjeta de recolección de muestras, se implementó un sistema de códigos de barras correspondiente a la Numeración Preimpresa (Figura 41a) con el objeto de hacer posible el ingreso automatizado de dicha numeración al SIGM. En cuanto a la estructura de los códigos de barras, la misma no sólo permite la lectura del número correspondiente sino que además incluye un dígito verificador $(1,2)$ a efectos de minimizar los potenciales errores que pueden generarse por ejemplo a consecuencia de una lectura incompleta de los mismos.

- Códigos de barras para identificación del remitente: además de los códigos de barras antes descriptos, también se implementó el uso de un sistema adicional de códigos de barras a efectos de posibilitar el ingreso automatizado de los datos del remitente $(1,2)$. Sin embargo, y dado que se trata de códigos de barras personalizados para cada Centro Asistencial, los mismos no están impresos en cada chequera, sino que por el contrario resulta necesario agregarlos a cada una de ellas por medio de una etiqueta adhesiva.

En la práctica, y a efectos de poder cumplimentar esta tarea, el Laboratorio de la FBA tiene a su cargo la responsabilidad de imprimir y proveer mensualmente a cada Centro Asistencial o Laboratorio una o más hojas con etiquetas adhesivas impresas con el código de barras correspondiente al Código de Identificación de cada uno de ellos, mientras que los responsables de la recolección de muestras deben hacerse cargo de pegar las mismas en el espacio diseñado para tal fin en la copia de la chequera destinada a la FBA (ver Figura 41a).

En cuanto al mecanismo previsto para la provisión de etiquetas, el mismo se sustenta en el propio SIGM, el cual determina en forma automática la cantidad de hojas y etiquetas con códigos de barras que se deben imprimir y enviar a cada Centro Asistencial o Laboratorio, haciendo uso para esto de los registros disponibles correspondientes al número de muestras remitidas mensualmente por cada uno de ellos y al stock estimado de etiquetas que deben poseer, de acuerdo a la cantidad que les fuera provista previamente. 
- Sistema de doble numeración: la utilización de un sistema de Numeración Preimpresa por parte de la FBA como elemento de identificación unívoca en las tarjetas de recolección de muestras es una medida cuya implementación ocurrió con anterioridad al proceso de automatización al cual se está haciendo referencia en este Capítulo, puesto que la misma data de Julio de 1992, apenas algo más de un año después de haber comenzado a incursionar en el área de la PN.

Este tipo de sistemas de numeración resulta de gran utilidad a efectos de lograr la identificación unívoca de cada RN, y a efectos de simplificar y asegurar el flujo de información entre el Laboratorio de PN y los Centros Asistenciales que remiten las muestras de sangre $(1,2)$. Sin embargo, el mismo no resulta un elemento apropiado para el manejo de las muestras dentro del propio Laboratorio puesto que es de esperar que la Numeración Preimpresa de las tarjetas que ingresan a diario sea sumamente diversa y que además presente importantes discontinuidades. Por este motivo, si dicha numeración fuera utilizada como numeración de referencia para organizar los Procesos Analíticos -tal como ocurrió en la FBA antes de la implementación del presente sistema automatizado de trabajo-, el procesamiento de las mismas no podría ser ejecutado de ninguna forma como un proceso continuo y de acceso permanente sino que requeriría trabajar con batchs completos de muestras, los cuales deberían ser ordenados, por ejemplo en orden creciente de Numeración Preimpresa, antes de poder ser procesados. Este hecho no sólo tornaría lento y complejo al sistema de trabajo en sí mismo, sino que además resultaría muy difícil de mantener bajo control, puesto que al no existir continuidad en la numeración podrían presentarse errores de transposición y de corrimiento de muestras con mucha mayor frecuencia y facilidad.

Estas dificultades podrían ser sorteadas con relativa simpleza implementando un sistema manual de numeración diaria (2). Sin embargo, esto no es tan simple de llevar a cabo en un Laboratorio de PN puesto que, por un lado, es necesario utilizar un sistema especial de identificación de muestras a fin de mantener la univocidad de la numeración utilizada para cada RN a lo largo del tiempo, y por el otro, porque la gran cantidad de muestras recibidas a diario hace muy dificultoso desde el 
punto de vista operativo utilizar un sistema de numeración manual de esta magnitud, que además sea simple y libre de errores.

- Definición de un formato unívoco de Numeración Diaria: en vista de lo antes expuesto, se definió un formato unívoco de Numeración Diaria basado en la siguiente estructura (2): AAMMDDXXXX, donde AA corresponde a los 2 últimos dígitos del año en curso, MM corresponde al mes, DD corresponde al día, y XXXX corresponde a la secuencia correlativa de numeración de las muestras de acuerdo al orden de ingreso al Laboratorio, comenzando cada día con el 0001 hasta el número máximo que se alcance ese mismo día.

Por ejemplo, si el día 24 de Agosto de 2009 ingresaron al Laboratorio 546 muestras, la numeración correspondiente a la primera de ellas será 0908240001 y la última 0908240546.

La implementación de un sistema de Numeración Diaria de estas características trae aparejadas numerosas ventajas, no sólo a nivel de los Procesos Analíticos -como por ejemplo en cuanto a la posibilidad que ofrece de permitir un acceso continuo y permanente de muestras en cada corrida eliminando la necesidad de un ordenamiento previo a su procesamiento y reduciendo significativamente el riesgo de errores durante el mismo-, sino que además hace una importante contribución a nivel de los Procesos Postanalíticos, permitiendo utilizar un sistema sumamente simple para el archivado y localización de las muestras de acuerdo al año, mes y día de ingreso.

Finalmente, se debe mencionar que la implementación de este sistema de doble numeración posibilita además que la Numeración Diaria sea la referencia de identificación a utilizar para el manejo interno de las muestras dentro del propio Laboratorio, conservándose la Numeración Preimpresa como referencia para la vinculación entre el Laboratorio de pesquisa y los Hospitales, Clínicas, Maternidades y Laboratorios que derivan sus muestras.

\section{- Equipamiento:}

- Lectoras de códigos de barras: se incorporaron 4 Lectoras de códigos de barras multi-haz (MS6720 Hand-Held Laser Scanner, Metrologic Instruments 
Inc., EE.UU.), las cuales fueron conectadas a un número similar de computadoras con el objeto de que trasmitan automáticamente las lecturas de la Numeración Preimpresa y de los Códigos de Identificación de los Centros Asistenciales al SIGM, eliminando así la necesidad de un ingreso manual $y$, consecuentemente, los errores de tipeo.

- Máquina numeradora automática secuencial: se incorporó una máquina numeradora automática secuencial (RapidPrint Modelo AN-E, Bidwell Industrial Group Inc., EE.UU.) con capacidad para imprimir números de 10 dígitos en un tamaño fácilmente visible. Dicha máquina, cuyo principio de funcionamiento es similar al de una máquina timbradora, permite trabajar con 6 dígitos fijos modificables manualmente (AAMMDD) y 4 dígitos móviles $(X X X X)$ que cambian en forma automática y secuencial.

- Ingreso automático y secuencial de la Numeración Diaria al SIGM: considerando que la Numeración Diaria no cuenta con un código de barras asociado que permita su ingreso automático al SIGM empleando una lectora, se definió un mecanismo alternativo que elimina la necesidad de tipear manualmente cada uno de estos números y posibilita el ingreso automático y secuencial de la misma.

La modalidad de funcionamiento de este mecanismo alternativo requiere necesariamente de un primer paso de ejecución manual en el cual el operador que está ingresando la información al SIGM debe tipear el Número Diario correspondiente a la primer muestra del rango de muestras que va a proceder a ingresar, y a partir de allí, una vez que se completó el ingreso de todos los datos de una muestra determinada, el propio SIGM genera en forma automática y secuencial el Número Diario correspondiente a la muestra inmediata posterior, habilitando además al operador para el ingreso de los datos demográficos del RN y de las pruebas solicitadas.

- Tarjeta para identificación de segundas muestras o repeticiones tal como ya fuera mencionado en capítulos anteriores, en la práctica se presentan diferentes situaciones que indefectiblemente culminan en la solicitud de recolección de una segunda muestra de sangre en papel de filtro. Entre estas situaciones se puede 
citar el incumplimiento de alguna de las condiciones de recolección de muestras, la calidad inapropiada de las mismas o la obtención de un resultado anormal, más allá de que en éste último caso, corresponde hacer la salvedad de que la decisión de solicitar una segunda muestra colectada en papel de filtro o de derivar directamente al RN para que sea sometido a una evaluación clínica y a pruebas confirmatorias, es función de la patología pesquisada, del valor del resultado obtenido y del algoritmo de decisión definido por parte del Programa.

Adicionalmente, y con independencia de la causa que haya motivado dicha solicitud, en todos los casos resulta estrictamente necesario tomar en consideración que cuando la segunda muestra correspondiente a un RN determinado es recibida en el Laboratorio de pesquisa, la misma debe estar perfectamente identificada como tal a efectos de hacer posible una rápida diferenciación entre aquellas que corresponden a primeras muestras y aquellas otras que corresponden a segundas muestras o Repeticiones.

De este modo, será posible acceder a una rápida localización de los registros del RN que ya están disponibles en el SIGM y que fueron generados al momento del ingreso de la primer muestra que desencadenó la solicitud, identificar la segunda muestra en dicho sistema como tal, y establecer una vinculación entre las diferentes muestras recibidas pertenecientes a un mismo RN.

En respuesta a esta necesidad se diseñó una tarjeta complementaria (Figura 42) con la finalidad de que los Centros Asistenciales adjunten la misma a cada una de las segundas muestras que requieran ser colectadas, previo llenado de un set mínimo de datos.

La introducción de un sistema de identificación como el que acaba de ser descripto resulta de vital importancia puesto que el mismo permite efectuar una correcta interpretación de los resultados obtenidos y una apropiada toma de decisiones, determinar con precisión la eficiencia del sistema de seguimiento del Programa en lo que respecta a la llegada de las segundas muestras solicitadas, y establecer la cobertura real del Programa a través de la contabilización del número real de neonatos testeados por primera vez y no del número total de 
muestras analizadas.

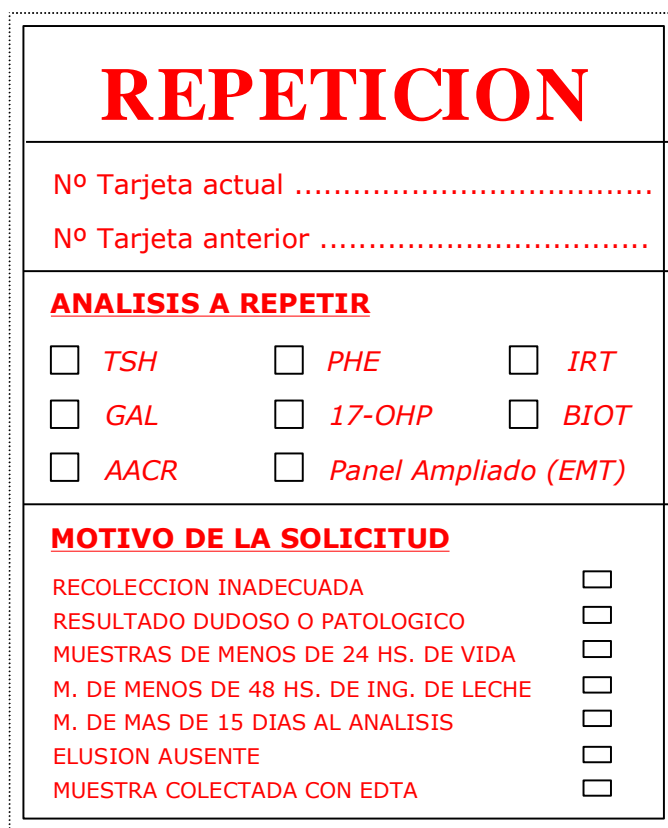

\section{Detección de

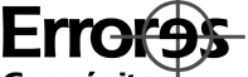 \\ Congénitos}

\section{INSTRUCCIONES}

Completar la información solicitada en esta tarjeta y abrochar la misma a la tarjeta correspondiente a la nueva muestra de sangre a remitir a la Fundación Bioquímica Argentina.

El Número de la tarjeta anterior podrá obtenerlo de la constancia de recolección de la primera muestra o bien del informe de resultados.

La utilización de esta identificación, así como el correcto llenado de la misma permitirá un seguimiento apropiado de las nuevas muestras solicitadas y redundará en una mayor celeridad para definir el diagnóstico.

Figura 42. Anverso y reverso de la tarjeta para identificación de segundas muestras o repeticiones.

- Tarjeta para identificación de muestras destinadas al monitoreo del tratamiento: adicionalmente a las pruebas de pesquisa realizadas a diario, y como parte de una serie de actividades asistenciales complementarias, el Laboratorio de la FBA también desempeña un rol activo en la fase de seguimiento del tratamiento de algunos ECM como la PKU o la MSUD, llevando a cabo el análisis periódico de DBS de pacientes ya diagnosticados con la finalidad de monitorear la marcha de dicho tratamiento. Tal como es de suponer, estas muestras tienen implicancias absolutamente diferentes de aquellas correspondientes a las muestras de pesquisa, y por lo tanto también deben ser identificadas como tales al momento del ingreso al Laboratorio a efectos de poder realizar una correcta interpretación de los resultados y de comunicar los mismos inmediatamente al médico tratante.

Con esta finalidad, y siguiendo una línea de trabajo similar a la descripta para el caso de las segundas muestras o Repeticiones, se diseñó una tarjeta para la rápida identificación y diferenciación de aquellas muestras de sangre que corresponden al monitoreo del tratamiento en pacientes ya diagnosticados, la cual 
es presentada en la Figura 43.

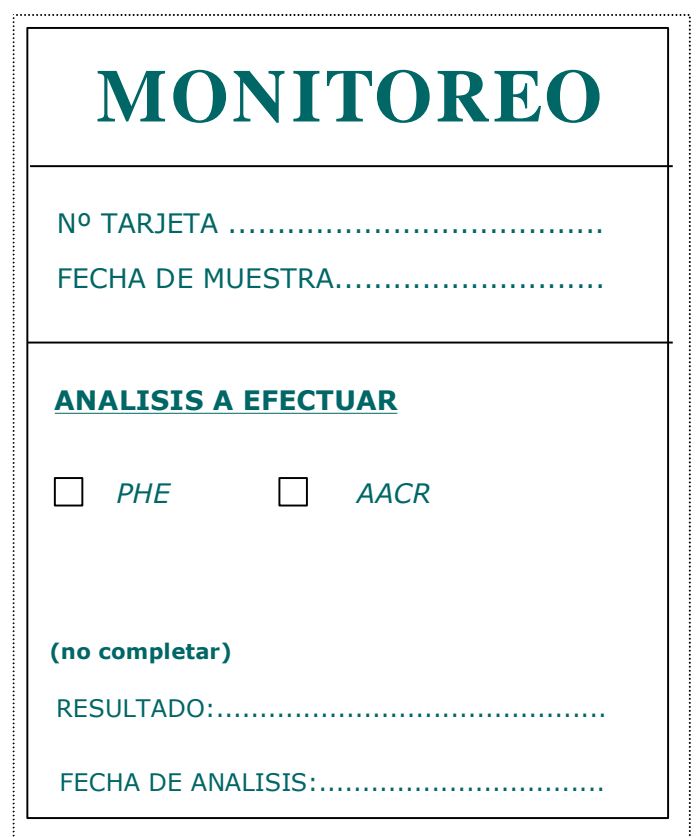

Figura 43. Tarjeta para identificación de monitoreos de tratamiento.

\section{- Listas de trabajo para la identificación de muestras en las diferentes} corridas analíticas: en relación a este punto, y antes de comenzar con la descripción de los detalles específicos inherentes al sistema de trabajo de la FBA, resulta necesario mencionar que se entiende por Lista de trabajo a una planilla o archivo conteniendo información organizada, mínima y suficiente de cada una de las muestras que han de ser analizadas en una corrida determinada para un analito en particular, ordenada de acuerdo al orden en que se han de procesar las mismas, y a través de la cual, a posteriori, resultará posible establecer una vinculación directa, unívoca y sin errores entre los resultados obtenidos en cada corrida y el número de identificación de la muestra a partir de la cual se obtuvieron dichos resultados.

Tomando en consideración este concepto, se programó el SIGM de manera tal que a través del mismo fuera posible generar Listas de trabajo con el formato de archivos de texto (.txt), que permitieran realizar la transferencia automática de la información correspondiente a las muestras a procesar tanto al software responsable del manejo del Puncher BSD-200 (Software BSD Worklist Translator - FBA), como al software Multicalc utilizado para el manejo de los diferentes 
Instrumentos de Lectura empleados en el Laboratorio, ya sea utilizando una red informática o a través de algún tipo de soporte digitalizado.

En cuanto a la estructura y organización de la información contenida en las mencionadas Listas de trabajo, y a pesar de que la misma fue definida tomando como referencia un formato común en el cual la información que identifica a cada una de las muestras se dispone en columnas a razón de una muestra por línea o renglón y siguiendo un orden creciente de numeración, las características particulares de los diferentes instrumentos a los cuales están destinadas las mismas determinaron que en la práctica se hayan tenido que definir 2 tipos de Listas de Trabajo, con mínimas diferencias en su estructura entre unas y otras:

- Listas de trabajo para el Puncher BSD-200: en el caso de este instrumento, la información que identifica a cada muestra, representada por la Numeración Diaria seguida de una serie de 7 dígitos que forman parte de un sistema binario, se dispone ordenadamente en una única columna.

A través de esta serie de 7 dígitos adicionales, los cuales por definición sólo pueden tomar valores de 0 ó 1, y de acuerdo a la información de cada RN que ha sido ingresada previamente al SIGM referente a las pruebas que le han sido solicitadas, la Lista de trabajo tiene la capacidad de transmitirle al Puncher BSD-200 la información necesaria para que éste último instrumento pueda identificar cuántas y cuáles pruebas se deben realizar a cada muestra en forma particular.

De este modo, el formato adoptado por la información correspondiente a cada muestra en las Listas de trabajo para el Puncher BSD-200 responde a la estructura AAMMDDXXXXabcdefg $\left({ }^{* 1}\right)$, donde $a, b, c, d, e, f$ y $g$ son los 7 dígitos adicionales antes mencionados.

Por ejemplo: 09082400011100000

09082400021111111

09082400031110000

$\left(^{\star 1}\right)$ para mayores detalles acerca del funcionamiento de este formato, ver sección "Puncheo y distribución de muestras en las microplacas correspondientes" en este mismo Capítulo. 
- Listas de trabajo para el Software Multicalc: en el caso del Software Multicalc, y a diferencia de lo descripto anteriormente para el Puncher BSD-200, las Listas de trabajo están organizadas en 2 columnas separadas por 2 espacios en blanco. La primera de estas columnas corresponde a la Numeración Diaria, en tanto la segunda corresponde a la Numeración Preimpresa seguida por 2 guiones, los cuales fueron incluidos con la finalidad de que cuando corresponda, los mismos puedan ser editados manualmente ingresando en su lugar alguno de los códigos de 2 caracteres previamente definidos para la validación de resultados $\left({ }^{2}\right)$.

$$
\begin{array}{r}
\text { Por ejemplo: } 0908240001 \text { 1875498-- } \\
09082400021965207-- \\
09082400032154387--
\end{array}
$$

$\left(\star^{2}\right)$ para mayores detalles acerca de los códigos de 2 caracteres y su modo de uso, ver sección "Validación de Resultados" en este mismo Capítulo.

La utilización de los códigos de validación antes mencionados en las Listas de trabajo se trata de un artilugio muy simple que permite la identificación de determinadas muestras a lo largo de la corrida, las cuales en razón de alguna característica intrínseca de las mismas o de alguna causa particular de índole técnica han de requerir una evaluación diferencial de sus resultados a lo largo del proceso general de validación e interpretación de los mismos.

Por otra parte, y en contraposición con lo que ocurre con el Puncher BSD200, el cual requiere una única Lista de trabajo para el proceso de corte y dispensado de las muestras independientemente de los analitos que se estén procesando, en el caso del Software Multicalc se requiere una Lista de trabajo específica para cada analito, lo cual determina que cada día se deban generar tantas Listas de trabajo como analitos se evalúen y corridas se realicen.

Finalmente, y con respecto a la nomenclatura utilizada para la identificación de dichas listas, la misma fue definida de acuerdo con las especificaciones 
del Software Multicalc, de forma tal que el nombre de cada una de ellas haga referencia al analito a medir y al número específico de cada corrida, y que además dicho nombre sea compatible con los Protocolos de Lectura definidos en el mencionado software, a fin de que los mismos puedan ser reconocidos por parte de este último.

En función de esto, la estructura del nombre de cada una de las Listas de trabajo se compone por el nombre del Protocolo de Lectura seguido de la extensión. WNN, donde $W$ es fijo e indica que se trata de un archivo de Listas de trabajo, y NN es un número variable -de 01 a 99- y corresponde al Número de la Corrida a realizar.

Por ejemplo: NTSH.W01

NEO-PHE.W01

NIRT.W01

- Plantillas de distribución de muestras: se entiende por Plantilla de distribución de muestras a un mapa o esquema en el cual se representa e identifica la posición correspondiente a cada una de las muestras que han de ser procesadas en las distintas microplacas que forman parte de una corrida determinada.

Tomando en consideración la definición anterior, se programó el SIGM de forma tal que a través del mismo fuera posible llevar a cabo la impresión de Plantillas de distribución de muestras a analizar con un formato equivalente a una microplaca de 96 pocillos, en las cuales se representa la distribución de los calibradores, controles y muestras a procesar en cada corrida para cada analito, identificándose cada una de las hojas con el nombre del Protocolo de Lectura, el Número de la Corrida y el Número de la microplaca que corresponde (Figura 44).

Por último, y en correspondencia con lo que fuera descripto anteriormente para el caso de las Listas de trabajo para el Software Multicalc, las Plantillas de distribución de muestras requieren ser generadas para cada analito en forma particular, imprimiéndose a razón de una plantilla o microplaca por hoja. 


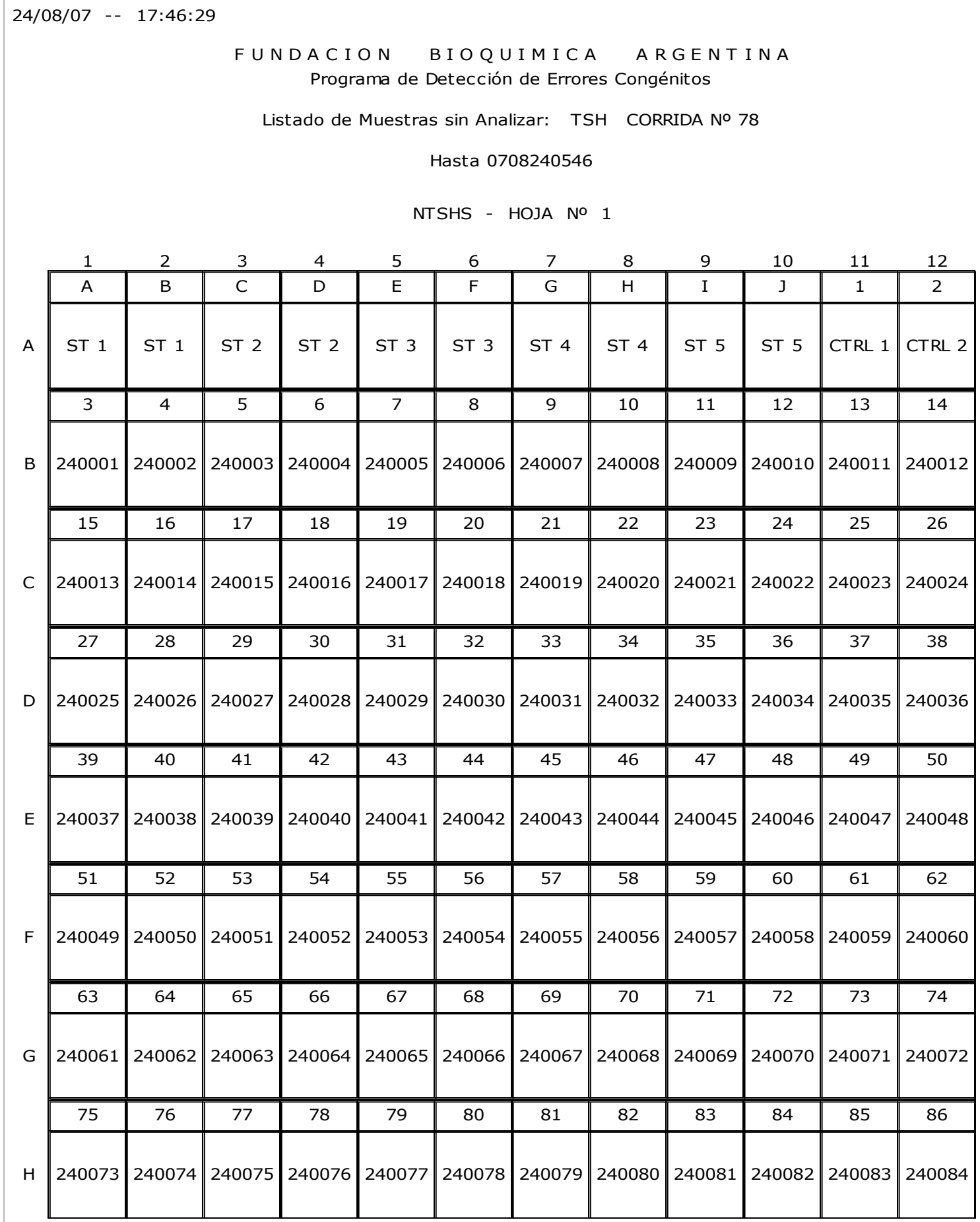

Figura 44. Plantilla de distribución de muestras

Finalmente, y como corolario a este segmento correspondiente a la automatización de los procesos Pre-analíticos, en la Figura 45 se presenta un esquema correspondiente al flujo de ingreso de datos al SIGM y a la generación de Listas de Trabajo. 


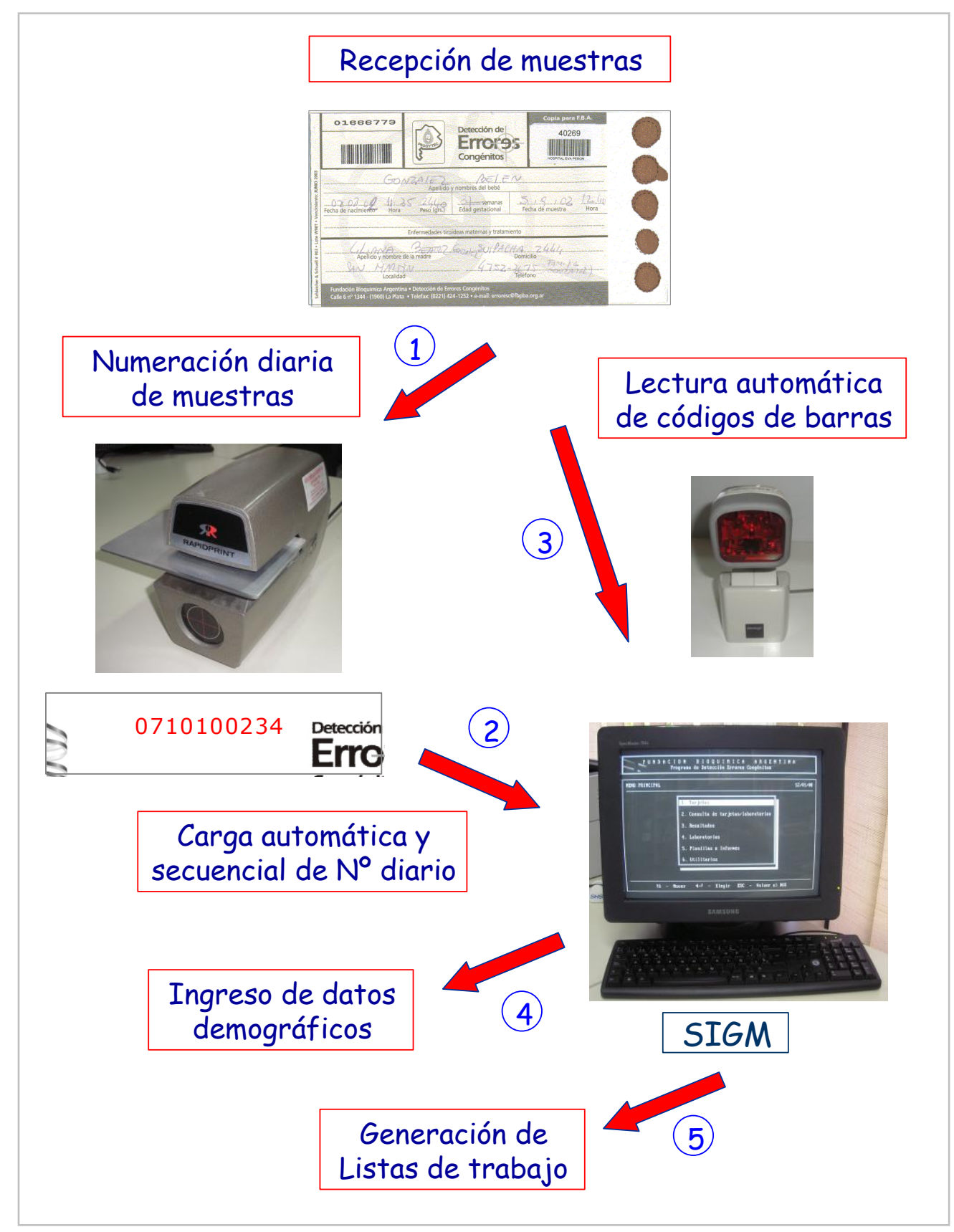

Figura 45. Flujo de trabajo correspondiente a los Procesos Pre-analíticos.

\section{Procesos Analíticos}

La automatización de los procesos Analíticos en el Laboratorio de Detección de Errores Congénitos de la FBA fue planificada en pos de alcanzar 6 objetivos concretos, los cuales son presentados a continuación:

1. Incrementar la capacidad operativa de trabajo.

2. Optimizar los recursos humanos.

3. Simplificar los procedimientos operativos. 
4. Optimizar los procedimientos analíticos.

5. Incrementar el rendimiento de los reactivos disminuyendo consecuentemente sus costos.

6. Eliminar la necesidad de recurrir a procedimientos manuales tanto para el cálculo de resultados como para la validación de las corridas.

A continuación serán descriptos los diferentes Procesos Analíticos que se ejecutan en el mencionado Laboratorio y los distintos instrumentos afectados a cada uno de dichos procesos, más allá de lo cual resulta oportuno mencionar que parte del equipamiento que será descripto en este Capítulo hoy día no es utilizado en la rutina diaria sino que cumple una función de backup y, por lo tanto, se encuentra afectado a los planes de contingencia previstos para aquellas situaciones en las que algún inconveniente de carácter técnico imposibilite el uso de los equipos utilizados a diario.

- "Puncheo" y distribución de muestras en las microplacas correspondientes: la automatización del proceso de "puncheo" o corte y de distribución o dispensado de muestras en las microplacas de ensayo correspondientes se hizo efectivo en la práctica a partir de la incorporación de un Puncher Automático BSD-200 de BSD Technologies International, Brisbane - Australia (Figura 46).

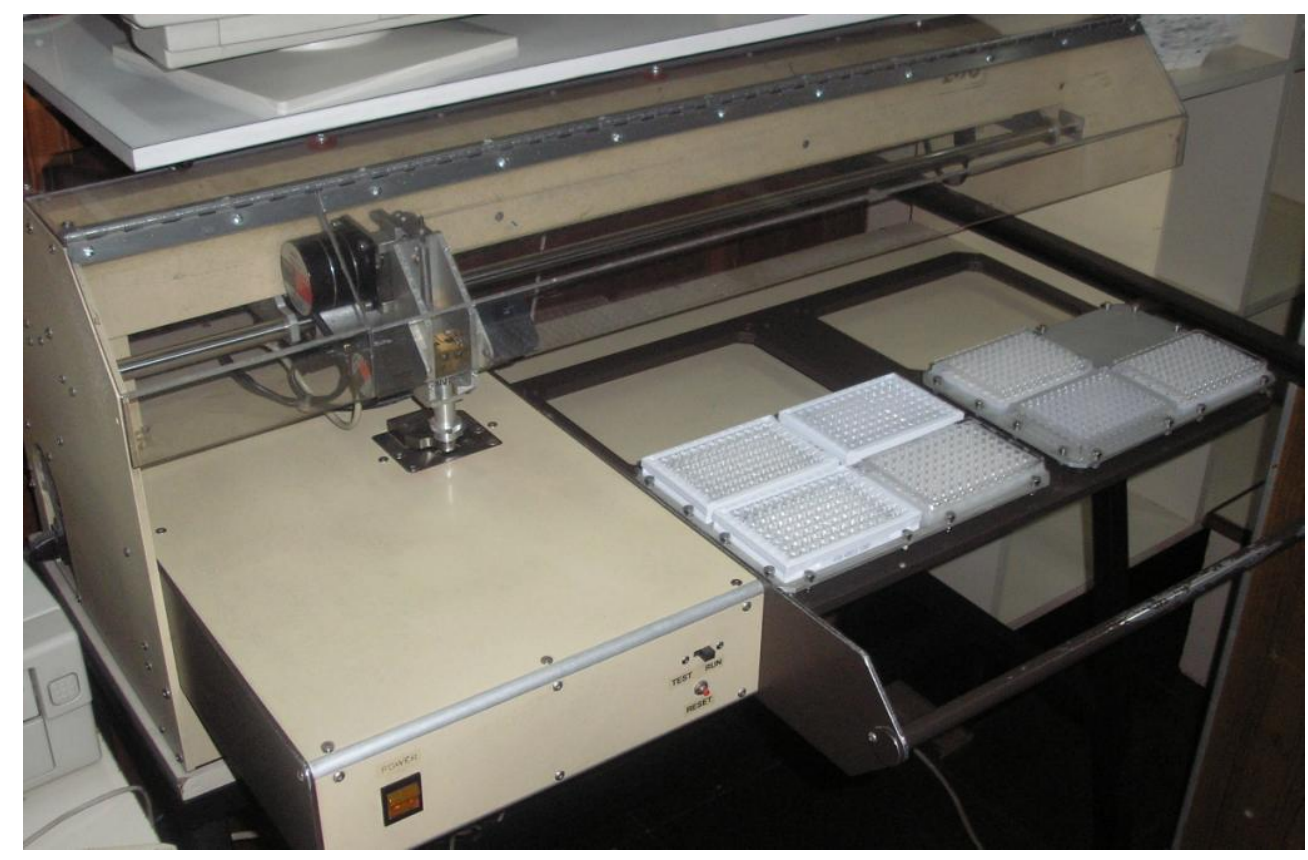

Figura 46. Puncher automático BSD-200. 
Sin embargo, el proceso de puesta en funcionamiento de este equipo en la rutina diaria no resultó una situación de sencilla resolución debido a que el diseño original del mismo fue concebido por sus fabricantes tomando en consideración las necesidades de los sistemas convencionales de PN, y por lo tanto no contemplaba la posibilidad de ser utilizado con sistemas no convencionales.

Esta situación, trasladada a nuestro medio, implicaba sencillamente que en las condiciones en las cuales el instrumento fue provisto, no existía ninguna posibilidad de poder trabajar simultáneamente con diferentes patrones de puncheo de muestras según las determinaciones solicitadas a cada RN, ni tampoco de utilizar Listas de trabajo externas.

Para solucionar este inconveniente fue necesario diseñar un sistema que, a través del software del instrumento, permitiera llevar a cabo no solamente la carga de Listas de trabajo externas sino también la interpretación de cuántas y cuáles determinaciones debían efectuarse a cada RN, lo cual a su vez requirió el desarrollo de un modelo teórico que cumpliera con las especificaciones antes mencionadas, y asegurarse además, que los fabricantes del instrumento tomarían a su cargo la tarea de compatibilizar el modelo teórico antes mencionado con el software del mismo.

En cuanto al modelo teórico propuesto -el cual fuera ideado por el autor de esta tesis-, se basó en la utilización de un código de identificación de muestras en cuya estructura se incluyó un componente basado en un sistema binario, el cual permite transmitir información al instrumento acerca de las pruebas que deben efectuarse a cada RN.

Con respecto a la estructura del mencionado código de identificación, y tal como ya fuera muy suscintamente descripto en la sección correspondiente a Listas de trabajo para el Puncher BSD-200, la misma está conformada por el Número Diario seguido de otros 7 dígitos adicionales que corresponden a los analitos evaluados para cada una de las 7 patologías pesquisadas, a saber:

AAMMDDXXXXabcdefg, donde a corresponde a Phe (PKU), b a TSH (HC), c a IRT (FQ), d a Galactosa (Galactosemia), e a 17OHP (HSC), f a Biotinidasa (Deficiencia 
de Biotinidasa) y g a Aminoácidos de Cadena Ramificada - BCAA (MSUD).

Por otra parte, y tal como también ya fuera expresado anteriormente, los 7 dígitos adicionales pueden tomar únicamente valores de 0 ó 1, habiéndose definido como criterio para la interpretación de los mismos que una prueba debe realizarse si el valor tomado por el dígito correspondiente a un analito determinado es 1 , y no debe realizarse si ese valor es 0.

Por ejemplo, en la muestra 09082400011100000, los 7 últimos dígitos del número anterior presentados en negrita y cursiva indican que dicha muestra debe ser procesada solamente para efectuar las pruebas de PKU e $H C$, mientras que las 5 pruebas restantes no deben realizarse.

El paso siguiente corrió por cuenta de los fabricantes del equipo, quienes diseñaron un software denominado BSD Worklist Translator - Fundación Bioquímica Argentina (Figura 47), el cual le confirió al software original del instrumento la capacidad de admitir el ingreso de Listas de trabajo externas y también de interpretar la información provista a través de las mismas.

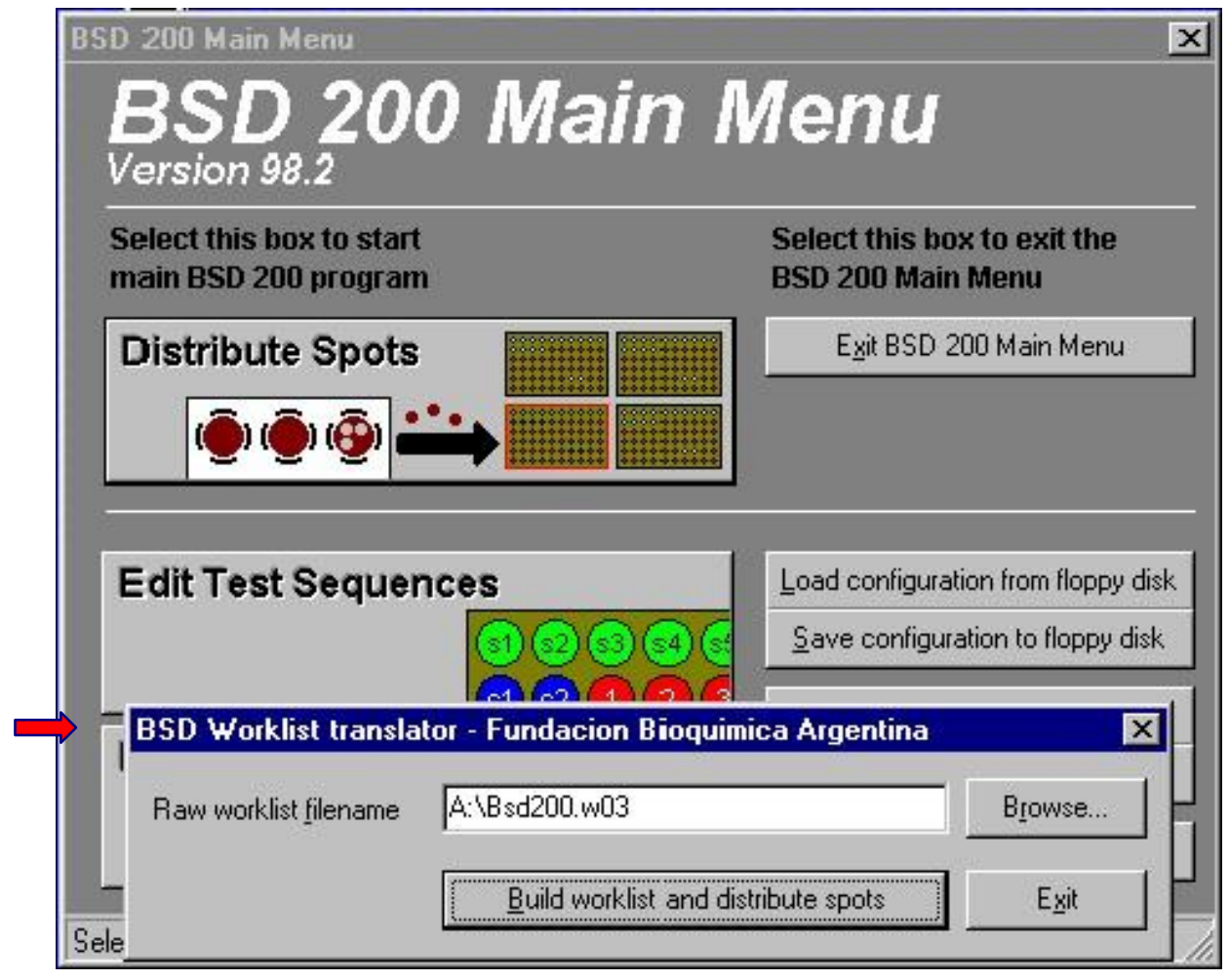

Figura 47. Software BSD Worklist Translator - FBA. 
De este modo, el mencionado software hace las veces de un traductor, transformando al Puncher BSD-200 en un equipo inteligente, capaz de interpretar la información provista a través de las Listas de trabajo correspondiente a las pruebas solicitadas a cada RN.

Como dato adicional, resulta oportuno mencionar que los últimos 7 dígitos que forman parte del código de identificación propuesto tienen la potencialidad de ser ampliados a un total de 16 dígitos (AAMMDDXXXXabcdefghijklmnop), dejando así abierta la posibilidad de efectuar el proceso de puncheo y distribución de muestras para 16 pruebas en forma simultánea, que es precisamente la capacidad máxima de procesamiento del Puncher BSD -200.

- Dispensado de reactivos: para el proceso de dispensado de reactivos se cuenta con dos tipos de sistemas modulares:

- DELFIA Plate Dispense (Wallac Oy, Turku - Finlandia): sistema monocanal, con capacidad de dispensado de volúmenes de 50, 100, y $200 \mu$ l a través de una bomba de localización inferior y de $200 \mu$ a través de una segunda bomba de localización superior (Figura 48). El mencionado instrumento está destinado al dispensado de los reactivos correspondientes a la metodología DELFIA, y forma parte del backup actual de equipamiento de Laboratorio.

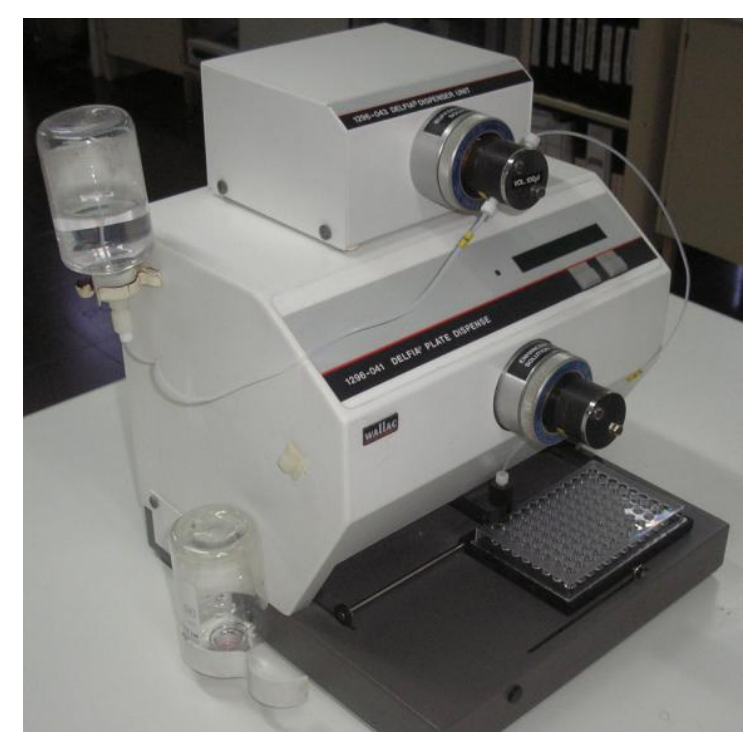

Figura 48. Dispensador monocanal DELFIA Plate Dispense. 
- Dispensador Multidrop (Labsystems Oy, Helsinski - Finlandia): sistema peristáltico multicanal de 8 canales, con capacidad de dispensado de volúmenes en el rango de 20 a $395 \mu \mathrm{l}$, regulable de a $5 \mu$ l (Figura 49).

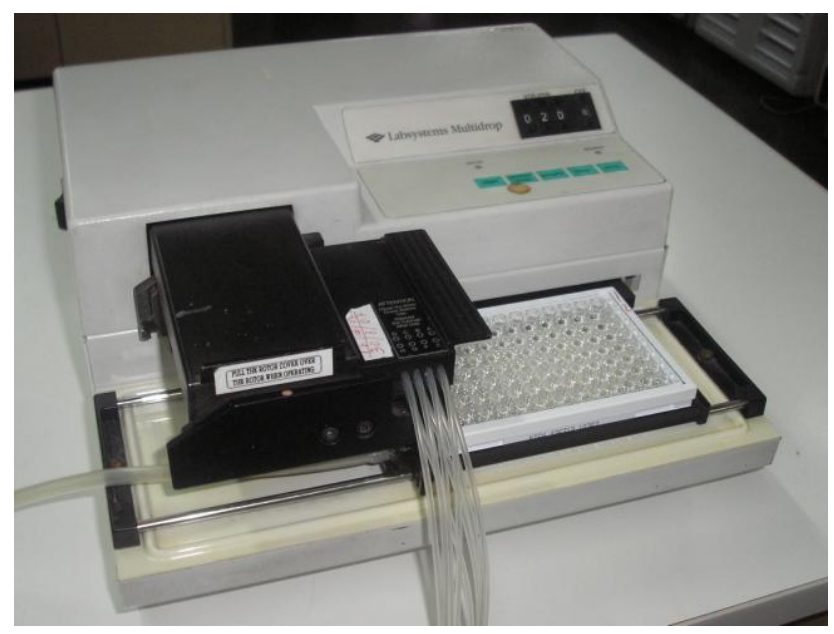

Figura 49. Dispensador multicanal Multidrop.

- Agitación de microplacas: para llevar a cabo el proceso de agitación de las microplacas durante las fases de elusión o incubación se cuenta con 2 agitadores DELFIA Plate Shake de Wallac Oy con capacidad para 4 microplacas cada uno y dos velocidades fijas de agitación de 950 y 1140 rpm respectivamente (Figura 50).

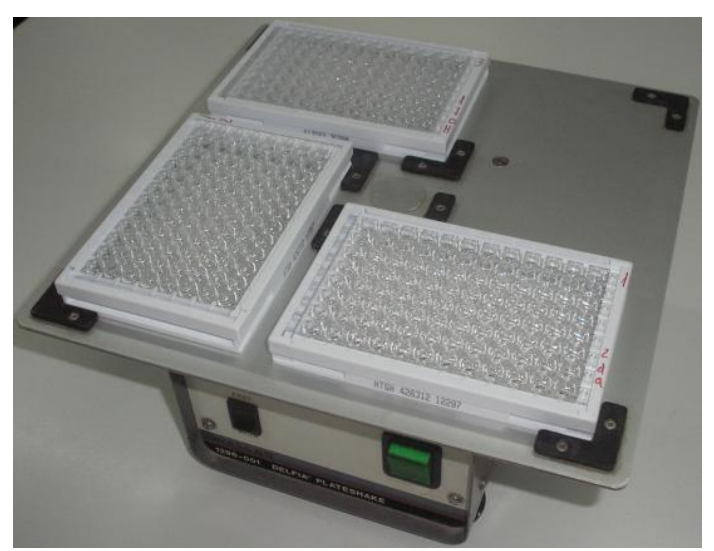

Figura 50. Agitador de microplacas DELFIA Plate Shake.

- Transferencia de eluidos: la transferencia de eluidos es un proceso que se utiliza exclusivamente en aquellas pruebas en las que se requiere que el eluido en el cual se encuentran los analitos de interés sea separado del pocillo que contiene el disco 
de papel de filtro impregnado con la sangre -previa fijación química de las proteínas plasmáticas y la hemoglobina a este último-, a fin de completar la etapa final de la reacción en otra microplaca compatible con el sistema de lectura utilizado. Este es el caso por ejemplo de las medidas de Phe, Galactosa y BCAA.

Para automatizar este proceso, el Laboratorio de la FBA cuenta con un Sistema Multiscreen Vaccum Manifold (Figura 51) y utiliza microplacas de transferencia de 96 pocillos Multiscreen Membrane Plate modelo MADVN-65 (Figura 52), en las cuales se realiza la fijación de la hemoglobina y las proteínas al papel, y la elusión del analito en cuestión. Ambos productos son de Millipore - EE.UU..

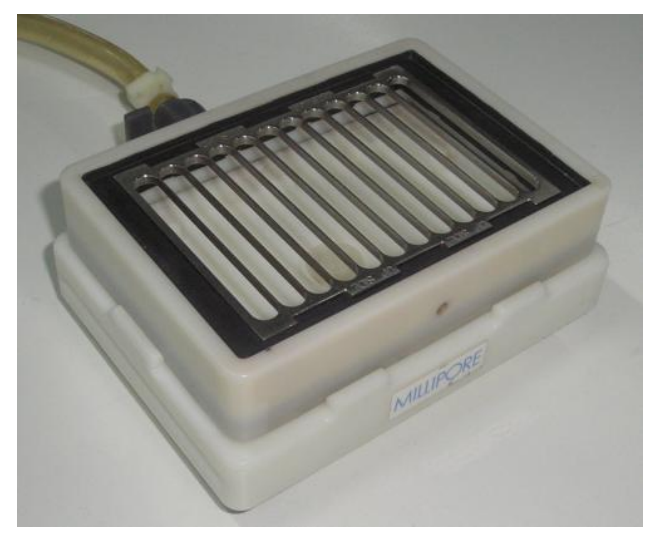

Figura 51. MultiScreen Vacuum Manifold.

Operativamente la transferencia del eluido propiamente dicha requiere la conexión del sistema Vaccum Manifold a una línea de vacío, con lo cual en un período de tiempo no superior a 15-20 segundos por microplaca, se hará efectiva la transferencia automática, cuantitativa y simultánea de los eluidos desde cada uno de los 96 pocillos de la microplaca de transferencia adonde se realizó la elusión a la microplaca en la cual se va a completar la etapa final de la reacción.

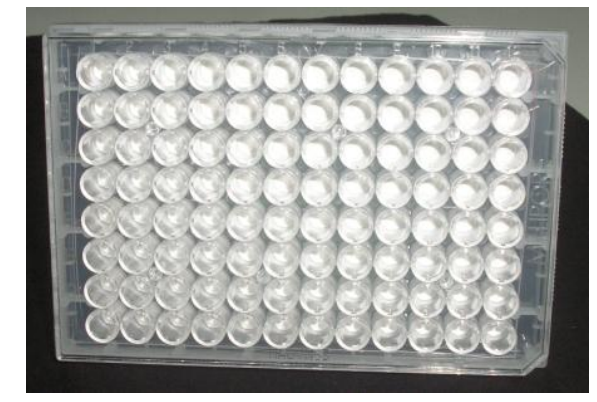

Figura 52. Microplaca MultiScreen Membrane Plate. 
- Remoción de discos: la remoción de discos de papel de filtro es un proceso que imprescindiblemente requiere ser realizado en todas aquellas pruebas en las cuales la sangre debe ser eluida completamente de los discos y en las que todas las etapas de la reacción son llevadas a cabo en el mismo pocillo, resultando por lo tanto un proceso aplicable casi con exclusividad a los diferentes inmunoensayos, como por ejemplo en aquellos utilizados para la medida de TSH, IRT o $170 H$ P.

En el laboratorio este procedimiento se realiza empleando un removedor de discos DELFIA Diskremove de Wallac Oy (Figura 53), el cual se trata de un sistema monocanal que aspira tanto el líquido contenido en cada pocillo como el disco de papel que aportó la muestra de sangre. Adicionalmente, y a pesar de que el mencionado instrumento fue diseñado para su utilización en la metodología DELFIA, el mismo puede ser empleado para cualquier tipo de inmunoensayo.

Finalmente, y tal como ocurre con los dispensadores DELFIA Plate Dispense, en la actualidad el removedor de discos DELFIA Diskremove no se utiliza en la rutina diaria, y por lo tanto forma parte del equipamiento de backup del Laboratorio.

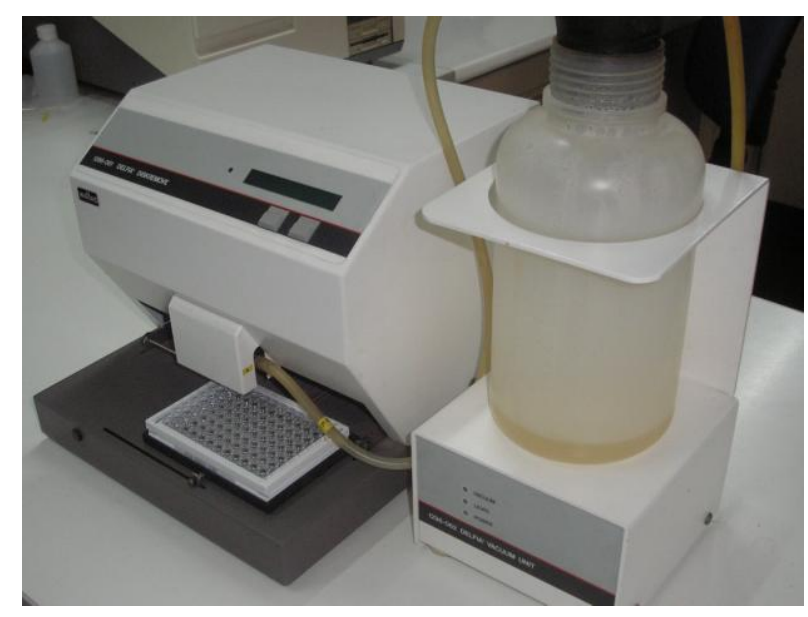

Figura 53. Removedor de discos DELFIA Diskremove.

- Centrifugado de microplacas: el centrifugado de microplacas es un proceso requerido en aquellas pruebas en las que la sangre contenida en el disco de papel de filtro debe ser eluida completamente del mismo, y en las cuales recién una vez completada la etapa inicial de la reacción se debe efectuar la separación de las 
proteínas plasmáticas y de la hemoglobina a través de un proceso de precipitación, para proceder finalmente a transferir el sobrenadante límpido a otra microplaca en la cual se ha de completar la etapa final de la reacción. Este es el caso por ejemplo de la medida de la enzima Biotinidasa.

En función de este requerimiento, en el Laboratorio de la FBA el proceso de centrifugación de las microplacas de ensayo (microplacas fondo en $\mathrm{V}$ ) se realiza empleando una Centrífuga Jouan B4i (Saint Herblain - Francia)(Figura 54).

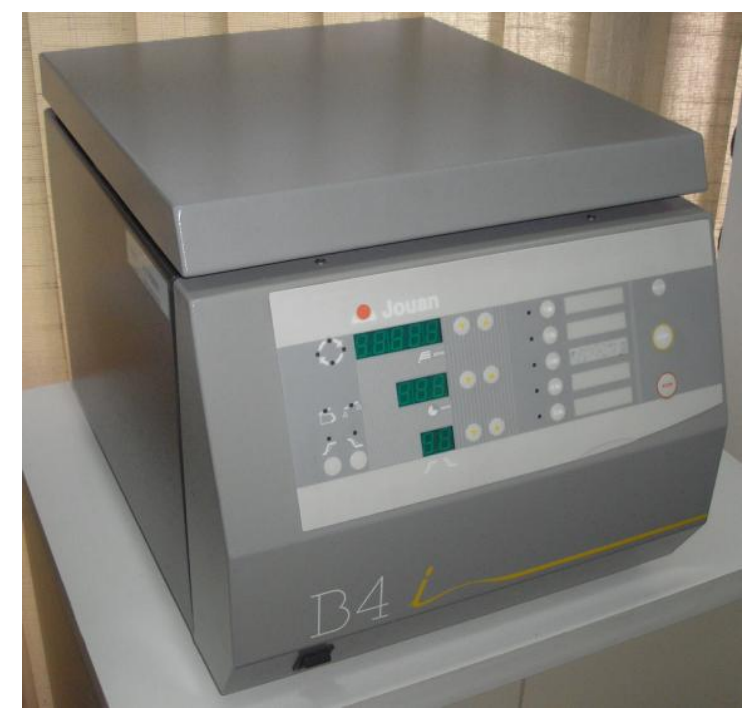

Figura 54. Centrifuga de microplacas Jouan B4i.

- Lavado de microplacas: el lavado de microplacas es un proceso casi privativo de los inmunoensayos que, para su automatización, requiere el empleo de un lavador de microplacas.

Este tipo de instrumento no se trata de un equipo diseñado con exclusividad para pruebas de PN, sino que por el contrario es el mismo tipo de sistemas de lavado utilizados en Laboratorios de análisis clínicos generales o de inmunología.

En el caso particular del Laboratorio de la FBA, el lavador utilizado es un LP4O Microplate Washer de ADIL Instruments (Schiltigheim - Francia) provisto por Wallac Oy (Figura 55), el cual hoy día no es utilizado en las pruebas de rutina, y por lo tanto también forma parte del instrumental disponible como backup. 


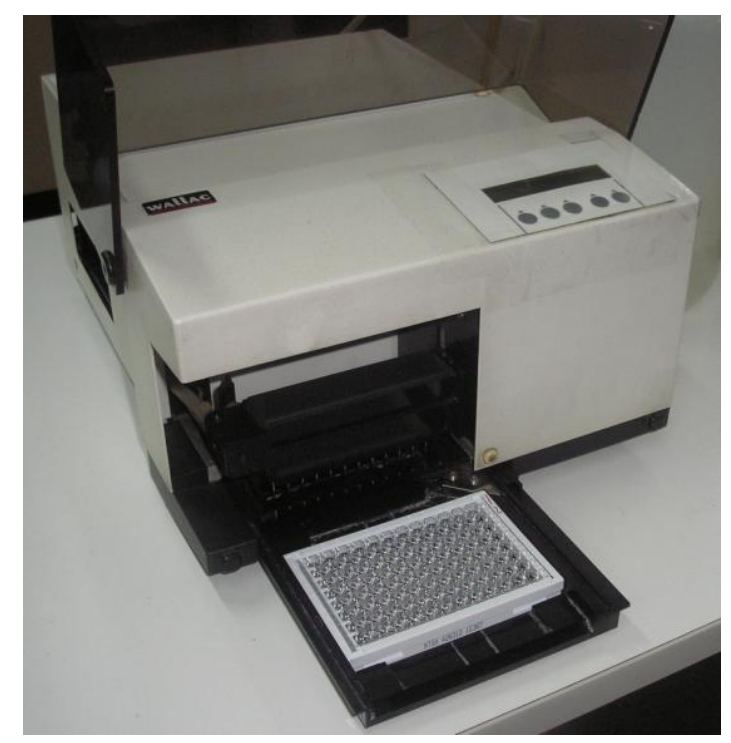

Figura 55. Lavador de microplacas LP4O Microplate Washer.

- Incubación de ensayos: los procesos de incubación correspondientes a algunos de los ensayos que requieren temperaturas específicas de incubación por encima de la temperatura ambiente son llevados a cabo utilizando 4 incubadores Incubator/Shaker Thermomix de Labsystems Oy (Figura 56).

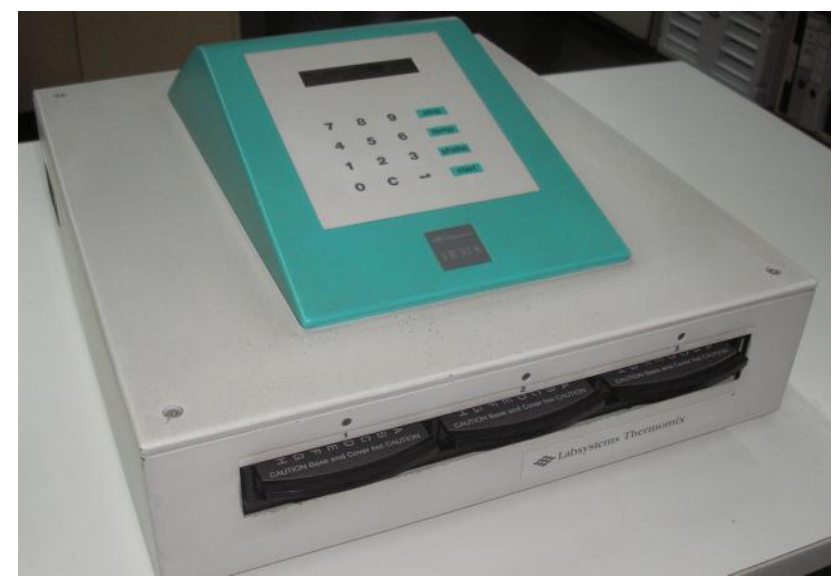

Figura 56. Incubador/Agitador Thermomix.

Los mencionados incubadores tienen capacidad para incubar 3 microplacas de 96 pocillos cada uno, un rango de trabajo que va desde $3^{\circ} \mathrm{C}$ por encima de la temperatura ambiente hasta $69^{\circ} \mathrm{C}$, y una velocidad de agitación regulable en forma continua o a intervalos de tiempo ajustables cada $250 \mathrm{rpm}$, en un rango operativo que va desde 400 a 1400 rpm. 
Este tipo de sistemas de incubación se caracteriza por utilizar un dispositivo para el calentamiento de las microplacas que asegura una temperatura homogénea entre los diferentes pocillos independientemente de si los mismos se encuentran ubicados en una posición periférica o en una posición central de la microplaca y, a su vez, dentro de cada pocillo, independientemente de si se trata de la superficie, el centro o el fondo de la mezcla de reacción.

- Lectura de ensayos: para cumplimentar el procedimiento de lectura de los diferentes ensayos realizados en el Laboratorio de la FBA se cuenta con diversos instrumentos que permiten medir distintos tipos de señales en correspondencia con el principio analítico utilizado por cada uno de ellos:

- Multiskan MCC 340 - Labsystems Oy: Fotómetro de microplacas de lectura vertical, con alcance en el espectro UV-Visible, provisto de 8 canales independientes de lectura (Figura 57). Este instrumento es utilizado actualmente en el Laboratorio de la FBA para la medida de la actividad de la enzima Biotinidasa.

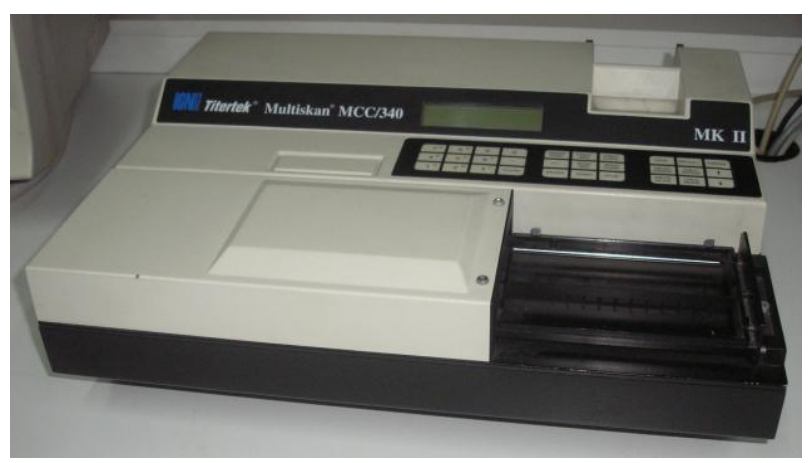

Figura 57. Fotómetro Multiskan MCC 340.

- Fluoroskan II Neonat - Labsystems Oy: Fluorómetro de microplacas de lectura vertical diseñado para la realización de medidas fluorométricas convencionales ("Prompt Fluorometry"), provisto de un único canal de excitación y detección de la señal emitida (Figura 58). En la actualidad este instrumento se encuentra disponible como elemento de backup para medidas fluorométricas convencionales como las requeridas en las determinaciones de Phe, Galactosa y $B C A A$. 


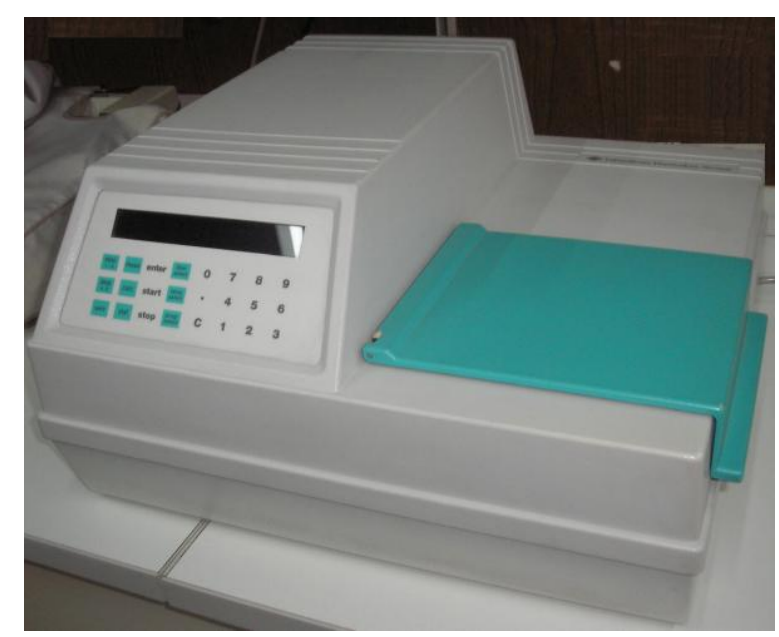

Figura 58. Fluorómetro Fluoroskan II Neonat.

- 1234 DELFIA Research Fluorometer - Wallac Oy: Fluorómetro de microplacas de lectura a tiempo resuelto, provisto de un único canal de excitación y detección de la señal emitida (Figura 59). Instrumento disponible actualmente como backup para la metodología DELFIA.

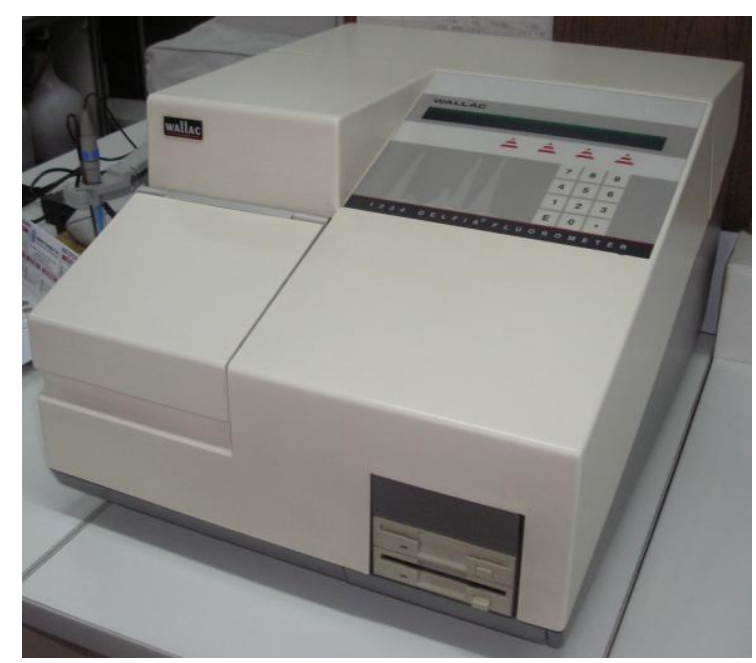

Figura 59. Fluorómetro a Tiempo Resuelto DELFIA 1234.

- Victor ${ }^{2}$ Multilabel Counter - Wallac Oy: Lector de microplacas multitecnología, provisto de un único canal de excitación y detección de la señal emitida, con capacidad para desempeñarse como Fluorómetro para lecturas fluorométricas convencionales, Fluorómetro para lecturas a tiempo resuelto, Fotómetro y Luminómetro (Figura 60). 

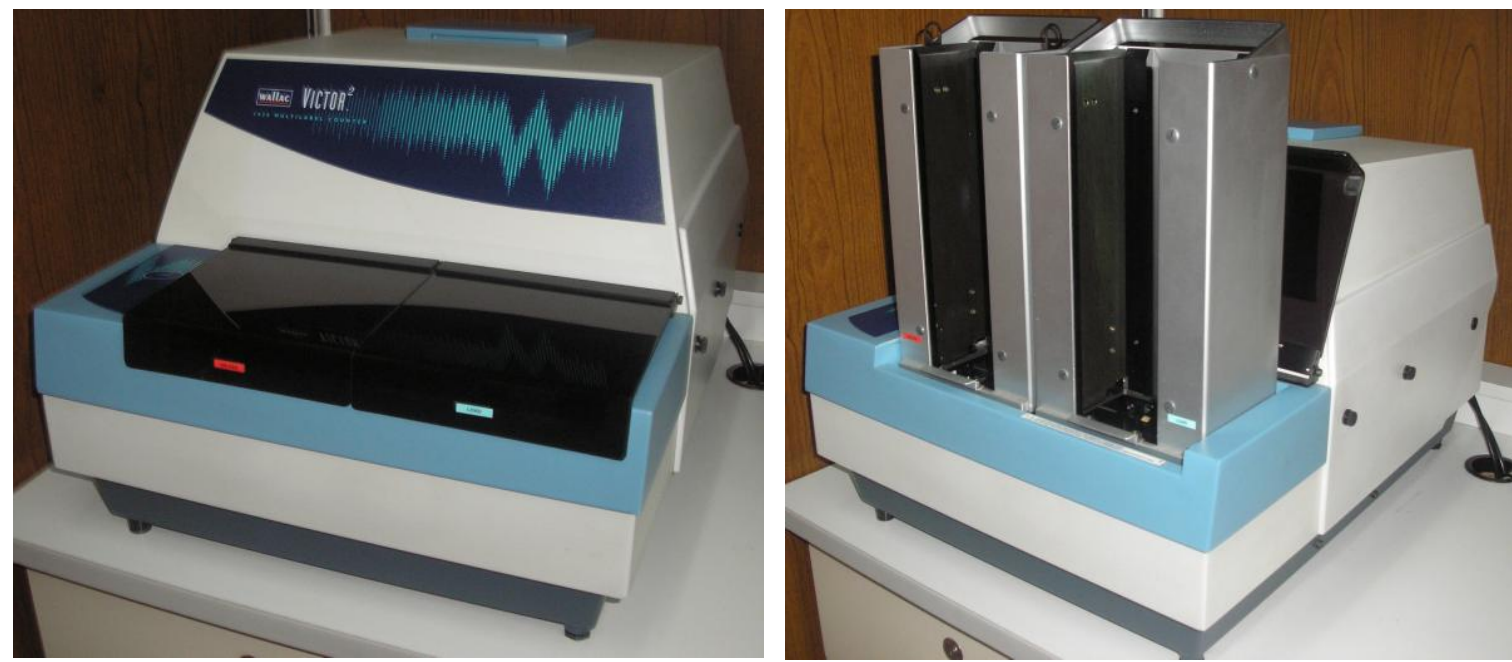

Figura 60. Lector Multitecnología Victor².

En la actualidad el Lector Victor ${ }^{2}$ es utilizado para las medidas fluorométricas convencionales en los métodos de dosaje de Phe, Galactosa y $B C A A$, ofreciendo un backup adicional para las medidas fotométricas $y$ fluorométricas a tiempo resuelto, y la potencialidad de incorporar una cuarta tecnología a través de la Luminometría.

Como dato adicional, y tal como se puede observar en la Figura 60, el Lector multitecnología Victor ${ }^{2}$ presenta una característica distintiva con respecto a los 3 instrumentos antes descriptos, y es que permite automatizar el proceso de lectura mediante la utilización de un sistema de "stackers" o torres.

Este sistema funciona de manera tal que en la torre de carga (torre del lado derecho en la Figura 60) se deben colocar apiladas todas las microplacas que forman parte del ensayo, dispuestas desde la primera a la última en sentido ascendente. De este modo, el instrumento toma la primer microplaca, completa la lectura y la coloca en la torre de descarga (torre del lado izquierdo en la Figura 60). Luego toma la segunda microplaca de la corrida, efectúa la lectura y así sucesivamente completa el ciclo hasta que la torre de carga queda vacía y la de descarga completa, aunque en este caso con las microplacas dispuestas en sentido inverso al que presentaban en la torre de carga, es decir ordenadas de la primera a la última, pero ahora en sentido descendente.

El uso de este tipo de dispositivos permite lograr que el operador se 
independice de tener que realizar manualmente el procedimiento de carga y descarga de cada una de las microplacas para completar el proceso de lectura, dando lugar de este modo a un importante ahorro en el tiempo requerido de trabajo.

Por último, es muy importante mencionar que los 4 instrumentos de lectura que fueran descriptos anteriormente tienen la particularidad de que admiten ser controlados por el Software Multi-Instrumento Multicalc de Wallac Oy.

Este hecho resultó de una enorme trascendencia para el funcionamiento y automatización del Laboratorio de la FBA puesto que permitió simplificar notablemente el flujo y manejo de la información, posibilitando el empleo de un formato único y uniforme para todos los ensayos.

En relación a esto también es importante destacar que si bien el Software Multicalc fue provisto con protocolos de comunicación para los 4 instrumentos de lectura antes descriptos, solamente en el caso de los lectores de Wallac Oy -los cuales de rutina son provistos configurados para trabajar bajo el comando del mencionado software-, no se requirió ningún tipo de elaboración especial para lograr dicha comunicación. En contraposición, en el caso de los 2 instrumentos de Labsystems fue necesario trabajar arduamente en la adaptación de los protocolos de comunicación y también en los dispositivos físicos de conexión entre los mencionados instrumentos y la computadora desde la cual se maneja el software, a fin de lograr una comunicación correcta y confiable entre los mismos.

- Procedimiento de análisis totalmente automatizado: La automatización completa de las diferentes pruebas de pesquisa en un único instrumento, exceptuando el proceso de puncheo y distribución de muestras en las diferentes microplacas, sólo pudo ser concretado en el caso de los inmunoensayos DELFIA, mediante el uso de 2 Autoanalizadores AutoDELFIA de Wallac Oy (Figura 61).

Estos autoanalizadores reúnen en su diseño todos los dispositivos necesarios para cumplimentar en un $100 \%$ todas las tareas que ya fueron descriptas como parte de las funciones de los equipos modulares, es decir que los mismos cuentan 
con la capacidad de dispensar reactivos, remover discos, incubar, agitar, lavar y efectuar lecturas fluorométricas a tiempo resuelto de las microplacas de ensayo, permitiendo además el manejo de los resultados a través del Software Multicalc antes mencionado. De este modo, ambos instrumentos son utilizados en la actualidad en las pruebas para la medida de TSH, IRT y $170 H$ P.

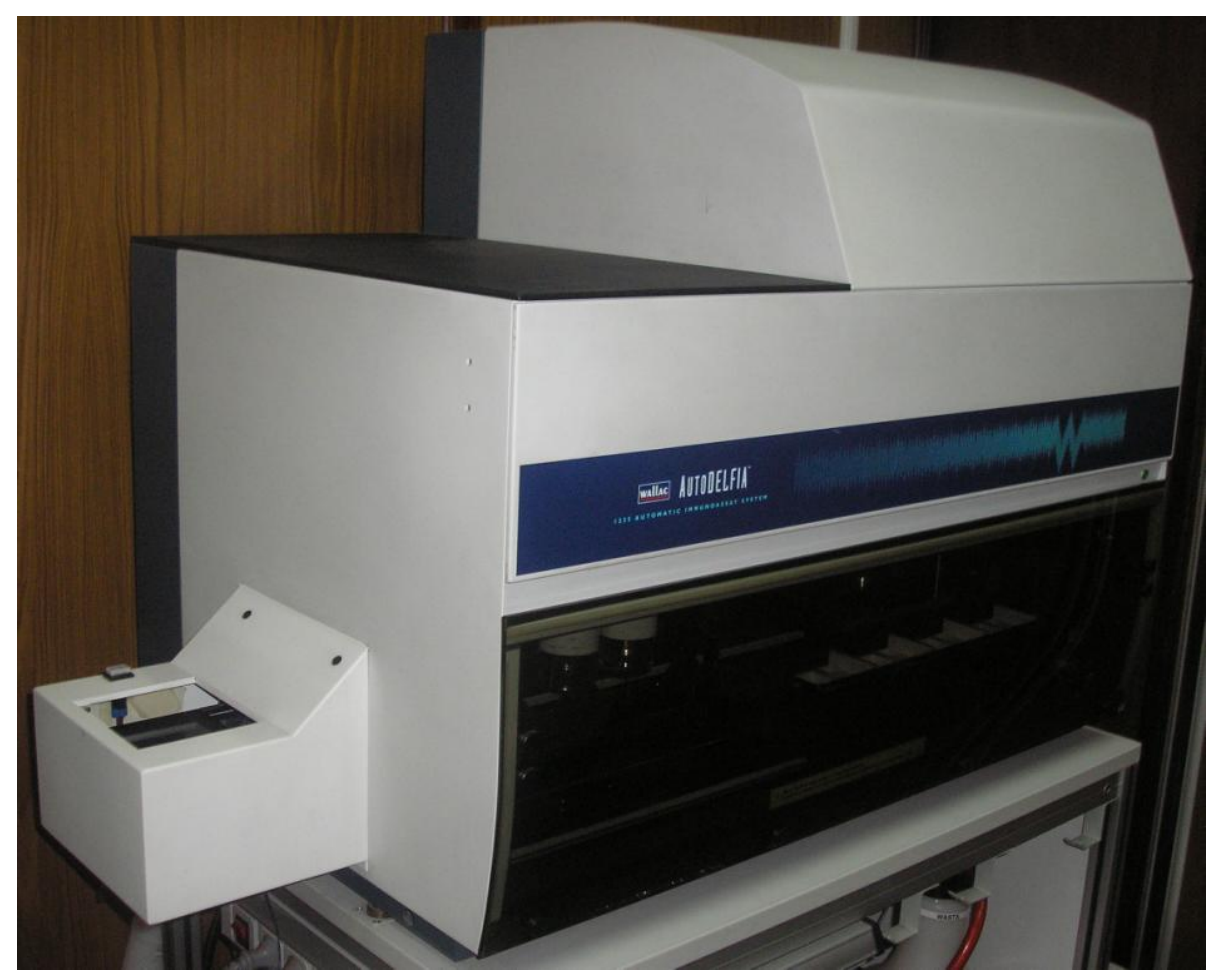

Figura 61. Autoanalizador AutoDELFIA.

- Cálculo de resultados, validación de corridas, seguimiento del control de calidad interno y seguimiento del desempeño de los métodos: con respecto a estos procedimientos, todos ellos se realizan en forma automatizada haciendo uso de algunos de los atributos específicos del Software Multicalc relacionados con los mismos.

En particular, para el cálculo de los resultados se emplean protocolos de ensayo previamente definidos en el mencionado software que permiten que los mismos sean calculados en forma automática inmediatamente después de haber efectuado la lectura de cada ensayo, mientras que para la validación de cada corrida se evalúan una serie de parámetros de desempeño como son la pendiente y 
la intersección de la curva de calibración, y los resultados correspondientes a los materiales de control interno procesados en cada corrida; de lo cual se deduce que el procedimiento de validación de corridas tiene un muy fuerte punto de contacto con los elementos de seguimiento del control de calidad interno y de las tendencias correspondientes a los parámetros de desempeño de cada método.

En relación a la ejecución sistemática de las acciones de seguimiento, las mismas pueden ser llevadas a cabo en forma gráfica a través de las cartas de control de Levey-Jennings (Figura 62) haciendo uso de otra de las propiedades del Software Multicalc, el cual permite además definir las Reglas de Westgard para cada protocolo de ensayo y aplicar las mismas en cada corrida en forma individual.

En el caso específico del control de calidad interno, y tal como es de esperar, las Reglas de Westgard se aplican a cada uno de los resultados obtenidos sobre los materiales de control procesados en cada corrida, mientras que en el caso de los parámetros de desempeño de los diferentes métodos, las mencionadas reglas se aplican sobre los datos correspondientes a la pendiente y a la intersección de cada curva de calibración.

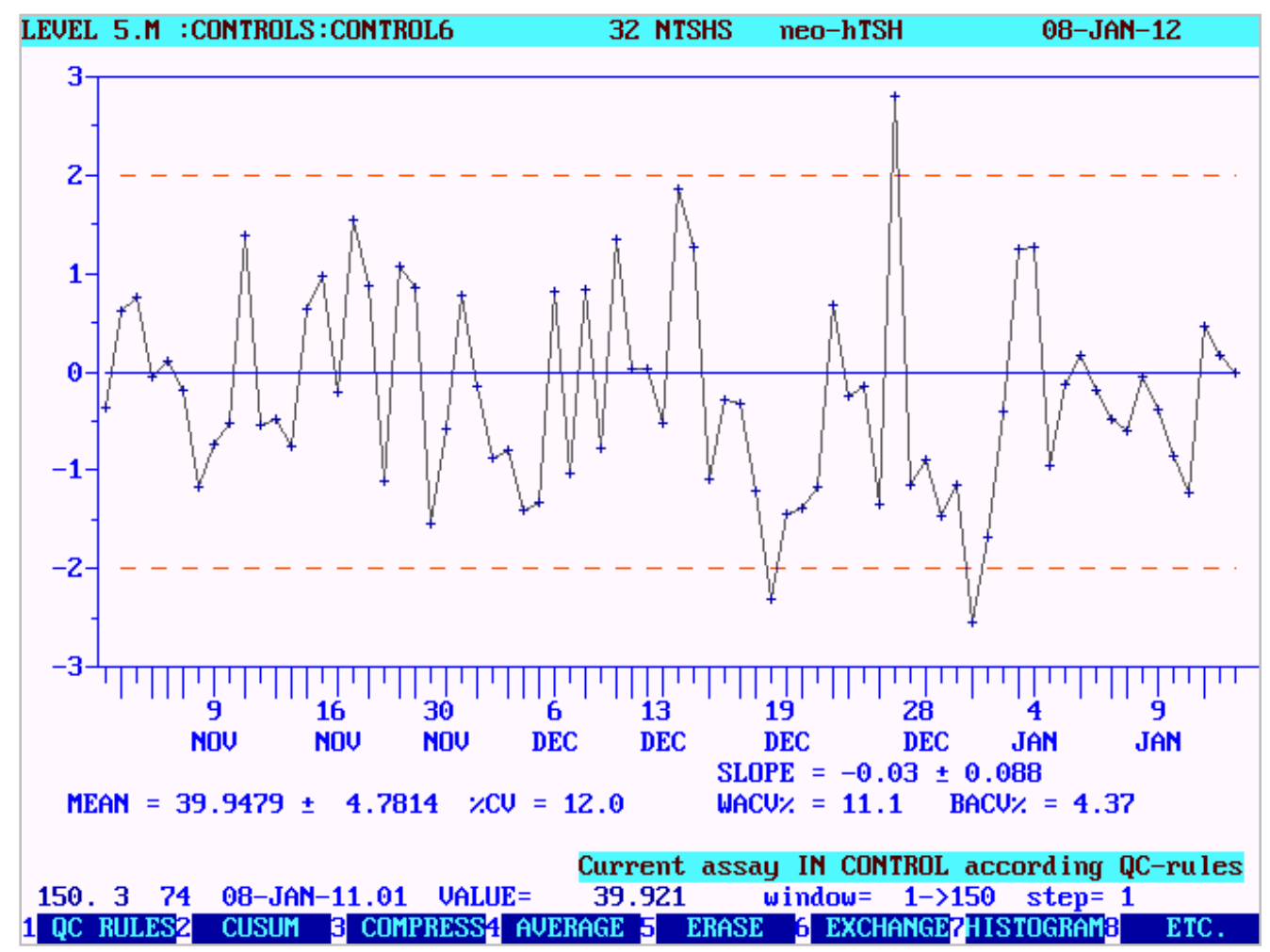

Figura 62. Carta de Control - Software Multicalc. 


\section{Procesos Post-analíticos}

La automatización de los procesos Post-Analíticos fue planificada tomando en consideración 4 objetivos concretos:

1. Reemplazar y eliminar en forma definitiva la carga manual de resultados.

2. Reducir la necesidad de una supervisión pormenorizada, muestra a muestra, durante los procesos de validación de resultados y de emisión de informes.

3. Agilizar la disponibilidad de los resultados en los Centros Asistenciales.

4. Simplificar los procesos de solicitud de segundas muestras, de seguimiento de recepción de las mismas, de solicitud de derivaciones y de reposición de materiales de trabajo.

- Carga y validación de resultados: a diferencia de la modalidad de trabajo utilizada en algunos laboratorios de PN en los cuales la validación de los resultados se realiza como parte de los Procesos Analíticos en el mismo software en el cual se calculan los resultados de cada corrida, en el Laboratorio de la FBA la validación de los mismos se realiza en el SIGM una vez que la corrida ya fue validada en el Software Multicalc y que los resultados ya fueron cargados en el mencionado SIGM.

La utilización de este tipo de estrategia de validación presenta como ventaja principal el hecho de que permite alcanzar un mayor grado de personalización en los criterios definidos para realizar la misma, ampliando así el espectro de condiciones posibles para la aceptación o rechazo de un resultado determinado.

- Carga de resultados: para concretar la automatización de este proceso se hizo uso de otra de las propiedades del Software Multicalc a través de la cual resulta factible generar archivos de Resultados.

Estos archivos se caracterizan por presentar una estructura básicamente idéntica a la de los archivos correspondientes a las Listas de trabajo ya descriptos como parte de los Procesos Pre-analíticos, con la diferencia de que en este caso se adiciona una tercer columna de datos -separada de la segunda por dos espacios-, en la cual queda registrado el resultado correspondiente a cada muestra para un analito determinado. 


\section{Por ejemplo: 0908240001 1875498-- 1.76 \\ 0908240002 1965207-- 1.24 \\ $09082400032154387--21.32$}

En cuanto a la nomenclatura utilizada para la identificación de estos archivos, la misma se definió siguiendo las especificaciones del Software Multicalc, con lo cual su estructura quedó conformada por el nombre del Protocolo de Lectura, seguido de la extensión. ANN, donde A es fijo e indica que se trata de un archivo de resultados y NN es un número variable -de 01 a 99- y corresponde al Número de la Corrida realizada.

Por ejemplo: NTSH.A01

\section{NEO-PHE.A01}

\section{NIRT.A01}

De este modo, el Software Multicalc generará tantos archivos de Resultados como analitos se evalúen y corridas se realicen, haciendo factible la carga automática de los resultados en el SIGM, ya sea a través de una red o de algún tipo de soporte digitalizado.

Adicionalmente, y a efectos de que este procedimiento de carga de resultados pueda ser cumplimentado exitosamente fue necesario programar el SIGM de forma tal de conferirle al mismo la capacidad de interpretar los archivos en cuestión y de asociar el número de identificación de cada muestra con el resultado que le corresponde a cada una de ellas para cada analito.

- Validación de resultados: tal como ya fuera mencionado con anterioridad -aunque en forma tangencial-, el SIGM fue programado de modo tal que durante el proceso de carga de resultados entren en juego una serie de criterios de validación previamente establecidos, los cuales en definitiva van a determinar que aquellos resultados que cumplan con algunos de estos criterios sean cargados al sistema, y que aquellos que no se ajusten a los mismos sean rechazados o queden en suspenso para su definición y eventual carga manual por parte del operador. 
La inclusión de estas reglas o criterios en el SIGM como parte del proceso de validación fue realizada con el objeto de reducir la necesidad de una supervisión manual pormenorizada de cada resultado individual por parte del operador, contribuyendo a su vez a evitar errores en la interpretación de los mismos y en la toma de decisiones clínicas.

En los hechos, la función que desempeñan estos criterios de validación consiste en:

a) bloquear o impedir la carga de aquellos resultados que por diferentes causas analíticas requieren ser repetidos en un nuevo análisis -ya sea sobre la misma o sobre una nueva muestra-, o que requieren que se confirme la identidad de una muestra determinada, es decir que ameritan una corroboración de la correspondencia entre un resultado determinado y la muestra de sangre a partir de la cual se obtuvo el mismo,

b) identificar a aquellos casos en los que el resultado es producto de:

- un segundo análisis de una misma muestra de sangre,

- una segunda muestra de sangre correspondiente a un RN determinado,

- una muestra remitida para monitorear la marcha del tratamiento de un paciente ya diagnosticado, 0

- una muestra cuyo resultado no debe ser informado por tratarse de una muestra de mala calidad, y

c) asegurar, como medida prioritaria, que todo resultado anormal o con características analíticas atípicas que esté disponible para ser informado, sea validado y chequeado previamente por el operador a cargo de la corrida, ahora sí en forma detallada y personalizada.

Con respecto a las características de las reglas de validación definidas en el SIGM, se debe mencionar que algunas de ellas están basadas exclusivamente en el valor numérico del resultado obtenido, mientras que otras se basan en la utilización de un sistema de códigos de 2 caracteres (números, letras o símbolos), el cual también fue ideado por el autor de esta tesis.

Este sistema de códigos fue introducido con la finalidad de que a través 
del mismo resultara posible contar en forma rápida y fácilmente accesible, con información adicional acerca de determinadas muestras de sangre, y de poder utilizar así dicha información en la validación e interpretación personalizada de los resultados.

Operativamente, la utilización de este sistema de códigos requiere que los mismos sean editados en las Listas de trabajo una vez que éstas ya fueron cargadas en el Software Multicalc y antes de que se efectúe la lectura de la corrida correspondiente, de manera tal de posibilitar que dichos códigos ya se encuentren asociados a los números de identificación de las diferentes muestras en los archivos de Resultados que se han de generar posteriormente. Esta tarea requiere por lo tanto, que el código de 2 caracteres antes mencionado sea tipeado en forma manual en las posiciones ocupadas por los dos guiones ubicados a continuación del Número Preimpreso que identifica a la muestra en cuestión en la Lista de trabajo que corresponde.

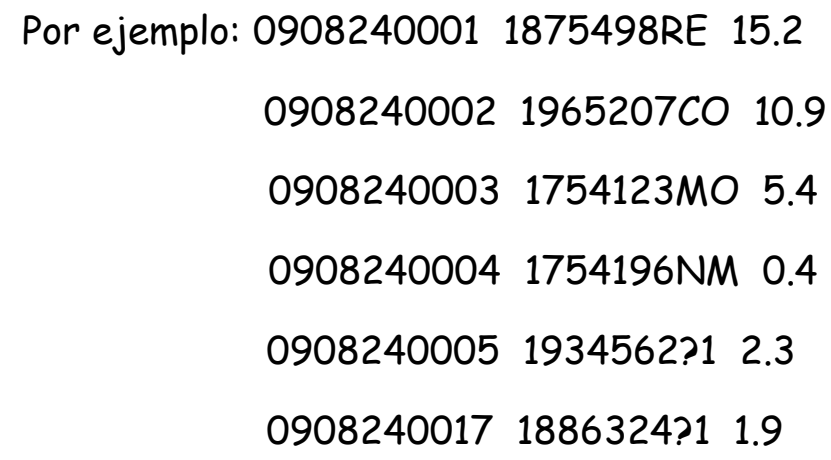

donde RE indica que se trata de un segundo análisis realizado a partir de una misma muestra, CO que corresponde al resultado de una segunda muestra solicitada a un RN determinado quien presentó un resultado anormal en la primera muestra, MO que se trata de una prueba de monitoreo de tratamiento, NM que se trata de una muestra cuyo resultado no debe ser informado por tratarse de una muestra de calidad insatisfactoria, y ?1 (o ?n en forma genérica) que se trata de 2 muestras con una probable transposición de discos.

NOTA: los 5 códigos presentados en los ejemplos anteriores fueron seleccionados solamente a efectos de ilustrar la descripción, siendo los mismos sólo algunos de los códigos utilizados en la práctica diaria. 
Por último, se debe mencionar que, a efectos de facilitar la ejecución del proceso de validación, y una vez que ha sido completada la carga de los resultados, el SIGM emite un listado impreso, discriminado por analito, con las observaciones correspondientes a:

- aquellos resultados que no fueron cargados en concordancia con lo establecido por alguna de las reglas de validación,

- aquellos resultados que no fueron cargados por no haber correspondencia entre la numeración -ya sea Diaria o Preimpresa- disponible en el archivo de Resultados y la registrada en el SIGM, 0

- aquellos resultados que fueron cargados pero que requieren una supervisión y definición personalizada por parte del operador.

- Emisión y envío de informes: el proceso de emisión y envío de informes de resultados fue previsto a través de una rutina definida en el SIGM, con una frecuencia y modalidad que actualmente varía según se trate de instituciones del sector público o privado.

De este modo, en el caso de los hospitales públicos, dichos procesos son realizados 2 veces por semana bajo una modalidad de trabajo que incluye la impresión de informes individuales de cada RN. En contraposición, en el caso de las instituciones privadas, los mencionados procesos son realizados a diario a través de una modalidad de trabajo que implica exclusivamente la generación de informes electrónicos en formato de planillas, dado que en estos casos la impresión de informes individuales es realizada solamente una vez por mes y expresamente para aquellos Laboratorios o Instituciones que previamente manifestaron su interés de recibir los informes impresos.

Estas diferencias entre uno y otro sector fueron definidas fundamentalmente en razón de las limitaciones existentes en lo que respecta a las posibilidades de acceso a correo electrónico o a internet por parte de los hospitales públicos, determinando así que el proceso de emisión de informes se realice según lo descripto anteriormente.

Independientemente de dichas diferencias, en ambos casos el objetivo buscado 
es el agilizar la recepción de resultados, disminuir la carga de trabajo asociada a los procesos de impresión, verificación, compaginación y ensobrado de los mismos, y lograr una reducción en los costos correspondientes a envíos postales.

A continuación se describen las diferentes modalidades de emisión de informes con las que se dispone actualmente:

- Informes de resultados impresos: los informes de resultados impresos son generados a partir del SIGM, tanto en forma individual para cada RN (Figura 63), como en formato de planillas personalizadas para cada Centro Asistencial.

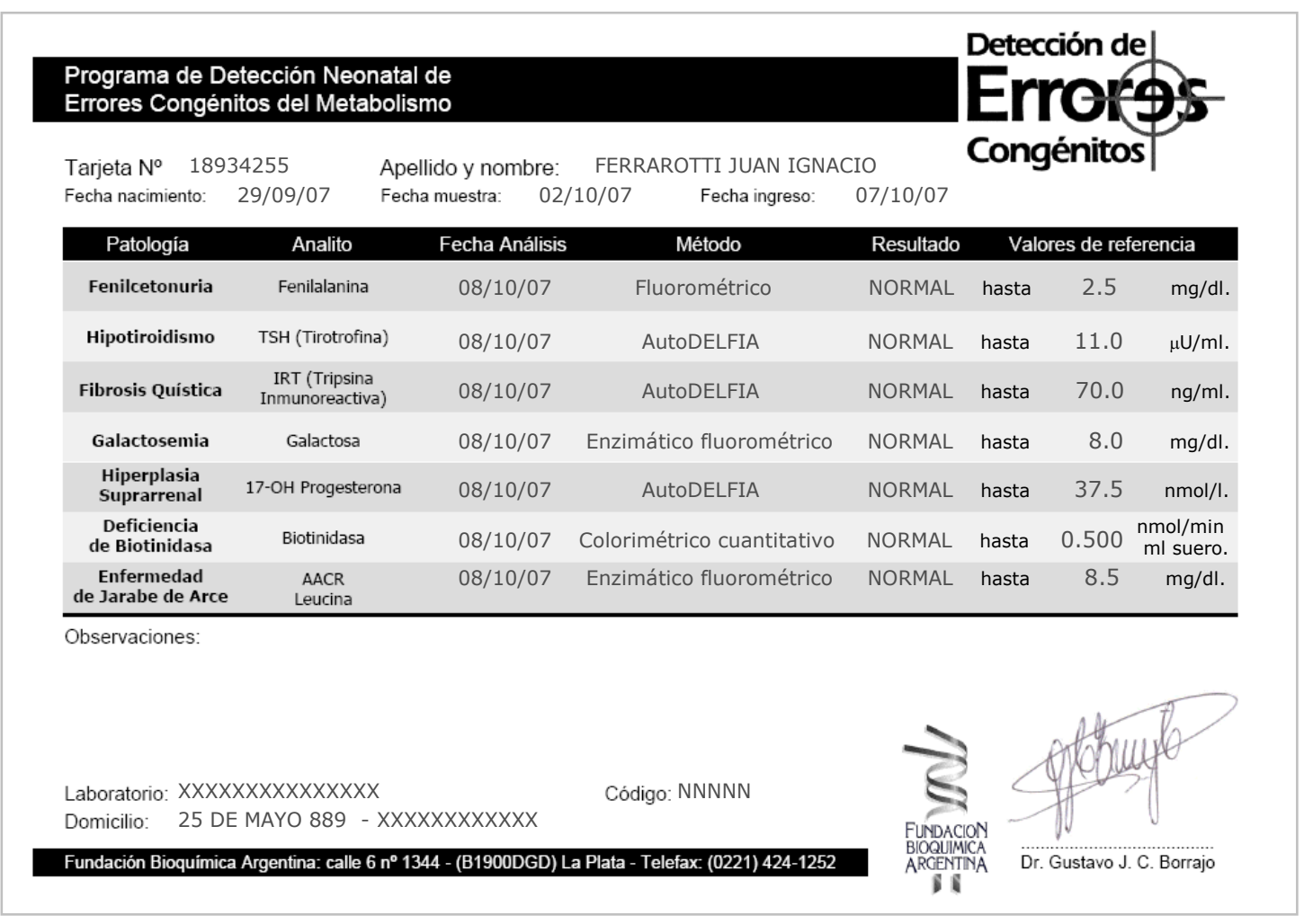

Figura 63. Informe impreso de resultados.

En cuanto al envío de informes, el mismo se efectúa por dos vías diferentes según sea el sector al cual pertenece cada Centro Asistencial, esto es a través del sistema de transporte específico previsto para el sector público ya mencionado en el Capítulo 1 (SODIC), o a través de correo postal o de comisionistas para el caso del sector privado.

- Informes electrónicos de resultados en formato .htm: esta alternativa para el envío electrónico de resultados, vigente desde Abril de 2002, se basa en la 
capacidad del SIGM de generar archivos de tipo .htm, en los cuales los resultados son presentados en forma de planillas personalizadas para cada Laboratorio o Institución.

En cuanto al envío de los mencionados archivos, el mismo es realizado por el SIGM en forma automática a la dirección de correo electrónico indicada por cada Centro Asistencial, una vez que el proceso de emisión de informes ha sido adecuadamente verificado y validado.

En la Figura 64 se presenta un ejemplo de informe electrónico de resultados de tipo. $\mathrm{htm}$.

\begin{tabular}{|c|c|c|c|c|c|c|c|c|c|c|c|c|}
\hline \multicolumn{13}{|c|}{$\begin{array}{l}\text { FUNDACION BIOQUIMICA ARGENTINA } \\
\text { Programa de Detección de Errores Congénitos }\end{array}$} \\
\hline \multicolumn{13}{|c|}{$\begin{array}{l}\text { Listado de muestras analizadas } \\
\text { Archivo de proceso: } 02 / 10 / 07-14: 39 \mathrm{hs} \text {. }\end{array}$} \\
\hline \multicolumn{13}{|c|}{ Domicilio: } \\
\hline \multicolumn{13}{|c|}{ 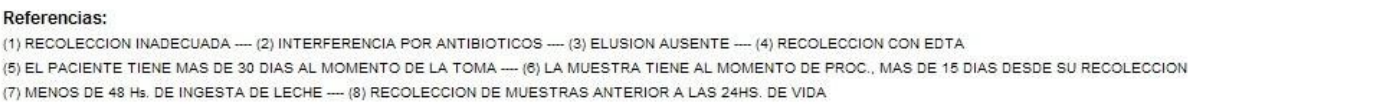 } \\
\hline $\begin{array}{l}\text { NUMERO } \\
\text { TARJ. }\end{array}$ & $\begin{array}{l}\text { NOMBRE } \\
\text { PACIENTE }\end{array}$ & $\begin{array}{l}\text { FECHA } \\
\text { MUESTRA }\end{array}$ & $\begin{array}{l}\text { COD. } \\
\text { A PROF. }\end{array}$ & $\begin{array}{c}\text { NOMBRE } \\
\text { PROFESIONAL }\end{array}$ & LOCALIDAD & Phe & TSH & IRT & GALACTOSA & 17-OHP & BIOTINIDASA & BCAA \\
\hline 2878713 & FREDES GENARO & $28 / 09 / 07$ & 1034 & & LA PLATA & NORMAL & NORMAL & NORMAL & NORMAL & NORMAL & NORMAL & NORMAL \\
\hline 2876716 & FERREYRA AGUSTIN & $29 / 09 / 07$ & 1034 & & LA PLATA & NORMAL & NORMAL & NORMAL & NORMAL & NORMAL & NORMAL & NORMAL \\
\hline 2878717 & MARQUEZ GUILLERMINA & $01 / 10 / 07$ & 1034 & & LA PLATA & NORMAL & NORMAL & NORMAL & NORMAL & NORMAL & NORMAL & NORMAL \\
\hline 2878729 & LAURE JUAN CRUZ & $26 / 09 / 07$ & 1034 & & LA PLATA & NORMAL & NORMAL & NORMAL & NORMAL & NORMAL & NORMAL & NORMAL \\
\hline 2878733 & LOPEZ LUCIA & $27 / 09 / 07$ & 1034 & & LA PLATA & NORMAL & NORMAL & NORMAL & NORMAL & NORMAL & NORMAL & NORMAL \\
\hline 2876730 & BALTAZAR BLANC & $27 / 09 / 07$ & 1034 & & LA PLATA & NORMAL & NORMAL & NORMAL & NORMAL & NORMAL & NORMAL & NORMAL \\
\hline 2876732 & RANNO IARA 240907 & $27 / 09 / 07$ & 1034 & & LA PLATA & NORMAL & NORMAL & NORMAL & NORMAL & NORMAL & NORMAL & NORMAL \\
\hline 2878712 & HARISPE JUAN MANUEL & $28 / 09 / 07$ & 1034 & & LA PLATA & NORMAL & NORMAL & NORMAL & NORMAL & NORMAL & NORMAL & NORMAL \\
\hline 2878714 & ISAGUIRRE CATALINA & $28 / 09 / 07$ & 1034 & & LA PLATA & NORMAL & NORMAL & NORMAL & NORMAL & NORMAL & NORMAL & NORMAL \\
\hline
\end{tabular}

Figura 64. Informe electrónico de resultados.

- Informes de resultados On-line: esta tercer alternativa para el acceso a los informes de resultados se basa en la posibilidad de efectuar consultas personalizadas en la página Web de la FBA: www.fba.org.ar, a través de la cual cada usuario, utilizando una clave de acceso personal, puede acceder no solamente a visualizar los informes individuales de cada RN, sino también a generar un archivo en formato pdf, y a imprimir los mismos con un diseño idéntico al utilizado en los informes impresos antes descriptos.

En cuanto a la información disponible en la Web, y en concordancia con los procesos de emisión de informes, la misma es actualizada a diario para el caso 
de Laboratorios o Instituciones del sector privado y 2 veces por semana en el caso de Hospitales públicos, una vez que dichos procesos ya han sido validados.

En la Figura 65 se presenta un ejemplo de la forma en que se visualizan dichos informes a través de la página Web de la FBA.

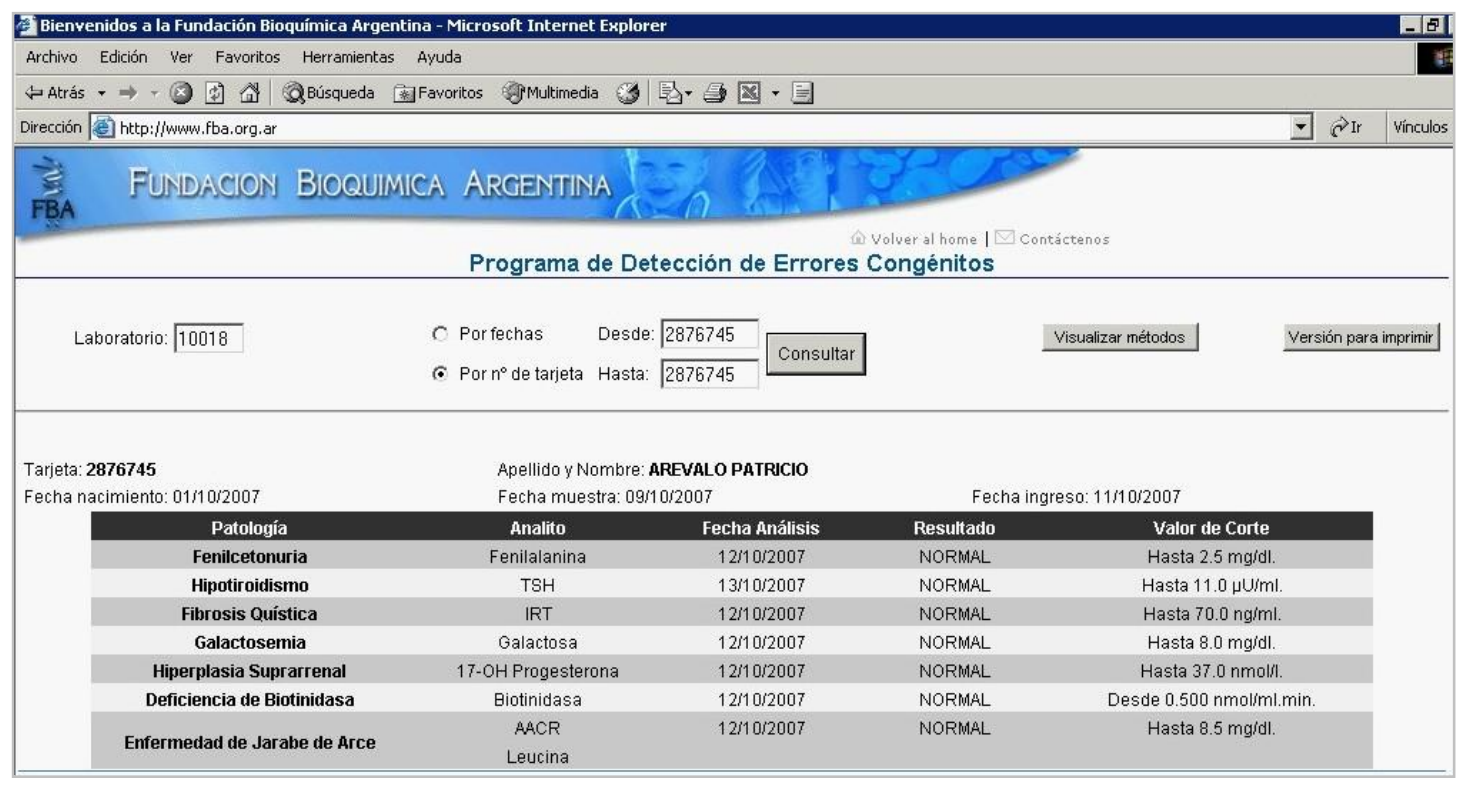

Figura 65. Visualización de informes a través de la Web.

- Informes de resultados de monitoreo: este tipo de informes constituye una variante de características muy específicas puesto que corresponde a los resultados de seguimiento del tratamiento en pacientes ya diagnosticados.

Dichos resultados requieren por su propia naturaleza, que el médico tratante tenga acceso a los mismos en forma inmediata a fin de evaluar la respuesta terapéutica y de realizar las acciones correctivas pertinentes sin demoras, en caso de que las mismas sean necesarias.

En función de esto, se diseñó una opción en el SIGM que permite generar un archivo de tipo $\mathrm{htm}$ con los resultados correspondientes a todos aquellos niños cuyas muestras fueron identificadas como monitoreo al momento del ingreso de las mismas en dicho sistema. En los mencionados archivos los resultados son organizados en forma de planilla, y el envío se realiza en forma automática desde el SIGM a la dirección de correo electrónico del médico tratante. (Figura 66). 


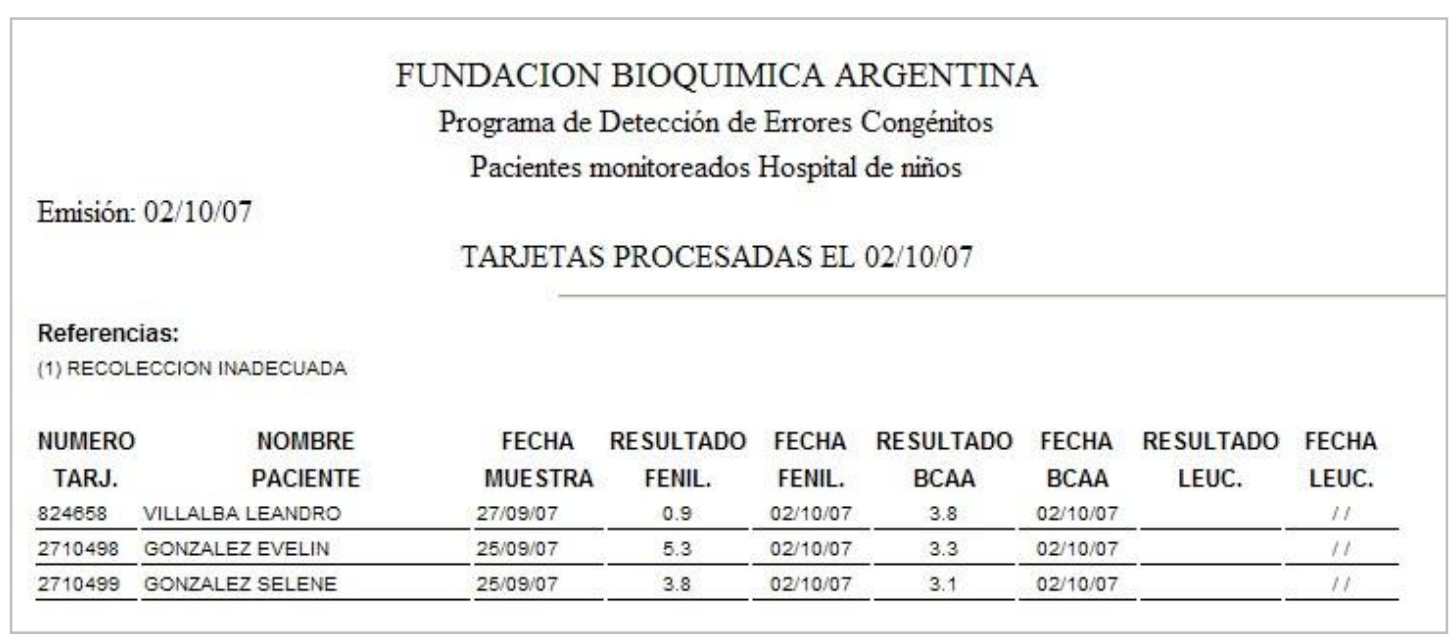

Figura 66. Informe electrónico de resultados de pacientes monitoreados.

- Solicitud de recolección de segundas muestras o de derivación de RN al Centro de Atención Especializada, por resultados anormales: en vista de la importancia que tiene este procedimiento en relación al potencial éxito en la detección y tratamiento precoz de un caso determinado, la comunicación de estas acciones desde el Laboratorio de pesquisa al Centro Asistencial no ha sido incluida dentro del proceso de automatización, sino que por el contrario, la modalidad a través de la cual se efectúa el mismo consiste en una comunicación inmediata y personalizada, vía telefónica, por parte del personal del Laboratorio con un responsable o con, al menos, un interlocutor válido del Centro Asistencial que remitió la muestra, que otorgue garantías de haber comprendido la indicación recibida, y que a su vez se haga responsable de transmitir dicha indicación internamente a quien corresponda, a fin de poner en marcha las acciones necesarias para la localización del RN en cuestión.

Por otra parte, resulta importante dejar en claro que en aquellos casos en los que las acciones que corresponda realizar ameriten la derivación inmediata del RN al Centro de Atención Especializada, el Laboratorio de pesquisa no sólo debe comunicar telefónicamente la conducta a seguir al Centro Asistencial que recolectó la muestra, sino que además debe notificar al Centro de Atención Especializada para que éste último registre el caso, coordine las acciones de localización y efectúe el seguimiento de la llegada del RN.

Esta notificación requiere entonces que el Laboratorio aporte tanto los resul- 
tados obtenidos en las pruebas de pesquisa como toda la información del RN, de su madre y del centro que recolectó la muestra.

Por este motivo, y a efectos de simplificar y optimizar dicha comunicación, se diseñó una Planilla de Derivación que se genera a partir del SIGM y que se remite vía fax al Centro de Atención Especializada, en la cual se incluye toda la información antes mencionada (Figura 67).

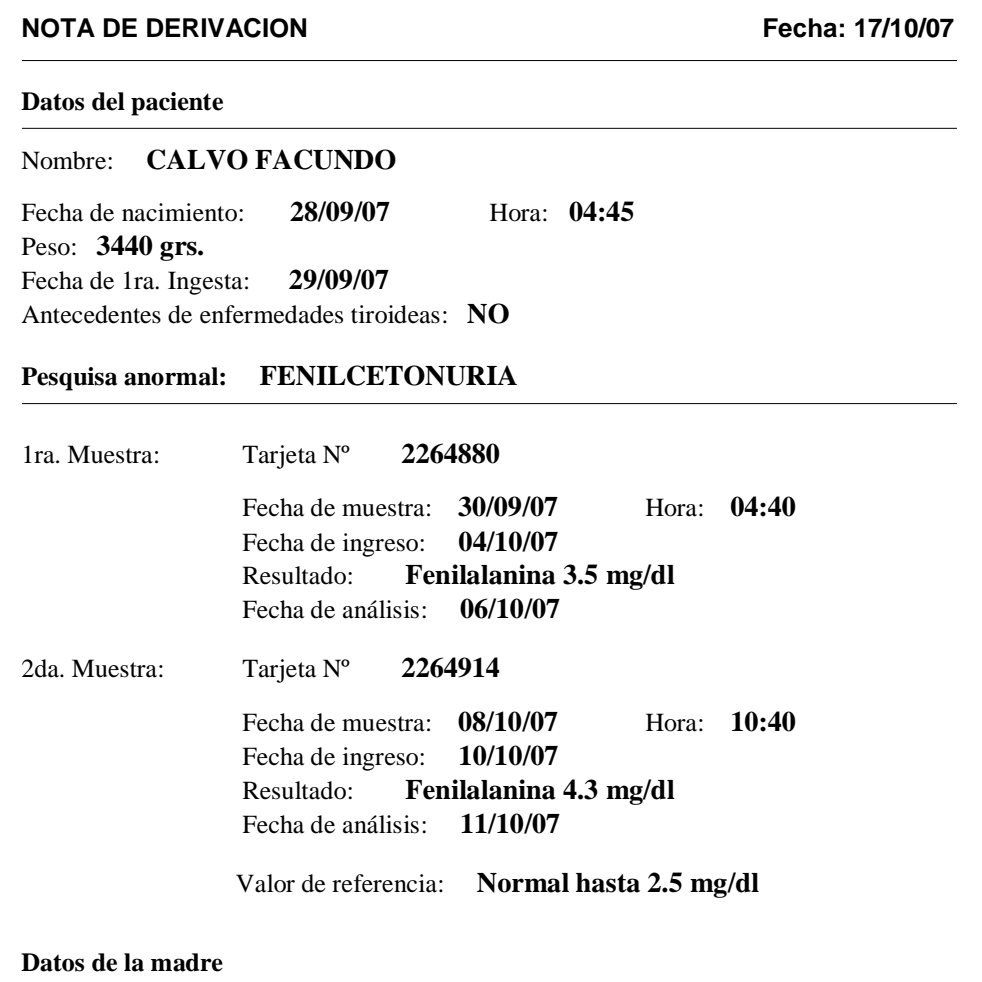

Nombre: BONZI YESICA

Domicilio: SAN MARTIN 1253

Localidad: MORON

Teléfono:

Datos del remitente

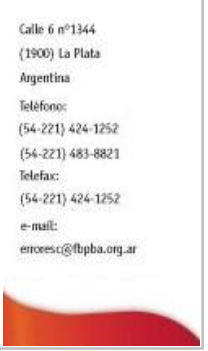

Responsable: HOSPITAL MUNICIPAL

Domicilio: ARRIBEÑOS 735

Localidad: MORON

Teléfono:

Figura 67. Planilla de derivación al Centro de Atención Especializada. 
- Solicitud de recolección de segundas muestras por recolección inadecuada 0 por incumplimiento de las condiciones de recolección: a diferencia de lo descripto en el ítem anterior, en aquellos casos en los que se requiere la recolección de una segunda muestra de sangre, ya sea tanto por recolección inadecuada como por incumplimiento de alguna de las condiciones de recolección pre-establecidas, la comunicación se realiza en forma automática a través del envío de archivos de tipo htm que son remitidos a la dirección de correo electrónico del Centro Asistencial. Dichos archivos contienen la información correspondiente a todos aquellos RN a los cuales resulta necesario recolectarle una segunda muestra organizada en forma de planilla, y de el/los analito/s a repetir y el/los motivo/s de dicha solicitud (Figura 68).

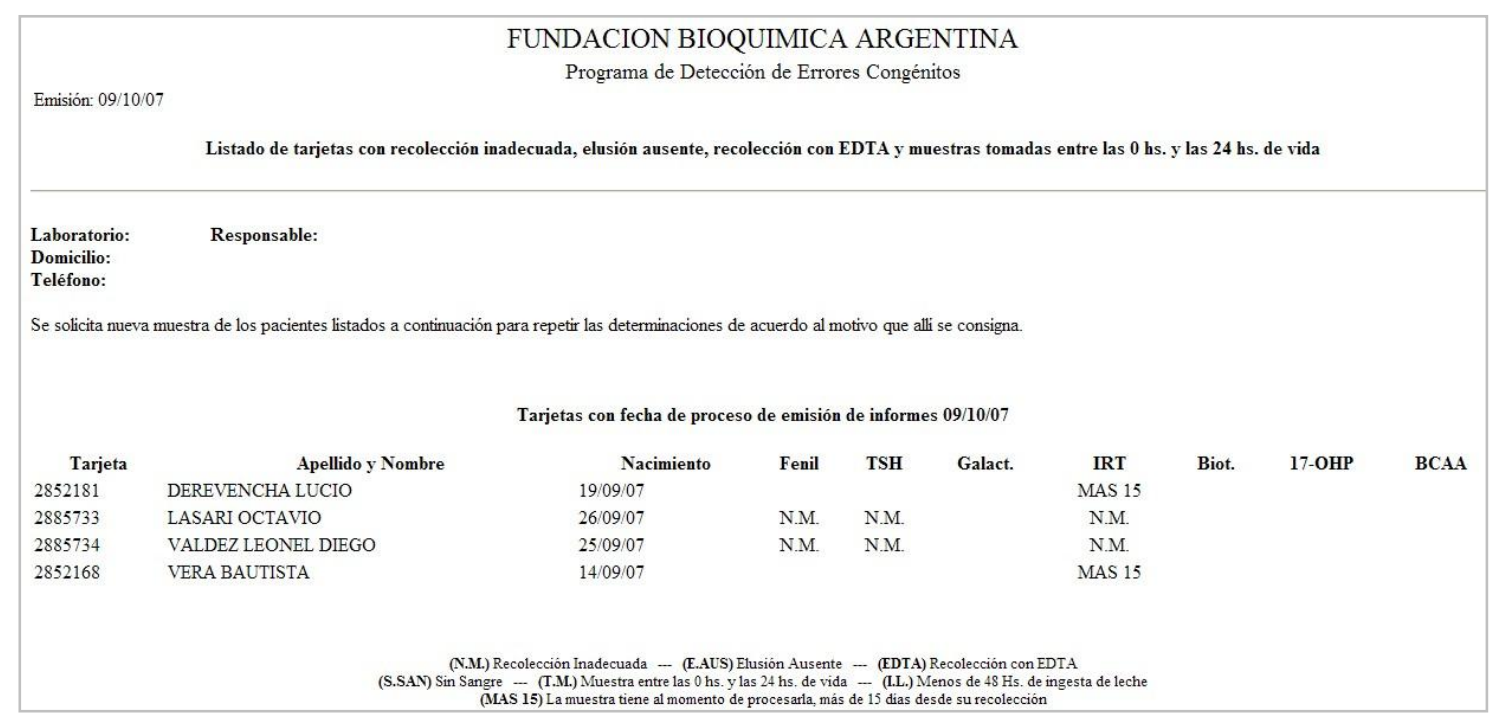

Figura 68. Archivo electrónico para solicitud de recolección de segundas muestras.

Como un mecanismo alternativo, en aquellos casos en los cuales no se cuenta con una dirección de correo electrónico del Centro Asistencial, la comunicación se realiza vía fax, para lo cual la información correspondiente se imprime en forma automática a partir del SIGM, también en un formato de planilla.

- Seguimiento de llegada de segundas muestras: uno de los parámetros utilizados en la evaluación del desempeño global de un Programa de PN es precisamente el índice de recepción de segundas muestras solicitadas, el cual es una medida tanto 
del número de neonatos en los que fue posible completar la secuencia de acciones necesarias para confirmar o descartar una patología determinada, como del número de casos que quedaron inconclusos (ver Capítulo 7).

Con la finalidad de poder evaluar estadísticamente estos parámetros, se programó el SIGM a efectos de que a través del mismo fuera posible generar un listado impreso, denominado de Resultados Especiales, en el cual se lista a todos aquellos neonatos a los que se les solicitó una segunda muestra, independientemente de la causa que motivó dicha solicitud.

En el mencionado listado, los datos de los RN son ordenados y agrupados en primer término por analito, y luego según el motivo de la solicitud de la segunda muestra, ya sea por resultados dudosos, resultados patológicos, recolección inadecuada, recolección con anterioridad a las 24 horas de vida, recolección con anterioridad a las 24 horas de ingesta de leche requeridas para la PN de Galactosemia, recolección con anticoagulantes complejantes del $\mathrm{Ca}^{+2}$ (EDTA) o ausencia de elusión de la muestra del papel de filtro según corresponda, presentándose los datos ordenados dentro de cada una de estas subcategorías según la fecha del primer análisis, y el apellido y nombre del RN.

Por otra parte, este listado de Resultados Especiales no solamente incluye los datos correspondientes a la primera muestra de cada uno de estos RN sino que, además, en caso de que la segunda muestra haya sido recibida en el Laboratorio y haya sido identificada como tal en el SIGM al momento del alta de la misma, incluye también los datos correspondientes a ésta última (Figura 69).

Por último se debe destacar que a partir de este listado de Resultados Especiales no solamente es posible determinar el índice de llegada de segundas muestras, sino que además es posible realizar una búsqueda manual en el SIGM -a partir del apellido y nombre del RN- de todas aquellas segundas muestras que pudieran haber ingresado al laboratorio sin haber sido identificadas como tales. Este procedimiento, el cual forma parte de las acciones de seguimiento de un Programa de PN ha sido planificado de forma tal que el mismo se realice una vez 
por mes, trabajando sobre un período que comprende los 3 meses inmediatos anteriores.

$01 / 11 / 2007$

Página 1

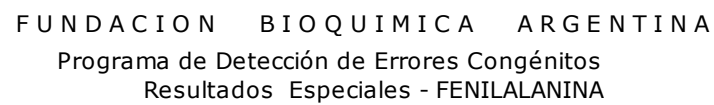

LISTADO DE MUESTRAS PROCESADAS ENTRE 01/09/07 Y 30/09/07

\begin{tabular}{|c|c|c|c|c|c|}
\hline TARJETA & F. PROCESO & APELLIDO Y NOMBRE & CODIGO & RESULTADO & INTERPRETACION \\
\hline 2870335 & $24 / 09 / 07$ & NIEVAS YAMILA & S0352 & 3.3 & DUDOSO \\
\hline $\begin{array}{l}2864043 \\
2885736\end{array}$ & $\begin{array}{l}25 / 09 / 07 \\
09 / 10 / 07\end{array}$ & ILUNDAI BENJAMIN & 20081 & $\begin{array}{l}2.6 \\
0.8\end{array}$ & $\begin{array}{l}\text { DUDOSO } \\
\text { NORMAL }\end{array}$ \\
\hline $\begin{array}{l}2864045 \\
2868265\end{array}$ & $\begin{array}{l}25 / 09 / 07 \\
09 / 10 / 07\end{array}$ & LEGUIZAMON ANTONELLA & 20081 & $\begin{array}{l}2.6 \\
1.9\end{array}$ & $\begin{array}{l}\text { DUDOSO } \\
\text { NORMAL }\end{array}$ \\
\hline 2868265 & 26/09/07 & CEJAS MAURO 0283525 & S0265 & 3.2 & DUDOSO \\
\hline \multicolumn{3}{|c|}{ Total de muestras con interpretación DUDOSO: } & 4 & & \\
\hline $\begin{array}{l}2736007 \\
2736587\end{array}$ & $\begin{array}{l}03 / 09 / 07 \\
19 / 09 / 07\end{array}$ & MORLIO MICAELA & 10297 & $\begin{array}{l}1.3 \\
1.8\end{array}$ & $\begin{array}{l}\text { MENOS DE } 24 \mathrm{Hs} \text {. } \\
\text { NORMAL }\end{array}$ \\
\hline $\begin{array}{l}2737915 \\
2742180\end{array}$ & $\begin{array}{l}11 / 09 / 07 \\
01 / 10 / 07\end{array}$ & VICENTE SOL & 20399 & $\begin{array}{l}1.2 \\
1.6\end{array}$ & $\begin{array}{l}\text { MENOS DE } 24 \mathrm{Hs} \text {. } \\
\text { NORMAL }\end{array}$ \\
\hline $\begin{array}{l}2851980 \\
2851965\end{array}$ & $\begin{array}{l}19 / 09 / 07 \\
27 / 09 / 07\end{array}$ & FERNANDEZ LUCA & 20111 & $\begin{array}{l}1.2 \\
1.4\end{array}$ & $\begin{array}{l}\text { MENOS DE } 24 \mathrm{Hs} \text {. } \\
\text { NORMAL }\end{array}$ \\
\hline 2869154 & $23 / 09 / 07$ & FERNANDEZ ANTONELA & S0482 & 0.9 & MENOS DE $24 \mathrm{Hs}$. \\
\hline 2736769 & $27 / 09 / 07$ & PERALTA SANTIAGO & 40271 & 1.1 & MENOS DE $24 \mathrm{Hs}$. \\
\hline $\begin{array}{l}2845038 \\
2890836\end{array}$ & $\begin{array}{l}28 / 09 / 07 \\
04 / 10 / 07\end{array}$ & DIAZ ARACELI MICAELA & 20379 & $\begin{array}{l}1.3 \\
1.1\end{array}$ & $\begin{array}{l}\text { MENOS DE } 24 \mathrm{Hs} \text {. } \\
\text { NORMAL }\end{array}$ \\
\hline \multicolumn{3}{|c|}{ Total de muestras con interpretación MENOS DE 24 Hs.: } & 6 & & \\
\hline $\begin{array}{l}2866811 \\
2888802\end{array}$ & $\begin{array}{l}07 / 09 / 07 \\
23 / 10 / 07\end{array}$ & ORTELLADO SANTIAGO & 30322 & $\begin{array}{l}\text { N.M. } \\
1.3\end{array}$ & $\begin{array}{l}\text { RECOL. INADEC. } \\
\text { NORMAL }\end{array}$ \\
\hline $\begin{array}{l}2740474 \\
2722050\end{array}$ & $\begin{array}{l}08 / 09 / 07 \\
16 / 09 / 07\end{array}$ & FLAMENCO BARBARA & 20400 & $\begin{array}{l}\text { N.M. } \\
1.7\end{array}$ & $\begin{array}{l}\text { RECOL. INADEC. } \\
\text { NORMAL }\end{array}$ \\
\hline 2722050 & $14 / 09 / 07$ & GOMEZ NATACHA & 20385 & N.M. & RECOL. INADEC. \\
\hline $\begin{array}{l}2870384 \\
2491514\end{array}$ & $\begin{array}{l}17 / 09 / 07 \\
23 / 09 / 07\end{array}$ & OJEDA THIAGO & 60219 & $\begin{array}{l}\text { N.M. } \\
1.1\end{array}$ & $\begin{array}{l}\text { RECOL. INADEC. } \\
\text { NORMAL }\end{array}$ \\
\hline $\begin{array}{l}2856220 \\
2935467\end{array}$ & $\begin{array}{l}21 / 09 / 07 \\
29 / 09 / 07\end{array}$ & LACUADRA EMANUEL & 10256 & $\begin{array}{l}\text { N.M. } \\
0.9\end{array}$ & $\begin{array}{l}\text { RECOL. INADEC. } \\
\text { NORMAL }\end{array}$ \\
\hline 2743203 & $23 / 09 / 07$ & LUGO LIZ & 20400 & N.M. & RECOL. INADEC. \\
\hline 2369707 & $23 / 09 / 07$ & SALAS MATEO JEREMIAS & 20407 & N.M. & RECOL. INADEC. \\
\hline 2869004 & 25/09/07 & LEGUIZAMON DIAMELA & S0415 & N.M. & RECOL. INADEC. \\
\hline $\begin{array}{l}2843268 \\
2886335\end{array}$ & $\begin{array}{l}27 / 09 / 07 \\
05 / 10 / 07\end{array}$ & VIVEROS BRIAN & 20111 & $\begin{array}{l}\text { N.M. } \\
1.4\end{array}$ & $\begin{array}{l}\text { RECOL. INADEC. } \\
\text { NORMAL }\end{array}$ \\
\hline $\begin{array}{l}2844603 \\
2886128\end{array}$ & $\begin{array}{l}27 / 09 / 07 \\
16 / 10 / 07\end{array}$ & VILLEGAS RAMIRO & 50215 & $\begin{array}{l}\text { N.M. } \\
1.8\end{array}$ & $\begin{array}{l}\text { RECOL. INADEC. } \\
\text { NORMAL }\end{array}$ \\
\hline \multicolumn{3}{|c|}{ Total de muestras con interpretación RECOL. INADEC.: } & 10 & & \\
\hline
\end{tabular}

Figura 69. Listado para el seguimiento de llegada de $2^{\circ}$ muestras. 
- Reclamo de llegada de segundas muestras: para todos aquellos casos en los cuales el Laboratorio de pesquisa no cuente con registros que certifiquen el ingreso de alguna de las segundas muestras solicitadas oportunamente, se programó el SIGM a efectos de que, a través del mismo, fuera posible generar notas personalizadas para cada Centro Asistencial y para cada RN en el cual no se cumplimentó dicha recolección (Figura 70).

La Plata, 13 de Noviembre de 2007

LABORATORIO: XXXXXXXXXX

CODIGO: 7799

DOMICILIO: TAPALQUÉ 234

CIUDAD: N. S. T. R.

CP:

Me dirijo a Ud. con el objeto de informarle que han transcurrido más de 20 días desde el momento en que el Laboratorio de Detección de Errores Congénitos de la Fundación Bioquímica Argentina solicitó una nueva muestra de sangre en papel de filtro del recién nacido PUCHETA AYELEN (fecha de nacimiento: 11/10/07)

para la repetición de las determinaciones que se listan a continuación:

$\begin{array}{clcl}\text { N }^{\circ} \text { de Tarjeta } & \text { Analito } & \text { Resultado } & \text { Causa } \\ 2902774 & \text { Galactosa } & \text { N.M. } & \text { RECOLECCION INADECUADA } \\ & \text { Biotinidasa } & \text { N.M. } & \text { RECOLECCION INADECUADA }\end{array}$

Por tal motivo se remite la presente nota a fin de que se efectivice la recolección y el envío de la muestra antes mencionada y a efectos de dejar constancia de la solicitud realizada oportunamente, dado que a la fecha de emisión de la presente dicha muestra aún no ha sido recibida en nuestro Laboratorio.

Sin otro particular y a la espera de una pronta respuesta lo saludo muy atentamente.

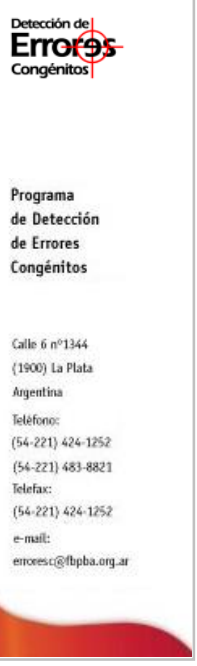

Figura 70 . Nota de reclamo de recolección de $2^{\circ}$ muestra. 
Por medio de estas notas, las cuales se remiten por vía postal, se deja constancia escrita de que no se registró el ingreso de la segunda muestra y se reitera la solicitud realizada oportunamente a fin de lograr que se efectivice la misma.

Es importante dejar en claro que estas acciones no sólo tienen por objetivo mejorar la eficiencia de captación de RN en los cuales la pesquisa permanece inconclusa, sino también aportar un respaldo legal adicional para el Laboratorio de pesquisa puesto que de esta forma se deja constancia de que el mismo ha cumplimentado todas las acciones que corresponde realizar de acuerdo a los algoritmos de trabajo establecidos.

En cuanto a la modalidad de ejecución de este proceso, las notas de reclamo son emitidas a diario y en forma automática a partir del SIGM, una vez que transcurrieron 20 días a contar a partir de la fecha de análisis para el caso de RN con resultados anormales, y 25 días para el caso de RN con recolección inadecuada o con incumplimiento de las condiciones de recolección.

\section{- Reposición de tarjetas de recolección de muestras y de etiquetas con códigos} de barras: la reposición de ambos tipos de materiales de trabajo se realiza empleando un sistema que permite racionalizar su uso y distribución, y asegurar la disponibilidad permanente de las mismas en los Centros Asistenciales.

- Tarjetas de recolección de muestras: la reposición de tarjetas de recolección de muestras por parte de la FBA a cada uno de los Centros Asistenciales se lleva a cabo en forma mensual a partir de la información provista por el SIGM en forma de listados impresos, quedando definido el número de tarjetas a reponer de acuerdo al número de muestras recibidas de cada uno de dichos Centros Asistenciales en el mes inmediato anterior.

- Etiquetas con códigos de barras: la reposición de etiquetas adhesivas con los códigos de barras impresos correspondientes al código de identificación de cada Centro Asistencial se realiza también en forma mensual y a partir de la información provista por el SIGM. Dicha información es calculada en base a los registros disponibles en el mismo en relación al stock de etiquetas remitidos a 
cada Centro Asistencial y al número acumulativo de muestras recibidas desde la última reposición de etiquetas. Esta información es posteriormente transferida al Programa WinLabel, a través del cual se lleva a cabo la impresión de los códigos de barras antes mencionadas en planchas de 65 etiquetas por hoja.

\section{BIBLIOGRAFIA}

1. Dobbins RH, Kling $S$, Wooden $H$. "Joint ASTPHLD/CORN Standardization Committee Report on Forms, Formats and Data Collection". Report of Joint ASTPHLD/CORN Committee on Neonatal Screening Standardization and Recommendations. Second Draft, 31-5, 1996.

2. Therrell B, "Automation and Computarization in Newborn Screening" en "Laboratory Methods for Neonatal Screening". Therrell BL Ed, American Public Health Association, Washington, 1-21, 1993. 


\section{CAPÍTULO 4}

VALIDACIÓN DE

METODOS DE

PESQUISA NEONATAL 



\section{- INTRODUCCIÓN}

La presencia de errores analíticos y de errores diagnósticos de diferentes orígenes en las pruebas de PN puede dar lugar tanto a la generación de resultados falsos negativos (FN) como de resultados falsos positivos (FP).

Los resultados FN tienen consecuencias desvastadoras para los RN afectados puesto que irremediablemente los conducirán a la muerte o a padecer un daño neurológico e incapacidad severa de por vida.

LoS FP en cambio, tienen consecuencias bastante menos graves puesto que en estos casos siempre existe una instancia posterior que permite descartar la patología. Sin embargo, y más allá de estas aseveraciones, debe tomarse en consideración que los FP también pueden dar lugar a efectos adversos asociados, causando una muy importante sobrecarga de trabajo en los sistemas de seguimiento del programa, un incremento en sus costos, una innecesaria carga de angustia y ansiedad en las familias de los niños con este tipo de resultados, y un descreimiento o pérdida de confianza por parte de la población en lo que respecta a la utilidad y beneficios de las pruebas de pesquisa.

De este modo, y en vista de las implicancias y consecuencias de ambos tipos de falsos resultados, resulta estrictamente necesaria la optimización de las pruebas de PN a fin de asegurar la obtención de resultados confiables, seguros y de alta calidad analítica, propiedad que puede ser verificada a través de la implementación sistemática del proceso de Validación de Métodos.

\section{- VALIDACIÓN DE MÉTODOS}

Se entiende por Validación de Métodos al proceso utilizado para confirmar que el procedimiento analítico bajo consideración presenta características de performance consistentes con el uso para el cual ha sido diseñado (1).

En un sentido más amplio, la Organización Mundial de la Salud (OMS) ha definido a la Validación de Métodos como la acción o proceso de demostrar que un procedimiento, proceso, sistema, equipamiento o método en uso, funciona tal como lo 
esperado y cumple con los resultados previstos (2).

En consecuencia, y tal como se puede inferir a partir de las definiciones anteriores, el objetivo del proceso de Validación consiste en asegurar la producción de resultados confiables y de alta calidad para análisis diagnósticos (3), resultando necesaria su ejecución toda vez que se requiera verificar que los parámetros de performance de un método son los esperados.

A continuación se listan 4 de las principales situaciones que en la práctica diaria ameritan la validación de un método:

a) toda vez que se introduce una nueva tecnología o un nuevo principio analítico en el Laboratorio.

b) toda vez que se efectúa un cambio en el procedimiento seguido por alguno de los métodos en uso -aún cuando dichos métodos ya hayan sido validados previamente-, como por ejemplo al realizar un cambio en el instrumental de lectura. En estos casos, la extensión que ha de requerir este proceso de validación o revalidación dependerá de la naturaleza de los cambios que hayan sido realizados y de las circunstancias en las cuales el método está siendo utilizado (1).

c) cuando los resultados del control de calidad indican que el desempeño de un método determinado está cambiando con el tiempo.

d) para demostrar la equivalencia entre 2 métodos, procedimiento denominado estudio de comparación de métodos.

En el caso particular de la PN, un proceso de Validación de Métodos apropiadamente ejecutado requiere ser abordado tanto desde el punto de vista analítico y diagnóstico, como desde el punto de vista operativo, de diseño y de costos. Sin embargo, es importante destacar que en la práctica ésta no resulta ser una tarea de sencilla resolución puesto que para llevar a cabo la misma se debe hacer frente a diversas dificultades resultantes de la escasa disponibilidad y del limitado acceso a las herramientas necesarias para su ejecución, fundamentalmente en lo que se refiere a la validación de algunos parámetros analíticos y diagnósticos.

Más concretamente, entre las dificultades encontradas para la validación de los parámetros analíticos se puede mencionar la escasa disponibilidad de métodos y 
estándares de referencia, de protocolos de validación específicos para pruebas de PN, y de recomendaciones o normativas referentes a los criterios de aceptación a utilizar; mientras que en lo que respecta a la validación de los parámetros diagnósticos las mismas se relacionan principalmente con las limitaciones para acceder a paneles de sensibilidad apropiados.

A continuación serán descriptos los principales parámetros que deben ser tomados en consideración en la validación de un método de PN.

\section{Parámetros analíticos}

- Especificidad: se define a la especificidad como la capacidad de un método de medir solamente aquel analito para el cual ha sido diseñado $(1,4)$.

En un sentido más amplio puede definirse también como la capacidad de determinar inequívocamente un analito en presencia de componentes que puede esperarse que estén presentes, los cuales típicamente pueden incluir impurezas, degradantes, elementos propios de la matriz y otros.

En función de esta última definición, la especificidad puede ser referida como un parámetro que evalúa la confiabilidad de las medidas en presencia de interferencias (1).

- Exactitud: la exactitud es una medida de la concordancia entre el valor medido experimentalmente y el valor verdadero o de referencia del analito en cuestión $(1,4-8)$.

Habitualmente la exactitud es utilizada como un indicador que refleja la presencia de errores sistemáticos. Sin embargo, cuando se aplica a una serie de resultados de una prueba determinada, la misma refleja una combinación de errores sistemáticos y aleatorios $(1,6)$.

La exactitud no posee un valor numérico $(5,8)$, siendo la inexactitud-conocida también como bias- el parámetro que permite su cuantificación (6):

$$
\text { Inexactitud }=[\text { Valor experimental }- \text { Valor verdadero }]
$$

- Precisión: la precisión es una medida de la concordancia entre replicados independientes de una serie de medidas obtenidas bajo condiciones estipuladas $(1,5-8)$. 
En otros términos, es un indicador de la variabilidad o dispersión de una medida en torno a su valor central que denota la presencia de errores aleatorios (1).

La precisión es un parámetro independiente del valor verdadero o especificado del analito en cuestión (1) y no posee un valor numérico $(5,8)$, por lo cual su expresión cuantitativa se realiza en términos de imprecisión a través de dos parámetros que son el Desvío Estándar (DS) y el Coeficiente de Variación (CV) (6).

Por otra parte, al hablar de precisión es importante establecer una diferenciación entre los conceptos de repetibilidad y reproducibilidad de un método. De este modo, cuando se habla de repetibilidad se hace referencia a los resultados de una serie de medidas obtenidos en condiciones de repetibilidad, es decir con el mismo método, en el mismo laboratorio, con el mismo operador, utilizando el mismo equipamiento y en intervalos cortos de tiempo; mientras que cuando se habla de reproducibilidad se hace referencia a los resultados de una serie de medidas obtenidos en condiciones de reproducibilidad, es decir con el mismo método, en diferentes laboratorios, con diferentes operadores y utilizando equipamiento diferente (1).

- Linealidad: se define la linealidad como la capacidad de un método de obtener resultados proporcionales a la concentración del analito medido $(1,4)$.

Por carácter transitivo, el rango de linealidad es el rango de concentraciones en el cual un método determinado da resultados proporcionales a la concentración del analito (1).

- Sensibilidad analítica: se define la sensibilidad analítica como el cociente entre el cambio en la respuesta de un instrumento de medida y el correspondiente cambio en la cantidad del analito medido (1). En otros términos, es un parámetro que queda definido por la pendiente de la curva de calibración (7), de manera tal que cuanto mayor sea dicha pendiente, mayor será la sensibilidad analítica del método.

En función de esta definición, se dice que un método posee una sensibilidad analítica apropiada cuando es capaz de responder dando lugar a pequeños cambios en la concentración del analito medido a partir de pequeños cambios en la señal de lectura. 
En la Figura 71 se ejemplifica comparativamente la situación de 2 métodos con diferente sensibilidad analítica (Sensibilidad Método $1>$ Sensibilidad Método 2).

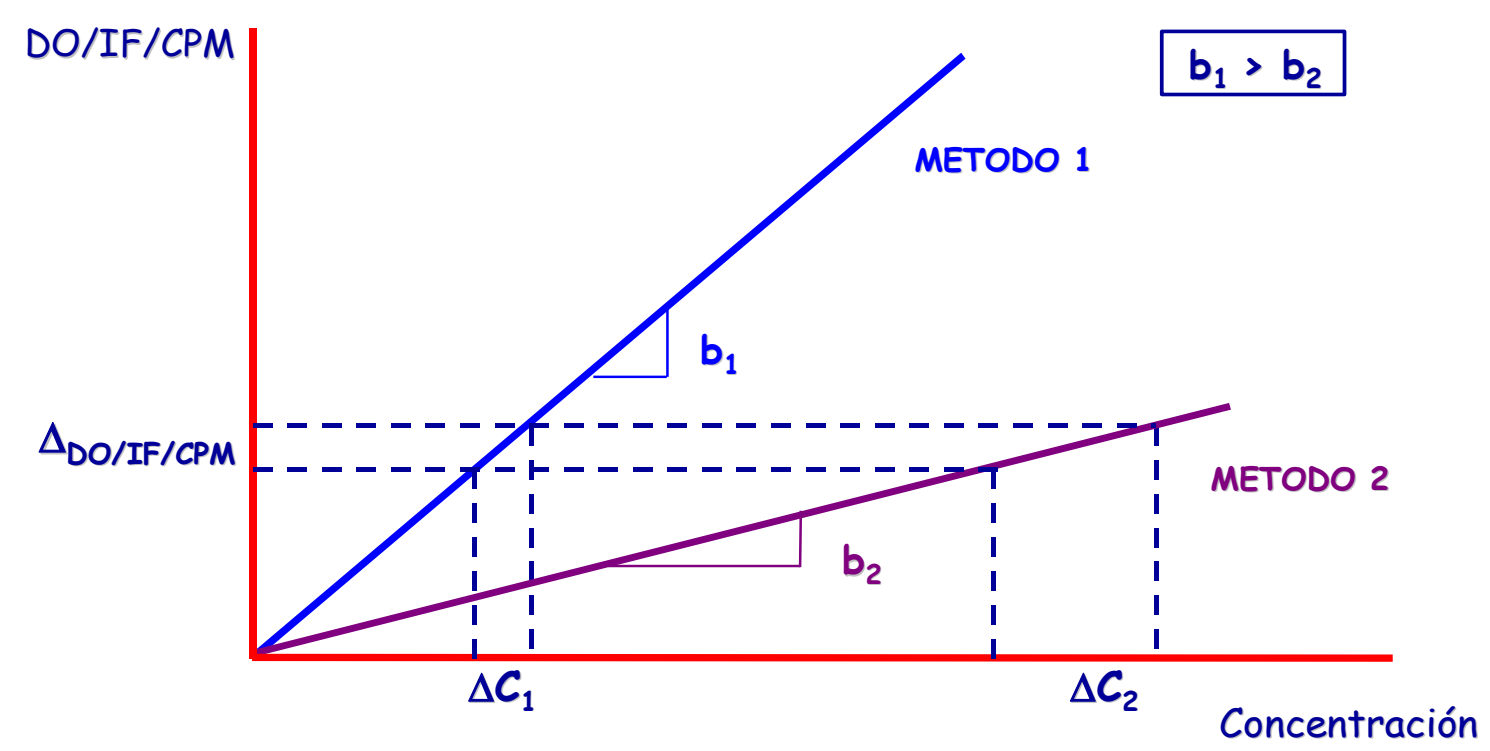

Figura 71. Sensibilidad analítica de un método.

DO: Densidad Óptica. IF: Intensidad de Fluorescencia. CPM: Cuentas por minuto

- Recuperación analítica: se entiende por recuperación analítica a la fracción de analito adicionada a una muestra antes de su análisis $(1,4)$. Es una medida de la eficiencia de un método para detectar todo el analito presente en una muestra (1), - más específicamente para detectar o "recuperar" todo el analito añadido exógenamente a una matriz biológica y extraído desde la misma (9).

El parámetro utilizado para su cuantificación es la recuperación analítica porcentual ( $R \%)$, la cual se determina según la siguiente fórmula:

$$
\mathrm{R} \%=\left[\left(C_{M E}-C_{M N E}\right) / C_{A}\right] \times 100
$$

donde $C_{M E}$ es la concentración medida en la muestra enriquecida, $C_{M N E}$ es la concentración medida en la muestra no enriquecida, y $C_{A}$ es la concentración de analito añadida exógenamente a la muestra enriquecida.

La recuperación analítica es una propiedad que depende de la matriz de la muestra, del procedimiento de análisis de la misma y de la concentración del analito medido (4), razón por la cual no necesariamente debe ser del $100 \%$, sino que la extensión de la misma debe ser consistente, precisa y reproducible (9).

Por otra parte, siempre se debe tener en cuenta que el analito introducido exó- 
genamente muy probablemente no se encuentre "vinculado o asido" al resto de los componentes de la matriz de la misma forma que el analito naturalmente presente, por lo cual la estrategia de enriquecimiento exógeno de la muestra puede aportar una impresión no real de la capacidad de recuperación analítica del método (1).

- Rango: es el intervalo de concentraciones dentro del cual un método determinado demuestra tener características analíticas apropiadas (4).

- Robustez: se define la robustez como la capacidad de un método de mantener inalteradas sus propiedades ante pequeños pero deliberados cambios en los parámetros del método, siendo por lo tanto un indicador de la confiabilidad que ha de presentar un método determinado cuando el mismo es utilizado a lo largo del trabajo diario $(1,4)$.

- Límite de Detección: el límite de detección es la mínima concentración de analito presente en una muestra que puede ser detectada aunque no necesariamente cuantificada, bajo las condiciones establecidas de una prueba $(1,4)$.

Según otros organismos también puede definirse como el mínimo contenido de analito que puede ser medido con razonable certeza estadística (1).

Experimentalmente se determina realizando una serie de 10 medidas independientes de los blancos de muestras, y empleando el siguiente criterio de cálculo:

$$
L D=X_{B L A N C O}+3 D S
$$

donde LD es el límite de detección, X la media de los replicados del blanco y DS el desvío estándar de dichas mediciones.

Por otra parte, $y$ considerando que tanto $X$ como DS son probablemente dependientes de la matriz del blanco, se debe tener en cuenta que el límite de detección también será dependiente de las características de dicha matriz (1).

Conocer el límite de detección de un método es una exigencia de real importancia, particularmente en aquellas medidas que se realizan a bajas concentraciones directamente vinculadas o asociadas a la toma de decisiones críticas.

- Límite de Cuantificación: se define al límite de cuantificación como la mínima concentración de un analito que puede ser determinada con aceptable precisión 
(repetibilidad) y exactitud bajo las condiciones establecidas de la prueba $(1,4) ; 0$, en una forma más simple, como el contenido de analito igual a o mayor que la concentración del punto más bajo de la curva de calibración (1).

Experimentalmente el límite de cuantificación se determina a través de un ensayo similar al del límite de detección, aunque en este caso empleando el siguiente criterio de cálculo:

$$
L Q=X_{B L A N C O}+n D S
$$

donde $L Q$ es el límite de cuantificación, X la media de los replicados del blanco, DS el desvío estándar de dichas mediciones y $n$ un número que, según el criterio adoptado, puede ser 5, 6 ó 10 .

El límite de cuantificación es sólo un valor indicativo que normalmente forma parte del estudio realizado para determinar el rango operativo de trabajo de un método, por lo cual consecuentemente, no debería ser utilizado en la toma de decisiones.

\section{Efecto de la exactitud y la precisión sobre los resultados de las} mediciones

Un análisis objetivo del efecto que ejercen los parámetros analíticos antes descriptos sobre los resultados de las mediciones $y$, consecuentemente sobre la calidad analítica y diagnóstica de las pruebas de pesquisa, permite determinar sin lugar a dudas que tanto la exactitud como la precisión son los parámetros que influyen más significativamente.

En función de esto, resulta muy importante tener presente que en la práctica es posible encontrar un espectro continuo de situaciones resultantes de la combinación de los diferentes desempeños que pueden presentar uno y otro parámetro, y que, por otra parte, sólo algunas de estas combinaciones resultan ser aceptables dado que el resto invalida automáticamente toda posibilidad de uso de dichos métodos en la rutina diaria, a causa precisamente, de sus propias características de performance.

A continuación, y por razones de orden práctico, solamente serán descriptas cuatro de estas situaciones, las cuales corresponden al comportamiento óptimo de un 
método y a tres situaciones extremas de desviación con respecto al mismo:

- Exactitud correcta - Precisión adecuada: es la situación óptima a la cual se debe aspirar con cualquier método de pesquisa. La misma se representa gráficamente en la Figura 72, en la cual $\boldsymbol{X}$ es el valor verdadero del analito evaluado y $\boldsymbol{s}$ su desvío estándar.

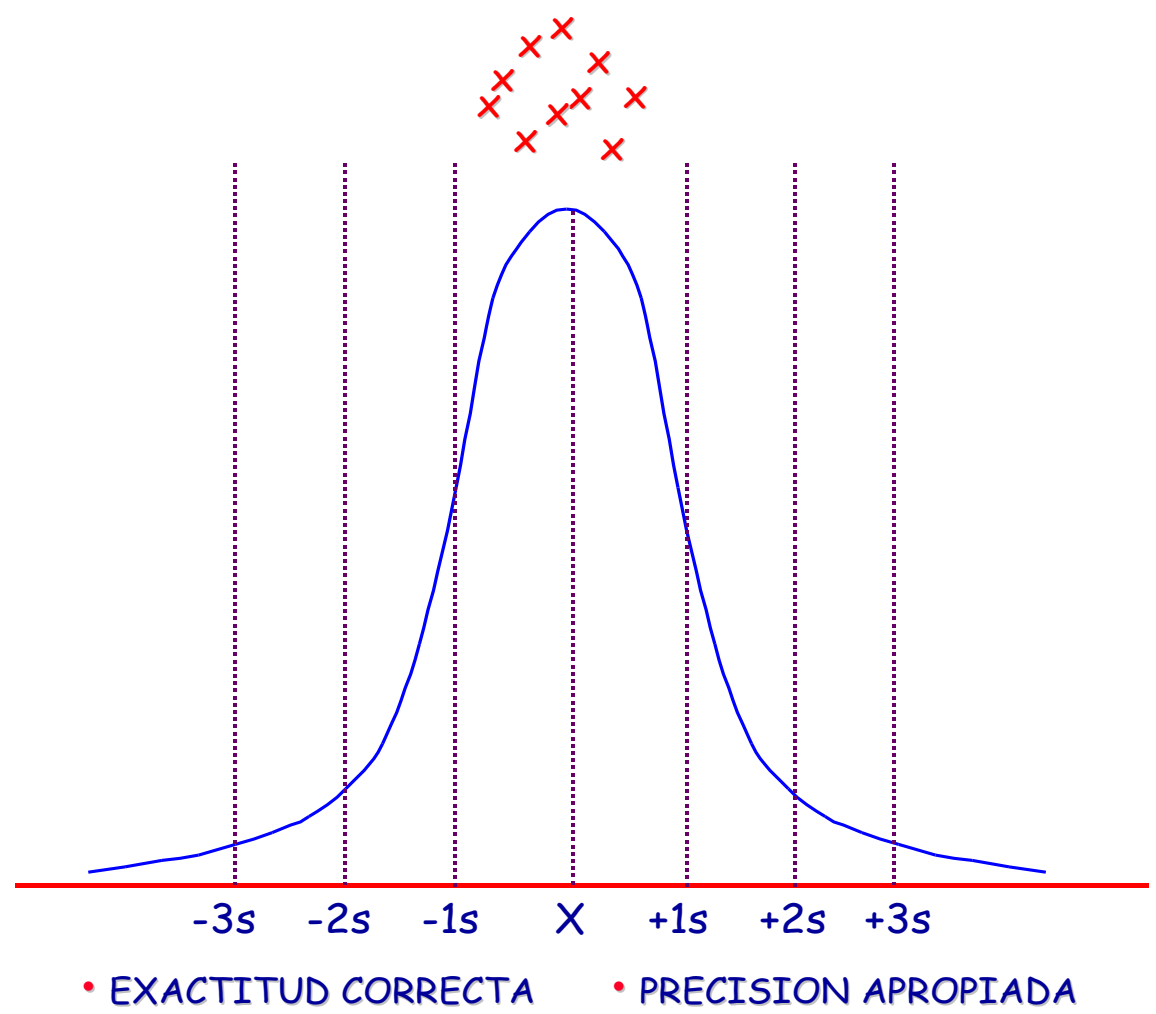

Figura 72. Comportamiento de un método exacto y preciso.

- Exactitud incorrecta - Precisión adecuada: en este caso particular, y al estar afectada solamente la exactitud del método, los efectos sobre la curva de distribución serán exclusivamente de carácter cuantitativo. Esto significa que la forma de la mencionada curva permanecerá inalterada, pero su posición con respecto a la curva de distribución correspondiente al desempeño óptimo estará desplazada hacia valores más bajos o más altos dependiendo de si la inexactitud que presenta el método es negativa o positiva respectivamente, dando dar lugar así, en uno y otro caso, a una subestimación del analito medido o a una sobreestimación del mismo, tal como se puede observar en la Figura 73. 


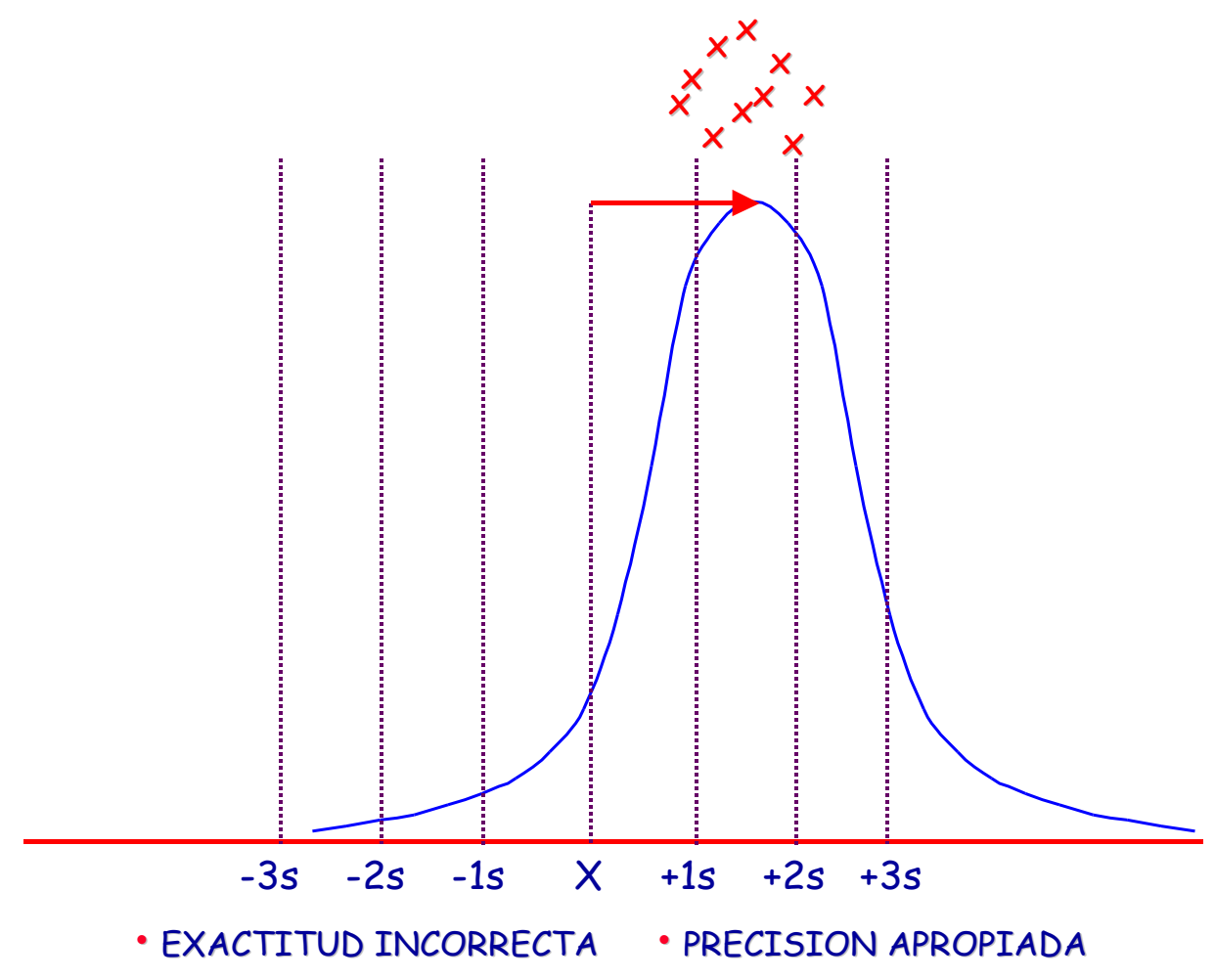

Figura 73. Comportamiento de un método inexacto y preciso.

En función de este concepto, y tal como ya fuera descripto en el Capítulo 2, dependiendo del signo que presente la inexactitud de un método, la misma puede afectar la interpretación de los resultados dando lugar tanto a la generación de resultados FP como de resultados FN, con una tasa de falsos resultados cuya magnitud será función del valor absoluto de dicha desviación (10) (ver Figura 37 Página 119).

No obstante esto, debe hacerse la salvedad de que en aquellas ocasiones en las cuales el VC utilizado por un Laboratorio para un analito particular y un método determinado fue correctamente definido pero trabajando en condiciones de inexactitud, el riesgo de falsos resultados ya no será tal puesto que también el VC estará desplazado hacia valores más altos o más bajos, y por lo tanto la diferenciación entre la población normal y la población afectada será llevada a cabo correctamente.

Esta última situación -entre otras- resulta determinante de la escasa comparabilidad analítica observada entre los resultados obtenidos por algunos Laboratorios de pesquisa, siendo además causal de serios problemas en el 
monitoreo del tratamiento de aquellas patologías cuyo seguimiento se realiza a través de dicho laboratorio, puesto que la inexactitud a la cual se hizo referencia anteriormente será determinante de que se efectúe una valoración incorrecta de los niveles reales del analito medido.

- Exactitud correcta - Precisión inapropiada: el comportamiento analítico resultante de esta combinación -en la cual solamente está afectada la precisión del método-, se traduce en un cambio en la forma de la campana de distribución con respecto a la que le corresponde a un método exacto y preciso, como consecuencia de la mayor dispersión de los valores y del concomitante incremento en el DS, hechos que en definitiva han de determinar que la curva de distribución se torne más baja y más ancha a medida que más impreciso resulta el método, tal como puede visualizarse en la Figura 74.

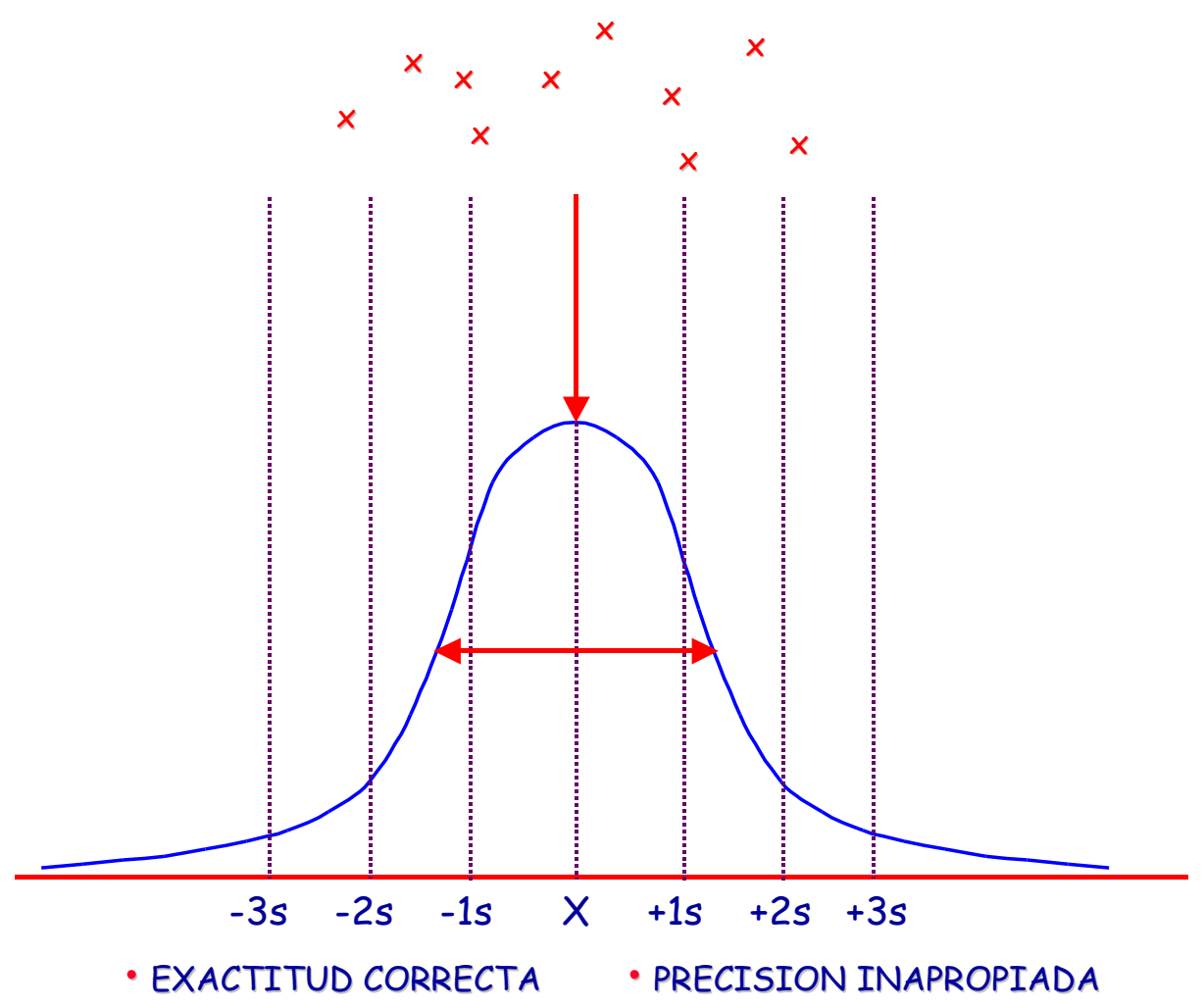

Figura 74: Comportamiento de un método exacto $e$ impreciso.

En la práctica diaria, este comportamiento es responsable de la escasa comparabilidad diagnóstica observada entre los resultados reportados por diferentes Laboratorios que utilizan el mismo percentilo para definir sus VC, los 
cuales, como es de esperar, presentarán idéntica especificidad pero con diferente sensibilidad (11) (Figura 36 - Página 117).

De forma equivalente, si un Laboratorio determinado define un VC en condiciones de precisión apropiadas, y en determinadas circunstancias y por el motivo que fuera, se produjera un incremento en la imprecisión del método, entonces resultarán modificadas tanto la forma de la distribución de individuos normales como la de individuos afectados, dando lugar así a una pérdida de sensibilidad y especificidad en el sistema de detección.

- Exactitud incorrecta - Precisión inapropiada: esta combinación extrema de inexactitud e imprecisión se trata de una situación verdaderamente crítica y riesgosa, la cual por sí misma invalida en forma absoluta toda posibilidad de implementación en la rutina diaria de cualquier método de Laboratorio que presente tales características analíticas. En la Figura 75 se representa gráficamente el efecto que la misma ejerce sobre la curva de distribución.

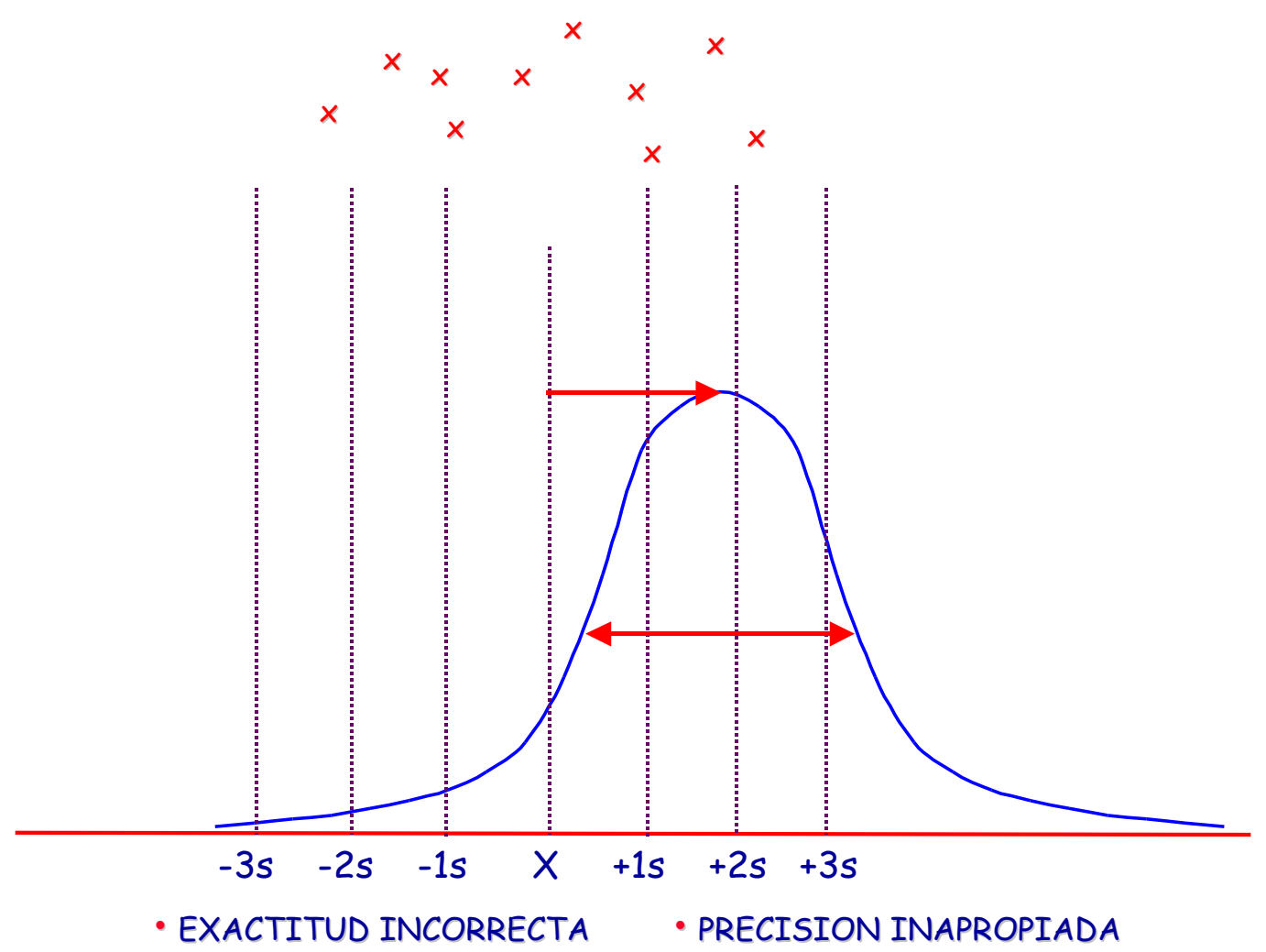

Figura 75. Comportamiento de un método inexacto e impreciso. 


\section{Parámetros diagnósticos}

Para un mejor entendimiento de los parámetros diagnósticos que deben ser validados en las pruebas de PN, es recomendable utilizar una tabla de doble entrada en la cual por un lado, se presenta la interpretación del resultado obtenido en la prueba de pesquisa y, por el otro, el estado de salud o enfermedad que caracteriza a cada individuo (12) (Tabla 27).

Tabla 27. Resultados de las pruebas de pesquisa vs. estado de enfermedad

\begin{tabular}{|c|c|c|c|}
\hline \multirow{2}{*}{ Resultado } & \multicolumn{2}{|c|}{ Estado de enfermedad } & \multirow{2}{*}{ Total } \\
\cline { 2 - 3 } & Ausente & Presente & \\
\hline Normal & NV & FN & $(N V+F N)$ \\
\hline Anormal & FP & PV & $(P V+F P)$ \\
\hline Total & $(N V+F P)$ & $(P V+F N)$ & $(P V+N V+F N+F P)$ \\
\hline
\end{tabular}

NV: Negativo Verdadero. PV: Positivo Verdadero. FN: Falso Negativo. FP: Falso Positivo.

- Sensibilidad (S): se define como la probabilidad de que un individuo enfermo presente un resultado anormal (5).

La sensibilidad es un parámetro que expresa la capacidad de un método de identificar correctamente a aquellos individuos que padecen la enfermedad $e$, indirectamente, da una idea del porcentaje de FN que presentará el mismo.

$$
S=P V /(P V+F N) \times 100
$$

- Especificidad (E): se define como la probabilidad de que un individuo sano presente un resultado normal (5).

La especificidad es un parámetro que expresa la capacidad de un método de identificar correctamente a aquellos individuos que no padecen la enfermedad $e$, indirectamente, da una idea del porcentaje de FP que presentará el mismo.

$$
E=N V /(N V+F P) \times 100
$$

- Exactitud o eficacia diagnóstica (ED): es la probabilidad de que un individuo sano o enfermo sea correctamente clasificado:

$$
E D=(N V+P V) /(P V+N V+F N+F P) \times 100
$$


- Valor predictivo positivo (VPP): es la probabilidad de que un individuo padezca realmente la enfermedad cuando el resultado de la prueba es anormal (5). Este parámetro es una medida del rendimiento de la prueba de detección (12).

$$
V P P=P V /(P V+F P) \times 100
$$

- Valor predictivo negativo (VPN): es la probabilidad de que un individuo sea sano cuando el resultado de la prueba es normal (5).

$$
V P N=N V /(N V+F N) \times 100
$$

- Prevalencia (P): es el número de casos detectados en la población total (5):

$$
P=(P V+F N) /(P V+N V+F N+F P) \times 100
$$

Por último, es importante destacar que tanto el VPP como el VPN de una prueba dependen de la sensibilidad y especificidad de la misma como así también de la prevalencia de la enfermedad (12), encontrándose entonces que el VPP aumenta a medida que se incrementan la especificidad y la prevalencia, y que el VPN aumenta a medida que se incrementa la sensibilidad y disminuye la prevalencia.

Este comportamiento característico puede ser más fácilmente comprendido al analizar las fórmulas ampliadas del VPP y del VPN que se presentan a continuación, en las cuales sustituyendo la prevalencia, sensibilidad y especificidad por sus fórmulas de cálculo correspondientes y operando matemáticamente, es posible llegar a las fórmulas simplificadas presentadas con anterioridad.

$$
\begin{aligned}
& V P P=P \times S /[P \times S+(1-P) \times(1-E)] . \\
& V P N=(1-P) \times E /[(1-P) \times E+P \times(1-S)] .
\end{aligned}
$$

En función de estos conceptos, prescindir de establecer el VPP y el VPN de una prueba mientras se está trabajando en la instancia inicial de validación de la misma no resulta un error, muy especialmente en aquellos casos en los cuales aún no se conoce la prevalencia de la patología pesquisada, ya sea tanto porque recién se está comenzando a realizar la pesquisa de la misma o porque aún no se ha podido establecer su prevalencia definitiva y real en la población objeto de estudio.

En contraposición, sí resulta estrictamente necesario que toda vez que se 
realice la validación de un método se determine su sensibilidad y especificidad diagnóstica, sin olvidar que ambos parámetros están estrechamente ligados a los VC definidos para separar la población normal de la población presuntamente afectada, y que por existir una relación inversa entre sensibilidad y especificidad deberá llegarse a una situación de equilibrio en la cual sea posible asegurar que los FN han sido minimizados a un valor lo más próximo posible a cero, y que los FP son mantenidos en un rango apropiado y manejable, capaz de no generar una excesiva sobrecarga de trabajo en las instancias de seguimiento del Programa.

\section{Parámetros operativos}

Considerando que las pruebas de PN son pruebas de aplicación masiva que requieren que cada Laboratorio analice diariamente un número significativo de muestras, entonces resulta incuestionable afirmar que los aspectos operativos de los métodos de medida van a jugar un rol crítico en lo que se refiere a la factibilidad de realización de las mencionadas pruebas en tiempo y forma. En consecuencia, los parámetros operativos más importantes a validar deben ser los siguientes:

- Sencillez y simpleza: como una condición estrictamente necesaria se requiere que los protocolos de ensayo de los métodos de medida a utilizar no involucren procedimientos complejos que dificulten la realización de las pruebas sino que, por el contrario, presenten características tales que hagan una contribución a la simplificación operativa de las mismas. De este modo, al realizar la validación de un método deberá prestarse especial atención al volumen, grado de manipulación y de preparación de muestras requeridos, al tamaño de las corridas a realizar, y a la habilidad técnica y condiciones de seguridad exigidas (5).

Entre los procedimientos que habitualmente forman parte de las pruebas de pesquisa y que resultan operativamente manejables en el Laboratorio sin mayores dificultades se encuentran el puncheo y distribución de muestras, el dispensado de reactivos, el lavado de microplacas, la transferencia de eluidos, la remoción de discos, la incubación y lectura de ensayos y, eventualmente, el centrifugado de microplacas. 
Complementariamente a lo antes mencionado, resulta importante que los tiempos de incubación de las pruebas -ya sean de procesos parciales o del ensayo en su conjunto-, se ajusten de manera tal que permitan su resolución a lo largo de un único turno de trabajo, o eventualmente post-incubación "overnight".

- Número de pasos en concordancia con el concepto anterior, los protocolos de ensayo de los métodos de pesquisa deben incluir la menor cantidad de pasos y procedimientos posibles. Además de esto, la preparación de los reactivos necesarios para la ejecución de dichos ensayos debe ser simple y sencilla, estableciéndose como situación ideal que los mismos sean provistos listos para usar.

- Formato de ensayo: otro elemento operativo de fundamental importancia es el hecho de que las determinaciones sean realizadas sobre un formato apropiado, fácilmente manejable y, de ser factible, generalizable a todas las pruebas.

En la actualidad este es un aspecto que se halla resuelto prácticamente en un $100 \%$ a través de la utilización de microplacas de 96 pocillos de diferentes características, como formato unificado de ensayo.

- Grado de automatización: como ya fuera mencionado con anterioridad en el Capítulo 2, la automatización no resulta ser una condición de trabajo estrictamente necesaria para los Laboratorios de pesquisa dado que la mayor parte de los procedimientos analíticos que se realizan en el mismo pueden ser ejecutados también en forma manual. Sin embargo, también es sabido que el proceso de automatización resulta fundamental puesto que a través del mismo es posible simplificar los procedimientos analíticos, lograr un óptimo grado de estándarización de las pruebas y reducir los requerimientos de horas hombre de trabajo.

De este modo, si la automatización resulta un proceso factible, la misma puede implementarse ya sea tanto a través del uso de equipamiento modular como de autoanalizadores con capacidad para ejecutar diferentes procesos, complementados con un sistema informático para el manejo de datos y con algún software específico que permita simplificar el cálculo, la evaluación, y la carga de resultados. 


\section{Parámetros de diseño}

Desde el punto de vista del diseño de los métodos de pesquisa, se debe poner énfasis en 3 aspectos principales:

- Características del método: es recomendable que los métodos a utilizar sean métodos diseñados específicamente para trabajar sobre muestras de sangre entera colectadas en papel de filtro (DBS), y concebidos para la realización de pruebas de detección de enfermedades congénitas en RN.

Por otra parte, y si bien no se trata de una exigencia excluyente, es importante priorizar el uso de métodos cuantitativos sobre el de métodos cualitativos o semicuantitativos.

Cumplir con esta última recomendación permite acceder a una mayor capacidad de diferenciación entre individuos afectados e individuos normales, detectar formas moderadas o leves de las patologías pesquisadas que de otra forma serían perdidas, y contar con un registro informatizado y/o impreso de las lecturas obtenidas a través de instrumentos específicos.

Este tipo de registros instrumentales no sólo resultan importantes desde el punto de vista analítico y diagnóstico sino también desde el punto de vista legal, puesto que contar con los mismos ofrece un respaldo de trazabilidad y verificabilidad del trabajo realizado, que de otra forma no podría ser cumplimentado en igual magnitud en el caso de que las lecturas se efectúen en forma visual o manual.

- Características de los calibradores: otro aspecto que resulta de fundamental importancia es que los calibradores a utilizar estén preparados en una matriz lo más similar posible a la de las muestras de sangre de los RN a pesquisar.

En relación a este punto, es importante destacar que en la práctica no es infrecuente encontrar situaciones en las cuales algunos calibradores están preparados con glóbulos rojos de origen animal en lugar de glóbulos rojos de origen humano, o que en lugar de suero o plasma han sido adicionados de una solución de albúmina o de solución fisiológica, y como es de suponer, estas diferencias de matriz pueden dar lugar a respuestas analíticas diferenciales entre los calibradores y las muestras de los RN, haciendo así una contribución 
adicional a la variabilidad analítica y a la generación de potenciales errores diagnósticos.

- Adaptaciones de métodos concebidos para trabajar sobre muestras líquidas: por último, es recomendable que los métodos de medida a utilizar en las pruebas de PN no sean métodos concebidos originalmente para trabajar sobre muestras de suero o plasma.

Eventualmente, y en caso de que no se cumpla con la recomendación anterior, resulta imprescindible que los mismos hayan sido sometidos previamente a las modificaciones, adaptaciones y evaluaciones necesarias a efectos de asegurar su correcto desempeño analítico y diagnóstico en todo el rango de concentraciones de interés clínico.

Como se puede inferir a partir del concepto anterior, la adaptación de este tipo de métodos para su empleo sobre DBS, no es un procedimiento contraindicado. No obstante esto, el mismo requiere esencialmente que dicha adaptación sea realizada con mucho criterio, para lo cual en primer lugar debe introducirse indefectiblemente el uso de calibradores preparados en la misma matriz que las muestras de sangre de los RN que han de analizarse.

Esta primer consideración resulta de vital importancia puesto que en caso de que se continúen utilizando los calibradores líquidos originales del método, preparados ya sea en solución acuosa o proteica, éstos no requerirán su elusión del papel de filtro, y consecuentemente el proceso de elusión de las muestras de RN carecerá de una contraparte en los calibradores que permita tener todo el proceso bajo control y asegurar que no se produjeron cambios en la respuesta a expensas de una variación en la eficiencia de la elusión.

Además de lo mencionado precedentemente, también debe tomarse en consideración que la respuesta analítica de un calibrador líquido estará sujeta a diferentes factores de reacción con respecto a los que ejercen su acción cuando se analizan DBS, es decir que en tal caso entrará en juego un efecto de matriz, el cual, dependiendo de las características del método, podrá tener mayor o menor influencia en los resultados finales. 


\section{Parámetros de costos}

Partiendo de las mismas premisas que fueron tomadas en consideración en el caso de los parámetros operativos, los métodos de pesquisa deben cumplir con la condición de que las pruebas deben ser baratas 0 , al menos, tener un costo accesible.

De esta forma será posible garantizar su implementación masiva en toda la población neonatal, haciendo así una contribución a la equidad de todos los individuos en cuanto a sus posibilidades de acceso al Sistema de Atención de Salud.

\section{- herRAMIENTAS PARA la VALIDACIÓN DE METOdOS}

Tal como se mencionara anteriormente, una de las principales dificultades encontradas en la práctica diaria para la ejecución del procedimiento de Validación de Métodos aplicado a las pruebas de PN es la escasa disponibilidad de herramientas apropiadas para llevar a cabo la validación de los parámetros analíticos y diagnósticos. A continuación se presentará una breve discusión del estado actual de situación:

\section{Herramientas para la validación de parámetros analíticos}

Dependiendo de cual sea el parámetro analítico que se esté pretendiendo evaluar y a efectos de cumplimentar satisfactoriamente el proceso de validación, en alguna de las etapas de dicho proceso, será necesario disponer de Métodos de Referencia, Materiales de Referencia, Materiales caracterizados en forma independiente, Materiales enriquecidos -incluyendo entre estos algún tipo de Materiales de Control-, muestras reales de RN, y también blancos de muestras.

Sumado a esto, y con independencia de los materiales que hayan de utilizarse para tal fin, en todos los casos se requerirá contar con Protocolos de Validación y con herramientas estadísticas apropiadas que permitan realizar una evaluación objetiva y certera de los mismos.

- Métodos de Referencia: la disponibilidad de Métodos de Referencia para la determinación de analitos en la pruebas de PN es absolutamente nula (13), razón por la cual no existe ninguna chance de utilizar este tipo de métodos para evaluar 
la exactitud de los métodos en estudio.

En vista de esta limitación, una alternativa válida y factible para sortear dicho impedimento es la realización de un Estudio de Comparación de Métodos con respecto a otros métodos que ya han sido previamente validados. A través de esta alternativa será posible estimar la inexactitud -o la "diferencia esperada"- entre ambos métodos a lo largo de un rango de concentraciones determinado (14).

- Materiales de Referencia: desde hace algo más de 10 años existen disponibles Materiales o Estándares Internacionales de Referencia de diversas procedencias preparados a partir de sangre entera impregnada en papel de filtro.

Dichos materiales fueron preparados con la finalidad de uniformar los valores asignados a los calibradores provistos por los kits comerciales o a aquellos calibradores preparados en el propio Laboratorio, y a través de esta acción, de hacer también una contribución a la armonización y comparabilidad de los resultados obtenidos en diferentes sitios.

En la Tabla 28 se presenta un detalle de los mismos incluyendo el año y el organismo responsable de su preparación.

Tabla 28. Materiales Internacionales de Referencia

\begin{tabular}{l|c}
\multicolumn{1}{c|}{ Material de Referencia } & Analitos \\
\hline - European Working Standard & Phe \\
- EWS-Phe-01 (1996) (15) & Phe \\
- EWS-Phe-02 (1999) & Phe \\
- EWS-Phe-03 (2003) & \\
\hline - Centers for Disease Control and Prevention (CDC)- EE. UU. & \\
- Amino Acids Reference Material (AARM) (1996) (16) & Phe - Val - Leu \\
- International Society for Neonatal Screening (ISNS) & Tyr - Met \\
- ISNS Certified Reference Materials for Thyrotropin & TSH \\
(ISNS-CRM-TSH) (1999) (17,18) & \\
- First ISNS Reference Preparation for Neonatal Screening & Phe - TSH \\
(1 ${ }^{\text {st }}$ ISNS-RPNS) (2004) (13,19) & $17 O H P$ \\
- Second ISNS Reference Preparation for Neonatal & Phe - TSH \\
Screening (2 ${ }^{\text {nd }}$ ISNS-RPNS) (2007) & $17 O H P-G a l$ \\
\hline
\end{tabular}


Cada uno de estos materiales ha sido distribuido oportunamente a fabricantes de reactivos, a organizadores de Programas de Evaluación Externa de Calidad y también a algunos Laboratorios específicos. Sin embargo, el problema subyacente relacionado con la asignación de valores a los calibradores no ha podido ser resuelto en forma completa puesto que, por un lado, estos materiales sólo cubren un muy limitado grupo y variedad de analitos, y por el otro, porque dependiendo de su procedencia, presentan diferentes características de preparación en cuanto a hematocrito, volumen de sangre por mancha y tipo de papel de filtro $(13,15-20)$.

Por este último motivo, y dado que en muchas ocasiones estas características difieren también de las correspondientes a los calibradores utilizados por algunos de los métodos de medida o de las correspondientes a las propias muestras de sangre de los RN, su valor como Material de Referencia está sujeto a un cierto grado de relatividad (20).

- Materiales caracterizados en forma independiente: en aquellas situaciones en las cuales se cuenta con algún tipo de material caracterizado por otro medio -como por ejemplo empleando un método del cual se conoce con certeza que presenta una inexactitud despreciable-, entonces dicho material puede ser utilizado como referencia para determinar por comparación, la inexactitud del método en estudio (1).

- Materiales enriquecidos: en el caso de algunos parámetros analíticos, como son por ejemplo la precisión y la recuperación analítica, no necesariamente se requiere la utilización de Materiales o Estándares de Referencia para su evaluación, sino que los mismos pueden ser validados trabajando sobre Materiales enriquecidos, cuyos niveles cubran todo el rango de concentraciones de relevancia clínica.

Estos materiales podrán ser preparados en el propio Laboratorio adicionando el analito de interés en forma exógena y previamente a la impregnación en el papel de filtro, sobre muestras de sangre de características similares a las muestras de RN, o eventualmente podrán tratarse de Materiales de Control provistos por algún Programa de Evaluación Externa de Calidad. 
En cualquiera de estos casos siempre debe tenerse en cuenta que las muestras de sangre utilizadas para efectuar el enriquecimiento pueden contener el analito de interés en cantidades no despreciables y por lo tanto la misma será cuantificada junto con la cantidad del analito adicionado exógenamente (1).

Además de los conceptos antes mencionados, es importante resaltar que el enriquecimiento no necesariamente debe quedar restringido al analito de interés en forma exclusiva, sino que también pueden adicionarse otras sustancias diferentes a fin de determinar por ejemplo, la magnitud de un efecto interferente (1).

- Muestras reales de RN: este tipo de materiales son de gran utilidad debido a la información que ellos aportan, por ejemplo en relación a la presencia de sustancias interferentes naturales, las cuales podrían ser encontradas en la rutina diaria (1).

Por otra parte, se trata de uno de los materiales de elección para utilizar en el Estudio de Comparación de Métodos, siendo necesario en este caso asegurar que se cubra todo el rango de concentraciones de interés clínico.

- Blancos de muestras: este tipo de material es requerido a efectos de poder determinar tanto el Límite de Detección como el Límite de Cuantificación, y su importancia radica en el hecho de que permite efectuar una estimación real del efecto de la matriz de la muestra y de potenciales sustancias interferentes que podrían ser encontrados al analizar muestras de RN (1). Esencialmente, los blancos de muestras están representados por matrices libres del analito de interés, razón por la cual en la práctica son sumamente difíciles de obtener.

- Protocolos de Validación: un aspecto de fundamental importancia a tomar en consideración con la finalidad de normatizar y estandarizar los procedimientos de Validación de Métodos, y de unificar los criterios definidos para la aceptación o rechazo de un método determinado, es la utilización de Protocolos de Validación previamente establecidos. En tal sentido el Instituto de Estándares Clínicos y de Laboratorio de los EE.UU. (CLSI, ex-NCCLS), es el organismo que realiza el mayor aporte al respecto (14,21-26), no obstante lo cual, resulta muy importante destacar que los protocolos publicados por este organismo no han sido 
desarrollados pensando en métodos de PN sino en métodos de Análisis Clínicos, y por otra parte que, al no tratarse de protocolos de acceso libre y gratuito, habitualmente no están disponibles en cualquier Laboratorio de PN puesto que para esto se requiere el desembolso de un costo muy significativo. Sumado a esto, y aunque existiera la posibilidad de un fácil acceso a los mencionados protocolos, algunos son tan elaborados y complejos en su diseño que su aplicación en un laboratorio de PN resultaría sumamente dificultosa.

Más allá de este último concepto, existen algunos protocolos muy simples como lo es el Protocolo EP10-A3 "Evaluación Preliminar de Procedimientos Cuantitativos de Medida del Laboratorio Clínico"(6) -considerado básicamente como un protocolo de "demostración" más que un protocolo de validación (27)-, el cual permite determinar en forma preliminar varios parámetros analíticos en forma simultánea (linealidad, exactitud, precisión, tendencias y contaminación cruzada), requiriéndose para ello disponer de un número mínimo de Materiales de Referencia o de Materiales de Control con valores previamente asignados, realizar un reducido número de corridas y determinaciones, y finalmente llevar a cabo un análisis estadístico de datos muy simple y accesible. A pesar de esto, y como lo indica el título del mismo, nunca debe olvidarse que se trata de un protocolo preliminar y que, por lo tanto, sólo permitirá detectar parámetros con características no aceptables en aquellos métodos que presenten una performance groseramente inaceptable.

\section{Herramientas para la validación de parámetros diagnósticos}

La validación de parámetros diagnósticos es un proceso que, a pesar de requerir la realización de un mayor número de determinaciones que el proceso de validación analítica, resulta ser de menor complejidad que éste último, especialmente en lo que respecta a la elaboración requerida para la evaluación de los resultados y para la obtención de las conclusiones correspondientes.

Independientemente de esto, en la práctica también está sujeto a algunas limitaciones, más precisamente en lo que se refiere a la disponibilidad de Paneles de Sensibilidad apropiados, dificultad que resulta más crítica aún por el hecho de que 
actualmente no existen paneles -ya sean tanto de origen comercial como provistos por Programas de Evaluación Externa de Calidad-, que puedan ser adquiridos para realizar este tipo de evaluaciones.

- Paneles de Sensibilidad: los Paneles de Sensibilidad pueden ser preparados en el propio Laboratorio a partir de las muestras de pesquisa de aquellos RN que poseen un diagnóstico previamente confirmado y certificado.

Para asegurar la confiabilidad de estos paneles también resulta necesario certificar que las condiciones de conservación de dichas muestras hayan sido las apropiadas (por ejemplo a $-20^{\circ} \mathrm{C}$ y adicionadas de desecantes).

La principal dificultad que se presenta en su preparación es la limitación en cuanto al acceso a un número significativo de muestras positivas, dificultad que surge como una consecuencia natural de la baja prevalencia que presentan las enfermedades investigadas.

- Paneles de Especificidad: los Paneles de Especificidad pueden ser fácilmente preparados en el Laboratorio a partir de las muestras de sangre que ingresan diariamente para su análisis.

En forma equivalente a lo mencionado precedentemente para los Paneles de Sensibilidad, en este caso resulta estrictamente necesario asegurar que todas las muestras que han de ser incluidas en la evaluación correspondan a RN certificadamente normales, mientras que en contraposición con los anteriores, los Paneles de Especificidad no presentan limitaciones en cuanto al número de muestras que resulta posible obtener en un período corto de tiempo a efectos de conformar los mismos.

Por último, un dato de gran utilidad práctica que merece ser comentado es que, en muchas ocasiones, la validación de los parámetros diagnósticos de un método no se realiza en forma absoluta, sino comparativamente contra un método de referencia 0 contra otro método que está utilizándose rutinariamente.

Para cumplimentar esta tarea se requiere que tanto los Paneles de Sensibilidad previamente preparados, como las muestras que ingresan a diario al Laboratorio para 
la realización de las pruebas de pesquisa y que van a ser incluidas como parte de los Paneles de Especificidad, sean analizadas simultáneamente con ambos métodos. Adicionalmente también es importante destacar que en este caso, las conclusiones finales no deben expresarse en términos absolutos de sensibilidad y especificidad, sino en forma relativa como porcentaje de correspondencia entre el método en estudio y el método utilizado como referencia.

\section{- PROBLEMAS detectados a tRaVÉs del PROCEDIMIENTO de VALIDACIÓN DE MÉTODOS}

Como corolario a este Capítulo, en la Tabla 29 se listan las principales dificultades que con mayor frecuencia pueden ser detectadas a lo largo del proceso de Validación de Métodos de PN.

Tabla 29. Problemas detectados en la validación de métodos de PN

- Inapropiada especificidad analítica:

- Reacciones cruzadas con anticuerpos empleados en diferentes inmunoensayos

- Reacción inespecífica con sustancias estructuralmente relacionadas o con sustancias interferentes

- Inadecuada sensibilidad analítica

- Falta de exactitud asociada a una incorrecta asignación de valores a los calibradores, presentándose las siguientes situaciones posibles:

- Sobre o subestimación constante a lo largo de todo el rango de trabajo

- Sobre o subestimación directa o inversamente proporcional a la concentración del analito

- Comportamiento dual por encima y por debajo de una concentración crítica determinada

- Recuperación analítica inadecuada asociada a la inexactitud del método

- Incrementada imprecisión

- Pérdida de linealidad a concentraciones elevadas

- Falta de robustez

- Inapropiada tasa de falsos negativos: baja sensibilidad diagnóstica

- Elevada tasa de falsos positivos: inapropiada especificidad diagnóstica

- Diferencias entre la matriz de los calibradores y la matriz de las muestras

- Calibradores preparados empleando un volumen de sangre por mancha muy inferior al recomendado para las muestras de RN 


\section{BIBLIOGRAFIA}

1. Eurachem Guide. "The Fitness for Purpose of Analytical Methods. A Laboratory Guide to Method Validation and Related Topics". First English Edition 1.0, 1998. www.eurachem.org/guides/valid.pdf

2. WHO. Expert Committee on Biological Standardization. "Glossary of Terms for Biological Substances Used for Texts of the Requirements". WHO unpublished document BS/95.1793. Geneva: World Health Organization; 1995.

3. ERNDIM BIOMED II Newsletter, N 1, October 1998.

4. ERNDIM BIOMED II Newsletter, № 2, June 1999.

5. Slazyk WE and Hannon WH. "Quality Assurance in the Newborn Screening Laboratory" en "Laboratory Methods for Neonatal Screening", Therrell BL Ed, American Public Health Association, Washington, 23-46, 1993.

6. Clinical and Laboratory Standards Institute (CLSI). "Preliminary Evaluation of Quantitative Clinical Laboratory Measurement Procedures"; Approved GuidelineThird Edition. CLSI document EP10-A3, Vol 26 N 34, 2006.

7. ISNS Standing Committee on Quality Assurance. "Lexicon of Terms to be used in Newborn Screening". 2005. www.isns-neoscreening.org/pdf/Lexicon8.pdf.

8. WQC Glossary. 2000. www.westgard.com.glossary.htm.

9. US Department of Health and Human Services - Food and Drug Administration. "Guidance for Industry. Bioanalytical Method Validation". May 2001. www.fda.gov/cder/guidance/4252fnl.htm.

10. Fraser CG. "Quality Specifications" en "Biological Variation: from Principles to Practice". Fraser CG Ed, First Edition, AACC Press, Washington, Chapter 2, 29$66,2001$.

11. Cuckle HS and Wald N. "Tests Using Single Markers" en "Antenatal and Neonatal Screening". Wald N and Leck I Eds, Second Edition, Oxford University Press, Oxford-New York, 1-22, 2000.

12. Richter Arís C, Cáceres AL. "Fase Posanalítica" en "Gestión de la Calidad en el Laboratorio Clínico", Fernández Espina C y Mazziotta D Eds. Editorial Médica Panamericana, Buenos Aires-Bogotá-Caracas, 513-36, 2005. 
13. Elvers $L H$, Loeber JG, Dhondt JL, Fukushi $M$, Hannon $W H$, Torresani $T$ and Webster D. "First ISNS Reference Preparation for Neonatal Screening for

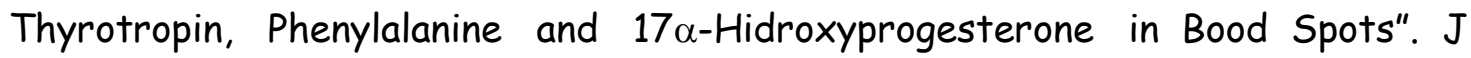
Inherit Metab Dis 30, 609, 2007.

14. NCCLS. "Method Comparison and Bias Estimation Using Patient Samples"; Approved Guideline- Second Edition. NCCLS document EP9-A2, Vol $22 \mathrm{~N}^{\circ} 19$, 2002.

15. Dhondt JL, Loeber JG, Elvers LH and Paux E. "Preparation of the First European Working Standard for Phenylalanine Determination in Dried Blood Spots". J Med Screen 5, 63-6, 1998.

16. Chace DH, Adam BW, Smith SJ, Alexander JR, Hillman SL and Hannon WR. "Validation of Accuracy-based Amino Acid Reference Materials in Dried-Blood Spots by Tandem Mass Spectrometry for Newborn Screening Assays". Clin. Chem. 45, 1269-1277 (1999).

17. Elvers LH, Loeber JG. "ISNS - International Filter Paper Reference Preparations for TSH" (Poster). Abstracts Book of the $5^{\text {th }}$ Meeting of the International Society for Neonatal Screening, Genova -Italy, 94, 2002.

18. Loeber JG, Elvers LH. "ISNS - International Filter Paper Reference Preparation for TSH". Proceedings of the 2002 Newborn Screening and Genetic Testing Symposium, Pheonix - Arizona, EE.UU., 218-220, 2002.

19. Elvers LH, Loeber JG, Dhondt JL, Fukushi M, Hannon WH, Torresani T, Webster D. "First ISNS Reference Preparation for Neonatal Screening for Thyrotropin, Phenylalanine and 17a-hydroxyprogesterone in Blood Spots". RIVM report 230011004/2005. http://www.rivm.nl/bibliotheek/rapporten/230011004.pdf.

20. Adam BW, Alexander JR, Smith SJ, Chace DH, Loeber JG, Elvers LH and Hannon WH. "Recoveries of Phenylalanine from Two Sets of Dried-Blood-Spot Reference Materials: Prediction from Hematocrit, Spot Volume, and Paper Matrix". Clin. Chem. 46, 126-8, 2000.

21. NCCLS. "Evaluation of Precision Performance of Quantitative Measurement Methods"; Approved Guideline-Second Edition. NCCLS document EP5-A2, Vol 24 
$N^{\circ} 25,2004$.

22. NCCLS. "Evaluation of the Linearity of Quantitative Measurement Procedures: $A$ Statistical Approach"; Approved Guideline. NCCLS document EP6-A, Vol 23 N 16, 2003.

23. Clinical and Laboratory Standards Institute (CLSI). "Interference Testing in Clinical Chemistry"; Approved Guideline-Second Edition. CLSI document EP7-A2, Vol 25 NN$^{0} 27,2005$.

24. NCCLS. "Evaluation of Matrix Effects"; Approved Guideline. NCCLS document EP14-A, Vol 18 NN$^{\circ} 2,2001$.

25. NCCLS. "User Demonstration of Performance for Precision and Accuracy"; Approved Guideline. NCCLS document EP15-A, Vol 18 № 22, 2001.

26. NCCLS. "Protocols for Determination of Limits of Detection and Limits of Quantitation"; Approved Guideline. NCCLS document EP17-A, Vol 24 N 34, 2004.

27. NCCLS. "A Framework for NCCLS Evaluation Protocols"; A Report. NCCLS document EP19-R, Vol $20 \mathrm{~N}^{\circ} 16,2002$. 


\section{CAPÍTULO 5}

CONTROL DE CALIDAD

INTERNO Y EVALUACION

EXTERNA DE CALIDAD

APLICADOS A

PESQUISA NEONATAL 



\section{- INTRODUCCIÓN}

Las tecnologías utilizadas en el Laboratorio de PN están representadas por un conjunto de procesos analíticos basados en diferentes principios metodológicos e instrumentales de características diversas, los cuales -independientemente de las limitaciones a las cuales se deba hacer frente en lo que respecta a recursos disponibles- requieren que la calidad de las pruebas sea monitoreada, sostenida y mejorada en forma permanente a medida que dichas tecnologías se expanden y evolucionan (1).

Por otra parte, y en vista de los objetivos específicos de la PN, resulta estrictamente necesario que todos los Laboratorios de pesquisa posean la capacidad tanto de proveer prestaciones de alta calidad analítica, como de analizar una gran cantidad de muestras en forma simultánea, de reportar rápidamente los resultados y de cumplimentar estas tareas a un costo adecuado y lo más accesible posible (2). Y si bien estos requerimientos se corresponden con las condiciones exigibles a los Laboratorios de análisis clínicos generales y mayormente no difieren de estas últimas, resulta muy importante dejar en claro que los Laboratorios de PN deben ser considerados como una categoría especial de Laboratorios puesto que en ellos entran en juego una serie de variables que les son propias y específicas (Tabla 30), y que pueden afectar los resultados en forma diferente, ya sea tanto desde el punto de vista cuali como cuantitativo (2).

Sumado a esto, si se evalúan en forma comparativa las implicancias clínicas que presentan los errores analíticos en uno y otro tipo de laboratorio, naturalmente se plantea la necesidad de fijar un mayor nivel de exigencia para los Laboratorios de PN -muy especialmente cuando se hace referencia al hecho de que los mismos deben poseer la capacidad de ofrecer prestaciones de alta calidad analítica- puesto que como es sabido, un resultado falso negativo en alguna de estas pruebas tiene consecuencias desvastadoras para los RN afectados, los cuales irremediablemente quedarán condenados a padecer un daño neurológico discapacitante severo e irreversible de por vida, o eventualmente serán conducidos a la muerte por una crisis metabólica aguda. 
Tabla 30. Características específicas de los Laboratorios de Pesquisa Neonatal

- Matriz y soporte de las muestras de sangre

- Técnica, tiempos y condiciones de recolección de muestras

- Condiciones de secado, transporte y conservación de muestras

- Características intrínsecas de las muestras:

- Tipo de papel de filtro

- Volumen de sangre por mancha

- Hematocrito

- Zona de corte o "puncheo": efecto cromatográfico

- Elusión de muestras

- Mayor imprecisión relativa en los métodos de medida

- Limitada disponibilidad de materiales de control interno independientes de la industria de reactivos diagnósticos

- Características de los materiales de control empleados en la Evaluación Externa de Calidad

- Utilidad de las medidas de tendencia central (media, mediana y moda) resultantes del análisis de muestras de RN como indicadores de desempeño a largo plazo de los métodos en uso

\section{Variables propias y específicas de los Laboratorios de Pesquisa Neonatal}

- Matriz y soporte de las muestras de sangre: tal como ya ha sido discutido en forma detallada en capítulos anteriores, los especímenes que se utilizan para la realización de las pruebas de PN no son muestras líquidas sino que se trata de muestras de sangre entera impregnadas en papel de filtro (DBS). Este hecho determina que el análisis de las mismas no se realice a partir de una medida volumétrica sino a partir de un área definida de papel de filtro impregnada con la sangre y que, consecuentemente, resulte necesario establecer una correlación o correspondencia entre dicha área de papel y la mencionada medida volumétrica.

De este modo, toda vez que se procese una muestra impregnada insuficientemente se estará introduciendo un factor de variabilidad adicional equivalente a cometer un error de pipeteo por defecto cuando se trabaja en un laboratorio de análisis clínicos empleando muestras líquidas. 
En cuanto a las dimensiones de los discos de papel de filtro a utilizar en las pruebas, resulta oportuno mencionar que a lo largo de la historia de la PN se ha experimentado una evolución permanente en este sentido, observándose que con el transcurso del tiempo los diámetros de los discos han sido progresivamente cada vez más pequeños. De esta forma se pasó de utilizar discos de $\approx 6.4 \mathrm{~mm}$ de diámetro $\left(1 / 4^{\prime \prime}\right)$ en sus inicios $(3,4)$ o inclusive de mayores dimensiones en algunos casos (5), a utilizar discos de $\approx 4,7 \mathrm{~mm}$ de diámetro (3/16") en una etapa intermedia (6), hasta llegar a la medida más utilizada en la actualidad de $\approx 3.2 \mathrm{~mm}$ de diámetro $\left(1 / 8^{\prime \prime}\right)$, área que en promedio, y dependiendo del tipo de papel de filtro utilizado, se corresponde con aproximadamente unos $3.2 \mu$ de sangre entera (7).

Independientemente de esto, más recientemente también se han comenzado a utilizar discos aún más pequeños -de $\approx 1,5 \mathrm{~mm}$ de diámetro (1/16")- para algunas pruebas específicas, como por ejemplo para el dosaje de ciertas enzimas lisosomales (8).

En principio, esta evolución en el tamaño del área de papel de filtro utilizada parecería no tener mayor trascendencia. Sin embargo en la práctica si la ha tenido, puesto que por un lado permitió una expansión permanente en el número de enfermedades pesquisadas sin haber introducido una necesidad concomitante de aumentar el volumen de sangre requerido de cada RN, mientras que por el otro ha permitido incrementar el rendimiento y la eficiencia del Laboratorio de pesquisa a través de la automatización del proceso de puncheo de muestras.

A efectos de ilustrar esta situación, en la Figura 76 se presenta un esquema en escala real de las diferentes dimensiones de los discos utilizados con respecto a una mancha estándar de $13 \mathrm{~mm}$ de diámetro.
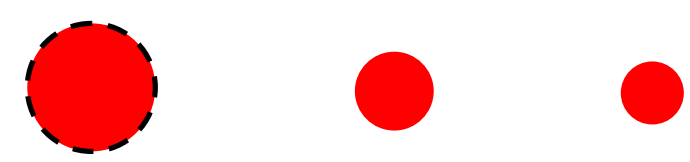

$13 \mathrm{~mm}$

$7.9 \mathrm{~mm}$

$6.4 \mathrm{~mm}$

$4.7 \mathrm{~mm}$

$3.2 \mathrm{~mm}$

$1.5 \mathrm{~mm}$

Figura 76. Esquema comparativo de diferentes diámetros de discos. 
- Técnica, tiempos y condiciones de recolección de muestras: tanto el procedimiento empleado para llevar a cabo la recolección de muestras como los tiempos y condiciones recomendados para la misma introducen una variabilidad adicional en las pruebas, la cual en algunos casos resulta ser de índole analítica mientras que en otros, particularmente en aquellos casos en los que las muestras son colectadas antes de las 24 horas de vida, resulta ser de carácter biológico pudiendo dar lugar tanto a resultados falsos negativos como a resultados falsos positivos.

Dicha variabilidad queda definida, entre otros, por factores como la adherencia a los tiempos y condiciones de recolección previamente definidos, la preparación del RN, el cuidado y la habilidad del extraccionista para realizar la punción, y la calidad de impregnación de la sangre en el papel de filtro (2).

- Condiciones de secado, transporte y conservación de muestras: una estricta adherencia a las normas definidas para la ejecución y cumplimentación de estos procedimientos constituye otro elemento clave a tomar en consideración a efectos de minimizar $y / 0$ eliminar determinadas variables vinculadas a los mismos, entre las cuales, las condiciones de temperatura y humedad juegan un rol fundamental.

De este modo, ajustándose a las recomendaciones establecidas (9) será posible realizar una contribución adicional a fin de garantizar una óptima calidad de las muestras, evitar una fijación indeseada de las proteínas al papel de filtro, y asegurar que los analitos se mantengan estables hasta el momento de su análisis.

\section{- Características intrínsecas de las muestras:}

o Tipo de papel de filtro: en relación al tipo de papel de filtro utilizado para la recolección de muestras se debe mencionar que el volumen de sangre absorbido por unidad de área de papel es función del tipo y lote del mismo $(7,10-11)$ y que por otra parte su capacidad de absorción está fuertemente influenciada por su uniformidad. Esta propiedad determina que, indefectiblemente, todo lote de 
papel de filtro que ha de ser puesto en circulación deba ser previamente validado en relación a sus características de absorción.

En tal sentido, el CLSI (9) ha desarrollado un protocolo que permite determinar la capacidad de absorción del papel de filtro expresada como volumen de suero absorbido por unidad de área de papel, habiéndose establecido que el rango aceptable de volumen de suero por cada disco de $\approx 3.2 \mathrm{~mm}$ de diámetro $\left(1 / 8^{\prime \prime}\right)$, cuando la mancha de sangre es obtenida a partir de una alícuota de $100 \mu$ de sangre entera, de hematocrito $55 \%$, y con glóbulos rojos intactos es de $1.54 \pm 0.17 \mu \mathrm{l}$; mientras que dicho rango es de $1.30 \pm 0.19 \mu \mathrm{l}$ cuando la mancha de sangre es obtenida en las mismas condiciones anteriores pero con glóbulos rojos lisados.

En la práctica, y en vista de que este procedimiento de validación excede el alcance de los Laboratorios de PN, y de que el mismo debería ser efectuado en forma objetiva por un organismo independiente de la industria, el Newborn Screening Quality Assurance Program (NSQAP) del Centers for Disease Control and Prevention (CDC) de Atlanta - EE.UU realiza periódicamente dicha validación a aquellos papeles de filtro comercializados mayoritariamente a nivel mundial, y emite anualmente un informe que refleja la capacidad de absorción de cada nuevo lote que es puesto en circulación $(1,7,12)$.

En las Figuras 77 y 78 se presentan los resultados reportados por el NSQAP-CDC correspondientes a las evaluaciones efectuadas empleando glóbulos rojos intactos y glóbulos rojos lisados respectivamente, sobre diferentes lotes de papel de filtro Schleicher \& Schuell (S \& S) \# 903 y Whatman \# 903 que fueron puestos en circulación oportunamente (7).

o Volumen y hematocrito de la muestra: El primer concepto que debe mencionarse en relación a estas dos variables es que los resultados obtenidos en las pruebas de pesquisa son influenciados en forma directa tanto por el "tamaño" de la gota de sangre con que se impregna el papel de filtro como por el hematocrito de la misma, encontrándose que a mayor volumen de sangre por mancha y a mayor hematocrito, mayor será la concentración del analito medido. 


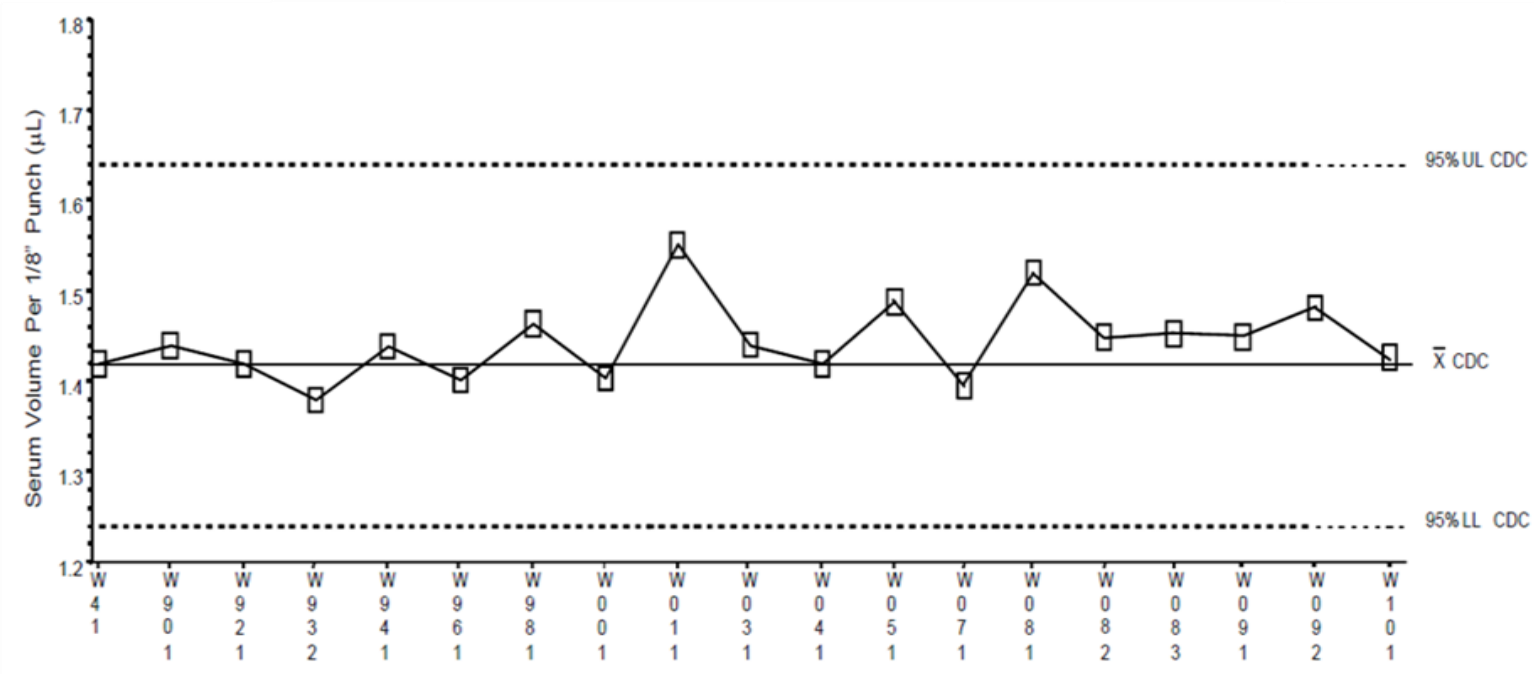

Lot Numbers in Chronological Order

Figura 77. Capacidad de absorción de diferentes lotes de papel de filtro $S$ \& S y Whatman \# 903 empleando glóbulos rojos intactos.

NOTA: Todos los lotes de papel de filtro previos al W041 corresponden a lotes comercializados bajo la denominación Schleicher \& Schuell \# 903, mientras que del W041 en adelante los mismos fueron comercializados bajo la denominación Whatman \# 903.

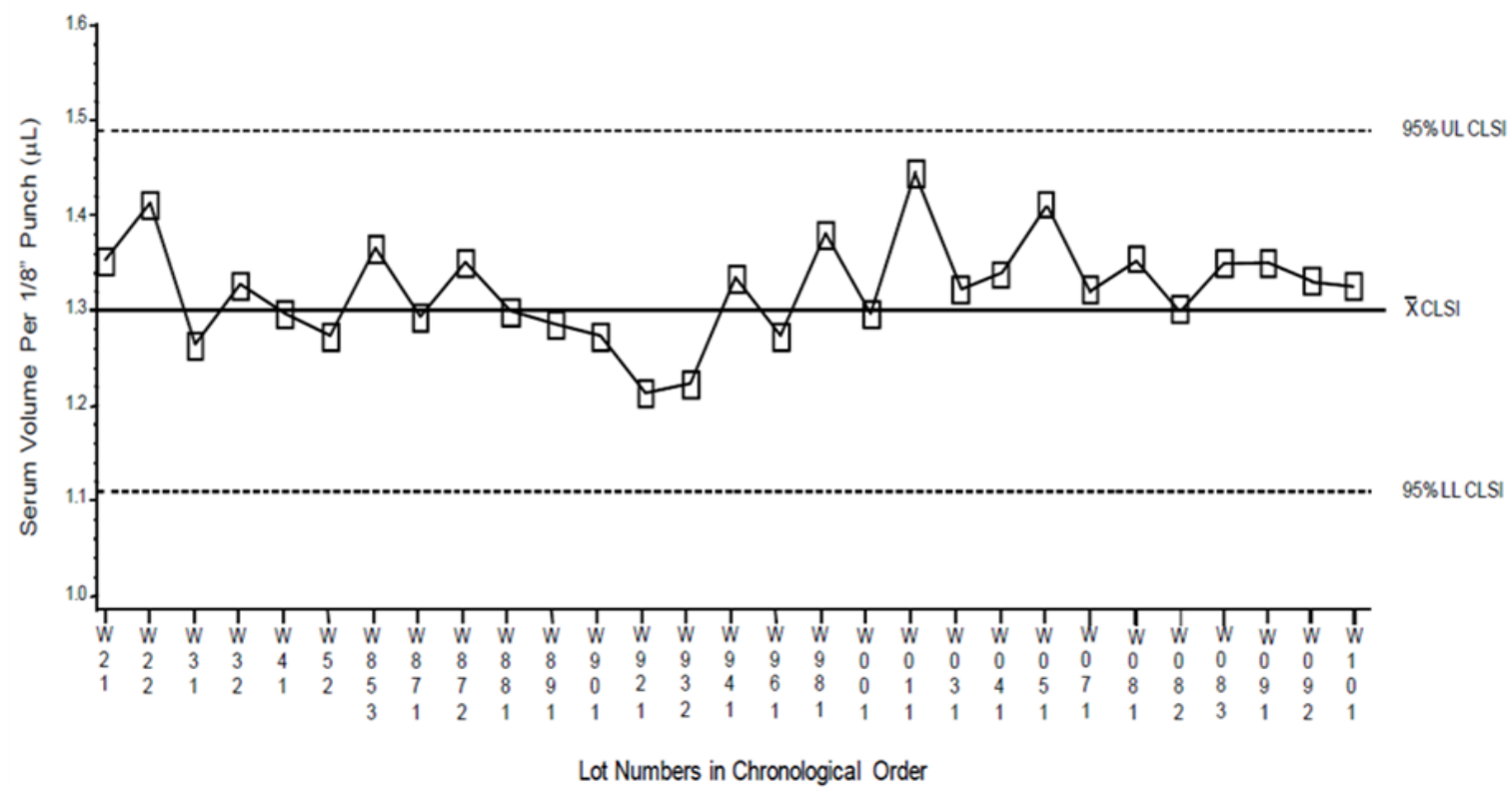

Figura 78. Capacidad de absorción de diferentes lotes de papel de filtro $S$ \& $S$ y Whatman \# 903 empleando glóbulos rojos lisados.

Esta afirmación resulta muy claramente ilustrada por las experiencias de Adam B. y colaboradores (13) quienes realizaron un estudio comparativo entre 2 materiales de referencia para Phe -uno preparado por el European Working Standard (EWS-01) y otro preparado por el CDC (AARM)-, los cuales diferían en el volumen de sangre utilizado para impregnar las manchas en el 
papel de filtro $(35 \mu \mathrm{l}$ vs $100 \mu \mathrm{l})$ y también en el hematocrito de la misma (50.1 $\%$ vs $53.0 \%$ ).

En dicho estudio pusieron en evidencia por un lado, que la recuperación analítica de Phe en muestras de sangre de hematocrito $55 \%$, enriquecidas con $8.0 \mathrm{mg} / \mathrm{dl}$ de Phe y dispensadas en papel de filtro S \& S \# 903 en volúmenes de 35 y $100 \mu \mathrm{l}$, fue un $10.9 \%$ superior en el caso de las manchas de mayor volumen $y$, por el otro, que una diferencia del orden del $3 \%$ en el hematocrito como la que se presentaba entre ambos materiales de referencia se traducía en una diferencia en la recuperación analítica del $3.1 \%$.

Adicionalmente, el efecto del hematocrito también ha sido puesto en evidencia en otras experiencias, en este caso sobre los niveles de aminoácidos y acilcarnitinas determinados por EMT, aunque en proporciones variables dependiendo del analito evaluado (14).

Por otra parte, se debe mencionar que el efecto del volumen y el hematocrito también puede ser puesto en evidencia a simple vista determinando el diámetro alcanzado por la mancha de sangre en el papel de filtro, aunque en este caso se encuentra que dicho diámetro será mayor cuanto mayor sea el volumen de sangre, pero será menor cuanto mayor sea el hematocrito. Esta última característica se debe al hecho de que a medida que la sangre se enriquece en el componente celular ("particulado") con respecto al componente líquido (plasma), la misma se torna más viscosa y se pone en juego una mayor resistencia a su difusión en la matriz del papel de filtro

En las Figuras 79 y 80 se presentan los resultados obtenidos sobre una serie de muestras preparadas artificialmente en el Laboratorio de la FBA, los cuales demuestran que cuanto mayor es el volumen de sangre de hematocrito constante utilizado para impregnar el papel de filtro, mayor resulta el diámetro de la mancha; mientras que cuanto mayor es el hematocrito para un mismo volumen de sangre por mancha, menor resulta su diámetro, observándose además que el diámetro de las manchas resulta prácticamente indistinguible para muestras con hematocrito en el rango de 40 a $60 \%$ (15). 


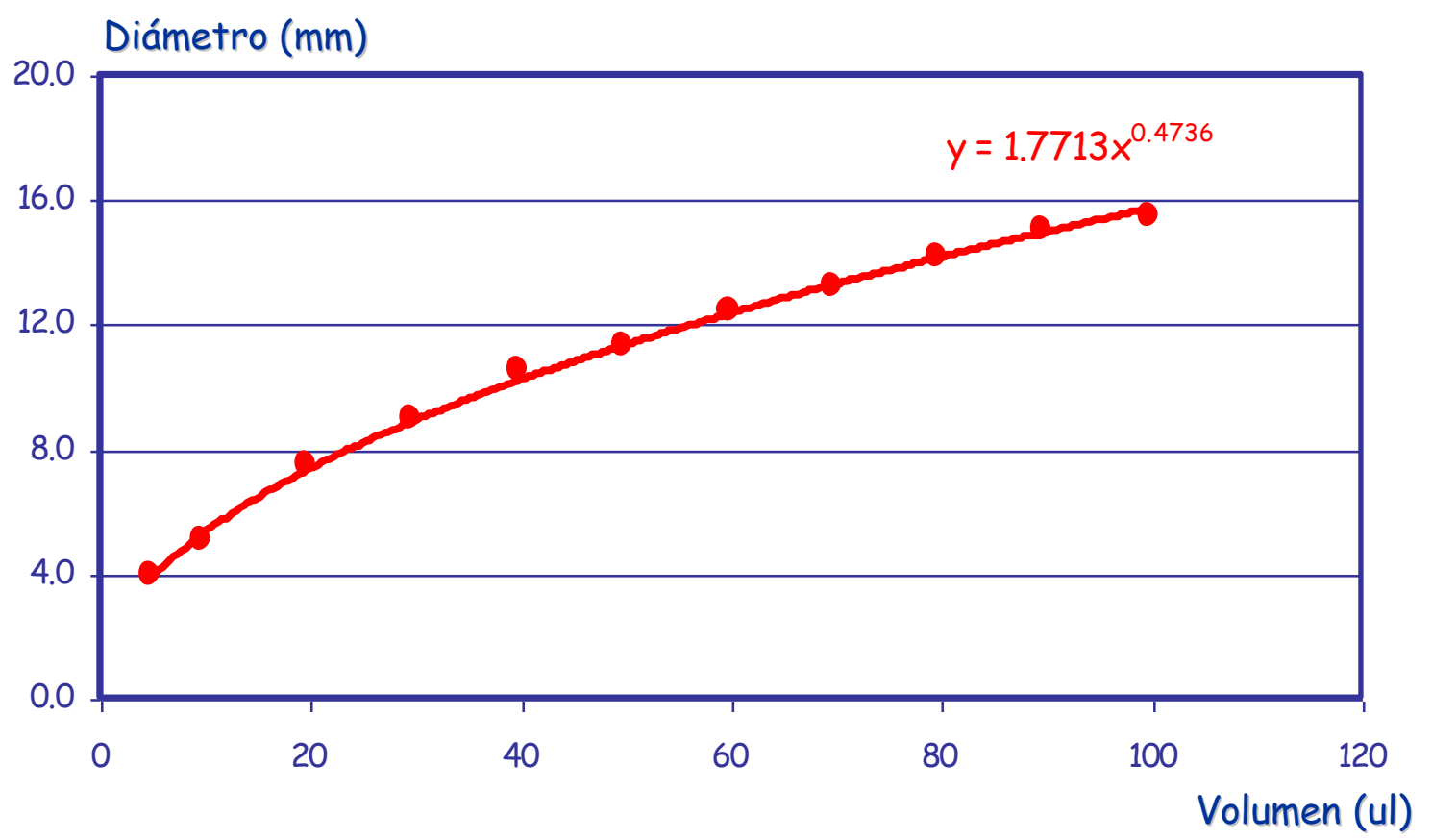

Figura 79. Efecto del volumen sobre el diámetro de las manchas de sangre impregnadas en papel de filtro (Hematocrito=50 \%).

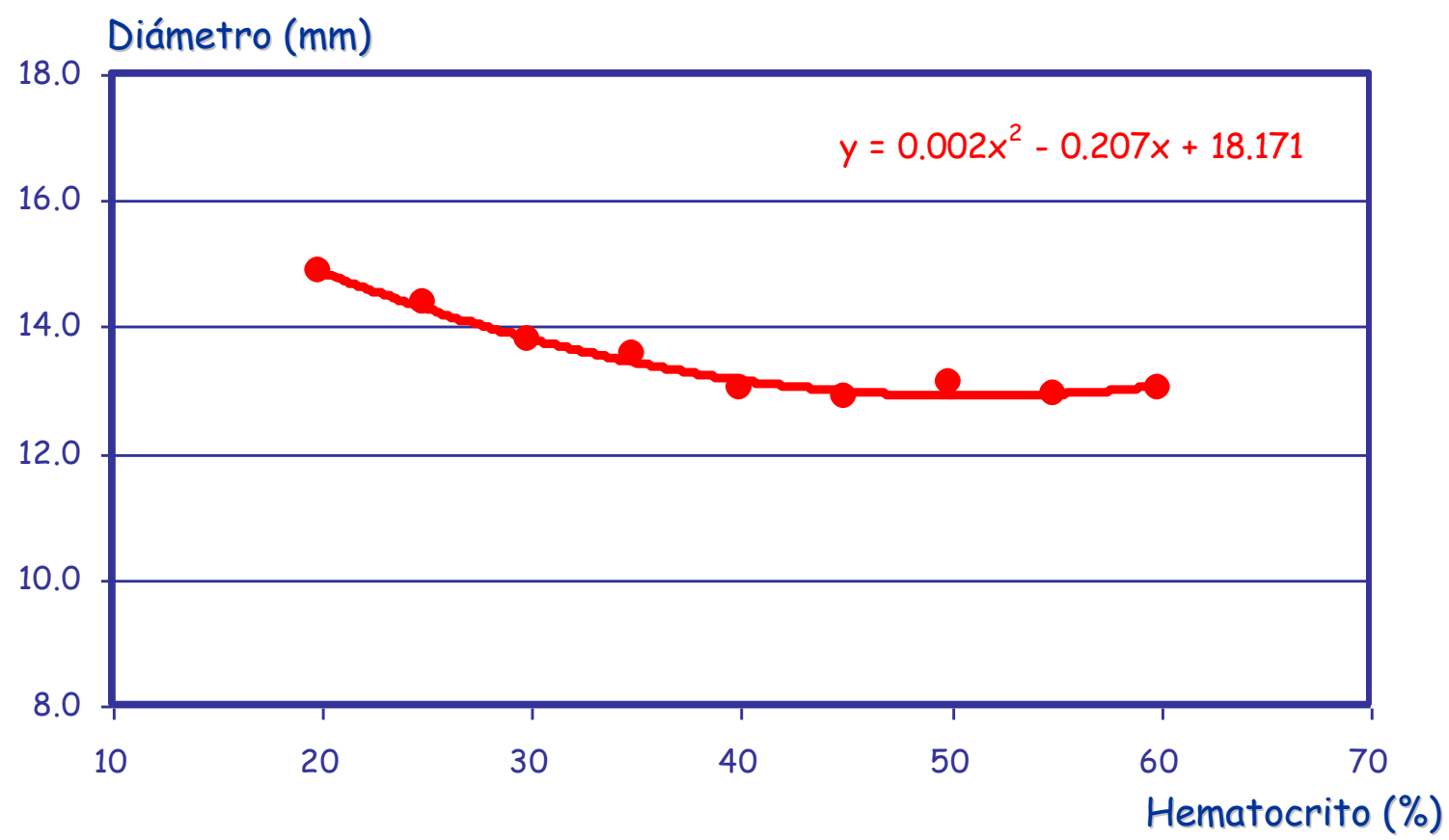

Figura 80. Efecto del hematocrito sobre el diámetro de las manchas de sangre impregnadas en papel de filtro (Vol/mancha=75 ul).

- Zona de corte o "puncheo" de muestras: un aspecto sumamente importante que debe ser tomado en consideración en relación a la zona de corte o "puncheo" de las muestras es que los resultados obtenidos al dosar un analito determinado pueden presentar diferencias estadísticamente significativas dependiendo de si el disco 
para el análisis es tomado de una posición central o de una posición periférica de la mancha, y de si el analito en estudio se encuentra localizado exclusivamente en el plasma -como ocurre por ejemplo con la TSH-, o exclusivamente en los glóbulos rojos -como se observa por ejemplo con la enzima Galactosa 1 Fosfato Uridil Transferasa.

Este fenómeno es debido a la presencia de un efecto cromatográfico que se traduce en una difusión diferencial entre los compartimientos líquido (plasma) y particulado (células sanguíneas) de la sangre en el papel de filtro, determinando que la mancha de sangre presente una mayor concentración de células en la zona central de la misma con respecto a su periferia.

En las Tablas 31 y 32 se presentan los resultados obtenidos en el Laboratorio de la FBA al analizar 5 manchas de sangre de hematocrito $50 \%$ correspondientes a 3 materiales de control preparados con diferentes niveles de TSH y Phe, los cuales fueron procesados tomando 5 discos de cada mancha, 4 de ellos de posiciones periféricas $(N, S, E$ y $O)$ y 1 de la posición central $(C)$ según se muestra en el esquema de la Figura 81 (16).

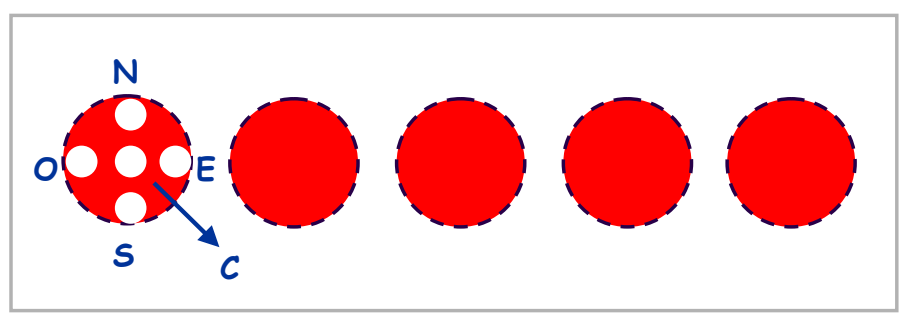

Figura 81. Posiciones central y periférica de puncheo de muestras.

Sobre cada uno de estos discos se llevó a cabo la medida de TSH y Phe en una única corrida empleando la metodología AutoDELFIA y un método Fluorométrico de Preparación propia para uno y otro analito respectivamente, y posteriormente se realizó un análisis estadístico de comparación de medias con un test de Student, agrupando por un lado los resultados correspondientes a las posiciones periféricas y por el otro los correspondientes a las posiciones centrales.

Tal como era de esperar, los resultados obtenidos permiten demostrar que en el caso de TSH se presentan diferencias significativas entre los niveles del 
analito medido, encontrándose que la concentración de TSH resulta más alta en las posiciones periféricas a consecuencia de la mayor proporción de plasma que presentan las mismas con respecto a las posiciones centrales, lo cual a su vez certifica la presencia del efecto cromatográfico antes descripto (16).

Tabla 31. Efecto de la zona de corte en la medida de TSH

\begin{tabular}{|c|c|c|c|c|c|}
\hline & \multicolumn{4}{|c|}{$T S H(\mu U / m /)$} & \\
\hline \multirow[t]{2}{*}{ Nivel } & \multicolumn{2}{|c|}{ Posiciones Periféricas } & \multicolumn{2}{|c|}{ Posiciones Centrales } & \\
\hline & $N$ & $X \pm D S$ & $\mathbf{N}$ & $x \pm D S$ & $\mathbf{p}$ \\
\hline$\# 1$ & 20 & $14.4 \pm 1.20$ & 5 & $12.3 \pm 0.69$ & $<0.005$ \\
\hline$\# 2$ & 20 & $39.1 \pm 2.83$ & 5 & $34.2 \pm 1.26$ & $<0.005$ \\
\hline$\# 3$ & 20 & $58.3 \pm 4.08$ & 5 & $53.2 \pm 2.15$ & $<0.05$ \\
\hline
\end{tabular}

En contraposición, en el caso de Phe, dichas diferencias no resultan significativas debido al hecho de que este aminoácido se distribuye igualmente entre el compartimiento plasmático y los glóbulos rojos (17), haciendo imperceptible la presencia del mencionado efecto.

Tabla 32. Efecto de la zona de corte en la medida de Phe

\begin{tabular}{|c|c|c|c|c|c|}
\hline \multirow{3}{*}{ Nivel } & \multicolumn{4}{|c|}{ Phe (mg/dl) } & \multirow[b]{3}{*}{$p$} \\
\hline & \multicolumn{2}{|c|}{ Posiciones Periféricas } & \multicolumn{2}{|c|}{ Posiciones Centrales } & \\
\hline & $\mathbf{N}$ & $X \pm D S$ & $N$ & $x \pm D S$ & \\
\hline$\# 1$ & 20 & $3.2 \pm 0.24$ & 5 & $3.2 \pm 0.23$ & ns \\
\hline$\# 2$ & 20 & $5.7 \pm 0.33$ & 5 & $5.4 \pm 0.18$ & ns \\
\hline$\# 3$ & 20 & $7.3 \pm 0.55$ & 5 & $7.5 \pm 0.25$ & ns \\
\hline
\end{tabular}

Independientemente de estos últimos resultados, una de las experiencias a las cuales se hizo referencia al describir la influencia del hematocrito sobre la medida de aminoácidos y acilcarnitinas por EMT (14) también incluyó una evaluación de la influencia de la zona de corte de los discos sobre los resultados de los mismos. De este modo se encontró un efecto directo sobre los niveles de varios analitos, el cual resultó especialmente significativo dentro de un subgrupo determinado de ellos a valores bajos de hematocrito, poniendo en evidencia además la interacción que existe entre ambos factores.

Por último, es importante destacar que la magnitud del efecto cromatográfico 
también resulta influenciada por el volumen de sangre utilizado para impregnar el papel de filtro, observándose que el mismo toma mayor relevancia cuanto mayor es el volumen de sangre por mancha.

- Elusión de las muestras: dependiendo del analito a evaluar y del principio analítico del método de medida utilizado se pueden presentar dos alternativas en relación al proceso de elusión de muestras, las cuales son descriptas a continuación:

o Elusión total de la sangre del papel de filtro: en estos casos se requiere llevar a cabo la elusión completa de la sangre utilizando para ello un buffer de elusión determinado, como se realiza por ejemplo en las medidas de TSH, IRT, $170 H P$ y Biotinidasa.

o Elusión selectiva de alguno de sus componentes: en estos casos es necesario realizar una primer etapa de desnaturalización o fijación diferencial de las proteínas plasmáticas y la hemoglobina al papel, proceso que a su vez puede ser realizado siguiendo dos estrategias diferentes:

- Por acción química: en esta alternativa la fijación de las proteínas al papel se realiza empleando un agente fijador como Ácido Tricloroacético, Etanol $70 \%$, Metanol/Acetona/Agua, Etanol/ $\mathrm{SO}_{4} \mathrm{Zn}$, etc.; y posteriormente se lleva a cabo la elusión del analito de interés, en algunos casos con la misma solución fijadora, o en otros con $\mathrm{H}_{2} \mathrm{O}$ o un buffer determinado, previa evaporación del agente fijador. Este procedimiento se utiliza entre otros, por ejemplo, en la determinación de Phe, Galactosa y BCAA empleando métodos fluorométricos o colorimétricos.

- Por acción física: en esta segunda alternativa la fijación se realiza empleando un tratamiento térmico en autoclave durante $3 \mathrm{~min}$ a $110^{\circ} \mathrm{C}$, como ocurre en la determinación de aminoácidos por el Método de Inhibición Bacteriana de Guthrie (3), en el cual después de la fijación, los analitos de interés difunden al medio de cultivo desde el disco impregnado con la sangre.

Independientemente de la forma en que se lleven a cabo la fijación y elusión de las muestras, este último proceso puede resultar afectado de manera sensible ya sea tanto por factores inherentes a las propias muestras como son la técnica 
de recolección y las condiciones de secado, transporte y conservación de las mismas, como por las variables que entran en juego a lo largo del proceso de elusión, determinando así que la eficiencia y el rendimiento del mismo resulten inferiores a lo esperable $y$ dando lugar consecuentemente a resultados caracterizados por una subestimación del analito en cuestión.

- Mayor imprecisión relativa en los métodos de medida: en relación a este concepto debe resaltarse que si bien la mayoría de los métodos empleados en las pruebas de pesquisa cumplen con la exigencias de precisión requeridas para un método cuantitativo, el hecho de que las mismas se realicen sobre DBS que presentan una variabilidad intrínseca asociada con sus propias características y también una variabilidad adicional relacionada con los diferentes procedimientos a los cuales se hallan sujetas, determina que aquella propiedad tenga una validez relativa y que, por lo tanto, sea esperable que los métodos de pesquisa presenten una mayor imprecisión que los métodos que han sido diseñados para trabajar sobre muestras líquidas (12); y que los rangos de tolerancia a utilizar en cuanto a la máxima imprecisión admitida sean más amplios que en estos últimos casos.

\section{- Limitada disponibilidad de materiales de control interno independientes de la} industria de reactivos diagnósticos: esta característica particular es responsable de que los Laboratorios de Pesquisa tengan un limitado acceso a materiales de control interno de un origen diferente de aquel que corresponde a la industria de reactivos diagnósticos, determinando en consecuencia que su capacidad de detección de errores a través del Control de Calidad Interno sea inferior a la esperable. Este punto será discutido en mayor detalle a continuación cuando se aborden los temas referentes al CC Interno.

- Características de los materiales de control empleados en la EEC: los materiales de control provistos por los Programas de EEC para pruebas de PN están caracterizados por una serie de variables entre las que se incluye la naturaleza y composición de la sangre utilizada para la preparación de los mismos, la fuente de los analitos con los cuales se lleva a cabo el enriquecimiento (1), el 
volumen de sangre empleado para obtener cada mancha, el hematocrito, el tipo de papel de filtro (13), la homogeneidad y estabilidad de los mismos, y los criterios utilizados para la asignación de valores (1).

Tal como se puede presuponer, cuanto más significativas sean las diferencias entre las características de los calibradores y las muestras de los RN con respecto a los materiales de control provistos por los Programas de EEC, entonces más complejo y dificultoso será obtener conclusiones objetivas acerca del desempeño de los métodos evaluados a través de dichos Programas.

\section{- Utilidad de los resultados obtenidos en el análisis de muestras de RN para el} CC: finalmente, un parámetro adicional de desempeño que adquiere un rol muy significativo en las pruebas de PN con respecto a la mayoría de las pruebas empleadas en los laboratorios de análisis clínicos generales, son las medidas de tendencia central resultantes del análisis de las muestras de RN, como son la media, la mediana y la moda (2).

Estos indicadores ofrecen un elemento adicional de enorme utilidad para el monitoreo de la estabilidad de los procedimientos de medida a largo plazo y para la detección inmediata de cambios sistemáticos a medida que estos se producen.

\section{- CONTROL DE CALIDAD INTERNO}

\section{Introducción}

Se puede definir al Control de Calidad $(C C)$ como el conjunto de técnicas y actividades operativas que son utilizadas para cumplimentar los requerimientos de calidad (18), mientras que el CC Interno puede ser definido como el conjunto de procedimientos establecidos por el laboratorio para el monitoreo continuo del funcionamiento y los resultados de las medidas, a fin de decidir si dichos resultados son suficientemente confiables como para ser reportados (18).

En términos prácticos, el CC Interno es un procedimiento en el que se lleva a cabo el análisis de muestras estables a efectos de verificar que el procedimiento analítico de medida está funcionando dentro de límites aceptables, siendo su objetivo 
asegurar la precisión requerida y detectar tendencias antes de que los procesos analíticos estén fuera de control (1).

De este modo, para garantizar que dicho objetivo pueda ser alcanzado exitosamente, el CC Interno debe ser ejecutado en forma sistemática, estar apropiadamente documentado, y contemplar la educación y el entrenamiento de todo el personal de Laboratorio (1).

\section{Implementación de un sistema de CC Interno en el Laboratorio de PN}

- Fuentes de materiales de control: es recomendable que para cada analito evaluado se utilicen materiales de control provenientes de al menos dos fuentes diferentes a fin de asegurar una máxima capacidad de detección de errores.

La implementación de un sistema de CC Interno utilizando exclusivamente materiales de control de una única fuente y calibradores que reconocen un mismo origen representa un riesgo importante de error y por lo tanto su uso en la práctica está contraindicado (1). Esta recomendación responde al hecho de que, en general, tanto los controles como los calibradores provenientes de una misma fuente son preparados siguiendo idénticos protocolos de preparación, de manera tal que, ante un error en la asignación de valores a los calibradores, dichos controles no serán capaces de detectar el defecto de calibración antes mencionado.

Esta situación puede presentarse en la práctica tanto cuando se trabaja en forma exclusiva con materiales de control y calibradores provistos por equipos de reactivos comerciales, como cuando se trabaja exclusivamente con materiales de control y calibradores preparados en el propio Laboratorio (19).

En la actualidad es posible acceder a materiales de control para PN de al menos 3 fuentes diferentes:

a) Materiales de control provistos como parte de los equipos de reactivos comerciales,

b) Materiales de control provistos por Programas de EEC, como por ejemplo por el NSQAP-CDC de Atlanta - EE.UU. (7), y

c) Materiales de control preparados en el propio Laboratorio. 
Con respecto a esta última alternativa, es decir a la preparación de materiales de control en el propio Laboratorio, y a pesar de que no se trata de un procedimiento complejo, en el caso de algunos analitos es muy difícil de concretar a consecuencia de la escasa disponibilidad de las fuentes de analitos necesarias para efectuar el enriquecimiento de dichos materiales.

\section{- Características de los materiales de control:}

- Composición: un requerimiento imprescindible en relación a la matriz de los materiales de control a utilizar es que la misma sea lo más similar posible a la de las muestras de RN (1), es decir que debe tratarse de sangre entera humana, con hematocrito ajustado al 50-55\% e impregnada en un papel de filtro de uso diagnóstico de las mismas características que el utilizado para la recolección de muestras de RN y para la preparación de los calibradores.

A pesar de esto, y tal como ya fuera mencionado anteriormente cuando se hizo referencia a la naturaleza y composición de algunos calibradores, en la práctica es posible encontrar materiales de control cuyas matrices difieren notablemente de la matriz de una muestra de RN, como se observa por ejemplo en aquellas preparaciones que utilizan glóbulos rojos de origen animal o en aquellas que emplean una solución de albúmina o solución fisiológica para sustituir al plasma humano (19).

- Homogeneidad: en cuanto a esta característica se requiere que los materiales de control sean suficientemente homogéneos de manera tal que su variabilidad intrínseca no contribuya sustancialmente a la variabilidad del sistema analítico, y por lo tanto esta propiedad debe ser validada previamente a su inclusión en la rutina diaria $(1,19)$.

- Estabilidad: con la finalidad de garantizar una vida útil apropiada de los diferentes lotes de producción, se requiere que los materiales de control sean estables en las condiciones de trabajo diario y de almacenamiento prolongado $(1,19)$, para lo cual los mismos deben ser conservados a $-20^{\circ} \mathrm{C}$ en bolsas herméticas adicionadas de desecantes e indicadores de humedad. 
- Niveles de los analitos: otro punto importante a considerar a fin de asegurar un óptimo desempeño del sistema de CC Interno es que los materiales de control a utilizar deben cubrir todo el rango de concentraciones de interés clínico (1). De esta forma, en cada corrida se deberán incluir necesariamente al menos 3 niveles distintos de concentración -normal, borderline y elevado-, quedando la posibilidad de desdoblar a este último nivel en un control moderadamente elevado y en otro francamente elevado si existe disponibilidad de materiales de control apropiados.

Por otra parte, los diferentes materiales de control deberán ser procesados distribuidos a lo largo de toda la corrida y recibir un tratamiento idéntico al de las muestras de RN que se analicen a diario (1).

Eventualmente, los mismos podrán ser colocados en posiciones fijas y predeterminadas a efectos de que, en aquellos métodos que utilizan el formato de microplacas, permitan asegurar también la identidad de éstas últimas (19).

- Acciones de implementación: para la implementación del CC Interno en el Laboratorio de PN los materiales de control previamente seleccionados deben ser procesados a diario en un mínimo de 20 corridas analíticas sucesivas e independientes, se debe verificar gráficamente la simetría en la distribución de los puntos, calcular la media (X) y la mediana (M) a efectos de comprobar si dicha distribución es normal, y finalmente determinar el desvío estándar (DS) y el coeficiente de variación (CV) $(1,20,21)$.

El valor obtenido de la $X$ será función del valor verdadero del analito en estudio y de la inexactitud del método utilizado, mientras que el DS y el CV -por ser ambos parámetros dependientes tanto de la variabilidad del proceso analítico como de la homogeneidad de los materiales de control-, darán una idea de la imprecisión corrida a corrida del método de medida, o en otras palabras, de la presencia de errores aleatorios que pueden estar afectando al mismo, los cuales en la práctica pueden ser atribuidos a errores de pipeteo o medida, a un inconsistente mezclado de reactivos y muestras, o a la variabilidad de los instrumentos de medida, incubadores, centrífugas o tiempos de incubación (1). En función de ésta última afirmación, para lograr una correcta interpretación de los 
resultados, resulta indispensable el registro de todas las condiciones de trabajo como reactivos, pipetas, instrumental, operador, temperaturas de incubación y lotes de calibradores y reactivos.

Finalmente, y como última exigencia a cumplimentar a efectos de poder dar inicio a la etapa de control propiamente dicha se requiere que el CV del método en uso se ajuste a las especificaciones de calidad previamente definidas (19).

- Seguimiento diario del CC interno: el seguimiento diario del CC Interno puede realizarse haciendo uso de 2 estrategias diferentes que permitirán verificar día a día que los métodos están funcionando en forma estacionaria y que no están sujetos a cambios bruscos no predecibles, posibilitando así mantener la consistencia analítica y eliminar cualquier tipo de subjetividad en la interpretación y evaluación de dicho desempeño analítico $(1,19)$ :

- Cartas de Control de Levey-Jennings: se trata de un sistema gráfico de seguimiento en el cual los resultados son expresados como número de DS (NDS) (20), al cual se define según la siguiente fórmula:

$$
\text { NDS }=(\text { Valor medido }-X) / D S
$$

En cuanto a la interpretación de los resultados, la misma es realizada con respecto a los Límites de Alarma y Acción a los cuales se define como $(X \pm 2 D S)$ y $(X \pm 3 D S)$ respectivamente.

En función de lo mencionado anteriormente, cuando una observación cae por fuera del Límite de Alarma se debe prestar especial atención al comportamiento de los controles en corridas sucesivas a efectos de determinar si ese resultado puede estar marcando una pauta del desempeño real del método.

En cambio, si la observación supera el Límite de Acción, entonces ningún resultado de la corrida puede ser informado, se debe proceder a tomar una acción correctiva concreta para resolver el problema surgido, y recién posteriormente se debe repetir la corrida completa $(1,19)$.

En la Figura 82 se presenta un ejemplo de una Carta de Control de Levey Jennings típica, en la cual también se incluyó la curva de distribución de las diferentes medidas realizadas. 


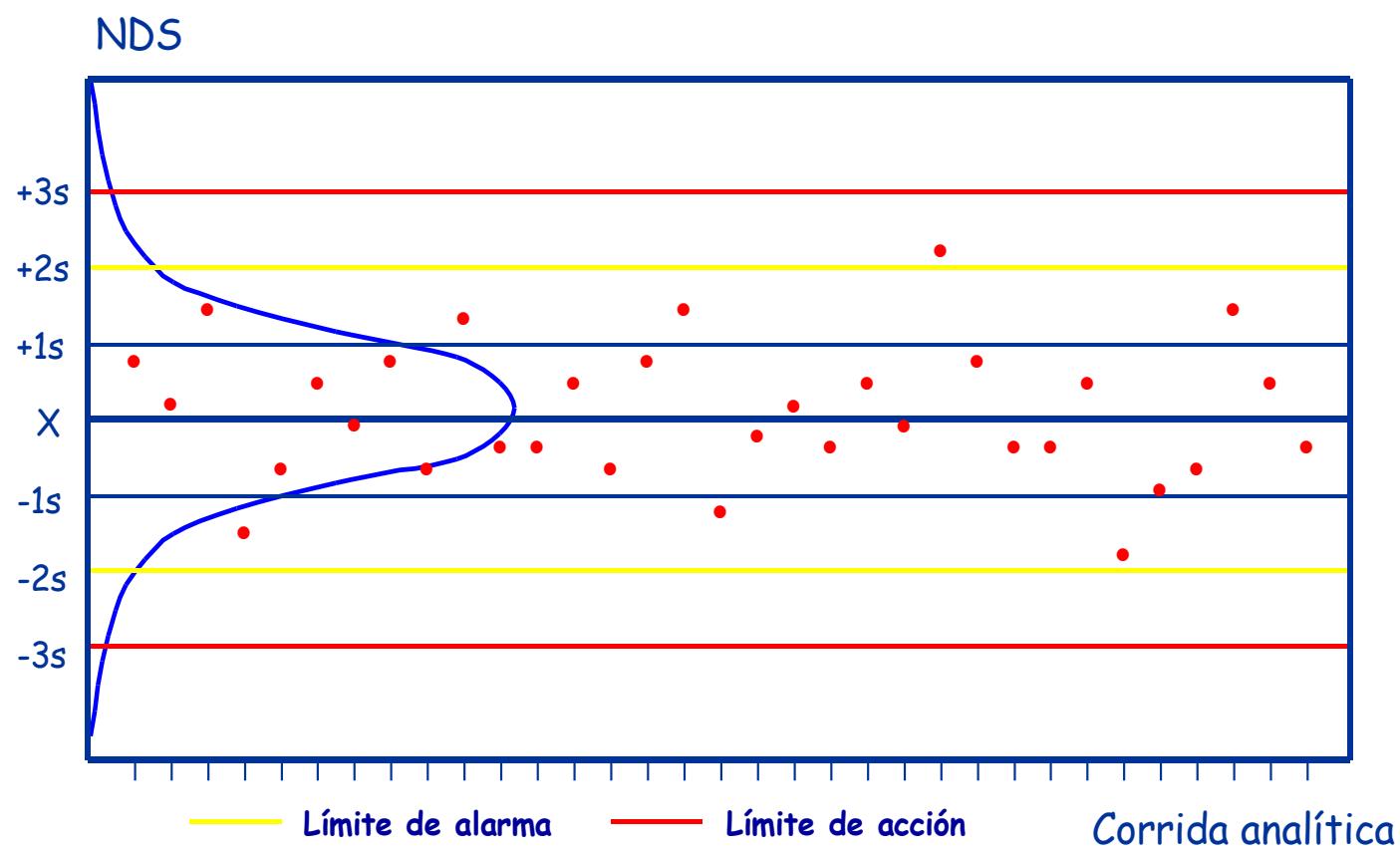

Figura 82. Carta de Levey-Jennings.

A través de las mencionadas Cartas de Control es posible establecer distintos patrones de comportamiento que orientan hacia la presencia de determinados tipos de errores (20), como por ejemplo la presencia de errores sistemáticos negativos o positivos, errores aleatorios o tendencias, a los cuales se representa gráficamente en las Figuras 83,84 y 85 respectivamente.

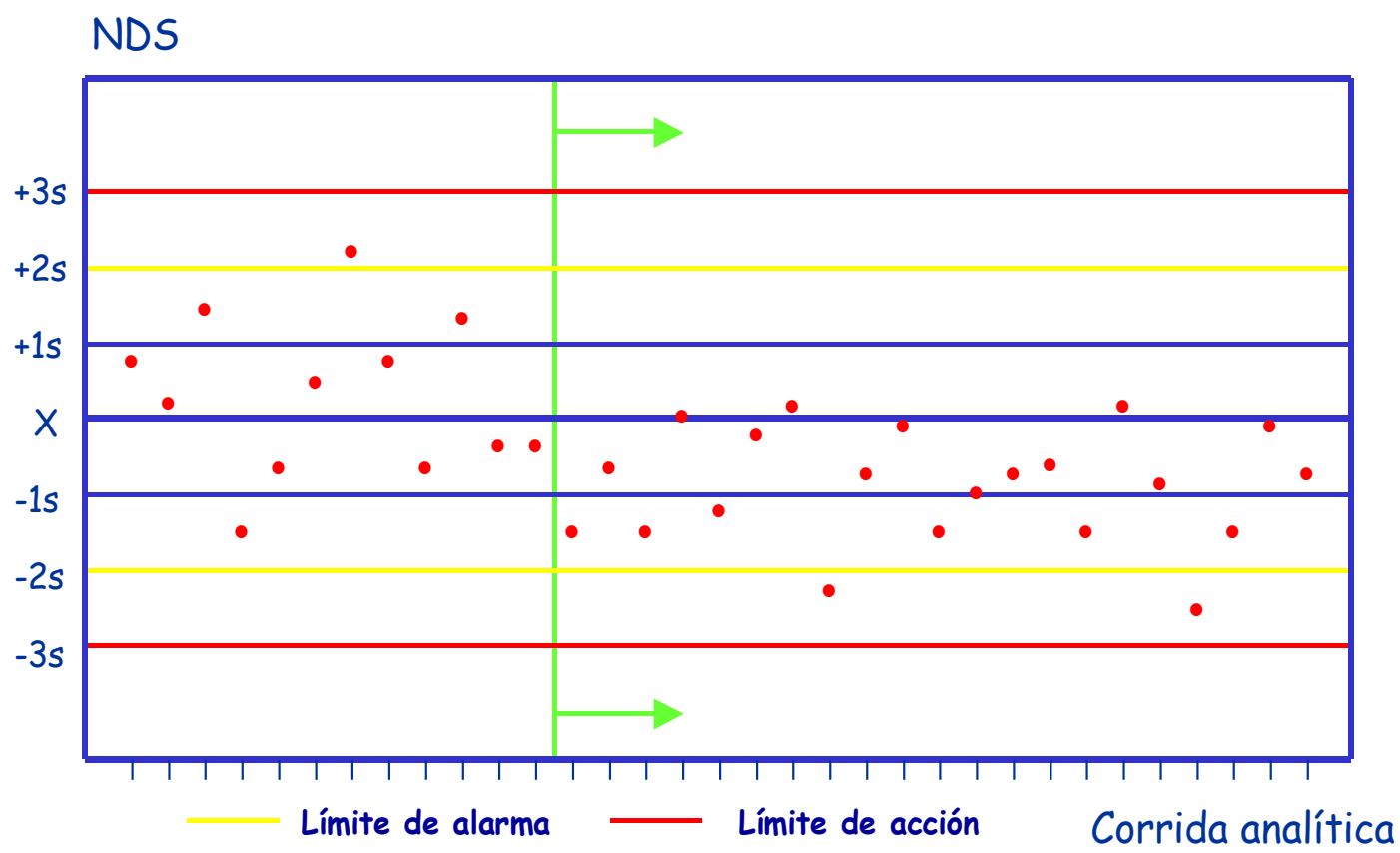

Figura 83. Detección de errores sistemáticos negativos. 


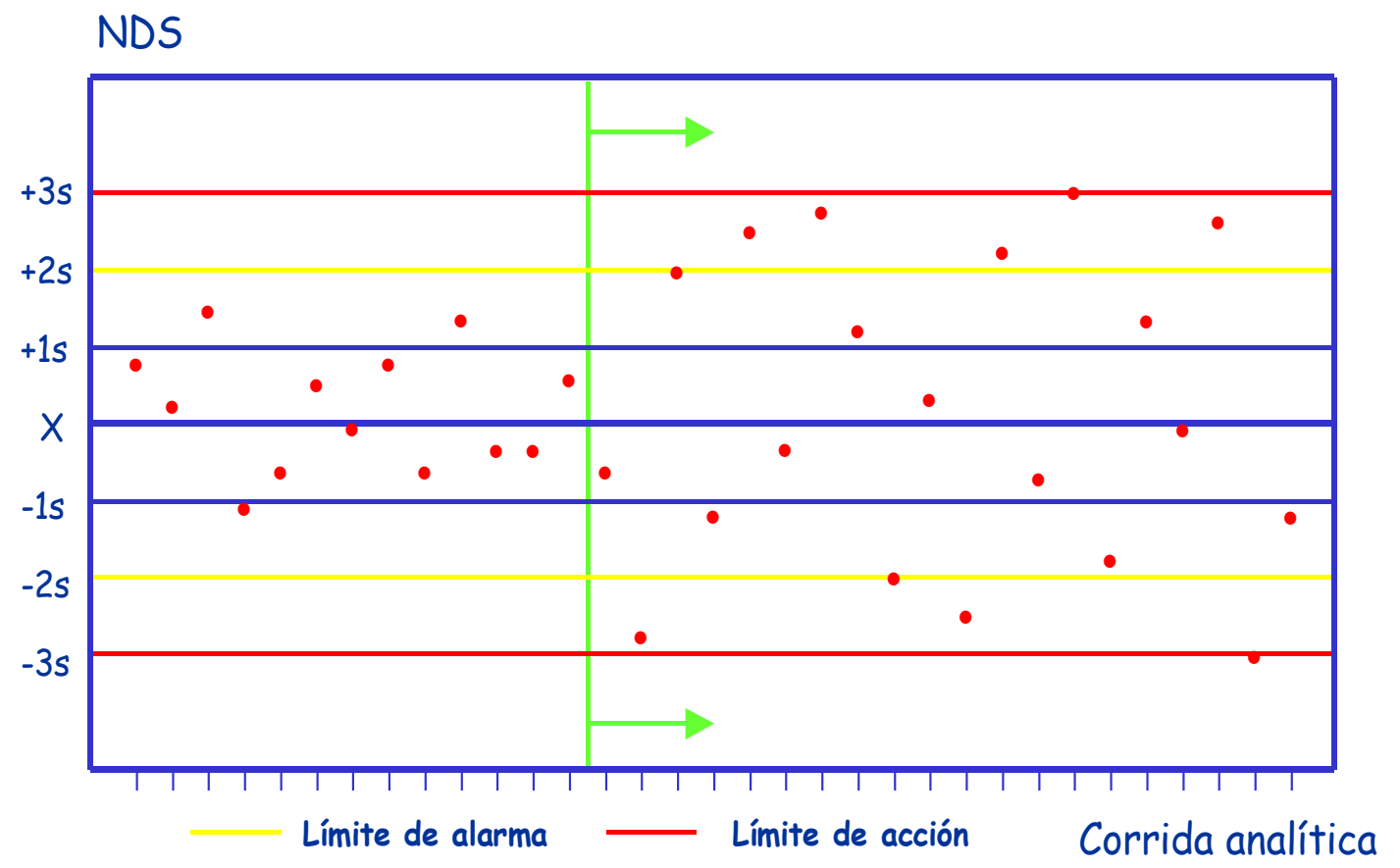

Figura 84. Detección de errores aleatorios.

NDS

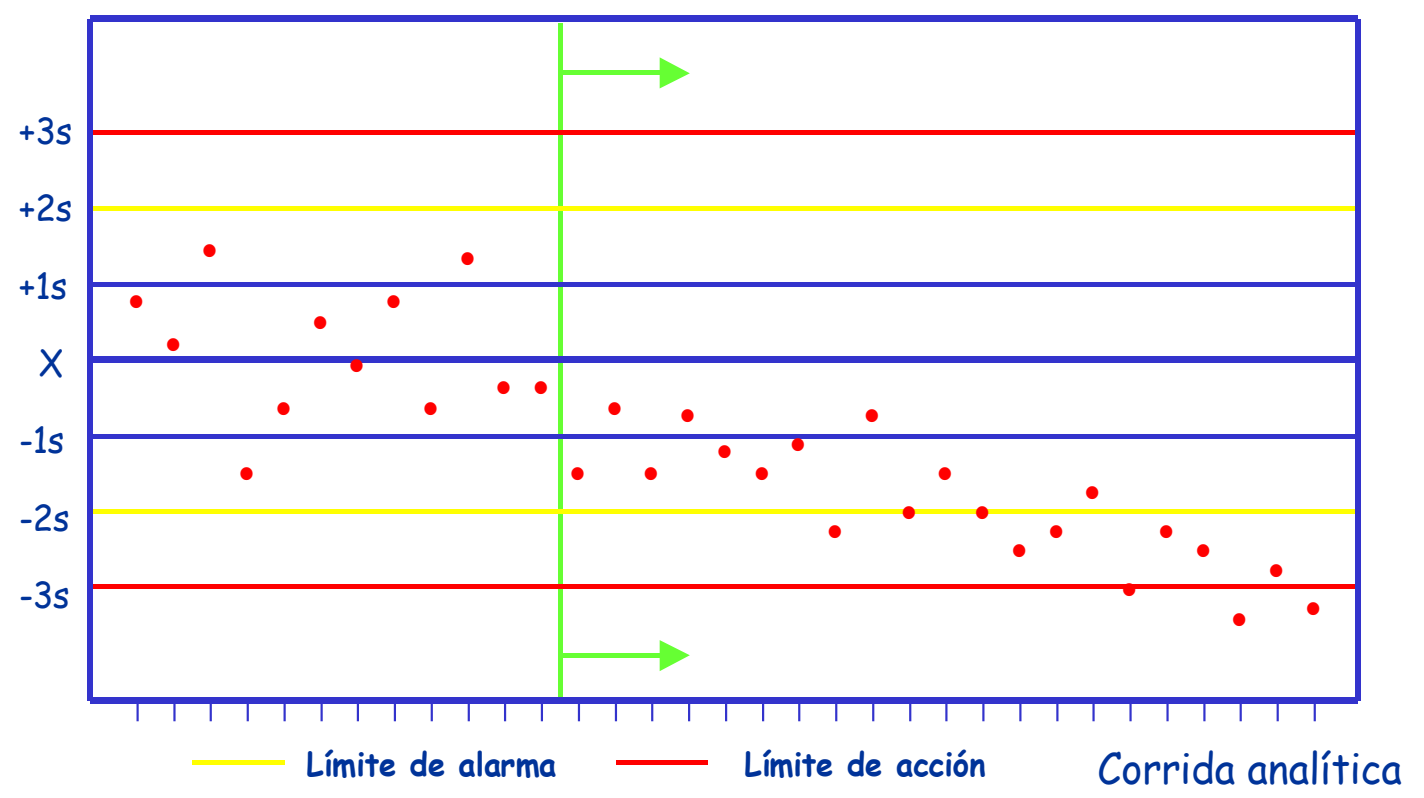

Figura 85. Detección de tendencias.

La principal limitación de este tipo de sistema gráfico de seguimiento del CC Interno, es que por tratarse de un sistema mínimo, las reglas de control definidas poseen un poder estadístico limitado cuando son tomadas en forma individual y utilizando solamente un único material de control por corrida. 
En razón de estas características, las mencionadas reglas presentan una baja sensibilidad para la detección de errores y una alta probabilidad de falsas alarmas, propiedades que sin lugar a dudas atentan en forma significativa contra la efectividad del sistema de control (19).

Por otra parte, debe destacarse que, si bien el uso de replicados de un único material de control incrementa la probabilidad de detectar errores aleatorios, esta medida tomada en forma aislada también incrementa la probabilidad de falsos rechazos.

En la práctica, para minimizar el número de falsos rechazos y maximizar la detección de errores, se deben analizar 2 o más materiales de control de diferentes concentraciones y por duplicado (1). Adicionalmente, una medida mucho más efectiva en tal sentido consiste en la implementación de un Sistema de control Multi-Regla.

- Sistema de Control Interno Multi-Regla de Westgard: se trata de un sistema de seguimiento que permite llevar a cabo una optimización en la interpretación de los resultados del CC Interno mediante la combinación de Reglas de Decisión seleccionadas que presentan una baja probabilidad de falsos rechazos y una alta probabilidad de detección de errores (22).

El sistema Multi-Reglas de Westgard es aplicable a sistemas de control con un mínimo de dos materiales de control por corrida, en el cual se combinan seis reglas que al ser analizadas permiten contar con una orientación acerca de si los errores detectados son de tipo sistemático o aleatorio (20-22).

En cuanto a las mencionadas reglas, y considerando que el objetivo de este Capítulo no es la discusión detallada de las mismas, a continuación sólo son descriptas muy sintéticamente, mientras que en la Figura 86 son presentadas esquemáticamente bajo la forma de un diagrama de flujo en el cual se representa el algoritmo de decisión secuencial a aplicar a cada una de las observaciones realizadas, el cual se pone en acción cuando una observación del control excede el límite de alarma clásico de (X \pm 2 DS): 
- $1_{2 s}$ : una observación por fuera de $(X \pm 2 D S)$. Esta regla es la que fija los límites de alarma en el Sistema Gráfico presentado anteriormente. La violación de la misma da lugar a un análisis posterior de las restantes reglas de decisión del sistema para determinar si la alarma se debe a un error analítico real o a razones puramente estadísticas.

- $1_{3 s}$ : una observación por fuera de $(X \pm 3$ DS). Esta regla determina automáticamente que la corrida está fuera de control y por lo tanto no se requiere mayor análisis. Es sensible principalmente a la presencia de errores aleatorios o de errores sistemáticos grandes.

- 22s: esta regla se viola cuando dos observaciones para el mismo control en pruebas sucesivas o dos observaciones en el mismo día correspondientes a diferentes controles exceden los 2 DS, encontrándose ambas observaciones del mismo lado de la media. La violación de esta regla denota la presencia de errores sistemáticos.

- $\mathbf{R}_{45}$ : esta regla rechaza la corrida cuando la diferencia entre el control de concentración elevada y el de concentración baja excede el valor de 4 DS, es decir cuando un valor excede el límite $(X+2 D S)$ y el otro excede (X - 2 DS). La violación de esta regla indica la presencia de errores aleatorios.

- 41s: esta regla se viola cuando cuatro observaciones consecutivas sobre un mismo control exceden el mismo límite de 1 DS, siendo indicativa de la presencia de errores sistemáticos.

En relación a este punto es importante destacar que si bien en la descripción original del Sistema Multi-Regla la violación a la misma implicaba el rechazo de la corrida, posteriormente, y teniendo en cuenta que se trata de cambios dentro de la región de aceptabilidad, se modificó el sentido de decisión de rechazo de la corrida a mantenimiento preventivo.

- 10X: esta regla se interpreta del mismo modo que la anterior, con la salvedad 
de que resulta violada cuando diez obseraciones del mismo control caen de un mismo lado de la media.

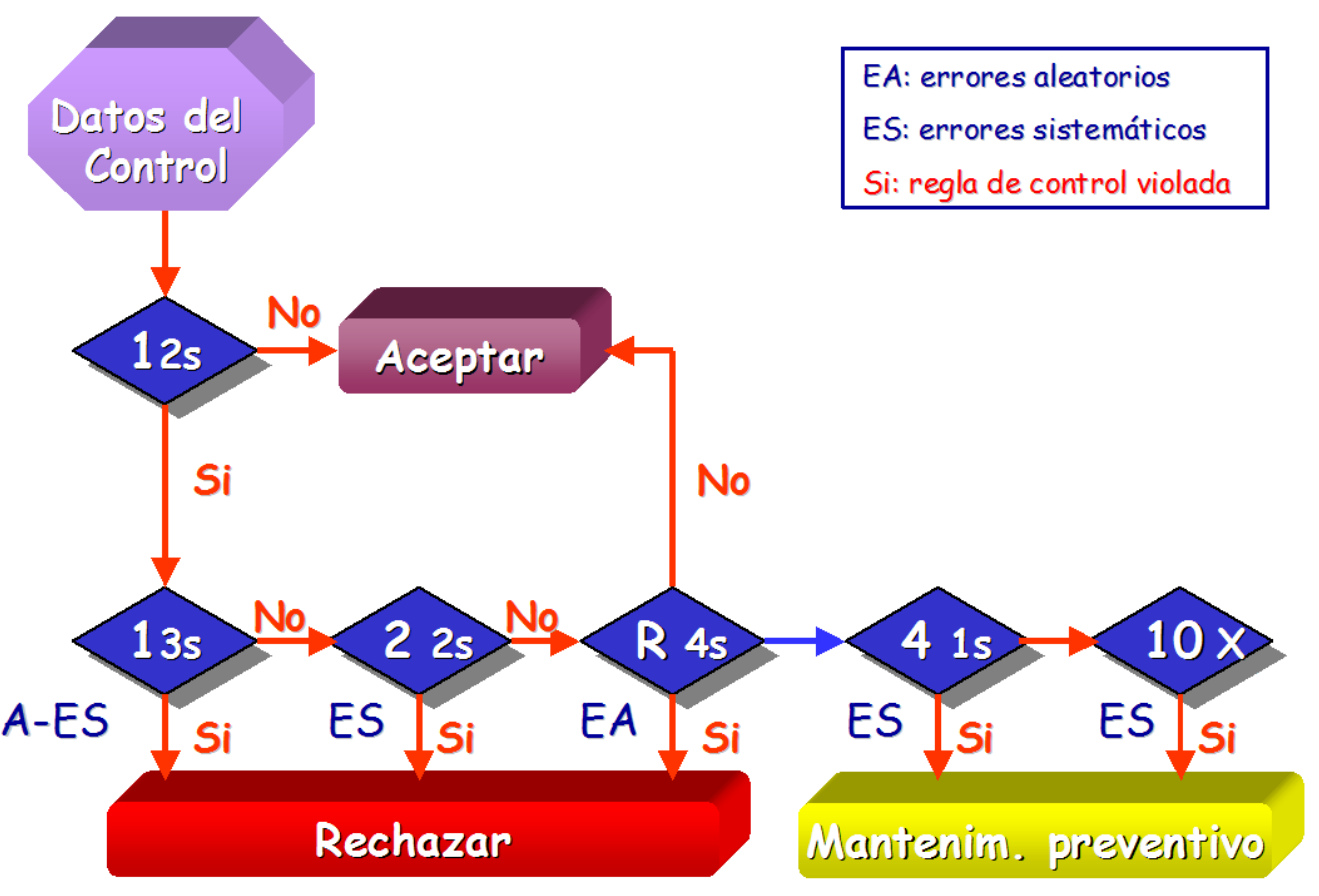

Figura 86. Sistema Multi-reglas de Westgard.

\section{- EVALUACION EXTERNA DE CALIDAD}

Se entiende por Evaluación Externa de Calidad (EEC) al sistema diseñado para la comparación objetiva de los resultados obtenidos por los laboratorios participantes a través de una agencia externa, ya sea entre sí o con respecto a valores de referencia, y cuyo objetivo principal es establecer la exactitud (23).

A diferencia de lo que se observa en el caso de las Pruebas de Suficiencia (Proficiency Testing), las cuales están vinculadas con actividades de tipo regulatorias, de carácter punitivo y con consecuencias económicas, la EEC persigue un fin educativo tendiente a lograr la armonización de los laboratorios para una mejora global de la red de laboratorios.

En relación a los objetivos, y si bien como se mencionó anteriormente el objetivo principal de la EEC es establecer la exactitud, a través de la misma se persiguen también objetivos generales, comunes a cualquier tipo de Laboratorio, y 
objetivos específicos, propios de los Laboratorios de PN (19), los cuales se detallan en la Tabla 33:

Tabla 33. Objetivos de la Evaluación Externa de Calidad

- Objetivos generales

- Establecer la exactitud

- Determinar el desempeño de los laboratorios participantes

- Detectar errores y establecer las posibles causas de los mismos

- Objetivos específicos para PN

- Propiciar el mejor conocimiento de las mediciones

- Lograr la correcta expresión de los resultados

- Normatizar y unificar las terminologías utilizadas en la descripción y evaluación de los métodos y Programas de PN

- Asesorar a los participantes para la correcta interpretación de los resultados individuales y globales de la EEC

- Lograr el correcto entendimiento de los conceptos estadísticos utilizados tanto en la EEC como en el CC Interno

- Promover la implementación de un sistema de CC Interno

La participación activa en Programas de EEC permite realizar el seguimiento del desempeño de los métodos utilizados en la rutina diaria, verificar su estabilidad a largo plazo, y sacar conclusiones objetivas acerca de la comparabilidad de los resultados reportados por los Laboratorios participantes (1).

Como regla general, siempre resulta recomendable la participación en al menos 2 Programas de EEC para cada analito, a efectos de contar con una evaluación más objetiva del desempeño de los métodos en uso (19).

Las actividades de la EEC son complementarias a las actividades del CC Interno, razón por la cual ambas constituyen dos piezas fundamentales e imprescindibles del sistema de Aseguramiento de la Calidad del Laboratorio de PN.

A continuación se presentará una breve descripción de los principales aspectos que hacen al funcionamiento de un Programa de EEC, presentándose mayores detalles en el Capítulo 6 al realizar la descripción del Programa de Evaluación Externa de Calidad para Pesquisa Neonatal (PEEC-PN) de la FBA: 
- Características de los materiales de control: Como norma de aplicación general, los materiales de control provistos por los Programas de EEC deben ser lo más similares posible a las muestras de RN y deben cubrir todo el rango de valores clínicamente relevantes.

Por otra parte, y a efectos de poder llevar a cabo una correcta interpretación de los resultados obtenidos resulta fundamental que cada laboratorio participante cuente con información concreta acerca de la fuente, composición, homogeneidad y estabilidad de los mismos, y también acerca de los procedimientos utilizados para la asignación de los valores esperados $(1,19)$.

- Modalidad de participación: Todos los materiales de control provistos por los Programas de EEC deben ser analizados por los operadores que habitualmente realizan las pruebas de rutina como parte de la carga diaria de trabajo del Laboratorio (1).

Una vez realizadas las pruebas, cada Laboratorio debe informar sus resultados tanto en forma cuali como cuantitativa al Programa de EEC, el cual efectuará una evaluación estadística con los resultados de todos los participantes.

En dicha evaluación, y dependiendo de las características del Programa, los resultados cuantitativos de cada Laboratorio serán comparados con respecto al valor asignado utilizando un método de referencia, o con respecto al valor de la media o la mediana de consenso global y/o con respecto al valor de la media o la mediana de consenso de cada método agrupado por principio analítico, en tanto que los resultados cualitativos (interpretación clínica) serán comparados con la clasificación realizada por el propio Programa de EEC de acuerdo a la concentración esperable de cada analito en cada material de control (19).

A través del reporte de resultados generado por los Programas de EEC cada Laboratorio podrá comparar su desempeño con el del total de los participantes y con el de aquellos Laboratorios que emplean su mismo principio analítico, pudiendo así obtener información acerca de la confiabilidad de los métodos utilizados, del 
desempeño de los sistemas de calibración y del cumplimiento de los objetivos específicos de calidad analítica (1).

Los errores sistemáticos detectados ya sea tanto a través de la participación en Programas de EEC, como también a través de la revisión a largo plazo del CC Interno, frecuentemente reconocen su origen en factores tales como la presencia de impurezas, asignación errónea de valores a los calibradores, funciones de calibración no lineales; o reactivos contaminados, inestables o mal preparados (1).

- Programas de EEC para PN: En la actualidad existen numerosos Programas de EEC para PN con alcance internacional distribuidos a lo largo de todo el mundo, los cuales proveen materiales de control para la evaluación de distintos analitos con una periodicidad variable de acuerdo a la modalidad de trabajo definida por cada Programa. En la Tabla 34 se enumeran los Programas de EEC internacionales más importantes, y se detallan sus principales características organizativas $(7,24,25)$.

También resulta importante destacar que además de los Programas antes mencionados cuyo alcance se extiende sin restricciones a Laboratorios de todos aquellos países que soliciten su participación, o en algunos casos a Laboratorios de una región determinada, existen también numerosos Programas de EEC de alcance nacional en países como España, Francia, Italia, Holanda, Japón, Corea, China, Tailandia, Nueva Zelanda, Argentina, Brasil, Colombia, Cuba y México entre otros $(10,24-26)$.

Finalmente, como conclusión y como corolario a este Capítulo, se debe mencionar que la simple participación en un Programa de EEC no es capaz de generar por sí misma una mejoría en el desempeño de un Laboratorio, sino que solamente a través de la implementación del CC Interno sumado a la información recibida desde los Programas de EEC, más las actividades de resolución de problemas por parte del propio Laboratorio, será posible alcanzar la esperada mejoría en el desempeño de los mismos (19). 
Tabla 34: Programas Internacionales de EEC para PN

\begin{tabular}{|c|c|c|c|c|}
\hline Programa & Analitos evaluados & $\begin{array}{l}\text { Controles } \\
\text { por envío }\end{array}$ & Frecuencia & Arancel \\
\hline $\begin{array}{l}\text { Proficiency Testing. } \\
\text { Centers for Disease } \\
\text { Control and } \\
\text { Prevention. Atlanta, } \\
\text { EE.UU. }\end{array}$ & $\begin{array}{l}\text { T4, TSH, 17OHP, } \\
\text { Galactosa, Phe, Met, } \\
\text { Leu, Tyr, Val, Cit, } \\
\text { Arg, Succinilacetona, } \\
\text { Acilcarnitinas (CO, } \\
\text { C2, C3, C3DC, C4, C5, } \\
C 5 O H, C 5 D C, C 6, C 8, \\
C 10, C 12, C 14, C 16, \\
C 16 O H \text { y C18), IRT, } \\
\triangle F 508, \text { Biotinidasa, } \\
\text { G1PUT, Hb y AC a- } \\
\text { Toxoplasma gondii. }\end{array}$ & 5 & Trimestral & Gratuito \\
\hline $\begin{array}{l}\text { Deutsche } \\
\text { Gesselschaft für } \\
\text { Klinische Chemie E.V. } \\
\text { Bonn, Alemania. }\end{array}$ & TSH y $170 H P$ & 4 & Trimestral & Gratuito \\
\hline $\begin{array}{l}\text { International Quality } \\
\text { Assurance Newborn } \\
\text { Screening. } \\
\text { Geestacht, Alemania. }\end{array}$ & $\begin{array}{l}\text { Phe, Met, Leu y } \\
\text { Galactosa. }\end{array}$ & 10 & Bimestral & Gratuito \\
\hline $\begin{array}{l}\text { New England Quality } \\
\text { Assurance Scheme. } \\
\text { Birmingham, Reino } \\
\text { Unido. }\end{array}$ & Phe y TSH & 6 & Bimestral & Arancelado \\
\hline $\begin{array}{l}\text { Programa de } \\
\text { Evaluación Externa de } \\
\text { Calidad - Fundación } \\
\text { Bioquímica Argentina. } \\
\text { La Plata, Argentina. }\end{array}$ & $\begin{array}{l}\text { Phe y TSH } \\
\text { IRT y Gal a partir de } \\
\text { Junio de } 2008 .\end{array}$ & 2 & Bimestral & Gratuito \\
\hline
\end{tabular}

\section{BIBLIOGRAFIA}

1. Slazyk WE and Hannon WH. "Quality Assurance in the Newborn Screening Laboratory" en "Laboratory Methods for Neonatal Screening", Therrell BL Ed, American Public Health Association, Washington, 23-46, 1993.

2. Westgard JO. "Defining Quality and Designing QC for Neonatal Screening" en Proceedings of QA/QC in Newborn Screening Workshop, Phoenix - Arizona, November 4, 2002. Disponible en www.westgard.com/qcapp18.htm. 
3. Guthrie R and Susi A. "A Simple Phenylalanine Method for Detecting Phenylketonuria in Large Populations of Newborn Infants". Pediatrics 32, 338-43, 1963.

4. Illig R. "Neonatal Screening for Hypothyroidism by TSH Determination in Dried Blood" en "Neonatal Screening for Inborn Errors of Metabolism". Bickel H, Guthrie R and Hammersen G Eds, Springer-Verlag, Berlin Heidelberg New York, 179-89, 1980.

5. Wu JT, Wu LH, Ziter FA and Ash O. "Manual Fluorometry of Phenylalanine from Blood Specimens Collected on Filter Paper: A Modified Procedure". Clin Chem 25, 470-2, 1979.

6. Borrajo GJC, Galdeano HL. "Estudio de un Método para Aplicar en Control Masivo de Fenilcetonuria. Evaluación de Sensibilidad, Reproducibilidad y Costos". Acta Bioquim Clin Latinoam 23, 289-302, 1989.

7. Newborn Screening Quality Assurance Program - Centers for Disease Control and Prevention. "2010 Annual Summary Report". Volume 28, January 2011.

8. Chamoles N, Niizawa G, Blanco M, Gaggioli D and Casentini C. "Glycogen Storage Disease Type II: Enzimatic Screening in Dried Blood Spots on Filter Paper". Clin Chim Acta 347, 97-102, 2004.

9. CLSI. "Blood Collection on Filter Paper for Neonatal Screening Programs". Approved Standard - Fifth Edition. CLSI Document LA4-A5, Vol 27 N 20, 2007.

10. Dhondt JL, Hannon WH, Torresani T and Webster D; "Summary of The Meeting Quality Assurance in Newborn Screening" en "New Horizons in Neonatal Screening". Farriaux JP and Dhondt JL Eds. Excerpta Medica, Amsterdam London, 379-382, 1994.

11. Slazyk WE, Phillips DL, Therrell BL and Hannon WH; "The Effect of Lot-to-Lot Variability in Filter Paper on the Quantification of Thyroxin, Thyrotropin, and Phenylalanine in Dried-Blood Specimens". Clin Chem 34, 53-58, 1988.

12. Webster D. "Quality Performance of Newborn Screening Systems: Strategies for Improvement". J Inherit Metab Dis, 30, 576-84, 2007. 
13. Adam BW, Alexander JR, Smith SJ, Chace DH, Loeber JG, Elvers LH and HannonWH. "Recoveries of Phenylalanine from Two Sets of Dried-Blood-Spot Reference Materials: Prediction from Hematocrit, Spot Volume, and Paper Matrix". Clin Chem 46, 126-8, 2000.

14. Holub M, Tuschl K, Ratschmann R, Strnadová KA, Mühl A, Heinze G, Sperl W and Bodamer OA. "Influence of Hematocrit and Localization of Punch in Dried Blood Spots on Levels of Amino Acids and Acylcarnitines Measured by Tandem Mass Spectrometry". Clin Chim Acta 373, 27-31, 2006.

15. Borrajo GJC y Pistaccio LG. "Efecto del Volumen y el Hematocrito en la Medida de TSH y Fenilalanina" (Poster). Acta Bioquím Clin Latinoam, Supl 1, 283, 2007.

16. Borrajo GJC, Pistaccio LG y Mazziotta D. "Evaluación de Homogeneidad en Materiales de Control para Pesquisa Neonatal". (Poster). Acta Bioquim Clin Latinoam, 38, 403, 2004.

17. Aldis B, Hoffman $G$ and Therrell BL. "Laboratory Methods for Phenylalanine Analysis on Newborn Screening Specimens" en "Laboratory Methods for Neonatal Screening", Therrell BL Ed, American Public Health Association, Washington, 47$75,1993$.

18. Eurachem Guide. "The Fitness for Purpose of Analytical Methods. A Laboratory Guide to Method Validation and Related Topics". First English Edition 1.0, 1998. www.eurachem.org/guides/valid.pdf

19. Borrajo GJC y Mazziotta D. "Control de Calidad en Programas de Pesquisa Neonatal", en "Errores Innatos en el Metabolismo del Niño". Colombo M, Cornejo V y Raimann E Editores. $2^{a}$ Edición. Editorial Universitaria. Santiago de Chile, 385402, Cap. 14, Parte 3, 2003.

20. Mazziotta D y Corrêa JA. "Control de Calidad" en "Gestión de la Calidad en el Laboratorio Clínico", Fernández Espina C y Mazziotta D Eds. Editorial Médica Panamericana, Buenos Aires-Bogotá-Caracas, 371-407, 2005.

21. Clinical and Laboratory Standards Institute. "Statistical Quality Control for Quantitative Measurement Procedures: Principles and Definitions"; Approved Guideline-Third Edition. CLSI document C24-A3, Vol 26 NN$^{\circ} 25,2006$. 
22. Westgard JO, Barry PL, Hunt MR and Groth TA. "A Multi-Rule Shewhart Chart for Quality Control". Clin Chem 27, 493-501, 1981.

23. ISO-REMCO N231, 1991.

24. Webster D, Dhondt JL, Hannon WH and Torresani T; "Description of Quality Assurance Programs in Newborn Screening". Screening 2, 219-228, 1993.

25. Borrajo GJC. "Newborn Screening in Latin America at the beginning of the 21st Century". J Inherit Metab Dis, 30, 466-81, 2007.

26. International Atomic Energy Agency. "Quality Assurance for the Newborn Screening System" en "Screening of Newborns for Congenital Hypothyroidism. Guidance for Developing Programs". International Atomic Energy Agency Ed., Vienna, 45-66, 2005. 


\section{CAPÍTULO 6}

DESARROLLOE

IMPLEMENTACION DE UN

PROGRAMA DE EVALUACION

EXTERNA DE CALIDAD PARA

PESQUISA NEONATAL EN

LATINOAMERICA 



\section{- INTRODUCCION}

La idea de llevar a cabo la implementación de un Programa de Evaluación Externa de Calidad (EEC) con alcance exclusivo sobre Laboratorios de Latinoamérica surgió como una consecuencia directa de la preocupación y, a su vez del convencimiento imperante en el seno de la primer Comisión Directiva de la Sociedad Latinoaméricana de Errores Innatos del Metabolismo y Pesquisa Neonatal (SLEIMPN), creada en La Habana - Cuba en Septiembre de 1997, en torno a la necesidad de contar con un Programa de EEC propio de la región, que nucleara exclusivamente a los Laboratorios de Latinoamérica y que, a través de estas acciones, estuviera en condiciones de recabar información real acerca de la situación y desempeño de los mismos, de establecer un diagnóstico y de ofrecer a cada uno de ellos la ayuda necesaria (1).

No obstante esto, y a pesar de que estas primeras ideas también dejaron claramente establecido el carácter prioritario de su puesta en funcionamiento, la implementación del mencionado Programa resultó retrasada por diferentes factores resultantes tanto de la necesidad de la propia SLEIMPN de lograr su afianzamiento y maduración como Sociedad, como de contar con un efector capacitado para ejecutar eficientemente dicha tarea.

De este modo, recién en Octubre de 1999 se dio el primer paso para su concreción cuando en Santiago de Chile, durante el desarrollo del II Congreso Latinoamericano de EIM y PN, el autor de esta Tesis presentó una propuesta y un plan de trabajo para la organización y ejecución del Programa de Evaluación Externa de Calidad para Pesquisa Neonatal (PEEC-PN) desde la Fundación Bioquímica Argentina (FBA), ocasión en la que también se creó la Comisión Permanente de Control de Calidad de la mencionada Sociedad y se dio el aval de toda la región para poner en marcha el proyecto.

Así fue que en el mes de Febrero de 2000, es decir sólo 4 meses después de presentada la propuesta, se efectuó el lanzamiento del PEEC-PN bajo la forma de un Programa Piloto de 1 año de duración, y en el mes Junio de ese mismo año se envió la primer encuesta a 32 Laboratorios de 8 países de Latinoamérica que habían acordado su participación en el mismo. 


\section{- ORGANIZACIÓN, CARACTERÍSTICAS Y ESTRATEGIA DE IMPLEMENTACIÓN}

- Organización: La organización del PEEC-PN se realizó sobre la base de 2 grupos de trabajo preexistentes: por un lado el Programa de Evaluación Externa de Calidad (PEEC) de la FBA y por el otro el Programa de Detección de Errores Congénitos, perteneciente también a esta misma Fundación.

Esta característica permitió la interacción en una misma institución de dos grupos de trabajo especializados -uno de ellos en temas de Calidad y el otro en temas de PN- con más de 10 años de experiencia en sus áreas específicas de trabajo, hecho que propició la rápida implementación y expansión del mencionado Programa, estableciéndose que el grupo de Detección de Errores Congénitos sería el responsable del manejo, ejecución y coordinación del mismo, bajo la tutela del Director General del PEEC.

- Diseño: El diseño del Programa fue realizado sobre la base de los objetivos generales y específicos de un Programa de EEC descriptos en el Capítulo 5. estableciéndose que la herramienta clave para poder alcanzar los mismos debía ser la ejecución de un proceso educativo continuo de carácter prioritario, buscando de este modo lograr la armonización entre los Laboratorios participantes para el mejoramiento de la red de Laboratorios en su conjunto.

Con respecto a los objetivos específicos y considerando que la PN se trata también de un área muy específica de trabajo, en algunos casos fue necesario definir los mismos de una forma más explícita, a efectos de asegurar su correcta interpretación y entendimiento por parte de los diversos participantes.

Por ejemplo, en relación a algunos de los objetivos mencionados en la Tabla 33 (Capítulo 5 - Página 223) se trató de dejar en claro que "Propiciar el mejor conocimiento de las mediciones" implicaba lograr una profundización en el conocimiento de los principios analíticos de los métodos en uso, de los analitos que se están midiendo y de las variables que afectan a dichas medidas; que "Lograr la correcta expresión de los resultados" implicaba lograr el conocimiento de los diferentes compartimientos -ya sea plasma, glóbulos rojos o ambos- en los cuales 
se localiza cada analito a efectos de que las unidades empleadas para informar los resultados estén correctamente expresadas; y que "Normatizar y unificar las terminologías utilizadas en la descripción de los métodos y Programas de PN", implicaba el conocimiento y el uso de definiciones claras y precisas en cuanto a exactitud, precisión, falsos positivos, falsos negativos, sensibilidad, especificidad, valor predictivo positivo, recitación, repeticiones, confirmaciones, incidencia, etc., a efectos de hacer posible así la comparación objetiva de resultados entre distintos Programas de PN.

- Características generales: En función de los conceptos antes mencionados se establecieron las características generales del PEEC-PN, las cuales se detallan en la Tabla 35.

Tabla 35. Características generales del PEEC-PN

- Patologías evaluadas: PKU e HC

- Analitos evaluados: Phe y TSH

- Materiales de control provistos: basados en sangre entera humana, HIV, HBV y HCV no reactiva, impregnada en papel de filtro Whatman \# 903, con hematocrito ajustado al $50 \%$.

- Frecuencia de envíos: bimestral

- Número de controles provistos en cada encuesta: 2, ambos conteniendo Phe y TSH

- Evaluación de resultados:

- Cuantitativa: realizada empleando estadísticas no paramétricas, con respecto a la mediana de consenso global. Aceptabilidad de resultados definida de acuerdo a criterios de aceptabilidad clínica.

- Cualitativa: realizada con respecto a la interpretación del resultado reportado por cada laboratorio.

- Informes de resultados:

- De cada encuesta: remitidos dentro de los 25 días a contar desde la fecha de cierre de la misma

- Anual: evaluación global e individual de los resultados correspondientes a un período de 6 encuestas.

- Arancel: gratuito

- Alcance: restringido a Laboratorios de toda Latinoamérica 
- Estrategia de implementación: tal como ya fuera mencionado anteriormente, el PEEC-PN fue lanzado en Febrero de 2000 bajo la forma de un Programa Piloto de 1 año de duración con la finalidad de que durante este período de trabajo se evaluara por un lado, tanto la magnitud de la respuesta a la convocatoria que fuera realizada oportunamente, así como la repercusión y aceptación de la misma por parte de los diferentes centros de PN de Latinoamérica, y por el otro, de que se efectuaran todos los ajustes y correcciones necesarios sobre las características y modalidad de trabajo, en concordancia con la experiencia recogida.

Dentro de este proyecto inicial también estaba previsto que, si una vez concluida la Prueba Piloto los resultados demostraban haber alcanzado las expectativas de éxito fijadas previamente, entonces se realizaría un relanzamiento del PEEC-PN como un Programa ya consolidado, lo cual en la práctica se hizo efectivo en el mes de Octubre de 2001 durante el III Congreso Latinoamericano de EIM y PN que se llevó a cabo en Cartagena de Indias Colombia. En la Figura 87 se presenta el folleto de difusión/inscripción utilizado al momento del mencionado relanzamiento.

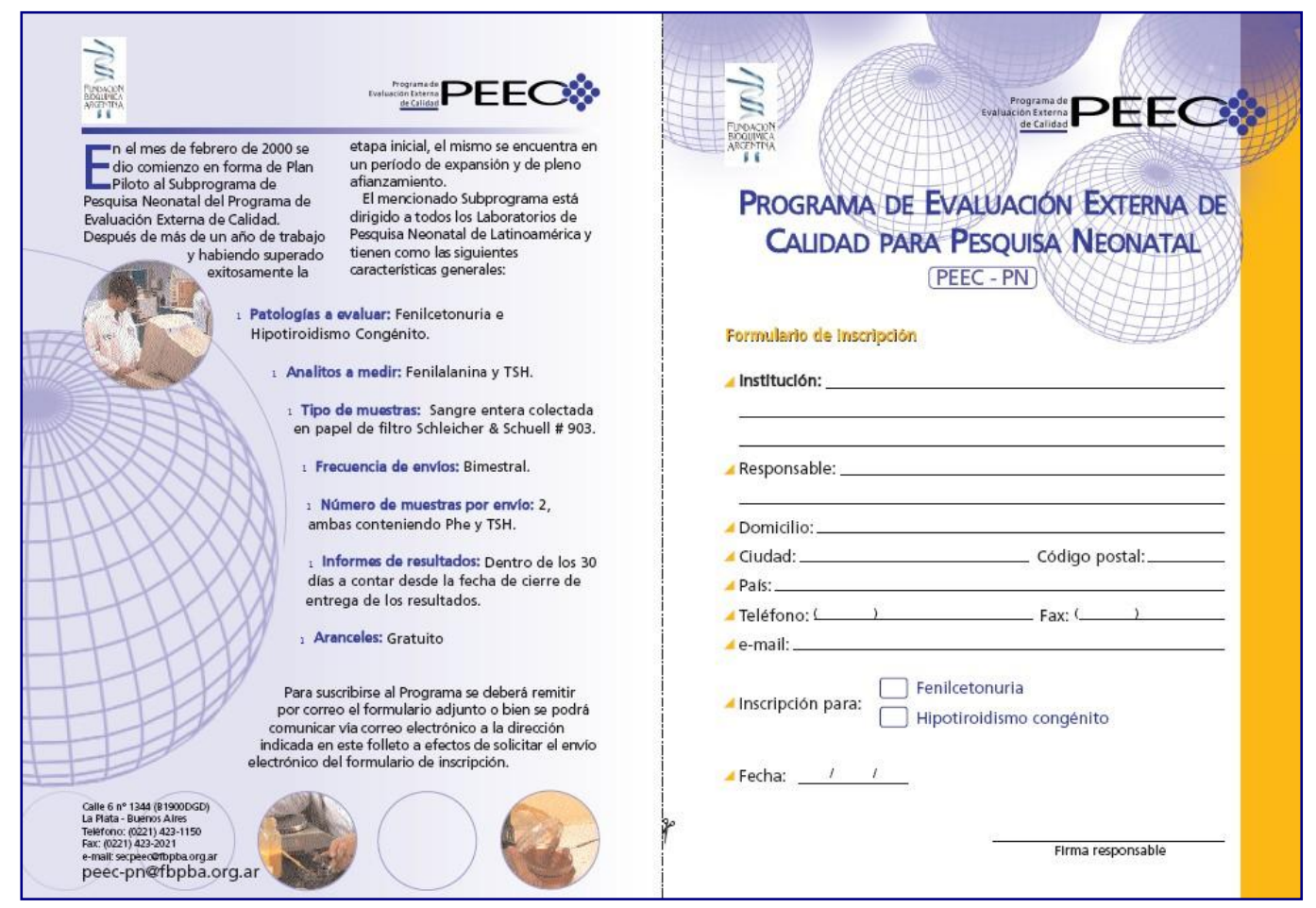

Figura 87. Folleto de difusión/inscripción del PEEC-PN. 
De este modo, la primera acción masiva de implementación llevada a cabo por parte del PEEC-PN se ejecutó en Febrero de 2000, y consistió en dar a conocer el proyecto a los diferentes grupos de PN de Latinoamérica haciendo uso del directorio de socios provisto por la SLEIMPN. Para esto, se remitió información por vía electrónica detallando las características del programa, los objetivos perseguidos y la modalidad de trabajo prevista, a la cual se adjuntó un Formulario de Inscripción y una Encuesta que debería ser completada y remitida a la FBA por aquellos Laboratorios interesados en participar.

El objetivo de haber incluido la Encuesta antes mencionada junto con el Formulario de Inscripción fue contar con la posibilidad de establecer con precisión y anticipación la línea de base que de alguna manera definiría el escenario real sobre el cual se llevarían a cabo las actividades del PEEC-PN.

En dicha Encuesta se solicitaba información relacionada con la organización, tamaño, complejidad y experiencia de los Laboratorios, las enfermedades pesquisadas, el número de muestras analizadas, la participación en otros Programas de EEC, la utilización de sistemas de CC interno y sus características, y las expectativas planteadas acerca de la cobertura de patologías y analitos ofrecida por el PEEC-PN.

- Preparación de materiales de control: En el Anexo 1 se presenta una descripción detallada de los materiales requeridos para la preparación de los materiales de control y de la técnica utilizada para tal fin, la cual fuera desarrollada en el Laboratorio de Detección de Errores Congénitos de la FBA sobre la base de la técnica de preparación utilizada por el NSQAP-CDC (2).

- Envíos: Los envíos por parte del PEEC-PN son realizados en forma bimestral. En cada uno de ellos se incluye:

- un instructivo en el cual se describen los principales detalles acerca de la modalidad de trabajo,

- una tabla de códigos de métodos, reactivos, calibradores, tipo de papel de 
filtro, interpretación de resultados y decisión,

- un formulario para el reporte de resultados,

- una tira de papel de filtro conteniendo 2 manchas de sangre de cada uno de los materiales de control provistos en cada encuesta, y

- el informe de la evaluación de resultados correspondiente a la encuesta inmediata anterior.

\section{PEF 08 Programa de Evaluación Externa de Calidad Pesquisa Neonatal}

ENCUESTA \# 45 - Octubre/07.

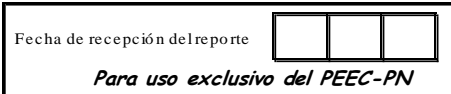

CODIGO DE IDENTIFICACION

Fecha de recepción
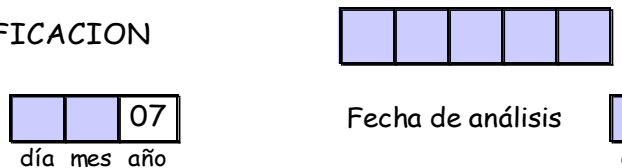

Fecha de análisis

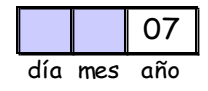

FENILALANINA

\begin{tabular}{|c|c|}
\hline Método & \\
\hline Calibradores & \\
\hline Valor de corte & $\mathrm{mg} / \mathrm{dl}$ \\
\hline
\end{tabular}

\begin{tabular}{|l||l|l|}
\hline Reactivo & & \\
\hline Papel de filtro & & \\
\hline
\end{tabular}

Resultados

\begin{tabular}{|c|c|c|c|l|l|}
\hline Control \# & \multicolumn{2}{|c|}{ Phe $(\mathrm{mg} / \mathrm{d})$} & Interpretación & Decisión \\
\hline 89 & & &, & & \\
\hline 90 & & &, & & \\
\hline
\end{tabular}

$\underline{\mathrm{TSH}}$

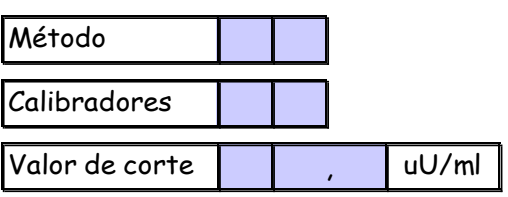

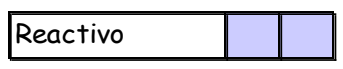

Papel de filtro

Resultados

\begin{tabular}{|c|c|c|c|l|l|}
\hline Control \# & \multicolumn{2}{|c|}{$T S H(u \mathrm{U} / \mathrm{m} /)$} & Interpretación & Decisión \\
\hline 89 & & &, & & \\
\hline 90 & & &, & & \\
\hline
\end{tabular}

IMPORTANTE: Todos los resultados deben expresarse por unidad de volumen de sangre entera.

Fundación Bioquímica Argentina. Calle 6 \# 1344. (1900) La Plata. Argentina.

Telefax (54)(221) 423-2021/4374/4375/4376/4377.

e-mail: peec-pn@fbpba.org.ar

Figura 88. Formulario para el reporte de resultados. 
Por otra parte, e inmediatamente después de despachados los sobres conteniendo los materiales antes descriptos vía correo postal, el PEEC-PN también remite por correo electrónico a todos los Laboratorios participantes un archivo conteniendo un formulario electrónico de reporte de resultados (Figura 88), y exclusivamente a aquellos Laboratorios pertenecientes a países diferentes de Argentina, una comunicación consignando el número de guía postal correspondiente al envío realizado, a efectos de facilitar el seguimiento de la correspondencia remitida a cada uno de ellos.

- Reporte de resultados: Los resultados obtenidos por los laboratorios participantes pueden ser reportados al PEEC-PN por 4 vías diferentes:

a) vía correo postal, utilizando el formulario impreso remitido por el PEEC-PN junto a los materiales de control de la encuesta,

b) vía fax, utilizando el mismo formulario que en la modalidad anterior,

c) vía e mail, empleando el formulario electrónico remitido oportunamente, y

d) On Line, a través de la página Web de la FBA (www.fba.org.ar) (Figura 89).

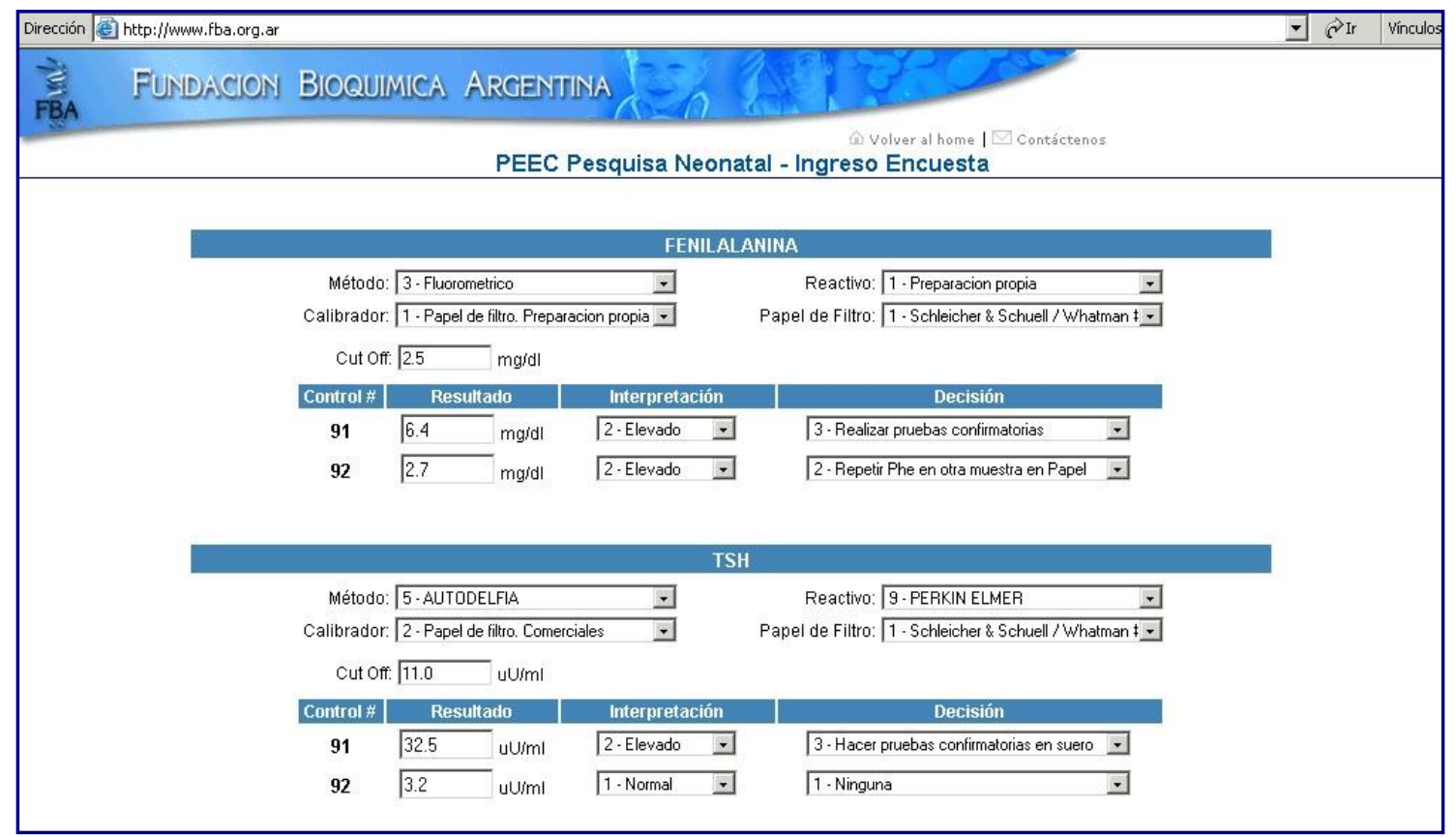

Figura 89. Carga On Line de resultados.

Independientemente de la disponibilidad de estas 4 opciones, el PEEC-PN siempre recomienda utilizar la carga On Line y el envío electrónico como 
alternativas prioritarias para el reporte de resultados, por su simplicidad, seguridad y rapidez.

- Evaluación e informe de resultados de cada encuesta: La evaluación de los resultados correspondientes a cada una de las encuestas comprende una primera sección en la cual se lleva a cabo un análisis descriptivo que incluye por un lado el $n^{\circ}$ de laboratorios inscriptos, el $n^{\circ}$ de respuestas recibidas, el $n^{\circ}$ de respuestas recibidas fuera de término y la distribución de las mismas según el país de procedencia (Figura 90); mientras que por el otro, incluye la distribución de los Laboratorios según el tipo de Método y Reactivo utilizado para el dosaje de cada analito, y según el Valor de Corte empleado para la interpretación de los resultados agrupados de acuerdo al principio analítico de medida utilizado (Figura 91).

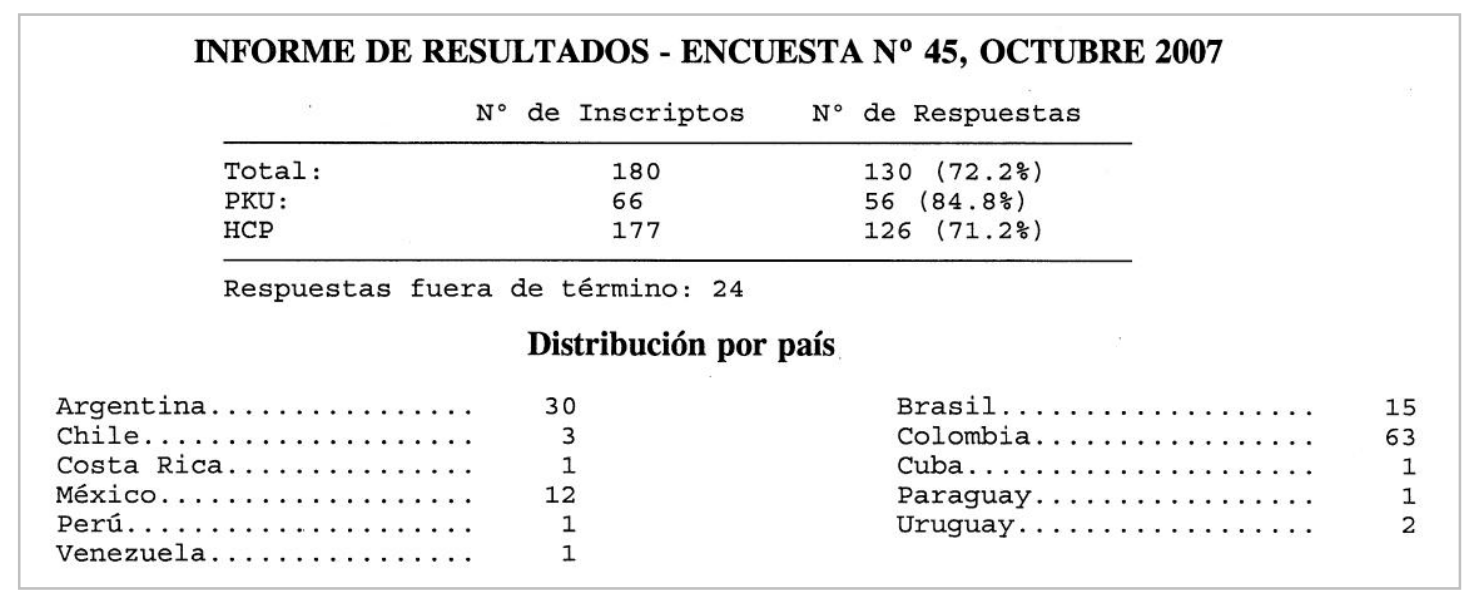

Figura 90. Evaluación general de los Laboratorios participantes.

En cuanto a los resultados analíticos propiamente dichos, los mismos son evaluados tanto desde el punto de vista cuantitativo como cualitativo, siguiendo para ello los criterios que se describen a continuación.

o Evaluación cuantitativa: la evaluación cuantitativa comprende un análisis estadístico global realizado sobre la totalidad de los resultados reportados por los Laboratorios participantes. Esta evaluación se realiza con independencia del principio analítico utilizado por cada uno de ellos en razón de que el número de Laboratorios no resulta estadísticamente significativo como para poder efec- 
tuar un análisis a fondo, discriminado por tipo de Método y Reactivo.

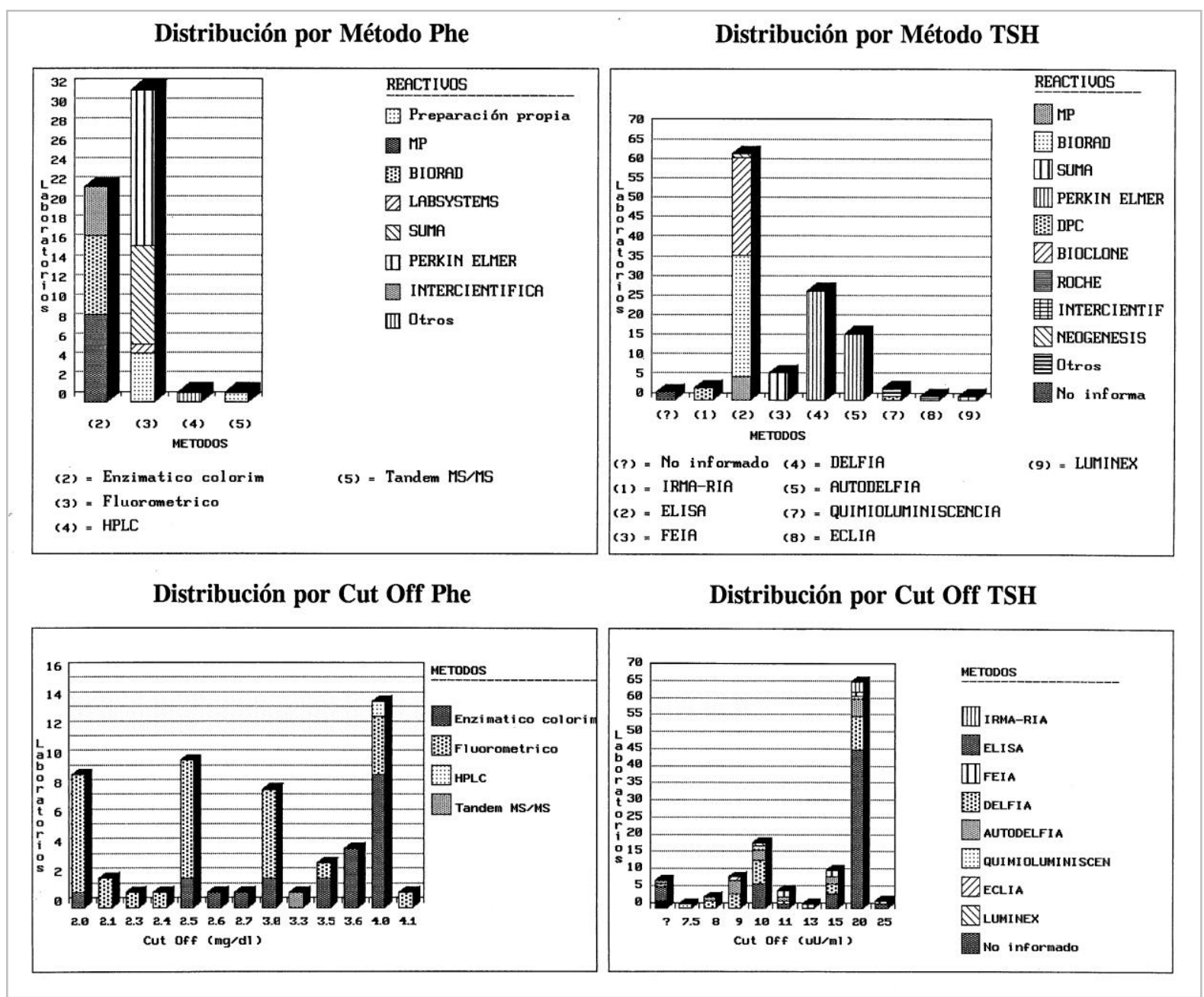

Figura 91. Distribución según Métodos, Reactivos y Valores de Corte utilizados.

Con respecto al tipo de estadísticas utilizadas en la evaluación, a lo largo de los 2 primeros años de trabajo se emplearon estadísticas paramétricas, pero en función de las características adoptadas por la distribución de los resultados, y de la evolución experimentada tanto en el diseño del propio programa como en el número y performance de los Laboratorios participantes, las mismas fueron sustituidas en Agosto de 2002 por estadísticas no paramétricas, las cuales se caracterizan por su robustez y por ser aplicables tanto a distribuciones normales como a no normales. De este modo los parámetros estadísticos y los criterios de aceptabilidad utilizados en cada período fueron los siguientes: 
- Período Junio 2000 - Julio 2002: en la Tabla 36 se presentan los parámetros estadísticos utilizados a lo largo de este período para describir el desempeño de los Laboratorios participantes.

Tabla 36. Estadísticas paramétricas

\begin{tabular}{|c|c|}
\hline Parámetros globales & Parámetros individuales \\
\hline - Media de Consenso $\left(X_{C}\right)$ & - Desvío Relativo Porcentual (DRP) \\
\hline - Desvío Estándar (DS) & - Número de Desvío Estándar (NDS) \\
\hline - Coeficiente de Variación (CV \%) & \\
\hline - Límite inferior $=X_{c}-2 D S$ & \\
\hline - Límite superior $=X_{C}+2 D S$ & \\
\hline
\end{tabular}

En cuanto a los criterios utilizados para definir la aceptación o el rechazo de un resultado, en esta primer etapa se empleó un criterio estrictamente estadístico definido por $\left(X_{C} \pm 2 D S\right)$, hecho que determinó que durante este período existiera plena coincidencia entre los resultados excluidos de la evaluación a partir del procedimiento de truncamiento estadístico y los resultados no aceptables.

Sumado a esto, y al solo efecto de realizar una aproximación, la mencionada evaluación también incluyó el cálculo de los principales parámetros estadísticos ( $X, D S$ y $C V$ ) correspondientes a los resultados agrupados por tipo de Método, aunque la misma sólo fue realizada en aquellos casos en los que se contó con 4 o más resultados por metodología.

- Período Agosto 2002 a la fecha: en la Tabla 37 se presentan los parámetros estadísticos utilizados en la evaluación a lo largo de este segundo período de trabajo.

Con respecto a los mencionados parámetros, se debe destacar que en este caso el DS no se calcula según la forma clásica y característica de las estadísticas paramétricas, sino empleando la siguiente fórmula:

$$
D S=R I / 1.349
$$


Tabla 37. Estadísticas no paramétricas

\section{Parámetros globales}

- Mediana de Consenso $\left(M_{C}\right)$

- Desvío Estándar (DS)

- Coeficiente de Variación (CV \%)

- Percentilo 25 (P25)

- Percentilo 75 (P75)

- Límite inferior $=$ P25 - 3 RI

- Límite superior $=$ P75 + 3 RI

NOTA: se define al Rango Intercuartil (RI), como: $R I=(P 75-P 25)$.
Parámetros individuales

- Desvío Relativo Porcentual (DRP)

- Número de Desvío Estándar (NDS)

\begin{tabular}{|c|c|c|c|c|}
\hline \multicolumn{5}{|c|}{ EVALUACION CUANTITATIVA } \\
\hline Analoto & \multicolumn{2}{|c|}{$\mathrm{PH}$} & \multicolumn{2}{|c|}{ TSt } \\
\hline Eontrol & \#89 & $\# 90$ & $\# 89$ & $\# 90$ \\
\hline Pantrelpantas & 56 & 56 & 126 & 125 \\
\hline $\mathbb{N}$ & 55 & 55 & 115 & 118 \\
\hline (H) & 2.1 & 4.2 & 27.4 & 6.0 \\
\hline $0 \mathrm{p}(6)$ & 0.44 & 0.89 & 5.34 & 1.52 \\
\hline ivi & 21.0 & 21.2 & 19.5 & 25.3 \\
\hline $\mathrm{PcS}(*)$ & 1.8 & 3.5 & 23.9 & 5.1 \\
\hline $\mathrm{PPS}(\mathrm{s})$ & 2.4 & 4.7 & 311 & 7.2 \\
\hline flceptab $\mathrm{IInf}$ & 1.53 & 3.36 & 21.24 & 4.39 \\
\hline 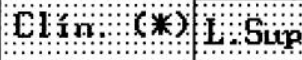 & 2.67 & 5.04 & 33.57 & 7.61 \\
\hline Exoluddos & 1 & 1 & 11 & 7 \\
\hline Result Eualit: & 0 & 0 & 0 & 0 \\
\hline Erm Transposso: & 1 & 1 & 1 & 1 \\
\hline Brr. Exponlunid & 0 & 0 & 5 & 4 \\
\hline
\end{tabular}

(*) UNIDADES: Phe $-\mathrm{mg} / \mathrm{dl}$ TSH $-\mathrm{UU} / \mathrm{ml}$

Figura 92. Evaluación cuantitativa global.

En la Figura 92 se puede observar la forma en que los parámetros antes descriptos son presentados en el informe del PEEC-PN, en el cual se incluye además un detalle de los límites de aceptabilidad clínica, de los resultados 
excluidos del análisis, de los resultados informados cualitativamente, de los errores de transposición y de los errores de expresión de unidades; mientras que en la Figura 93 se puede visualizar la forma en que se presentan los resultados individuales correspondientes a cada Laboratorio.

\begin{tabular}{|c|c|c|c|c|c|}
\hline \multicolumn{6}{|c|}{ Resultado del laboratorio } \\
\hline \multicolumn{2}{|r|}{ Analito } & \multicolumn{2}{|c|}{$\mathrm{phe}$} & \multicolumn{2}{|c|}{ TSH } \\
\hline & eontroj & $\# 89$ & $\# 90$ & $\# 89$ & $\# 90$ \\
\hline & $x i$ & 2.6 & 4.8 & 29.4 & 6.4 \\
\hline & QMRP & 23.8 & 14.3 & 7.3 & 6.7 \\
\hline PQRP & pax permit & \pm 27.0 & \pm 20.0 & \pm 22.5 & \pm 26.9 \\
\hline & MS & 1.1 & 0.7 & 0.4 & 0.3 \\
\hline
\end{tabular}

Figura 93. Evaluación cuantitativa individual.

En relación a los criterios de aceptabilidad utilizados, en este período se sustituyó el criterio estadístico empleado en la etapa anterior, por un criterio basado en la máxima desviación admisible para la toma de decisiones clínicas con respecto a los valores aceptados como verdaderos, al cual se designó como Criterio de Aceptabilidad Clínica.

De este modo, los nuevos límites de aceptabilidad fueron definidos inicialmente -tanto para Phe como para TSH- como límites fijos e independientes de la concentración del analito, en un DRP de $\pm 25 \%$.

No obstante lo mencionado anteriormente, debe destacarse que, de acuerdo con la planificación realizada al implementar este nuevo criterio de aceptabilidad -en la cual se previó la introducción progresiva de estándares de calidad más estrictos a efectos de propiciar una superación permanente en el desempeño de los Laboratorios participantes a partir de la utilización de límites de aceptabilidad más exigentes-, con posterioridad los mencionados límites se fueron modificando tal como lo demuestra la información presentada en la Tabla 38.

Adicionalmente también se debe destacar que estos cambios no sólo afecta- 
ron la magnitud de los límites de aceptabilidad, sino también la forma de definición de los mismos.

Esta última acción se realizó con la finalidad de optimizar los criterios de aceptabilidad a utilizar dentro del rango de valores normales de ambos analitos puesto que, a este nivel, necesariamente debe admitirse una mayor tolerancia en los límites definidos. Esto se debe al hecho de que las implicancias clínicas de la desviación de un resultado particular con respecto al valor verdadero o al valor de consenso son mucho menores que en los niveles de decisión clínica, y por otra parte porque a bajas concentraciones entra en juego una mayor variabilidad intrínseca de los métodos de medida determinada por la relación hiperbólica inversa que existe entre el CV y la concentración, lo cual indudablemente puede dar lugar a que algunos resultados sean innecesariamente clasificados como no aceptables.

En función de esto, se pasó de utilizar límites fijos e independientes de la concentración del analito, a emplear límites ajustados según el nivel de cada uno de ellos como puede visualizarse en la Tabla 38.

Tabla 38. Evolución experimentada en los criterios de aceptabilidad

\begin{tabular}{|c|c|c|c|}
\hline Período & Tipo de Criterio & Phe & TSH \\
\hline $\begin{array}{c}\text { Jun/00- } \\
\text { Jul/02 }\end{array}$ & Estadístico & $X \pm 2 D S$ & $X \pm 2 D S$ \\
\hline $\begin{array}{l}\text { Ago/02- } \\
\text { May/05 }\end{array}$ & $\begin{array}{c}\text { Clínico. } \\
\text { Fijo e independiente } \\
\text { de la concentración } \\
\text { del analito }\end{array}$ & $D R P= \pm 25.0 \%$ & DRP $= \pm 25.0 \%$ \\
\hline $\begin{array}{l}\text { Jun/05- } \\
\text { May/07 }\end{array}$ & $\begin{array}{c}\text { Clínico. } \\
\text { Ajustado según la } \\
\text { concentración del } \\
\text { analito }\end{array}$ & $\begin{array}{c}- \text { Phe } \leq 3.5 \mathrm{mg} / \mathrm{dl}: \\
\text { DRP variable }= \\
( \pm 40.0 \% \mathrm{a} \pm 22.5 \%) \\
\text { - Phe }>3.5 \mathrm{mg} / \mathrm{dl}: \\
\text { DRP }= \pm 22.5 \%\end{array}$ & $\begin{array}{c}\text { - TSH } \leq 8.0 \mu \mathrm{U} / \mathrm{ml}: \\
\text { DRP variable }= \\
( \pm 40.0 \% a \mathrm{a} \pm 25.0 \%) \\
\text { - TSH }>8.0 \mu \mathrm{U} / \mathrm{ml}: \\
\text { DRP }= \pm 25.0 \%\end{array}$ \\
\hline Jun/07- & $\begin{array}{c}\text { Clínico. } \\
\text { Ajustado según la } \\
\text { concentración del } \\
\text { analito }\end{array}$ & $\begin{array}{l}- \text { Phe } \leq 3.5 \mathrm{mg} / \mathrm{dl}: \\
\text { DRP variable }= \\
\quad( \pm 37.5 \% \mathrm{a} \pm 20.0 \%) \\
\text { - Phe }>3.5 \mathrm{mg} / \mathrm{dl}: \\
\text { DRP }= \pm 20.0 \%\end{array}$ & $\begin{array}{c}\text { - TSH } \leq 8.0 \mu \mathrm{U} / \mathrm{ml}: \\
\text { DRP variable }= \\
( \pm 40.0 \% a \pm 22.5 \%) \\
\text { - TSH }>8.0 \mu \mathrm{U} / \mathrm{ml}: \\
\text { DRP }= \pm 22.5 \%\end{array}$ \\
\hline
\end{tabular}


Como puede inferirse a partir de la descripción anterior, el hecho de que los criterios empleados para definir los límites utilizados en el truncamiento estadístico de datos y los límites de Aceptabilidad Clínica sean diferentes determina que en la práctica los valores numéricos de dichos límites también sean diferentes, y que por lo tanto, en función de esta propiedad, se pueda establecer una clara diferenciación entre resultados estadísticamente aceptables y resultados clínicamente aceptables.

Por otra parte, y siguiendo una modalidad de evaluación similar a la utilizada en el período anterior, en esta segunda etapa también se calcularon los principales parámetros estadísticos (M, DS, CV) para cada tipo de Método, aunque en este caso agrupados además por tipo de Método y Reactivo tal como se muestra en la Figura 94.

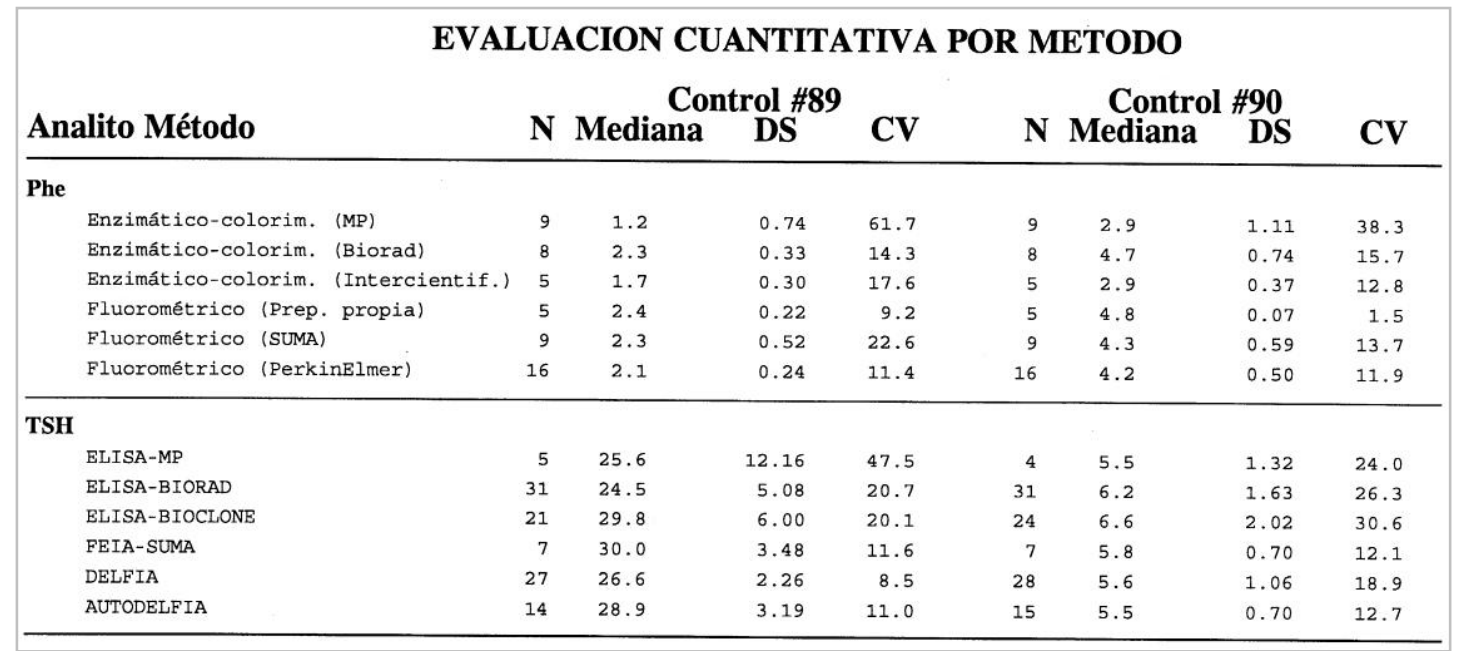

Figura 94. Evaluación cuantitativa por tipo de Método y Reactivo.

En otro orden de cosas también es importante mencionar que, independientemente del tipo de estadísticas utilizado, en ambos períodos fueron excluidos del cálculo todos aquellos resultados interpretados como errores de transposición o de expresión de unidades, y también aquellos resultados cuyos valores se alejaron significativamente de la distribución general ("outliers") a través de un procedimiento de truncamiento estadístico.

Finalmente, y para completar la evaluación cuantitativa, con los resultados de cada Laboratorio se realizó también un análisis gráfico para cada analito 
mediante la confección de Gráficos de Convergencia de Youden (Figura 95), tomando como referencia en cada período los parámetros estadísticos correspondientes, es decir $X_{c},-2 D S$ y $+2 D S$ en el primero de ellos, y $M_{c}$ y Límites Inferior (LI) y Superior (LS) de Aceptabilidad Clínica en el segundo.
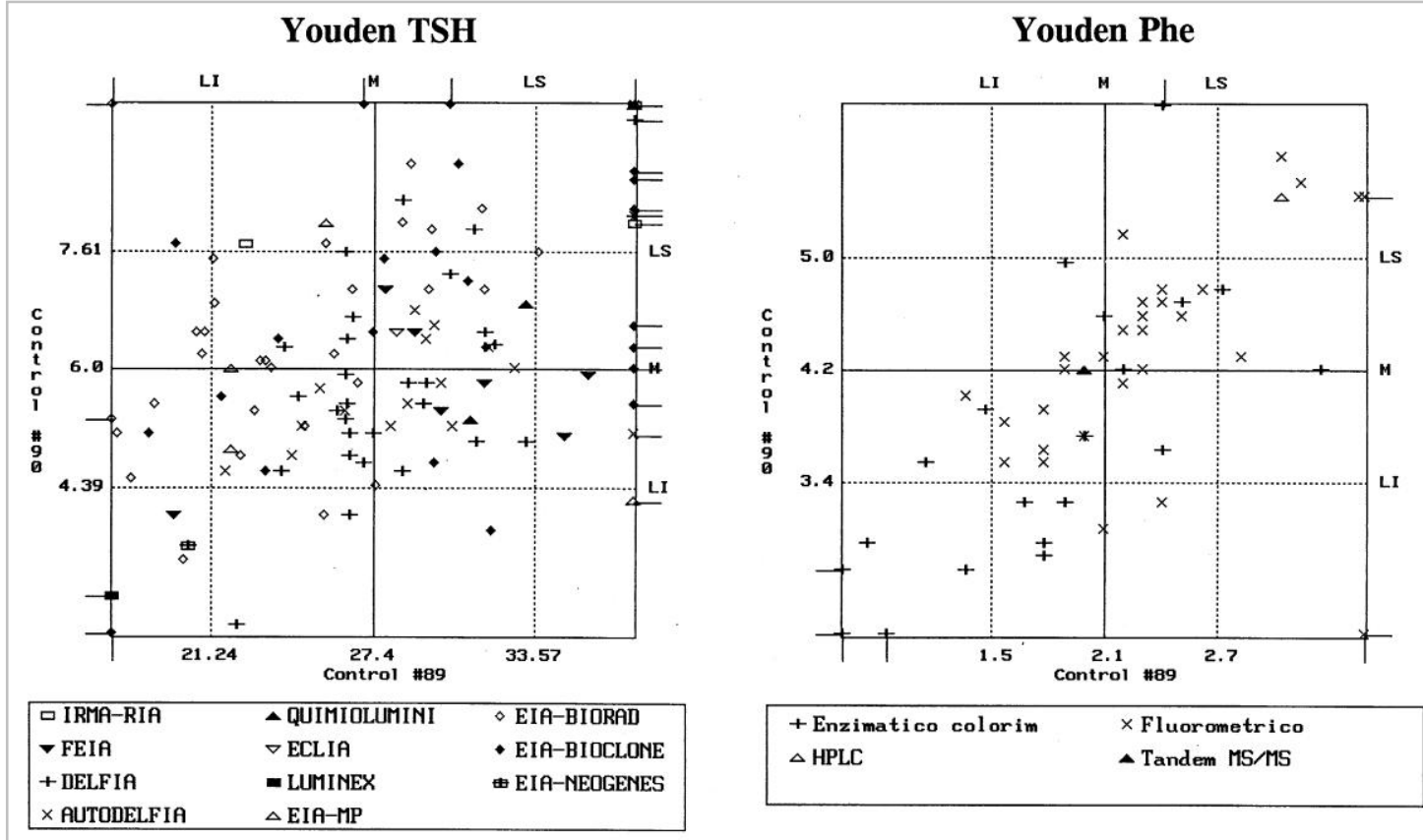

Figura 95. Gráficos de Youden.

\begin{tabular}{|c|c|c|c|c|c|c|c|c|c|c|}
\hline \multicolumn{11}{|c|}{ EVALUACION CUALITATIVA } \\
\hline \multicolumn{6}{|c|}{ nrteropereron } & \multicolumn{3}{|c|}{ oecrenon: } & \multirow{2}{*}{\multicolumn{2}{|c|}{ 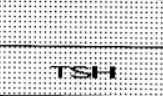 }} \\
\hline 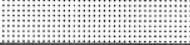 & 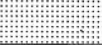 & \multicolumn{2}{|c|}{$p \times$} & \multicolumn{2}{|c|}{ 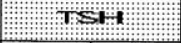 } & 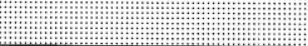 & \multicolumn{2}{|c|}{$r \times$} & & \\
\hline \multicolumn{2}{|l|}{ Control } & $\# 89$ & $\# 90$ & $\# 89$ & $\# 98$ & Control & $\# 89$ & $\# 98$ & $\# 89$ & $\# 98$ \\
\hline \multicolumn{2}{|l|}{1 - Normal } & 46 & 11 & Oans & $119(*)$ & 1 - Ninguna & 45 & 18 & 9 & $117(*)$ \\
\hline \multicolumn{2}{|l|}{2 - El evado } & $18(*)$ & $45(*)$ & $116(*)$ & 12 & 2 - Repetir en papel & $8(*)$ & $29(*)$ & 16 & 3 \\
\hline \multicolumn{2}{|l|}{$28-0$ tra } & & & & & 3 - Confirmación & 3 & 17 & $68(*)$ & 1 \\
\hline \multicolumn{2}{|l|}{ No informa } & & & 2 & 2 & 4 - Rep. en papel y suero & & & 38 & 1 \\
\hline \multirow{2}{*}{\multicolumn{6}{|c|}{ Falsos Negativos }} & $28-0$ tra & & & & \\
\hline & & & & & & No inf orma & & & 3 & 3 \\
\hline \multicolumn{11}{|c|}{ OBSERVACIONES } \\
\hline \multicolumn{11}{|c|}{ Su laboratorio respondió correctamente la encuesta } \\
\hline \multicolumn{11}{|c|}{ ACEPTABILIDAD CLINICA } \\
\hline \multicolumn{6}{|c|}{ Control \#89 } & Control \#90 & & & & \\
\hline & Phe & \multicolumn{4}{|c|}{ Aceptable } & Aceptable & & & & \\
\hline & TSH & \multicolumn{4}{|c|}{ Aceptable } & Aceptable & & & & \\
\hline
\end{tabular}

Figura 96. Evaluación Cualitativa, Observaciones y Aceptabilidad Clínica. 
- Evaluación cualitativa: La evaluación cualitativa de los resultados reportados por los Laboratorios participantes comprende un análisis de las interpretaciones y decisiones tomadas por cada uno de ellos con sus propios resultados, con respecto a la clasificación efectuada por el PEEC-PN de acuerdo a los niveles teóricos de cada analito en cada control y a los valores de consenso globales obtenidos a partir del análisis cuantitativo (Figura 96).

o Observaciones: finalmente el informe de resultados presenta también un recuadro de observaciones, en el cual se indica para cada laboratorio la condición de aceptable o no aceptable de cada resultado informado; detallándose además si los resultados fueron remitidos con posterioridad a la fecha de cierre de la encuesta, cuales fueron excluidos del análisis estadístico ("outliers"), cuales correspondieron a errores de transposición de resultados, de expresión en las unidades de TSH o de interpretación de los mismos, y cuales correspondieron a resultados falsos negativos o falsos positivos; mientras que si no se presentó ninguna de las situaciones antes detalladas la observación hace referencia a que "el Laboratorio respondió correctamente la encuestd" tal como se puede visualizar en la Figura 96.

o Comentarios editoriales: adicionalmente a toda la información antes descripta que forma parte del informe de resultados de cada encuesta, el PEEC-PN remite también un texto adjunto, en el cual se explican suscintamente los criterios utilizados para realizar la evaluación estadística y se incluye una sección en la que, a modo de editorial, se realizan comentarios específicos acerca de aquellos resultados que merecen una opinión por parte del PEEC-PN, más allá de la interpretación que cada participante pueda realizar a partir de su propio análisis del informe de resultados en sí mismo.

- Informe anual: tal como ya fuera mencionado en la Tabla 35, además del informe propio de cada encuesta, el PEEC-PN también emite un informe anual en el cual se evalúan en conjunto los resultados de las 6 encuestas correspondientes al período en cuestión, en general, desde un punto de vista diferente al abordado en los informes individuales de cada una de las encuestas. 
El mencionado informe anual comprende un análisis detallado de los siguientes aspectos:

o Descripción general en relación a la participación de los laboratorios:

- Número de respuestas totales recibidas y de respuestas recibidas para cada analito con respecto al número de Laboratorios inscriptos y de Laboratorios registrados para Phe y para TSH en cada encuesta (Figura 97).

- Número de respuestas recibidas fuera de término.

- Número total de laboratorios inscriptos en el período, incluyendo el número de altas y bajas experimentadas, y el motivo de estas últimas.

- Crecimiento porcentual respecto del período anual anterior.

- Distribución de participantes de acuerdo al país de procedencia.

- Clasificación de los materiales de control provistos en cada encuesta como elevados, normales o indeterminados de acuerdo a la $M_{c}$ determinada para cada uno de ellos.

\begin{tabular}{|l|c|c|c|c|c|c|}
\hline & \multicolumn{7}{|c|}{ Encuesta \# } \\
\cline { 2 - 7 } & 37 & 38 & 39 & 40 & 41 & 42 \\
\hline$N^{0}$ de respuestas recibidas/ & $133 / 159$ & $131 / 164$ & $131 / 167$ & $125 / 169$ & $141 / 170$ & $149 / 180$ \\
$N^{0}$ de inscriptos - Totales & $(83.6 \%)$ & $(79.9 \%)$ & $(78.4 \%)$ & $(74.0 \%)$ & $(82.9 \%)$ & $(82.8 \%)$ \\
\hline$N^{0}$ de respuestas recibidas/ & $50 / 57$ & $51 / 58$ & $48 / 60$ & $47 / 60$ & $48 / 59$ & $58 / 63$ \\
$N^{0}$ de inscriptos - Phe & $(87.7 \%)$ & $(87.9 \%)$ & $(80.0 \%)$ & $(78.3 \%)$ & $(81.4 \%)$ & $(92.1 \%)$ \\
\hline$N^{0}$ de respuestas recibidas/ & $127 / 153$ & $126 / 159$ & $127 / 163$ & $122 / 165$ & $137 / 166$ & $145 / 176$ \\
$N^{0}$ de inscriptos - TSH & $(83.0 \%)$ & $(79.2 \%)$ & $(77.9 \%)$ & $(73.9 \%)$ & $(82.5 \%)$ & $(82.4 \%)$ \\
\hline$N^{0}$ de respuestas fuera de & 19 & 31 & 54 & 35 & 30 & 30 \\
término & $(14.3 \%)$ & $(23.7 \%)$ & $(41.2 \%)$ & $(28.0 \%)$ & $(21.3 \%)$ & $(20.1 \%)$ \\
\hline
\end{tabular}

Figura 97. Informe Anual: Resultados generales.

o Desempeño colectivo: esta sección incluye un análisis estadístico detallado, similar al realizado para cada control en cada encuesta particular tal como se puede visualizar en la Figura 98. En el mismo se incluyen los siguientes parámetros:

- Número de respuestas recibidas para cada analito.

- Número de respuestas estadísticamente aceptables, excluidas de la evaluación ("outliers") y cualitativas. 
- Número de errores de transposición y de interpretación de resultados, y número de errores de expresión de unidades.

- Número de falsos negativos y falsos positivos.

- Concentración teórica del analito en la preparación, $M_{C}$, DS y CV.

\begin{tabular}{|c|c|c|c|c|c|c|c|c|c|c|c|c|c|c|}
\hline Phe & \multicolumn{10}{|c|}{ Control \# } & \multirow{2}{*}{ Total } & \% \\
\hline$N^{\circ}$ de respuestas & $\mathbf{7 3}$ & $\mathbf{7 4}$ & $\mathbf{7 5}$ & $\mathbf{7 6}$ & $\mathbf{7 7}$ & $\mathbf{7 8}$ & $\mathbf{7 9}$ & $\mathbf{8 0}$ & $\mathbf{8 1}$ & $\mathbf{8 2}$ & $\mathbf{8 3}$ & $\mathbf{8 4}$ & & \\
\hline Recibidas & 50 & 50 & 51 & 51 & 48 & 48 & 47 & 47 & 48 & 48 & 58 & 58 & 604 & \\
\hline Aceptables & 50 & 48 & 50 & 50 & 48 & 48 & 46 & 46 & 48 & 48 & 57 & 56 & $\mathbf{5 9 5}$ & $\mathbf{9 8 . 5}$ \\
\hline Excluidas & 0 & 2 & 1 & 1 & 0 & 0 & 1 & 1 & 0 & 0 & 1 & 2 & 9 & 1.5 \\
\hline Cualitativas & 0 & 2 & 0 & 0 & 0 & 0 & 0 & 0 & 0 & 0 & 0 & 0 & 2 & 0.3 \\
\hline Errores de transpos. & 0 & 0 & 0 & 0 & 0 & 0 & 1 & 1 & 0 & 0 & 0 & 0 & 2 & 0.3 \\
\hline Errores de unidades & 0 & 0 & 0 & 0 & 0 & 0 & 0 & 0 & 0 & 0 & 0 & 0 & 0 & 0.0 \\
\hline Errores de interpret. & 0 & 0 & 2 & 0 & 3 & 0 & 1 & 1 & 0 & 0 & 0 & 0 & 7 & 1.2 \\
\hline Falsos negativos & - & - & - & 1 & - & 1 & 4 & - & - & 2 & - & 3 & 11 & 4.4 \\
\hline Falsos positivos & - & 1 & - & - & - & - & - & - & 0 & - & - & - & 1 & 1.0 \\
\hline
\end{tabular}

Tabla IV. Evaluación general Phe.

\begin{tabular}{|l|c|c|c|c|c|c|c|c|c|c|c|c|}
\hline & \multicolumn{10}{|c|}{ Phe (mg/dl) } \\
\hline \multicolumn{1}{|c|}{ Control \# } & $\mathbf{7 3}$ & $\mathbf{7 4}$ & $\mathbf{7 5}$ & $\mathbf{7 6}$ & $\mathbf{7 7}$ & $\mathbf{7 8}$ & $\mathbf{7 9}$ & $\mathbf{8 0}$ & $\mathbf{8 1}$ & $\mathbf{8 2}$ & $\mathbf{8 3}$ & $\mathbf{8 4}$ \\
\hline Concentración teórica & 4.0 & 1.5 & 5.0 & 7.5 & 4.0 & 8.0 & 5.5 & 3.0 & 1.5 & 6.0 & 3.5 & 7.0 \\
\hline Mediana de consenso & 2.6 & 1.2 & 4.0 & 6.5 & 4.1 & 8.3 & 5.7 & 3.3 & 1.5 & 5.0 & 3.0 & 5.2 \\
\hline Desvio estándar & 0.87 & 0.44 & 1.00 & 1.45 & 1.06 & 1.65 & 1.07 & 0.80 & 0.44 & 0.76 & 0.67 & 0.91 \\
\hline CV \% & 33.5 & 36.7 & 25.0 & 22.3 & 25.9 & 19.9 & 18.8 & 24.2 & 29.3 & 15.2 & 22.3 & 17.5 \\
\hline
\end{tabular}

Tabla V. Resultados Phe.

Figura 98. Informe Anual: Desempeño colectivo.

o Métodos:

- Distribución de laboratorios de acuerdo al principio analítico utilizado.

- Análisis y discusión detallada del desempeño de cada Método y Reactivo, incluyendo un estudio de correlación con respecto a los valores de consenso.

o Resultados excluidos, falsos negativos y falsos positivos:

- Distribución según el tipo de método utilizado en forma absoluta y también relativa a la cantidad de respuestas reportadas con cada uno de ellos.

- Influencia de los errores de transposición, interpretación y de expresión de unidades como generadores de resultados excluidos y de falsos resultados.

- Frecuencia de presentación de resultados excluidos, falsos negativos y falsos positivos por laboratorio.

o Aceptabilidad Clínica:

- Análisis detallado del Índice de Aceptabilidad Clínica para cada analito en cada control. 
- Distribución absoluta de respuestas aceptables y no aceptables según el principio analítico utilizado para la medida, e incidencia relativa (porcentual) de resultados aceptables para cada uno de ellos en forma particular.

o Desempeño individual de cada Laboratorio:

- Análisis gráfico del DRP con sus respectivos límites de aceptabilidad para ambos analitos y para cada uno de los controles evaluados (Figura 99).

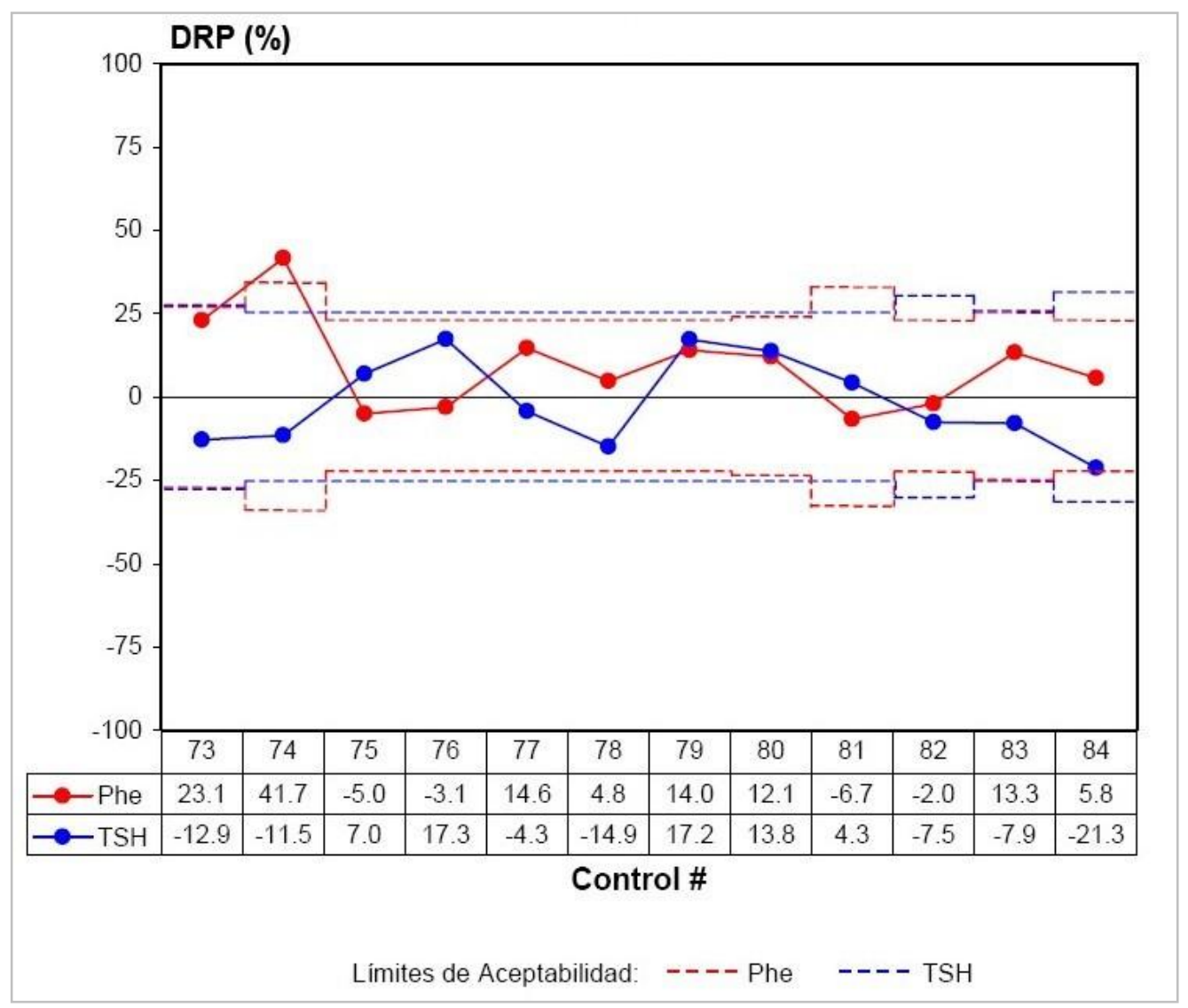

Figura 99. Informe Anual: Evaluación gráfica y personalizada del DRP.

- Resumen sinóptico presentado en forma de Tabla incluyendo los parámetros generales más importantes que caracterizan el desempeño de cada participante en cada Encuesta y para cada control, a saber: participación, respuestas recibidas fuera de término, resultados excluidos, resultados cualitativos, errores de transposición, errores de interpretación, errores de unidades, falsos negativos, falsos positivos y aceptabilidad clínica (Figura 100). Con respecto a la información incluida dentro de este ítem, y por tratarse de información específica de cada Laboratorio participante, la misma sólo es 
remitida en forma personalizada a cada Laboratorio, y por lo tanto no se trata de información de acceso general.

\begin{tabular}{|c|c|c|c|c|c|c|c|c|c|c|}
\hline \multirow[t]{2}{*}{ Control \# } & \multirow[b]{2}{*}{$F T$} & \multicolumn{9}{|c|}{ Phe } \\
\hline & & $P$ & RE & $R C$ & $E T$ & EI & $E U$ & $F N$ & $F P$ & $A C$ \\
\hline 73 & & SI & & & & & & & & A \\
\hline 74 & & SI & & & & & & & & NA \\
\hline 75 & & SI & & & & & & & & $A$ \\
\hline 76 & & SI & & & & & & & & $A$ \\
\hline 77 & & SI & & & & & & & & A \\
\hline 78 & & SI & & & & & & & & A \\
\hline 79 & & SI & & & & & & & & A \\
\hline 80 & & SI & & & & & & & & A \\
\hline 81 & & SI & & & & & & & & A \\
\hline 82 & & SI & & & & & & & & A \\
\hline 83 & SI & SI & & & & & & & & A \\
\hline 84 & SI & SI & & & & & & & & A \\
\hline Total & 2 & 12 & 0 & 0 & 0 & 0 & 0 & 0 & 0 & 1 \\
\hline
\end{tabular}

\begin{tabular}{|c|c|c|c|c|c|c|c|c|c|c|}
\hline \multirow[t]{2}{*}{ Control \# } & & \multicolumn{9}{|c|}{ TSH } \\
\hline & $F T$ & $P$ & RE & $R C$ & $E T$ & $E I$ & EU & $F N$ & $F P$ & $A C$ \\
\hline 73 & & SI & & & & & & & & $A$ \\
\hline 74 & & SI & & & & & & & & A \\
\hline 75 & & SI & & & & & & & & A \\
\hline 76 & & SI & & & & & & & & A \\
\hline 77 & & SI & & & & & & & & A \\
\hline 78 & & SI & & & & & & & & A \\
\hline 79 & & SI & & & & & & & & $A$ \\
\hline 80 & & SI & & & & & & & & A \\
\hline 81 & & SI & & & & & & & & $A$ \\
\hline 82 & & SI & & & & & & & & A \\
\hline 83 & SI & SI & & & & & & & & A \\
\hline 84 & SI & SI & & & & & & & & A \\
\hline Total & 2 & 12 & 0 & 0 & 0 & 0 & 0 & 0 & 0 & 0 \\
\hline
\end{tabular}

Tabla XVI: Desempeño individual: FT: respuestas recibidas fuera de término, P: Participación, RE: resultado exeluido, RC: resultado eualitativo, ET: error de transposición, EI: error de interpretación, EU: error de unidades, FN: falso negativo, FP: falso positivo, AC: aceptabilidad clínica (A: aceptable, NA no aceptable).

Figura 100. Informe Anual: Desempeño individual.

\section{- RESULTADOS}

- Período evaluado: Junio/2000 - Mayo/2007.

A los fines de la evaluación, y en concordancia con la modalidad de trabajo definida por el PEEC-PN, el mismo será dividido en 7 períodos anuales -no coincidentes con el año calendario- identificados desde el \# 1 al \# 7. 
- Laboratorios inscriptos y participación: a lo largo de sus primeros 7 años de trayectoria el PEEC-PN recibió la solicitud de inscripción de un total de 270 Laboratorios de 13 países de Latinoamérica que incluyen a Argentina, Bolivia, Brasil, Chile, Colombia, Costa Rica, Cuba, Ecuador, México, Paraguay, Perú, Uruguay y Venezuela, siendo éste un indicador que evidencia claramente la trascendencia que el mencionado Programa adquirió en la región con el transcurso del tiempo.

A efectos de ilustrar algunos aspectos relacionados con la participación de los diferentes Laboratorios que se han inscripto en el mencionado Programa, a continuación serán presentados diferentes análisis gráficos, los cuales sin lugar a dudas son un claro reflejo tanto de la forma en que la PN está siendo implementada y ejecutada en los diferentes países de Latinoamérica como de las propias características de dichos Laboratorios.

o Número de Laboratorios inscriptos en el PEEC-PN en cada período anual:

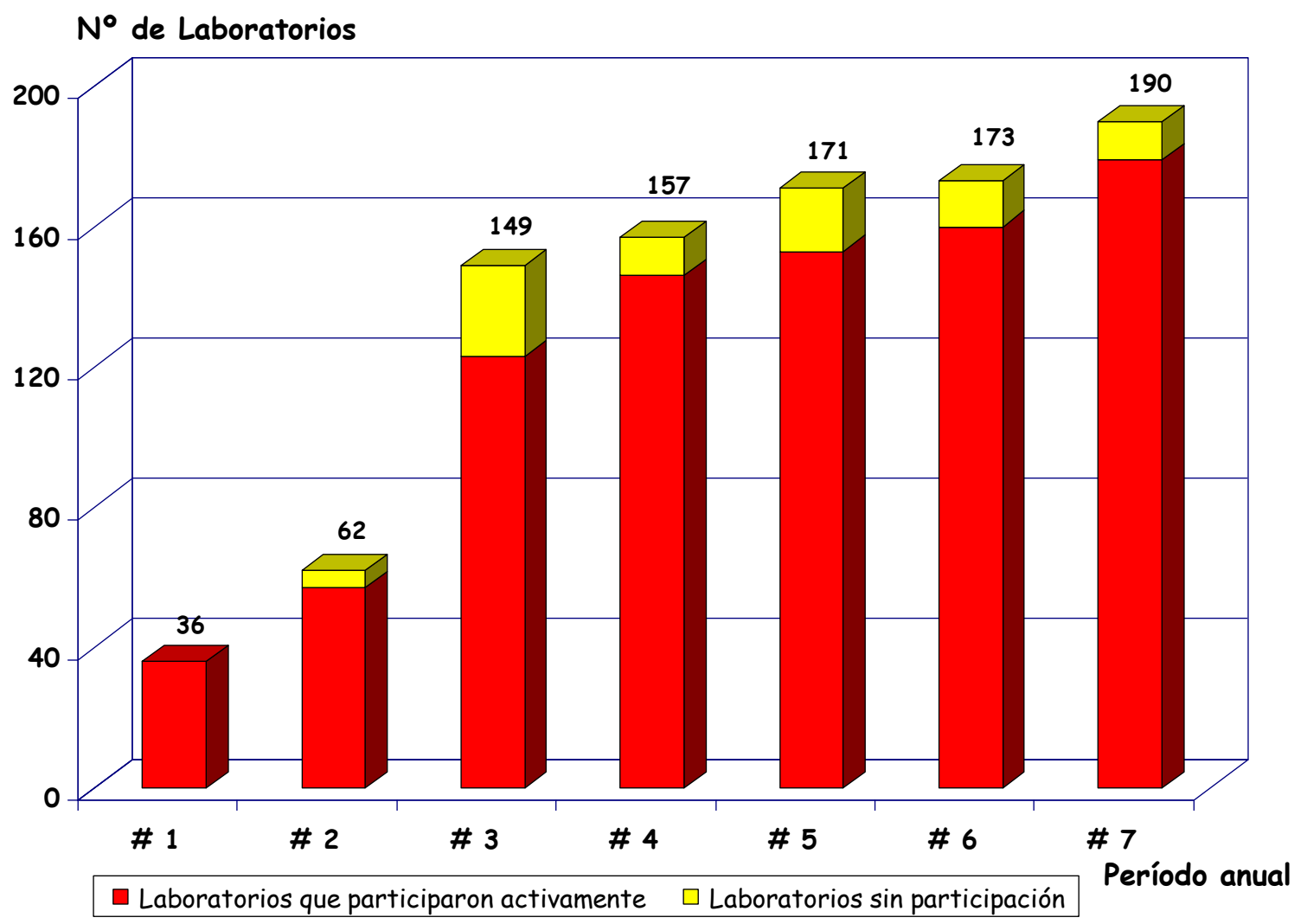

Figura 101. Número de Laboratorios inscriptos en cada período anual.

NOTA: Los laboratorios indicados como "Laboratorios sin participación" corresponden a Laboratorios que se inscribieron en el PEEC-PN pero nunca reportaron resultados. 
Como puede visualizarse en la Figura 101, el número de Laboratorios inscriptos ha mostrado un crecimiento continuo a lo largo del tiempo, observándose un marcado punto de inflexión en el Período Anual \# 3.

Como dato particular, del total de 270 Laboratorios inscriptos que se mencionaran anteriormente hubo 29 de ellos (10.7 \%) que, a pesar de haberse inscripto, nunca reportaron sus resultados ("Laboratorios sin participación").

A su vez, dentro de este grupo de 29 Laboratorios hay 2 que se diferencian del resto por el hecho de que se trata de Laboratorios que se inscribieron en la última encuesta incluida dentro del período evaluado y que no remitieron los resultados correspondientes a dicha encuesta, pero que con posterioridad han mantenido una participación activa.

o Distribución de Laboratorios inscriptos según el país de procedencia:

\section{$N^{\circ}$ de Laboratorios}

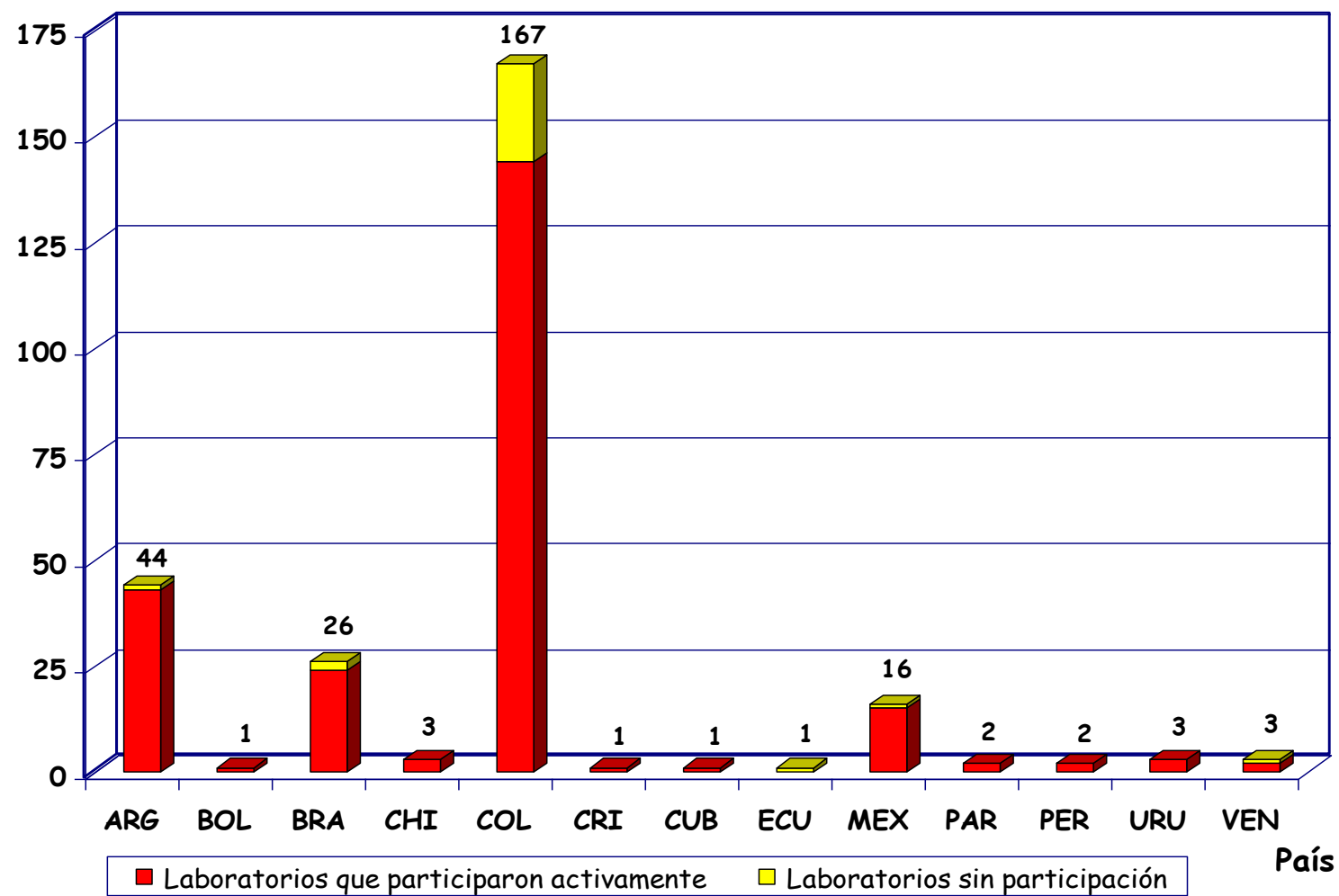

Figura 102. Distribución del total de Laboratorios inscriptos según el país de procedencia.

En relación a la distribución de Laboratorios según el país de procedencia el dato más destacado es la preponderancia de Laboratorios de Colombia, cuya 
contribución alcanza al $61.9 \%$ del total de inscriptos. Este hecho no es ni más ni menos que un reflejo contundente de la modalidad de ejecución de la PN en dicho país, la cual -si bien es obligatoria por Ley- no está prevista en forma centralizada, sino que por el contrario, al ser considerada como parte de las acciones rutinarias correspondientes a la atención integral del parto, cada institución que atiende un nacimiento es responsable de realizar las mencionadas pruebas de pesquisa (3).

De este modo se ha dado lugar a una atomización muy significativa en centenares de Laboratorios de análisis clínicos que en ocasiones no están en condiciones de dar continuidad a las pruebas de pesquisa en razón de diferentes causas que incluyen desde complicaciones operativas relacionadas con el escaso número de RN pesquisados hasta motivos económicos relacionados con el bajo rendimiento de reactivos y los altos costos resultantes, situación que también se ve reflejada en el hecho de que 23 de los 29 Laboratorios que nunca remitieron resultados $(79.3 \%)$ provienen precisamente de este país.

Por otra parte, y como dato adicional se debe mencionar que 6 de estos 23 Laboratorios $(26.1 \%$ ) solicitaron voluntariamente su baja en el PEEC-PN inmediatamente después de la primer encuesta en la cual participaron, poniendo en evidencia así que los mismos ni siquiera estuvieron en condiciones de concretar la implementación de las pruebas de pesquisa.

Volviendo al análisis de la distribución de Laboratorios según el país de procedencia, y en contraposición con el elevado número de Laboratorios inscriptos en el PEEC-PN provenientes de Colombia, se encuentran otros países que apenas cuentan con 1, 2 o a lo sumo 3 representantes. Este hecho también tiene relación con la situación de la PN en cada país $y$, mayoritariamente, refleja 2 situaciones extremas y contrapuestas: por un lado, países que cuentan con un programa nacional centralizado como es el caso de Chile, Costa Rica y Uruguay (3) y, por el otro, países en los cuales las actividades de PN son mínimas y realizadas desde laboratorios privados como es el caso de Ecuador y Bolivia (3). 
Por último, y como se puede inferir a partir de la Figura 103, el marcado punto de inflexión observado en el número de Laboratorios inscriptos en el Período Anual \# 3 también resultó influenciado en forma directa por la modalidad de implementación de la PN en Colombia puesto que en este país la obligatoriedad de la misma se estableció por Ley en el año 2000, determinando así que a partir de fines de 2001 y, fundamentalmente, desde mediados de 2002 en adelante, se desencadenara un proceso de incorporación masiva de Laboratorios al PEEC-PN.

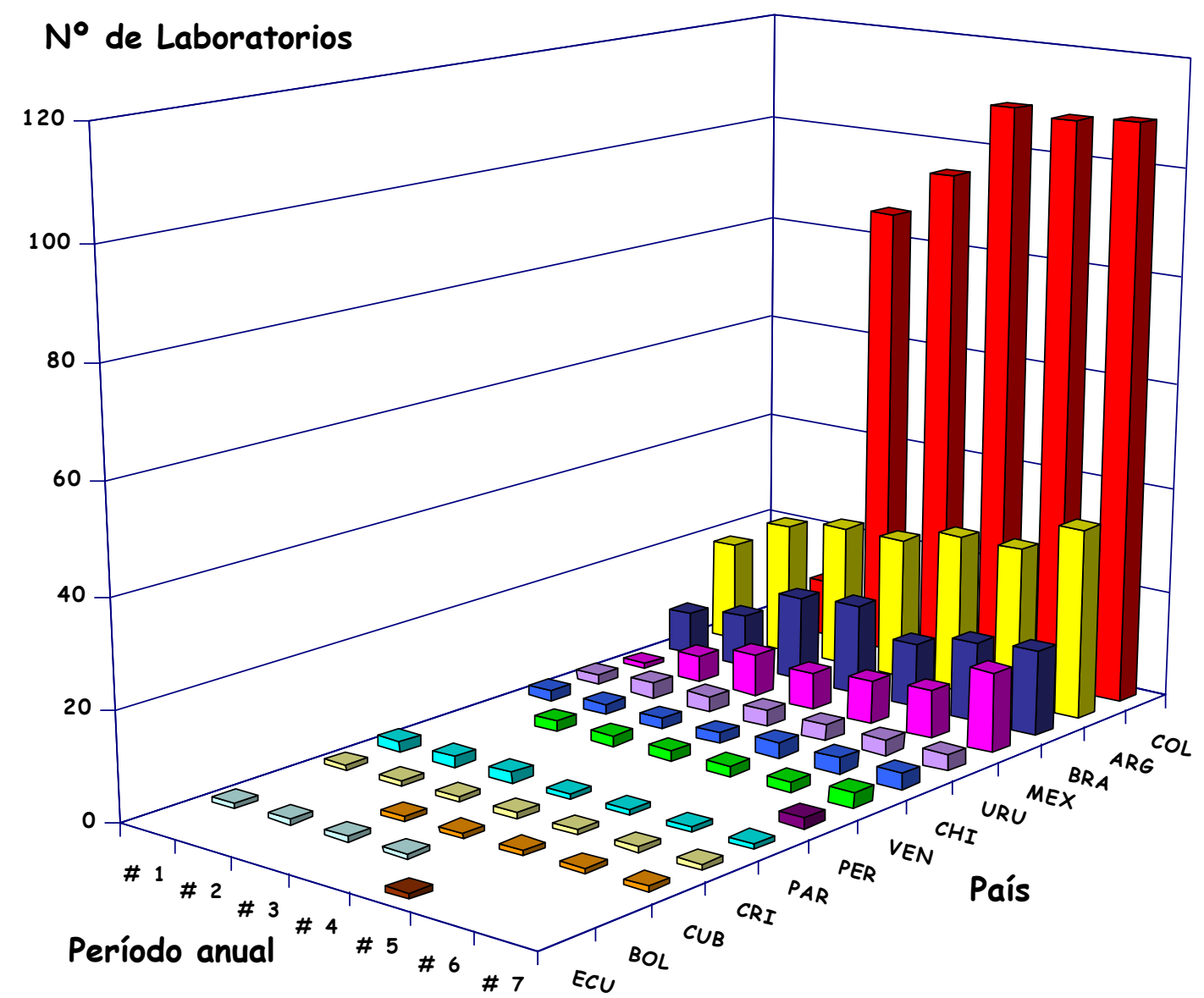

Figura 103. Distribución de Laboratorios inscriptos en cada período anual según el país de procedencia.

o Cumplimiento y compromiso de participación:

El análisis conjunto de las informaciones presentadas en las Figuras 101 y 103 con respecto al número total de Laboratorios inscriptos, pone en evidencia que éste último número resultó ser significativamente superior al número de Laboratorios inscriptos en cada uno de los 7 períodos anuales evaluados. Este 
hecho pone en evidencia que existe un recambio permanente de Laboratorios participantes determinado por nuevos Laboratorios que solicitan su ingreso al Programa mientras que otros cancelan su participación voluntariamente o bien son dados de baja por el PEEC-PN por no remitir resultados en 4 encuestas consecutivas. Sumado a esto, existe también un componente adicional de recambio que pasa desapercibido en el análisis gráfico realizado, determinado por Laboratorios que son dados de baja-mayoritariamente por el PEEC-PN- y que con posterioridad solicitan su reinscripción al mismo.

Por otra parte, si se analiza la contribución absoluta de cada uno de los diferentes países participantes al mencionado recambio, se encuentra que el mayor aporte a lo largo de los 7 años evaluados le corresponde a Colombia con 58 Laboratorios dados de baja (34.7\% del total de inscriptos de ese mismo país), seguido por Brasil con 10 (38.5\%) y Argentina con 8 (18.2 \%), encontrándose que las mencionadas bajas han sido motivadas mayormente por los siguientes hechos: en el caso de Colombia como consecuencia de la modalidad de implementación de la PN ya mencionada anteriormente; en el caso de Brasil debido a la implementación en 2001 de un Programa Nacional de PN que tiene a su cargo la tarea de acreditar a todos aquellos Centros de Referencia que han de formar parte de la red estatal (3), razón por la cual aquellos Laboratorios que no forman parte de dicha red deben interrumpir su prestación y por lo tanto discontinuar su participación en el PEEC-PN; mientras que finalmente en el caso de Argentina debido a que diferentes Laboratorios -tanto del sector privado como del sector público caracterizados por su pequeña magnitud en relación al número de neonatos pesquisados anualmente-, decidieron discontinuar su participación por causas diversas.

En relación a la adherencia al Programa, en la Figura 104 se presenta la distribución de Laboratorios en función del porcentaje de participación, es decir, de acuerdo al número de encuestas en las cuales remitieron sus respuestas con respecto al total de encuestas en las cuales participaron.

Como se puede visualizar en dicha Figura, sólo 41 Laboratorios (15.2 \%) 
presentaron asistencia perfecta en todas las encuestas en las cuales les correspondió participar a partir del momento de la inscripción de cada uno de ellos en el PEEC-PN. Por otra parte, el análisis global de la información incluida en la Figura 104 permite determinar que prácticamente el 50 \% de los Laboratorios remitieron sus respuestas en al menos el $80 \%$ de las encuestas en las cuales participaron, mientras que un 26.7 \% adicional mostró un cumplimiento regular reportando sus resultados entre el 50 y el $80 \%$ de las mismas.

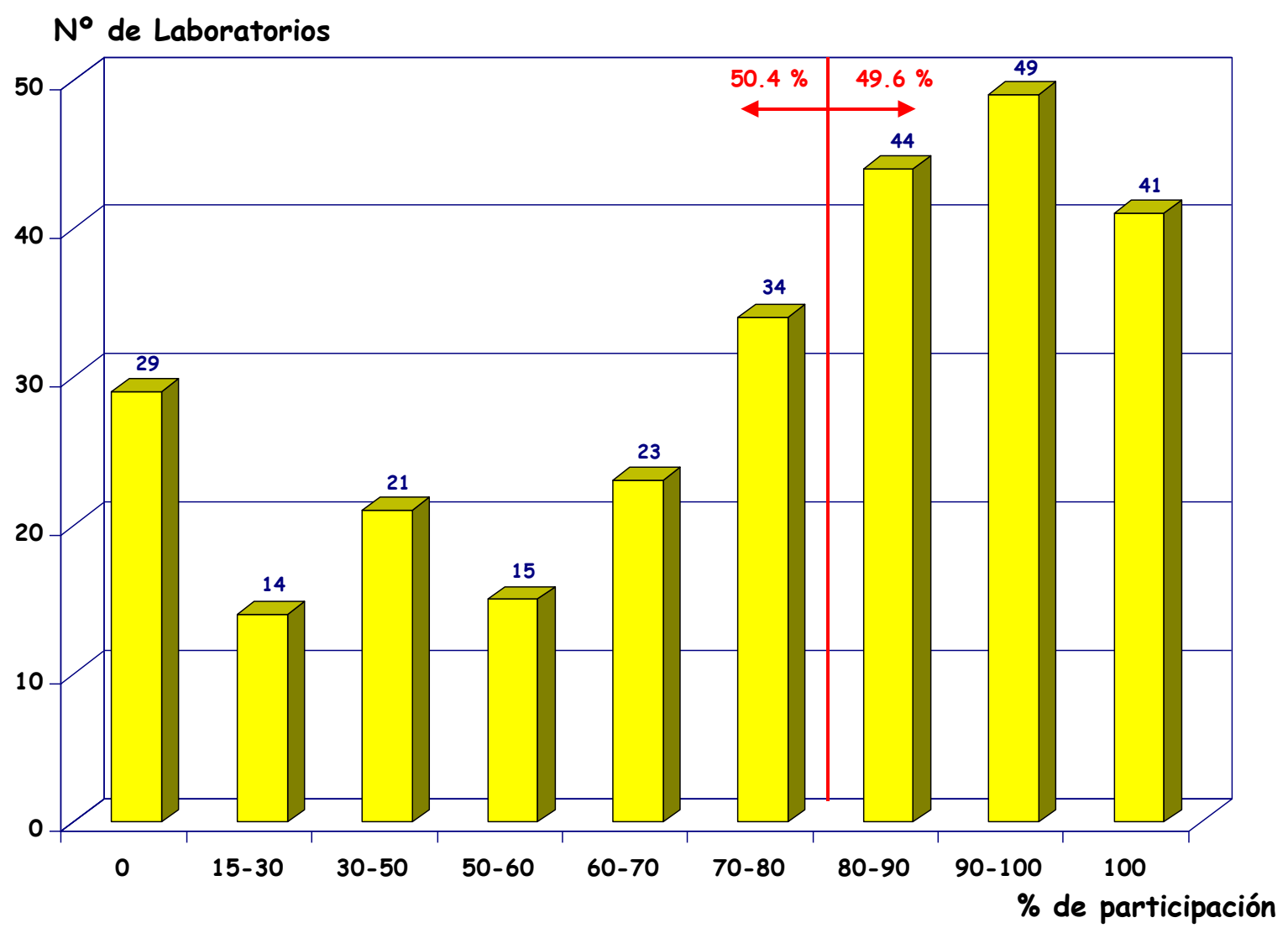

Figura 104. Distribución de Laboratorios según el porcentaje de participación.

- Distribución de Laboratorios según el analito: en relación a la distribución de Laboratorios según el analito en el cual participan, también se encuentra una situación muy particular que una vez más refleja la modalidad de implementación de la PN en algunos países de Latinoamérica.

Como se puede observar en la Figura 105, prácticamente la totalidad de los Laboratorios inscriptos en cada período anual (97\% en promedio) se inscribieron para TSH, pero sin embargo, no ocurrió lo mismo en el caso de Phe. De hecho, a 
partir del Período Anual \# 3 comenzó a evidenciarse un desbalance muy significativo en el número de Laboratorios inscriptos para uno y otro analito, el cual se ha mantenido casi invariable a lo largo de los últimos 4 períodos evaluados en torno a una proporción Phe : TSH de $1: 2.8$ en promedio.

Esta característica particular es el resultado de la situación que se presenta específicamente en 2 países: en primer lugar en Colombia, adonde la obligatoriedad para la realización de la PN solamente incluye al $\mathrm{HC}$ por lo cual la pesquisa de PKU directamente no se realiza o se realiza escasamente en algunos Laboratorios específicos, y en la medida de que Colombia es el país que hace la mayor contribución al número de participantes, entonces esta situación se refleja significativamente al analizar la población total de participantes; mientras que en segundo lugar en México, país en el cual la pesquisa de PKU no se realiza en forma sistemática, situación que determina que prácticamente el $70 \%$ de los Laboratorios inscriptos provenientes de éste último país no participen en Phe.

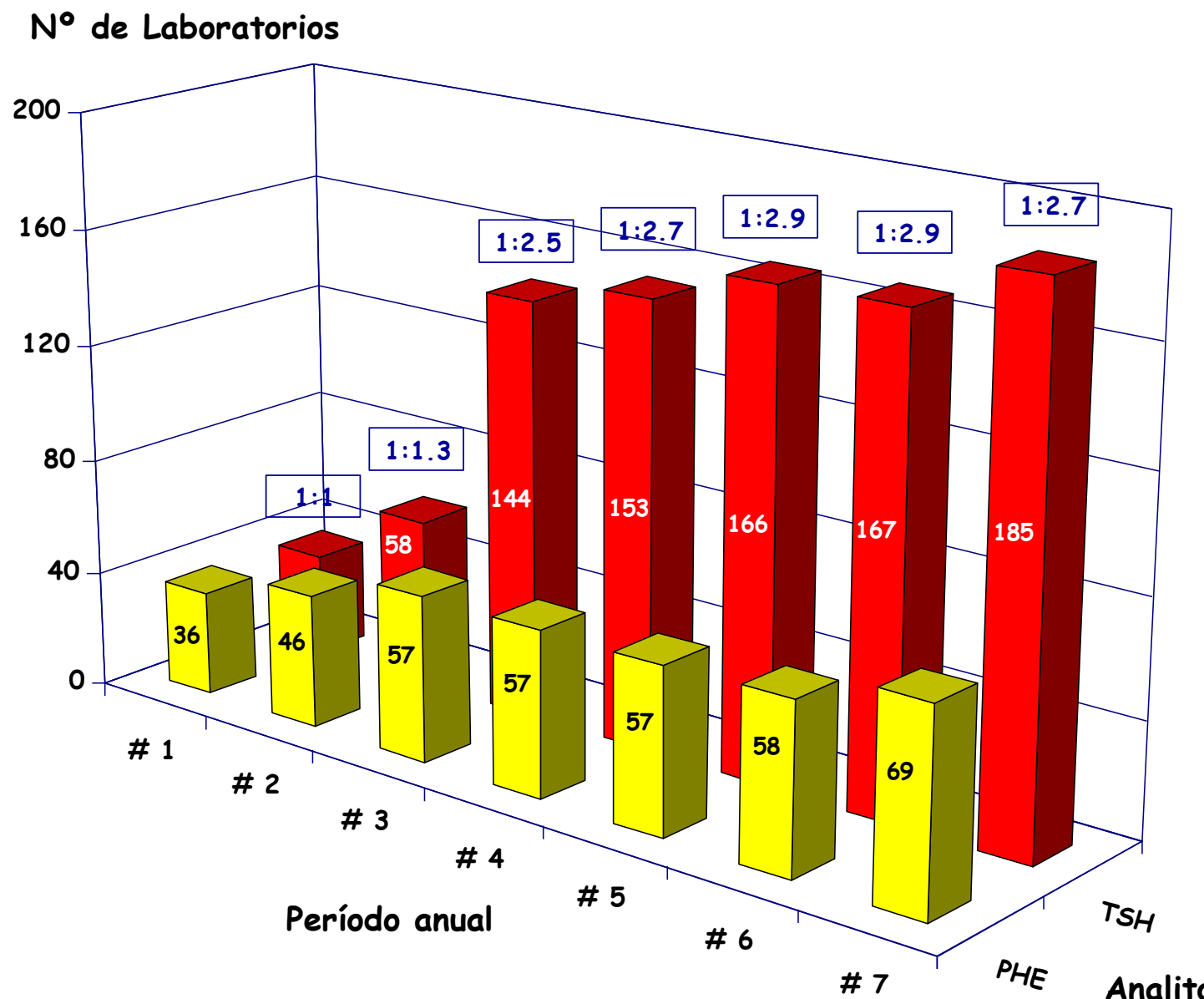

Figura 105. Distribución de Laboratorios según el analito. 
- Distribución de Laboratorios por métodos: en relación a los métodos utilizados para la medida de ambos analitos, la evaluación de la contribución porcentual de cada uno de ellos a lo largo del período en estudio muestra algunas tendencias que pueden visualizarse claramente en las Figuras 106 y 107.

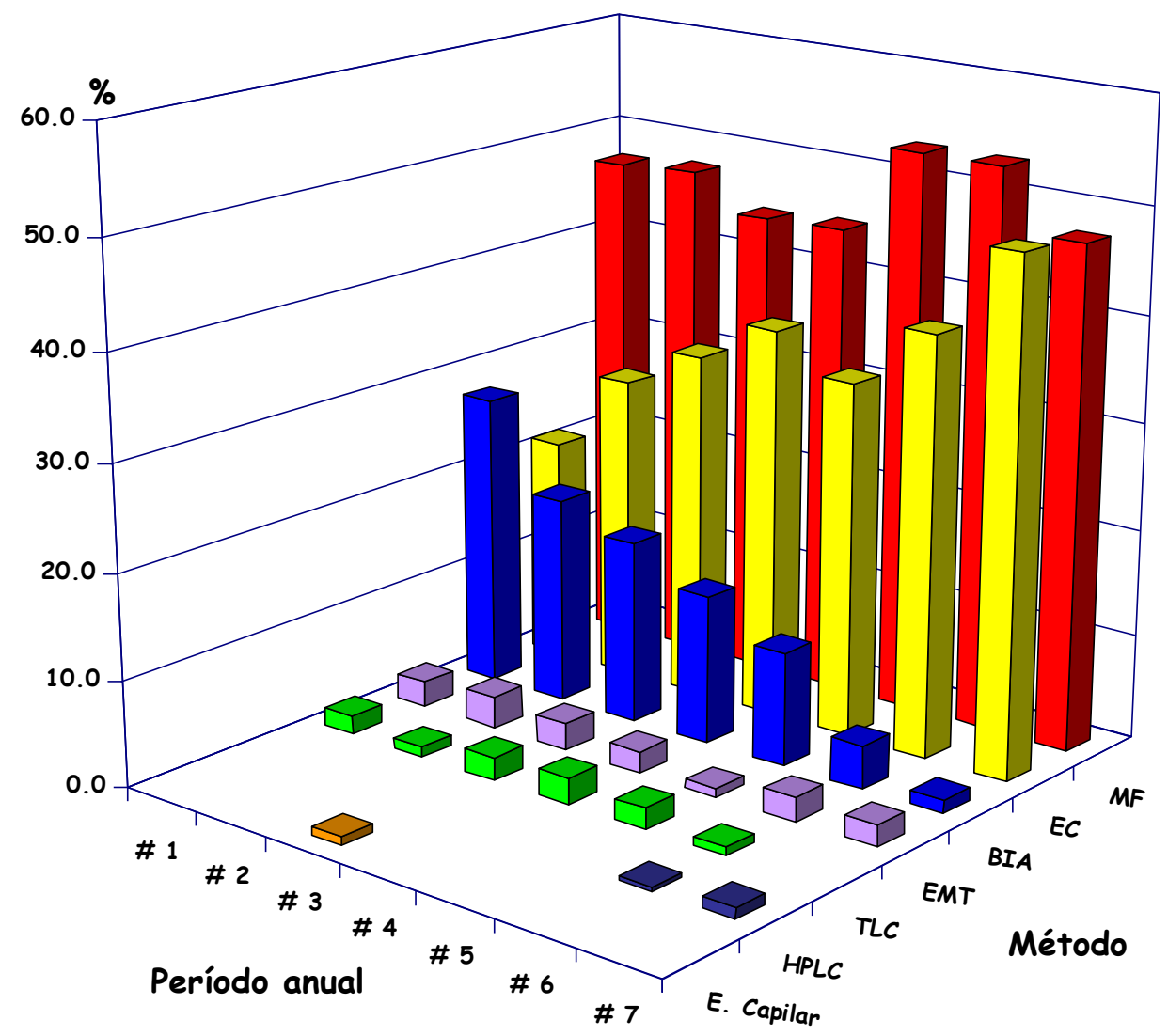

Figura 106. Distribución de Laboratorios según métodos para Phe.

En el caso de Phe el hecho más significativo es la preponderancia que tomaron los métodos Fluorométricos (MF) y Enzimáticos-Colorimétricos (EC) con el transcurso del tiempo, la cual alcanzó al $95.7 \%$ del total de los métodos utilizados.

Concomitantemente, este crecimiento estuvo acompañado de una disminución progresiva en la utilización del método de Inhibición Bacteriana (BIA) hasta resultar mínima en el último período anual (1.3\%).

Por otra parte y en relación a la Espectrometría de Masa en Tándem (EMT), Cromatografía en Capa Fina (TLC), Cromatografía Líquida de Alta Performance (HPLC) y Electroforesis Capilar, las mismas han sido utilizadas en mínimas proporciones y con ligeras variaciones a lo largo de los 7 años de trabajo. 


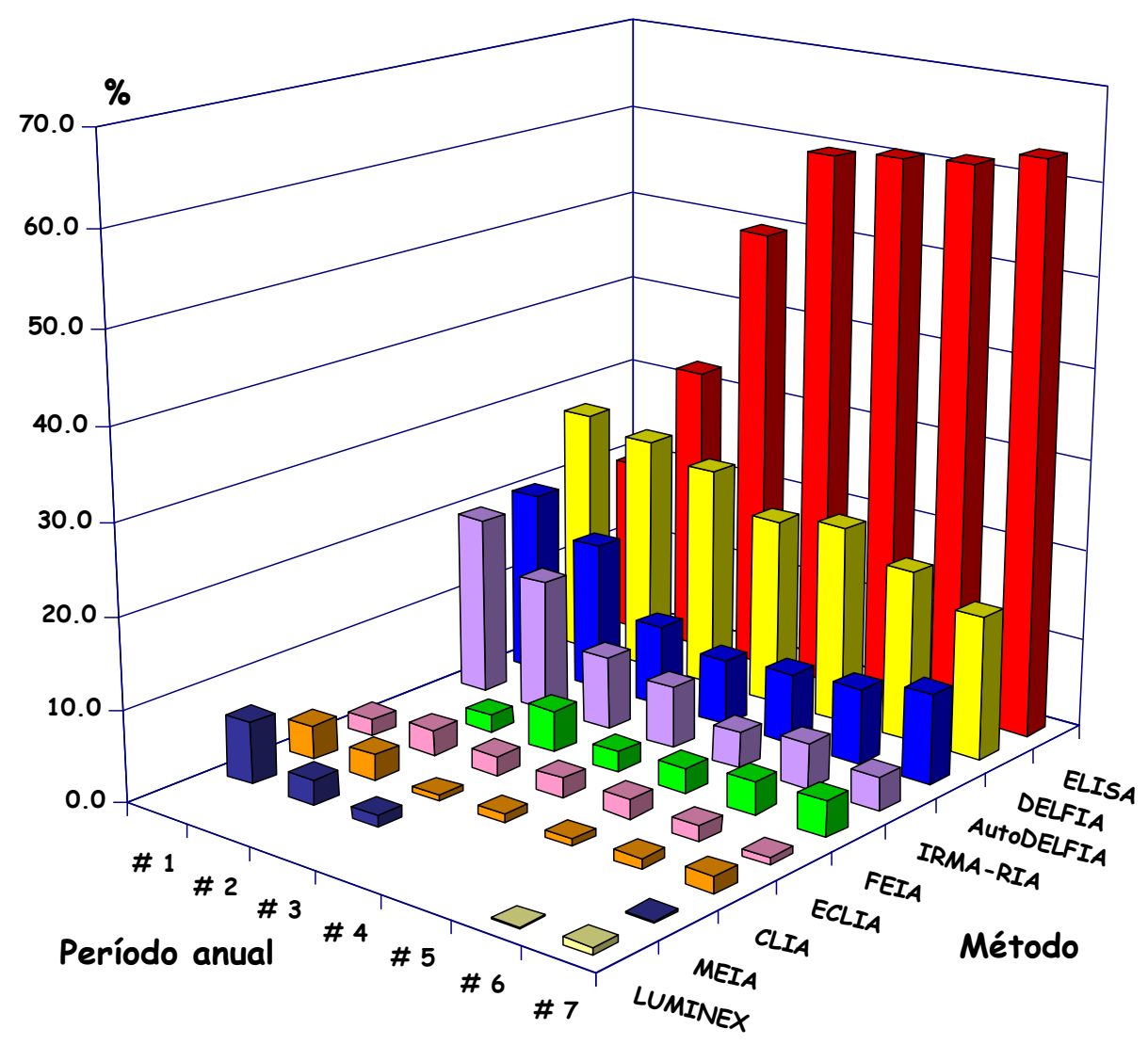

Figura 107. Distribución de Laboratorios según métodos para TSH.

En lo que se refiere a TSH, el hallazgo más significativo es la marcada preponderancia de los Enzimoinmunoensayos Colorimétricos (EIA), métodos que a partir del Período Anual \# 4 representaron más del $60 \%$ de los métodos utilizados por los Laboratorios participantes, una vez más a expensas de la contribución realizada por los laboratorios de Colombia. En segundo lugar se ubican los Inmunoensayos Florométricos a Tiempo Resuelto, tanto en su alternativas modular (DELFIA) como automatizada (AutoDELFIA), las cuales en conjunto comprenden algo más del $25 \%$ de los métodos utilizados, con una ligera tendencia creciente en cuanto a la utilización de la última de estas dos opciones.

Con respecto al resto de las metodologías utilizadas se debe destacar la reducción progresiva en la utilización de los Inmunoensayos Radiométricos (IRMARIA), el ligero crecimiento en los Inmunoensayos Fluorométricos (FEIA), y finalmente la utilización en mínimas proporciones de las metodologías Electroquimioluminiscencia (ECLIA), Quimioluminiscencia (CLIA), Enzimoinmunoensayo en Micropartículas (MEIA) y Luminex, algunos de los cuales son métodos 
desarrollados para trabajar sobre muestras de suero o plasma que han sido adaptados para trabajar en DBS.

- Aceptabilidad Clínica: sin lugar a dudas uno de los parámetros que mejor refleja el desempeño global del conjunto de Laboratorios participantes en el PEEC-PN es precisamente la Aceptabilidad Clínica, motivo por el cual a continuación se presentará una análisis detallado de la evolución experimentada por la misma a lo largo del tiempo, y también de la forma en que este parámetro ha sido utilizado como un indicador para decidir la introducción de estándares de calidad de mayor nivel de exigencia, en concordancia con la evolución presentada en la Tabla 38.

A efectos de simplificar la comprensión de la estrategia de evaluación utilizada, en primer lugar se debe mencionar que los límites de aceptabilidad fueron definidos siguiendo un criterio empírico de forma tal que como mínimo el 60 \% de los Laboratorios participantes presentaran resultados aceptables, y por otra parte que el desempeño global de dichos Laboratorios en cada encuesta en relación a la Aceptabilidad Clínica fue caracterizado empleando el Indice de Aceptabilidad Clínica, el cual se definió como el porcentaje de Laboratorios que presentaron resultados aceptables para cada material de control provisto por el PEEC-PN con respecto al total de Laboratorios que remitieron sus resultados; mientras que en cada período anual se lo hizo a través de un índice equivalente al anterior denominado Indice Anual de Aceptabilidad Clínica, definido como el promedio de los Indices de Aceptabilidad Clínica correspondientes a los 12 materiales de control remitidos para cada analito a lo largo de un Período Anual determinado.

En la Tabla 39 se presentan los Indices Anuales de Aceptabilidad Clínica correspondientes a los Períodos Anuales \# 3, 4, 5, 6 y 7: mientras que en las Figuras 108 y 109 se presentan los Indices de Aceptabilidad Clínica para cada uno de los materiales de control remitidos por el PEEC-PN y las tendencias experimentadas por los mismos representadas por sendas rectas de regresión (4).

Como se puede inferir a partir de los resultados anteriores, a lo largo de los Períodos Anuales \# 3, 4 y 5 los Indices de Aceptabilidad Clínica tanto de Phe como de TSH mostraron un mejoramiento progresivo, aunque de una magnitud 
significativamente superior en el caso de Phe. Este mejoramiento puede evidenciarse tanto en los Indices Anuales de Aceptabilidad presentados en la Tabla 39 como en la pendiente de la línea de tendencia representada en la Figura 108, hechos que en definitiva respaldaron la introducción de un límite de aceptabilidad más exigente para este último analito a partir del Período Anual \# 6 (ver Tabla 38).

Tabla 39. Indices Anuales de Aceptabilidad Clínica

\begin{tabular}{|c|c|c|c|}
\hline Anual & Concentración (Min:Máx) & CV & Aceptabilidad Clínica \\
\hline \multicolumn{4}{|c|}{ Phe (mg/dl) } \\
\hline \# 3 & $4.1(1.5 ; 6.8)$ & $28.9 \%$ & $56.2 \%$ \\
\hline \# 4 & $4.4(1.6 ; 6.5)$ & $23.9 \%$ & $65.4 \%$ \\
\hline \# 5 & $5.6(1.2 ; 17.1)$ & $24.1 \%$ & $70.6 \%$ \\
\hline \# 6 & $4.9(1.1 ; 10.3)$ & $21.1 \%$ & $67.1 \%$ \\
\hline \# 7 & $4.2(1.2 ; 8.3)$ & $24.2 \%$ & $68.3 \%$ \\
\hline \multicolumn{5}{|c|}{ TSH ( $\mu \mathrm{U} / \mathrm{ml})$} \\
\hline \# 3 & $19.1(0.9 ; 60.3)$ & $30.7 \%$ & $59.2 \%$ \\
\hline \# 4 & $22.1(5.4 ; 49.3)$ & $28.2 \%$ & $61.8 \%$ \\
\hline \# 5 & $23.4(4.3 ; 56.7)$ & $26.8 \%$ & $62.2 \%$ \\
\hline \# 6 & $22.6(1.1 ; 46.9)$ & $29.6 \%$ & $63.4 \%$ \\
\hline \# 7 & $19.0(4.7 ; 32.6)$ & $24.0 \%$ & $67.2 \%$ \\
\hline
\end{tabular}

NOTA: las concentraciones y CV's indicados en esta Tabla corresponden a valores promedio de los 12 materiales de control incluidos en cada Período Anual.

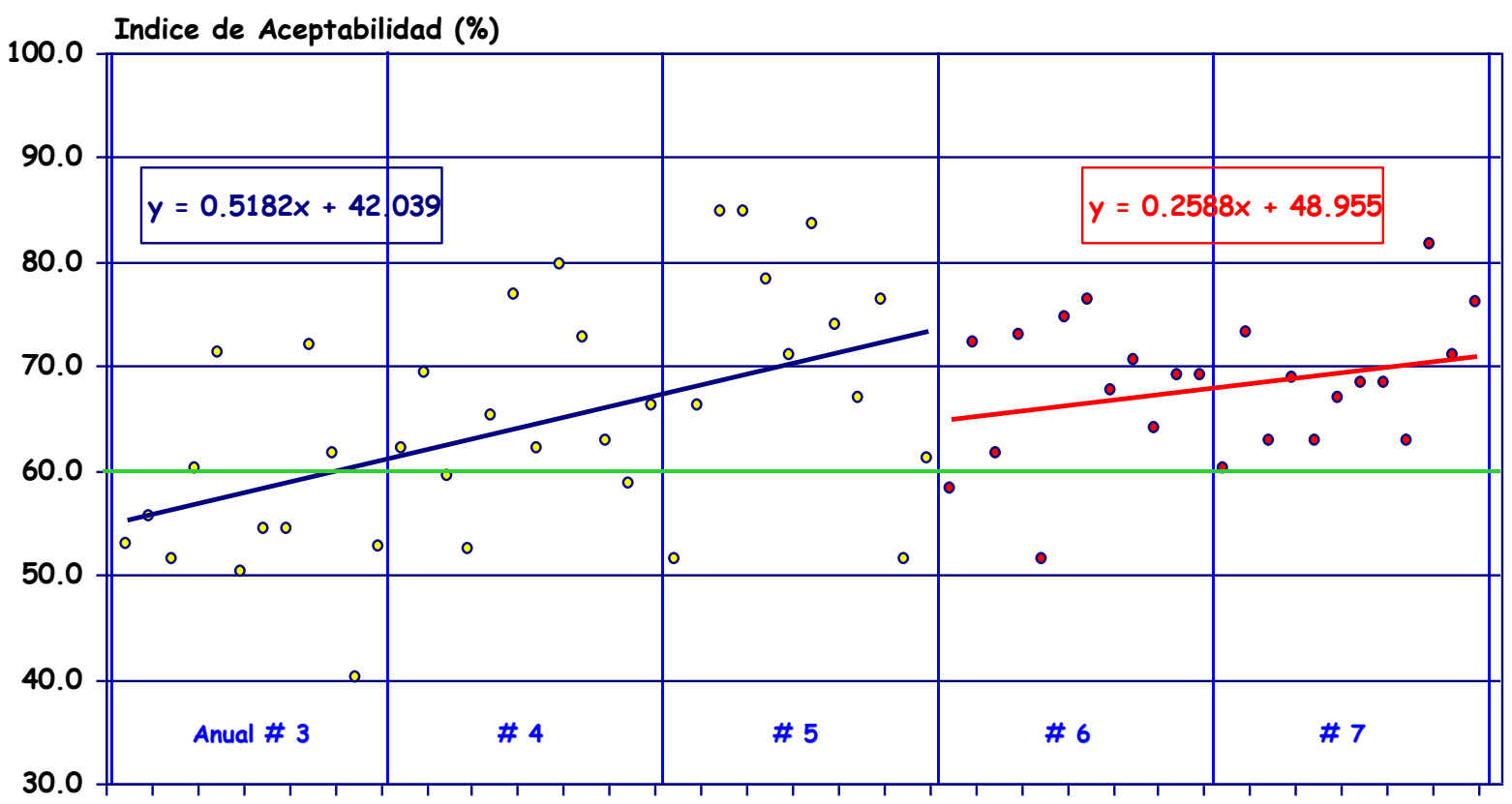

$24262830323436384042444648505254565860626466 \quad 687072747678 \quad 808284$ Control \#

Figura 108. Comportamiento de la Aceptabilidad Clínica en la medida de Phe. 


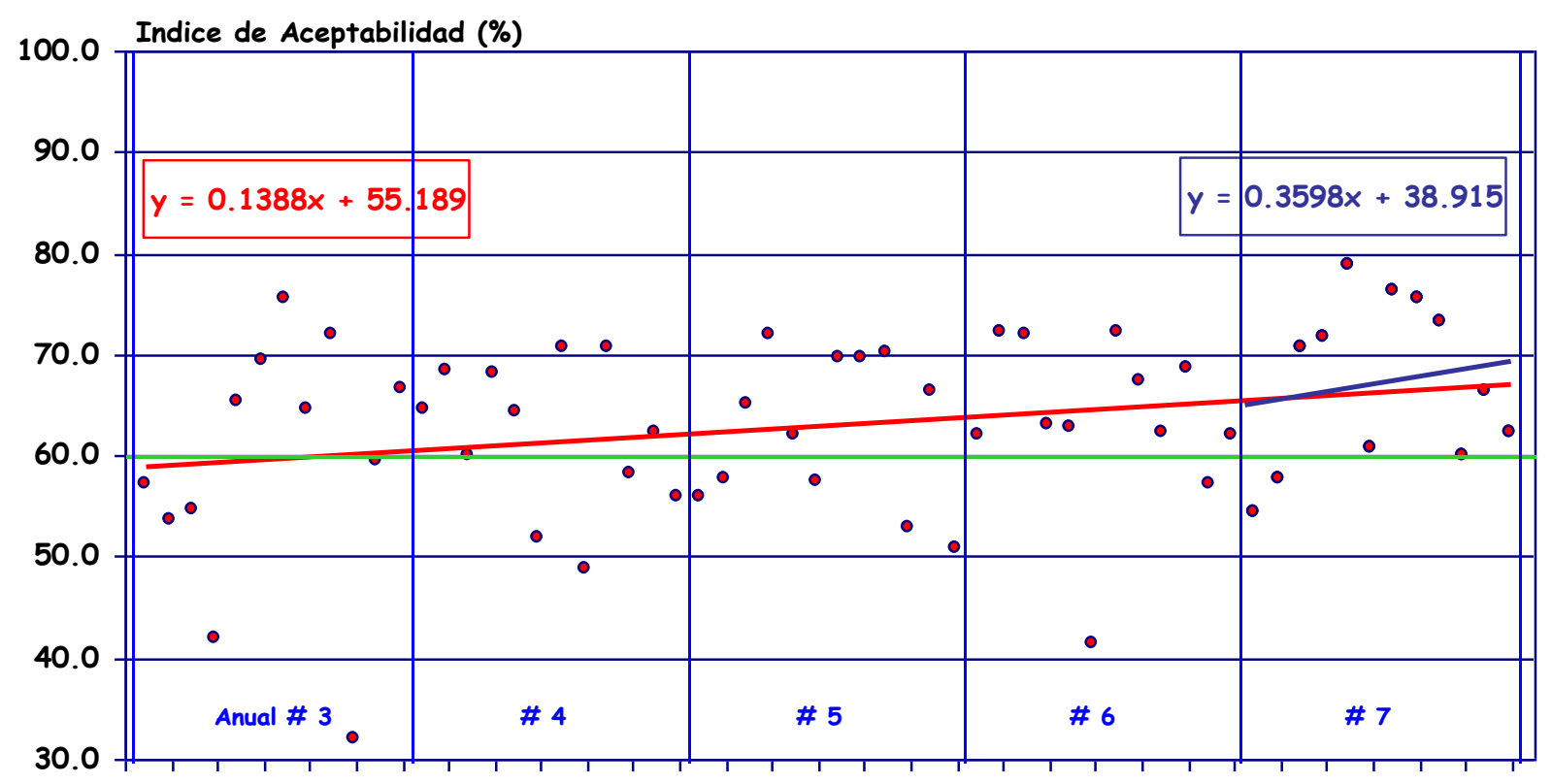

$24262830323436384042444648505254565860626466 \quad 687072747678 \quad 808284$ Control \#

Figura 109. Comportamiento de la Aceptabilidad Clínica en la medida de TSH.

En contraposición con estos hallazgos, en el caso de TSH los mencionados índices no presentaron un margen suficiente como para permitir incorporar un estándar de calidad más elevado, razón por la cual los mismos se mantuvieron sin cambios en los Períodos Anuales \# 6 y \# 7.

Sin embargo, y al igual que en el caso de Phe, en el Período Anual \# 6 se introdujo una modificación en el criterio de definición de los límites de aceptabilidad, los cuales comenzaron a ajustarse según la concentración del analito de manera tal que cuando la misma se encuentra por debajo de un valor crítico -3.5 mg/dl en el caso de Phe y $8.0 \mu \mathrm{U} / \mathrm{ml}$ en el caso de TSH-, los mencionados límites se ajustan linealmente en función de dicha concentración.

Finalmente, el mejoramiento significativo observado en los Indices de Aceptabilidad Clínica de Phe a lo largo de los Períodos Anuales \# 6 y \# 7, y de TSH en el último de estos dos períodos (Figuras 108 y 109), permitió introducir nuevos límites de Aceptabilidad más exigentes para el Período Anual \# 8, tal como ya fuera mencionado en la Tabla 38.

Con respecto a las diferencias de comportamiento observadas en los Indices de Aceptabilidad entre Phe y TSH, las mismas pueden ser atribuidas a la 
confluencia tanto de causas operativas como de causas analíticas: por un lado, el hecho de que los Laboratorios participantes en TSH mostraron un recambio permanente -del orden del 27 \%-situación que se contrapone con lo observado en el caso de Phe cuya población de Laboratorios se mantuvo estable y sin cambios significativos a lo largo del tiempo; y por otro lado, el hecho de que los resultados de TSH mostraron una mayor variabilidad en los resultados globales como se puede visualizar en los CV presentados en la Tabla 39, una mayor diversidad en los Métodos y Reactivos utilizados para reportar los mismos, y también diferencias más significativas en el desempeño entre los diferentes grupos de Métodos y Reactivos con respecto a lo observado en Phe.

- Falsos resultados: de manera equivalente a lo que se mencionara para el caso de la Aceptabilidad Clínica como indicador de desempeño global de la población de Laboratorios participantes, la evaluación de las tasas de falsos resultados, conjuntamente con las causas que originaron los mismos, son un claro indicador de la eficiencia diagnóstica de los mencionados Laboratorios.

El primer concepto que se debe tomar en consideración para abordar esta evaluación es que la clasificación diagnóstica reportada por cada Laboratorio para cada analito es realizada sobre el supuesto de que cada uno de los materiales de control provistos por el PEEC-PN corresponden a una muestra de sangre entera de un RN a término, con peso al nacimiento normal, con ingesta de leche adecuada, con 48 hs. de vida al momento de la recolección, sin ningún tipo de tratamiento ni procedimiento que pudiera modificar sus resultados, y con un hematocrito del $50 \%$.

Por otra parte, también se debe tener en cuenta que la clasificación de un material de control determinado por parte del PEEC-PN se efectúa sobre la base de la mediana de consenso resultante de la evaluación estadística, razón por la cual las tasas de Falsos Negativos (FN) y de Falsos Positivos (FP) son calculadas exclusivamente sobre aquellos controles clasificados como "elevados" o "normales" respectivamente, y no sobre el total de materiales de control remitidos. En la Tabla 40 se presentan los criterios utilizados por el PEEC-PN para clasificar a un material de control como normal, indeterminado o elevado para uno y otro analito. 
Tabla 40. Criterios de clasificación de materiales de control

\begin{tabular}{|c|c|c|c|}
\hline Analito & Normal & Indeterminado & Elevado \\
\hline Phe & $<2.0 \mathrm{mg} / \mathrm{dl}$ & $2.0 \mathrm{mg} / \mathrm{dl} \geq \mathrm{Phe}<5.0 \mathrm{mg} / \mathrm{dl}$ & $\geq 5.0 \mathrm{mg} / \mathrm{dl}$ \\
\hline TSH & $<9.0 \mu \mathrm{U} / \mathrm{ml}$ & $9.0 \mu \mathrm{U} / \mathrm{ml} \geq \mathrm{TSH}<25.0 \mu \mathrm{U} / \mathrm{ml}$ & $\geq 25.0 \mu \mathrm{U} / \mathrm{ml}$ \\
\hline
\end{tabular}

o Falsos resultados en la medida de Phe (5):

- Comportamiento de las tasas de FN y FP: en la Tabla 41 se presenta un resumen de los resultados FN y FP reportados en la medida de Phe, mientras que en las Figuras 110 y 111 se presenta la evolución experimentada en las tasas de ambos falsos resultados a lo largo de los 7 períodos anuales evaluados, incluyendo además la contribución de los errores no analíticos propiamente dichos.

Tabla 41. Falsos resultados en la medida de Phe

\begin{tabular}{|c|c|c|c|c|c|}
\hline & $\begin{array}{l}N^{\circ} \text { Falsos } \\
\text { resultados }\end{array}$ & $\begin{array}{c}\text { Total } \\
\text { respuestas }\end{array}$ & $\begin{array}{c}\text { Tasa } \\
\text { FR }\end{array}$ & $\begin{array}{c}\text { Errores } \\
\text { Transposición }\end{array}$ & $\begin{array}{c}\text { Errores } \\
\text { Interpretación }\end{array}$ \\
\hline FN & 95 & 1403 & $6.8 \%$ & $10(10.5 \%)$ & $5(5.3 \%)$ \\
\hline FP & 22 & 529 & $4.2 \%$ & $5(22.7 \%)$ & $0(0.0 \%)$ \\
\hline
\end{tabular}

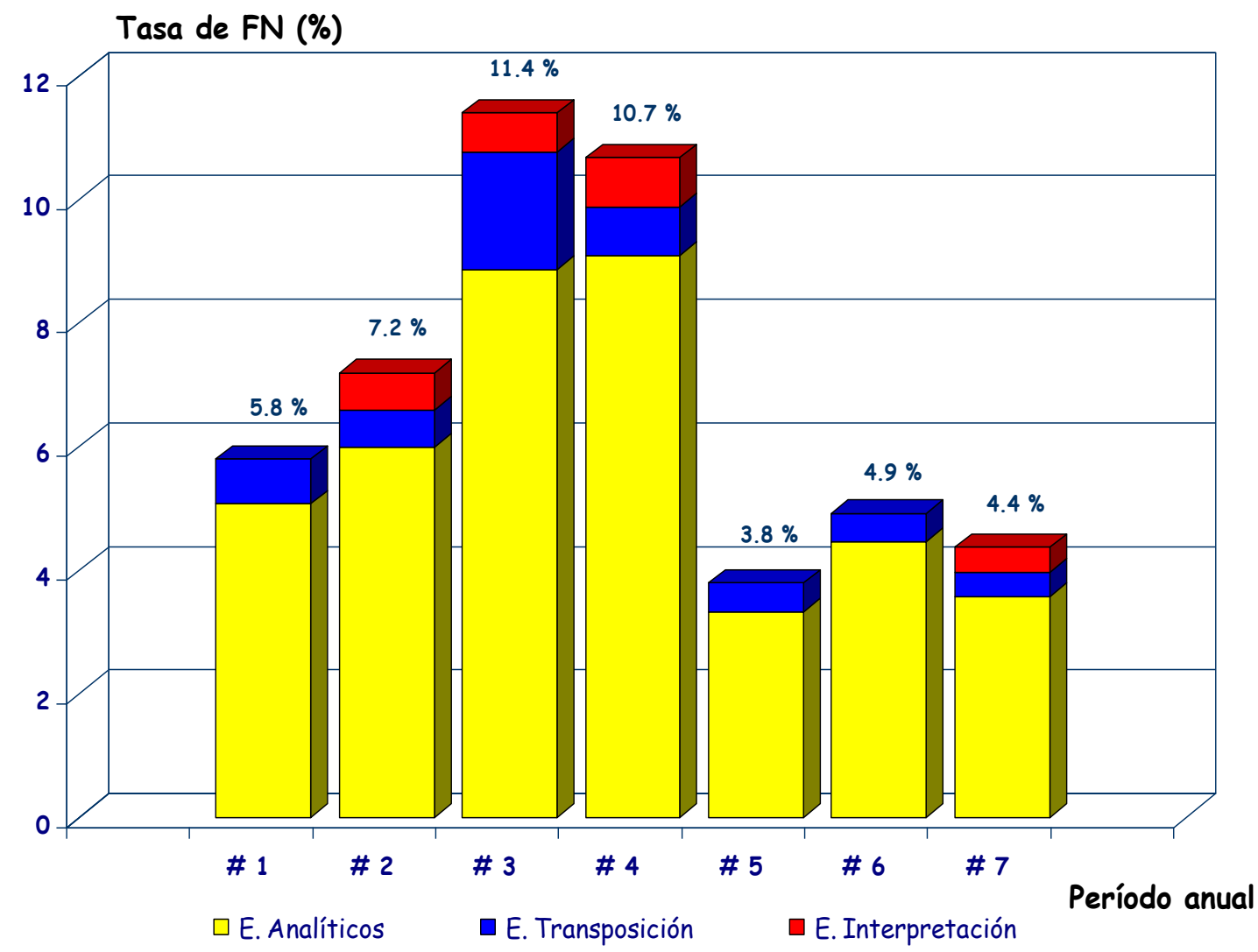

Figura 110. Evolución de la tasa de falsos negativos en la medida de Phe. 


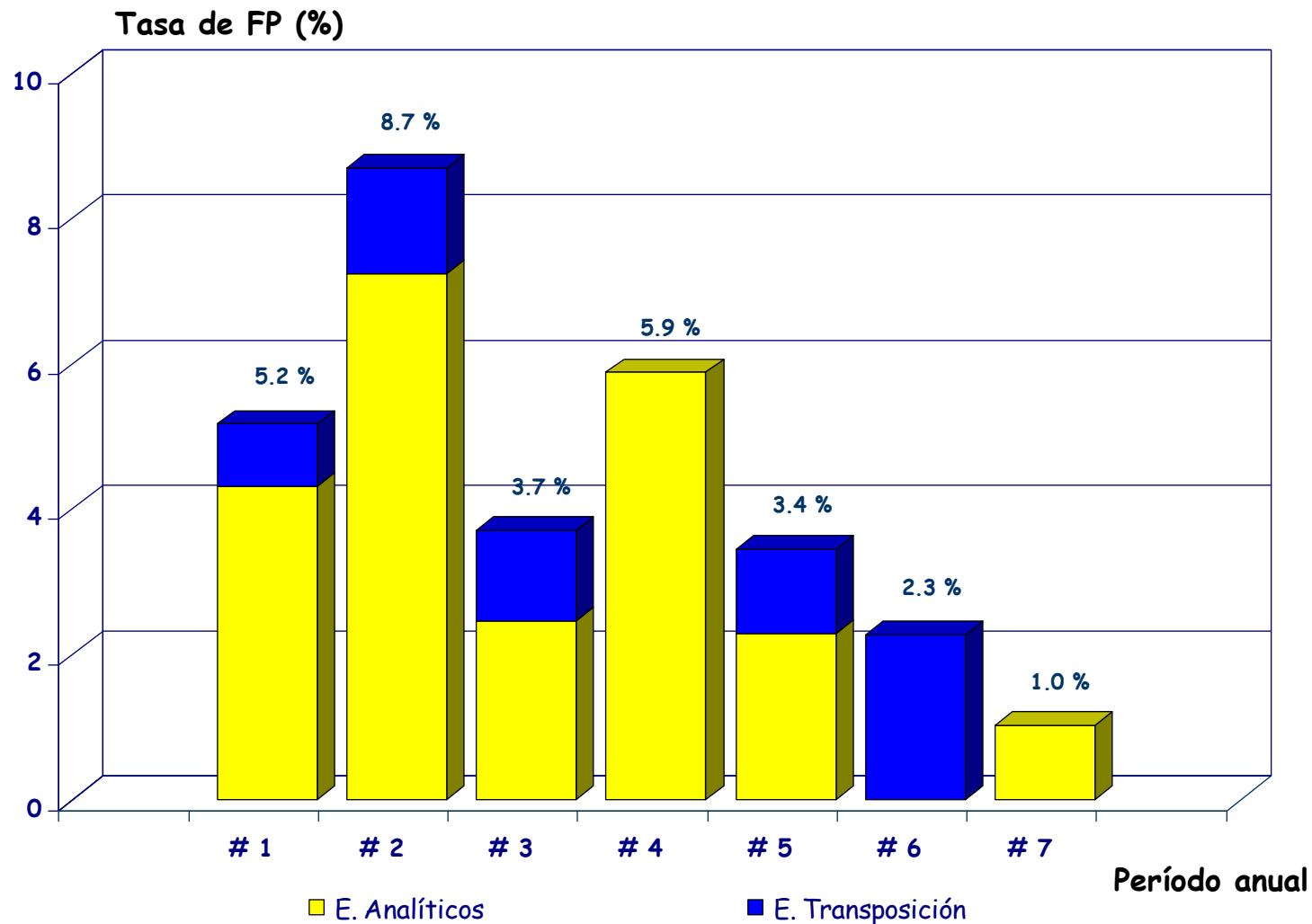

Figura 111. Evolución de la tasa de falsos positivos en la medida de Phe.

El análisis de la información anterior permite sacar varias conclusiones de interés:

a) La tasa global de FN (6.8\%) se encuentra muy por encima de los valores esperables, observándose además una contribución muy significativa -del $15.8 \%$ - de errores de origen propiamente no analíticos como son los errores de transposición y de interpretación de resultados.

NOTA: los errores de transposición de resultados son aquellos que se originan cuando el resultado del Control $A$ es informado en el lugar del Control $B$ y viceversa, mientras que los errores de interpretación son aquellos en los cuales un resultado anormal de acuerdo al Valor de Corte utilizado por el laboratorio es informado como normal, y viceversa.

b) La evolución en la tasa de FN alcanzó valores críticos -superiores al 10.0 $\%$ - en los Anuales \# 3 y \# 4, y a partir de allí se ha mantenido en promedio en el orden del $4.5 \%$.

c) En el caso de la tasa global de FP, y a pesar de que la misma presenta valores más apropiados que la tasa global de FN (4.2\%), aún se encuentra muy por encima de los valores esperables, observándose además una mayor influencia de los errores de transposición, los cuales 
representan el $22.7 \%$ del total de errores no analíticos (en este caso no se presentaron errores de interpretación de resultados).

d) La evolución de la tasa de FP ha mostrado diversas fluctuaciones a lo largo del tiempo, con una clara tendencia decreciente en los últimos 3 períodos, llegando a un valor óptimo del $1.0 \%$ en el Período Anual \# 7.

- Distribución de FN y FP según el método de medida: en las Figuras 112 y 113 se presentan las distribuciones del porcentaje de falsos resultados con respecto al número total de respuestas reportadas con cada uno de los métodos de medida.

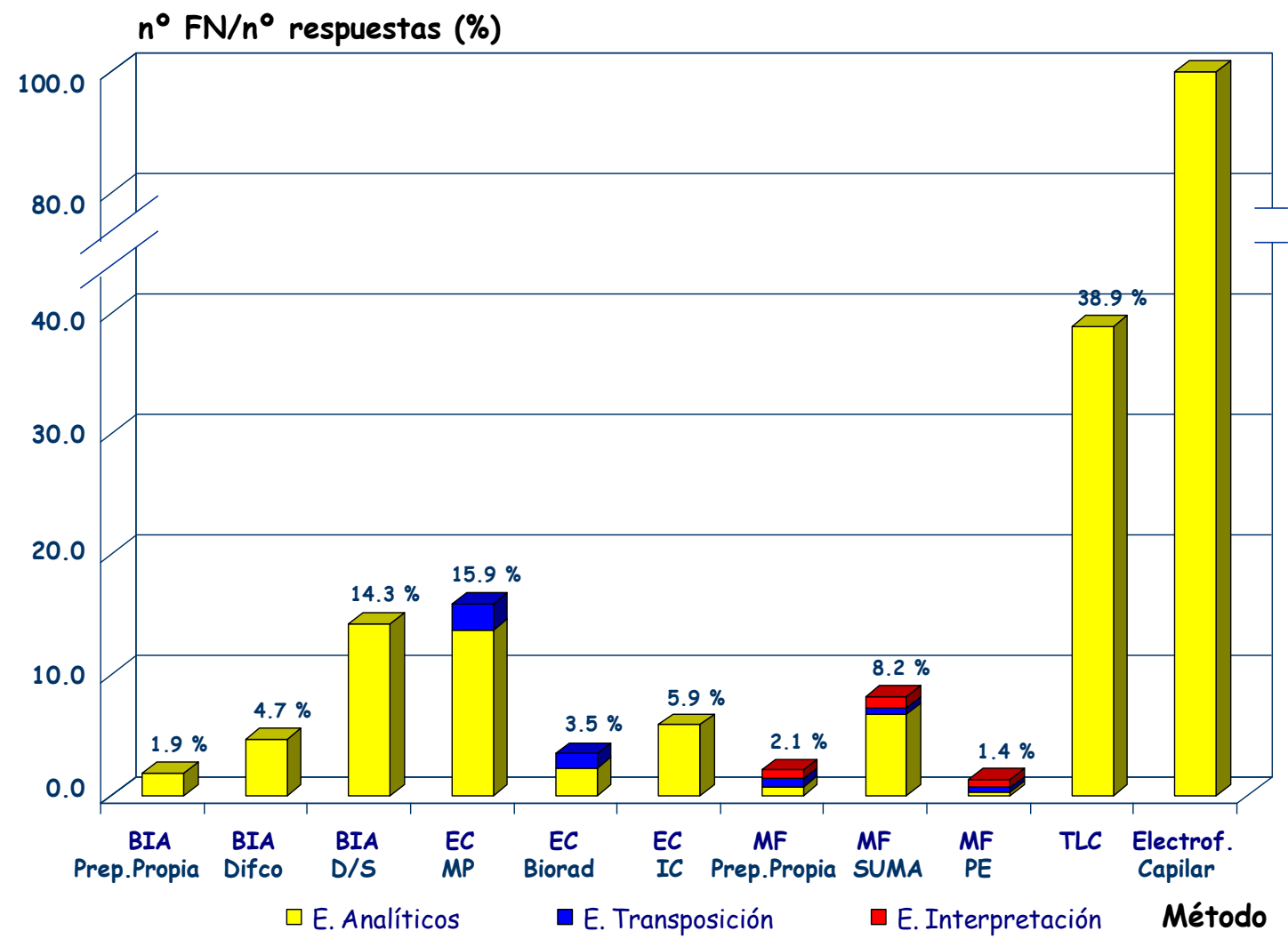

Figura 112. Incidencia relativa de falsos negativos según el método de medida de Phe. (D/S: Difco/Sigma, IC: Intercientífica, PE: PerkinE/mer).

NOTA: los métodos BIA-Sigma (6), EC-Quantase (33), MF-Labsystems (29), EMT (27) y HPLC (4) que no aparecen representados en la Figura anterior no presentaron ningún resultado FN. Entre paréntesis se indica el número de respuestas reportadas con cada uno de ellos sobre el total de 1403 resultados reportados.

El análisis de la incidencia de los FN según el método de medida muestra dos principios analíticos con una muy mala performance como la TLC (38.9 \%) y la Electroforesis Capilar (100.0\%), resultando oportuno destacar que el 
primero de estos 2 métodos dejó de utilizarse en el Período Anual \# 7, y que el segundo de ellos sólo fue utilizado en el Período Anual \# 3, originándose su magra performance en tan solo 2 resultados reportados sobre 2 materiales de control con niveles elevados de Phe.

Adicionalmente también se presentaron tasas muy elevadas de FN en los métodos EC-MP (15.9\%) y BIA-Difco (14.3\%), y una regular performance en el MF-SUMA $(8.2 \%)$ y EC-IC (5.9\%).

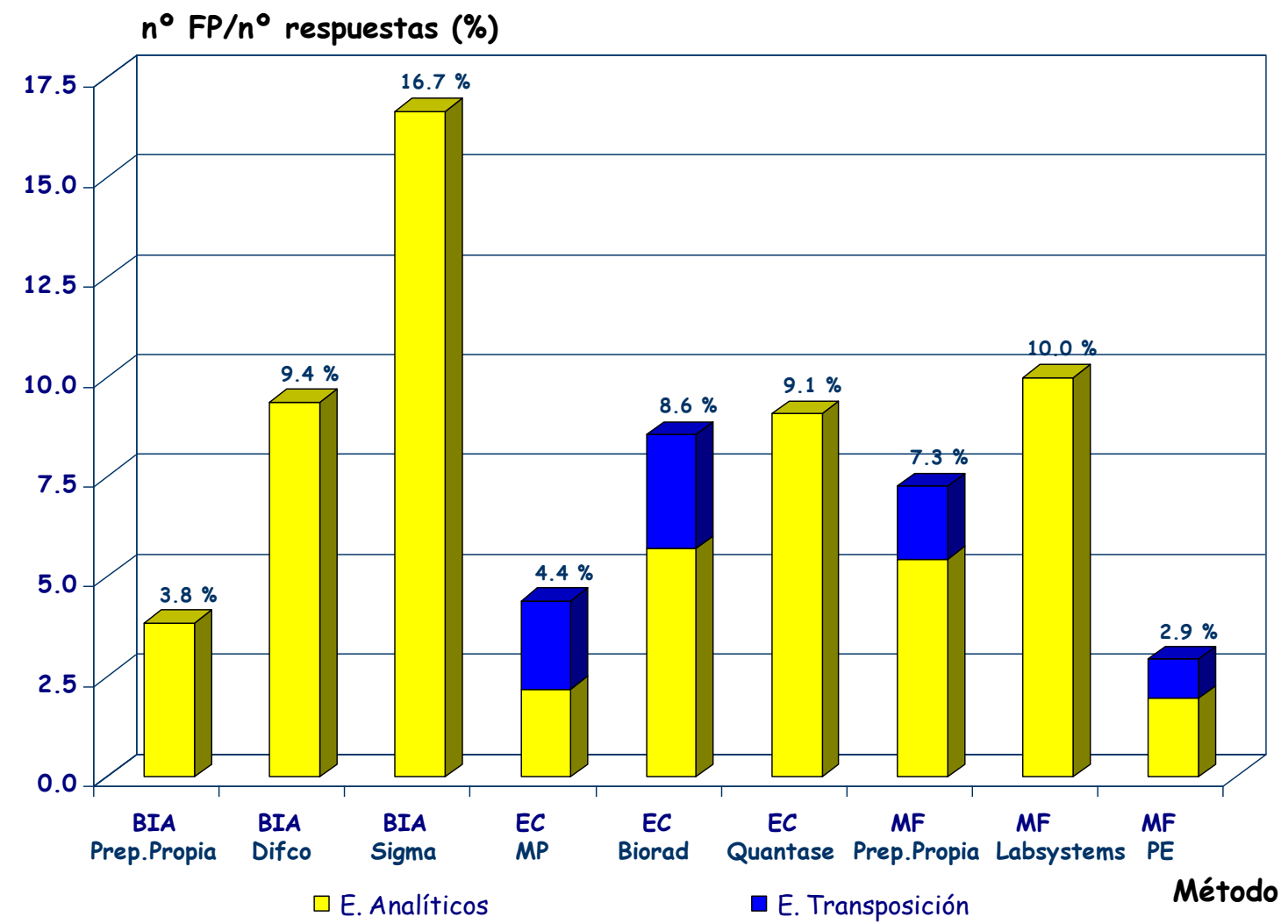

Figura 113. Incidencia relativa de falsos positivos según el método de medida de Phe.

NOTA: los métodos BIA-Difco/Sigma (13), EC-IC (35), MF-SUMA (82), TLC (9) y EMT (10) que no aparecen representados en la Figura anterior no presentaron ningún resultado FP. Entre paréntesis se indica el número de respuestas reportadas con cada uno de ellos sobre el total de 529 resultados reportados.

Con respecto a los resultados FP se destaca por su muy elevada tasa de FP el método BIA-Sigma (16.7\%), y también varios métodos más que presentaron una muy pobre performance como es el caso del BIA-Difco, los EC de Biorad y Quantase, y los MF de Preparación Propia y Labsystems, resultando 
importante mencionar que en 2 de estos últimos métodos los errores de transposición tuvieron una influencia significativa como generadores de FP. Como dato de interés para destacar, obsérvese el desempeño característico de varios de los métodos en uso en relación a que algunos de ellos presentan una elevada tasa de FN y $0 \%$ de FP (BIA-Difco/Sigma, EC-IC, MF-SUMA y TLC), mientras que otros presentan una elevada tasa de FP y $0 \%$ de FN (BIA-Sigma, EC-Quantase y MF-Labsystems), poniendo en evidencia así un claro problema de equilibrio entre sensibilidad y especificidad a consecuencia probablemente de una inapropiada definición de sus valores de corte (VC).

- Distribución de FN y FP según el país de procedencia: en las Figuras 114 y 115 se presentan las distribuciones del porcentaje de falsos resultados con respecto al número total de respuestas reportadas provenientes de cada país.

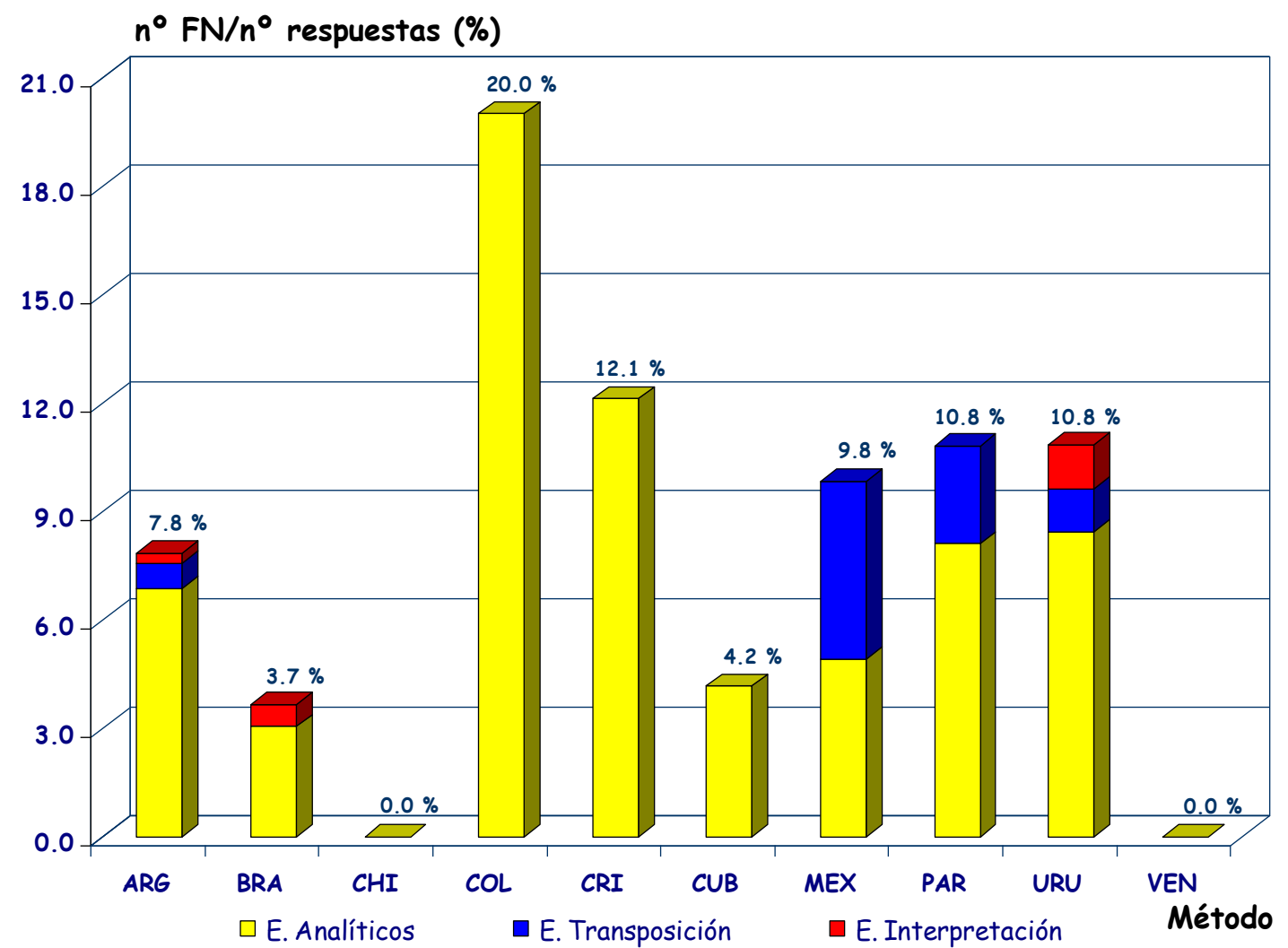

Figura 114. Incidencia relativa de falsos negativos según el país de procedencia en la medida de Phe.

Con respecto a la distribución de FN según el país de procedencia se observa una panorama bastante variado en el cual se destacan Chile y Venezuela en 
un extremo por presentar una tasa óptima de $\mathrm{FN}$ de $0 \%$, y Colombia en el extremo opuesto por presentar una muy mala performance con una tasa del $20.0 \%$ de FN.

En otro orden de cosas, México se caracterizó por ser el país en el cual se presentó la mayor incidencia de FN originados en errores no analíticos, los cuales representan el $50 \%$ de los mismos. Y si bien este hecho es bien visto por un lado puesto que diluye la carga sobre los errores analíticos, por el otro pone en evidencia importantes errores de desatención al momento de reportar los resultados, los cuales pueden tener consecuencias tan graves y serias como las de los propios errores analíticos.

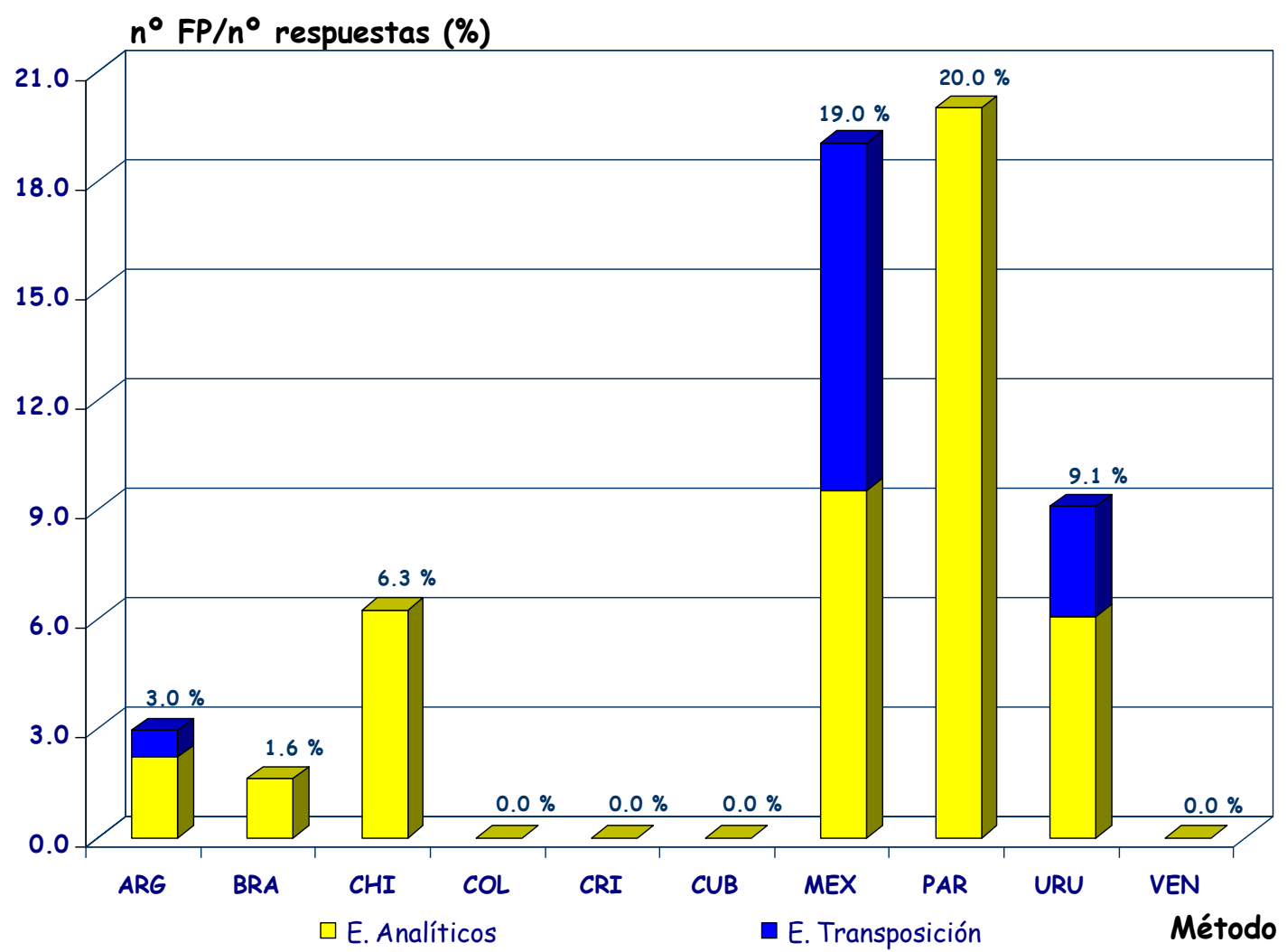

Figura 115. Incidencia relativa de falsos positivos según el país de procedencia en la medida de Phe.

En el caso de los FP, los resultados muestran una mejor situación y una menor variedad de desempeños que en el caso de los FN. Por un lado, un desempeño óptimo en el caso de Colombia, Costa Rica, Cuba y Venezuela con $0 \%$ de FP, y en el otro extremo Paraguay y México con valores críticos del 
20.0 y $19.0 \%$ para uno y otro respectivamente.

Obsérvese una vez más la influencia de los Errores de Transposición en el caso de México, y la pauta de desequilibrio entre sensibilidad y especificidad en el caso de Colombia, Costa Rica y Cuba, los cuales presentan tasas de FN del $20.0,12.1$ y $4.2 \%$ respectivamente y $0 \%$ de tasas de FP; mientras que Chile en la situación opuesta, presenta una tasa de FP del $6.3 \%$ y $0 \%$ de FN.

- Distribución de FN según el valor de corte: un último aspecto a evaluar en lo que respecta a Phe es la distribución de los FN reportados en función de los VC correspondientes a cada uno de los Laboratorios. Este análisis se basa en un razonamiento elemental que permite inferir que cuanto mayor es el VC utilizado para interpretar los resultados mayor es el riesgo de FN, y en consecuencia es razonable esperar que muchos de los falsos resultados que fueron reportados hayan sido producto de utilizar VC demasiado elevados.

En la Tabla 42 se presenta un detalle de su distribución incluyendo por un lado la totalidad de FN, mientras que por el otro habiendo excluido previamente aquellos FN originados en causas no analíticas, es decir aquellos FN debidos a errores de transposición y de interpretación de resultados.

Tabla 42. Distribución de falsos negativos según el valor de corte de Phe

\begin{tabular}{|c|c|c|c|c|}
\hline \multirow{2}{*}{$\begin{array}{c}\text { Valor de Corte } \\
\text { (mg/dl) }\end{array}$} & \multicolumn{2}{|c|}{ Total } & \multicolumn{2}{|c|}{ Causados por E. Analíticos } \\
\hline & $N^{0} F N$ & $\%$ & $N^{0} F N$ & $\%$ \\
\hline 2.2 & 2 & $2.1 \%$ & -- & -- \\
\hline 2.5 & 7 & $7.4 \%$ & 2 & $2.7 \%$ \\
\hline 2.7 & 1 & $1.1 \%$ & 1 & $1.4 \%$ \\
\hline 2.8 & 1 & $1.1 \%$ & 1 & $1.4 \%$ \\
\hline 3.0 & 3 & $3.2 \%$ & 2 & $2.7 \%$ \\
\hline 3.4 & 4 & $4.2 \%$ & 4 & $5.5 \%$ \\
\hline 3.6 & 11 & $11.6 \%$ & 11 & $15.1 \%$ \\
\hline 3.7 & 1 & $1.1 \%$ & 1 & $1.4 \%$ \\
\hline 4.0 & 53 & $55.8 \%$ & 46 & $63.0 \%$ \\
\hline 5.0 & 4 & $4.2 \%$ & 4 & $5.5 \%$ \\
\hline 8.0 & 1 & $1.1 \%$ & 1 & $1.4 \%$ \\
\hline
\end{tabular}

NOTA: 7 resultados FN fueron reportados empleando un método cualitativo razón por la cual los mismos no fueron contabilizados en la presente Tabla. 
De este modo se puede observar que 51 de los $73 \mathrm{FN}$ pertenecientes al grupo seleccionado (69.9 \%) corresponden a Laboratorios que interpretaron su resultados empleando $V C \geq 4.0 \mathrm{mg} / \mathrm{dl}$, hecho que no hace más que confirmar la hipótesis planteada inicialmente.

o Falsos resultados en la medida de TSH (5):

- Comportamiento de las tasas de FN y FP: en la Tabla 43 se presenta un resumen de los resultados FN y FP reportados en la medida de TSH, mientras que en las Figuras 116 y 117 se presenta la evolución experimentada en las tasas de ambos falsos resultados a lo largo del período evaluado, incluyendo además la contribución de los errores no analíticos propiamente dichos.

Tabla 43. Falsos Resultados en la medida de TSH

\begin{tabular}{|c|c|c|c|c|c|c|}
\hline & $\begin{array}{l}\text { No Falsos } \\
\text { resultados }\end{array}$ & $\begin{array}{c}\text { Total } \\
\text { respuestas }\end{array}$ & $\begin{array}{c}\text { Tasa } \\
\text { FR } \\
\end{array}$ & $\begin{array}{c}\text { Errores } \\
\text { Transposición }\end{array}$ & $\begin{array}{c}\text { Errores } \\
\text { Interpretación }\end{array}$ & $\begin{array}{l}\text { Errores } \\
\text { Unidades }\end{array}$ \\
\hline FN & 100 & 2650 & $3.8 \%$ & $21(21.0 \%)$ & $12(12.0 \%)$ & -- \\
\hline FP & 40 & 1349 & $3.0 \%$ & $14(35.0 \%)$ & $2(5.0 \%)$ & $5(12.5 \%)$ \\
\hline
\end{tabular}

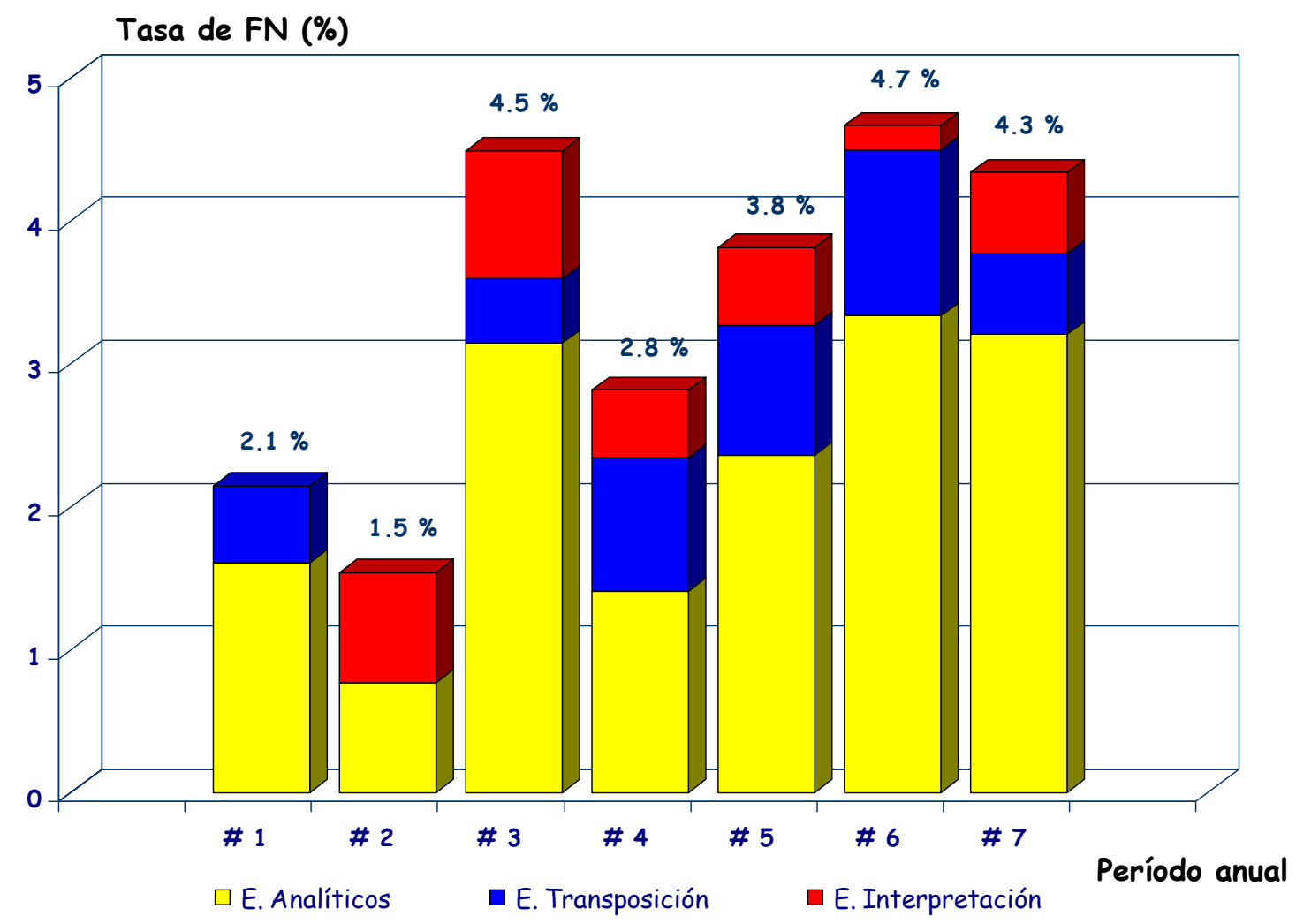

Figura 116. Evolución en la tasa de falsos negativos en la medida de TSH. 


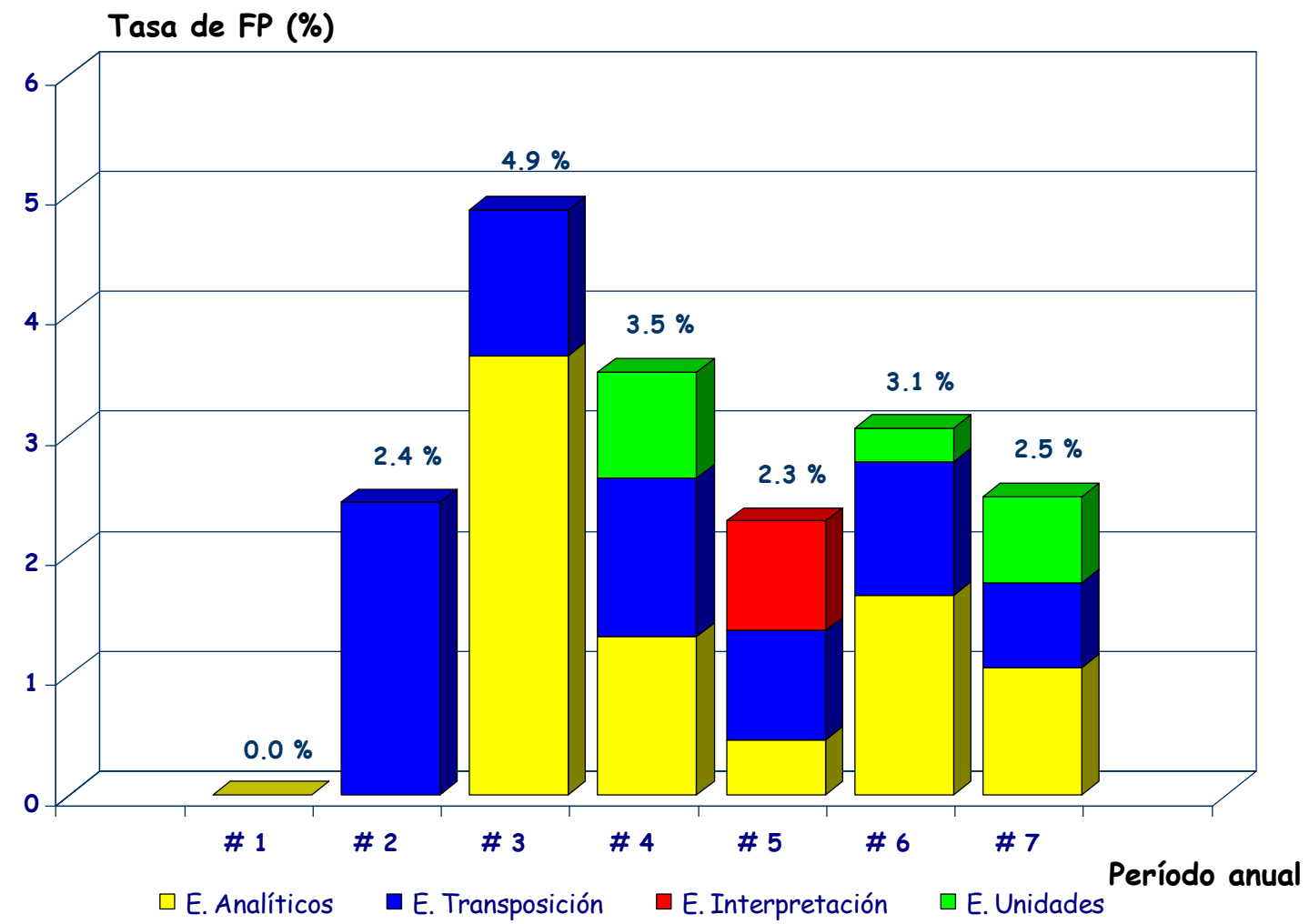

Figura 118. Evolución en la tasa de falsos positivos en la medida de TSH.

Tal como se puede visualizar en la Tabla 43, las tasas globales de falsos resultados correspondientes a TSH presentaron valores más apropiados que los observados en Phe, muy especialmente en lo que respecta al grupo de resultados FN. No obstante esto, y en contraposición con la situación observada en Phe, en el caso de TSH se presentó una incidencia muy superior de errores no analíticos, la cual resultó del $33.0 \%$ en los FN y del $52.5 \%$ en los FP, debiendo destacarse además que dentro de éste último grupo de falsos resultados entró en juego una categoría diferente de errores no analíticos, representada por los errores de expresión de unidades.

NOTA: Los errores de expresión de unidades son aquellos que se presentan cuando los resultados son reportados en $\mu \mathrm{U} / \mathrm{ml}$ de suero $y$ no por $\mathrm{ml}$ de sangre entera tal como es solicitado por el PEEC-PN.

En relación a los errores no analíticos antes mencionados, una vez más resulta oportuno hacer referencia a la magnitud de los mismos puesto que ellos representan un tercio del total de resultados FN y más de la mitad del total de resultados FP, reflejando así un alarmante nivel de desatención al momento de interpretar y reportar los resultados. 
En cuanto a la evolución experimentada en las tasas de falsos resultados, los

FN mostraron un comportamiento relativamente errático a lo largo de los 7 años evaluados presentando una ligera tendencia a aumentar a partir del Período Anual \# 4, mientras que en el caso de los FP ese mismo período anual marcó el inicio de una moderada tendencia decreciente en la correspondiente tasa de falsos resultados.

- Distribución de FN y FP según el método de medida: en las Figuras 118 y 119 se presentan las distribuciones del porcentaje de falsos resultados con respecto al número total de respuestas reportadas con cada uno de los métodos de medida.

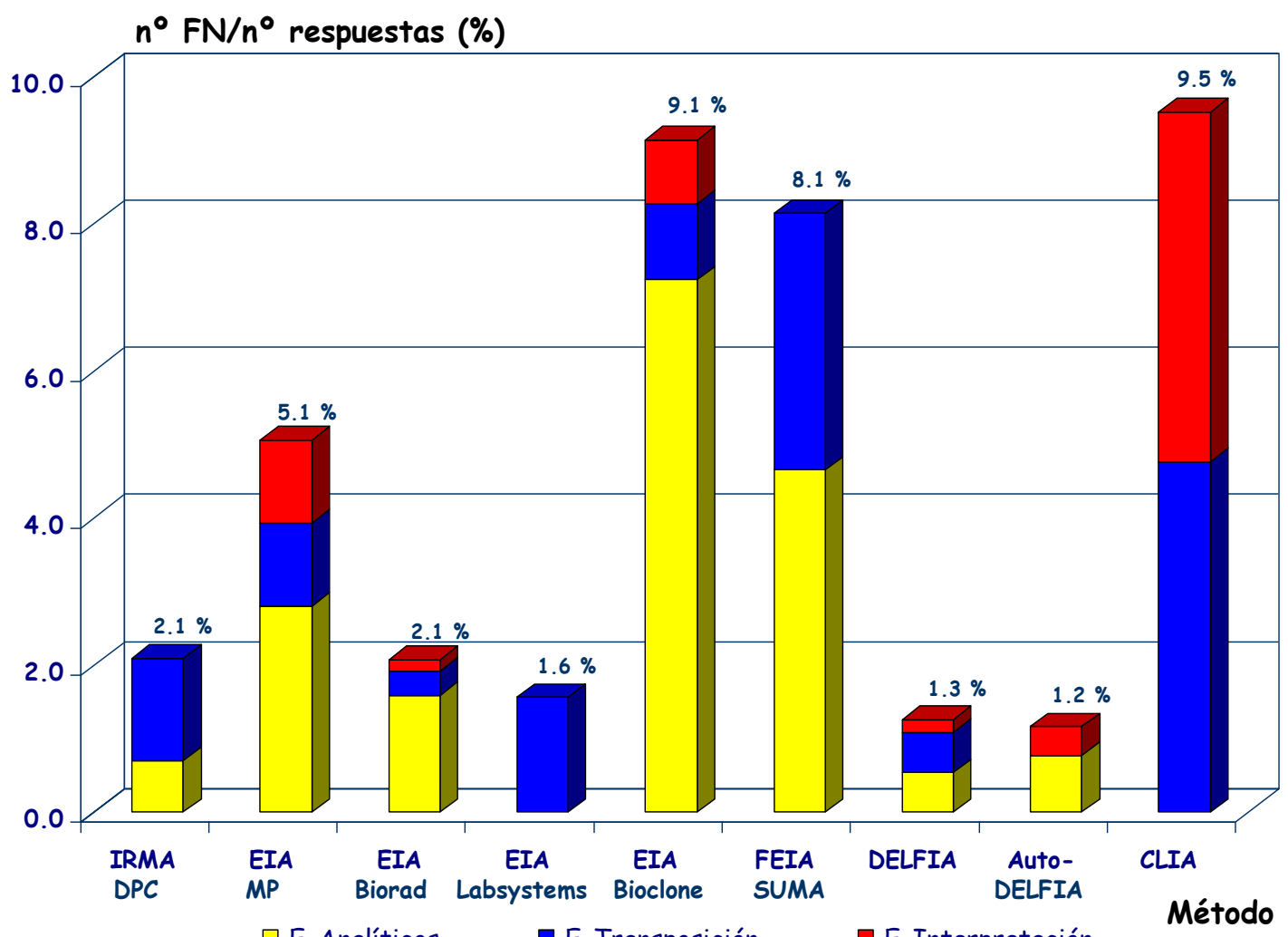

Figura 118. Incidencia relativa de falsos negativos según el método de medida de TSH.

NOTA: los métodos IRMA-Preparación propia (18), EIA-IC (15), EIA-Neogénesis (4), MEIA (21), ECLIA (44) y LUMINEX (5) que no aparecen representados en la Figura anterior no presentaron ningún resultado FN. Entre paréntesis se indica el número de respuestas reportadas con cada uno de ellos sobre el total de 2650 resultados reportados.

La evaluación de la incidencia de los resultados FN según el método de medida permite dividir a los mismos en 4 categorías, de las cuales el 
desempeño más crítico les corresponde al EIA-Bioclone (9.1\%), FEIA-SUMA $(8.1 \%)$ y CLIA $(9.5 \%)$. Sin embargo, es importante destacar que estos 3 métodos difieren notablemente en cuanto a las causas que desencadenaron dichos falsos resultados, al punto extremo de que el 100 \% de los FN reportados con el método CLIA corresponden a errores no analíticos.

Una situación similar también se observa en el caso del EIA-Labsystems en el cual todos los FN reportados corresponden a errores de transposición.

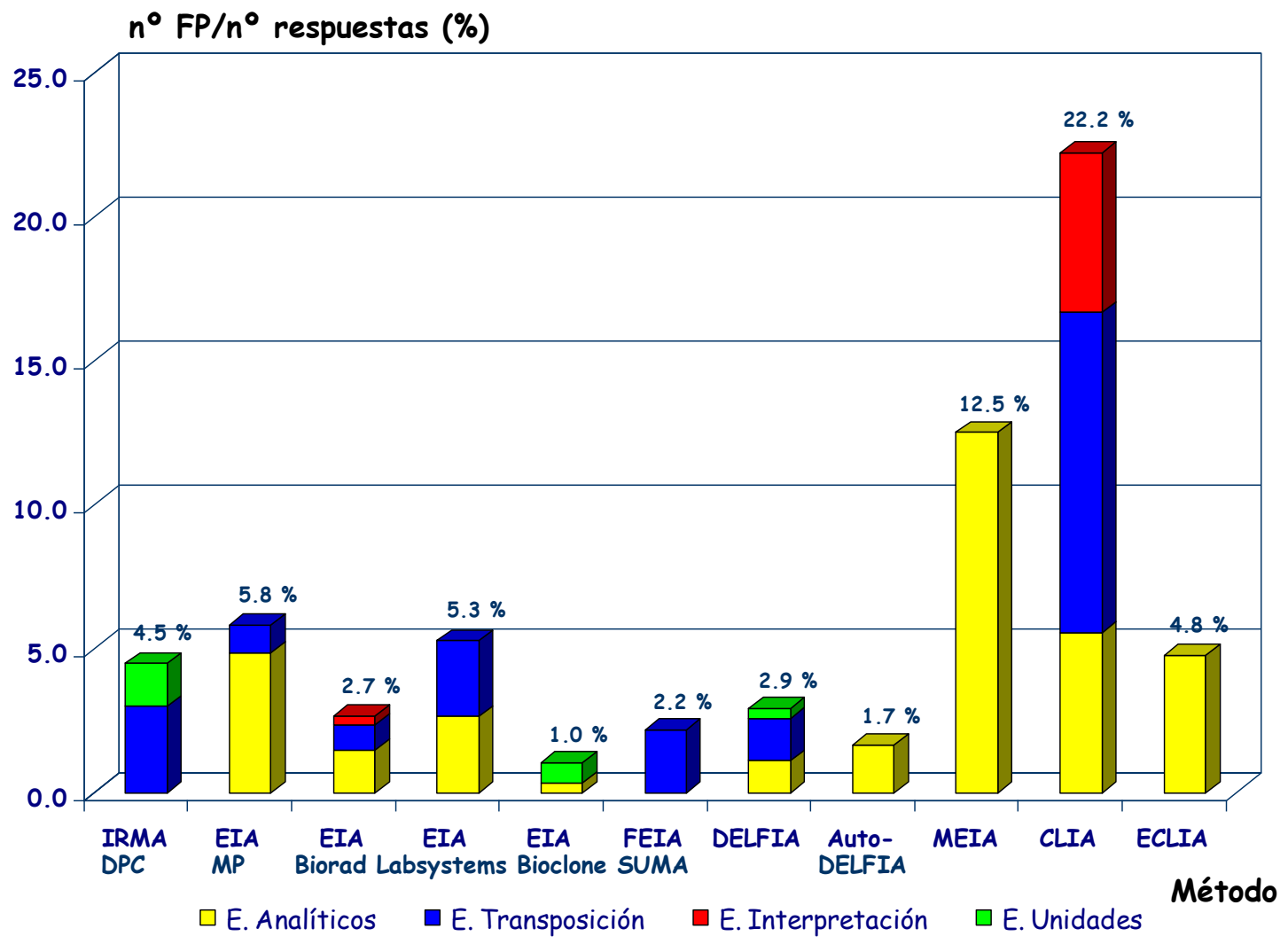

Figura 119. Incidencia relativa de falsos positivos según el método de medida de TSH.

NOTA: los métodos IRMA-Preparación propia (6), EIA-IC (7), EIA-Neogénesis (3) y LUMINEX (2) que no aparecen representados en la Figura anterior no presentaron ningún resultado FP. Entre paréntesis se indica el número de respuestas reportadas con cada uno de ellos sobre el total de 1349 resultados reportados.

Con respecto a los FP se encuentran 2 métodos que se diferencian claramente del resto por su muy elevada tasa de FP: el CLIA (22.2 \%) -una vez más con una significativa incidencia de errores no analíticos- y el MEIA (12.5\%), mientras que el resto de los métodos muestran un comportamiento relativamente homogéneo. Dentro de este último grupo, y en relación a los 
errores no analíticos se debe mencionar al IRMA-DPC y al FEIA-SUMA, cuyos FP fueron ocasionados en un $100 \%$ por errores de transposición y de expresión de unidades en el primero de ellos, y exclusivamente por errores de transposición en el segundo.

Por otra parte, y en contraste con la observación realizada al analizar en conjunto la incidencia de FN y FP sobre los métodos de medida de Phe, en el caso de TSH sólo se planteó una situación equivalente en los métodos MEIA y ECLIA, los cuales mostraron una elevada tasa de FP, de 12.5 y $4.8 \%$ respectivamente, y $0 \%$ de $F N$, poniendo así en evidencia un desequilibrio significativo entre sensibilidad y especificidad. A diferencia de éstos, la gran mayoría de los restantes métodos de medida de TSH mostraron proporciones variables tanto de resultados FN como de resultados FP.

- Distribución de FN y FP según el país de procedencia: en las Figuras 120 y 121 se presentan las distribuciones del porcentaje de falsos resultados con respecto al número total de respuestas reportadas provenientes de cada país.

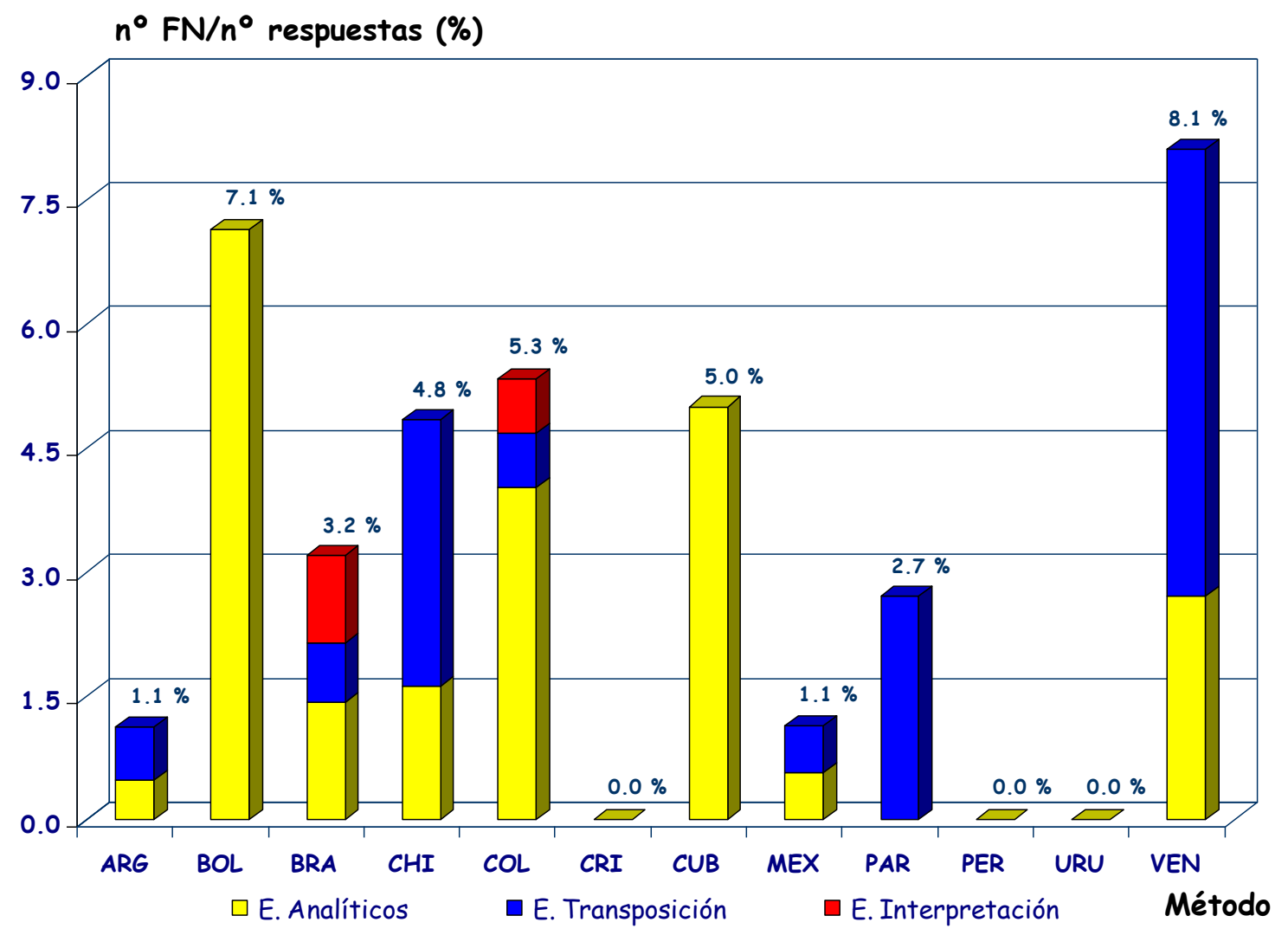

Figura 120. Incidencia relativa de falsos negativos según el país de procedencia en la medida de TSH. 
El análisis de la distribución correspondiente a los resultados FN muestra una relativa diversidad de resultados, destacándose Costa Rica, Perú y Uruguay por presentar una tasa óptima de FN de $0 \%$. No obstante esto y $\sin$ desmerecer este desempeño se debe destacar que la participación de Perú y Uruguay en este analito es de muy reciente data, con solamente 4 participaciones cada uno. En el extremo opuesto se encuentran Venezuela (8.1\%) y Bolivia $(7.1 \%)$, aún a pesar de que Bolivia discontinuó su participación con posterioridad al Período Anual \# 4.

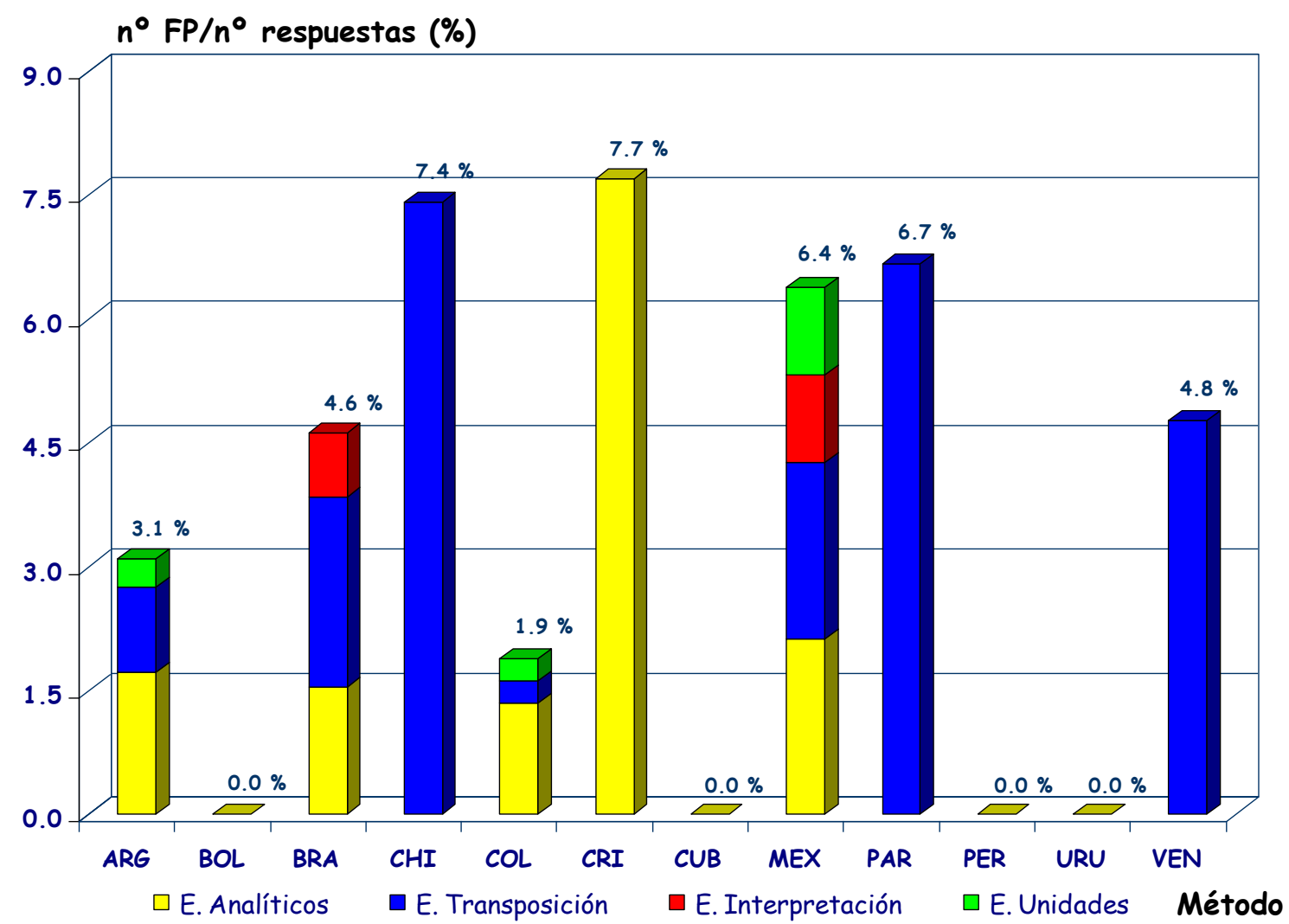

Figura 121. Incidencia relativa de falsos positivos según el país de procedencia en la medida de TSH.

En el caso de los FP, los resultados muestran un desempeño óptimo de Bolivia, Cuba, Perú y Uruguay con 0 \% de FP, siendo válidas las mismas observaciones realizadas anteriormente para Perú y Uruguay en cuanto a la inmediatez de su participación, y para Bolivia en cuanto a la discontinuación de su actividad en el Período Anual \# 5. En el otro extremo de performance se encuentran Chile $(7.4 \%)$, Costa Rica $(7.7 \%)$, México $(6.4 \%)$ y Paraguay 
(6.7 \%), de los cuales sólo Costa Rica reconoce un 100 \% de FP originados en causas analíticas.

En relación a la influencia de los errores de transposición sobre ambos tipos de falsos resultados debe destacarse que la totalidad de los FN y FP de Paraguay, la totalidad de FP de Chile y Venezuela, y 2/3 partes de los FN de estos 2 últimos países, fueron ocasionados exclusivamente por este tipo de errores.

Finalmente, y con respecto a aquellas situaciones que de alguna manera marcan un desequilibrio entre sensibilidad y especificidad de los métodos en uso, en el caso de TSH sólo se encuentran 3 casos plenamente representativos: por un lado Bolivia y Cuba, los cuales presentan $0 \%$ de FP y tasas elevadas o moderadamente elevadas de $\mathrm{FN}$ (7.1 y $5.0 \%$ respectivamente); y por el otro Costa Rica con una tasa de $0 \%$ de FN y del $7.7 \%$ de FP.

- Distribución de FN según el valor de corte: con respecto a la influencia de los VC sobre los resultados FN, en la Tabla 44 se presenta un detalle de su distribución incluyendo por un lado a la totalidad de los mismos, mientras que por el otro habiendo excluido previamente a aquellos FN originados por causas no analíticas.

Tabla 44. Distribución de falsos negativos según el valor de corte de TSH

\begin{tabular}{|c|c|c|c|c|}
\hline \multirow{2}{*}{$\begin{array}{c}\text { Valor de Corte } \\
(\mu \cup / m l)\end{array}$} & \multicolumn{2}{|c|}{ Total } & \multicolumn{2}{|c|}{ Causados por E. Analíticos } \\
\hline & $N^{0} F N$ & $\%$ & $N^{0} F N$ & $\%$ \\
\hline 9.0 & 1 & $1.0 \%$ & - & - \\
\hline 10.0 & 17 & $17.0 \%$ & 8 & $11.9 \%$ \\
\hline 11.0 & 1 & $1.0 \%$ & - & - \\
\hline 13.0 & 1 & $1.0 \%$ & - & - \\
\hline 15.0 & 6 & $6.0 \%$ & 3 & $4.5 \%$ \\
\hline 16.0 & 1 & $1.0 \%$ & 1 & $1.5 \%$ \\
\hline 20.0 & 70 & $70.0 \%$ & 53 & $79.1 \%$ \\
\hline 25.0 & 2 & $2.0 \%$ & 1 & $1.5 \%$ \\
\hline 40.0 & 1 & $1.0 \%$ & 1 & $1.5 \%$ \\
\hline
\end{tabular}

De acuerdo con los resultados presentados en la Tabla anterior, se puede determinar que 55 de los 67 FN reportados pertenecientes al último de 
estos dos grupos $(82.1 \%$ ) corresponden a Laboratorios que utilizaron VC $\geq$ $20.0 \mu \mathrm{U} / \mathrm{ml}$ para interpretar sus resultados, hecho que, en correspondencia con la observación presentada en el caso de Phe, confirma que la mayor parte de los resultados FN corresponden a Laboratorios que emplean VC superiores a lo esperado.

o Frecuencia de falsos resultados por Laboratorio: un último aspecto que requiere ser discutido en relación a los falsos resultados, es la frecuencia con que los mismos se presentaron en los diferentes Laboratorios participantes.

A efectos de ilustrar este panorama en la Tabla 45 se presenta el número de falsos resultados reportados por Laboratorio, expresados como frecuencia de resultados FN y FP.

Tabla 45. Frecuencia de falsos resultados por Laboratorio

\begin{tabular}{|c|c|c|c|c|}
\hline \multirow{2}{*}{$\begin{array}{c}N^{0} \text { de falsos } \\
\text { resultados }\end{array}$} & \multicolumn{2}{|c|}{ Phe } & \multicolumn{2}{|c|}{$T S H$} \\
\hline & $F N$ & $F P$ & $F N$ & $F P$ \\
\hline 0 & $48(57.8 \%)$ & $59(77.6 \%)$ & $168(73.0 \%)$ & $195(85.9 \%)$ \\
\hline 1 & 15 & 14 & 39 & 26 \\
\hline 2 & 7 & 1 & 14 & 4 \\
\hline 3 & 2 & 2 & 5 & 2 \\
\hline 4 & 5 & & 2 & \\
\hline 5 & 3 & & 2 & \\
\hline \multicolumn{5}{|l|}{6} \\
\hline 7 & 2 & & & \\
\hline 11 & 1 & & & \\
\hline Total Lab. & 83 & 76 & 230 & 227 \\
\hline
\end{tabular}

Este tipo de análisis presenta una gran relevancia por el hecho de que la primer impresión resultante del análisis de las tasas globales de FN y FP que fueron presentadas anteriormente para ambos analitos refleja un desempeño muy alejado del esperable, el cual engloba a toda la población de Laboratorios participantes sin realizar ningún tipo de distinción.

Sin embargo, y en contraposición con esta visión general, el análisis personalizado presentado en la Tabla 45 permite determinar que un porcentaje 
muy significativo de Laboratorios nunca reportó algún tipo de falsos resultados para uno u otro analito.

Adicionalmente, si se efectúa un análisis comparativo de la información provista en la Tabla 45 se encuentra una mejor situación en el caso de los FP con respecto a los FN para un mismo analito, y también en el caso de TSH con respecto a Phe para una misma categoría de falsos resultados.

Por otra parte, si se determina el número de Laboratorios que no presentaron resultados FN y FP analizados simultáneamente, y no como indicadores aislados tal como fueran presentados en la Tabla 45, se encuentra que en Phe el $47.4 \%(36 / 76)$ y en TSH el $66.4 \%$ (148/223) de los mismos nunca reportaron una clasificación incorrecta de los materiales de control provistos por el PEEC-PN, poniendo nuevamente en evidencia una mejor situación para TSH con respecto a Phe.

En el otro extremo se pueden observar situaciones muy alarmantes como las que se presentaron en aquellos Laboratorios que reportaron 7 y 11 resultados FN en Phe, y situaciones algo menos críticas en aquellos que reportaron 4 y 5 resultados FN tanto en Phe como en TSH, poniendo de manifiesto en todos los casos la presencia de potenciales problemas analíticos o de definición de VC de relevancia.

- Conclusiones: el análisis de diversos parámetros que caracterizan a la población de Laboratorios que participó en el PEEC-PN a lo largo de los 7 años evaluados, entre los que se incluyen la distribución según el país de origen, la adherencia y compromiso de participación con el Programa, la información provista por cada uno de ellos al momento de solicitar su inscripción y los resultados que hacen propiamente al desempeño de cada uno de ellos, permitió establecer que los mismos presentan una gran heterogeneidad en cuanto a su grado de complejidad, a la modalidad de organización de la PN en cada país o región, al número de muestras analizadas y a la diversidad de principios analíticos utilizados.

Por otra parte, las elevadas tasas de falsos resultados observadas como parte del análisis global determinan la necesidad de que un cierto número de 
Laboratorios realice un replanteo del desempeño analítico y diagnóstico de los métodos en uso y de la definición de sus propios VC, mientras que la incidencia de falsos resultados relacionados con errores de transposición e interpretación de resultados y de expresión de unidades pone en evidencia un preocupante grado de desatención al momento de reportar los resultados obtenidos sobre los materiales de control provistos por el PEEC-PN.

Más allá de las observaciones anteriores que tratan de poner énfasis en los aspectos que deben ser mejorados, es importante reconocer y destacar que en Latinoamérica existe un número altamente significativo de Laboratorios de PN que han mostrado un desempeño óptimo a lo largo del período evaluado y que han cumplido satisfactoriamente con los estándares de calidad establecidos por parte del PEEC-PN.

\section{BIBLIOGRAFIA}

1. Borrajo GJC y Mazziotta D. "Control de Calidad en Programas de Pesquisa Neonatal" en "Errores Innatos en el Metabolismo del Niño". Colombo M, Cornejo V y Raimann E Editores. $2^{a}$ Edición. Editorial Universitaria. Santiago de Chile, 385402, Cap. 14, Parte 3, 2003.

2. Slazyk WE and Hannon WH. "Quality Assurance in the Newborn Screening Laboratory" en "Laboratory Methods for Neonatal Screening", Therrell BL Ed, American Public Health Association, Washington, 23-46, 1993.

3. Borrajo GJC. "Newborn Screening in Latin America at the beginning of the 21st Century". J Inherit Metab Dis, 30, 466-81, 2007.

4. Borrajo GJC, Pistaccio LG y Mazziotta D. "Utilización de Criterios de Aceptabilidad Clínica Aplicados a la Evaluación Externa de Calidad (Póster). Acta Bioquím Clin Latinoam, Supl 1, 284, 2007.

5. Borrajo GJC, Pistaccio LG y Mazziotta D. "Evaluación de Causas y Características de Falsos Resultados Reportados al PEEC-PN. (Póster). Acta Bioquím Clin Latinoam, Supl 1, 72, 2007. 


\section{ANEXO 1: PREPARACIÓN DE MATERIALES DE CONTROL DE SANGRE ENTERA IMPREGNADA EN PAPEL DE FILTRO}

\section{- MATERIALES NECESARIOS:}

o Glóbulos rojos:

1. Preparar un pool de glóbulos rojos grupo $O$, factor $\mathrm{Rh}(-)$ a partir del excedente de muestras de sangre entera colectadas con EDTA de 15-20 individuos adultos sanos, donantes de sangre, HIV, HBV y HCV no reactivos, obtenidas para la realización de estudios inmunohematológicos (3-5 $\mathrm{ml}$ de sangre/tubo).

2. Volcar el contenido de todos los tubos en 2 tubos cónicos de $50 \mathrm{ml}$ con tapa a rosca, asegurándose de colocar volúmenes similares en ambos tubos.

3. Centrifugar durante 10 minutos a $3500 \mathrm{rpm}$. Descartar el plasma y la capa de células formada sobre la superficie del paquete de glóbulos rojos conteniendo plaquetas y glóbulos blancos, aspirando con una pipeta Pasteur descartable.

4. Lavar los glóbulos rojos con solución fisiológica de $\mathrm{NaCl} 9.0 \mathrm{~g} / \mathrm{l}$. Para esto llevar ambos tubos a volumen con la mencionada solución (Vol. final = $45 \mathrm{ml}$ ), homogeneizar por inversión y centrifugar nuevamente por 10 minutos a 3500 rpm. Descartar el líquido de lavado y la capa de células formada sobre la superficie del paquete de glóbulos rojos conteniendo plaquetas y glóbulos blancos, aspirando con una pipeta Pasteur descartable.

5. Repetir el paso 4 dos veces más.

6. Realizar un lavado adicional en las mismas condiciones que en el paso 4 pero empleando un pool de sueros de individuos normales preparado tal como se describe más abajo, en lugar de solución fisiológica. Descartar el suero del sobrenadante.

7. Volcar el contenido de ambos tubos cónicos en un único tubo cónico de $50 \mathrm{ml}$ con tapa a rosca. Homogeneizar por inversión suave.

8. Medir el hematocrito, el cual deberá estar en el orden del $85 \pm 5 \%$. 
9. Almacenar en heladera a $4{ }^{\circ} \mathrm{C}$ hasta el momento de uso.

o Suero normal:

1. Preparar un pool de sueros de cualquier grupo y factor a partir del excedente del suero proveniente de muestras de sangre colectadas sin anticoagulante de 30-40 individuos adultos sanos, donantes de sangre, HIV, HBV y HCV no reactivos, obtenidos para la realización de estudios inmunoserológicos, asegurándose que los sueros seleccionados sean límpidos y libres de lípidos en todos los casos (3-4 $\mathrm{ml}$ de suero/tubo).

2. Volcar el contenido de todos los tubos en un frasco apropiado con tapa a rosca, con capacidad de 100 a $150 \mathrm{ml}$.

3. Incubar el pool de sueros 30 minutos adicionales a $37^{\circ} \mathrm{C}$ a efectos de asegurar la desfibrinación completa del mismo.

4. Centrifugar el pool de sueros 5 minutos a $3500 \mathrm{rpm}$ a efectos de eliminar cualquier coágulo de fibrina que pudiera estar presente. Si aún así se encontraran microcoágulos o partículas proceder a efectuar un filtrado del mismo.

5. Almacenar en heladera a $4{ }^{\circ} \mathrm{C}$ hasta el momento de uso.

o Solución concentrada de Phe (100 mg/dl de enriquecimiento):

1. Pesar $50 \mathrm{mg}$ de Phe (SIGMA P-2126) en balanza analítica.

2. Disolver la cantidad antes indicada de Phe en $5 \mathrm{ml}$ de solución fisiológica y recién una vez completada la disolución llevar a volumen final de $50 \mathrm{ml}$ con el pool de sueros antes descripto. De este modo, se obtiene una solución concentrada de Phe cuya concentración será igual a la suma de la Phe endógena o basal del pool de sueros, más la Phe adicionada exógenamente $(100 \mathrm{mg} / \mathrm{dl})$.

3. Almacenar en heladera a $4{ }^{\circ} \mathrm{C}$ hasta el momento de uso.

o Sueros con niveles elevados de TSH:

1. Obtener sueros de diferentes individuos con niveles elevados de TSH, ya sea en forma espontánea o por estimulación post prueba de TRH, colectados para la realización de estudios del eje tiroideo, y cuyos niveles hayan sido 
previamente valorados con métodos apropiados.

NOTA: En el caso particular del PEEC-PN, la fuente a partir de la cual se obtienen estos sueros son Laboratorios de Análisis Clínicos especializados en Endocrinología.

2. Efectuar las pruebas serológicas pertinentes a efectos de determinar que los mismos sean HIV, HBV y HCV no reactivos.

3. Preparar diferentes pooles de sueros con TSH elevada, mezclando para ello aquellos sueros que presenten niveles similares de la hormona en cuestión.

4. Realizar una preparación de sangre entera enriquecida con TSH en pequeña escala (200 $\mu \mathrm{l}$ de volumen final), mediante el agregado de volúmenes preestablecidos de los pooles de sueros con niveles elevados de TSH a sangre entera de hematocrito $50 \%$, de manera tal de alcanzar un rango de concentraciones analíticamente apropiado para valorar la concentración de TSH en DBS.

5. Impregnar 1 o 2 gotas de dicha sangre en papel de filtro y determinar la concentración de TSH en las mismas utilizando la metodología AutoDELFIA TSH Neonatal - PerkinElmer o la que se encuentre disponible.

6. Almacenar aquellos pooles de sueros con TSH elevada que van a ser utilizados en la preparación del lote actual en heladera a $4^{\circ} \mathrm{C}$ hasta el momento de uso, mientras que aquellos que van a ser utilizados recién en la preparación de otro lote en un tiempo posterior, en freezer $a-20^{\circ} \mathrm{C}$.

\section{- PROCEDIMIENTO DE PREPARACIÓN}

o Preparación de la sangre entera con hematocrito $50 \%$ :

1. Permitir que todos los componentes necesarios para la preparación alcancen temperatura ambiente.

2. Mezclar 1 volumen del pool de glóbulos rojos lavados y $n$ volúmenes del pool normal de sueros en un recipiente apropiado, de manera tal de obtener sangre entera con un hematocrito de aproximadamente $50 \%$.

NOTA: El volumen del pool de sueros a adicionar dependerá del hematocrito alcanzado en el pool de glóbulos rojos lavados con suero. Por ejemplo si el mencionado hematocrito fuera $85 \%$, entonces n será igual a 0.7 .

3. Homogeneizar la sangre por inversión suave. 
4. Medir el hematocrito utilizando un contador hematológico, y proceder a quitar o a agregar el volumen apropiado de suero según corresponda, a fin de ajustar el hematocrito al $50 \%$.

5. Dividir el volumen total de sangre entera con hematocrito ajustado en tantas fracciones como materiales de control se vayan a preparar. En el caso del PEEC-PN, distribuir en 2 tubos cónicos de $50 \mathrm{ml}$ con tapa a rosca (Figura 122).

6. Almacenar en heladera a $4{ }^{\circ} \mathrm{C}$ hasta el momento de uso.

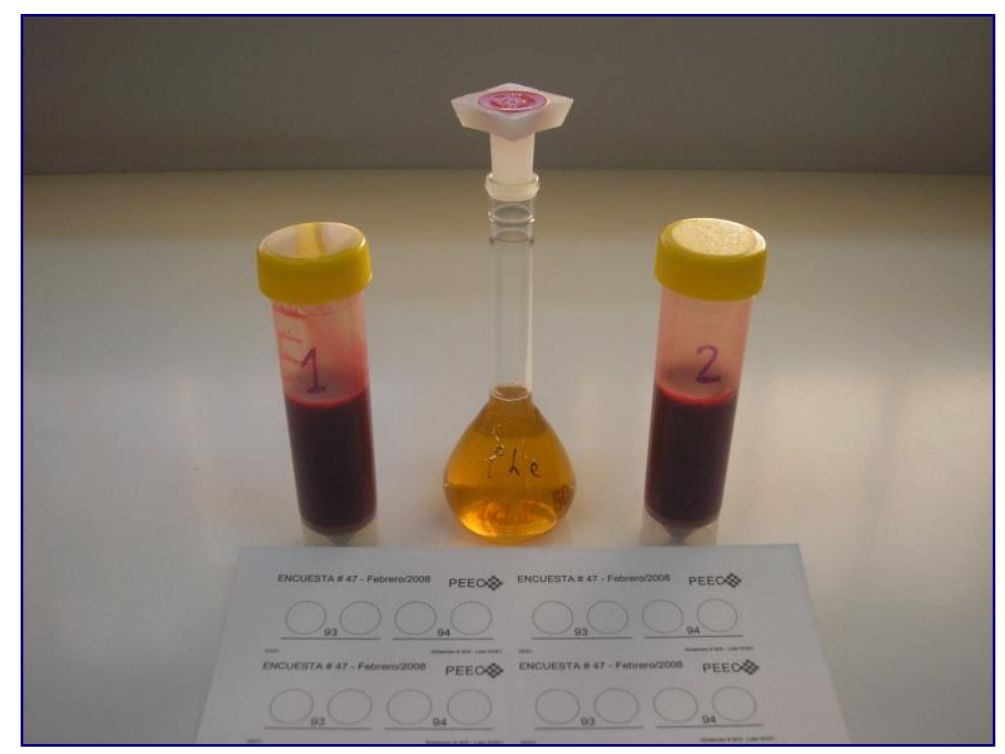

Figura 122. Preparación de sangre entera para materiales de control.

\section{o Preparación de la sangre entera enriquecida en Phe y TSH:}

1. Definir la concentración de Phe y TSH final que se pretende lograr en cada material de control.

2. Calcular el volumen de la solución concentrada de Phe y del pool de sueros con niveles elevados de TSH que se debe agregar a cada uno de ellos en función de la información definida en el punto 1 y de las concentraciones de Phe y TSH en cada una de estas soluciones.

3. Centrifugar ambas fracciones de sangre entera con hematocrito ajustado durante 5 minutos a 2000 rpm y extraer de cada una de ellas un volumen de suero igual a la suma del volumen de solución concentrada de Phe y del pool de sueros con niveles elevados de TSH que se deben agregar. 
4. Agregar el volumen apropiado de la solución concentrada de Phe y del pool de sueros con niveles elevados de TSH, de acuerdo a lo calculado previamente.

5. Homogeneizar por inversión y dejar estabilizar por un plazo de 1-2 horas a temperatura ambiente o eventualmente a $4^{\circ} \mathrm{C}$.

o Preparación de los materiales de control impregnados en papel de filtro:

1. Imprimir la plantilla correspondiente al lote de controles a preparar en hojas de papel de filtro Whatman \# 903 cortadas en dimensiones A4.

2. Colocar las hojas de papel de filtro en el bastidor diseñado para tal fin de manera tal que las mismas se mantengan en posición horizontal y suficientemente tensas como para asegurar que no se deformen durante el proceso de dispensado (Figura 123).

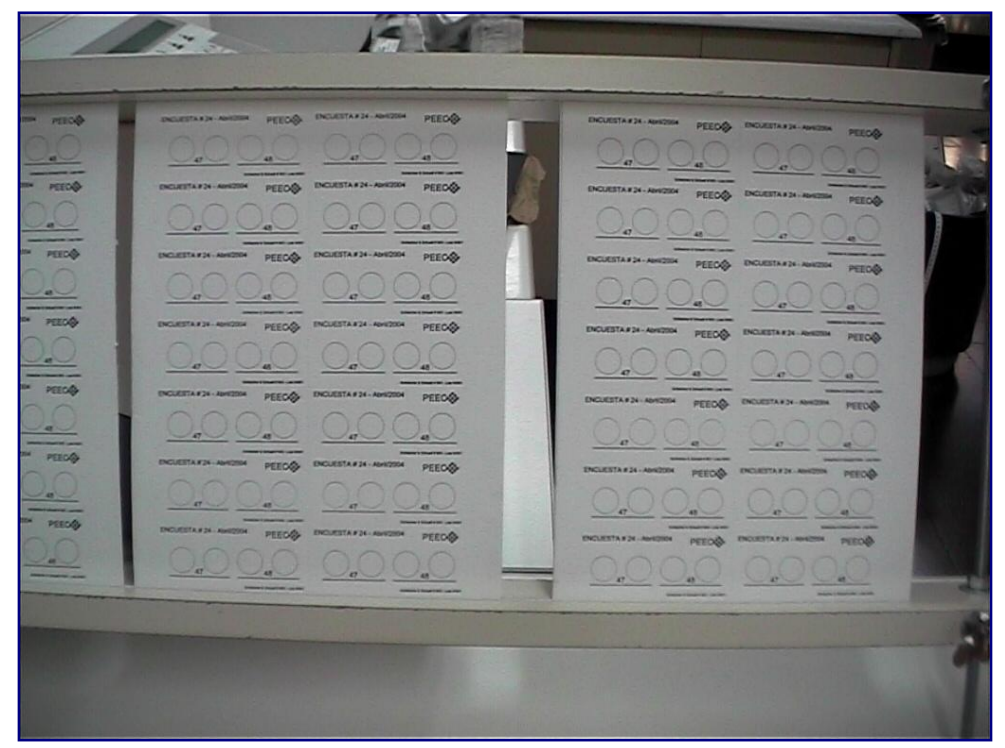

Figura 123. Bastidor para la fijación de las hojas de papel de filtro (vista superior).

3. Homogeneizar la sangre por inversión suave en reiteradas ocasiones.

4. Dispensar la sangre entera en los círculos impresos en el papel de filtro a razón de $70 \mu$ por mancha (Figuras 124 a y b).

5. Homogeneizar la sangre por inversión cada 20 manchas dispensadas.

6. Completar el proceso de dispensado y dejar secar una noche en posición horizontal a temperatura ambiente (Figura 125), respetando las condiciones 
de secado de muestras descriptas en el Capítulo 2.

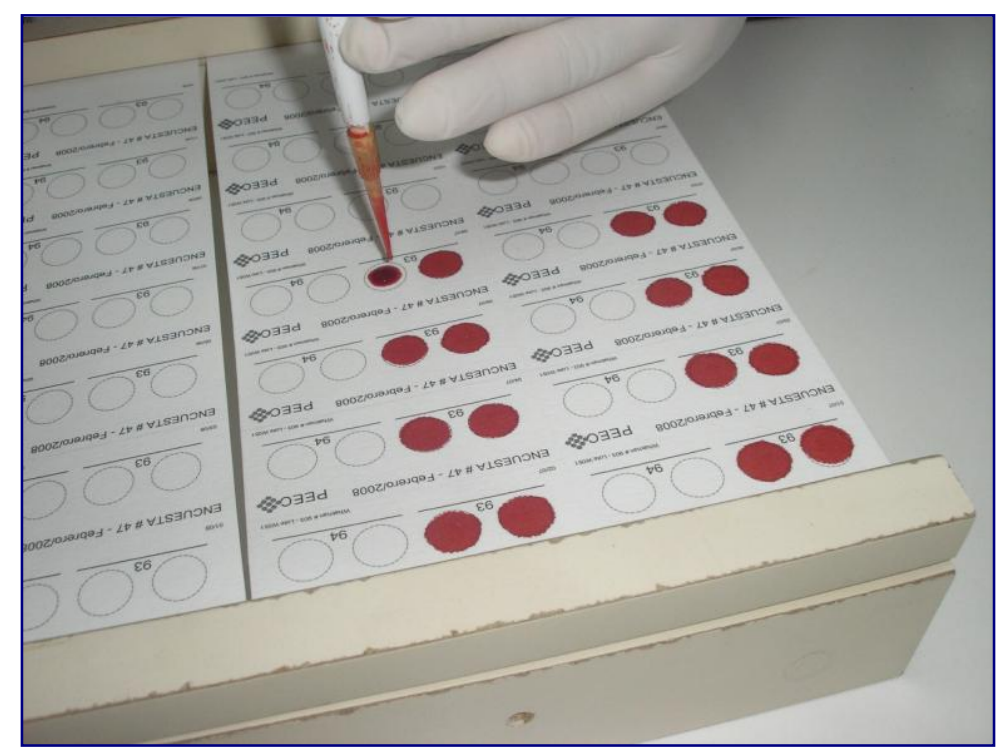

Figura 124a. Impregnación de materiales de control.

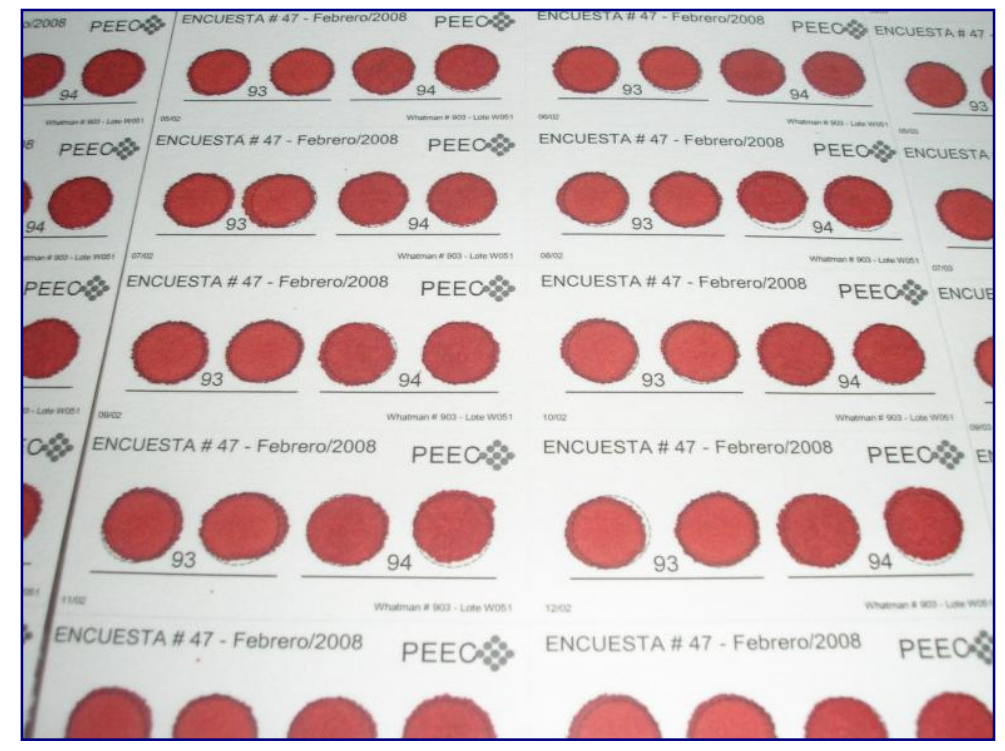

Figura 124b. Impregnación de materiales de control.

7. Cortar las tiras de papel de filtro por la línea punteada que delimita a unas de otras.

8. Descartar aquellas muestras cuyas manchas sean inapropiadas o incompletas, de diámetro inferior o mayor al previsto, que macroscópicamente no resulten uniformes, o que presenten microcoágulos o agregados celulares. 
9. Colocar las tiras en bolsas de plástico aluminizadas con cierre hermético tipo zip-closure, agregando varios desecantes y un indicador de humedad.

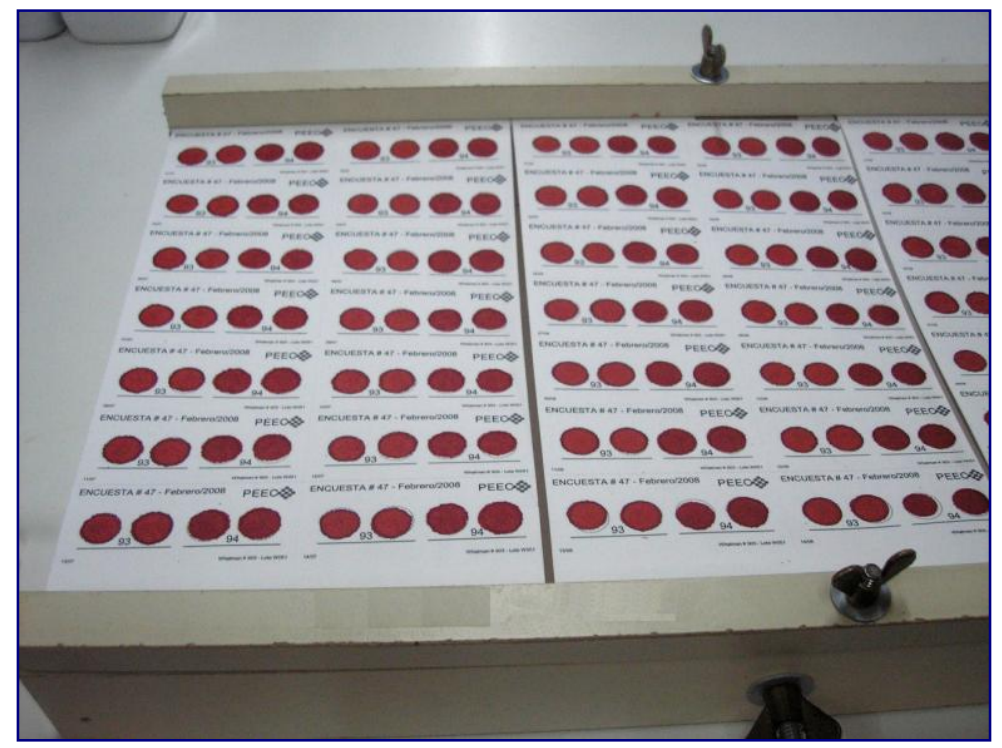

Figura 125. Secado de materiales de control.

10. Almacenar en freezer a $-20^{\circ} \mathrm{C}$ hasta su distribución.

11. Después de 3 o 4 días de almacenamiento en freezer, separar una tira de controles y determinar los niveles de Phe y TSH para corroborar la correspondencia entre los valores experimentales y los valores teóricos previstos en la preparación.

NOTA: en el caso del PEEC-PN los dosajes de Phe y TSH se realizan por Flurometría de Preparación Propia y AutoDELFIA respectivamente.

\section{- comentarios acerca de la pREPARACIÓN}

- La cantidad de glóbulos rojos O (-) y del pool de sueros indicados en el apartado correspondiente a Materiales necesarios resulta suficiente para la preparación de 2 materiales de control dispensados a razón de aproximadamente 400 manchas de cada uno de ellos (30 $\mathrm{ml}$ de sangre entera de cada material de control).

- Dado que el pool de sueros se prepara a partir de individuos de cualquier grupo y factor, el pool de glóbulos rojos debe prepararse necesariamente a partir de individuos $O(-)$ a efectos de que al mezclar ambos pooles no se produzca la 
hemólisis de estos últimos.

- El hecho de utilizar pooles de glóbulos rojos y de sueros de varios individuos tiene por finalidad minimizar la variabilidad biológica individual.

- El lavado adicional de los glóbulos rojos con el pool de sueros es realizado con el objetivo de eliminar el excedente de solución fisiológica que queda ocluida entre los glóbulos rojos y que no puede ser eliminada por centrifugación. De este modo se asegura que la matriz de los materiales de control tenga la mayor similitud posible a la de las muestras de RN.

- La remoción de la capa de células formada sobre la superficie del paquete de glóbulos rojos tiene por finalidad eliminar la presencia de pequeños microagregados de plaquetas y leucocitos que al ser impregnados en el papel de filtro le confieren a las manchas un aspecto de baja calidad, con una apariencia tal como si presentaran pequeños microcoágulos.

- La preparación de la solución concentrada de Phe es realizada en suero con el objetivo de preservar la matriz de los materiales de control lo más similar posible a la de las muestras de RN.

- La extracción de un volumen de suero normal idéntico al volumen de solución concentrada de Phe y del pool de sueros con niveles elevados de TSH a agregar a la sangre entera tiene por finalidad asegurar que no se modifique el hematocrito final de la preparación. 


\section{CAPÍTULO 7}

DESARROLLO DE UN SISTEMA

INTEGRAL DE CONTROL DE

CALIDAD PARA UN PROGRAMA

DE PESQUISA NEONATAL 



\section{- INTRODUCCIÓN}

La implementación de un Sistema Integral de Control de Calidad para un Programa de PN es un proceso que se sustenta en la aplicación de una serie de conceptos muy frecuentemente utilizados en el área de salud entre los cuales se incluyen Calidad, Control de Calidad, Aseguramiento de la Calidad, Gestión de Calidad, Sistema de Gestión de Calidad y Sistema Integral de Gestión de Calidad.

En función de esto, y a efectos de lograr una mejor y más simple comprensión de los principios y fundamentos teóricos requeridos, dichos conceptos serán definidos a continuación en forma detallada.

- Calidad: es el conjunto de características de un producto o servicio que le confieren al mismo la aptitud necesaria para satisfacer $e$, incluso superar, las necesidades y expectativas del cliente o usuario $(1,2)$.

- Control de Calidad (CC): es el conjunto de técnicas y actividades operativas que son utilizadas para cumplimentar los requerimientos de calidad (1). En otros términos se puede decir que el CC es la parte de la Gestión de Calidad orientada a examinar y conocer el grado de cumplimiento de los requisitos establecidos o requeridos por los procesos, productos o servicios del laboratorio (2), y dado que el mismo se realiza al final de cada uno de estos procesos es de naturaleza reactiva.

- Aseguramiento de la Calidad: es el conjunto de acciones planeadas y sistemáticas incluidas en el sistema de calidad, necesarias para proporcionar confianza de que se cumplen los requisitos de calidad determinados o exigidos (1-3).

El Aseguramiento de la Calidad es también una parte de la Gestión de Calidad (2), y dado que el mismo se aplica durante cada uno de los procesos, es de naturaleza preventiva o proactiva.

- Gestión de Calidad: es el conjunto de actividades necesarias para el control, aseguramiento y mejora de la calidad de acuerdo con la política de calidad y las responsabilidades fijadas en el Sistema de Gestión de Calidad (2).

- Sistema de Gestión de Calidad: es la estructura organizativa establecida para regir y actualizar el conjunto de responsabilidades, procesos, acciones y recursos 
que exige la Gestión de Calidad (2).

- Sistema Integral de Gestión de Calidad es el conjunto de medios, recursos y actividades del Sistema de Gestión de Calidad integrados en la organización, estructura y gestión del Laboratorio (2).

De este modo, cuando el concepto de Aseguramiento de la Calidad es aplicado a un Programa de PN, "proporcionar confianza de que se cumplen las condiciones de calidad exigidas por las necesidades del usuario" implica que el mencionado Programa debe asegurar tanto la detección como el tratamiento oportuno y apropiado de todos los individuos afectados, y también garantizar el desarrollo de cada uno de ellos con sus capacidades físicas, psíquicas e intelectuales intactas a lo largo de toda su vida.

En consecuencia, toda vez que se hace referencia al concepto de Calidad aplicado a la PN -y a semejanza de lo que ocurre en prácticamente todas las actividades del área de la salud-, el mismo no debe quedar estrictamente circunscripto o limitado a la etapa analítica del Laboratorio, sino que por el contrario debe ser mucho más amplio y abarcativo, involucrando también a las etapas pre- y post- analíticas (4-6).

Esta exigencia no resulta un hecho casual sino que, por el contrario, la misma surge como una consecuencia directa de que la única forma posible de garantizar un óptimo desempeño de cada uno de los efectores involucrados en los distintos niveles de ejecución de un Programa de PN es a través de la implementación de un Sistema de Control de Calidad de alcance integral, actividad que en definitiva redundará en una máxima eficacia y eficiencia del sistema de pesquisa en su conjunto( $\left.{ }^{\star}\right)$.

(*) la eficacia es un concepto que expresa la relación entre los resultados obtenidos y los objetivos predeterminados, mientras que la eficiencia es un concepto que expresa la relación entre los resultados obtenidos y los medios utilizados para ello (2).

Por las razones antes expuestas, y a efectos de que todo Programa de PN pueda dar cumplimiento a las condiciones de calidad exigidas, resulta necesario que cada uno de ellos evalúe su eficacia y eficiencia en forma continua y permanente a lo largo del tiempo, ya sea tanto en lo que se refiere a su desempeño global como también en lo que respecta al desempeño específico de cada uno de sus efectores, 
puesto que, sólo de esta forma, será posible determinar cual es la contribución de cada uno de ellos al cumplimiento de los objetivos generales.

En la práctica, la concreción de estos objetivos es un proceso complejo que requiere de 3 elementos fundamentales: por un lado el monitoreo permanente de la calidad del sistema por parte de los responsables del mismo $(5,7-8)$, mientras que por el otro, tanto el esfuerzo cooperativo de todos los efectores involucrados en los distintos niveles de ejecución (8), como la disponibilidad de los datos e información aportados por cada uno de ellos.

- elementos a considerar en el diseño de UN sistema INTEGRAL DE CONTROL DE CALIDAD PARA PESQUISA NEONATAL

El proceso de diseño y desarrollo de un Sistema Integral de CC para PN requiere definir en primera instancia quienes serán los efectores del sistema, cuáles serán sus alcances y responsabilidades, y cuáles serán los índices o indicadores que han de ser utilizados a efectos de poder cuantificar el desempeño de cada uno de ellos en forma puntual, el de los diferentes niveles de ejecución, y el del propio Programa en su conjunto.

\section{Efectores del Sistema de Pesquisa Neonatal}

Los efectores del Sistema de PN están representados por el conjunto de instituciones, organizaciones, servicios o equipos de trabajo responsables de ejecutar las tareas inherentes al Programa de PN en sus diferentes niveles de ejecución. Los mismos pueden ser agrupados en 4 categorías:

- Centros Asistenciales: son los encargados de ejecutar las siguientes tareas (4, 9-11):

o Instrucción, educación y provisión de información correcta y actualizada a los padres.

o Aseguramiento de que todos los RN son pesquisados.

o Obtención de consentimientos o disentimientos informados en aquellos casos en 
los que los mismos sean requeridos.

o Recolección de muestras de sangre satisfactorias y envío de las mismas al Laboratorio de pesquisa en tiempo y forma.

o Recepción de resultados y entrega de informes de resultados a los padres.

o Implementación inmediata de las acciones de localización de aquellos neonatos con muestras inadecuadas o resultados anormales, ya sea para la toma de una segunda muestra o para su derivación a un Centro de Atención Especializada.

Esta categoría de efectores, a los cuales habitualmente se conoce con el nombre de "efectores de recolección de muestras", está representada por Maternidades públicas y privadas, Hospitales, Clínicas, Sanatorios, Unidades Sanitarias y Laboratorios de análisis clínicos, siendo los responsables de la ejecución de las tareas asignadas a la misma todos aquellos integrantes del equipo de salud que se encuentran en el entorno del RN en el momento del nacimiento, y también aquellas personas afectadas al cuidado del mismo durante el período neonatal.

Como se desprende de los conceptos expresados anteriormente las responsabilidades asignadas a este grupo de efectores comienzan con el nacimiento de un niño o con el ingreso del mismo a un Centro Asistencial, y culminan una vez que se recibe y documenta el resultado de las pruebas de pesquisa en los registros médicos del paciente (4).

En relación al procedimiento de recolección de muestras resulta importante dedicarle un párrafo aparte, puesto que cada uno de los responsables a cargo de dicho procedimiento en los diferentes Centros Asistenciales debe asegurar que las muestras de sangre sean colectadas de acuerdo con las normas o recomendaciones establecidas por el propio Programa y que, además, estas muestras se ajusten a los requerimientos de calidad exigidos en cuanto a sus características, uniformidad, impregnación y volumen de sangre por mancha $(6,12)$.

Por otra parte, estos efectores también son responsables de asegurar que los datos demográficos de todos los RN sean completados de manera correcta, puesto que un inadecuado llenado de los mismos puede conducir a dificultades y/o errores tanto en el análisis e interpretación de los resultados, como en la 
localización del propio RN $(6-7,10)$.

- Laboratorio de Pesquisa: es el encargado de llevar a cabo las siguientes tareas $(4,9,11)$ :

o Documentación precisa de todas las actividades que involucran muestras de sangre de RN.

o Definición y puesta en práctica de criterios de recolección de muestras.

o Educación de los efectores de recolección de muestras.

o Análisis de muestras de sangre de todos los RN y reporte de resultados en forma oportuna.

o Comunicación a los Centros Asistenciales y al Centro de Atención Especializada de los datos de todos aquellos RN que requieren su localización.

o Comunicación de las directivas e indicaciones pertinentes en relación a la conducta a seguir con aquellos RN que requirieron su derivación al Centro de Atención Especializada.

o Almacenamiento de datos y registros.

o Implementación y documentación de un apropiado sistema de Aseguramiento de Calidad.

o Seguimiento de la llegada de segundas muestras solicitadas por resultados anormales o por recolección inadecuada.

Esta segunda categoría de efectores está representada por Laboratorios centralizados, altamente desarrollados y especializados en $\mathrm{PN}$, siendo los responsables de la ejecución de sus tareas el personal administrativo, técnicos de laboratorio y bioquímicos que forman parte de la planta de recursos humanos de los mismos.

Las responsabilidades del Laboratorio de pesquisa comienzan con la recepción de las muestras de sangre de los RN y culminan cuando todas las pruebas han sido completadas, los resultados reportados y el CC documentado; los resultados anormales o de muestras insatisfactorias han sido apropiadamente comunicados a los responsables de ejecutar las acciones de localización (4); las segundas muestras solicitadas han sido recibidas, analizadas y reportadas; y los neonatos 
referidos al Centro de Atención Especializada han concurrido a los mismos. Eventualmente en aquellos casos en los cuales se han completado y agotado todas las instancias de seguimiento definidas por el Programa con resultados negativos, las responsabilidades culminan documentando apropiadamente las acciones realizadas.

- Centro de Atención Especializada: es el encargado de las siguientes actividades $(4,9,11)$ :

o Confirmación diagnóstica en niños con resultados anormales.

o Implementación inmediata del tratamiento.

o Tratamiento y seguimiento a largo plazo de los neonatos afectados.

o Comunicación de la información final del diagnóstico a los Centros Asistenciales y al médico pediatra encargado de la atención general del paciente.

o Evaluación de la efectividad de las acciones terapéuticas implementadas.

o Coordinación centralizada de las acciones de localización de los RN que así lo requieran.

o Provisión de resultados para la evaluación del funcionamiento del Programa a largo plazo.

En general, los Centros de Atención Especializada están representados por instituciones de alta complejidad, especializadas y capacitadas para llevar a cabo el diagnóstico de las enfermedades en cuestión, siendo los responsables de las tareas que les competen diferentes integrantes del equipo de salud entre los que se incluyen bioquímicos, médicos especializados en el manejo de las diferentes enfermedades congénitas pesquisadas, genetistas, nutricionistas, psicólogos y asistentes sociales.

Las responsabilidades del Centro de Atención Especializada comienzan con la recepción de la comunicación de que un $\mathrm{RN}$ con resultados anormales en las pruebas de pesquisa ha sido referido al mismo, y finalizan con la documentación de que el diagnóstico ha sido confirmado o descartado y de que, en aquellos casos en que corresponda, está siendo tratado (4).

- Sistema de Transporte de muestras: es el responsable de las siguientes tareas:

o Retiro de muestras de sangre de los RN en los diferentes Centros Asistenciales. 
o Traslado y entrega de las mismas en el Laboratorio de Pesquisa.

o Transporte de informes de resultados y del material de trabajo necesario para la continuidad del Programa desde el Laboratorio de Pesquisa hacia los diferentes Centros Asistenciales.

Tal como ya fuera definido en el Capítulo 1, este sistema de transporte puede presentar diferentes características dependiendo de lo establecido por cada Programa y en consecuencia en función de estas características variarán los responsables de las tareas que le competen.

Las responsabilidades del mismo comienzan cuando las muestras de sangre correspondientes a un determinado Centro Asistencial fueron recepcionadas para su transporte y culminan una vez que las mismas han sido entregadas en el Laboratorio de pesquisa.

Finalmente, un último concepto que debe mencionarse en relación a los diferentes efectores que intervienen en la ejecución de las distintas tareas que forman parte de las actividades de un Programa de PN es que en aquellos casos en los cuales las acciones de seguimiento son ejecutadas por un equipo específico de trabajo, algunas de las tareas que en el presente capítulo fueron definidas como parte de las responsabilidades a cargo del Laboratorio de pesquisa recaen sobre el mencionado Equipo de Seguimiento.

\section{Indices o indicadores de desempeño}

En términos generales los índices o indicadores de desempeño pueden ser definidos como información seleccionada y asociada a un fenómeno determinado, destinada a observar periódicamente la evolución de dicho fenómeno con respecto a objetivos periódicamente establecidos (13).

A través de estos indicadores es posible conocer el nivel de calidad inicial de un proceso, fijar los objetivos de un modo cuantitativo, medir la eficacia de las soluciones adoptadas, monitorear la evolución de los resultados conseguidos, verificar si se han podido alcanzar los objetivos planteados $y$, en caso de que los resultados sean satisfactorios, incorporar las soluciones antes mencionadas 
al Sistema de Gestión de Calidad y monitorear las mismas a lo largo del tiempo (13).

A los fines prácticos, resulta una condición necesaria que los indicadores de desempeño presenten las siguientes características (13):

a) simples en cuanto a la factibilidad de recolección de datos, elaboración, cálculo y comprensión,

b) aceptables y creíbles,

c) pertinentes y específicos, es decir capaces de ofrecer un dato cuantitativo que refleje claramente la evidencia que se pretende controlar y únicamente para la variable que se está evaluando,

d) reproducibles, esto es que sean capaces de reproducir a lo largo del tiempo, los valores de una medida realizada en condiciones idénticas,

e) fiables, veraces y precisos.

- Indicadores de desempeño de un Programa de PN: La implementación de un Sistema Integral de CC para un Programa de PN es un proceso que requiere no solamente la selección de indicadores apropiados que reflejen de manera cierta y objetiva el funcionamiento del mismo, sino también el diseño de un plan adecuado de Aseguramiento de la Calidad y la confección de un Manual de Calidad.

Hablando específicamente de los diferentes indicadores de desempeño a utilizar, la mayor parte de ellos, excepto aquellos que estiman la eficiencia del tratamiento y del seguimiento a largo plazo, pueden ser determinados a partir de la información de cada RN y de los resultados de los análisis correspondientes que se encuentran disponibles en el Laboratorio de Pesquisa. De este modo, y de acuerdo al tipo de información que ofrece cada uno de ellos, los diferentes indicadores pueden ser clasificados en al menos 6 categorías, las cuales se describen a continuación:

o Indices que estiman la cobertura:

- Número de RN evaluados.

- Número de RN vivos. 
- Tasa de cobertura:

[(Número de RN evaluados/Número de RN vivos $) \times 100]$.

o Indices que estiman el cumplimiento del marco de tiempo óptimo establecido para cada etapa:

- Edad de recolección de muestras:

[Fecha de toma de muestra - Fecha de nacimiento].

- Tiempo de tránsito de las muestras al laboratorio:

[Fecha de ingreso al Laboratorio - Fecha de toma de muestra].

- Frecuencia de envíos de muestras al laboratorio.

- Tiempo de análisis:

[Fecha de análisis - Fecha de ingreso al Laboratorio].

- Edad de primera consulta al Centro de Atención Especializada:

[Fecha de consulta - Fecha de nacimiento].

- Edad de diagnóstico e inicio de tratamiento:

[Fecha de inicio de tratamiento - Fecha de nacimiento].

o Indices que estiman la calidad de las muestras:

- Número y porcentaje de muestras satisfactorias.

- Número y porcentaje de muestras insatisfactorias.

Con respecto a éste último índice, el mismo resulta de la evaluación de diversos aspectos inherentes a las muestras de sangre, razón por la cual es habitual que el mismo sea desglosado en los diferentes componentes que contribuyen al mismo, a saber:

- Porcentaje de muestras con llenado incompleto de datos demográficos.

- Porcentaje de muestras con calidad inapropiada de recolección: volumen, uniformidad, grado de impregnación del papel, hemólisis, presencia de coágulos, exposición a agentes potencialmente interferentes, secado, etc.

- Porcentaje de muestras que no cumplen con las condiciones de recolección establecidas: tiempos mínimos y máximos recomendados de recolección, 
tiempo mínimo de ingesta de leche previo a la toma de muestras, empleo de anticoagulantes, etc.

o Indices que estiman la eficiencia del sistema de detección:

- Prevalencia de cada una de las patologías pesquisadas.

- Tasa de falsos negativos.

- Sensibilidad.

- Tasa de falsos positivos.

- Especificidad.

- Tasa de recitación.

- Valor predictivo positivo.

o Indices que estiman la eficiencia de las acciones de seguimiento en el corto plazo:

- Número de segundas muestras solicitadas según analito y causa (ya sea por recolección inadecuada o por resultados anormales).

- Número de segundas muestras recibidas con sus respectivos tiempos de recolección, tránsito y análisis.

- Número de RN derivados al Centro de Atención Especializada para confirmar o descartar el diagnóstico.

- Número de RN que concurren al Centro de Atención Especializada.

o Indices que estiman la eficiencia del tratamiento y seguimiento a largo plazo:

- Indicadores de morbilidad específicos para cada enfermedad: coeficiente de desarrollo/coeficiente intelectual, número y duración de las hospitalzaciones, porcentaje con complicaciones específicas, etc.

- Indicadores de cumplimiento del tratamiento: adherencia a los monitoreos de laboratorio, adherencia a las consultas pre-establecidas por el centro responsable del tratamiento y seguimiento, registros de dietas.

- Indicadores de resultados a largo plazo y funcionalidad: escolaridad alcanzada, empleo, adaptación psico-social, posibilidades de éxito reproductivo $(4,8)$. 
- planificación y desarRollo de un sistema integral de CONTROL DE CALIDAD PARA EL PROGRAMA DE DETECCIÓN DE ERRORES CONGÉNITOS DE LA FUNDACIÓN BIOQUÍMICA ARGENTINA.

El proceso de planificación y desarrollo de un Sistema Integral de CC previsto para su posterior implementación en el Programa de Detección de Errores Congénitos de la FBA, requirió la ejecución de la siguiente serie de acciones:

a. Definición del objetivo planteado a través de la implementación del mencionado Sistema Integral de CC.

b. Selección de los indicadores de desempeño a utilizar, estableciendo cuáles de ellos podían ser determinados a partir de la información disponible en el Sistema Informatizado de Gestión de Muestras (SIGM) previamente descripto en el Capítulo 2, y cuales requerían del ingreso de información adicional no disponible en las bases de datos a partir de los procedimientos ejecutados rutinariamente.

c. Definición de los desarrollos informáticos requeridos ya sea tanto para el cálculo de los indicadores de desempeño previamente seleccionados, como para la generación de bases de datos complementarias conteniendo la información necesaria para el cálculo de aquellos indicadores que así lo requirieran.

d. Diseño de un informe o perfil de desempeño en el cual se presenten los diferentes indicadores evaluados de una manera simple y fácilmente comprensible.

e. Definición de la modalidad y estrategia de implementación más apropiada a efectos de alcanzar exitosamente el objetivo planteado.

- Objetivo: Tal como es lógico suponer, tanto la planificación, diseño y desarrollo del Sistema Integral de CC como su modalidad de implementación fueron concebidos en función de la finalidad perseguida a través del mismo.

De acuerdo a esto, y como primera medida, se estableció que el objetivo del mencionado sistema sería lograr un mejoramiento progresivo de la calidad del 
Programa de PN a través del monitoreo permanente de los diferentes indicadores de desempeño disponibles, de la ejecución de un proceso educativo basado fundamentalmente en la entrega de informes periódicos del perfil de desempeño propio de cada uno de los efectores del Programa, y del asesoramiento necesario para corregir los problemas detectados.

- Indicadores de desempeño: los indicadores de desempeño fueron seleccionados tomando en consideración por un lado, la factibilidad de que los mismos pudieran ser determinados a partir de la información disponible en el SIGM Y, por el otro, considerando las limitaciones operativas existentes en cuanto al acceso informatizado $e$ inmediato a los registros correspondientes a las etapas de confirmación, tratamiento y seguimiento a largo plazo.

En función de estas consideraciones se tomó la decisión de incluir como parte del perfil de desempeño a un conjunto de indicadores fácilmente accesibles desde el punto de vista del cálculo, a través de los cuales resultara posible estimar la tasa de cobertura, el cumplimiento de los marcos óptimos de tiempos y la eficiencia de las acciones de seguimiento en el corto plazo.

No obstante esto, y en vista de la importancia que tiene el proceso de recolección de muestras y de las implicancias del mismo, también se consideró estrictamente necesaria la inclusión de un grupo de indicadores que permitieran estimar la calidad de dichas muestras de sangre, más allá de que previamente a la decisión de implementar el Sistema Integral de CC al cual se está haciendo referencia, no se disponía de bases de datos conteniendo registros relacionados con tales propiedades.

- Desarrollos informáticos: En cuanto al sistema informatizado para el cálculo y evaluación de los diferentes indicadores de desempeño, el mismo fue desarrollado en estrecha vinculación con el SIGM.

Dicho sistema consta de 2 componentes principales: el primero de ellos es el que permite ingresar a la base de datos toda la información requerida 
correspondiente a la calidad de cada una de las muestras de sangre que han sido recibidas y vincular estos registros con el SIGM; mientras que el segundo componente es el que permite efectuar la evaluación estadística de la información disponible en la base de datos (datos demográficos de cada RN y resultados de las pruebas de pesquisa), el cálculo de los tiempos insumidos en cada uno de los procesos ejecutados, y la cuantificación de los diferentes criterios tomados en consideración para definir la condición de satisfactoria o insatisfactoria de cada una de las muestras de sangre recibidas.

Las Figuras 126a-c ilustran la forma en que la información correspondiente a la calidad de cada una de las muestras de sangre es registrada en el mencionado sistema, y también la forma como se visualizan los datos demográficos de cada RN y los errores resultantes tanto del llenado incompleto de los mismos en la tarjeta de recolección como del incumplimiento de las condiciones de recolección establecidas por el programa.

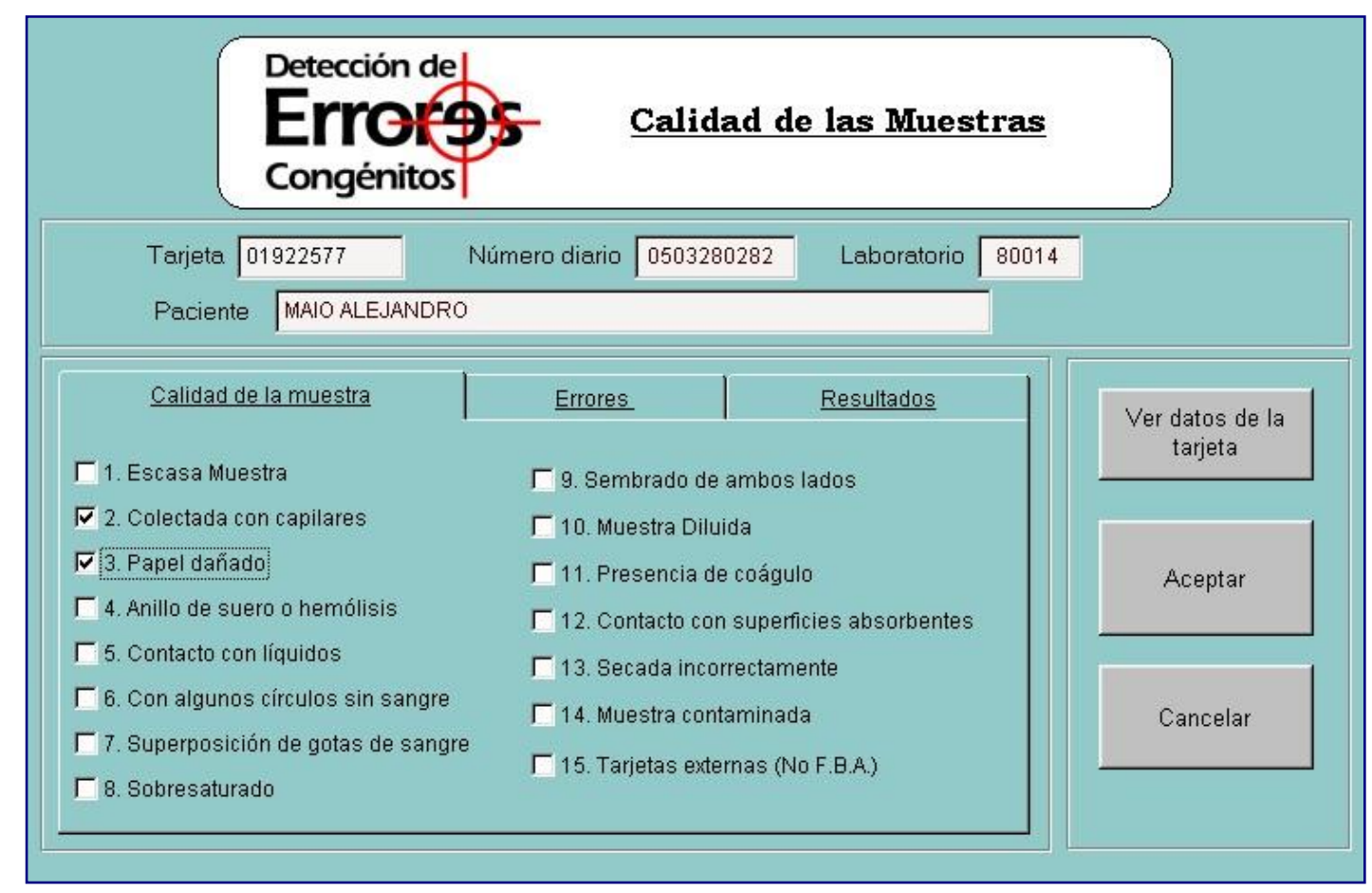

Figura 126a. Sistema para el registro de la calidad de las muestras. Ingreso de las características de la muestra. 


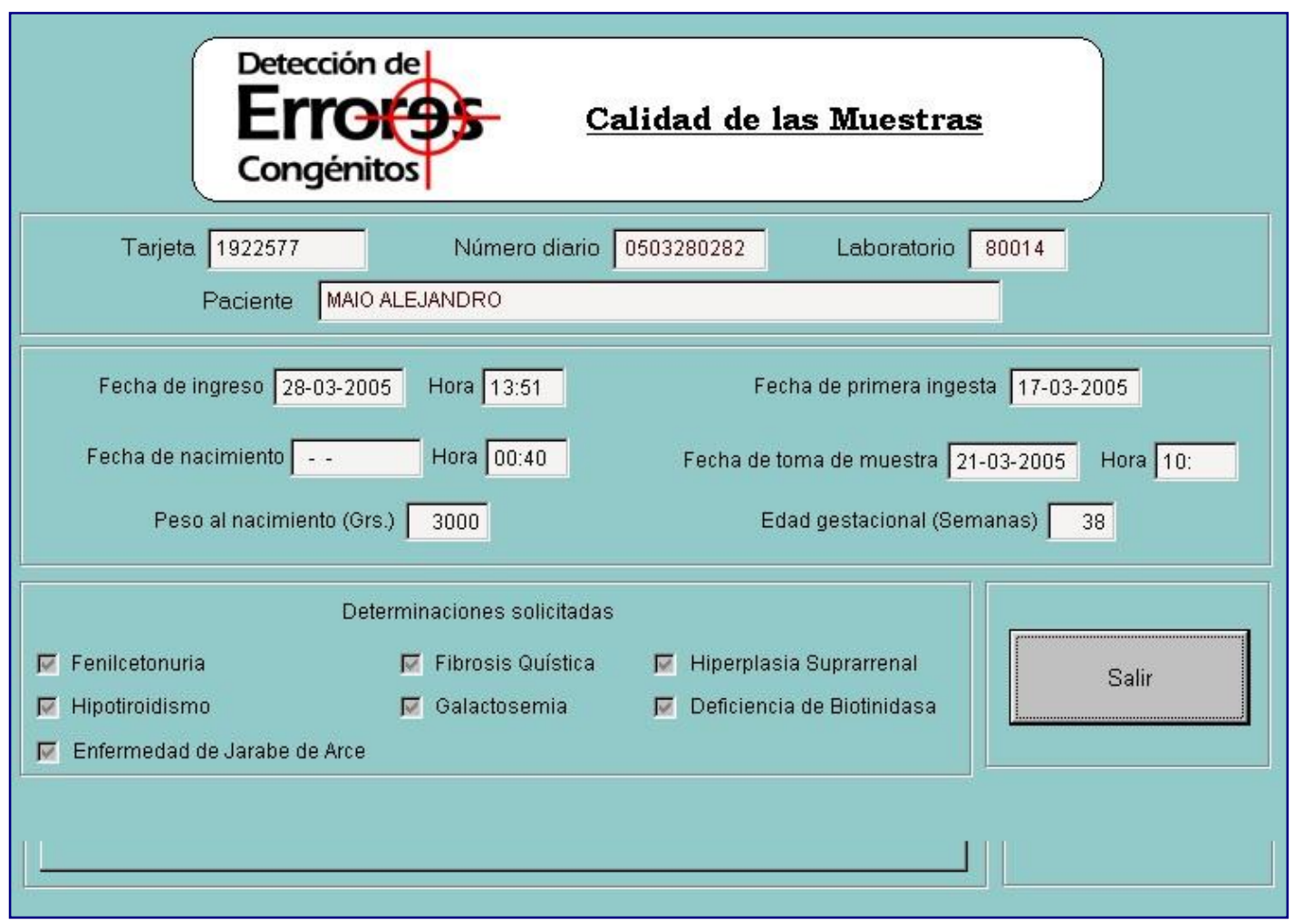

Figura 126b. Sistema para el registro de la calidad de las muestras. Visualización de datos demográficos del RN.

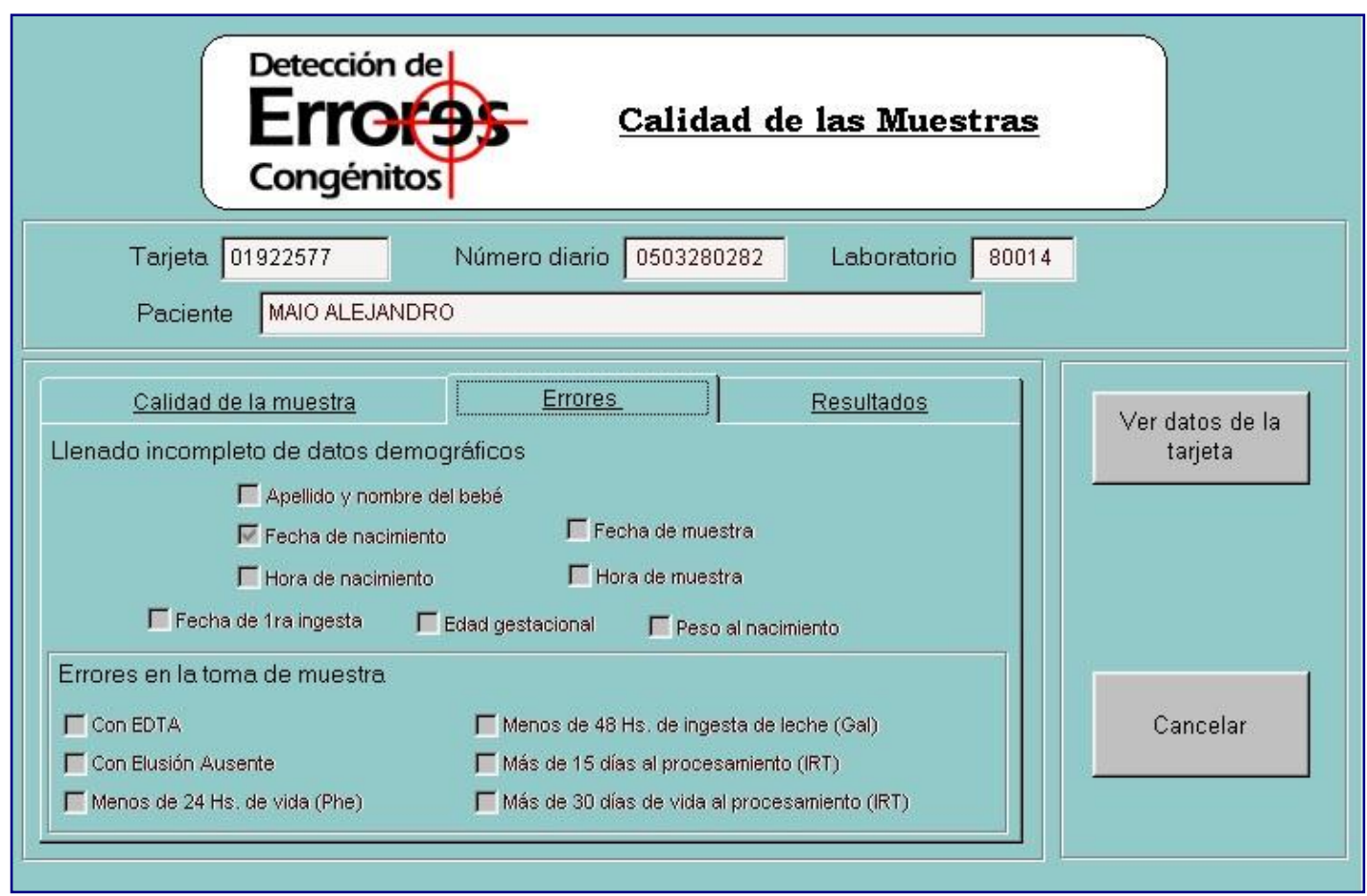

Figura 126c. Sistema para el registro de la calidad de las muestras. Visualización de errores por datos demográficos incompletos y por incumplimiento de las condiciones de recolección. 
- Perfil de desempeño: El último aspecto a considerar en relación al diseño del Sistema Integral de $C C$, es la forma en que los resultados de la evaluación del desempeño serían presentados a cada uno de los efectores, de manera tal que los mismos pudieran ser visualizados e interpretados en una forma ordenada $y$ fácilmente comprensible.

Para tal fin se diseñó un perfil de CC de desempeño amplio y explícito, el cual puede ser generado tanto en forma global para el Programa en su conjunto, como para un grupo determinado de efectores agrupados según el sector de procedencia (Hospitales Provinciales, Hospitales Municipales, Laboratorios Privados) o según la Provincia a la cual pertenecen; y muy especialmente en forma personalizada para cada uno de los Centros Asistenciales que participan del programa, puesto que en definitiva, éstos últimos constituyen el blanco específico al cuál está dirigido este tipo de evaluación.

En las Figuras $127 a-c$ se presenta un ejemplo del perfil de $C C$ de desempeño generado para el conjunto de efectores de recolección de muestras en particular.

En relación a la información ofrecida en estos perfiles, la misma resulta fácilmente comprensible y no requiere mayores aclaraciones, excepto en el caso de algunos conceptos referidos a la calidad de las muestras, los cuales son definidos a continuación:

- muestra satisfactoria: es aquella en la cual han sido completados correctamente todos los datos demográficos solicitados en la tarjeta de recolección, la calidad de la muestra de sangre es óptima y se respetaron las condiciones de recolección establecidas por el Programa para cada analito evaluado.

- muestra insatisfactoria: es aquella que no cumple con alguna de las características mencionadas en la definición anterior.

En relación a la forma en que se contabiliza el número de muestras insatisfactorias, se debe mencionar que dicho número es independiente de la cantidad de condiciones que incumple, es decir que una o varias condiciones incumplidas dan lugar siempre a una sola muestra insatisfactoria.

- muestra insuficiente: es aquella que no permite la realización de ninguna de las 
pruebas de laboratorio por presentar un volumen de sangre insuficiente $y$ características de impregnación inapropiadas.

- muestra escasa: es aquella que, a pesar de haber sido impregnada a partir de un volumen de sangre inferior que el definido como óptimo, permite la realización de alguna de las pruebas solicitadas.

- Modalidad y estrategia de implementación: Finalmente, y en cuanto a la modalidad de implementación propuesta para el Sistema Integral de CC de desarrollo propio, se definió una estrategia de trabajo por medio de la cual en una primer etapa se ha de ofrecer un perfil de desempeño amplio. Esta decisión se tomó con el objetivo de que cada uno de los efectores del Programa de PN pueda conocer en detalle, a través de los distintos indicadores de desempeño, las diversas situaciones que pueden estar afectando la calidad de los resultados de las pruebas de pesquisa, y por ende del Programa en su conjunto.

Por este motivo, y muy especialmente en lo que respecta a la calidad de las muestras de sangre, el perfil incluye un detalle minucioso de las causas que pueden afectar a la misma, aún a pesar de ser concientes de que muchas de estas situaciones pueden no ser significativas como generadoras de resultados analíticos incorrectos, ineficiencia o pérdida de casos. No obstante esto, se consideró que el hecho de mantener un perfil explícito hasta tanto se logre que todos los efectores se familiaricen con los diversos parámetros utilizados, se trata de una acción de gran relevancia educativa, previéndose simplificar el perfil en forma progresiva recién en etapas posteriores y de acuerdo con los resultados obtenidos.

En cuanto a la periodicidad de distribución de los informes, está previsto que los mismos sean entregados en forma semestral.

Adicionalmente, y a efectos de facilitar la comprensión del perfil y de hacer posible una autoevaluación por parte de cada uno de los efectores, también ha sido previsto que junto con el primer reporte se va a remitir un instructivo en el cual estarán claramente definidos cada uno de los conceptos utilizados en el perfil y los valores establecidos como aceptables y óptimos para cada uno de los indicadores reportados. 


\section{Fundación Bioquímica Argentina \\ Programa de Detección de Errores Congénitos \\ Evaluación de Calidad de Desempeño Individual}

Laboratorio: Todos

Domicilio: 9 DE JULIO Y NEUQUEN

Localidad: 28 DE NOVIEMBRE

Código postal: 9408

Período evaluado: 01-01-04 al 31-12-04

Número de primeras muestras recibidas

200,215

\begin{tabular}{|lr|lr|}
\hline \multicolumn{4}{|c|}{ Determinaciones Solicitadas } \\
\hline Fenilcetonuria & 197998 & Hiperplasia Suprarrenal & 30456 \\
\hline Hipotiroidismo & 194982 & Defic. de Biotinidasa & 27493 \\
\hline Fibrosis Quística & 65498 & Enf. de Jarabe de Arce & 0 \\
\hline Galactosemia & 36445 & & \\
\hline
\end{tabular}

Evaluación de Tiempos de Recolección, Envío y Análisis de Primeras Muestras

Tiempo de recolección de primeras muestras (días) (1)

\begin{tabular}{|r|r|r|r|rr|rr|}
\hline$N^{\circ}$ de muestras & Promedio & Desvio Estandar & Mediana & \multicolumn{4}{|c|}{ Rango } \\
\hline 167735 & 5.8 & 33.5 & 2.6 & Mínimo & 0.0 & Máximo & $10,960.0$ \\
\hline
\end{tabular}

Tiempo de envío al laboratorio (días) (1)

\begin{tabular}{|r|r|r|r|rr|rr|}
\hline$N^{\circ}$ de muestras & Promedio & Desvío Estandar & Mediana & \multicolumn{3}{|c|}{ Rango } \\
\hline 193424 & 7.8 & 8.5 & 7 & Mínimo & 0 & Máximo & 1,102 \\
\hline
\end{tabular}

Tiempo de análisis (días)

\begin{tabular}{|c|c|c|c|c|c|c|c|c|}
\hline Determinación & № de muestras & Promedio & Desvío Estandar & Mediana & \multicolumn{4}{|c|}{ Rango } \\
\hline Fenilcetonuria & 197993 & 1.4 & 0.8 & 1 & Mínimo & 0 & Máximo & 7 \\
\hline Hipotiroidismo & 194968 & 1.0 & 0.2 & 1 & Minimo & 0 & Máximo & 10 \\
\hline Fibrosis Quística & 65449 & 1.1 & 0.4 & 1 & Mínimo & 0 & Máximo & 10 \\
\hline Galactosemia & 36349 & 1.5 & 0.9 & 1 & Mínimo & 0 & Máximo & 10 \\
\hline Hiperplasia Suprarrenal & 30359 & 1.0 & 0.4 & 1 & Mínimo & 0 & Máximo & 10 \\
\hline Defic. de Biotinidasa & 27398 & 1.5 & 0.9 & 1 & Mínimo & 0 & Máximo & 10 \\
\hline Enf. de Jarabe de Arce & 0 & 0.0 & 0.0 & 0 & Mínimo & 0 & Máximo & 0 \\
\hline
\end{tabular}

Cantidad de envíos realizados por mes

\begin{tabular}{|c|c|c|c|c|c|}
\hline & & \multirow{2}{*}{\multicolumn{2}{|c|}{ Feb-2004 20}} \\
\hline Dic-2003 & 1 & Ene-2004 & 21 & & \\
\hline Abr-2004 & 19 & May-2004 & 20 & Jun-2004 & 21 \\
\hline Ago-2004 & 21 & Sep-2004 & 22 & Oct-2004 & 20 \\
\hline
\end{tabular}

\begin{tabular}{|ll|}
\hline Mar-2004 & 23 \\
\hline \hline Jul-2004 & 21 \\
\hline Nov-2004 & 21 \\
\hline
\end{tabular}

(1) Los datos correspondientes a estos items fueron calculados exclusivamente para aquellas muestras que presentaban los datos necesarios para dicho cálculo.

Figura 127a. Perfil de control de calidad de desempeño. 


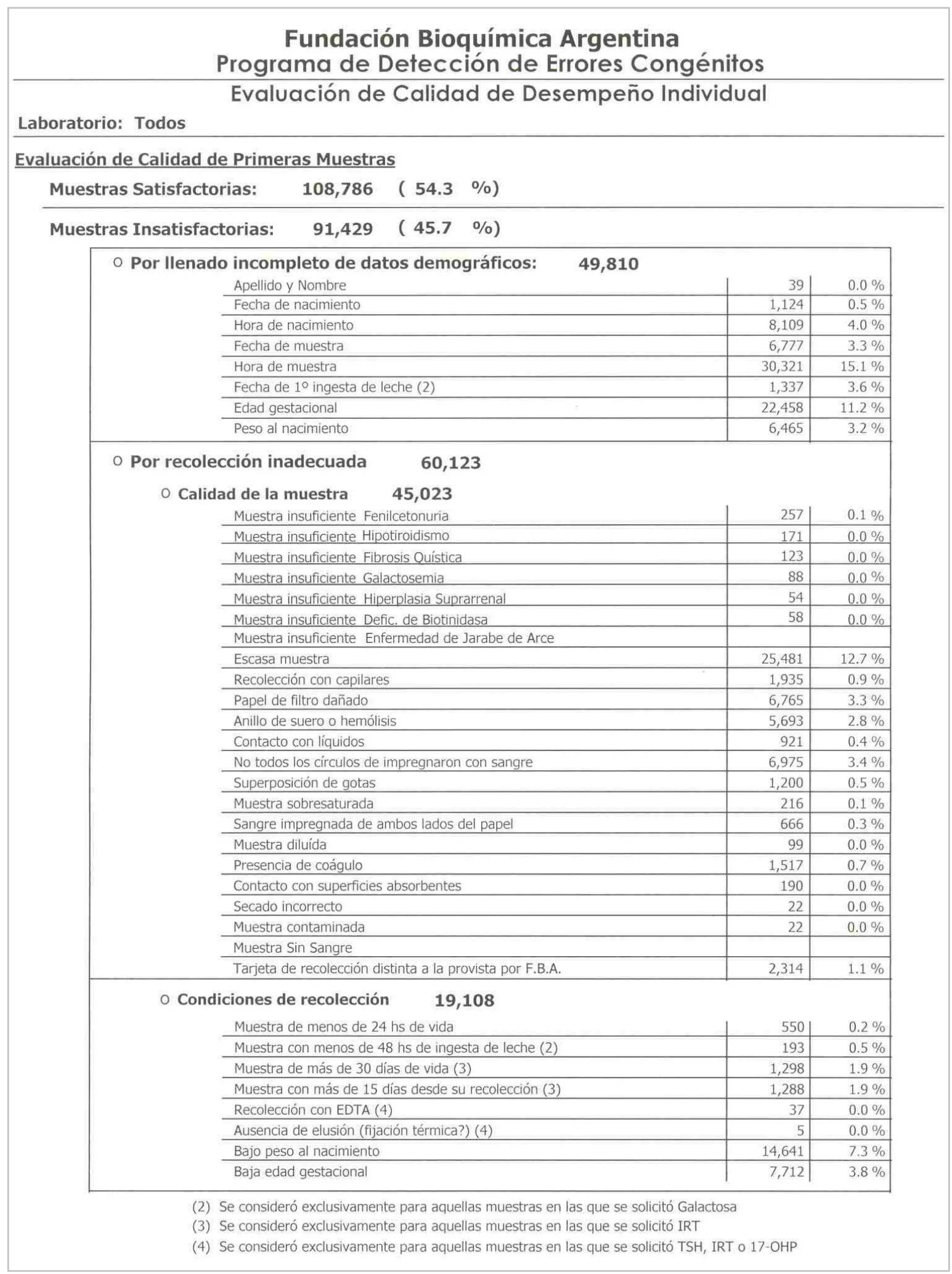

Figura 127b. Perfil de control de calidad de desempeño. 


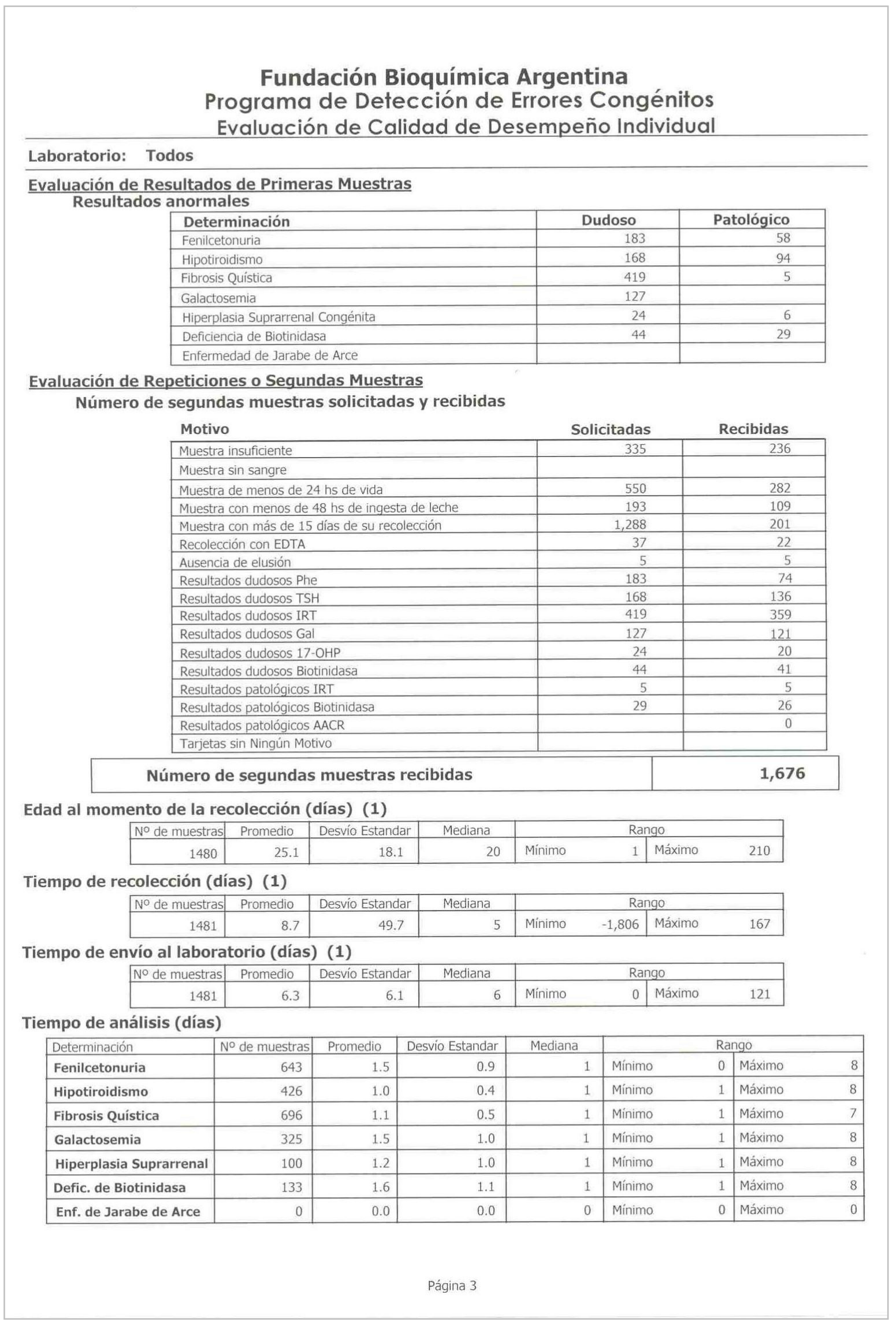

Figura 127c. Perfil de control de calidad de desempeño. 
En conclusión, a través del desarrollo e implementación del Sistema Integral de CC antes descripto se pretende establecer un patrón de medida que permita determinar tanto el tipo como la magnitud de los errores que se puedan estar cometiendo, detectar quienes son aquellos efectores que necesitan asistencia y establecer el impacto generado por las intervenciones educativas y de asesoramiento sobre el funcionamiento general, con lo cual será posible a su vez optimizar el desempeño de cada uno de los efectores de salud involucrados en las tareas del Programa de PN, y maximizar la efectividad y eficiencia del Programa en su conjunto.

\section{BIBLIOGRAFIA}

28. Eurachem Guide. "The Fitness for Purpose of Analytical Methods. A Laboratory Guide to Method Validation and Related Topics". First English Edition 1.0, 1998. www.eurachem.org/guides/valid.pdf.

29. Fernández Espina C. "Introducción a la Calidad: Conceptos Generales" en "Gestión de la Calidad en el Laboratorio Clínico", Fernández Espina C y Mazziotta D Eds. Editorial Médica Panamericana, Buenos Aires-Bogotá-Caracas, 1-26, 2005.

30. Fernández Espina C. "El aseguramiento de la Calidad en el Laboratorio Clínico". Acta Bioquím Clín Latinoam, 33, 49-67, 1999.

31. International Atomic Energy Agency. "Quality Assurance for the Newborn Screening System" en "Screening of Newborns for Congenital Hypothyroidism. Guidance for Developing Programs". International Atomic Energy Agency Ed., Vienna, 45-66, 2005.

32. International Atomic Energy Agency. "Basic Aspects in the Screening of Newborns with Emphasis on the Detection of Hypothyroidism" en "Screening of Newborns for Congenital Hypothyroidism. Guidance for Developing Programs". International Atomic Energy Agency Ed., Vienna, 21-41, 2005.

33. Torresani T. "Quality Control Requirements in Neonatal Screening". Eur J Pediatr 162, S54-S56, 2003.

34. Therrell BL, Panny SR, Davidson A, Eckman J, Hannon WH, Henson MA, Hillard M, Kling S, Levy HL, Meaney FJ, McCabe ERB, Mordaunt V, Pass K, Shapira E and 
Tuerck J. "U.S. Newborn Screening System Guidelines: Statement of the Council of Regional Networks for Genetic Services". Screening 1, 135-47, 1992.

35. Pass KA, Lane PA, Fernhoff PM, Hinton CF, Panny SR, Parks JS, Pelias MZ, Rhead WJ, Ross SI, Wethers DL and Elsas LJ. "U.S. Newborn Screening System Guidelines II: Follow-up of Children, Diagnosis, Management, and Evaluation Statement of the Council of Regional Networks for Genetic Services (CORN)". Journal of Pediatrics 137, S1-S46, 2000.

36. Tuerck JM, Buist NR, Skeels MR, Miyahira RS and Beach PG. "Computarized Surveillance of Errors in Newborn Screening Practices". American Journal of Public Health, 77, 1528-31, 1987.

37. Webster D, Dhondt JL, Hannon WH, Loeber $G$ and Torresani T. "Quality Assurance and Standardization: Summary of the Satellite Meeting, Turku, Finland, 11-12 June 1999". Acta Paediatrica, Suppl 432, 7-12, 1999.

38. Tuerck JM, Steiner RD, LaFranchi SL, Thomas G, Skeels MR, Hermerath AC and Rien L. "The Norwest Regional Newborn Screening Program Practitioner's Manual". 7th Edition. 2004. http://www.dhs.state.or.us/publichealth/nbs/index.cfm.

39. Slazyk WE and Hannon WH. "Quality Assurance in the Newborn Screening Laboratory" en "Laboratory Methods for Neonatal Screening", Therrell BL Ed, American Public Health Association, Washington, 23-46, 1993.

40. Fernández Espina C. "Seguimiento y Mejora Continua de la Calidad" en "Gestión de la Calidad en el Laboratorio Clínico". Fernández Espina C y Mazziotta D Eds. Editorial Médica Panamericana, Buenos Aires-Bogotá-Caracas, 167-196, 2005. 


\section{SECCIÓN II}

RESULTADOS DELA

IMPLEMENTACIÓN DELA

PESQUISA NEONATAL

DE ENFERMEDADES CONGÉNITAS 



\section{CAPÍTULO 8}

PESQUISA NEONATAL

$D E$

FENILCETONURIA 



\section{- INTRODUCCIÓN}

La Fenilcetonuria (PKU) es un ECM de la Fenilalanina (Phe) que se transmite con un patrón de herencia autosómico recesivo, y que reconoce su origen en el 97-99 $\%$ de los casos en una deficiencia de la enzima Phe-Hidroxilasa hepática, presentándose con una incidencia de $1: 10.000$ a $1: 20.000$ nacidos vivos. A consecuencia del mencionado bloqueo enzimático la Phe no puede ser hidroxilada para dar lugar a la formación de Tirosina (Tyr), razón por la cual la Phe se acumula en sangre generando una hiperfenilalaninemia (HPA) cuya magnitud dependerá del grado de afectación de la Phe-Hidroxilasa (1-3).

La PKU en su forma clásica y severa se caracteriza porque en ausencia de tratamiento causa retraso mental profundo $e$ irreversible, acompañado de un cuadro neurológico de convulsiones, irritabilidad, hipertonicidad, hiperactividad, trastornos de conducta y de la marcha, dificultad para el habla, y por otros síntomas como microcefalia, retraso madurativo y de crecimiento, hipopigmentación, y presencia de un olor característico a moho o a ratón en la orina y sudor de los individuos afectados.

No obstante esta descripción, la enfermedad carece de manifestaciones clínicas en el período neonatal, y cuando el cuadro clínico se hace evidente permitiendo al médico disponer de elementos para efectuar un diagnóstico en base a los síntomas, el daño neurológico ya resulta sumamente grave e irreversible.

En contraposición con esto, cuando la enfermedad se diagnostica precozmente a través de la PN y se trata antes de los primeros 15-20 días de vida, es posible evitar la expresión del cuadro clínico y el individuo puede desarrollarse normalmente.

En relación al tratamiento, el mismo se basa en la implementación de una dieta restringida en Phe en forma estricta, de manera tal de mantener niveles sanguíneos del aminoácido de 1-4 mg/dl o de 2-6 mg/dl, dependiendo del criterio seguido para el mismo (2). Independientemente de esto, en los últimos años han surgido nuevas alternativas que incluyen la suplementación con aminoácidos neutros (Tyr, Trp, Met, Leu, Ile, Val, Lys, Thr, His, Arg, comercializados bajo el nombre de Prekunil囚) (4); la suplementación con Tetrahidrobiopterina o BH4 (Hidrocloruro de Sapropterina, comercializado bajo el nombre de $\left.\operatorname{Kuvan}^{\circledR}\right)(5,6)$; la terapia enzimática de sustitución 
basada en la administración oral o endovenosa de la enzima Fenilalanina-Amonio Liasa peguilada (PEG-PAL) que permite metabolizar la Phe acumulada sin dar lugar a la formación de productos tóxicos $(7,8)$; la preparación de diversos suplementos alimenticios basados en el uso del Glicomacropéptido (9) -un glicofosfopéptido de 64 aminoácidos con muy bajo contenido de Phe que se obtiene en el proceso de producción de quesos-; y en el empleo de chaperonas que pueden estabilizar o promover el correcto plegamiento de la Phe-Hidroxilasa mutada (10). Como es de suponer, todas estas alternativas tienen por objetivo lograr la flexibilización del tratamiento desde el punto de vista de la restricción a la ingesta proteica, a expensas de generar un incremento en la tolerancia individual a la Phe y brindar al individuo la posibilidad de acceder a una mayor variedad de alimentos y sabores.

Desde el punto de vista de las manifestaciones bioquímicas, es importante mencionar que si bien la característica principal de la PKU es la HPA, no todos aquellos neonatos que presenten una HPA serán fenilcetonúricos. Esto depende fundamentalmente del grado de afectación de la enzima Phe-Hidroxilasa, característica que determina que en la práctica sea posible encontrar un espectro continuo de posibilidades que va desde la ausencia absoluta de la enzima hasta la presencia de una cierta actividad residual remanente, lo cual se refleja tanto en los niveles de Phe que pueden alcanzarse en sangre bajo una dieta libre, como en la relación Phe/Tyr. De esta forma, y empleando los dos parámetros antes mencionados es posible clasificar a las HPA en dos grandes categorías: las formas PKU y las formas HPA propiamente dichas, y en varias subcategorías, las cuales son presentadas en la Tabla 46.

Tabla 46. Clasificación de Hiperfenilalaninemias (HPA)

\begin{tabular}{|c|c|c|}
\hline Diagnóstico & Phe (mg/dl) & Phe/Tyr \\
\hline PKU Clásica & $>20$ & $>10$ \\
\hline PKU Moderada & $10-20$ & $3-10$ \\
\hline PKU por deficiencia de $\mathrm{BH} 4$ & Elevada & Normal o Elevada \\
\hline HPA Persistente & $3-10$ & $1,5-3$ \\
\hline HPA Transitoria & Elevada & $1-3$ \\
\hline Hipertirosinemia & Normal o Elevada & $<0,5$ \\
\hline
\end{tabular}


Con referencia a la clasificación presentada en la Tabla anterior, se debe mencionar que las formas PKU y las HPA también presentan otros rasgos distintivos como por ejemplo: a) la presencia de Acido Fenilpirúvico en orina, la cual resulta positiva en las PKU y negativa en las HPA; b) la tolerancia a la Phe, la cual es inferior a $350 \mathrm{mg} /$ día en las formas PKU Clásicas, de 350-400 mg/día en las formas PKU Moderadas y de 400-600 mg/día o mayor en las HPA persistentes (3); y c) la necesidad de implementación de un tratamiento, la cual resulta una condición ineludible en las formas PKU, mientras que no se requiere en las HPA, excepto en aquellos casos en que los individuos afectados alcancen niveles de Phe $>7 \mathrm{mg} / \mathrm{dl}$ con una relación Phe/Tyr > 3, bajo una dieta libre.

En cuanto a la PKU por Deficiencia de BH4 (1-3\% del total de casos), y a diferencia de las 3 formas mencionadas anteriormente, la misma no se origina en una deficiencia en la enzima Phe-Hidroxilasa, sino en una deficiencia en la vía de síntesis de novo o en la vía de reciclado del cofactor BH4. En este caso, el cuadro clínico resulta más severo que en la PKU Clásica puesto que la BH4 es también un cofactor de Tyr- y Trp-Hidroxilasa, -enzimas necesarias para la síntesis de dopamina, adrenalina, nor-adrenalina y serotonina-, y en consecuencia los individuos afectados no responden al tratamiento basado estrictamente en la restricción dietaria de Phe (1-3).

Por otra parte, las HPA transitorias incluidas en la clasificación anterior pueden originarse en un fenómeno de inmadurez hepática que hace que la Phe no pueda ser metabolizada normalmente, o bien pueden deberse a la presencia de algún otro tipo de afectación hepática como hepatitis, sepsis o un ECM como la Galactosemia; mientras que las Hipertirosinemias pueden ser causadas tanto por la sobrecarga proteica resultante de la administración al RN durante los primeros días de vida de leche de vaca entera en lugar de leche materna o de leches maternizadas, por inmadurez hepática, o bien por un ECM de Tyr.

Con respecto a las pruebas para la confirmación del diagnóstico, las mismas comprenden la medida de Phe y Tyr en suero del RN, la determinación de diversos marcadores de funcionalismo hepático, el dosaje de la actividad de la enzima Dihidropteridina Reductasa (DHPR), la determinación del patrón de excreción urinario de 
biopterinas y la respuesta a la prueba de sobrecarga con Phe, debiendo complementarse con estudios mutacionales en aquellos casos en que se disponga de los mismos.

\section{Pesquisa Neonatal}

- Período de trabajo evaluado: Enero 1991 - Diciembre 2009.

A lo largo del período evaluado de 19 años de trabajo se sucedieron una serie de cambios en diferentes aspectos relacionados con la PN de PKU, como por ejemplo en las recomendaciones para la toma de muestras, en los métodos utilizados, en los criterios de interpretación de resultados y en el algoritmo de trabajo. Dichas modificaciones fueron producto de la evolución experimentada tanto en los aspectos analíticos como diagnósticos de la PN, la cual indefectiblemente generó la necesidad de implementar dichos cambios a fin de poder continuar avanzando en el marco del proceso de mejoramiento continuo de la calidad. Esta situación, tal como podrá visualizarse en los Capítulos siguientes, puede extrapolarse y hacerse extensiva también a cada una de las patologías que serán descriptas en los mismos.

- Métodos: en la Tabla 47 se presentan los diferentes métodos utilizados en la PN de PKU y a continuación se describe el fundamento de los mismos:

Tabla 47. Métodos utilizados en la PN de PKU

\begin{tabular}{cll}
\hline Periodo & & \multicolumn{1}{c}{ Método } \\
${$\cline { 1 - 1 }$}{\text { Método de Inhibición Bacteriana de Guthrie de }}$ \\
desarrollo propio.
\end{tabular}$} \\
{\text { May/1997 - Ago/1998 }} &{\begin{array}{l}\text { Método Fluorométrico comercial. Labsystems, Oy. } \\
\text { Finlandia. } \\
\text { Sep/1998 - Dic/2009 }\end{array}} &{\begin{array}{l}\text { Método Fluorométrico de desarrollo propio, basado } \\
\text { en el método de Mc Caman y Robins modificado. }\end{array}} \\
{\hline} \end{array}$

- Método de Inhibición Bacteriana de Guthrie (BIA) de desarrollo propio: Fundamento: la inhibición del crecimiento del Bacillus subtilis Cepa ATCC 6633 por parte del inhibidor $\beta$-2-D-L-Tienilalanina en el medio de Demain modificado es revertida por la presencia de Phe presente en muestras de sangre impregnadas en papel de filtro, permitiendo así el crecimiento del Bacillus subtilis 
alrededor de cada disco en forma de halo, cuyo diámetro será proporcional a la concentración de Phe en la muestra.

El desarrollo del método antes mencionado fue realizado en la Cátedra de Bioquímica Patológica de la Facultad de Ciencias Exactas de la UNLP (11) tomando como punto de partida la publicación realizada por Robert Guthrie y Ada Susi en 1963 (12) (Figura 128).

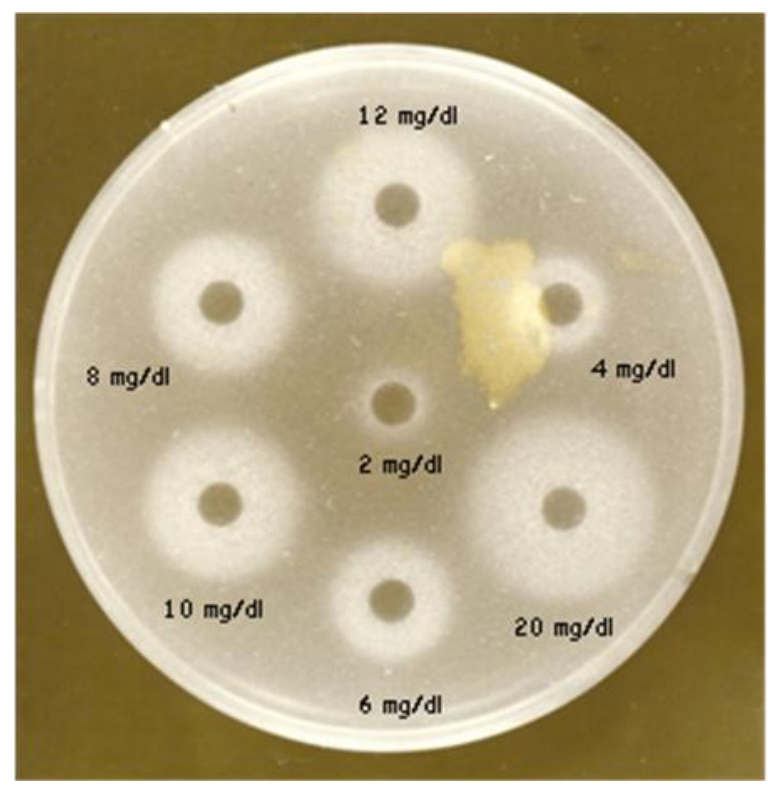

Figura 128. Método de Inhibición Bacteriana de Guthrie.

Para el desarrollo y optimización del mismo se llevó a cabo la preparación de todos los reactivos necesarios (medio de Demain modificado, esporos del Bacillus subtilis ATCC 6633, inhibidor $\beta$-2-D-L-Tienilalanina y calibradores de Phe preparados en DBS), la optimización y evaluación de los diferentes parámetros de ensayo (concentración de esporos e inhibidor, espesor del agar, efecto de anticoagulantes, antibióticos y hemoglobina, y tiempo de lectura), y se introdujeron algunas modificaciones a la técnica original en función de las características de los materiales y elementos disponibles.

Por otra parte, y dado que el método BIA es un método semicuantitativo de lectura visual, para la realización de las pruebas de pesquisa fueron utilizadas 2 modalidades diferentes de trabajo:

- Pruebas de pesquisa propiamente dichas. en este caso las muestras de los RN 
eran procesadas junto con calibradores de Phe de 2 y $4 \mathrm{mg} / \mathrm{dl}$, y en caso de valores aumentados se procedía a la semicuantificación de la misma según la modalidad que se describe a continuación.

- Pruebas de semicuantificación de la Phe y de monitoreo de pacientes en tratamiento: en este caso las muestras cuyos valores semicuantitativos pretendían conocerse eran procesados junto con una curva de calibración completa, incluyendo 7 calibradores de Phe de concentraciones de 2, 4, 6, 8, 10,12 y $20 \mathrm{mg} / \mathrm{dl}$ tal como se visualiza en la Figura 128.

También es importante mencionar que a medida que el alcance de la PN de PKU se fue incrementando y que, consecuentemente el número de muestras de RN incluidas en cada corrida pasó a ser significativo, se debieron introducir una serie de modificaciones tendientes a simplificar el procedimiento desde el punto de vista operativo y a "automatizar" la técnica dentro de la medida de lo que sus propias limitaciones lo permitieron:

- Modificación de la escala del ensayo: se sustituyeron las placas de Petri descartables de tamaño estándar ( $9 \mathrm{~cm}$ de diámetro), por placas plásticas reutilizables de $24 \mathrm{~cm} \times 24 \mathrm{~cm}$, diseñadas para cultivos celulares.

- Modificación del proceso de plaqueo del medio de cultivo, esporos e inhibidor: se introdujo una variante en la técnica, consistente en la utilización de un horno microondas para fundir del agar, asociado a un cambio en la escala de los volúmenes requeridos de cada uno de los mismos.

- Modificación del proceso de "sembrado" de los discos de muestras sobre el medio de cultivo: para este fin se diseñó una plataforma reutilizable de dimensiones coincidentes con las dimensiones internas de la placa de cultivo y de una altura $0,5 \mathrm{~cm}$ mayor que la profundidad de la placa, en cuya superficie se colocó una plantilla plastificada con un arreglo pre-definido para asegurar una correcta distribución de las muestras en el medio de cultivo a través de un procedimiento de improntado.

En el Anexo 2, se describe en detalle el protocolo de ensayo del Método BIA de desarrollo propio en sus 2 alternativas de trabajo. 
- Método Fluorométrico - Labsystems, Oy:

Fundamento: La Phe presente en muestras de sangre entera colectadas en papel de filtro es eluida previa fijación de la hemoglobina y de las proteínas al papel con Etanol 70 \%. Posteriormente el eluido se hace reaccionar con una mezcla del dipéptido L-Leucil-L-Alanina y Ninhidrina en buffer Succinato de pH 5,8 a $60^{\circ} \mathrm{C}$ para dar lugar a la formación de Hidridantina (Figura 129), un complejo fluorescente que es estabilizado mediante la adición de una solución alcalina de $\mathrm{Cu}^{+2}$. El compuesto fluorescente formado puede ser cuantificado en un Fluorómetro a $\lambda_{E X C / E M}=390 \mathrm{~nm} / 485 \mathrm{~nm}$, siendo su intensidad de fluorescencia proporcional a la concentración de Phe presente en la muestra.

Este método fue ejecutado siguiendo el protocolo descripto por el fabricante.

- Phe + Ninhidrina + Leu-Ala

Hidridantina + Fenilacetaldehído $+\mathrm{NH}_{3}$

Figura 129. Fundamento del Método Fluorométrico para la medida de Phe.

- Método Fluorométrico de desarrollo propio: El desarrollo y optimización de este método, basado en el método de McCaman y Robins modificado (13), fue realizado en el propio Laboratorio de Detección de Errores Congénitos de la FBA a partir de lo descripto por Yamaguchi et al (14).

Fundamento: el fundamento de este método es el mismo que el descripto para el método comercial de Labsystems, con la diferencia de que en este caso la fijación de las proteínas al papel se lleva a cabo con una mezcla de Metanol/Acetona/ $\mathrm{H}_{2} \mathrm{O}$, y la elución se realiza con $\mathrm{H}_{2} \mathrm{O}$ destilada, previa evaporación de la mezcla fijadora.

Para el desarrollo del mismo se llevó a cabo la preparación de todos los reactivos necesarios, la optimización de los diferentes parámetros de ensayo y se introdujeron dos modificaciones a la técnica original a fin de lograr fundamentalmente el máximo nivel de automatización posible, las cuales se describen a continuación:

- Utilización de microplacas de transferencia de 96 pocillos MultiScreen 
Membrane Plate modelo MADVN-65 de Millipore (Figura 52 - Página 153), para automatizar el proceso de transferencia de eluidos empleando el dispositivo Vacuum Manifold de Millipore.

- Cambio de la solución fijadora, del Acido Tricloroacético 0,3 N propuesto por Yamaguchi a la mezcla Metanol/Acetona/ $\mathrm{H}_{2} \mathrm{O}$, y posterior elución con $\mathrm{H}_{2} \mathrm{O}$ destilada, determinando así que se trabaje con un eluido prácticamente neutro contra el eluido fuertemente ácido resultante del método original, hecho que en la práctica determina a su vez, que el método presente una mayor sensibilidad analítica.

En el Anexo 3, se describe en detalle la preparación de reactivos y el protocolo de ensayo correspondiente al Método Fluorométrico de desarrollo propio.

- Condiciones para la recolección de muestras: en el período comprendido entre Enero de 1991 y Marzo de 1995 las condiciones de recolección de muestras utilizadas establecían la necesidad de una ingesta de leche de 48 horas previa a la toma de muestras de acuerdo con lo establecido por algunas de las experiencias internacionales. Dicho criterio fue modificado a partir de Abril de 1995 por un requerimiento mínimo de 24 horas de vida, fundamentalmente por el hecho de que a partir de ese momento, y dada la implementación del Prodytec, se comenzaría a trabajar con Hospitales públicos en los cuales en general las altas se producen más precozmente, y de este modo se trató de asegurar que la recolección de las muestras de los RN se llevara a cabo antes de que se produjera el alta de las maternidades, aunque sin afectar la eficiencia diagnóstica del sistema de detección.

- Control de Calidad: El control de calidad de los métodos utilizados en la PN de PKU se llevó a cabo mediante la implementación de un estricto Sistema de Control de Calidad Interno y mediante la participación en 4 Programas diferentes de Evaluación Externa de Calidad (EEC):

- Control de Calidad Interno: Para la implementación del Sistema de Control de Calidad Interno se utilizaron materiales de control de diferentes procedencias, entre los que se pueden citar los provistos por Programas de EEC como el 
NSQAP-CDC a través de su componente Quality Control $\left(^{*}\right)$, los provistos en kits comerciales como de ICN Biomedicals Inc o Labsystems Oy, o aquellos preparados en nuestro propio Laboratorio ( $\left.{ }^{\star}\right)$.

NOTA: los materiales marcados con (*) son los que se encuentran en uso en la actualidad.

- Evaluación Externa de Calidad: a continuación se listan los Programas de EEC en los cuales se participó en el período evaluado.

- Newborn Screening Quality Assurance Program. Centers for Disease Control and Prevention (NSQAP-CDC). Atlanta - EE.UU., desde Julio de 1994 hasta la fecha.

- Internacional Quality Assurance for Newborn Screening. Geesthacht Alemania, desde Enero de 1996 hasta la fecha.

- Newborn Screening Quality Assurance Program - Human Genetic Society for Australasia (NSQAP-HGSA). Auckland - New Zealand, desde Noviembre de 1996 hasta Enero de 2003 (programa discontinuado por sus propios organizadores).

- Programa de Evaluación Externa de Calidad para Pesquisa Neonatal (PEEC-PN). Fundación Bioquímica Argentina. La Plata - Argentina, desde Junio de 2000 hasta la fecha.

- Valores de Corte: en la Tabla 48 se presentan los diferentes VC utilizados en la PN de PKU a lo largo del período evaluado, y a continuación se presenta una discusión detallada de los mismos:

Tabla 48. Valores de corte utilizados en la PN de PKU

\begin{tabular}{ccccc}
\hline Período & & $V C_{1}$ & & $V C_{2}$ \\
\cline { 1 - 1 } Ene/1991 - Mar/1995 & & $4,0 \mathrm{mg} / \mathrm{dl}$ & & --- \\
Mayr/1995 - Abr/1997 & & $3,0 \mathrm{mg} / \mathrm{dl}$ & & $6,0 \mathrm{mg} / \mathrm{dl}$ \\
\hline
\end{tabular}

Con respecto a los VC se debe mencionar que el VC inicial establecido en 4,0 $\mathrm{mg} / \mathrm{dl}$ fue definido tomando como referencia las experiencias publicadas por otros Programas de PN. Este VC se mantuvo vigente por algo más de 4 años, hasta que en Abril de 1995 se introdujo la primera modificación en respuesta al cambio en 
las exigencias para la recolección de muestras descripto anteriormente, a partir del cual dicho procedimiento comenzaba a realizarse más tempranamente y sin requerir un mínimo de ingesta de leche previa. En función de esto, el $V C_{1}$ fue llevado a un valor más bajo de $3,0 \mathrm{mg} / \mathrm{dl}$ definido teóricamente, con la finalidad de evitar posibles falsos negativos en muestras colectadas entre las 24 y las 48 hs. de vida, incorporándose además un segundo $V C$ de $6,0 \mathrm{mg} / \mathrm{dl}\left(V C_{2}\right)$, a efectos de definir en qué situaciones correspondía solicitar la recolección de una segunda muestra colectada en papel de filtro o bien derivar el RN al Centro de Atención Especializada para la realización de las pruebas confirmatorias.

En cuanto a la segunda modificación introducida en el $V C_{1}$, la misma se realizó en Mayo de 1997 a partir de la incorporación del Método Fluorométrico, el cual por sus propias características analíticas de performance presenta una capacidad para diferenciar bajas concentraciones de Phe muy superior a la del método BIA. De este modo, y después de haber realizado un estudio de distribución poblacional, el $V C_{1}$ se llevó a $2,5 \mathrm{mg} / \mathrm{dl}$, manteniéndose inalterado el $V C_{2}$.

- Algoritmo de trabajo: En la Figura 130 se describe el algoritmo de trabajo utilizado en la actualidad para la pesquisa de PKU, en el cual las unidades de Phe están expresadas en $\mathrm{mg} / \mathrm{dl}$.

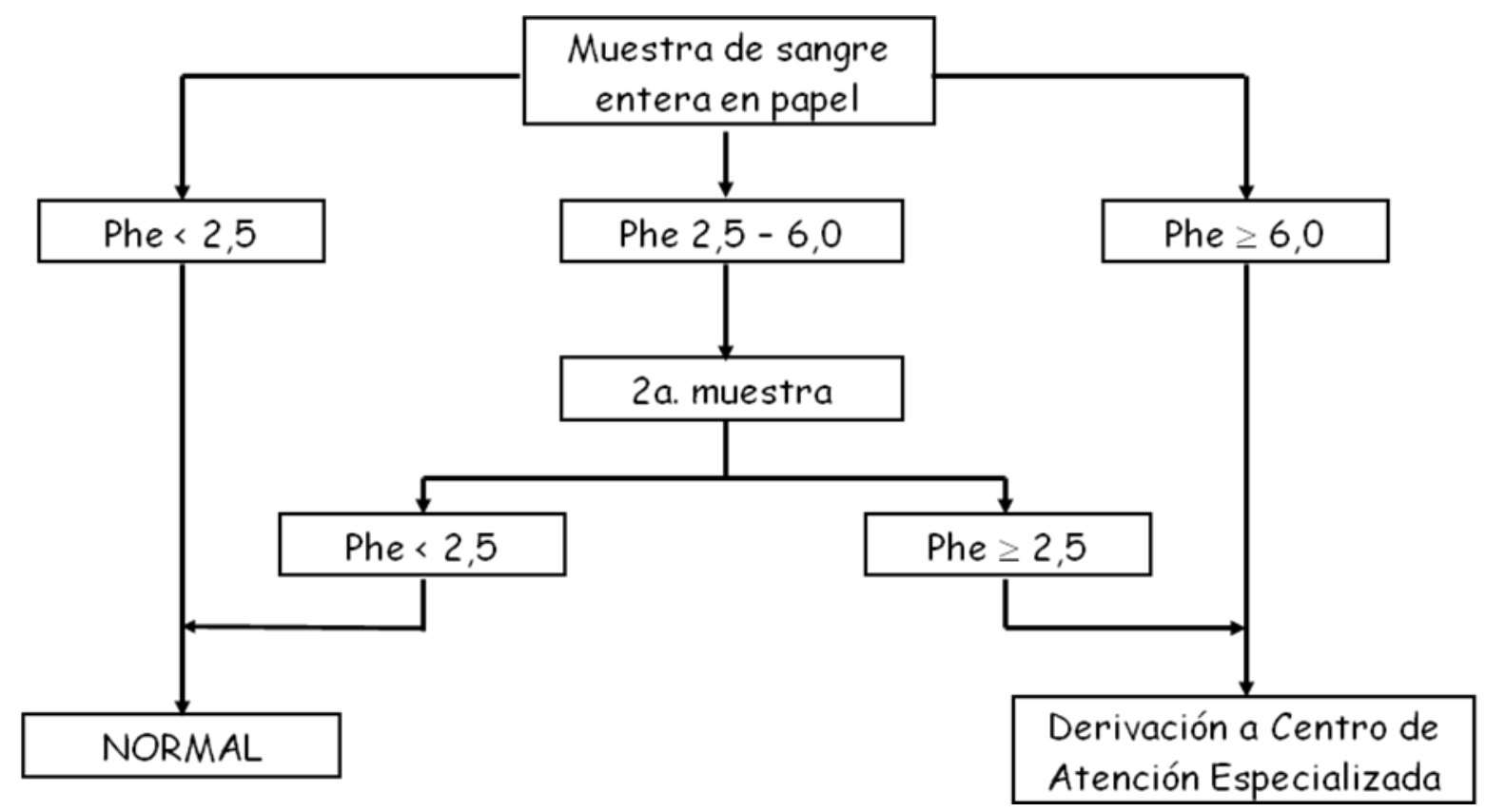

Figura 130. Algoritmo actual de trabajo para la PN de PKU. 
Como puede observarse en el mencionado algoritmo, cuando el resultado de Phe en la pesquisa inicial es mayor o igual al VC de 2,5 mg/dl, y dependiendo de la concentración de Phe obtenido, se definen dos conductas a seguir:

a) Si la concentración de Phe es $\geq 2,5 \mathrm{mg} / \mathrm{dl}$ y $<6,0 \mathrm{mg} / \mathrm{dl}$, y dado que la experiencia determina que en estos casos la probabilidad de que alguna de las formas severas de la enfermedad se confirme es relativamente baja y que, además, en este rango de concentraciones se presentan mayoritariamente los aumentos transitorios de Phe y las HPA persistentes, entonces se procede a solicitar la recolección de una segunda muestra a efectos de evitar la movilización de las familias puesto que estas situaciones pueden resolverse sin necesidad de realizar una derivación inmediata y sin generar mayores riesgos sobre la salud física y mental del niño. En la práctica, los resultados comprendidos dentro de este rango de concentraciones de Phe se definen como resultados "Dudosos".

b) Si la concentración de Phe es $\geq 6,0 \mathrm{mg} / \mathrm{dl}$, y dado que para este nivel del aminoácido la probabilidad de que alguna de las formas severas de la patología se confirme es alta, entonces se procede a solicitar la derivación inmediata del RN al Centro de Atención Especializada a efectos de que allí se realicen la pruebas confirmatorias que van a permitir confirmar o descartar la patología, y en caso de que se confirme proceder a implementar el tratamiento sin demoras. En la práctica, los resultados comprendidos dentro de este rango de concentraciones de Phe se definen como resultados "Patológicos".

- Resultados: En relación a la forma en que se llevó a cabo la PN de PKU en el Laboratorio de Detección de Errores Congénitos de la FBA, se debe mencionar que desde el comienzo de la misma hasta Abril de 1995 en que se implementó el Prodytec, la misma se ejecutó a demanda y bajo la forma de Laboratorio aislado de pesquisa. No obstante esto, y a pesar de no disponer de una estructura definida de Programa, durante esos primeros 4 años de trabajo se contó con el respaldo de los Servicios de Neurología y de Laboratorio Central del Hospital de 
Niños "Sor María Ludovica" de La Plata para las instancias de confirmación, diagnóstico, tratamiento y seguimiento de los casos detectados.

En la Figura 131 se muestra la evolución experimentada en el número de RN pesquisados año a año para PKU a lo largo del período evaluado, incluyendo además información acerca de la distribución según la procedencia de las muestras (Provincia de Buenos Aires e Interior del País). Por otra parte, en la Figura 132 se presentan los principales resultados de la secuencia de pesquisa incluyendo el número total de neonatos pesquisados, de RN a los cuales se les solicitó una segunda muestra, de RN derivados, y el número de casos detectados tanto de PKU como de HPA persistentes con sus correspondientes incidencias.

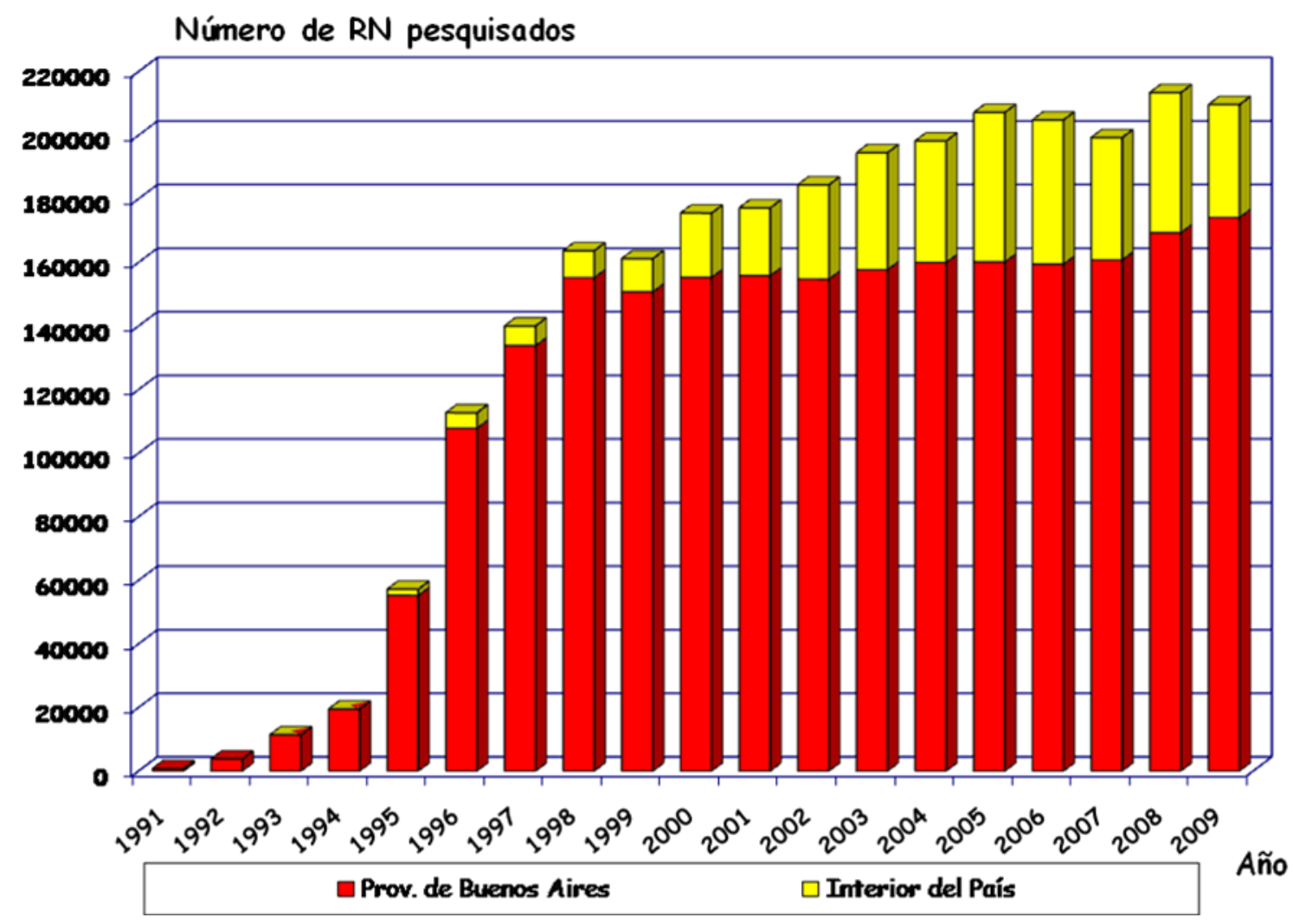

Figura 131. Número de RN pesquisados año a año para PKU.

Como puede observarse en la Figura anterior, el número de RN pesquisados experimentó un crecimiento exponencial en los años 1995 y 1996 a partir de la implementación del Prodytec, y de allí en más dicho número continuó en ascenso hasta superar en 2005 la barrera de los 200.000 RN al año, número que se mantuvo prácticamente estable hasta el año 2009. 
Del mencionado gráfico también se desprende el crecimiento sostenido que presentó la contribución porcentual del interior del país, la cual alcanzó un máximo del $22,7 \%$ del total de RN pesquisados también en el año 2005, para luego ir decayendo progresivamente hasta el $15,0 \%$ en 2009. Este último comportamiento encuentra una explicación en el hecho de que desde 2007 en adelante, y a partir de la implementación del Programa Nacional de Fortalecimiento de la Detección Precoz de Enfermedades Congénitas por parte del Ministerio de Salud de la Nación, varias provincias que realizaban las pruebas de pesquisa de sus Hospitales públicos a través de la FBA comenzaron a resolverla por su propia cuenta, lo cual también fue determinante de la disminución en el número absoluto de RN pesquisados a lo largo del año 2007.

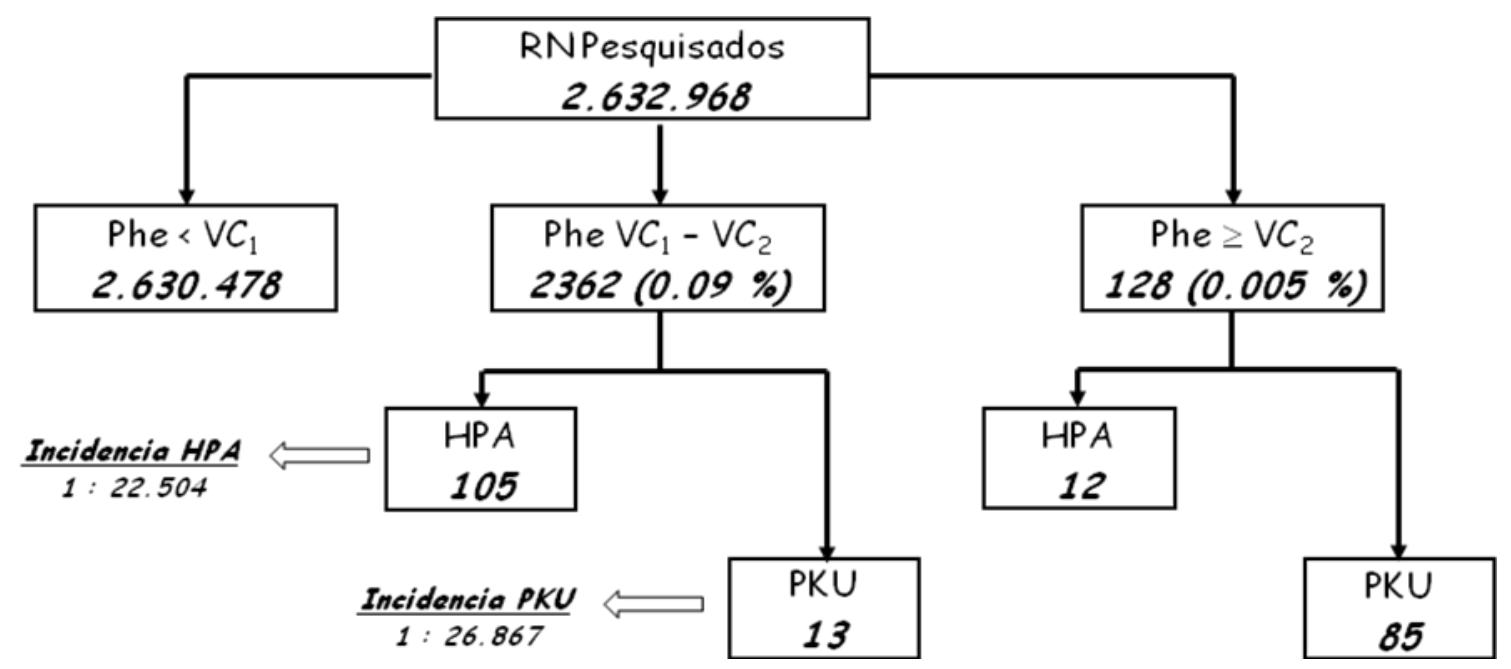

Figura 132. Resultados de la pesquisa de PKU.

Con respecto a los números presentados en la Figura 132, es importante destacar la baja tasa de recitación por resultados anormales la cual no supera el $0,10 \%, y$ también el hecho de que las incidencias tanto de PKU como de HPA persistentes se encuentran muy por debajo de las descriptas bibliográficamente para EE.UU. y algunos países de Europa, resultando una incidencia conjunta de ambas formas de $1: 12.246$. Además debe mencionarse que hasta la fecha no han sido reportados resultados falsos negativos, siendo este otro parámetro que refleja la eficiencia del sistema de detección. 
En relación a los casos detectados con alguna de las diferentes formas de HPA, en la Tabla 49 se presenta la distribución de los mismos según la provincia de procedencia.

Tabla 49. Distribución de casos detectados por Provincia

\begin{tabular}{|c|c|c|}
\hline Provincia & PKU & HPA \\
\hline Buenos Aires & 86 & 106 \\
\hline Santa Fe & 4 & 5 \\
\hline Chubut & 2 & 1 \\
\hline Neuquén & 2 & -- \\
\hline San Juan & 1 & 3 \\
\hline Salta & 1 & -- \\
\hline Jujuy & 1 & -- \\
\hline Corrientes & 1 & -- \\
\hline Entre Ríos & -- & 2 \\
\hline Total & 98 & 117 \\
\hline
\end{tabular}

Finalmente, en la Tabla 50 se presentan algunos parámetros estadísticos que caracterizan el desempeño del sistema de detección.

Tabla 50. Parámetros estadísticos de la PN de PKU

\begin{tabular}{lc}
\hline \multicolumn{2}{c}{ Tasas de recitación } \\
\hline - Por resultados dudosos & $0,090 \%$ \\
- Por resultados patológicos & $0,005 \%$ \\
- Por recolección inadecuada de muestras & $0,27 \%$ \\
- Por muestras < 24 horas & $0,34 \%$ \\
\hline \multicolumn{2}{c}{ Recuperación de segundas muestras solicitadas } \\
\hline - Por recolección inadecuada de muestras \\
- Total período evaluado \\
- Período 2005-2009 \\
- Por muestras < 24 horas \\
- Total período evaluado \\
- Período 2005-2009
\end{tabular}

De los resultados anteriores se desprende que el número de RN que se deben localizar por causas diferentes de las que corresponden a resultados anormales 
alcanza el 0,61\%, es decir aproximadamente 6 de cada 1000 niños, de los cuales algo más del 50 \% son producto de una recolección de muestras efectuada con anterioridad a las 24 horas de vida. No obstante esto, en la práctica la recuperación de los mismos no llega a ser del 100 \% alcanzándose índices que toman diferentes magnitudes según que el motivo de la solicitud de segundas muestras sea por recolección inadecuada o por muestras colectadas antes de las 24 horas de vida, observándose además una importante evolución de más de 10 puntos en el primero de estos dos parámetros al comparar los últimos 5 años con respecto a los números generales del período evaluado.

\section{BIBLIOGRAFIA}

1. Levy H and Albers S. "Genetic Screening of Newborns". Annu Rev Hum Genet, 01 , $139-77,2000$.

2. National Institutes of Health Consensus Development Panel. "Phenylketonuria: Screening and Management". Pediatr 108, 972-82, 2001.

3. Campistol Plana J, Lambruschini Ferri N, Gómez López L, Gutierrez Sánchez A, Fusté Rich E y Vilaseca Buscá M. "Hiperfenilalaninemia", en "Diagnóstico y Tratamiento de las Enfermedades Metabólicas Hereditarias". Sanjurjo P, Baldellou A Eds. Editorial Ergon - Madrid, 3ª Edición. Capítulo 29, 423-39, 2010.

4. Matalon R, Michals-Matalon K, Bhatia G, Grechanina E, Novikov P, McDonald J et al. "Large neutral Amino Acids in the Treatment of Phenylketonuria". J Inherit Metab Dis 29, 732-8, 2006.

5. Blau N, Erlandsen H. "The Metabolic and Molecular Bases of TetrahydrobiopterinResponsive Phenylalanine Hydroxylase Deficiency". Mol Genet Metab 82, 101-11, 2004.

6. Sanford M, Keating G. "Sapropterin. A Review of its Use un the Treatment of Primary Hyperphenylalaninemia". Drugs 69, 461-76, 2009.

7. Sarkissian C, Shao Z, Blain F, Peevers R, Su H, Heft R et al. "A Different Approach to Treatment of Phenylketonuria: Phenylalanine Degradation with Recombinant Phenylalanine Ammonia Lyase". Proc Natl Acad Sci USA 96,2339-44, 
1999.

8. Sarkissian C, Gamez A, Wang L, Charbonneau M, Fitzpatrick P, Lemontt J et al."Preclinical Evaluation of Multiple Species of PEGylated Recombinant Phenylalanine Ammonio Lyase for the Treatment of Phenylketonuria". Proc Natl Acad Sci USA 105, 20894-9, 2008.

9. Ney D, Gleason S, van Calcar S, MacLeod E, Nelson K, Etzel M, Rice G, Wolff J. "Nutritional Management of PKU with Glycomacropeptide from Cheese Whey". J Inherit Metab Dis 32, 32-9, 2009.

10.Pey A, Ying M, Cremades N, Velázquez-Campoy A, Scherer $T$, Thöny B et al. "Identification of Pharmacological Chaperones as Potential Therapeutic Agents to Treat Phenylketonuria". J Clin Invest 118, 2858-67, 2008.

11. Borrajo G, Galdeano H. "Estudio de un Método para Aplicar en Control Masivo de Fenilcetonuria. Evaluación de Sensibilidad, Reproducibilidad y Costos". Acta Bioquím Clín Latinoam, 23; 289-302; 1989.

12.Guthrie $R$ and Susi $A$. "A Simple Phenylalanine Method for Detecting Phenylketonuria in Large Populations of Newborn Infants". Pediatr 32, 338-43, 1963.

13. Wu J, Wu L, Ziter F and Ash O. "Manual Fluorometry of Phenylalanine from Blood Specimens Collected on Filter Paper: A Modified Procedure". Clin Chem 25, 470-2, 1979.

14. Yamaguchi A, Mizushima Y, Fukushi M, Shimizu Y, Kikuchi $Y$ and Takasugi N. "Microassay System for Newborn Screening for Phenylketonuria, Maple Syrup Urine Disease, Homocystinuria, Histidinemia and Galactosemia with Use of a Fluorometric Microplate Reader". Screening, 1, 49-62, 1992. 


\section{ANEXO 2: METODO DE INHIBICION BACTERIANA DE GUTHRIE PARA LA MEDIDA DE FENILALANINA EN DBS, DE DESARROLLO PROPIO (11).}

- PREPARACION DE REACTIVOS: La preparación del medio de cultivo, esporos e inhibidor utilizados en el presente método, se lleva a cabo según lo descripto en la publicación de referencia (11).

\section{- pRotocolo de ensayo para PLACAS DE PETRI (9 cm de diámetro):}

1. Pesar $225 \mathrm{mg}$ de agar y colocar en un tubo de ensayo de $20 \mathrm{~mm}$ de diámetro.

2. Agregar $7,0 \mathrm{ml}$ de $\mathrm{H}_{2} \mathrm{O}$ destilada y colocar en baño maría a ebullición para fundir el agar.

3. Una vez que el agar está fundido, agregar $7,5 \mathrm{ml}$ de medio de Demain modificado. Homogeneizar en vortex.

4. Colocar nuevamente en baño maría y dejar que la temperatura descienda hasta $60-65^{\circ} \mathrm{C}$.

5. Mientras tanto, colocar en una placa de Petri descartable 0,3 $\mathrm{ml}$ de una solución acuosa del inhibidor B-2-D-L-Tienilalanina (Sigma T-4875) de concentración $13,0 \mathrm{mg} / \mathrm{dl}$ y 0,3 $\mathrm{ml}$ de una suspensión de esporos de B. subtilis ATCC 6633 de concentración 3,6.107 esporos/ml.

6. Cuando la temperatura del baño alcance los $60-65^{\circ} \mathrm{C}$, volcar el contenido de un tubo de ensayo en la placa de Petri.

7. Asegurarse de que tanto los esporos como el inhibidor se distribuyan homogéneamente en el medio de cultivo, para lo cual es necesario realizar movimientos de rotación de la placa de Petri en ambos sentidos y movimientos de vaivén hacia arriba, abajo, izquierda y derecha, evitando siempre que el contenido de la misma se derrame por fuera de la placa.

8. Dejar solidificar colocando la placa sobre una superficie perfectamente horizontal, asegurándose que la profundidad del medio de cultivo sea la misma en toda la placa.

9. Cortar las muestras de RN, calibradores y controles a incluir en cada placa uti- 
lizando un puncher de 3/16" (4,75 mm).

10. Una vez que el medio de cultivo se solidificó, colocar los discos sobre la superficie del mismo utilizando una pinza y una plantilla para asegurar su correcta distribución, a fin de evitar la superposición de los halos de crecimiento. Presionar ligeramente los discos contra la superficie del medio de cultivo a fin de asegurar que los mismos queden perfectamente adheridos.

11. Incubar durante 16 horas a $37^{\circ} \mathrm{C}$, colocando las placas en estufa en posición invertida.

12. Leer los halos de crecimiento bacteriano empleando una regla milimetrada.

13.Para semicuantificar, graficar el diámetro de los halos de crecimiento $(\mathrm{mm})$ de los calibradores en función del log Phe $(\mathrm{mg} / \mathrm{dl})$, e interpolar de allí los valores correspondientes a la muestras de RN.

\section{- protocolo de ensayo para placas de $24 \mathrm{~cm} \times 24 \mathrm{~cm}$ :}

1. Pesar $1,8 \mathrm{~g}$ de agar y colocarlos en un frasco de vidrio de $200 \mathrm{ml}$ de capacidad.

2. Agregar $55,2 \mathrm{ml}$ de $\mathrm{H}_{2} \mathrm{O}$ destilada.

3. Fundir el agar utilizando un horno microondas, realizando 5 pulsos de calentamiento de 45", evitando la ebullición violenta.

4. Una vez que el agar está fundido, calentar el medio de Demain modificado a $60-80{ }^{\circ} \mathrm{C}$ en el horno microondas y agregar $60 \mathrm{ml}$ del mismo al frasco que contiene el agar. Tapar con un tapón de goma y homogeneizar por inversión suave.

5. Dejar que la temperatura descienda hasta $70^{\circ} \mathrm{C}$.

6. Agregar al frasco $2,4 \mathrm{ml}$ de la solución de inhibidor $\beta-D$-L-Tienilalanina de concentración $13,0 \mathrm{mg} / \mathrm{dl}$ y 2,4 $\mathrm{ml}$ de la suspensión de esporos de B. subtilis ATCC 6633 de concentración 3,6.107 esporos $/ \mathrm{ml}$.

7. Volcar el contenido de un frasco en una placa de cultivo de $24 \mathrm{~cm} \times 24 \mathrm{~cm}$.

8. Asegurarse de que el medio de cultivo conteniendo los esporos y el inhibidor bañe rápidamente la superficie interna de la placa a fin de evitar que se solidifique prematuramente en forma inhomogénea. 
9. Dejar solidificar el medio sobre una superficie perfectamente horizontal, asegurándose que la profundidad del medio de cultivo sea la misma en toda la placa.

10. Cortar las muestras de RN, calibradores y controles a incluir en cada placa utilizando un puncher de 3/16" (4,75 mm) y colocarlos sobre la plantilla diseñada sobre la superficie del dispositivo ideado para el improntado de muestras. Asegurarse de procesar calibradores con niveles de Phe próximos al VC en cada una de las esquinas de la placa, en la posición central y sobre cada una de las diagonales a fin de chequear que la altura del medio de cultivo sea homogénea en toda la placa.

11. Una vez que el medio de cultivo se solidificó, invertir la placa y colocarla cuidadosamente sobre el dispositivo para el improntado de muestras, de manera tal que el medio de cultivo quede apoyado sobre la plantilla plastificada $y$, consecuentemente, sobre las muestras. Presionar ligeramente la placa a fin de asegurar que los discos queden perfectamente adheridos. Levantar cuidadosamente la placa para evitar la eventual caída de algún disco.

12. Incubar durante 16 horas a $37^{\circ} \mathrm{C}$, colocando las placas en estufa en posición invertida.

13. Leer los halos de crecimiento bacteriano empleando una regla milimetrada.

14.Para semicuantificar, graficar el diámetro de los halos de crecimiento $(\mathrm{mm})$ de los calibradores en función del log Phe ( $\mathrm{mg} / \mathrm{dl})$, e interpolar de allí los valores correspondientes a la muestras de RN. 


\section{ANEXO 3: METODO fLUOROMETRICO PARA LA MEDIDA DE FENILALANINA EN DBS, DE DESARROLLO PROPIO.}

\section{- PREPARACION DE REACTIVOS:}

o Solución Fijadora: mezclar Metanol, Acetona y $\mathrm{H}_{2} \mathrm{O}$ destilada en proporciones $70: 70: 20$. Conservar en frasco color caramelo a temperatura ambiente.

o L-Leu-L-Ala (20 mM): disolver 1,025 g de L-Leucil-L-Alanina (Sigma, L-9250) en $250 \mathrm{ml}$ de $\mathrm{H}_{2} \mathrm{O}$ destilada. Fraccionar a razón de $10 \mathrm{ml}$ por tubo en tubos con tapa a rosca tipo Falcon y almacenar en freezer $a-20^{\circ} \mathrm{C}$.

o Ninhidrina (60 mM): disolver 5,36 g de Ninhidrina (Sigma, N-4876) en $500 \mathrm{ml}$ de $\mathrm{H}_{2} \mathrm{O}$ destilada. Filtrar por vacío con papel Whatman $\mathrm{N}^{\circ} 1$. Conservar en frasco color caramelo en heladera a $2-8^{\circ} \mathrm{C}$.

o Buffer Succinato 0,76 M - pH 5,80: pesar 410,6 g de Succinato Acido Disódico Hexahidratado (MP Diagnostic, Cat. 102929) y disolver en $1600 \mathrm{ml}$ de $\mathrm{H}_{2} \mathrm{O}$ destilada. Ajustar el pH a 5,80 $\pm 0,02$ gota a gota con $\mathrm{HCl}$ concentrado. Ajustar el volumen a $2000 \mathrm{ml}$ y filtrar por vacío con papel Whatman $\mathrm{N}^{\circ} 1$. Controlar nuevamente el pH. Fraccionar en frascos plásticos a razón de $200 \mathrm{ml}$ por frasco. Almacenar en freezer a $-20^{\circ} \mathrm{C}$.

o Tartrato de Cobre 0,6 mM en $\mathrm{CO}_{3} \mathrm{Na}_{2} 60 \mathrm{mM}$ : pesar $300 \mathrm{mg}$ de $\mathrm{SO}_{4} \mathrm{Cu} .5 \mathrm{H}_{2} \mathrm{O}$ (Merck, Cat. 1.02790), $348 \mathrm{mg}$ de Tartrato de Na y K tetrahidratado (Merck, Cat. PX1590) y disolver en $2000 \mathrm{ml}$ de $\mathrm{H}_{2} \mathrm{O}$ destilada. Agregar $12,8 \mathrm{~g}$ de $\mathrm{CO}_{3} \mathrm{Na}_{2}$ (Biopack, Art. 972107). Filtrar por vacío con papel Whatman $\mathrm{N}^{\circ} 1$ y fraccionar en botellas color caramelo a razón de $1000 \mathrm{ml}$ por botella. Conservar en heladera a $2-8{ }^{\circ} \mathrm{C}$.

\section{- pRotocolo de ensayo:}

1. Punchear discos de $1 / 8^{\prime \prime}(3,2 \mathrm{~mm})$ de diámetro correspondientes a calibradores, controles y muestras de RN en microplacas de transferencia MADVN 65 de Millipore de 96 pocillos, a razón de un disco por pocillo.

2. Dispensar $20 \mu$ de Solución Fijadora, Metanol/Acetona/Agua en cada pocillo. 
3. Dejar evaporar la Solución Fijadora durante una noche a temperatura ambiente asegurándose el acceso de una apropiada corriente de aire para aumentar la eficiencia del proceso de evaporación.

NOTA: Para protocolos cortos, es posible evaporar la Solución Fijadora en estufa a $37^{\circ} \mathrm{C}$ durante 1 hora.

4. Dispensar $70 \mu \mathrm{l}$ de $\mathrm{H}_{2} \mathrm{O}$ destilada a cada pocillo.

5. Agitar durante 15 minutos en agitador DELFIA Plate Shake (Figura 50 - Página 152) para asegurar una completa elución de la Phe.

6. Transferir cuantitativamente el contenido de cada pocillo a cada uno de los pocillos correspondientes de una placa de fluorometría blanca (Whiteplate, Labsystems Oy), utilizando un sistema Vacuum Manifold (Millipore).

7. Preparar la mezcla de reacción L-Leucil-L-Alanina/Ninhidrina en buffer Succinato de $\mathrm{pH} 5,8$ en proporciones $1: 2: 5$.

8. Dispensar $80 \mu$ de mezcla de reacción en cada pocillo.

9. Cubrir la microplaca con una placa plástica no adhesiva y colocar en incubadores Thermomix - Labsystems Oy, los cuales han sido precalentados a $60^{\circ} \mathrm{C}$

10.Incubar durante 105 minutos a $60^{\circ} \mathrm{C}$, con agitación solamente durante el primer minuto a $900 \mathrm{rpm}$.

11. Sacar las placas de los incubadores y dispensar en cada pocillo $150 \mu$ de la Solución de Tartrato de Cobre fría.

12. Dejar reposar 15 minutos a temperatura ambiente y leer en Fluorómetro a $\lambda_{\text {EXC/EM }}=390 / 485 \mathrm{~nm}$.

13. Graficar la intensidad de fluorescencia de cada uno de los calibradores en función de la concentración de Phe de cada uno de ellos, construir la curva de calibración e interpolar de la misma los valores de Phe de los controles y de las muestras de RN. 


\section{CAPÍTULO 9}

PESQUISA NEONATAL DE

HIPOTIROIDISMO

CONGÉNITO 



\section{- INTRODUCCIÓN}

El Hipotiroidismo Congénito $(H C)$ es la situación clínica resultante de una disminución de la actividad biológica de las hormonas tiroideas a nivel tisular, ya sea por deficiente producción de las mismas o por resistencia a su acción (1).

Esta enfermedad constituye la endocrinopatía más frecuente en el período neonatal (2), y es una de las causas más comunes de deficiencia mental prevenible en la infancia (3), razón por la cual su diagnóstico inmediato y tratamiento precoz son de vital importancia para evitar el daño neurológico irreversible asociado a la misma.

La frecuencia con que se manifiesta el HC es variable según las poblaciones, encontrándose que la misma oscila entre $1: 2.000$ y $1: 4.000$ nacidos vivos, con una media de $1: 2.500$ nacidos vivos (4-7).

La tiroxina $0 T_{4}$-una hormona producida y secretada por la glándula tiroidesdesempeña un rol muy importante en el organismo como regulador de la velocidad de diferentes procesos metabólicos, cumpliendo un papel crítico en la niñez a nivel del crecimiento óseo y cerebral. Por este motivo, en ausencia de tratamiento la patología presenta efectos devastadores sobre el crecimiento y desarrollo de los individuos afectados causando retraso mental y diversas complicaciones neuropsicológicas como anormalidades motrices, problemas de aprendizaje y trastornos del habla (7).

Clínicamente el $95 \%$ de los RN que padecen $H C$ no presentan signos $\mathrm{y} / \mathrm{o}$ sintomas evidentes al nacer, resultando imprescindible recurrir a la realización de las pruebas de PN para su detección precoz. No obstante esto, al examen físico los RN pueden revelar una o varias manifestaciones inespecíficas que incluyen: fontanela posterior abierta más allá de la primera semana de vida, ictericia prolongada, macroglosia, distensión abdominal, hernia umbilical, hipotermia, palidez, piel seca y marmórea, facies típicas, constipación, hipotonía, hipoactividad, sueño prolongado, llanto ronco y bradicardia, con o sin bocio $(8,9)$; síntomas que apenas en un $5 \%$ de los casos permiten acceder a un diagnóstico clínico hacia fines del primer mes de vida.

En lo que respecta a la etiología del HC, el mismo puede clasificarse en 4 grandes grupos (2), los cuales son presentados en la Tabla 51: 


\section{Tabla 51. Etiología del HC}

\section{HC Primarios Permanentes}

- Por alteración del desarrollo de la glándula tiroides (75-85 \%)

- Disgenesias tiroideas

a) Agenesia

b) Hipoplasia

c) Ectopía

d) Hemitiroides

- Por alteración de la síntesis de las hormonas tiroideas (15-20 \%)

- Dishormonogénesis

a) Defectos en el NIS (simporter Na-Ioduro)

b) Defectos en la Tiroperoxidasa (TPO) $(7,8)$

c) Defectos en laTiroxidasa 2 (THOX2)

d) Defectos en las Deshalogenasas

e) Defectos en la Tiroglobulina (TG)

\section{HC Primarios Transitorios}

- Hipertirotropinemias idiopáticas

- Uso de drogas antitiroideas en la madre

- Pasaje transplacentario de anticuerpos maternos

- Exposición al Iodo

HC Centrales (Hipotálamo - Hipofisarios)

- Defectos en el desarrollo Hipotálamo-Hipofisario

- Deficiencia aislada de TSH

\section{HC Periféricos}

- Por resistencia a las Hormonas Tiroideas

- MCT-8

- Hemangioendotelioma hepático

En relación al tratamiento, el mismo consiste en la suplementación con hormona tiroidea (levo- $\left.\mathrm{T}_{4}\right)$, resultando imprescindible que su implementación se efectivice antes de los 15 días de vida con una dosis adecuada que varía entre $10-15 \mu \mathrm{g} / \mathrm{Kg} / \mathrm{día}$, según la severidad del $H C$ inicial $(2,3,12,13)$.

A través de este tratamiento se plantea como objetivo inmediato la normalización en los niveles de $T_{4}$ y $T_{4 L i b r e}$ dentro de las 2 semanas de iniciado el mismo, y de los niveles de TSH dentro del primer mes de vida, debiendo asegurarse la 
continuidad del mencionado tratamiento hasta los 3 años de edad, o eventualmente de por vida en caso de confirmarse un $H C$ permanente $(2,3,8)$.

Desde el punto de vista de la PN, existen 3 tipos de estrategias posibles para la detección del HC (Tabla 52), sin embargo, la estrategia más utilizada en la actualidad -principalmente en Europa, Australia, Japón, Nueva Zelanda, Canadá, Latinoamérica y algunos estados de los EE.UU.-, es la que lleva a cabo la medida primaria de TSH, aún a pesar de que la misma no permite detectar los HC centrales y de que podría perder aquellos casos de HC Primario que se presentan con un aumento retrasado de TSH (14).

Tabla 52. Estrategias de PN de HC

- Medida primaria de TSH

- Medida primaria de $T_{4}$ y seguimiento con TSH a todos aquellos RN con $T_{4}$ baja

- Medida simultánea de $\mathrm{T}_{4}$ y TSH

Para la confirmación del diagnóstico, se requiere realizar una anamnesis exhaustiva incluyendo el estado tiroideo materno (drogas y medicamentos), historia familiar, examen clínico completo y la realización de un perfil tiroideo que incluya la determinación de $\mathrm{TSH}$ y $\mathrm{T}_{4} \circ \mathrm{T}_{4 L i b r e}$ séricas. Complementariamente también se recomienda la medición de Tiroglobulina (TG), y en caso de que existan antecedentes maternos de autoinmunidad, la determinación de anticuerpos anti-Tiroperoxidasa, anti-TG y antireceptor de TSH (TRAb), y de Globulina transportadora de tiroxina (TBG) (8).

En cuanto a la realización de estudios complementarios como la Radiografía de rodilla, la Ecografía tiroidea, el Eco-Doppler y el Centellograma con Tecnecio 99, los mismos resultan de gran ayuda para orientar al diagnóstico etiológico. Sin embargo, dichos estudios pueden ser opcionales y no deben retrasar el inicio del tratamiento.

Por último se debe mencionar que en aquellos niños en quienes el diagnóstico de $H C$ permanente no se hubiera podido confirmar con los estudios realizados en el período neonatal, pero además tampoco hubiera sido posible descartar la patología, resulta necesario implementar el tratamiento, darle continuidad hasta los 3 años de edad, y recién en ese momento proceder a suspender el mismo durante 15-20 días para realizar las medidas de TSH, $T_{4} \circ T_{4} L, T_{3}$ y $T G$, los cuales sumados a los 
hallazgos obtenidos por ecografía y centellografía permitirán establecer el diagnóstico definitivo de la enfermedad (8).

\section{Pesquisa Neonatal}

- Período de trabajo evaluado: Julio 1992 - Diciembre 2009.

- Métodos: en la Tabla 53 se presentan los diferentes métodos utilizados en la PN de HC y a continuación se presenta una discusión acerca de los mismos:

Tabla 53. Métodos utilizados en la PN de HC

\begin{tabular}{|c|c|}
\hline Período & Método \\
\hline \multirow[t]{2}{*}{ Jul/1992 - Nov/1994 } & ELISA, Enzymun-test TSH - Boehringer \\
\hline & Mannheim adaptado para DBS, automatizado. \\
\hline \multirow[t]{2}{*}{ Dic/1994 - Jun/1997 } & DELFIA Neonatal hTSH -Wallac Oy. \\
\hline & Finlandia. \\
\hline Jul/1997 - Dic/2009 & $\begin{array}{l}\text { AutoDELFIA Neonatal hTSH - PerkinElmer, } \\
\text { Finlandia. }\end{array}$ \\
\hline
\end{tabular}

- Enzimoinmunoensayo (ELISA) Enzymun-test TSH de Boehringer Mannheim, adaptado para DBS, automatizado con un autoanalizador ES-22:

Fundamento: la TSH presente en DBS es eluida del papel de filtro e incubada con un buffer conteniendo anticuerpos monoclonales dirigidos contra la subunidad $\beta$ de la TSH unidos a Biotina y anticuerpos policlonales anti-TSH conjugados con Peroxidasa en tubos recubiertos con Estreptavidina. Después de remover los discos de papel y de lavar los tubos, la reacción se revela agregando el cromógeno ABTS [2,2'-azino-di-(3-etilbenztiazolina) 6-sulfonato], el cual desarrollará un color verde intenso cuantificable a 492 nm, cuya intensidad es proporcional a la concentración de TSH presente en la muestra.

Con respecto al método en cuestión, el mismo se trabajó siguiendo las especificaciones del fabricante (15) y en forma automatizada empleando para ello un Autoanalizador ES-22 de Boehringer Mannheim, con una capacidad máxima de trabajo de 140 muestras por corrida. Y si bien cuando se comenzó con esta pesquisa, la disponibilidad del método en cuestión permitió la 
implementación de aquella, el mismo adolecía de diversos problemas tanto analíticos como operativos, a consecuencia de tratarse de un método diseñado para trabajar sobre muestras de suero o plasma que fue adaptado para trabajar sobre DBS A continuación se describen las limitaciones observadas:

a) Provisión de calibradores preparados en solución proteica, en lugar de calibradores preparados en sangre entera e impregnados en papel de filtro, poniendo en juego un importante efecto de matriz.

b) Tiempos de incubación con conjugado muy diferentes para las muestras de sangre y para los calibradores (22 horas vs 150 minutos).

c) Marcada influencia de las variaciones en la temperatura ambiente a lo largo de la etapa de incubación de las muestras con el conjugado.

d) Valor máximo de TSH cuantificable demasiado bajo: $45 \mu \mathrm{U} / \mathrm{ml}$.

e) Necesidad de utilización de un factor de corrección para convertir los resultados desde los calibradores líquidos a DBS.

f) Necesidad de remover los discos de papel de filtro de los tubos en forma manual.

En vista de estas limitaciones, desde el propio Laboratorio de la FBA se procedió a introducir una serie de modificaciones en el mismo a fin de mejorar su performance analítica:

a) Se introdujo el empleo de calibradores de TSH preparados en DBS, eliminando así el efecto de matriz, y la necesidad de utilizar un factor de corrección para el cálculo de la concentración de TSH en DBS.

b) Se modificaron las condiciones de incubación con conjugado, desde temperatura ambiente a $4{ }^{\circ} \mathrm{C}$ en heladera, eliminando así la influencia de las variaciones térmicas.

c) Se amplió el valor máximo de TSH cuantificable hasta $80 \mu \mathrm{U} / \mathrm{ml}$.

- Inmunoensayo Fluorométrico a Tiempo Resuelto DELFIA Neonatal hTSH, de Wallac Oy:

Fundamento: la TSH presente en DBS es eluida del papel de filtro e incubada con un buffer conteniendo anticuerpos monoclonales conjugados con $\mathrm{Eu}^{+3}$ 
dirigidos contra determinantes antigénicos localizados parcialmente en la subunidad $\beta$ y parcialmente en la subunidad $\alpha$ de la $\mathrm{TSH}$, en pocillos recubiertos con anticuerpos monoclonales dirigidos contra la subunidad $\beta$ de la TSH. Después de remover los discos de papel y de lavar los pocillos se adiciona una solución intensificadora que disocia el $\mathrm{Eu}^{+3}$ de su unión al anticuerpo y forma un quelato fluorescente que se cuantifica en un Fluorómetro a Tiempo Resuelto, cuya intensidad de fluorescencia es proporcional a la concentración de TSH en la muestra (Figura 133).

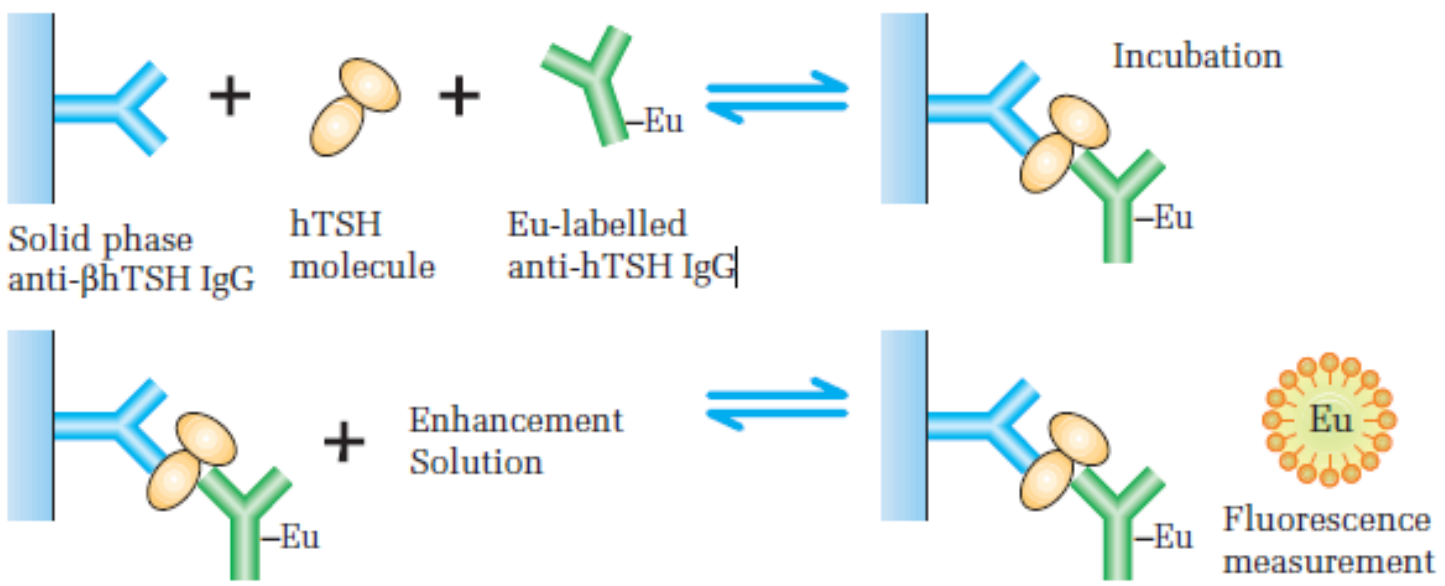

Figura 133. Método DELFIA para la medida de TSH.

En cuanto a las condiciones de uso del método DELFIA, el mismo fue utilizado siguiendo el protocolo descripto por el fabricante y trabajando con el equipamiento modular -dispensador, agitador, lavador, removedor y lectorprevisto para tal fin, ya descripto en el Capítulo 3.

- Inmunoensayo Fluorométrico a Tiempo Resuelto AutoDELFIA Neonatal hTSH, de PerkinElmer:

Fundamento: el principio analítico de este método es el mismo que el descripto para el método DELFIA Neonatal hTSH, con la diferencia de que en este caso el procedimiento de ensayo se lleva a cabo en forma completamente automatizada, empleando un autoanalizador AutoDELFIA de PerkinElmer (ver Figura 61 - Página 161).

En lo que respecta a las condiciones de uso del método AutoDELFIA, el mismo fue utilizado siguiendo el protocolo descripto por el fabricante. 
- Condiciones para la recolección de muestras: en concordancia con lo descripto en el Capítulo 8 para el caso de la PKU, en el período comprendido entre Julio de 1992 y Marzo de 1995, las condiciones de recolección de muestras utilizadas establecian la necesidad de una ingesta de leche de 48 horas previa a la toma de muestras, mientras que a partir de Abril de 1995 se redujo el tiempo mínimo de recolección a 24 horas de vida, fijándose el tiempo máximo en 7 días de vida.

- Control de Calidad: El control de calidad de los métodos utilizados en la PN de HC se llevó a cabo mediante la implementación de un estricto Sistema de Control de Calidad Interno y mediante la participación en 4 Programas diferentes de Evaluación Externa de Calidad (EEC):

- Control de Calidad Interno: Para la implementación del Sistema de Control de Calidad Interno se utilizaron materiales de control de diferentes procedencias, entre los que se pueden citar los provistos por Programas de EEC como el NSQAP-CDC a través de su componente Quality Control $\left(^{*}\right)$ y los provistos en los kits comerciales DELFIA y AutoDELFIA $\left(^{*}\right)$.

NOTA: los materiales de control marcados con (*) son los que se encuentran en uso en la actualidad.

- Evaluación Externa de Calidad: a continuación se listan los Programas de EEC en los cuales se participó en el período evaluado.

- Newborn Screening Quality Assurance Program. Centers for Disease Control and Prevention (NSQAP-CDC). Atlanta - EE.UU., desde Julio de 1994 hasta la fecha.

- Deutsche Gesselschaft für Klinische Chemie. Bonn-Alemania, desde Febrero de 1994 hasta la fecha.

- Newborn Screening Quality Assurance Program - Human Genetic Society for Australasia (NSQAP-HGSA). Auckland - New Zealand, desde Noviembre de 1996 hasta Enero de 2003 (programa discontinuado por sus propios organizadores).

- Programa de Evaluación Externa de Calidad para Pesquisa Neonatal (PEEC-PN).

Fundación Bioquímica Argentina. La Plata-Argentina, desde Junio de 2000 
hasta la fecha.

- Valores de Corte: en la Tabla 54 se presentan los diferentes VC utilizados en la PN de $H C$ en el período evaluado, y a continuación se presenta una discusión detallada de los mismos:

Tabla 54. Valores de corte utilizados en la PN de HC

\begin{tabular}{ccccc}
\hline Período & & $V C_{1}$ & & $V C_{2}$ \\
\cline { 1 - 1 } Jul/1992 - Mar/1995 & & $20,0 \mu N / m l$ & & --- \\
Abr/1995 - Nov/1996 & & $20,0 \mu N / m l$ & & $30,0 \mu \mathrm{N} / \mathrm{ml}$ \\
Dic/1996 - Sep/1997 & & $15,0 \mu \mathrm{U} / \mathrm{ml}$ & & $30,0 \mu \mathrm{U} / \mathrm{ml}$ \\
Oct/1997 - Jul/2001 & & $13,0 \mu \mathrm{U} / \mathrm{ml}$ & & $30,0 \mu \mathrm{N} / \mathrm{ml}$ \\
Ago/2001 - Dic/2009 & & $11,0 \mu \mathrm{N} / \mathrm{ml}$ & & $25,0 \mu \mathrm{U} / \mathrm{ml}$ \\
\hline
\end{tabular}

Como se puede visualizar en la Tabla anterior, cuando se dio inicio a la PN de HC se estableció un VC inicial de $20,0 \mu \mathrm{U} / \mathrm{ml}$, criterio que fue definido tomando como referencia las experiencias publicadas por otros Programas de PN.

Usando este VC se continuó trabajando hasta Noviembre de 1996, con la particularidad de que a partir de la implementación del Prodytec en Abril de 1995, se introdujo un segundo $V C$ de $30,0 \mu \mathrm{U} / \mathrm{ml}\left(V C_{2}\right)$, a efectos de disponer de un criterio para definir en qué ocasiones solicitar la recolección de una segunda muestra en papel de filtro y en cuáles derivar el RN al Centro de Atención Especializada para la realización de las pruebas confirmatorias (4).

La segunda modificación introducida afectó específicamente al $V C_{1}$, el cual en Diciembre de 1996 se redujo a $15,0 \mu \mathrm{U} / \mathrm{ml}$ (4) tomando como referencia los resultados de una serie de experiencias presentadas en el "III Congreso de la International Society for Neonatal Screening (ISNS)" que ponían en evidencia un potencial riesgo de resultados falsos negativos en algunas dishormonogénesis que podían presentarse con valores de TSH inferiores a $20,0 \mu \mathrm{N} / \mathrm{ml}(16,17)$.

Posteriormente, y en concomitancia con la implementación de la metodología AutoDELFIA en Julio de 1997, se decidió llevar a cabo un estudio de distribución poblacional, a partir del cual, tomando como referencia el percentil 99,9 se definió un nuevo $V C_{1}$ de 13,0 $\mathrm{N} / \mathrm{ml}$, el cual fue puesto en vigencia en Octubre de 1997. 
Finalmente, la última modificación se introdujo en el mes de Agosto de 2001, y en este caso la misma no respondió a un cambio real en el VC sino a una corrección en la inexactitud inherente al método de medida tal como se estaba trabajando hasta ese momento, ocasionada por las diferencias existentes en la capacidad de absorción entre el papel de filtro utilizado para la recolección de muestras (S\&S \# 903) y el empleado para la preparación de los calibradores provistos en los kits de la línea DELFIA/AutoDELFIA (S\&S \# 2992). Y si bien hasta el momento en que PerkinElmer comenzó a proveer los calibradores impregnados en papel \# 903 se había dado por supuesto que ambos papeles eran absolutamente equivalentes, la capacidad de absorción del papel \# 903 era alrededor de un 17 \% superior a la del \# 2992 tal como demostraron Adam y colaboradores (18), determinando así que al analizar las muestras de sangre de RN colectadas en papel \# 903 con respecto a calibradores impregnados en papel \# 2992 se produjera una sobreestimación de los niveles de TSH, dando lugar a su vez a un desplazamiento de la distribución poblacional hacia valores más altos. En función de esto, los resultados del estudio poblacional que permitieron establecer el $V C_{1}$ en $13,0 \mu \mathrm{U} / \mathrm{ml}$ fueron correctos desde el punto de vista de su exactitud diagnóstica, pero incorrectos desde el punto de vista de su exactitud analítica, y consecuentemente cuando PerkinElmer comenzó a proveer calibradores preparados en papel \# 903, espontáneamente se produjo una corrección en la inexactitud de la medición, y la distribución poblacional se desplazó hacia valores más bajos, resultando necesario modificar los VC en una magnitud equivalente a fin de poder mantener el percentil 99,9 como criterio de definición del mismo. De este modo, el $V C_{1}$ y el $V C_{2}$ quedaron definidos en 11,0 y $25,0 \mu \mathrm{U} / \mathrm{ml}$ respectivamente.

Con posterioridad a esta modificación, y a efectos de reconfirmar los VC antes mencionados se procedió a corroborar periódicamente los mismos a través de nuevos estudios poblacionales, de los cuales a continuación se presentan los resultados de uno de ellos. En dicho estudio, se evaluó una población de 454.494 RN sanos y 486 RN afectados cuyas distribuciones se presentan en las Figuras 134 y 135 , observándose en la primera de estas dos figuras que el percentil 99,9 
establecido como criterio para la definición de $V C_{1}$ se corresponde exactamente con el valor de TSH de $11,0 \mu \mathrm{U} / \mathrm{ml}$ definido previamente (19).

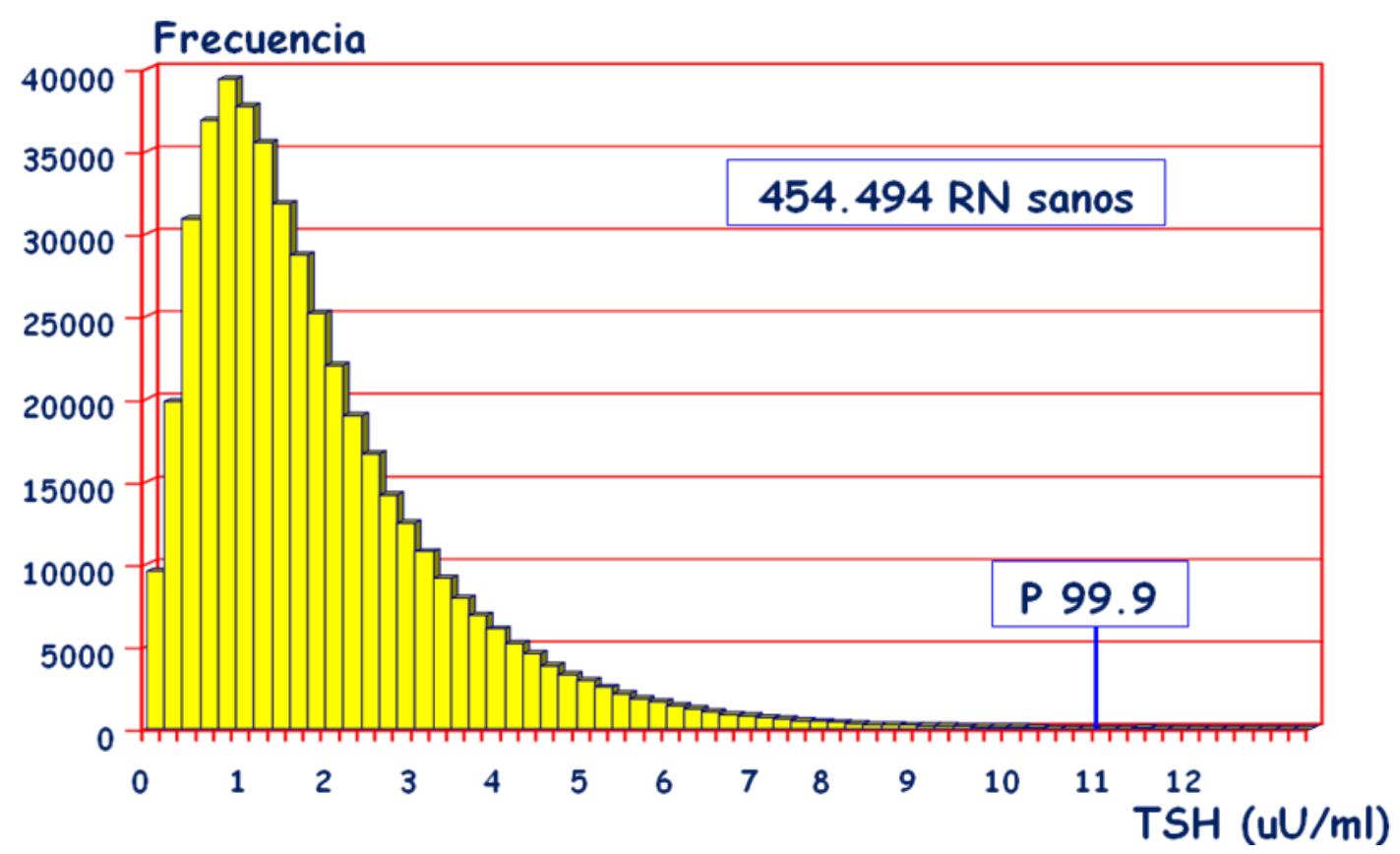

Figura 134. Distribución poblacional de TSH en RN normales.

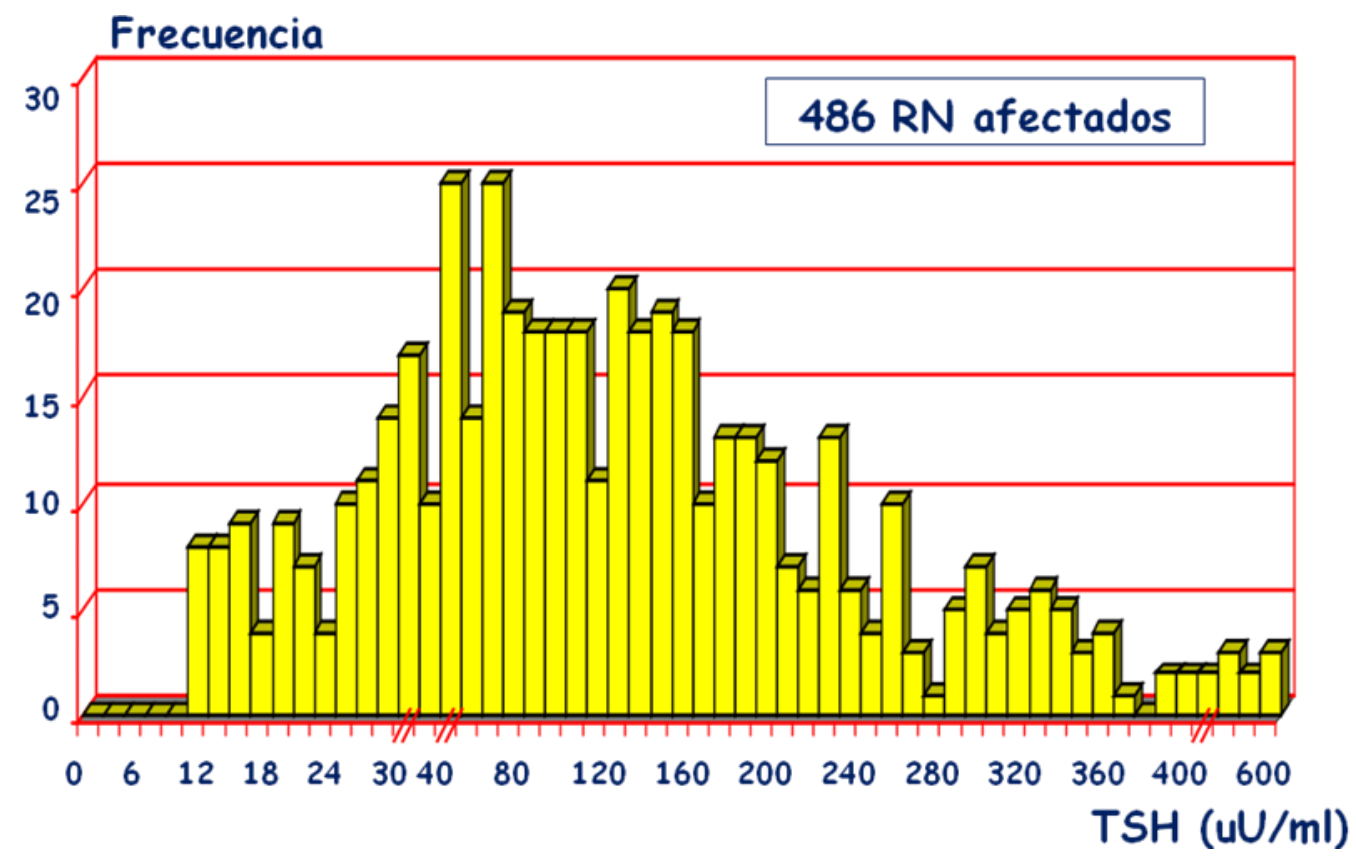

Figura 135. Distribución poblacional de TSH en RN afectados.

- Algoritmo de trabajo: En la Figura 136 se describe el algoritmo de trabajo utilizado en la actualidad para la pesquisa de $H C$, en el cual las unidades de TSH están expresadas en $\mu \mathrm{U} / \mathrm{ml}$. 
De manera equivalente a lo descripto en el caso de PKU, en la pesquisa de HC se definieron 2 rangos de resultados anormales: Resultados Dudosos con 11,0 $\mu \mathrm{U} / \mathrm{ml} \leq \mathrm{TSH}<25,0 \mu \mathrm{U} / \mathrm{ml}$, y Resultados Patológicos con TSH $\geq 25,0 \mu \mathrm{N} / \mathrm{ml}$, los cuales desde el punto de vista de las acciones a poner en marcha a partir de dicho resultado, tienen exactamente las mismas implicancias que en el caso anterior.

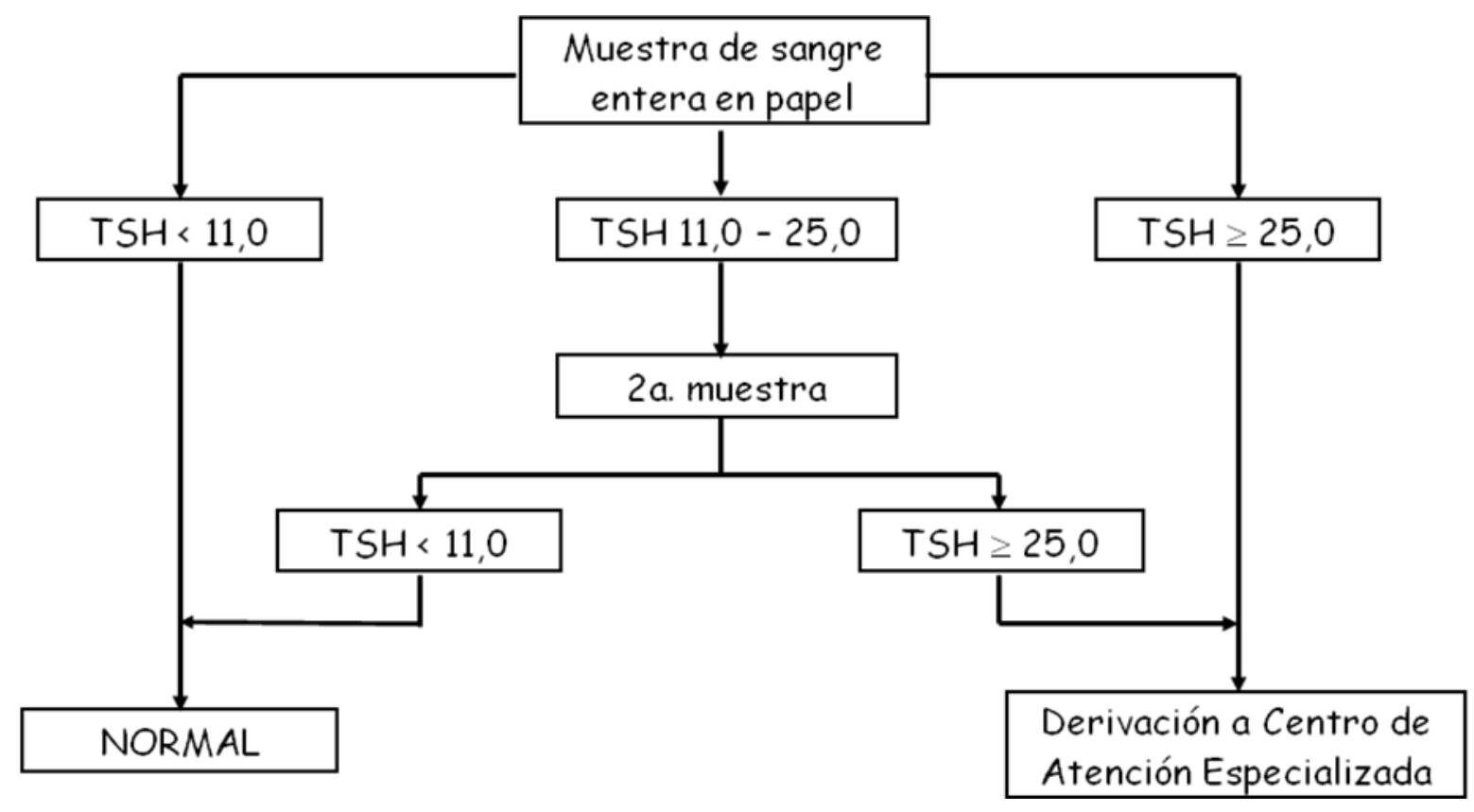

Figura 136. Algoritmo actual de trabajo para la PN de $H C$.

- Resultados: La PN de HC en el Laboratorio de Detección de Errores Congénitos de la FBA siguió un esquema de implementación idéntico al descripto en el Capítulo 8 para PKU, en el sentido de que inicialmente la misma se ejecutó a demanda y bajo la forma de Laboratorio aislado de pesquisa hasta que se concretó la implementación del Prodytec en Abril de 1995. A pesar de esto, durante esos primeros 3 años de trabajo se contó con el respaldo de los Servicios de Endocrinología y de Laboratorio Central del Hospital de Niños "Sor María Ludovica" de La Plata para las instancias de confirmación, diagnóstico, tratamiento y seguimiento de los casos detectados.

En la Figura 137 se muestra la evolución experimentada en el número de RN pesquisados año a año y en la contribución porcentual de la Provincia de Buenos Aires y del Interior del País a dicho número. Por otra parte, en la Figura 138 se 
presentan los principales resultados correspondientes a la secuencia general de pesquisa incluyendo el número total de neonatos pesquisados, el número de RN a los cuales se les solicitó una segunda muestra, el número de RN derivados, el número de casos detectados y la incidencia resultante.

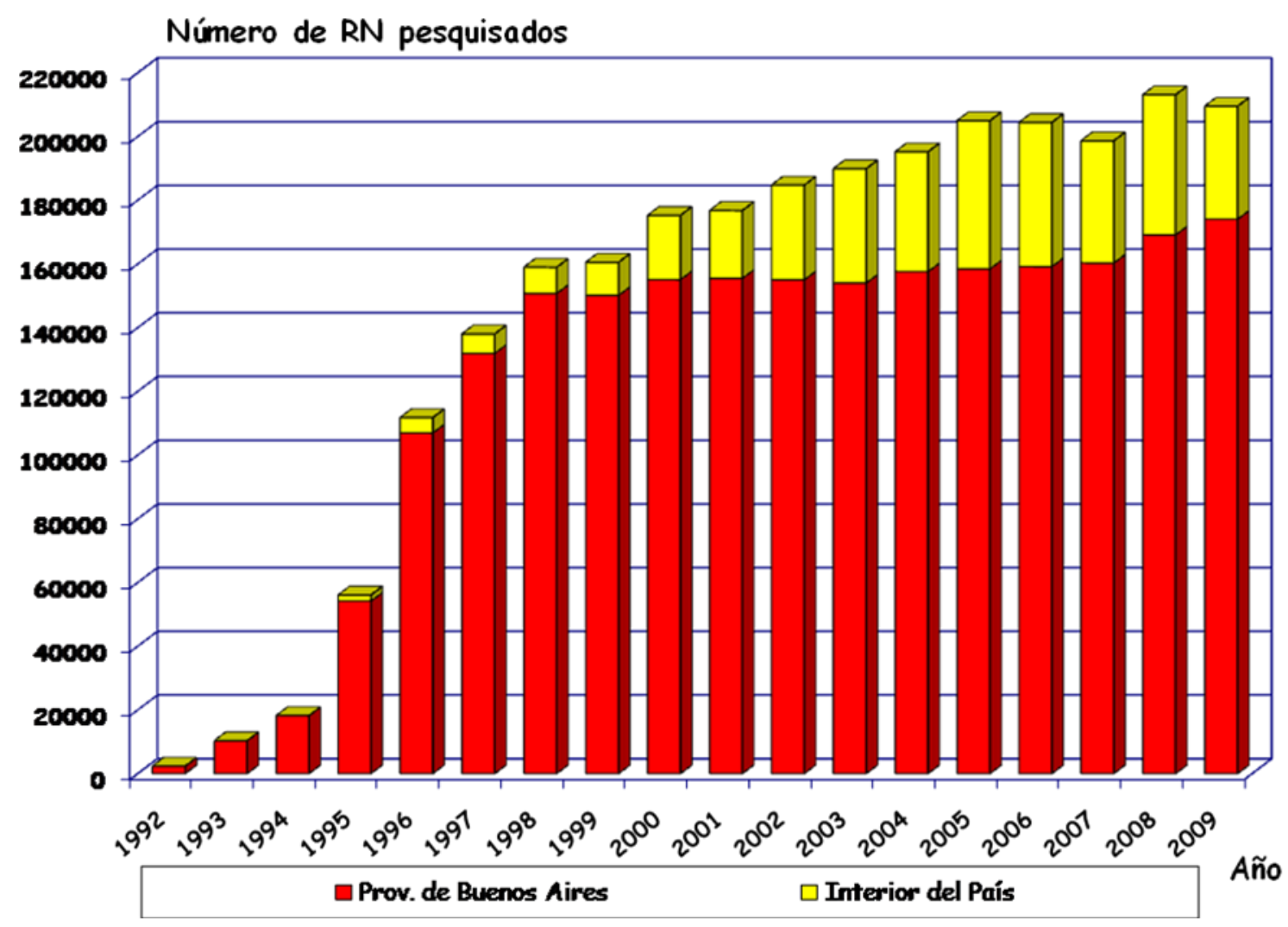

Figura 137. Número de RN pesquisados año a año para $H C$.

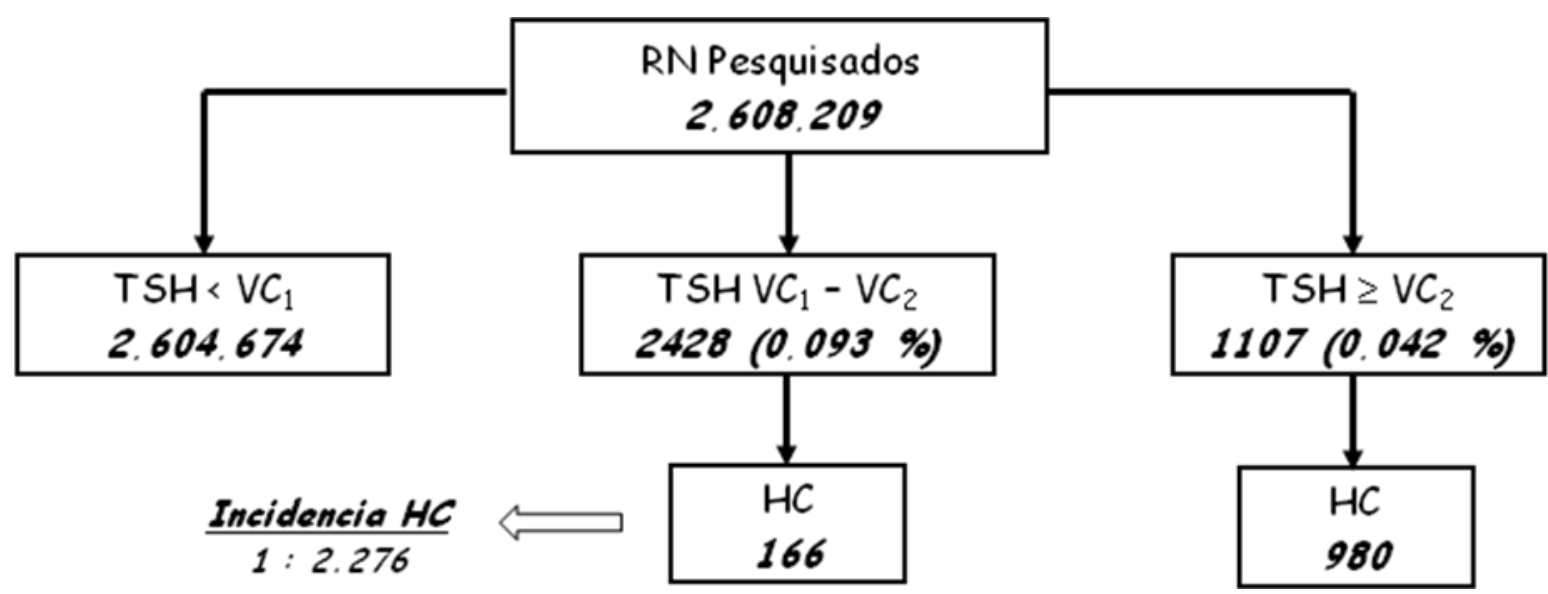

Figura 138. Resultados de la pesquisa de $H C$. 
Con respecto a los resultados presentados en la Figura 137, los mismos admiten un análisis equivalente al presentado para la pesquisa de PKU tanto en lo que hace al crecimiento exponencial observado en los años 1995 y 1996, como a la contribución porcentual del Interior del país y al número de RN pesquisados desde el año 2005 en adelante.

Por otra parte, los resultados presentados en la Figura 132 ponen en evidencia una óptima tasa de recitación general por resultados anormales, la cual no supera el 0,14 \%, encontrándose además que dicho índice se encuentra estabilizado desde 2001 en torno del 0,12\%.

En cuanto a la incidencia del HC, la misma resultó ser de $1: 2.276$ nacidos vivos, presentando un elevado grado de concordancia con las incidencias publicadas internacionalmente y no habiéndose reportado hasta la fecha resultados falsos negativos. Adicionalmente, en la Tabla 55 se presenta la distribución de casos detectados según la provincia de procedencia.

Tabla 55. Distribución de casos detectados por Provincia

\begin{tabular}{|c|c|c|c|}
\hline Provincia & $F Q$ & Provincia & $F Q$ \\
\hline Buenos Aires & 992 & Santiago del Estero & 9 \\
\hline Santa Fe & 49 & Salta & 7 \\
\hline San Juan & 25 & Río Negro & 7 \\
\hline Ciudad de Buenos Aires & 11 & Jujuy & 6 \\
\hline Entre Ríos & 11 & Córdoba & 5 \\
\hline Chubut & 10 & Formosa & 2 \\
\hline Corrientes & 10 & Santa Cruz & 2 \\
\hline
\end{tabular}

Total: 1146

Finalmente, en la Tabla 56 se presentan una serie de parámetros estadísticos que caracterizan al desempeño del sistema de detección, entre los cuales se puede ver que la pesquisa de HC presentó una tasa de recitación por muestras mal colectadas del 0,19\%, un valor inferior al observado en el caso de PKU del 0,27\%. Esta característica responde al hecho de que en aquellos casos en los que el volumen de sangre impregnado en el papel de filtro es insuficiente, pero permite realizar al menos una sola prueba, siempre se da a prioridad a la medida de TSH 
debido a que la incidencia del $H C$ es del orden de 10 veces más alta que la de la PKU. Por otra parte, y a pesar de que en el caso de $H C$ se presentan 2 motivos adicionales de solicitud de segundas muestras que tienen que ver con las muestras colectadas con EDTA y con aquellas muestras en las cuales la hemoglobina queda fijada al papel y no eluye, la tasa general de recitación por causas diferentes de las que corresponden a resultados anormales fue del 0,22 \%, es decir casi 3 veces inferior a la observada en el caso de PKU.

Tabla 56. Parámetros estadísticos de la PN de HC

\begin{tabular}{lc}
\hline \multicolumn{2}{c}{ Tasas de recitación } \\
\hline - Por resultados dudosos & $0,093 \%$ \\
- Por resultados patológicos & $0,042 \%$ \\
- Por recolección inadecuada de muestras & $0,19 \%$ \\
- Por recolección con EDTA & $0,02 \%$ \\
- Por muestras que no eluyen & $0,01 \%$ \\
\hline \multicolumn{2}{c}{ Recuperación de segundas muestras solicitadas } \\
\hline - Por recolección inadecuada de muestras \\
- Total período evaluado \\
- Período 2003-2009 \\
- Por recolección con EDTA \\
- Total período evaluado \\
- Período 2001-2009 \\
- Por muestras que no eluyen
\end{tabular}

Por último, y en lo que respecta a la recuperación de segundas muestras solicitadas por recolección inadecuada y por recolección con EDTA, los datos generales muestran que la misma se encuentra por encima del $50 \%$, con una pauta concreta de un incremento en la recuperación de RN en los últimos 7 a 9 años según el caso, pero aún así dejando un margen importante de RN que a consecuencia de las dificultades que se presentan en el proceso de recolección de muestras pierden la posibilidad de acceder a la pruebas de PN.

\section{BIBLIOGRAFIA}

1. Mayayo E, Santiesteban P, Vicens-Calvet E. Patología Tiroidea Fetal y Neonatal. 
Tratado de Endocrinología Pediátrica y de la Adolescencia. Argente J., Carrascosa A. EDIMSA. 647-700, 1999.

2. Grüters A, Krude H. Update on the Management of Congenital Hypothyroidism. Horm Res 68 (suppl. 5), 107-11, 2007.

3. American Academy of Pediatrics, Susan Rose, and the Section on Endocrinology and Committee on Genetics, American Thyroid Association, Rosalind Brown, and the Public Health Committee and Lawson Wilkins Pediatric Endocrine Society. "Update of Newborn Screening and Therapy for Congenital Hypothyroidism". Pediatr 117, 2290-2303, 2006.

4. Santucci Z, Ansaldi M, Pattin J, Spécola N, Apezteguía M y BorrajoG. "Programa de Pesquisa Neonatal de Hipotiroidismo Congénito de la Provincia de Buenos Aires". Arch Argent Pediatr 100, 456-67, 2002.

5. González V, Santucci Z, Pattin J, Apezteguía M y Borrajo G. "Programa de Pesquisa Neonatal de Hipotiroidismo Congénito de la Provincia de Buenos Aires: 1.377.455 Niños Evaluados en Diez Años de Experiencia". Arch Argent Pediatr 105, 390-7, 2007.

6. Borrajo G. "Newborn Screening in Latin America at the Beginning of the 21st Century. J Inherit Metab Dis 30, 466-81, 2007.

7. International Atomic Energy Agency. "Congenital Hypothyroidism" en "Screening of Newborns for Congenital Hypothyroidism. Guidance for Developing Programs". International Atomic Energy Agency Ed., Vienna, 11-18, 2005.

8. Borrajo G, Fideleff G, Herzovich V, Testa G. "Hipotiroidismo Congénito: Pesquisa, Confirmación y Seguimiento". Tercer Consenso Argentino Sobre Patologías Endocrinológicas. Rev Argent Endocrinol Metab, 46, 50-4, 2009.

9. Fisher D, Gruter A. "Disorders of the Thyroid in the Newborn and Infant" en "Pediatric Endocrinology". Sperling M, Saunders Elsevier, 204-216, 2008.

10. Bakker B, Bikker $H$, et al. "Two Decades of Screening for Congenital Hypothyroidism in the Netherlands: TPO Gene Mutations in Total Iodide Organification Defects (an Update)". J Clin Endocrinol Metab 85, 3708-12, 2000.

11. Rodrigues $C$, Jorge P et al. "Mutation Screening of the Thyroid Peroxidase Gene in 
a Cohort of 55 Portuguese Patients with Congenital Hypothyroidism. Eur $\mathrm{J}$ Endocrinol 152, 193-8, 2005.

12. Working Group on Neonatal Screening of the European Society for Paediatric Endocrinology. "Revised Guidelines for Neonatal Screening Programmes for Primary Hypothyroidism". Horm Res 42, 49-52, 1999.

13.Grüters A, Jenner A, Krude $H$. "Long-term Consequences of Congenital Hypothyroidism in the Era of Screening Programmes. Best Practice Res Clin Endocrinol Metab 16, 369-82, 2002.

14.LaFranchi S. "Newborn Screening Strategies for Congenital Hypothyroidism: an Update". J Inherit Metab Dis 33 Suppl 2, S225-S233, 2010.

15. Torresani T, Illig R. "Thyrotropin Enzyme-Immunoassay in Dried Blood Spots: $A$ Spectrophptometric Method for Neonatal Thyroid Screening". J Clin Chem Clin Biochem 24, 199-203, 1986.

16. Naruse H, Watanabe N, Harada S. et al. "Necessity of Low Cut Off Level of TSH in Neonatal Hypothyroid Screening". Proceedings of the Third Meeting of the International Society for Neonatal Screening, Boston-USA 1996; 228-231.

17. Cohen A, Dassori A, Zecca S, et al. "Screening TSH Measurements in Neonates with Dyshormonogenesis: The Choice of Increased Recall Rate vs. Increased False Negative". Abstracts of the Third Meeting of the International Society for Neonatal Screening and 12th National Neonatal Screening Symposium. BostonUSA. 1996; 35, O/P 12.

18. Adam BW, Alexander JR, Smith SJ, Chace DH, Loeber JG, Elvers LH and HannonWH. "Recoveries of Phenylalanine from Two Sets of Dried-Blood-Spot Reference Materials: Prediction from Hematocrit, Spot Volume, and Paper Matrix". Clin Chem 46, 126-8, 2000.

19. Borrajo G, Pistaccio L, Gómez F, Di Carlo C, Castillo P y Dietz M. "Definición de Valores de Corte de TSH Empleando Distribuciones Poblacionales de Individuos Normales y Afectados". Libro de Resúmenes "V Congreso Latinoamericano de Errores Innatos del Metabolismo y Pesquisa Neonatal". San José - Costa Rica 2005. 


\section{CAPÍTULO 10}

PESQUISA NEONATAL

$D E$

FIBROSIS QUÍSTICA 



\section{- INTRODUCCIÓN}

La Fibrosis Quística (FQ) es un desorden genético heterogéneo que se transmite con un patrón de herencia autosómico recesivo, causado por un defecto en una proteína involucrada en el transporte de iones cloruros a través de las membranas apicales de células epiteliales denominada CFTR o Regulador de Conductancia de Transmembrana de FQ $(1,2)$.

En la actualidad se conocen más de 1.400 mutaciones que pueden afectar al gen del CFTR, siendo la más frecuente la mutación $\triangle F 508$ que se encuentra presente en promedio en 2/3 de los alelos de FQ a nivel mundial (1-3). En contraposición con esto, del grupo de las restantes mutaciones, solamente 20 de ellas aparecen con una frecuencia individual superior al $1 \%$, mientras que el resto son muy raras 0 , en algunos casos, propias de un determinado grupo poblacional $(1,3)$.

Dada la localización del CFTR, el cuadro de la enfermedad afecta diversos órganos y tejidos con función exócrina como pulmón, vías aéreas superiores, páncreas, tracto gastrointestinal, árbol hepatobiliar, útero, vasos deferentes y glándulas sudoríparas, de manera tal que la FQ es considerada una exocrinosis (2).

Clínicamente, la enfermedad se caracteriza por la triada enfermedad pulmonar crónica y recurrente, insuficiencia pancreática exócrina e incremento de electrolitos en el sudor (4), y se manifiesta con una incidencia aproximada de $1: 2.500$ a $1: 6.000$ nacidos vivos. Por otra parte, y además de los signos característicos antes mencionados, los individuos afectados de FQ presentan una mayor incidencia de íleo meconial (15-20\%), deficiencia nutricional, esteatorrea, dolor y distensión abdominal, retraso de crecimiento, bronquitis crónica, obstrucción bronquial, infecciones respiratorias que se hacen cada vez más frecuentes con la edad, afectación pancreática endócrina, azoospermia obstructiva, ausencia bilateral congénita de vasos deferentes $y$, en general, mueren a edad temprana por insuficiencia respiratoria 0 , eventualmente, por disbalance electrolítico y deshidratación (2-4).

En relación a las posibilidades que se presentan para acceder al diagnóstico sintomático temprano, antes de la implementación de la pesquisa la FQ planteaba un serio dilema dada la superposición y confusión de sus síntomas con los correspondien- 
tes a otras enfermedades como Alergias Alimentarias, Enfermedad Celíaca, Asma, Bronquitis y Bronquiolitis (2), hecho que indefectiblemente daba lugar a una necesidad de reiteradas consultas al médico, a la realización de pruebas diagnósticas y hospitalizaciones innecesarias, a un consecuente incremento en los costos de atención de salud, y a la aparición de un severo cuadro de angustia y ansiedad en las familias de los niños afectados.

A diferencia de esto, la posibilidad de acceder a un diagnóstico precoz y a la implementación de un tratamiento apropiado en forma oportuna a través de la PN permite reducir tanto la extensión y severidad de la morbilidad como la tasa de mortalidad temprana asociados a la enfermedad, ofreciéndole a los individuos afectados la posibilidad de un diagnóstico temprano, una mejor calidad de vida con una evidente mejoría en el crecimiento, desarrollo cognitivo y expectativa de vida, y la posibilidad de acceder a la mejor situación para el consejo genético y una apropiada planificación familiar (5).

En cuanto al tratamiento de la enfermedad, el mismo se basa en la corrección de la insuficiencia pancreática exócrina mediante el reemplazo enzimático, en la reversión de las deficiencias nutricionales secundarias y vitamínicas a través de la administración de suplementos, en el tratamiento de la enfermedad pulmonar obstructiva mediante fisioterapia y drenaje postural, y en la prevención, control y tratamiento de las infecciones pulmonares secundarias a través de la administración de antibióticos, antiinflamatorios, broncodilatadores y agentes mucolíticos, empleando para esto la terapia inhalatoria $(1,2)$.

En lo que respecta a la implementación de la PN, el marcador de elección es la Tripsina Inmunorreactiva (IRT) (5) la cual se encuentra aumentada en la sangre de los individuos afectados a consecuencia del bloqueo que sufren los ductos pancreáticos a causa de la acumulación de las secreciones viscosas características de la enfermedad $(4,6)$. Sin embargo, la medida de IRT en una única muestra de sangre no resulta apropiada debido a que presenta una muy baja especificidad y valor predictivo positivo, por lo cual ha sido necesario diseñar diferentes estrategias de detección en 2 pasos, las cuales en todos los casos utilizan la medida de IRT como prueba inicial. 
De este modo, las más utilizadas son las estrategias IRT/IRT, IRT/DNA $(5,7)$ e IRT/PAP (Proteína Asociada a Pancreatitis) (8), las cuales en la práctica presentan diferentes características de performance, quedando sujeta la elección de una u otra a determinados factores como son el propósito establecido como objetivo del Programa, la composición étnica de la población sobre la cual se ha de trabajar, la frecuencia y distribución de las mutaciones que afectan al gen del CFTR, la complejidad del Laboratorio de pesquisa, la disponibilidad de personal idóneo para la realización de las pruebas, y el presupuesto que se disponga para implementar dichas estrategias (5).

Un dato de vital importancia para mencionar en relación a la pesquisa es que a diferencia de lo que ocurre en el caso de PKU e HC, los métodos de medida de IRT carecen de la robustez que caracteriza a los métodos de medida de Phe y TSH, razón por la cual los mismos quedan sujetos a una importante variabilidad analítica que puede dar lugar tanto a resultados falsos positivos como falsos negativos; y sumado a esto, la IRT no resulta ser un analito tan estable en DBS como aquellos, por lo cual las muestras deben ser procesadas indefectiblemente dentro de los 15 días de recolectadas puesto que en caso contrario un resultado normal no permitirá descartar la patología debido al riesgo de que se presenten resultados falsos negativos $(1,7,9)$.

Adicionalmente las propias características de la enfermedad determinan que la variabilidad biológica individual juegue un papel no menor -fundamentalmente debido a que no todas las mutaciones en el gen del CFTR resultan en niveles elevados de IRT-, dejando abierta la posibilidad a que se presenten resultados falsos negativos (2).

Por todos estos motivos debe quedar claramente establecido que la PN de FQ no permite asegurar la detección del 100 \% de los casos, y por lo tanto todo niño con síntomas sugestivos de la enfermedad, aunque tenga un resultado de pesquisa normal, debe ser referido al Test del Sudor para confirmar o descartar la patología.

En tal sentido también resulta importante mencionar que a efectos de minimizar esta variabilidad biológica se debe tener en cuenta que aquellos RN que se presentan con íleo meconial poseen una probabilidad superior al 30\% de resultados falsos negativos (3), por lo cual todo RN con esta manifestación debe ser referido 
directamente al Test del Sudor independientemente del resultado de la pesquisa (5). Sumado a esto, también se debe recordar que en los individuos fibroquísticos la IRT disminuye en forma progresiva a valores normales aproximadamente a partir de los 30 días de vida a consecuencia de la sustitución paulatina del tejido pancreático funcional por tejido fibroso y graso $(3,7)$, por lo cual en caso de que la pesquisa no se haya realizado dentro de los tiempos recomendados la misma no podrá llevarse a cabo más allá de los 30 días de vida $(1,6,7)$.

Finalmente, y en relación a la confirmación diagnóstica, el Test del Sudor por iontoforesis con pilocarpina continúa siendo el "estándar de oro", pudiendo recurrirse también a estudios moleculares y a la medida de potenciales transepiteliales nasales como herramientas complementarias (3), aunque siempre tomando en consideración que las pruebas de biología molecular pueden dar lugar a situaciones de indefinición debido a la presencia de mutaciones desconocidas o poco frecuentes.

Para concluir con esta descripción general, en la Tabla 57 se presentan los criterios que se deben cumplir para confirmar la presencia de la patología.

Tabla 57. Criterios para la confirmación del diagnóstico de FQ

- Presencia de 1 o más características fenotípicas de la enfermedad, o

- Antecedentes de un hermano afectado, 0

- Resultado positivo en las pruebas de pesquisa neonatal, $y$

- Test del sudor anormal en 2 o más ocasiones, 0

- Identificación de 2 mutaciones del CFTR, o

- Demostración de diferencia de potencial transepitelial nasal anormal

\section{Pesquisa Neonatal}

- Período de trabajo evaluado: Julio 1995 - Diciembre 2009.

- Estrategia de trabajo: dadas las características del Laboratorio y los métodos disponibles se decidió utilizar la estrategia IRT/IRT, procediéndose a realizar la confirmación mediante la realización del Test del Sudor.

- Métodos: en la Tabla 58 se presentan los diferentes métodos utilizados en la PN de FQ: 
Tabla 58. Métodos utilizados en la PN de FQ

\begin{tabular}{lll}
\hline Período & & \multicolumn{1}{c}{ Método } \\
\cline { 1 - 1 } & $\begin{array}{l}\text { DELFIA Neonatal IRT -Wallac Oy. } \\
\text { Finlandia. }\end{array}$ \\
& AutoDELFIA Neonatal IRT - PerkinElmer. \\
& Finlandia.
\end{tabular}

- Inmunoensayo Fluorométrico a Tiempo Resuelto DELFIA Neonatal IRT, de Wallac Oy:

Fundamento: la IRT presente en DBS es eluida del papel de filtro e incubada con un buffer conteniendo anticuerpos monoclonales anti-IRT conjugados con $\mathrm{Eu}^{+3}$ en pocillos recubiertos con anticuerpos monoclonales anti-IRT dirigidos contra un determinante antigénico diferente al anterior. Después de remover los discos de papel y de lavar los pocillos se adiciona una solución intensificadora que disocia el $\mathrm{Eu}^{+3}$ de su unión al anticuerpo y forma un quelato fluorescente que se cuantifica en un Fluorómetro a Tiempo Resuelto, cuya intensidad de fluorescencia es proporcional a la concentración de IRT en la muestra (Figura 139).

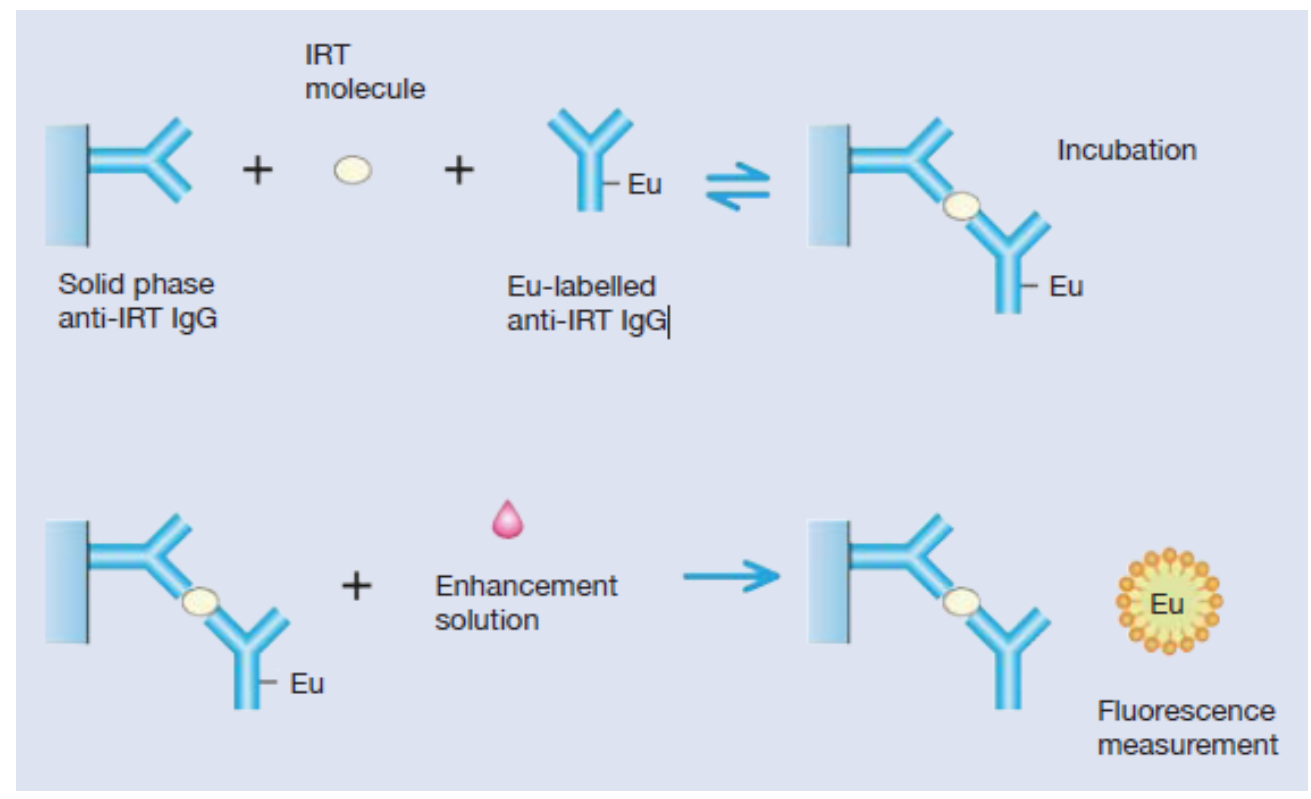

Figura 139. Método DELFIA para la medida de IRT.

En cuanto a las condiciones de uso del método DELFIA, el mismo fue utilizado siguiendo el protocolo descripto por el fabricante y trabajando con el 
equipamiento modular -dispensador, agitador, lavador, removedor y lectorprevisto para tal fin, ya descripto en el Capítulo 3.

- Inmunoensayo Fluorométrico a Tiempo Resuelto AutoDELFIA Neonatal IRT, de PerkinElmer:

Fundamento: el principio analítico de este método es el mismo que el descripto para el método DELFIA Neonatal hTSH, con la diferencia de que en este caso el procedimiento de ensayo se lleva a cabo en forma completamente automatizada, empleando un autoanalizador AutoDELFIA de PerkinElmer (ver Figura 61 - Página 161).

En lo que respecta a las condiciones de uso del método AutoDELFIA, el mismo fue utilizado siguiendo el protocolo descripto por el fabricante.

- Condiciones para la recolección de muestras: a largo de todo el período evaluado se fijó el tiempo recomendado para la recolección de muestras entre las 24 horas y el $7^{\circ}$ día de vida, poniendo un especial énfasis en los siguientes aspectos:

a) en la importancia de que las muestras de sangre fueran remitidas al Laboratorio inmediatamente después de la recolección a fin de que pudieran ser procesadas antes de los 15 días a contar a partir del momento en que se colectaron las mismas (9)

b) en que la recolección de las muestras en todos los casos se llevara a cabo antes de los 30 días de vida del RN, y

c) en las situaciones especiales que podían conducir a resultados falsos negativos, como es el caso de los RN que se presentan con íleo meconial.

- Control de Calidad: El control de calidad de los métodos utilizados en la PN de FQ se llevó a cabo mediante la implementación de un estricto Sistema de Control de Calidad Interno y mediante la participación en 4 Programas diferentes de Evaluación Externa de Calidad (EEC):

- Control de Calidad Interno: Para la implementación del Sistema de Control de Calidad Interno se utilizaron materiales de control de diferentes procedencias, entre los que se pueden citar los provistos en los kits comerciales DELFIA y AutoDELFIA $\left(^{*}\right)$, aquellos preparados en nuestro propio Laboratorio a partir de 
sueros de individuos con pancreatitis y los provistos por Programas de EEC como el NSQAP-CDC a través de su componente Quality Control (*).

NOTA: los materiales de control marcados con $\left(^{*}\right)$ son los que se encuentran en uso en la actualidad.

- Evaluación Externa de Calidad: a continuación se listan los Programas de EEC en los cuales se participó en el período evaluado.

- IRT - International Quality Assurance Scheme. Caen - Francia, desde Mayo de 1995 hasta Julio de 2008 (programa discontinuado por sus propios organizadores).

- Newborn Screening Quality Assurance Program - Human Genetic Society for Australasia (NSQAP-HGSA). Auckland - Nueva Zelanda, desde Noviembre de 1996 hasta Enero de 2003 (programa discontinuado por sus propios organizadores).

- Newborn Screening Quality Assurance Program. Centers for Disease Control and Prevention (NSQAP-CDC). Atlanta - EE.UU., desde Enero de 2004 hasta la fecha.

- Programa de Evaluación Externa de Calidad para Pesquisa Neonatal (PEEC-PN).

Fundación Bioquímica Argentina. La Plata - Argentina, desde Junio de 2008 hasta la fecha.

- Valores de Corte: en la Tabla 59 se presentan los diferentes VC utilizados en la $P N$ de $F Q$ en el período evaluado, y a continuación se presenta una discusión de los mismos:

Tabla 59. Valores de corte utilizados en la PN de FQ

\begin{tabular}{lcccc}
\hline \multicolumn{1}{c}{ Período } & & $V C_{1}$ & & $V C_{2}$ \\
\cline { 1 - 1 } Jul/1995 - Ago/1996 & & $70,0 \mathrm{ng} / \mathrm{ml}$ & & $120,0 \mathrm{ng} / \mathrm{ml}$ \\
Jun/2001 - Ene/2002 & & $70,0 \mathrm{ng} / \mathrm{ml}$ & & $120,0 \mathrm{ng} / \mathrm{ml}$ \\
Feb/2002 - Dic/2009 & & $70,0 \mathrm{ng} / \mathrm{ml}$ & & $250,0 \mathrm{ng} / \mathrm{ml}$ \\
\hline
\end{tabular}

A diferencia de lo ocurrido con las pesquisas de PKU e HC en las cuales los VC iniciales fueron definidos tomando como referencia las experiencias de otros programas, en el caso de la pesquisa de FQ dicho VC fue establecido a partir de 
un estudio poblacional fijando como punto de corte el percentil 99,5.

Por otra parte, y a pesar de que en este caso desde el comienzo se definió un segundo $V C\left(V C_{2}\right)$ que permitía clasificar a los resultados como "Dudosos" o "Patológicos", el mismo no tenía ningún tipo de influencia en cuanto a las acciones que debían implementarse a partir de la obtención de un resultado anormal en la pesquisa inicial, puesto que en todos los casos la decisión consistió en solicitar la recolección de una segunda muestra colectada en papel de filtro para repetir la medida de IRT.

Tal como se puede visualizar en la Tabla 59, y a pesar de que el desempeño del método de medida de IRT se caracterizó por mostrar un cierto grado de inestabilidad lote a lote a lo largo del tiempo presentando consecuentemente variaciones permanentes en su especificidad, los cambios experimentados en los VC fueron mínimos.

El primero de ellos se produjo en Septiembre de 1996, y consistió en un incremento del $V C_{1}$ de 70,0 a $80,0 \mathrm{ng} / \mathrm{ml}$, en respuesta al incremento sostenido que se había experimentado en la tasa de recitación por resultados anormales, la cual prácticamente había llegado a duplicarse con respecto al valor previsto de acuerdo al estudio poblacional, fundamentalmente a expensas de RN con niveles de IRT sólo ligeramente aumentados por encima de $70,0 \mathrm{ng} / \mathrm{ml}$.

Este VC se mantuvo en uso durante prácticamente 5 años, hasta que a partir de la introducción de la metodología AutoDELFIA en Agosto de 2000 se puso en evidencia una marcada disminución en la tasa de recitación por resultados anormales, la cual en promedio llegó a ser del 0,27 \%. En función de esto, se decidió hacer un nuevo estudio poblacional una vez que se dispuso de una cantidad de RN suficientes como para que los resultados del mismo fueran representativos de la realidad, y el $V C_{1}$ volvió ajustarse en $70,0 \mathrm{ng} / \mathrm{ml}$.

En cuanto a la última modificación, la misma fue sólo de forma y no de fondo, y consistió en llevar el $V C_{2}$ de $120,0 \mathrm{ng} / \mathrm{ml}$ a $250,0 \mathrm{ng} / \mathrm{ml}$. El mencionado cambio fue introducido solamente con la finalidad de disminuir el impacto que producía el informe de resultados que indicaba un resultado "patológico", fundamentalmente 
tratando de mantener esa denominación casi con exclusividad para aquellos casos en los que la probabilidad de que la patología se confirme es muy alta.

- Algoritmo de trabajo: En la Figura 140 se describe el algoritmo de trabajo utilizado en la actualidad, en el cual las unidades de IRT están expresadas en $\mathrm{ng} / \mathrm{ml}$.

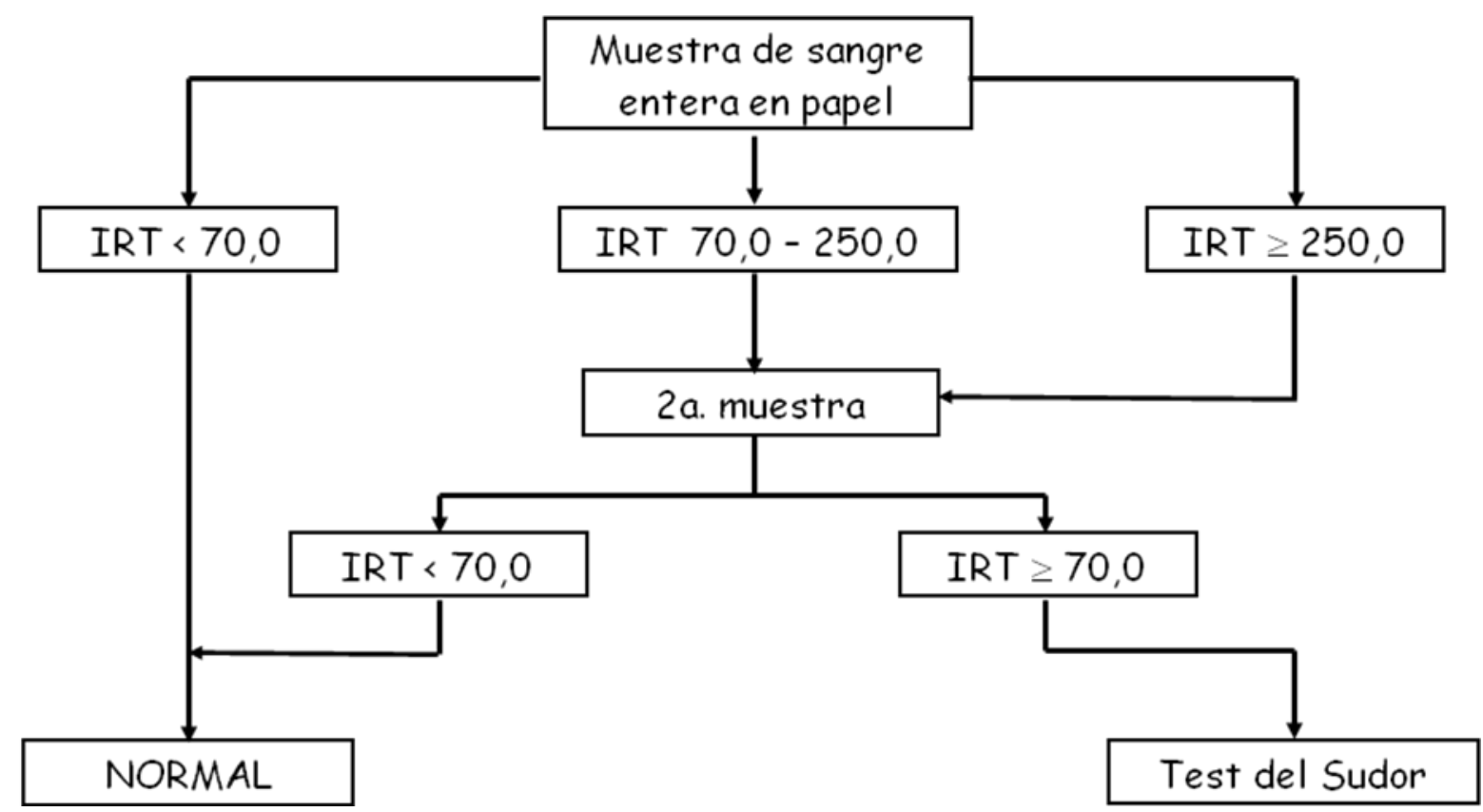

Figura 140. Algoritmo actual de trabajo para la PN de FQ.

- Resultados: La implementación de la PN de FQ en el Laboratorio de Detección de Errores Congénitos de la FBA tuvo la particularidad de que se concretó apenas unos meses después de que se sancionara la Ley Nacional 24438/94 que establece la obligatoriedad de la realización de dicha pesquisa. Sin embargo, el hecho de que la mencionada Ley, al igual que la Ley Nacional 26279/07 que reemplazó a la legislaciones vigentes hasta ese momento en materia de PN, no tuviera alcance a nivel de la Provincia de Buenos Aires determinó que la pesquisa se realizara exclusivamente a demanda y sin contar con una estructura real de Programa, más allá de lo cual tanto el Servicio de Neumonología como el Servicio de Laboratorio Central del Hospital de Niños "Sor María Ludovica" de La Plata brindaron el respaldo necesario para las instancias de confirmación, diagnóstico, tratamiento y seguimiento de algunos de los casos detectados. 
En este punto resulta necesario aclarar que si bien a lo largo de todo el período evaluado como parte de este análisis, la realización de la PN de FQ en el ámbito de la Provincia de Buenos Aires se realizó en forma no obligatoria, en Diciembre de 2008 se sancionó la Ley Provincial 13905 que determina la obligatoriedad de dicha pesquisa junto a la de otras 6 enfermedades congénitas. Independientemente de esto, y a consecuencia de que dicha Ley aún no se reglamentó, a lo largo del año 2009 la pesquisa de FQ continuó ejecutándose bajo la misma modalidad que durante los años previos.

En la Figura 141 se muestra la evolución experimentada en el número de RN pesquisados para FQ en el período 1995-2009, mientras que en la Figura 142 se presentan los principales resultados correspondientes a la secuencia general de pesquisa incluyendo el número total de neonatos pesquisados, el número de RN a los cuales se les solicitó una segunda muestra, el número de RN a los cuales se les indicó la realización del test del sudor, el número de casos confirmados, el número de falsos negativos en RN con íleo meconial (IM), el número de falsos negativos reales del sistema de detección y la incidencia resultante.

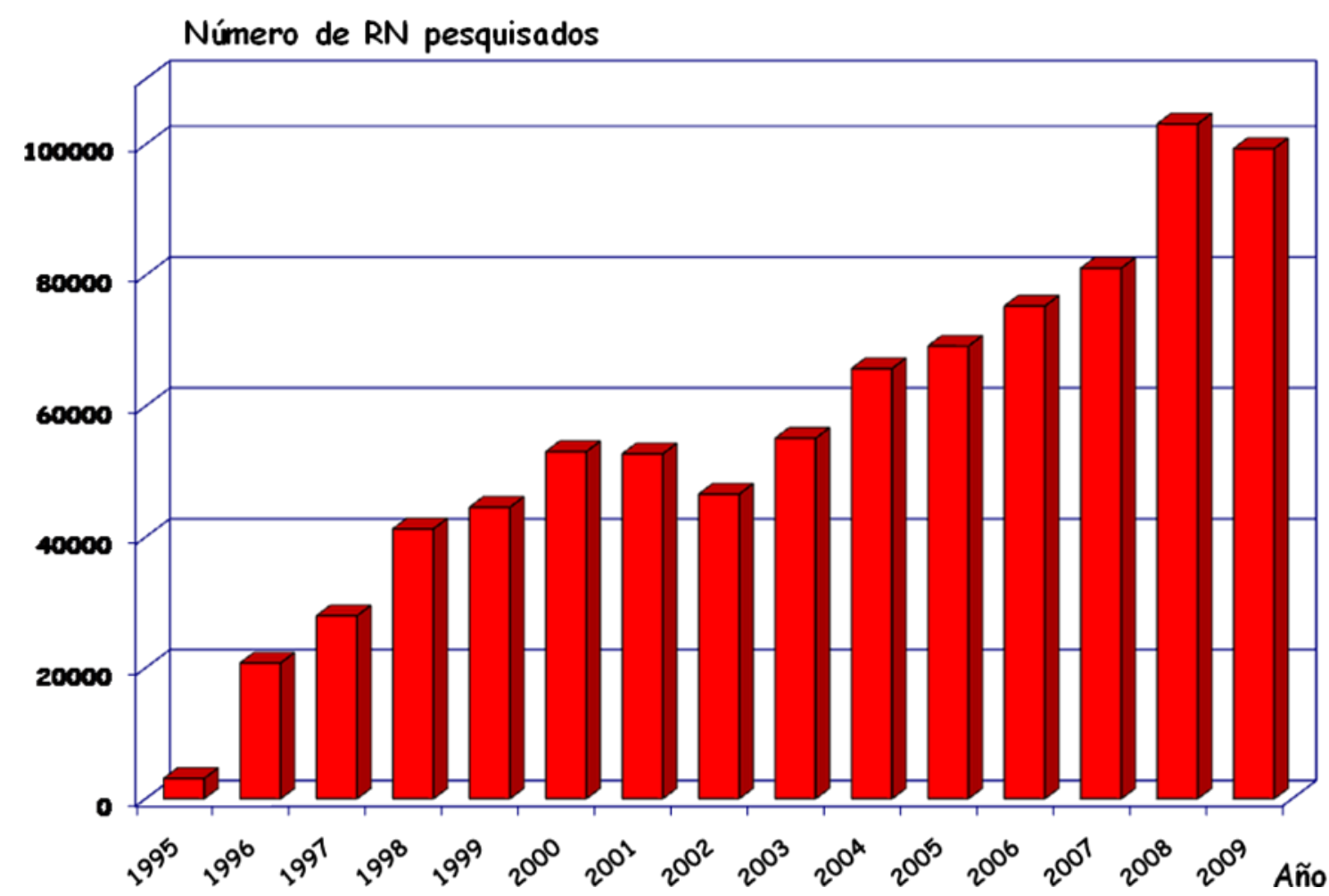

Figura 141. Número de RN pesquisados año a año para $F Q$. 
En cuanto a la información brindada en la Figura 141, existen varios hallazgos particulares para destacar. En primer lugar, que el número de RN pesquisados a lo largo de los primeros años de trabajo experimentó un crecimiento muy superior al observado con otras patologías también pesquisadas a demanda en sus instancias iniciales, hecho atribuible a la influencia indirecta ejercida por la Ley Nacional 24438/94 que determinó un crecimiento sostenido hasta el año 2002, año en que, a consecuencia de la crisis económica nacional y del colapso que sufrió el sistema de salud en general, se produjo una disminución en el número de RN pesquisados. De allí en más nuevamente se experimentó un crecimiento sostenido, con un nuevo punto de inflexión en el año 2008 que llevó a superar el número de 100.000 RN pesquisados al año, sustentado ahora en la influencia indirecta de la sanción de la Ley Nacional 26279/07. Por último se debe mencionar que la caída en el número de RN pesquisados en 2009 respondió al hecho de que algunas provincias, como Chubut y Santa Fe ( $2^{\circ}$ Circunscripción y Municipalidad de Rosario), que realizaban las pruebas de pesquisa de sus Hospitales públicos a través de la FBA comenzaron a resolverla por su propia cuenta a partir de la implementación del Programa $\mathrm{Na-}$ cional de Fortalecimiento de la Detección Precoz de Enfermedades Congénitas del Ministerio de Salud de la Nación, tal como ya fuera mencionado en el Capítulo 8.

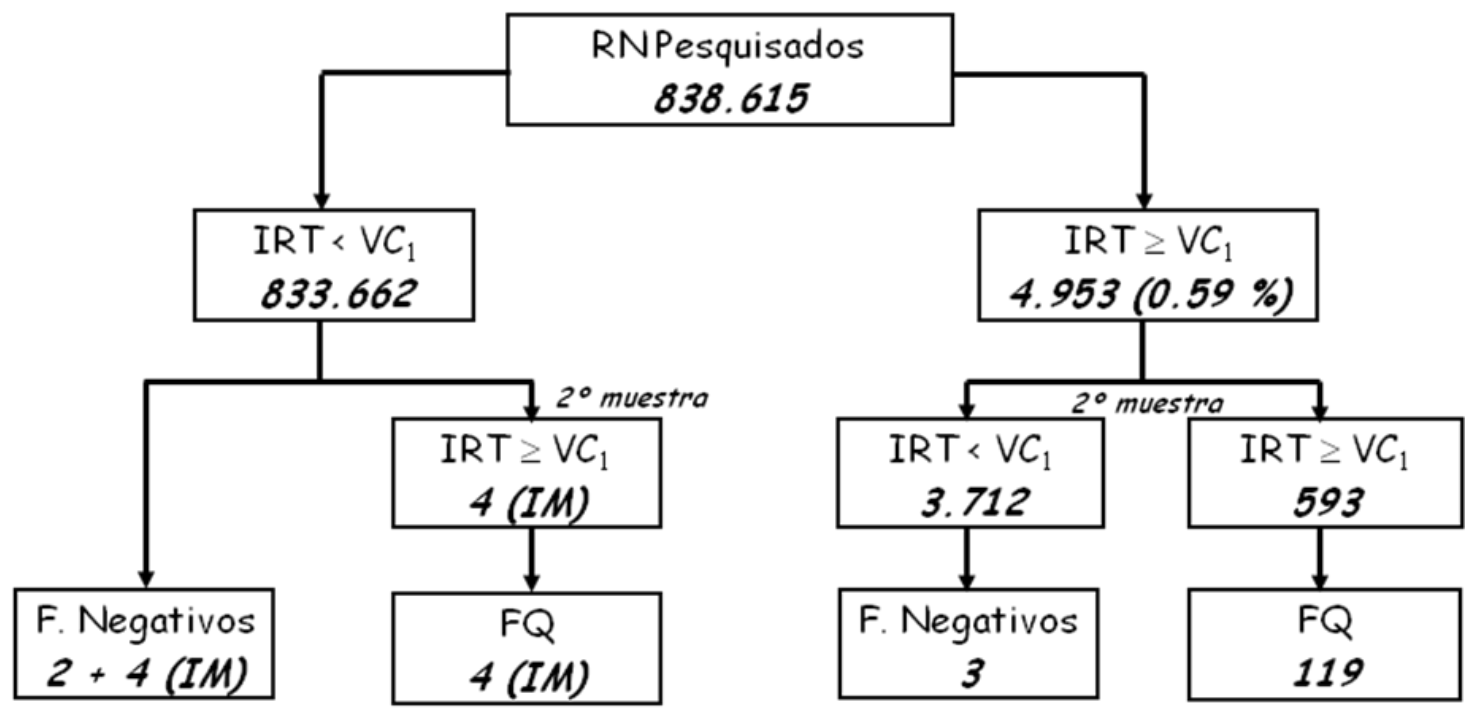

$\Longrightarrow$ Incidencia $F Q$

$1: 6.353$

Figura 142. Resultados de la pesquisa de FQ. 
En lo que respecta a la secuencia de pesquisa presentada en la Figura 142, el dato más importante que surge de la misma es el hecho de que de los 132 casos de FQ que fueron confirmados, 13 de ellos correspondieron a resultados falsos negativos. Esta es una situación que de antemano se conoce que puede presentarse en la práctica debido tanto a la variabilidad analítica que presentan los métodos de medida como a la variabilidad biológica individual observada en vinculación con las diferentes mutaciones que afectan al gen del CFTR.

Sin embargo, y más allá de que 13 resultados falsos negativos sobre 132 casos totales detectados implica una sensibilidad que apenas supera el $90 \%$, este parámetro debe calcularse excluyendo los RN que se presentaron con un cuadro de IM, porque como es sabido esta manifestación clínica se asocia con una elevada probabilidad de resultados falsos negativos, y en consecuencia la presencia de IM debe ser un signo de alerta para el pediatra quien, independientemente de la realización de las pruebas de pesquisa y de los resultados que se obtengan en la misma, debe indicar la realización del Test del Sudor. De acuerdo a esto, y según la información presentada en la Figura 142, se puede ver que 8 de los 13 resultados falsos negativos correspondieron a RN que se presentaron con IM, los cuales en todos los casos tuvieron niveles normales de IRT en la primera muestra, más allá de lo cual a 5 de ellos se les solicitó una segunda muestra una vez resuelto el cuadro de IM, encontrándose niveles elevados de IRT en 4 de ellos.

De este modo, se puede considerar que los falsos negativos reales de la estrategia de pesquisa utilizada fueron 5, determinando así que la sensibilidad real del sistema de detección es del 96,0 \% (119/124), un valor acorde con lo descripto bibliográficamente para la estrategia IRT/IRT.

El análisis detallado de estos 5 falsos negativos pone en evidencia que 2 de ellos se presentaron en la primera muestra, mientras que los 3 restantes tuvieron una primera muestra con IRT elevada, presentándose el resultado falso negativo recién en la segunda. En lo que respecta a las causas de estos falsos resultados, en 3 de ellos no fue posible hallar una razón que permitiera explicar el nivel normal de IRT, mientras que de los 2 restantes, en uno de ellos la segunda muestra 
ingresó al laboratorio a los 21 días desde que fue colectada, con lo cual la inestabilidad de la IRT más allá de los 15 días de dicha recolección puede haber determinado que se encontraran valores normales de dicho analito; en tanto en el segundo caso el RN tenía exactamente 30 días de vida al momento de la recolección de la segunda muestra, pudiendo ser la causante del resultado normal un estado de insuficiencia pancreática avanzada.

También resulta importante destacar que el último de estos 5 resultados falsos negativos data del mes de Noviembre de 2005, con lo cual la sensibilidad de la estrategia de pesquisa en los últimos 4 años, sobre un total de alrededor de 365.000 neonatos pesquisados, fue del $100 \%$.

Otro hallazgo importante para destacar es la incidencia encontrada para la $F Q$, la cual ha permanecido estable a lo largo de los últimos años en un valor siempre próximo a $1: 6.000$ nacidos vivos, desbaratando así la hipótesis de que la FQ en nuestro medio debía tener una incidencia del orden de $1: 2.500$ nacidos vivos, y que por lo tanto el nivel de subdiagnóstico que se suponía que existía tanto en la era pre-pesquisa como aún hoy día considerando que la cobertura nacional no llega a ser del $100 \%$, es muy inferior a lo que se estimaba. Como dato ilustrativo, en la Tabla 60 se presenta la distribución de casos detectados según la provincia de procedencia.

Tabla 60. Distribución de casos detectados por Provincia

\begin{tabular}{|c|c|c|c|}
\hline Provincia & $F Q$ & Provincia & $F Q$ \\
\hline Buenos Aires & 96 & Chubut & 2 \\
\hline Santa Fe & 12 & Salta & 1 \\
\hline San Juan & 4 & Entre Ríos & 1 \\
\hline Santiago del Estero & 4 & Jujuy & 1 \\
\hline Ciudad de Buenos Aires & 3 & Córdoba & 1 \\
\hline Río Negro & 3 & Mendoza & 1 \\
\hline Corrientes & 2 & Tierra del Fuego & 1 \\
\hline
\end{tabular}

Total: 132

Por último, en la Tabla 61 se presentan una serie de parámetros estadísticos que caracterizan al desempeño del sistema de detección. 
Tabla 61. Parámetros estadísticos de la PN de FQ

\begin{tabular}{lc}
\hline \multicolumn{2}{c}{ Parámetros generales } \\
$\begin{array}{l}\text { - Incidencia } \\
\text { - Sensibilidad diagnóstica }\end{array}$ & $1: 6.353$ \\
- Total período evaluado & $96,0 \%$ \\
- Período 2006-2009 & $100,0 \%$ \\
\hline \multicolumn{2}{c}{ Tasas de recitación } \\
\hline \multicolumn{2}{c}{ - Por resultados anormales } \\
- Por recolección inadecuada de muestras \\
- Por recolección con EDTA \\
- Por muestras que no eluyen \\
\hline \multicolumn{2}{c}{ Recuperación de segundas muestras solicitadas } \\
\hline - Por recolección inadecuada de muestras & $0,30 \%$ \\
- Por recolección con EDTA & $0,03 \%$ \\
- Por muestras que no eluyen & $59,9 \%$ \\
\hline
\end{tabular}

En relación a la información presentada en la Tabla anterior, se debe destacar que, a diferencia de lo observado en el caso de las pesquisas de PKU e HC, las cuales presentan una tasa de recitación por resultados anormales en el rango de valores óptimos, en el caso de la pesquisa de FQ la misma resulta ser el componente más importante de solicitud de segundas muestras, duplicando inclusive a la tasa de recitación por muestras mal colectadas. De este modo, el índice de 0,59 \% hallado para todo el período evaluado indica que aproximadamente 6 de cada 1000 RN debieron ser localizados para llevar a cabo la recolección de una segunda muestra.

Adicionalmente, resulta llamativa la diferencia observada en el porcentaje de cumplimiento de recolección de segundas muestras por recolección inadecuada entre FQ $(71,5 \%)$ y la presentada en Capítulos anteriores para PKU e HC, la cual tomó valores en promedio para todo el período evaluado del 58,0 \%. Dicha diferencia de comportamiento puede atribuirse al hecho de que, dado que la pesquisa de FQ se realiza demanda, la población pesquisada proviene mayoritariamente del sector privado en el cual la localización y recuperación de los RN afectados por estas causas resultó ser un procedimiento más efectivo que en el sector público. 


\section{BIBLIOGRAFIA}

(A) "Consenso Nacional de Fibrosis Quística". Claudio Castaños, Fernando Rentería y Grupo de Consenso. Arch Argent Pediatr, Supl 106, e1-52, 2008.

(B) MMWR. "Newborn Screening for Cystic Fibrosis. Evaluation of Benefits and Risks and Recommedations for State Newborn Screening Programs. Morbidity and Mortality Weekly Report, 53, RR-13, 2004

(C) Wilcken B. "Newborn Screening for Cystic Fibrosis: Its Evolution and a review of the current situation". Screening 2, 43-62, 1993.

(D) Comeau a, Accurso F, White T, Campbell P, Hoffman G, Parad R, Wilfond B et al. "Guidelines for Implementation of Cystic Fibrosis Newborn Screening Programs; Cystic Fibrosis Foundation Workshop Report". Pediatr 119, e495-e518, 2007.

(E) De Boeck K, Wilschanski M, Castellani C, Taylor C, Cuppens H, Dodge J, Sinaasapel M. "Cystic Fibrosis: Terminology and Diagnostic Algorithms". Thorax 61, 627-35, 2006.

(F) Heeley AF and Bangert SK. "The Neonatal Detection of Cystic Fibrosis by Measurement of Immunoreactive Trypsin in Blood". Ann Clin Biochem 29, 361-376, 1992.

(G) Borrajo G. "Pesquisa Neonatal de Fibrosis Quística", en "Fibrosis Quística". Segal E, Fernández A y Rentería F Editores. $1^{a}$ Edición. Editorial Journal. Buenos Aires, 63-77, Cap. 15, 2003

(H) Borrajo G, Adam M, Castillo P, Di Carlo C, Gómez F y Pistaccio L. "¿Es la IRT una Molécula Estable?". Libro de Resúmenes Congreso Nacional Bioquímico CUBRA IV, Tucumán - Argentina, 1997.

(I)Sarles J, Berthézène $P$, Le Louarn $C$, Somma $C$, Perini J, Catheline $M$ et al. "Combining Immunoreactive Trypsinogen and Pancreatitis-Associated Protein Assays, a Method of Newborn Screening for Cystic Fibrosis that Avoids DNA Analysis". J Pediatr 147, 302-5, 2005. 


\section{CAPÍTULO 11}

PESQUISA NEONATAL

$D E$

GALACTOSEMIA 



\section{- INTRODUCCIÓN}

La Galactosemia es un ECM de la Galactosa ( $G a l$ ) que se transmite con un patrón de herencia autosómico recesivo, y que puede originarse en la deficiencia de alguna de las 3 enzimas involucradas en su ruta metabólica principal: Galactokinasa (GAL-K), Galactosa-1-Fosfato Uridil Transferasa (GAL-T) y UDP-Galactosa-4Epimerasa (GAL-E) (1-5).

Tanto desde el punto de vista clínico -debido a la severidad del cuadro que produce-, como de la incidencia con que se presenta -la cual se estima del orden de $1: 25.000$ a $1: 50.000$ nacidos vivos en la población caucásica (2)-, la deficiencia de la enzima GAL-T, conocida como Galactosemia Clásica, resulta ser la de mayor importancia.

Clínicamente la Galactosemia Clásica se trata de una patología que en ausencia de tratamiento produce múltiple afectación de órganos, pudiendo aparecer los primeros síntomas desde fines de la primera semana de vida en adelante. Dichos síntomas comprenden progresivamente rechazo del alimento, vómitos, diarrea, pérdida de peso, hipotonía, letargia, hemólisis, anemia, cataratas, ictericia, hepatoesplenomegalia, insuficiencia hepatocelular, sangrado, disfunción tubular renal, formación de ascitis, cirrosis, retraso mental, edema cerebral, encefalopatía y muerte por sepsis, principalmente a expensas de Escherichia coli (1-5).

En cuanto a las otras dos deficiencias enzimáticas, la deficiencia de GAL-E en su forma severa presenta un cuadro clínico de características similares al anterior, pero posee una incidencia mucho menor que la correspondiente a la forma Clásica; mientras que, a diferencia de las dos anteriores, la deficiencia de GAL-K presenta un cuadro menos severo, caracterizado fundamentalmente por la presencia de cataratas congénitas (4).

En función de estas características, y dadas tanto la severidad del cuadro agudo como la inmediatez con que el mismo se pone de manifiesto después que el niño comienza a ingerir leche conteniendo lactosa, resulta estrictamente necesario que la PN se realice muy tempranamente a efectos de implementar en forma inmediata un tratamiento basado en la restricción dietaria de Galactosa a fin de evitar tanto el 
deterioro progresivo del RN como el riesgo de muerte asociados a la ausencia de tratamiento.

Desde el punto de vista molecular, han sido identificadas más de 180 mutaciones que pueden afectar al gen que codifica para la enzima GAL-T, las cuales se caracterizan por presentar una gran diversidad en cuanto al grado de afectación de la enzima y a la actividad residual de la misma. Este hecho determina que en la práctica sea posible encontrar un espectro continuo de posibilidades que se extiende desde la ausencia absoluta de actividad enzimática como ocurre con la mutación p.Q188R, hasta la presencia de una actividad remanente del $50 \%$ en el caso de mutaciones leves como la mutación p.N314D o variante Duarte de amplia distribución a nivel mundial; pasando por situaciones intermedias como es el caso de mutaciones no tan severas como la p.S135L, propia de poblaciones Afro-Americanas, la cual presenta una actividad residual del $5 \%(1,4,5)$.

Independientemente de esta amplia variedad de mutaciones y de la diversidad de combinaciones que en la práctica pueden presentarse afectando a uno u otro alelo, debe destacarse que el cuadro típico de la Galactosemia Clásica sólo se va a poner de manifiesto cuando la actividad residual de la enzima sea nula, hecho que se da cuando la mutación P.Q188R se presenta en estado homocigota, por lo cual las restantes combinaciones posibles de mutaciones pueden dar lugar a cuadros desde leves a benignos, los cuales habitualmente son agrupados como Deficiencias Parciales de la enzima GAL-T.

Bioquímicamente la Galactosemia Clásica se caracteriza por presentar niveles aumentados de Gal, Gal-1P, Galactitol y Galactonato en sangre y orina, resultando estos metabolitos, y principalmente la Gal-1P y el Galactitol los responsables de la patogenia de la enfermedad.

En lo que respecta a la PN, la misma se puede abordar efectuando tanto la medida de metabolitos aumentados (Gal total) como la medida específica de cada una de las enzimas deficientes. Ambas estrategias de trabajo presentan una serie de ventajas y desventajas tanto desde el punto de vista analítico como diagnóstico (4) que requieren ser evaluadas antes de la implementación de la pesquisa, y a efectos de 
su sistematización, las mismas son presentadas en la Tabla 62.

Tabla 62. Ventajas y desventajas de las estrategias de PN de Galactosemia

\begin{tabular}{|c|c|c|}
\hline Característica & Metabolitos aumentados & Enzimas afectadas \\
\hline $\begin{array}{l}\text { - Ingesta de leche previa } \\
\text { a la toma de muestra }\end{array}$ & Requerida, mínimo 24 hs. & No requerida \\
\hline - Estabilidad & Buena & $\begin{array}{l}\text { Regular, afectada por } \\
\text { altas temperaturas }\end{array}$ \\
\hline - Transfusiones. & $\begin{array}{l}\text { Afectación mínima por } \\
\text { efecto de dilución }\end{array}$ & $\begin{array}{l}\text { Invalida los resultados. } \\
\text { Requiere el recambio de } \\
\text { los GR del donante. }\end{array}$ \\
\hline - Sangre de cordón & No válida & Válida \\
\hline - Alcance & $\begin{array}{l}\text { Detecta las } 3 \text { deficiencias } \\
\text { enzimáticas }\end{array}$ & $\begin{array}{l}\text { Sólo detecta la deficiencia } \\
\text { específica que se analiza }\end{array}$ \\
\hline
\end{tabular}

En cuanto a las pruebas necesarias para la confirmación del diagnóstico, las mismas comprenden la medida específica de las enzimas GAL-T, GAL-E y GAL-K en hemolizados de glóbulos rojos, determinaciones que se han de realizar no solamente en los casos índice sino también en sus padres, y también la medida de Gal-1P en hemolizados de glóbulos rojos. Adicionalmente, y en caso de que se disponga de métodos moleculares, se deberá realizar la búsqueda de las mutaciones causantes de la deficiencia (5).

Finalmente, se debe mencionar que a pesar de que durante muchos años se creyó que la eliminación de la Gal de la dieta era una terapia efectiva para prevenir las complicaciones propias de la Galactosemia a largo plazo, el seguimiento de los pacientes detectados permitió demostrar que, a pesar del tratamiento estricto y de su implementación precoz, los individuos afectados desarrollan síntomas tardíos como retraso mental, trastornos del lenguaje, dispraxia verbal, anormalidades motoras $e$ insuficiencia ovárica, las cuales surgen como consecuencia de un fenómeno de autointoxicación resultante de la producción endógena de Gal a partir del recambio de diversas macromoléculas galactosiladas como cerebrósidos, glicoproteínas y glicolípidos, y también de un proceso adicional de galactosilación deficiente de varias glicoproteínas (1). 


\section{Pesquisa Neonatal}

- Período de trabajo evaluado: Julio 1995 - Diciembre 2009.

- Métodos: en la Tabla 63 se presentan los diferentes métodos utilizados en la PN de Galactosemia y a continuación se describe el fundamento de los mismos:

Tabla 63. Métodos utilizados en la PN de Galactosemia

\begin{tabular}{|c|c|}
\hline Período & Método \\
\hline Jul/1995 - Abr/2000 & Método Enzimático Colorimétrico, Immuchem Galactose \\
\hline & MW Enzyme Assay. ICN Biomedicals, Inc. EE.UU.. \\
\hline May/2000 - Dic/2009 & $\begin{array}{l}\text { Método Enzimático Fluorométrico de desarrollo propio, } \\
\text { basado en el método de Yamaguchi y cols. }\end{array}$ \\
\hline
\end{tabular}

- Método Enzimático Colorimétrico Immuchem Galactose MW Enzyme Assay ICN Biomedicals Inc:

Fundamento: la Gal total presente en muestras de sangre entera colectadas en papel de filtro es eluida con Acido Tricloroacético previa fijación de la hemoglobina y de las proteínas al papel. Luego el eluido se neutraliza e incuba en un primer paso con Fosfatasa Alcalina para liberar la Gal de la Gal-1P presente en la muestra, y posteriormente con una mezcla que contiene Gal-Deshidrogenasa, $\mathrm{NAD}^{+}, \mathrm{PMS}$ (Metosulfato de Fenotiazina) y un sustrato derivado del Nitroblue de Tetrazolium (NBT), para dar lugar a la formación de un producto coloreado derivado del Azul de Formazán (Figura 143) que puede ser cuantificado en un espectrofotómetro UV-Visible a $540 \mathrm{~nm}$, siendo su absorbancia proporcional a la concentración de Gal total presente en la muestra.

- Gal Total $=$ Gal-Libre + Gal-1P

$$
\text { Gal-1P } \stackrel{\text { Fosfatasa Alcalina }}{\longrightarrow} \text { Gal Libre }
$$

Gal-Deshidrogenasa

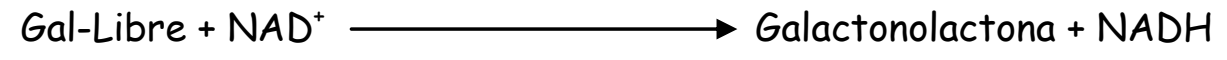

PMS

$\mathrm{NADH}+$ Derivado NBT $\longrightarrow \mathrm{NAD}^{+}+$Derivado Azul de Formazán

Figura 143. Fundamento del Método Enzimático - Colorimétrico de ICN para la medida de Gal. 
A lo largo del período de trabajo correspondiente, este método fue ejecutado siguiendo el protocolo descripto por el fabricante.

- Método Enzimático - Fluorométrico de desarrollo propio: El desarrollo y optimización de éste método, basado en la descripción de Yamaguchi y colaboradores modificado $(6,7)$, fue realizado en el propio Laboratorio de Detección de Errores Congénitos de la FBA.

Fundamento: La Gal total presente en muestras de sangre entera colectadas en papel de filtro es eluida con $\mathrm{H}_{2} \mathrm{O}$ destilada, previa fijación de la hemoglobina y de las proteínas al papel con una mezcla Metanol/Acetona/ $\mathrm{H}_{2} \mathrm{O}$. El eluido se hace reaccionar posteriormente con Fosfatasa Alcalina para liberar la Gal de la Gal-1P presente en la muestra, y luego con Galactosa Deshidrogenasa que actúa específicamente sobre la Gal Libre para dar lugar a la formación de Galactonolactona y NADH, el cual por acción de la enzima Diaforasa transforma el sustrato Resazurina en el producto fluorescente Resorufina (Figura 144) que puede ser cuantificado en un fluorómetro a $\lambda_{E X C / E M}=544 \mathrm{~nm} / 590 \mathrm{~nm}$, siendo su intensidad de fluorescencia proporcional a la concentración de Galactosa Total presente en la muestra.

- Gal Total = Gal Libre + Gal-1P

$$
\text { Gal-1P } \stackrel{\text { Fosfatasa Alcalina }}{\longrightarrow} \text { Gal Libre }
$$

Gal-Deshidrogenasa

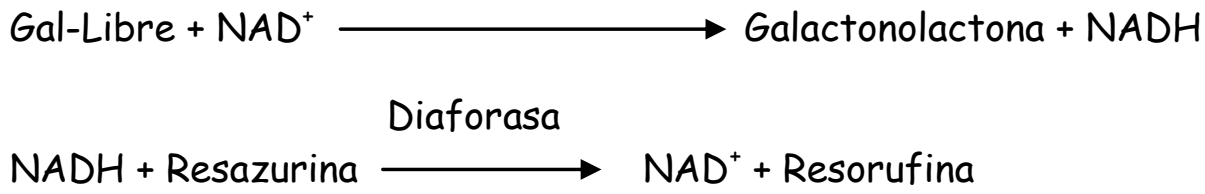

Figura 144. Fundamento del Método Enzimático - Fluorométrico de desarrollo propio para la medida de Gal.

Para el desarrollo del mismo se llevó a cabo la preparación y adecuación de todos los reactivos necesarios, la optimización de los diferentes parámetros de ensayo y se introdujeron algunas modificaciones a la técnica original a fin de lograr fundamentalmente el máximo nivel de automatización posible y la mayor 
eficiencia del método. Las mismas son descriptas a continuación:

- Utilización de microplacas de transferencia de 96 pocillos MultiScreen Membrane Plate modelo MADVN-65 de Millipore (Figura 52 - Página 153), para automatizar el proceso de transferencia de eluidos empleando el dispositivo Vacuum Manifold de Millipore.

- Preparación y adecuación de los diferentes reactivos de acuerdo a las drogas madre disponibles en nuestro medio.

- Modificación del tiempo y la temperatura de fijación de 30 minutos a $37^{\circ} \mathrm{C}$ a una noche a temperatura ambiente, a efectos de poder trabajar con un protocolo "overnight".

- Separación de los procesos de incubación con Fosfatasa Alcalina y GalDeshidrogenasa/Diaforasa/NAD /Resazurina a efectos de mejorar la eficiencia del proceso de hidrólisis de la Gal-1P por parte de la Fosfatasa Alcalina.

- Modificación del tiempo y la temperatura de incubación con las enzimas anteriores de una única incubación de 60 minutos a $37^{\circ} \mathrm{C}$ a dos incubaciones de 45 minutos a temperatura ambiente.

En el Anexo 4, se describe en detalle la preparación de reactivos y el protocolo de ensayo correspondiente al Método Enzimático - Fluorométrico de desarrollo propio.

- Condiciones para la recolección de muestras: a lo largo de todo el período evaluado, las condiciones de recolección de muestras recomendadas en forma particular para la pesquisa de Galactosemia establecían la necesidad de una ingesta de leche de 48 horas previa a la toma de muestras, y un plazo máximo de 7 días de vida.

- Control de Calidad: El control de calidad de los métodos utilizados en la PN de Galactosemia se llevó a cabo mediante la implementación de un estricto Sistema de Control de Calidad Interno y mediante la participación en 4 Programas diferentes de Evaluación Externa de Calidad (EEC):

- Control de Calidad Interno: Para la implementación del Sistema de Control de 
Calidad Interno se utilizaron materiales de control de diferentes procedencias, entre los que se pueden citar los provistos por Programas de EEC como el NSQAP-CDC a través de su componente Quality Control $\left({ }^{*}\right)$, los provistos en el kit comercial de ICN Biomedicals Inc, o aquellos preparados en nuestro propio Laboratorio (*).

NOTA: los materiales de control marcados con $\left(^{*}\right)$ son los que se encuentran en uso en la actualidad.

- Evaluación Externa de Calidad: a continuación se listan los Programas de EEC en los cuales se participó en el período evaluado.

- Newborn Screening Quality Assurance Program. Centers for Disease Control and Prevention (NSQAP-CDC). Atlanta - EE.UU., desde Abril de 1995 hasta la fecha.

- Internacional Quality Assurance for Newborn Screening. Geesthacht Alemania, desde Enero de 1996 hasta la fecha.

- Newborn Screening Quality Assurance Program - Human Genetic Society for Australasia (NSQAP-HGSA). Auckland - New Zealand, desde Noviembre de 1996 hasta Enero de 2003 (programa discontinuado por sus propios organizadores).

- Programa de Evaluación Externa de Calidad para Pesquisa Neonatal (PEEC-PN). Fundación Bioquímica Argentina. La Plata - Argentina, desde Junio de 2008 hasta la fecha.

- Valores de Corte: en la Tabla 64 se presentan los diferentes VC utilizados en la PN de Galactosemia a lo largo del período evaluado, y a continuación se presenta una discusión detallada de los mismos:

Tabla 64. Valores de corte utilizados en la PN de Galactosemia

\begin{tabular}{ccccc}
\hline Período & & $V C_{1}$ & & $V C_{2}$ \\
\cline { 1 - 1 } \cline { 5 - 5 } Jul/1995 - Ago/1996 & & $8,0 \mathrm{mg} / \mathrm{dl}$ & & $12,0 \mathrm{mg} / \mathrm{dl}$ \\
Dic/1998 - Abr/2000 & & $9,0 \mathrm{mg} / \mathrm{dl}$ & & $30,0 \mathrm{mg} / \mathrm{dl}$ \\
May/2000 - Dic/2009 & & $8,0 \mathrm{mg} / \mathrm{dl}$ & & $30,0 \mathrm{mg} / \mathrm{dl}$ \\
\hline
\end{tabular}


Con respecto a los VC utilizados se debe mencionar que el $V C$ inicial fue definido en forma preliminar a partir de un estudio de distribución poblacional, habiéndose reevaluado y modificado un año después, una vez que se contó con una cantidad de datos con mayor significación estadística. Como se puede observar en la Tabla 64, a lo largo de todo ese período se estableció el $V C_{2}$ en $12,0 \mathrm{mg} / \mathrm{dl}$ a efectos de definir una categoría de resultados "Dudosos" y otra de resultados "Patológicos". Sin embargo, la decisión de proceder a la derivación de un RN a partir del resultado obtenido en la primera muestra recién se comenzó a realizar de manera concreta empleando el $V C_{2}$ a partir de haber acumulado algo de experiencia en la detección de casos de Galactosemia Clásica, hecho que determinó que en Diciembre de 1998 el mismo fuera fijado en un valor de 30,0 mg/dl.

Finalmente, la última modificación en el VC se introdujo en Mayo del año 2000. en concomitancia con la puesta en rutina del Método Enzimático - Fluorométrico de desarrollo propio y después de haber realizado un estudio de distribución poblacional, conservándose en $30,0 \mathrm{mg} / \mathrm{dl}$ el VC para definir la derivación de los casos positivos al Centro de Atención Especializada.

- Algoritmo de trabajo: En la Figura 145 se describe el algoritmo de trabajo utilizado en la actualidad para la pesquisa de Galactosemia en el cual las unidades de Gal están expresadas en mg/dl.

Como puede observarse en dicha Figura, y a diferencia de la modalidad de trabajo descripta previamente para el caso de PKU, HC y FQ, el algoritmo de pesquisa empleado en este caso contempla la posibilidad de la recolección de hasta una tercera muestra en aquellos casos que continúan presentando valores de Gal ligeramente aumentados por encima del $V C_{1}, y$ sin sobrepasar el $V C_{2}$. De este modo se busca evitar la movilización de las familias para su atención en el Centro de Atención Especializada en aquellos casos en los cuales el aumento de Gal puede deberse a una causa transitoria, de las cuales la más frecuente es la inmadurez hepática. No obstante esta afirmación, y a pesar de que en la práctica resulta altamente improbable que una forma Clásica se presente con niveles de Gal apenas ligeramente aumentados, en estos casos se indica una vigilancia particular de 
ciertos aspectos como el rechazo del alimento, la presencia de vómitos y diarreas y cualquier otro signo de descompensación que podría ser sugestivo de una Galactosemia Clásica.

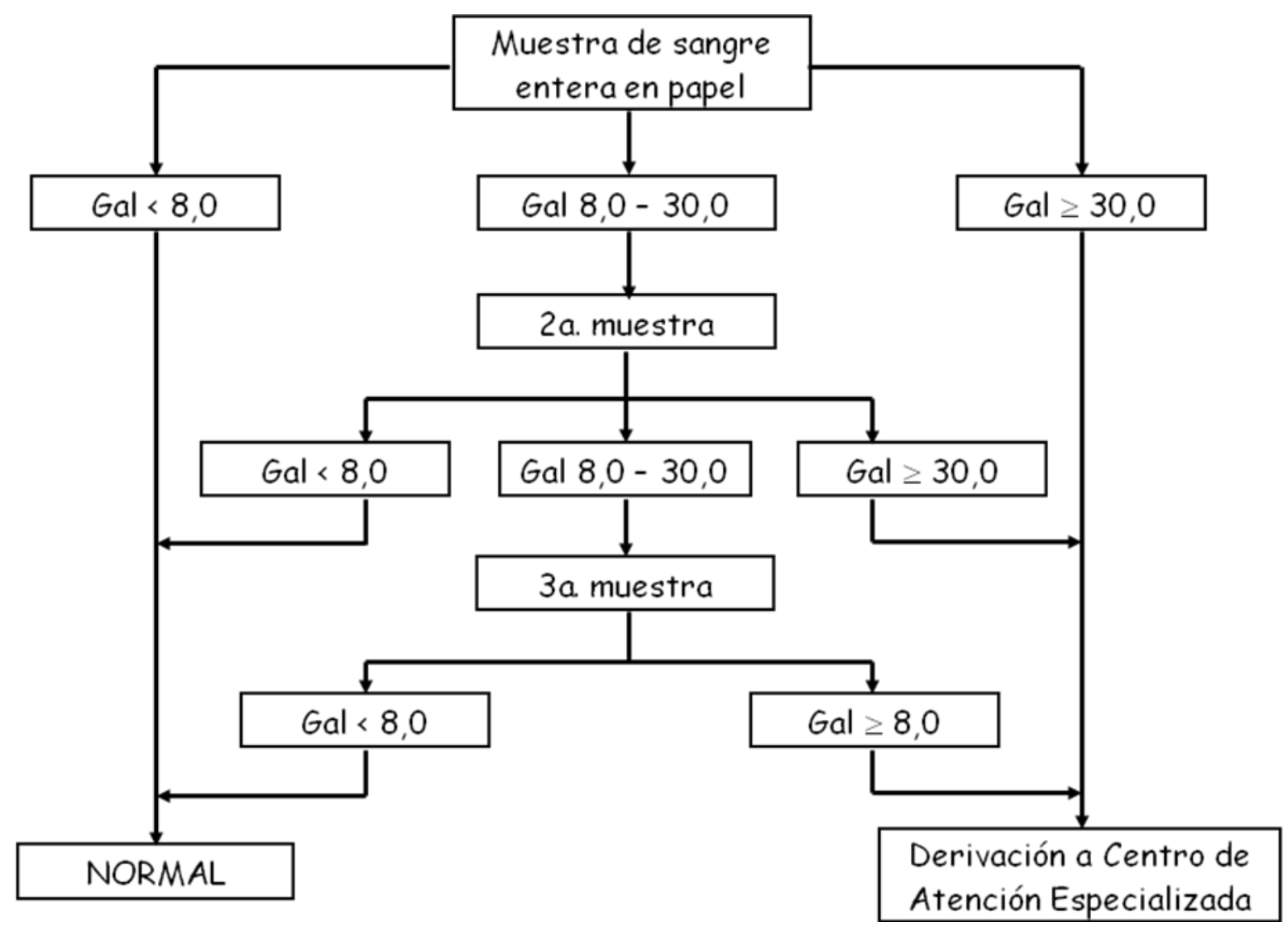

Figura 145. Algoritmo actual de trabajo para la PN de Galactosemia.

- Resultados: La PN de Galactosemia fue implementada en el Laboratorio de Detección de Errores Congénitos de la Fundación Bioquímica Argentina en el mes de Julio de 1995 simultáneamente con la PN de FQ y siguiendo una modalidad de ejecución equivalente en cuanto a que la misma se ofrecía a demanda y sin una estructura de Programa. Sin embargo, la forma en que evolucionaron ambas pesquisas presentó características sumamente diferentes, fundamentalmente por el hecho de que por aquel entonces no existía una Ley que definiera la obligatoriedad para la PN de ECM de Gal. Recién en 2007 dicha pesquisa fue declarada obligatoria por la Ley Nacional 26279, pero por razones inherentes a las características federales de nuestro país en lo que hace a temas legislativos, y en la medida que la Provincia de Buenos Aires no adhirió a la mencionada Ley, 
entonces a lo largo del período 1995-2009 la misma se ejecutó en forma no obligatoria, aunque con el respaldo de los Servicios de Neurología y de Laboratorio Central del Hospital de Niños "Sor María Ludovica" de La Plata para las instancias de confirmación, diagnóstico, tratamiento y seguimiento de los casos detectados. No obstante esto, y tal como ya fuera mencionado en el Capítulo 10, en Diciembre de 2008 la Provincia de Buenos Aires declaró la obligatoriedad, entre otras, de la PN de Galactosemia, aunque la falta de reglamentación de la misma determinó que dicha obligatoriedad no fuera implementada dentro del período evaluado como parte de este análisis.

En la Figura 146 se muestra la evolución experimentada en el número de RN pesquisados anualmente para Galactosemia en el período evaluado, mientras que en la Figura 147 se presentan los principales resultados correspondientes a la secuencia general de pesquisa incluyendo el número total de neonatos pesquisados, el número de RN con resultados anormales, el número de casos detectados tanto de Galactosemia Clásica como de Deficiencias Parciales de GAL-T, de Deficiencias de GAL-K y de Deficiencias de GAL-E, incluyendo sus respectivas incidencias.

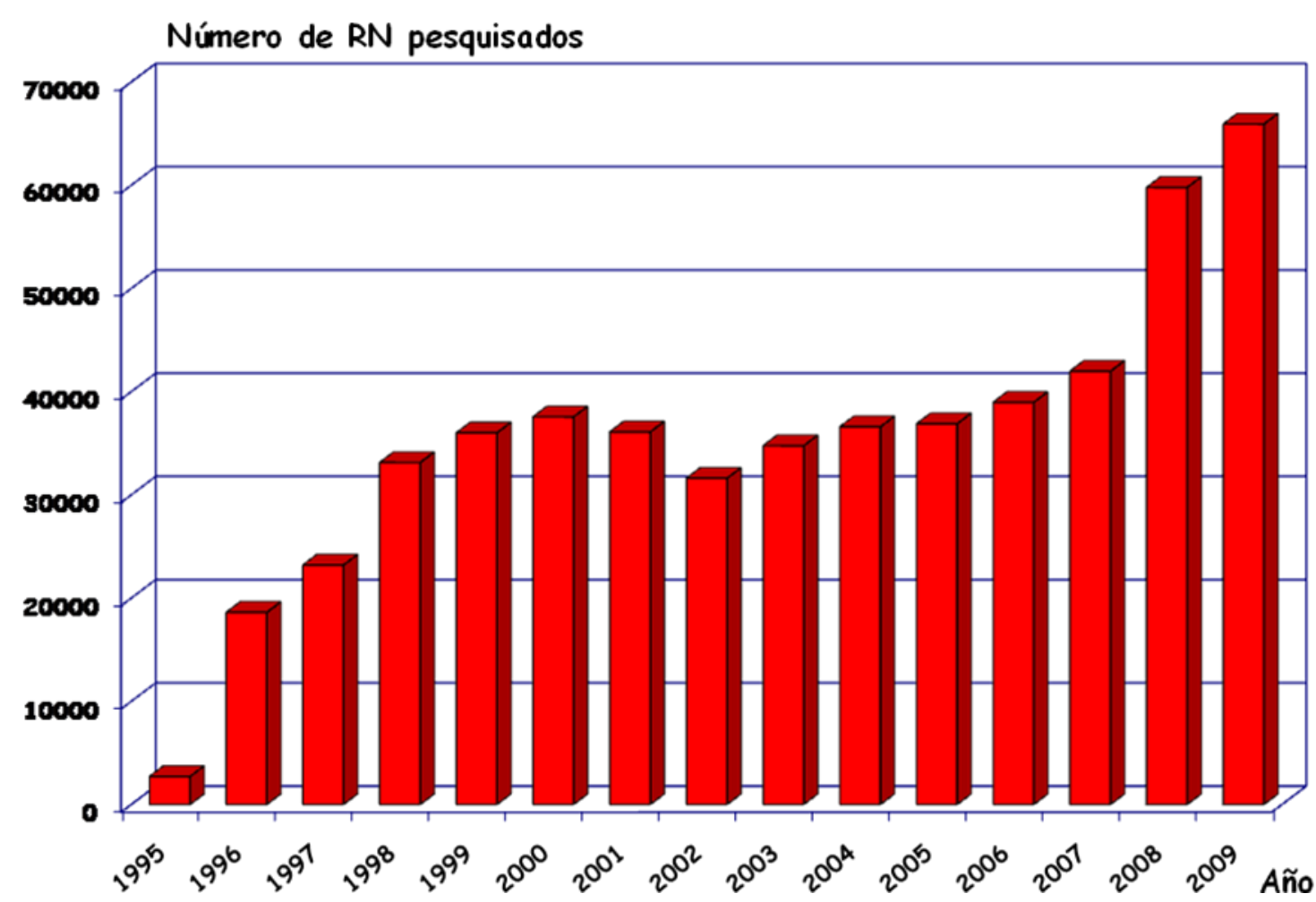

Figura 146. Número de RN pesquisados año a año para Galactosemia. 


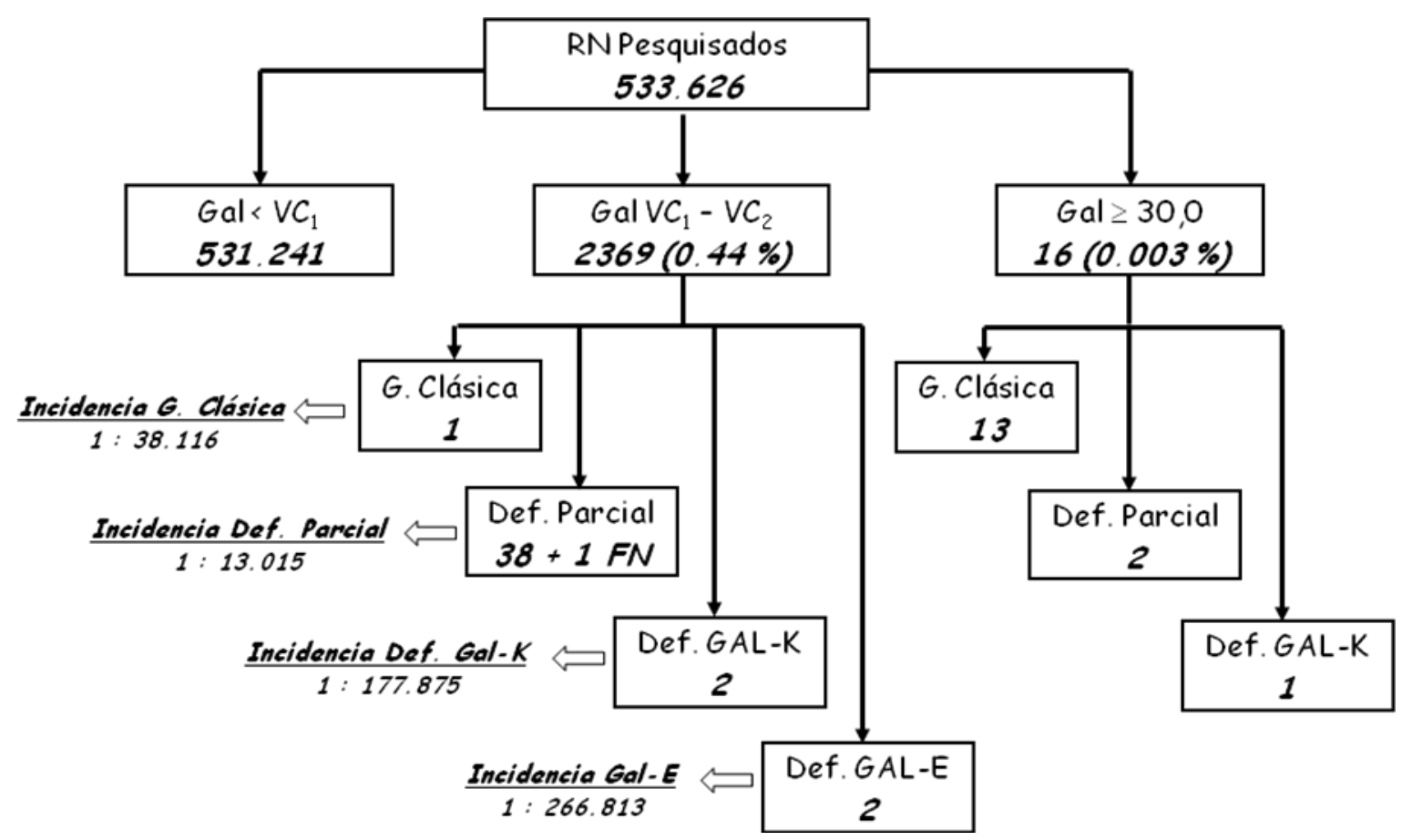

Figura 147. Resultados de la pesquisa de Galactosemia.

Con respecto a la información presentada en la Figura 146, y a diferencia de lo observado en las pesquisas de PKU, HC y FQ ya discutidas en Capítulos anteriores, en este caso es posible visualizar que después de un período inicial de algo más de 3 años de un crecimiento intenso, se llegó a una meseta entre los años 1999 y 2005 con un promedio del orden de las 36.000 muestras anuales, excepto en el año 2002 en el cual se presentó un decaimiento significativo a expensas de la crisis económica del 2001. Posteriormente se experimentó un pequeño despegue en los años 2006 y 2007, y recién en 2008 se evidenció un verdadero punto de inflexión que implicó un incremento en el número de RN pesquisados del orden del $50 \%$, crecimiento que se sostuvo durante el año 2009 pero en una magnitud inferior. Este último comportamiento encuentra su explicación en la sanción de la Ley Nacional 26279/07, la cual influenció indirectamente la magnitud en que se solicitaba esta pesquisa de manera equivalente a lo observado en el caso de FQ.

Por otra parte, y en contraposición con lo ocurrido en 2009 con la pesquisa de FQ como consecuencia de la implementación del Programa Nacional de Fortalecimiento de la Detección Precoz de Enfermedades Congénitas del Ministerio de Salud de la Nación, en el caso de la PN de Galactosemia no se evidenció ninguna 
influencia. Esta diferencia se debe al hecho de que las Provincias que remitían las muestras de sangre de sus RN del sector público a la FBA y que comenzaron a resolver dichas pruebas por su propia cuenta previamente sólo solicitaban la realización de las pruebas definidas como obligatorias por la Ley Nacional 24438/94, es decir PKU, HC y FQ.

En lo que respecta a la información presentada en la Figura 147, y dado que hasta Noviembre de 1998 el algoritmo de trabajo no tenía definido un criterio claro para decidir la derivación de RN en forma directa al Centro de Atención Especializada sobre la base del resultado de la muestra inicial de pesquisa, en la misma se consideró como criterio de derivación general una concentración de Gal $\geq 30,0 \mathrm{mg} / \mathrm{dl}$ para todos los casos, puesto que en la práctica los $3 \mathrm{RN}$ detectados con Galactosemia Clásica dentro de ese período presentaron niveles francamente aumentados de Gal y muy por encima de dicho valor. De este modo puede observarse que de los 16 RN que cumplieron con esta condición, en 13 de ellos se diagnosticó una Galactosemia Clásica, en 2 una Deficiencia Parcial de la enzima GAL-T y en el restante una Deficiencia de GAL-K. También es importante comentar que solamente un caso de Galactosemia Clásica presentó un valor de Gal inferior a 30,0 mg/dl en la primera muestra, más precisamente de 28,8 mg/dl, independientemente de lo cual la derivación del mismo se efectuó en forma inmediata a partir de dicho resultado. Por otra parte, los 2 casos de Deficiencia de GAL-K y uno de los casos de Deficiencia de GAL-E detectados presentaron niveles superiores a $30,0 \mathrm{mg} / \mathrm{dl}$ en la segunda muestra solicitada, mientras que se presentó un resultado falso negativo en 2 muestras diferentes correspondientes a una Deficiencia Parcial de GAL-T, caso que fue reportado no por el cuadro clínico, dado que se trata de una forma benigna y asintomática, sino por el antecedente de un hermano afectado que había sido previamente detectado por este mismo Programa.

Para concluir el análisis de estos datos se debe destacar la incidencia significativa de la Galactosemia Clásica de 1 : 38.116 nacidos vivos y de las Deficiencias Parciales de GAL-T de $1: 13.015$, las cuales se corresponden con la 
información disponible en la literatura a partir de la experiencia de otros programas de PN (3).

En cuanto a la distribución de los casos detectados según la procedencia de los mismos, y dado que la mayor parte de las muestras recibidas provenían de la Provincia de Buenos Aires, se cuenta con muy pocos casos detectados del Interior del país, tal como se puede visualizar en la Tabla 65.

Tabla 65. Distribución de casos detectados por Provincia

\begin{tabular}{|c|c|c|c|c|}
\hline Provincia & G. Clásica & Def. Parcial & D. GAL-K & D. GAL-E \\
\hline Buenos Aires & 12 & 39 & 3 & 2 \\
\hline Santa Fe & 1 & -- & -- & -- \\
\hline San Juan & 1 & -- & -- & -- \\
\hline Santiago del Estero & -- & 2 & -- & -- \\
\hline Total & 14 & 41 & 3 & 2 \\
\hline
\end{tabular}

Finalmente, para culminar la discusión de la PN de Galactosemia, en la Tabla 66 se presentan diferentes parámetros estadísticos que caracterizan el desempeño del sistema de detección.

Tabla 66. Parámetros estadísticos de la PN de Galactosemia Tasas de recitación

- Por resultados anormales en primera muestra

- Total período evaluado $0,45 \%$

- Período 2003-2008 $0,31 \%$

- Año 2009 $0,45 \%$

- Por resultados anormales en segunda muestra $0,039 \%$

- Por recolección inadecuada de muestras $0,43 \%$

Recuperación de segundas muestras solicitadas

- Por recolección inadecuada de muestras

- Total período evaluado $65,7 \%$

- Período 2003-2009 $76,5 \%$

Tal como puede visualizarse en la Tabla anterior, la PN de Galactosemia presenta 2 componentes que hacen a la tasa de recitación por resultados anormales puesto que el algoritmo de pesquisa prevé la solicitud de una tercera muestra en 
aquellos casos que mantienen niveles aumentados de Gal en la segunda muestra pero por debajo de $30,0 \mathrm{mg} / \mathrm{dl}$. De este modo la magnitud de dichos parámetros refleja que 45 de cada 10.000 RN pesquisados requirieron la solicitud de una segunda muestra, y que de estos, el 8,8 \% requirió la solicitud de una tercera muestra. Por otra parte, es importante mencionar que un total de 48 RN presentaron niveles aumentados de Gal aún en la tercera muestra (datos no mostrados en Figuras y Tablas anteriores), requiriendo consecuentemente su derivación al Centro de Atención Especializada, entre los cuales, 19 de ellos fueron confirmados con un diagnóstico final de Deficiencia Parcial de GAL-T.

Como dato particular se debe mencionar que en el período 2003-2008 la tasa de recitación se mantuvo en promedio por debajo del índice general del período en un valor óptimo del 0,31\%, pero que en el último año evaluado el mismo se incrementó hasta el 0,45\%.

En cuanto a la tasa de recitación por recolección inadecuada de muestras, la Galactosemia presenta el índice más alto de las cuatro patologías discutidas hasta el momento, hecho que está directamente relacionado con las prioridades definidas en el caso de muestras colectadas con un volumen insuficiente de sangre que determina que solamente sea posible la realización de algunas de las pruebas solicitadas. Paradójicamente, el índice de recuperación de RN por este mismo motivo correspondiente al período 2001-2009, tomó un valor del 76,5 \% el cual también es el más alto del grupo de 4 patologías al que se hizo referencia anteriormente. La magnitud de este índice no solamente tiene que ver con el hecho de que los RN pesquisados pertenecen mayoritariamente al sector privado, sino que también provienen en mayor proporción de la Provincia de Buenos Aires, acotándose de esta forma el área de distribución de los mismos.

\section{BIBLIOGRAFIA}

15. Bosch A. "Classical Galactosemia Revisited". J Inherit Metab Dis, 29, 516-25, 2006.

16. Baldellou Vazquez A y García Jiménez M. "Errores Congénitos del Metabolismo de la Galactosa", en "Diagnóstico y Tratamiento de las Enfermedades 
Metabólicas Hereditarias". Sanjurjo P, Baldellou A Eds. Editorial Ergon Madrid, $3^{a}$ Edición. Capítulo 27, 399-409, 2010.

17. Fridovich J and Walter J. "Galactosemia" en "The Online Metabolic and Molecular Bases of Inherited Disease". Valle, Beaudet, Vogelstein, Kinzler, Antonarakis, Ballabio Eds. McGraw-Hill. $8^{\text {th }}$ Edition. Chapter 72, 2008.

18. Levy H and Albers S. "Genetic Screening of Newborns". Annu Rev Hum Genet, 01, 139-77, 2000.

19. American Academy of Pediatrics, Kaye $C$ and the Committee on Genetics. "Newborn Screening Fact Sheets". Pediatr, 118, 934-63, 2006.

20. Yamaguchi A, Fukushi M, Mizushima Y, Shimizu Y, Takasugi N, Arashima S, Ohyanagi K. "Microassay for Screening Newborns for Galactosemia with use of a Fluorometric Microplate Reader". Clin Chem. 35, 1962-4, 1989.

21. Yamaguchi A. "Fluorometric Approach to Screening and Diagnosis Tests for Inborn Errors of Metabolism". Comunicación personal. 1998. 


\section{ANEXO 4: METODO ENZIMATICO - FLUOROMETRICO PARA LA MEDIDA DE GALACTOSA EN DBS, DE DESARROLLO PROPIO.}

\section{- PREPARACION DE REACTIVOS:}

o Solución Fijadora: mezclar Metanol, Acetona y $\mathrm{H}_{2} \mathrm{O}$ destilada en proporciones 70:70:20. Conservar en frasco color caramelo a temperatura ambiente.

o Solución madre de Diaforasa $(500 \mathrm{U} / \mathrm{ml})$ : disolver el contenido de un Frasco de Diaforasa (Worthington, Cat. 4330) en un volumen tal de buffer Fosfato $0,01 \mathrm{M}$ de $\mathrm{pH} 7,2$ de manera de obtener una actividad de $500 \mathrm{U} / \mathrm{ml}$. Fraccionar en frascos de vidrio a razón de $612 \mathrm{U} /$ frasco y almacenar en freezer $\mathrm{a}-20^{\circ} \mathrm{C}$.

o Buffer Fosfato 0,01 M - pH 7,2:

- $\mathrm{KPO}_{4} \mathrm{H}_{2}$ : pesar $68 \mathrm{mg}$ de $\mathrm{KPO}_{4} \mathrm{H}_{2}$ (Merck, Art. 4873) y disolver en $50 \mathrm{ml}$ de $\mathrm{H}_{2} \mathrm{O}$ destilada.

- $K_{2} \mathrm{PO}_{4} \mathrm{H}$ : pesar $87 \mathrm{mg}$ de $\mathrm{K}_{2} \mathrm{PO}_{4} \mathrm{H}$ (Merck, Art. 5104) y disolver en $50 \mathrm{ml}$ de $\mathrm{H}_{2} \mathrm{O}$ destilada.

Para la obtención del Buffer Fosfato 0,01 M-pH 7,2, agregar poco a poco el $\mathrm{KPO}_{4} \mathrm{H}_{2}$ sobre los $50 \mathrm{ml}$ de $\mathrm{K}_{2} \mathrm{PO}_{4} \mathrm{H}$ hasta alcanzar $\mathrm{pH}=7,2$. Conservar en heladera a $4^{\circ} \mathrm{C}$.

o Solución de trabajo de Diaforasa $(4,5 \mathrm{U} / \mathrm{m} /)$ : descongelar un frasco conteniendo $612 \mathrm{U}$ de Solución madre de Diaforasa y llevar a volumen final de $136 \mathrm{ml}$ con $\mathrm{H}_{2} \mathrm{O}$ destilada. Fraccionar en crioviales con tapa a rosca a razón de $2,4 \mathrm{ml}$ por tubo y almacenar en freezer $\mathrm{a}-20^{\circ} \mathrm{C}$.

o Gal-Deshidrogenasa $(1,34 \mathrm{U} / \mathrm{m} /)$ : pesar 18,2 $\mathrm{mg}$ de Gal-Deshidrogenasa (Codexis, Cat. GalDH-102) de actividad específica 10,0 U/mg y disolver en 136 $\mathrm{ml}$ de buffer Tris 0,05 M. Fraccionar en crioviales con tapa a rosca a razón de $2,4 \mathrm{ml}$ por tubo y almacenar en freezer $\mathrm{a}-20^{\circ} \mathrm{C}$.

o $\beta$-NAD (9,0 mM): pesar $814.6 \mathrm{mg}$ de $\beta$-NAD (Codexis, Cat. 16.50) y disolver en $136 \mathrm{ml}$ de $\mathrm{H}_{2} \mathrm{O}$ destilada. Fraccionar en crioviales con tapa a rosca a razón de $2,4 \mathrm{ml}$ por tubo y almacenar en freezer $\mathrm{a}-20^{\circ} \mathrm{C}$. 
o Solución madre de Resazurina (10 mM): pesar 29,6 mg de Resazurina (Sigma, $\mathrm{R}-2127,85 \%$ pureza) y disolver en $10 \mathrm{ml}$ de $\mathrm{H}_{2} \mathrm{O}$ destilada. Conservar en heladera a $4{ }^{\circ} \mathrm{C}$.

o Tris-Resazurina (0,106 mM): antes de usar mezclar $30 \mathrm{ml}$ de Buffer Tris 0,2 $M$ de $\mathrm{pH} 8,0$ y $322 \mu$ de Resazurina $10 \mathrm{mM}$.

o Buffer Tris 0,2 M-pH 8,0:

- Tris Base: pesar 12,12 g de Tris Base (Sigma, T-1503) y disolver en $500 \mathrm{ml}$ de $\mathrm{H}_{2} \mathrm{O}$ destilada.

- Tris-HCl: pesar 15,8 g de Tris-HCl (Sigma, T-3253) y disolver en $500 \mathrm{ml}$ de $\mathrm{H}_{2} \mathrm{O}$ destilada.

Para la obtención del Buffer Tris 0,2 M- pH 8,0, agregar poco a poco el Tris Base sobre los $500 \mathrm{ml}$ de Tris- $\mathrm{HCl}$ hasta alcanzar $\mathrm{pH} \mathrm{8,0.} \mathrm{Conservar} \mathrm{en}$ heladera a $4{ }^{\circ} \mathrm{C}$.

o Solución madre de Fosfatasa Alcalina (425 U/m/): disolver el contenido de un Frasco de Fosfatasa Alcalina (MP Biomedicals, Cat. 159347) en un volumen tal de buffer Tris 0,005 M, de manera de obtener una actividad de $425 \mathrm{U} / \mathrm{ml}$. Fraccionar en frascos de vidrio a razón de $2 \mathrm{ml} /$ frasco (850 U) y almacenar en freezer $\mathrm{a}-20{ }^{\circ} \mathrm{C}$.

o Solución de trabajo de Fosfatasa Alcalina $(106,3 \mathrm{U} / \mathrm{ml})$ : descongelar un frasco conteniendo $850 \mathrm{U}$ de Solución madre de Fosfatasa Alcalina y agregar 8 $\mathrm{ml} \mathrm{de}\left(\mathrm{NH}_{4}\right)_{2} \mathrm{SO}_{4} 3,2 \mathrm{M}$.

o Sulfato de amonio (3,2 M): pesar 42,3 g de $\left(\mathrm{NH}_{4}\right)_{2} \mathrm{SO}_{4}$ (J.T. Baker, 0792-19), $1,4 \mathrm{mg}$ de $\mathrm{ZnCl}_{2}$ (Anedra, Art. 7439) y $203 \mathrm{mg}$ de $\mathrm{MgCl}_{2} .6 \mathrm{H}_{2} \mathrm{O}$ (Merck, Art. 1.05833). Disolver el $\left(\mathrm{NH}_{4}\right)_{2} \mathrm{SO}_{4}$ poco a poco en $85 \mathrm{ml} \mathrm{de} \mathrm{H}_{2} \mathrm{O}$ destilada, agregar el $\mathrm{ZnCl}_{2}$ y el $\mathrm{MgCl}_{2} \cdot 6 \mathrm{H}_{2} \mathrm{O}$. Ajustar el pH a 7,6 con $\mathrm{NaOH} 1 \mathrm{M}$. Llevar a volumen final de $100 \mathrm{ml}$.

o Reactivo 1 (Fosfatasa Alcalina): diluir la Fosfatasa Alcalina 106,3 U/ml en Buffer Tris 0,2 M en proporciones $30: 586$, y preparar un volumen acorde a la cantidad de muestras a procesar.

o Reactivo 2 (Gal-Deshidrogenasa, Diaforasa, NAD+, Tris-Resazurina): pre- 
parar la mezcla enzimática en un volumen acorde a la cantidad de muestras a procesar en las proporciones $100: 100: 100: 325$ de Gal-Deshidrogenasa (1,34 $\mathrm{U} / \mathrm{ml})$, Diaforasa $(4,5 \mathrm{U} / \mathrm{ml}), \mathrm{NAD}^{+}(9,0 \mathrm{mM})$ y Tris-Resazurina $(0,106 \mathrm{mM})$.

\section{- pRotocolo de ensayo:}

14. Punchear discos de $1 / 8^{\prime \prime}(3,2 \mathrm{~mm})$ de diámetro correspondientes a calibradores, controles y muestras de RN en microplacas de transferencia MADVN 65 de Millipore de 96 pocillos, a razón de un disco por pocillo.

15. Dispensar $20 \mu$ de Solución Fijadora, Metanol/Acetona/Agua en cada pocillo.

16. Dejar evaporar la Solución Fijadora durante una noche a temperatura ambiente asegurándose el acceso de una apropiada corriente de aire para aumentar la eficiencia del proceso de evaporación.

NOTA: Para protocolos cortos, es posible evaporar la Solución Fijadora en estufa a $37^{\circ} \mathrm{C}$ durante 1 hora.

17. Dispensar $70 \mu \mathrm{l}$ de $\mathrm{H}_{2} \mathrm{O}$ destilada en cada pocillo.

18. Agitar durante 15 minutos en shaker DELFIA Plate Shake (Figura 50 - Página 152) para asegurar una completa elución de la Gal.

19. Transferir cuantitativamente el contenido de cada pocillo a cada uno de los pocillos correspondientes de una placa de fluorometría blanca (Whiteplate, Labsystems Oy), utilizando un sistema Vacuum Manifold (Millipore).

20. Preparar el Reactivo 1 (Fosfatasa Alcalina) y dispensar $50 \mu$ en cada pocillo.

21. Incubar durante 45 minutos a temperatura ambiente.

22. Preparar el Reactivo 2 (Gal-Deshidrogenasa/Diaforasa/NAD ${ }^{+} / T_{r i s-}$ Resazurina) y dispensar $50 \mu$ en cada pocillo.

23. Incubar durante 45 minutos a temperatura ambiente.

24. Leer en Fluorómetro a $\lambda_{\text {EXC/EM }}=544 / 590 \mathrm{~nm}$.

25. Graficar la intensidad de fluorescencia de cada uno de los calibradores en función de la concentración de Gal de cada uno de ellos, construir la curva de calibración e interpolar de la misma los valores de Gal de los controles y de las muestras de RN. 


\section{CAPÍTULO 12}

PESQUISA NEONATAL DE

HIPERPLASIA SUPRARRENAL

CONGÉNITA 



\section{- INTRODUCCIÓN}

La Hiperplasia Suprarrenal Congénita $(H S C)$ es un grupo de desórdenes autosómicos recesivos resultantes de la deficiencia en alguna de las 5 enzimas involucradas en la síntesis de Cortisol en la corteza adrenal (1-3).

En el estado de enfermedad, el bloqueo que se produce en los pasos iniciales de la esteroidogénesis adrenal afecta tanto la producción de mineralocorticoides como la de glucocorticoides y hormonas sexuales, causando consecuentemente anomalías en la regulación de la homeostasis sal-agua y en la diferenciación sexual, mientras que el aumento compensatorio que se produce a nivel de la ACTH da lugar a un crecimiento hiperplásico de las glándulas suprarrenales $(1,2)$.

Desde el punto de vista etiológico, y de acuerdo a la enzima que se encuentra afectada, la HSC puede clasificarse en 5 grandes grupos (Tabla 67) cuyas características clínicas y severidad dependen fundamentalmente del nivel en el cual se localiza la deficiencia enzimática y de las características de las mutaciones que las originan.

\section{Tabla 67. Etiología de la HSC}

- Deficiencia de 21-Hidroxilasa

- Clásica

a) Perdedora de sal

b) Virilizante simple

- No clásica

- Hiperplasia Adrenal Lipoídea $\left(^{\star}\right)$

- Deficiencia de 17- $\alpha$-Hidroxilasa

- Deficiencia de 3- $\beta$-Hidroxiesteroide Deshidrogenasa

- Deficiencia de 11- $\beta$-Hidroxilasa

(*) Deficiencia en la Proteína de Respuesta Esteroidogénica Aguda (StAR).

De las 5 variantes de HSC antes mencionadas, la más frecuente resulta ser la Deficiencia de 21-Hidroxilasa, a la cual le corresponde aproximadamente el $90 \%$ del total de casos. Esta deficiencia tiene la particularidad de que, dependiendo de la mutación que esté afectando al gen Cyp-21 que codifica para la enzima en cuestión, puede resultar afectada simultáneamente la síntesis de Aldosterona y Cortisol, como 
ocurre en la formas Perdedoras de sal que presentan una actividad nula de la enzima; - exclusivamente la síntesis de Cortisol, dando lugar así a las formas Virilizantes simples, que presentan una actividad residual de la enzima del 1 al $2 \%$.

En cuanto a la forma Clásica de Deficiencia de 21-Hidroxilasa, la misma se presenta con una incidencia del orden de $1: 12.000$ a $1: 15.000$ nacidos vivos (3), caracterizándose clínicamente por el hallazgo de genitales ambiguos en niñas al nacimiento, y por una serie de manifestaciones que afectan a ambos sexos como crecimiento somático post-natal y maduración esquelética acelerada, cierre temprano de epífisis óseas, estatura baja, abundante vello púbico y corporal, pubertad precoz, fertilidad disminuida, y en el $75 \%$ de los casos una producción disminuida de Aldosterona con pérdidas de sal, las cuales pueden dar lugar a crisis salinas que si no son detectadas y tratadas precozmente pueden conducir a la muerte del RN. Como se puede inferir de la descripción anterior los varones presentan un mayor riesgo que las niñas, puesto que al no presentar signos declarados de enfermedad al nacimiento, excepto la hiperpigmentación del escroto y el aumento de tamaño del pene, no existe posibilidad de sospecha clínica, quedando expuestos consecuentemente al riesgo de desarrollo de las crisis salinas (1-3).

A diferencia de esto, y dado que en las formas Virilizantes simples no está afectada la síntesis de Aldosterona, en estos casos no existe riesgo de muerte, encontrándose la presencia de genitales ambiguos en las niñas al nacimiento y la confirmación tardía del diagnóstico en varones a partir del desarrollo de signos resultantes del exceso de andrógenos, como pubertad precoz y estatura baja.

En lo que respecta a las formas No Clásicas, las mismas son sumamente frecuentes, encontrándose en aproximadamente 1 : 500 nacidos vivos (3). No obstante esto, y dado que la actividad de la 21-Hidroxilasa varía del 20 al $60 \%$, se trata de una patología leve que se caracteriza por una producción normal de Cortisol y Aldosterona a expensas de una leve a moderada sobreproducción de precursores de hormonas sexuales. Esta característica determina que al nacimiento no se observen síntomas de exposición a andrógenos, por lo cual los RN afectados pueden resultar asintomáticos o desarrollar algunos signos post-natales de exceso de andrógenos como 
hirsutismo, oligomenorrea y acné.

En relación a las restantes formas de HSC, y dada la baja frecuencia con que se presentan las mismas, solamente se debe hacer referencia a la Deficiencia de 11- $\beta$ Hidroxilasa, no sólo porque representa aproximadamente el 10 \% del total de casos, sino también porque la misma presenta un cuadro clínico de características similares a los de la Deficiencia de 21-Hidroxilasa con acumulación de 11-Deoxicorticosterona, que da lugar a un cuadro de hipertensión en pacientes no tratados (1).

Desde el punto de vista del tratamiento, y considerando los riesgos asociados a las crisis salinas, el mismo debe iniciarse antes de los 10 días de vida. Dicho tratamiento consiste en la administración de glucocorticoides (hidrocortisona, prednisona, dexametasona), y en caso que se trate de formas perdedoras de sal también se les debe administrar mineralocorticoides (fludrocortisona) y realizar una suplementación con sodio (3). A través de dicho tratamiento se plantea como objetivo lograr una correcta asignación del sexo en niñas, y tanto en varones como en mujeres lograr que el organismo sea capaz de mantener un balance adecuado de sales y agua, alcanzando parámetros normales de crecimiento, maduración sexual y fertilidad en la vida adulta.

Con respecto a la PN, y dada la precocidad con que pueden ponerse de manifiesto las crisis salinas, resulta imprescindible obtener los resultados de la misma dentro de la primera semana de vida a efectos de poder evitar la morbi-mortalidad asociada con la enfermedad. Dicha pesquisa se realiza midiendo los niveles de $17 \alpha-$ OH-Progesterona (17OHP), resultando necesario llevar a cabo la definición de VC ajustados según la edad gestacional (EG) o el peso al nacimiento, a fin de lograr una adecuada especificidad del sistema de detección (4). Adicionalmente también se debe tener en cuenta que existen diversas situaciones que pueden dar lugar a un incremento inespecífico en los niveles de 170HP como por ejemplo en RN de menos de 31 semanas de gestación a consecuencia de una expresión retrasada de la enzima 11- $\beta$-Hidroxilasa, $y$ en RN pretérmino y RN a término debido tanto a una alterada función hepática o renal, como a situaciones de estrés post-natal y de recolección de muestras con anterioridad a las 24 horas de vida. Por otra parte; en el caso particular de algunos reactivos comerciales también se puede presentar una especificidad 
inapropiada por reactividad cruzada de los antisueros provistos en los mismos con otros esteroides adrenales como $17 \mathrm{OH}$-Pregnenolona y Sulfato de $17 \mathrm{OH}$-Pregnenolona, los cuales pueden estar aumentados por el efecto inhibitorio de los estrógenos maternos sobre la enzima 3- $\beta$-Hidroxisteroide Deshidrogenasa (1).

A través de la medida de 170HP será posible detectar tanto las Deficiencias de 21-Hidroxilasa como así también algunos casos de Deficiencia de 11- $\beta$-Hidroxilasa.

Finalmente, y en relación a la confirmación diagnóstica, la misma requiere la determinación de 170HP post-extracción, ionograma, dosaje de Renina, prueba de estimulación con ACTH con medidas de 17OHP y Cortisol basales y post-estimulación, y la búsqueda de mutaciones del gen Cyp21 por biología molecular $(1,5)$.

\section{Pesquisa Neonatal}

- Período de trabajo evaluado: Diciembre 1997 - Diciembre 2009.

- Métodos: en la Tabla 68 se presentan los diferentes métodos utilizados en la PN de HSC y a continuación se presenta una discusión acerca de los mismos:

Tabla 68. Métodos utilizados en la PN de HSC

\begin{tabular}{|c|c|}
\hline Período & Método \\
\hline Dic/1997 - Mar/2000 & $\begin{array}{l}\text { DELFIA Neonatal } 17 \alpha-O H \text {-Progesterone; } \\
\text { Wallac Oy. Finlandia. }\end{array}$ \\
\hline $\mathrm{Abr} / 2000-\mathrm{Dic} / 2009$ & $\begin{array}{l}\text { AutoDELFIA Neonatal } 17 \alpha-O H-P r o g e s t e r o n e ; \\
\text { PerkinElmer. Finlandia. }\end{array}$ \\
\hline
\end{tabular}

- Inmunoensayo Fluorométrico a Tiempo Resuelto DELFIA Neonatal $17 \alpha-O H$ Progesterone, de Wallac Oy:

Fundamento: la 17OHP presente en DBS es eluida del papel de filtro e incubada con un buffer conteniendo una cantidad limitada de anticuerpos policlonales IgG específicos obtenidos de conejo dirigidos contra la 17OHP, en pocillos recubiertos con anticuerpos anti-IgG de conejo. En un segundo paso se agrega un buffer conteniendo 170HP marcada con $\mathrm{Eu}^{+3}$ de manera tal que se produzca una competencia entre la $170 \mathrm{HP}$ marcada y la $170 \mathrm{HP}$ fría. Después de remover los discos de papel y de lavar los pocillos se adiciona una solución 
intensificadora que disocia el $\mathrm{Eu}^{+3}$ de su unión al anticuerpo y forma un quelato fluorescente que se cuantifica en un Fluorómetro a Tiempo Resuelto, cuya intensidad de fluorescencia es inversamente proporcional a la concentración de 170HP presente en la muestra (Figura 148).

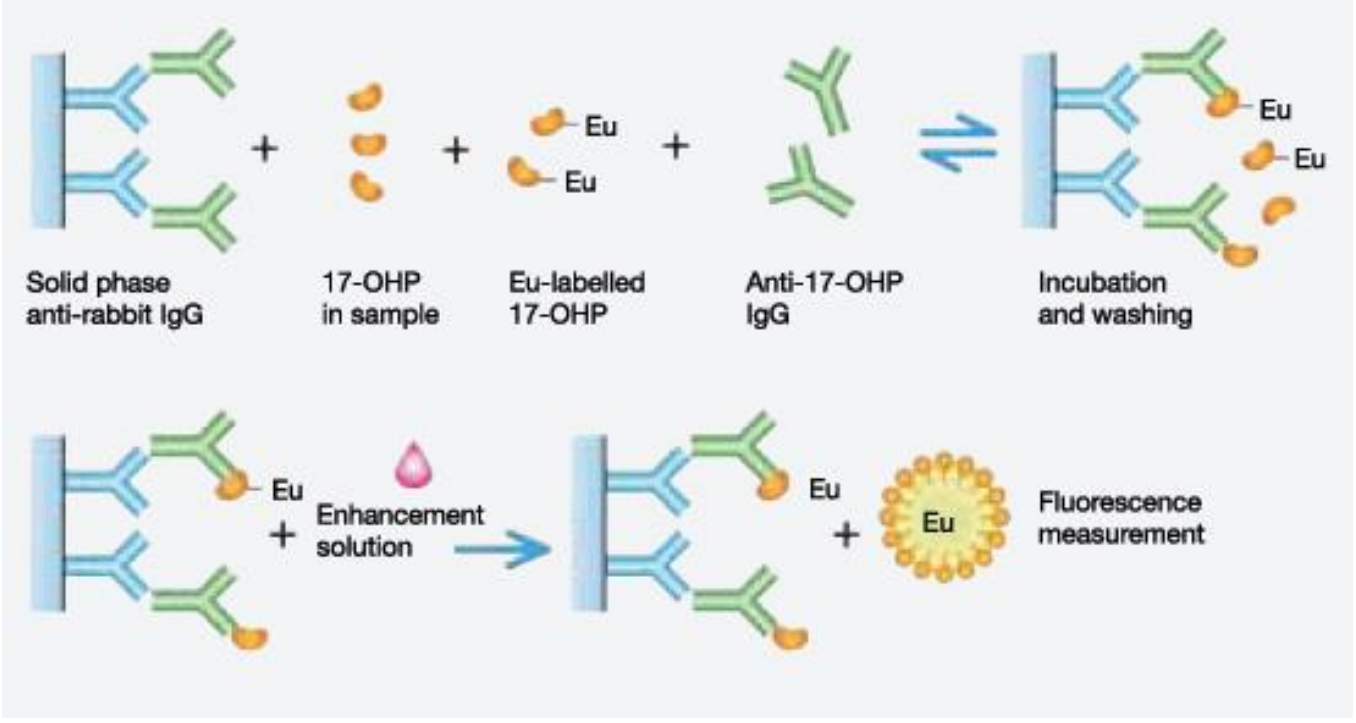

Figura 148. Método DELFIA para la medida de 170HP.

En cuanto a las condiciones de uso del método DELFIA, el mismo fue utilizado siguiendo el protocolo descripto por el fabricante y trabajando con el equipamiento modular -dispensador, agitador, lavador, removedor y lectorprevisto para tal fin, ya descripto en el Capítulo 3.

- Inmunoensayo Fluorométrico a Tiempo Resuelto AutoDELFIA Neonatal $17 \alpha$ OH-Progesterone, de PerkinElmer:

Fundamento: el principio analítico de este método es el mismo que el descripto para el método DELFIA Neonatal $17 \alpha-\mathrm{OH}-$ Progesterone, con la diferencia de que en este caso el procedimiento de ensayo se lleva a cabo en forma completamente automatizada, empleando un autoanalizador AutoDELFIA de PerkinElmer (ver Figura 61 - Página 161).

En lo que respecta a las condiciones de uso del método AutoDELFIA, el mismo fue utilizado siguiendo el protocolo descripto por el fabricante.

- Condiciones para la recolección de muestras: en concordancia con lo descripto 
en Capítulos anteriores para PKU, HC y FQ, el tiempo mínimo recomendado para la recolección de muestras fue establecido a partir de las 24 horas de vida, fijándose el tiempo máximo en 7 días de vida.

- Control de Calidad: El control de calidad de los métodos utilizados en la PN de HC se llevó a cabo mediante la implementación de un estricto Sistema de Control de Calidad Interno y mediante la participación en 3 Programas diferentes de Evaluación Externa de Calidad (EEC):

- Control de Calidad Interno: Para la implementación del Sistema de Control de Calidad Interno se utilizaron materiales de control de diferentes procedencias, entre los que se pueden citar los provistos por Programas de EEC como el NSQAP-CDC a través de su componente Quality Control $\left(^{*}\right)$ y los provistos en los kits comerciales DELFIA y AutoDELFIA $\left(^{*}\right)$.

NOTA: los materiales de control marcados con $\left(^{*}\right)$ son los que se encuentran en uso en la actualidad.

- Evaluación Externa de Calidad: a continuación se listan los Programas de EEC en los cuales se participó en el período evaluado.

- Newborn Screening Quality Assurance Program. Centers for Disease Control and Prevention (NSQAP-CDC). Atlanta - EE.UU., desde Abril de 1996 hasta la fecha.

- Deutsche Gesselschaft für Klinische Chemie. Bonn -Alemania, desde Mayo de 1997 hasta la fecha.

- Newborn Screening Quality Assurance Program - Human Genetic Society for Australasia (NSQAP-HGSA). Auckland - New Zealand, desde Noviembre de 1996 hasta Enero de 2003 (programa discontinuado por sus propios organizadores).

- Valores de Corte: en relación a los VC utilizados para la PN de HSC, se debe mencionar que durante el primer año y medio de trabajo se utilizaron VC fijos establecidos según las recomendaciones presentadas en el " $5^{\text {th }}$ Joint Meeting of the European Society for Paediatric Endocrinology" (6), estableciéndose valores específicos para RN a término (> 36 semanas de EG) y RN pretérmino ( $\leq 36$ 
semanas de $E G$ ), los cuales en una primera instancia solamente diferían en el $V C_{2}$ utilizado para definir la derivación del RN para su confirmación (Tabla 69).

Tabla 69. Valores de corte fijos utilizados en la PN de HSC

\begin{tabular}{|c|c|c|}
\hline Período & $V C_{1}$ & $V C_{2}$ \\
\hline \multicolumn{3}{|l|}{ Dic/1997 - Jul/1998 } \\
\hline - RN a término & $30,0 \mathrm{nmol} / \mathrm{L}$ & $60,0 \mathrm{nmol} / \mathrm{L}$ \\
\hline - RN pretérmino & $30,0 \mathrm{nmol} / \mathrm{L}$ & $100,0 \mathrm{nmol} / \mathrm{L}$ \\
\hline \multicolumn{3}{|l|}{ Ago/1998 - Jul/1999 } \\
\hline - RN a término & $30,0 \mathrm{nmol} / \mathrm{L}$ & $60,0 \mathrm{nmol} / \mathrm{L}$ \\
\hline - RN pretérmino & $40,0 \mathrm{nmol} / \mathrm{L}$ & $100,0 \mathrm{nmol} / \mathrm{L}$ \\
\hline
\end{tabular}

Como puede observarse en la Tabla anterior, el único cambio introducido en los VC fijos aconteció en Agosto de 1998, y fue efectuado sobre el $V C_{1}$ con la finalidad de reducir el porcentaje de falsos positivos que se estaban presentando en RN pretérmino.

Posteriormente, y en la medida de que ya se disponía de una cantidad de datos estadísticamente significativa como para poder realizar un estudio de distribución poblacional dividido en rangos de peso al nacimiento, se procedió a definir los VC ajustados precisamente en función de esta última variable (Tabla 70).

Tabla 70. VC ajustados según el peso al nacimiento para la PN de HSC

\begin{tabular}{|c|c|c|c|}
\hline Período & \multicolumn{3}{|c|}{ Peso al nacimiento } \\
\hline ------------------------------- & $\leq 1100 \mathrm{~g}$ & $1100 g-3500 g$ & $\geq 3500 \mathrm{~g}$ \\
\hline Ago/1999 - Jul/2001 & 100,0 & $V C=105742\left(P^{-0.9963}\right)$ & 30,0 \\
\hline Ago/2001 - Dic/2005 & 150,0 & $V C=2122342\left(P^{-1.3657}\right)$ & 30,0 \\
\hline & $\leq 1100 \mathrm{~g}$ & $1100 g-4400 g$ & $\geq 4400 \mathrm{~g}$ \\
\hline Ene/2006 - Oct/2008 & 174,0 & Función polinomial 1 (ord. 4) & 30,0 \\
\hline & $\leq 1500 \mathrm{~g}$ & $1500-2500$ & $\geq 3600 \mathrm{~g}$ \\
\hline Nov/2008 - Mar/2009 & 70,0 & 25,0 & 15,0 \\
\hline & $\leq 900 \mathrm{~g}$ & $900 g-4065 g$ & $\geq 4065 \mathrm{~g}$ \\
\hline Abr/2009 - Ago/2009 & 111,0 & Función polinomial 2 (ord. 4) & 18,0 \\
\hline & $\leq 900 \mathrm{~g}$ & $900 \mathrm{~g}-3650 \mathrm{~g}$ & $\geq 3650 \mathrm{~g}$ \\
\hline Sep/2009 - Dic/2009 & 110,0 & Función polinomial 3 (ord. 4) & 22,3 \\
\hline
\end{tabular}

NOTA: los VC indicados en la presente tabla están indicados en nmol/L de 17OHP. 
En este punto resulta oportuno mencionar que la decisión de realizar el ajuste del VC según el peso al nacimiento y no según la EG se basó en el hecho de que el primero resultaba un dato más confiable y reportado en una proporción mucho mayor de tarjetas de recolección de muestras que el correspondiente a la EG. Por otra parte, y dada la complejidad de las fórmulas correspondientes a las funciones polinomiales de orden 4 utilizadas para realizar el ajuste del VC en algunos de los períodos presentados en la Tabla 70, las mismas no fueron expresadas en forma explícita y detallada, sino solamente bajo una denominación genérica.

De este modo, el primer VC ajustado según el peso al nacimiento se definió para la metodología DELFIA en Agosto de 1999 trabajando para esto con una población de 24.158 RN con pesos al nacimiento en el rango de 690 a 5900 g, y habiéndose realizado un ajuste para el rango de pesos comprendidos entre 1100 y $3500 \mathrm{~g}$ a través de una función potencial (7). En la Figura 149 se presenta gráficamente la forma en que quedaron definidos dichos VC.

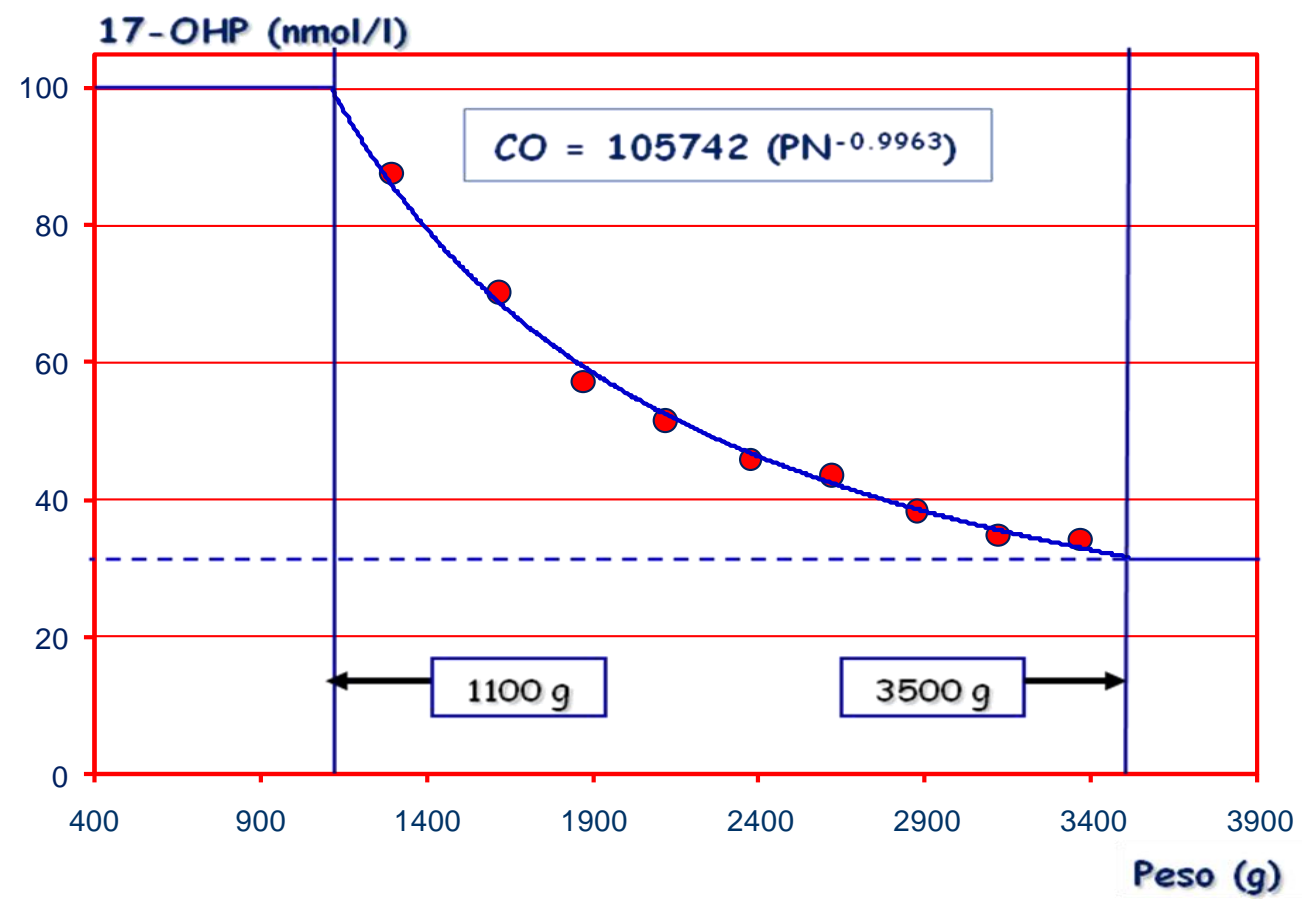

Figura 149. VC ajustado según el peso al nacimiento para la metodología DELFIA.

Posteriormente, en Agosto de 2001, y una vez que la metodología DELFIA fue sustituida por la metodología AutoDELFIA, se realizó una nueva definición de los 
VC trabajando sobre una población de 36.955 RN. Así se encontró una vez más la posibilidad de establecer un ajuste del VC para RN en el rango de pesos comprendidos entre 1100 y $3500 \mathrm{~g}$ a través de una función potencial. No obstante esta similitud cualitativa, fue posible observar un incremento significativo en los VC a medida que disminuía el peso al nacimiento, hasta llegar a un VC de 150,0 $\mathrm{nmol} / \mathrm{L}$ para $\mathrm{RN} \leq 1100 \mathrm{~g}$, contra un valor de 100,0 nmol/L que les correspondía trabajando con la metodología DELFIA (8).

De esta forma, utilizando el VC antes descripto se continuó trabajando hasta Julio de 2005, habiéndose pesquisado una población de 121.032 RN con índices óptimos de especificidad y sensibilidad representados por una tasa de recitación por valores anormales del 0,17 \% y de falsos negativos de $0 \%$. Sin embargo, este desempeño no pudo ser mantenido a lo largo del tiempo debido al hecho de que en Agosto de 2005 la compañía PerkinElmer introdujo en el mercado nacional una nueva versión del kit AutoDELFIA Neonatal 17 $\alpha-\mathrm{OH}-$ Progesterone (versión B015-112), en el cual se sustituyeron los anticuerpos policlonales IgG específicos anti-17OHP obtenidos de conejo que se venían utilizando hasta ese momento por otros provistos por una fuente diferente, dando lugar así a una respuesta del método caracterizada por una muy baja especificidad.

En función de este cambio, y dado que el desconocimiento absoluto de la performance del nuevo kit no permitió prever una reevaluación de los VC con suficiente anticipación, fue necesario continuar trabajando con el VC previamente establecido para las versiones anteriores del kit AutoDELFIA durante un período de 5 meses, con lo cual el desempeño del método se tornó muy deficiente mostrando una tasa de recitación por valores anormales del 1,11 \% (9).

Recién en Enero de 2006 fue posible introducir un nuevo VC para esta versión del kit, a partir de un estudio realizado sobre una población de $13.271 \mathrm{RN}$, definiéndose un VC ajustado a través de una función polinomial de orden 4 para el rango de peso al nacimiento entre 1100 y $4400 \mathrm{~g}$ tal como se menciona en la Tabla 70 y se puede visualizar en la Figura 150, en la cual se presenta también la fórmula 
de la función polinomial utilizada para el ajuste (10).

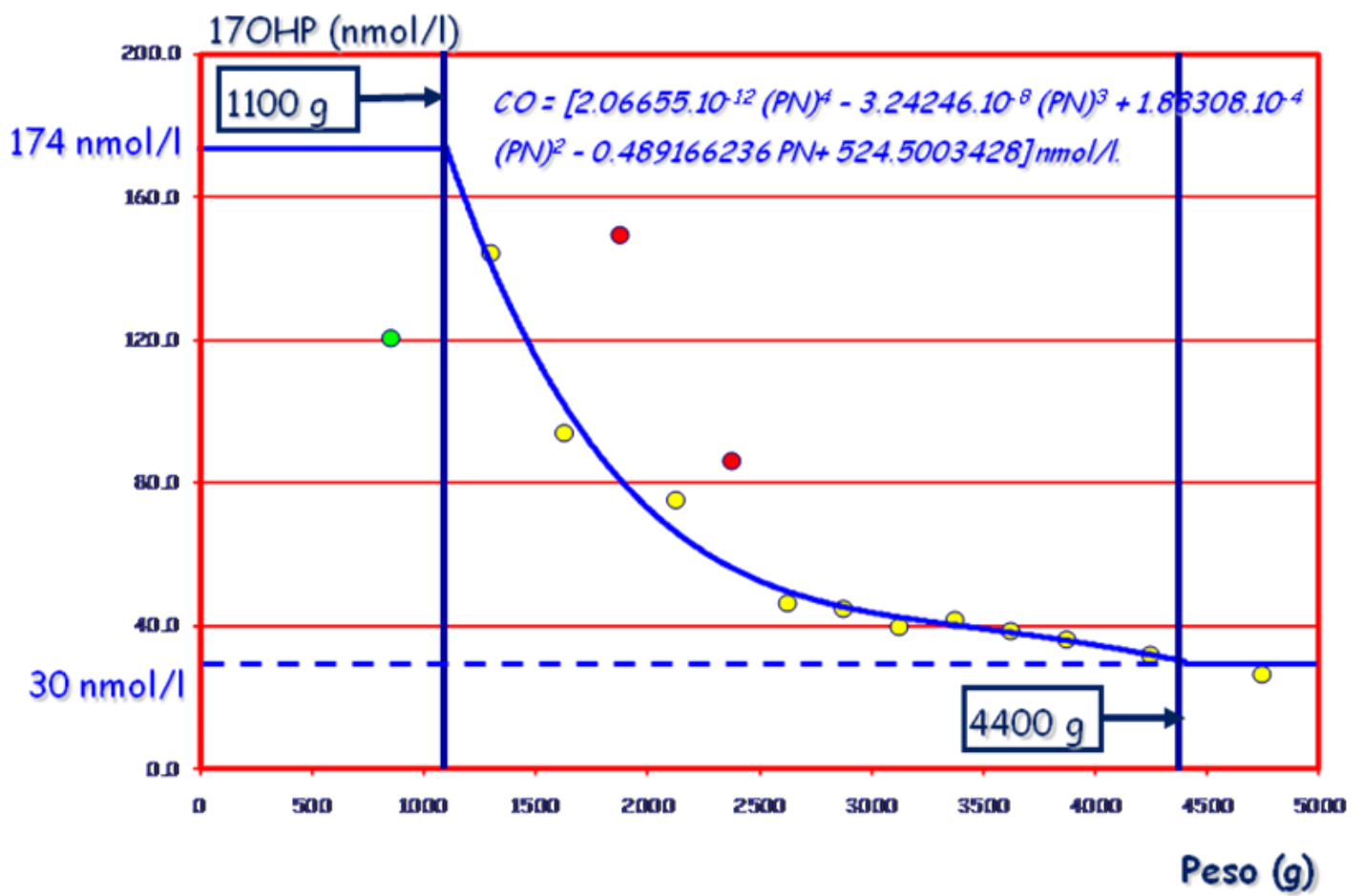

Figura 150. VC ajustado según el peso al nacimiento para la metodología AutoDELFIA B015-112.

Utilizando este ajuste se continuó trabajando hasta Octubre de 2008, habiéndose pesquisado 115.634 RN con una tasa de recitación por valores anormales del $0,65 \%$, dato que de alguna manera refleja la variabilidad observada en la especificidad lote a lote de esta versión, poniendo en evidencia así la inestabilidad en la performance del mismo a lo largo del tiempo.

Posteriormente, y más precisamente en Noviembre de 2008, PerkinElmer volvió a introducir una nueva versión del kit AutoDELFIA Neonatal $17 \alpha-\mathrm{OH}-$ Progesterone, más específicamente la versión B024-112, en la cual los principales cambios consistían en el uso de un nuevo antisuero más específico y en la disminución de la concentración del trazador (17OHP-Eu+3) a efectos de lograr una curva de calibración de mayor pendiente y así mejorar la precisión en el rango de concentraciones clínicamente relevantes.

Este nuevo cambio volvió a plantear un enorme desafío en lo que respecta a la interpretación de los resultados no sólo debido a la mejoría en la especificidad del método, sino fundamentalmente debido al hecho de que los valores de 
170HP observados en la distribución poblacional resultaban significativamente más bajos que para las versiones anteriores. Esta particularidad resultó tener una gran trascendencia práctica puesto que a diferencia de lo ocurrido al momento de poner en rutina la versión B015-112, para la cual se pudo continuar trabajando con los VC previamente definidos generando exclusivamente un riesgo de una incrementada tasa de resultados falsos positivos, en el caso de la versión B024-112 la decisión de continuar utilizando los VC previamente establecidos generaba un riesgo concreto de encontrar resultados falsos negativos, lo cual como es sabido tiene efectos devastadores sobre los niños con ese tipo de resultados.

En función de esto, y tratando de anticiparse a los hechos, se realizó un estudio poblacional previamente a la introducción de la versión B024-112 en la rutina diaria sobre un grupo de $2.133 \mathrm{RN}$, a efectos de definir un VC preliminar. Sin embargo, y dado lo reducido de dicho número de RN no fue posible obtener resultados que permitieran establecer un ajuste empleando una función matemática, por lo cual se debieron definir VC escalonados para 4 diferentes grupos de peso al nacimiento tal como se muestra en la Tabla 66, de donde se desprende que el cambio más significativo quedó plasmado en el hecho de que para $R N \geq 3600 \mathrm{~g}$, cuyo VC hasta ese momento siempre había sido definido en un valor de $30,0 \mathrm{nmol} / \mathrm{L}$, a partir del uso de esta nueva versión pasó a ser de 15,0 nmol/L, aunque probablemente con un cierto sesgo resultante de haber planteado una situación preliminar altamente conservadora a efectos de evitar potenciales resultados falsos negativos.

De esta forma, empleando los VC escalonados, se trabajó durante un período de 5 meses hasta tanto se dispuso de resultados de un número apropiado de RN como para poder hacer una nueva definición del VC. Así, trabajando sobre un grupo de 23.089 RN, en Abril de 2009 se estableció un VC ajustado según una nueva función polinomial de orden 4 para $\mathrm{RN}$ con peso al nacimiento en el rango comprendido entre 900 y $4065 \mathrm{~g}$ (11), tal como se puede observar en la Tabla 70 y en la Figura 151. 


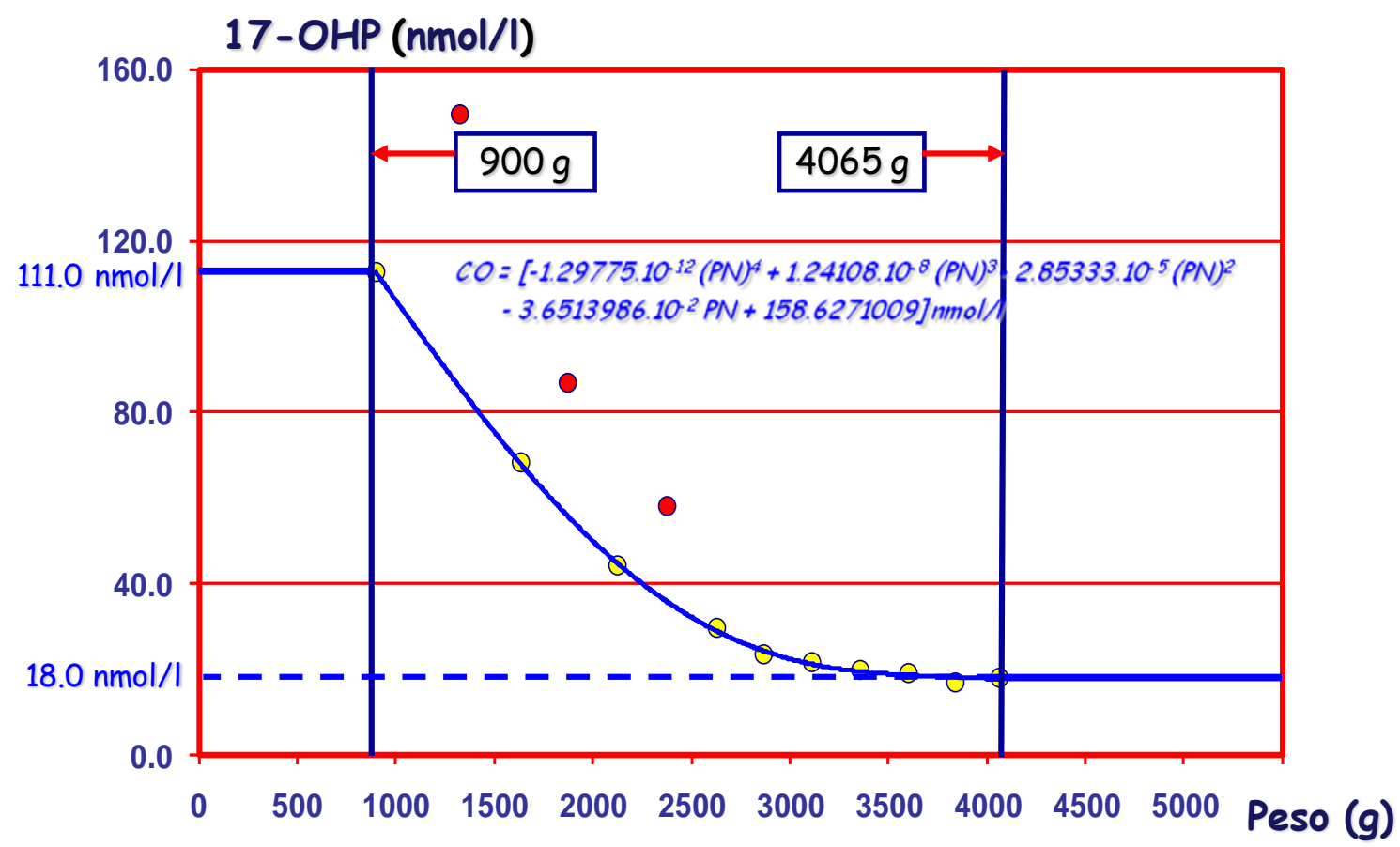

Figura 151. VC ajustado según el peso al nacimiento para la metodología AutoDELFIA B024-112.

Por último, en Septiembre de ese mismo año se realizó una nueva reevaluación del VC, ahora trabajando sobre una población de 44.172 RN, obteniéndose resultados que cualitativamente presentan características muy similares a los empleados hasta ese momento, pero con un ajuste que determinó un ligero incremento en el VC a medida que aumentaba el peso al nacimiento, hasta llegar a un $V C$ de $22,3 \mathrm{nmol} / \mathrm{L}$ para $R N \geq 3650 \mathrm{~g}$, contra un valor de $18,5 \mathrm{nmol} / \mathrm{L}$ que les correspondía según el criterio anterior.

- Algoritmo de trabajo: En la Figura 152 se describe el algoritmo de trabajo utilizado en la actualidad para la pesquisa de HSC, en el cual las unidades de $170 H P$ están expresadas en $\mathrm{nmol} / \mathrm{L}$.

Como puede observarse en dicha Figura, y de manera equivalente a lo descripto en el caso de Galactosemia, en la pesquisa de HSC el algoritmo contempla la posibilidad de la recolección de hasta una tercera muestra en aquellos casos en los que en la segunda muestra aún se continúan presentando valores de 170HP aumentados hasta un orden de $40 \mathrm{nmol} / \mathrm{L}$ por encima del $V C_{1}$, y sin sobrepasar el $V C_{2}$ el cual como se deduce del concepto anterior queda definido según $\left(V C_{1}+40\right.$ 
$\mathrm{nmol} / \mathrm{L})$. De este modo se busca evitar la movilización de las familias para su atención en el Centro de Atención Especializada en aquellos casos en los cuales el aumento de 170HP puede deberse a alguna de las causas de aumento inespecífico de la misma que fueron descriptas anteriormente o a consecuencia de situaciones de estrés que afecten al RN, dado que la secreción de hormonas adrenales resulta muy fuertemente influenciada por dicha variable.

Adicionalmente también debe tomarse en consideración que, si en alguno de estos casos se confirmara la patología, con certeza se trataría de alguna de las formas leves que no ponen en riesgo la vida del RN.

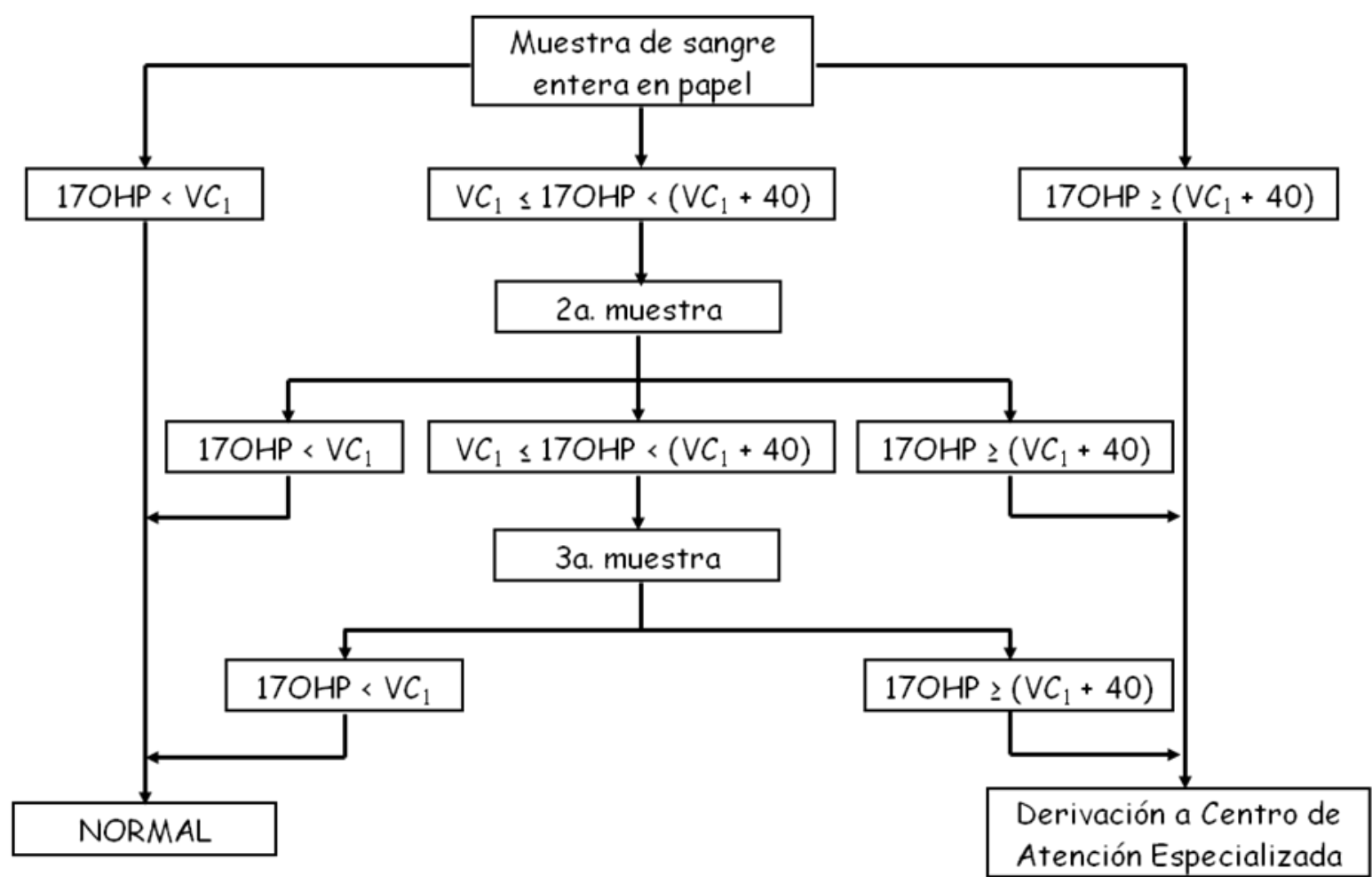

Figura 152. Algoritmo de trabajo para la PN de HSC.

- Resultados: La PN de HSC fue implementada en el Laboratorio de Detección de Errores Congénitos de la Fundación Bioquímica Argentina en Diciembre de 1997 empleando una modalidad de ejecución absolutamente equivalente a la ya descripta para el caso de FQ y Galactosemia, es decir a demanda y sin una estructura de Programa pero con el respaldo de los Servicios de Endocrinología y de Laboratorio Central del Hospital de Niños "Sor María Ludovica" de La Plata para las instancias 
de confirmación, diagnóstico, tratamiento y seguimiento de los casos detectados.

El hecho de que no existiera una legislación que definiera la obligatoriedad de dicha pesquisa determinó que la misma fuera ejecutada desde sus inicios hasta fines de 2009 exclusivamente a demanda, más allá de que en Agosto de 2007 se sancionara la Ley Nacional 26279 que define su obligatoriedad-aunque sin alcance sobre la Provincia de Buenos Aires-, y de que además en Diciembre de 2008 se sancionara la Ley 13905 de la Provincia de Buenos Aires que declara la obligatoriedad, entre otras, de la pesquisa de esta enfermedad. Más allá de esto, la falta de reglamentación de esta última Ley determinó que dicha obligatoriedad no fuera puesta en práctica dentro del período evaluado como parte de este análisis.

En la Figura 153 se muestra la evolución experimentada en el número de RN pesquisados año a año para HSC, mientras que en la Figura 154 se presentan en forma esquemática los resultados de la secuencia de pesquisa, incluyendo el número total de neonatos pesquisados, el número de RN a los cuales se les solicitó una segunda muestra, el número de RN derivados, el número de casos detectados de las diferentes formas de HSC y la incidencia resultante para cada una de ellas.

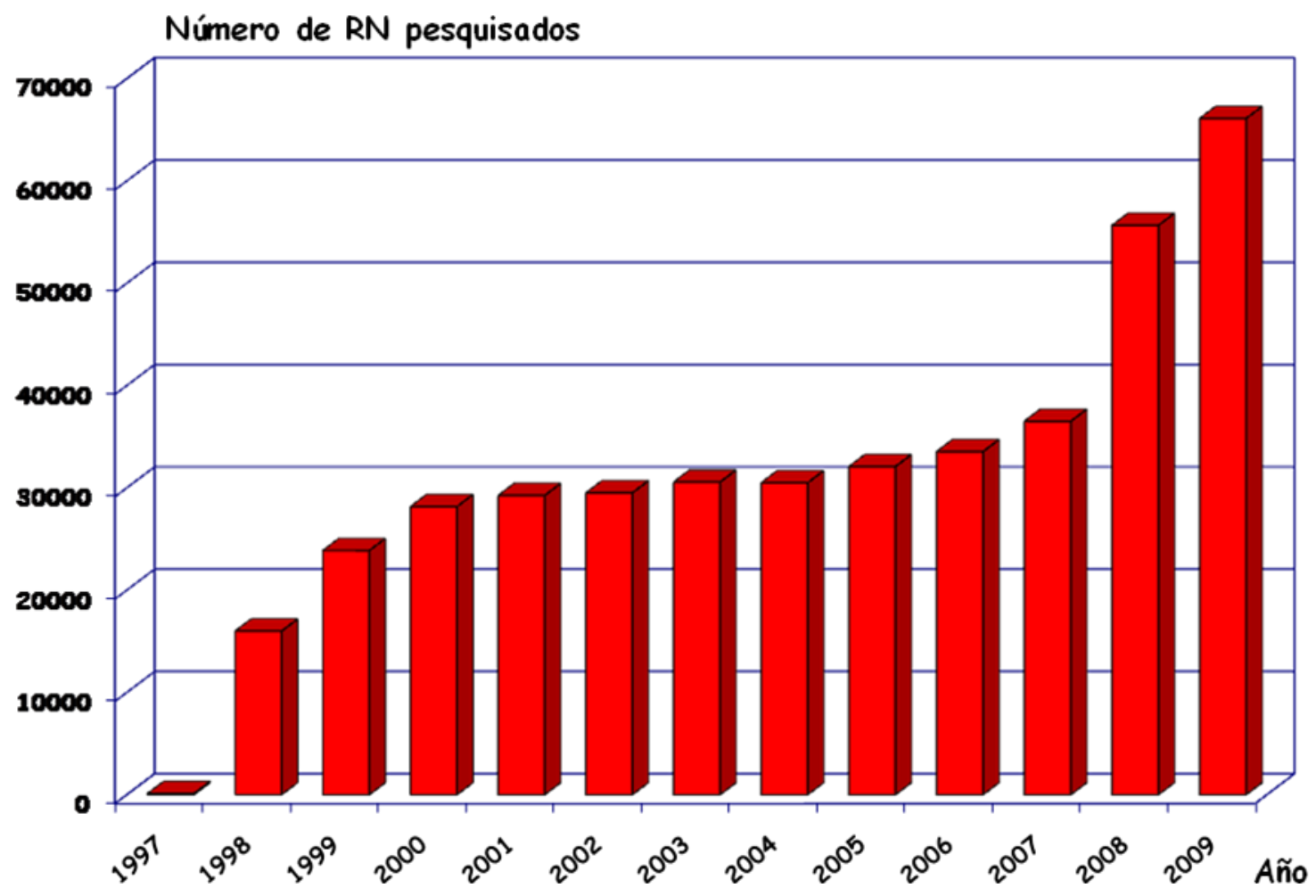

Figura 153. Número de RN pesquisados año a año para HSC. 


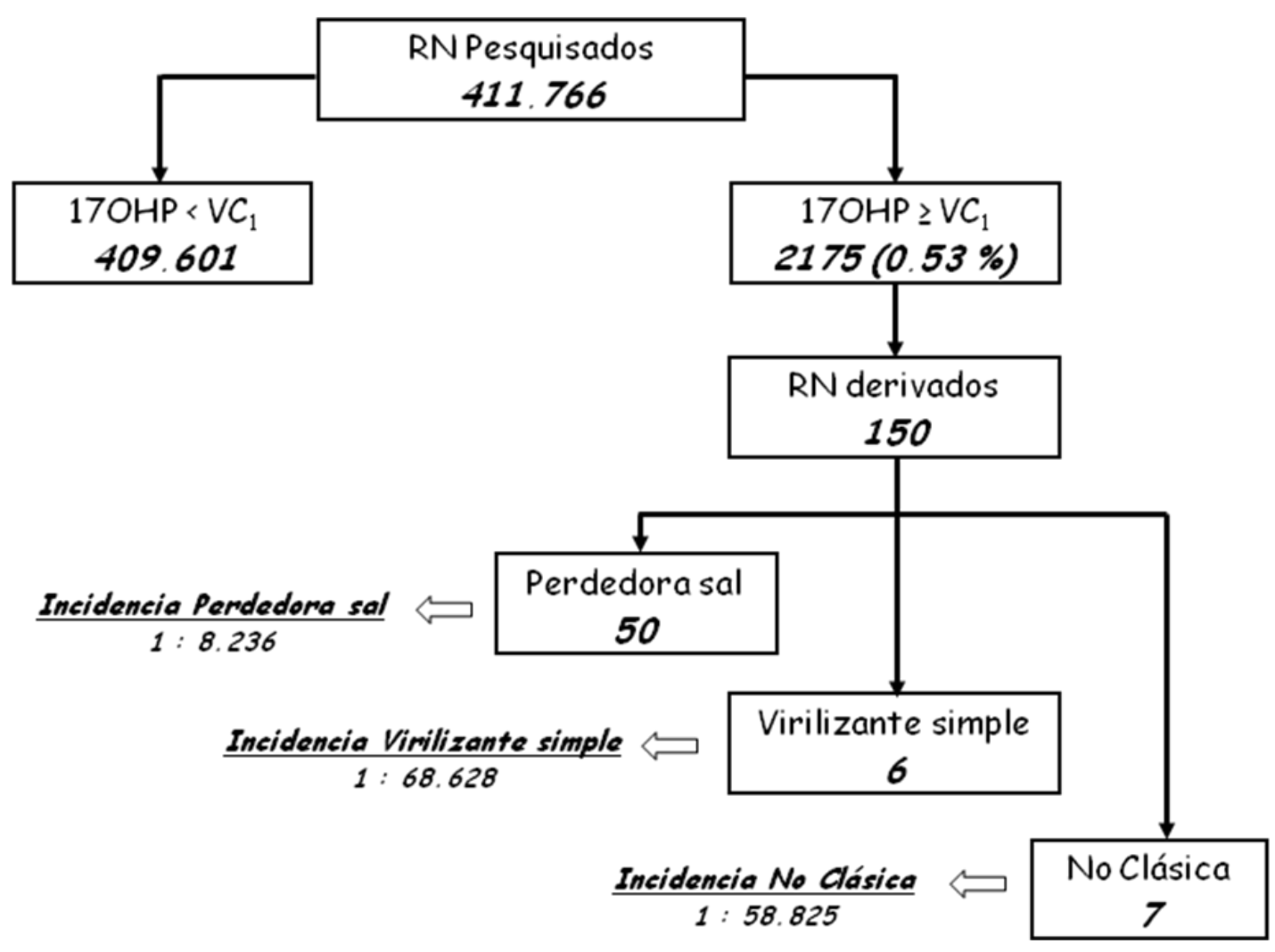

Figura 154. Resultados de la pesquisa de HSC.

En lo que respecta a la evolución experimentada en el número de RN pesquisados, y tal como se desprende de la Figura 153, durante los 2 primeros años de trabajo se evidenció un crecimiento sostenido que se estabilizó entre los años 2000 y 2004 en un promedio anual algo inferior a las 30.000 muestras por año, y con la particularidad de que no se observó el efecto descripto para FQ y para Galactosemia originado por la crisis económica de fines de 2001. Este comportamiento no es casual, sino que es el resultados de la captación de Centros Asistenciales del sector privado que por aquel entonces efectuaban la PN de HSC con otros Programas o Laboratorios de pesquisa, los cuales a consecuencia del colapso en el sistema de salud dejaron de ofrecer momentáneamente la medida de 17OHP, siendo absorbidos entonces por el Laboratorio de la FBA. En los años inmediatos posteriores volvió a experimentarse una ligera tendencia a incrementar el número de RN pesquisados, pero el verdadero salto cuantitativo se produjo en el año 2008 a consecuencia de la sanción de la Ley Nacional 26279, la cual influenció indirectamente la magnitud en que solicitaba esta prueba de pesquisa. 
Adicionalmente, a lo largo del año 2009 también se experimentó un crecimiento sostenido, permitiendo así superar la barrera de los 65.000 neonatos al año y duplicar con creces los números correspondientes al período 2000-2004.

En cuanto a los resultados específicos de la pesquisa, los mismos son presentados en la Figura 154 en forma resumida y esquemática puesto que, como se mencionó anteriormente al hacer referencia al algoritmo de decisión utilizado, en el caso de la HSC se contempla la posibilidad de recolección de hasta una tercera muestra, por lo cual la decisión de derivar a un RN al Centro de Atención Especializada puede ocurrir a partir del resultado obtenido en la primera, segunda o tercera muestra. En función de esto y de la complejidad de dicha secuencia, en la mencionada Figura se muestran solamente y en forma resumida el número total de RN que presentaron niveles aumentados de 170HP en la primera muestra y el número de RN que debieron ser derivados, independientemente de la instancia en que esto ocurrió.

De este modo, y de acuerdo a la tasa de recitación resultante es posible visualizar que 53 de cada 10.000 RN requirieron su localización y que, del total de estos niños, 150 (6,9\%) debieron ser derivados para su confirmación. También resulta importante mencionar que 235 RN presentaron niveles aumentados de $170 \mathrm{HP}$ en la segunda muestra, y que 54 de estos niños mantuvieron dichos niveles elevados en una tercera muestra de sangre (datos no mostrados en la Figura anterior).

Con respecto a los casos detectados y a la incidencia resultante, más específicamente en lo que tiene que ver con las formas Perdedoras de sal, se encontró que en 18 de los 50 casos detectados ya existía una sospecha clínica al momento de la realización de la pesquisa a expensas de la ambigüedad genital observada en estos niños. Sin lugar a dudas este hecho ha sido responsable de la introducción de un sesgo en el dato resultante de la incidencia para estas variantes, debido a que en muchos de estos casos la solicitud de realización de la pesquisa se efectuó en forma dirigida, determinando entonces que la incidencia hallada para la HSC Perdedora de sal $(1: 8.236)$ no sea representativa de la población en estudio sino 
que se encuentre sesgada por las causas antes mencionadas.

Adicionalmente, y sólo a los fines ilustrativos, en la Tabla 71 se presenta la distribución de los casos detectados según la provincia de procedencia de los mismos.

Tabla 71. Distribución de casos detectados por Provincia

\begin{tabular}{|c|c|c|c|}
\hline Provincia & Perdedora sal & Virilizante S. & No Clásica \\
\hline Buenos Aires & 39 & 6 & 5 \\
\hline Ciudad de Buenos Aires & 5 & -- & 1 \\
\hline Entre Ríos & 3 & -- & -- \\
\hline Santa Fe & 1 & -- & 1 \\
\hline Santiago del Estero & 1 & -- & -- \\
\hline Salta & 1 & -- & -- \\
\hline Total & 50 & 6 & 7 \\
\hline
\end{tabular}

Por último, en la Tabla 72 se presentan algunos parámetros estadísticos que caracterizan el desempeño del sistema de detección.

Tabla 72. Parámetros estadísticos de la PN de HSC Tasas de recitación

- Por resultados anormales en primera muestra

- Total período evaluado $0,53 \%$

- Período Ago/2001 - Jul/2005 $0,17 \%$

- Período Ago/2005 - Dic/2005 $1,11 \%$

- Período Ene/2006 - Oct/2008 $0,65 \%$

- Período Nov/2008 - Mar/2009 $0,37 \%$

- Período Abr/2009 - Ago/2009 $0,43 \%$

- Período Sep/2009 - Dic/2009 $0,23 \%$

- Por resultados anormales en segunda muestra $0,057 \%$

- Por recolección inadecuada de muestras $0,29 \%$

- Por recolección con EDTA $0,04 \%$

- Por muestras que no eluyen $0,01 \%$

Recuperación de segundas muestras solicitadas

- Por recolección inadecuada de muestras $75,3 \%$

- Por recolección con EDTA $70,3 \%$

- Por muestras que no eluyen $64,9 \%$ 
Como puede observarse en la Tabla anterior, la tasa de recitación por resultados anormales experimentó innumerables fluctuaciones a lo largo de todo el período evaluado debido a los cambios sucedidos en las características de los métodos utilizados para la medida de 170HP, y a los ajustes que fue necesario realizar a efectos de optimizar fundamentalmente -tal como ya fuera descripto con anterioridad-, la especificidad del sistema de detección. De este modo se puede ver que la mejor condición de trabajo se logró en el período Ago/2001 Jul/2005 con una tasa óptima de recitación del 0,17\%, y que el último ajuste realizado en los VC permitió alcanzar una condición más que aceptable con una tasa de recitación del 0,23\%.

En lo que respecta a la tasa de recitación por muestras mal colectadas, se puede ver que la misma se encuentra ubicada en un orden intermedio entre las halladas para las pesquisas de PKU y FQ, y obviamente muy por debajo de la de Galactosemia, precisamente por el hecho de que su incidencia y la severidad del cuadro clínico propio de las formas Perdedoras de sal determinan que, en aquellos casos en los cuales no se dispone de una cantidad de sangre suficiente como para realizar la totalidad de las pruebas solicitadas, su pesquisa se priorice a la de FQ y Galactosemia.

En lo que hace a la recuperación de segundas muestras solicitadas, el índice encontrado para muestras mal colectadas $(75,3 \%)$ es el más alto de las 5 patologías discutidas hasta este momento, mientras que los correspondientes a muestras colectadas con EDTA y a muestras que no eluyen son significativamente más altos que los observados en el caso de $H C$ y $F Q$, que son las otras 2 patologías cuyas pruebas se realizan empleando la metodología DELFIA/AutoDELFIA y que por lo tanto pueden resultar afectadas por este tipo de situaciones.

\section{BIBLIOGRAFIA}

20. Torresani T, Biason-Lauber A. "Congenital Adrenal Hyperplasia: Diagnistic Advances". J Inherit Metab Dis, 30, 563-75, 2007.

21. American Academy of Pediatrics, Kaye $C$ and the Committee on Genetics. "Newborn Screening Fact Sheets". Pediatr, 118, 934-63, 2006. 
22. American Academy of Pediatrics - Section on Endocrinology and Committee on Genetics. "Technical Report: Congenital Adrenal Hyperplasia". Pediatr 106, $1511-$ $8,2000$.

23. Olgemöller B, Roscher A, Liebl B, Fingerhut R. "Screening for Congenital Adrenal Hyperplasia: Adjustment of 17-Hidroxyprogesterone Cut-Off Values to Both Age and Birth Weight Markedly Improves the Predictive Value". J Clin Endocrinol Metab, 88, 5790-4, 2003.

24. Therrell B. "Newborn Screening for Congenital Adrenal Hyperplasia". Endocrinol Metab Clin North America 30, 15-30, 2001.

25. Honour $J$ and Torresani T. "Draft ESPE Guidelines for Neonatal Screening for Congenital Adrenal Hyperplasia $(C A H)$ ". Proceedings of the " $5^{\text {th }}$ Joint Meeting of the European Society for Paediatric Endocrinology". Stockholm -Sweden, 1997.

26. Pistaccio L, Gómez F, Di Carlo C, Adam M, Lanz M, Castillo P y Borrajo G. "Cut-Off Ajustado al Peso al Nacimiento en la Pesquisa Neonatal de Hiperplasia Suprarrenal Congénita". Libro de Resúmenes "XXXVIII Reunión de la Sociedad Latinoamericana de Investigación Pediátrica (SLAIP) y XIV Reunión de la Sociedad Latinoamericana de Endocrinología Pediátrica (SLEP)". Ushuaia - Tierra del Fuego, 2000.

27. Pistaccio L, Gómez F, Di Carlo C, Castillo P, Lanz M, Adam M y Borrajo G. "Valores de Corte para 17OH-Progesterona Ajustados según el Peso al Nacimiento por Del-fia y AutoDelfia". Libro de Resúmenes "III Congreso Latinoamericano de Errores Innatos del Metabolismo y Pesquisa Neonatal". Cartagena - Colombia, 2001.

28. Borrajo G, Pistaccio L, Gómez F, Di Carlo C, Castillo P y Dietz M. "Evaluación Comparativa de dos Versiones del Kit AutoDELFIA Neonatal 17 OH-Progesterone". Libro de Resúmenes "V Congreso Latinoamericano de Errores Innatos del Metabolismo y Pesquisa Neonatal". San José - Costa Rica, 2005.

29. Borrajo G, Pistaccio L, Gomez F, Di Carlo C, Castillo P and Dietz M. "Definition of a 17OH-Progesterone Birth Weight Adjusted Cut-Off Value Using AutoDELFIA Method Version B015". Proceedings of the " 6 th Meeting of the 
International Society for Neonatal Screening (ISNS)". Awaji, Hyogo \& Tokushima - Japón, 2006.

30. Borrajo G, Gómez F, Di Carlo C, Castillo P, Dietz M. "Birth Weight Adjusted Cut-off Value for the AutoDELFIA Neonatal $17 \alpha-\mathrm{OH}$-Progesterone Kit, Version B024-112 (Abstract)". Rev Invest Clin 61, 73, 2009. 
CAPÍTULO 13

PESQUISA NEONATAL

DE DEFICIENCIA

DE BIOTINIDASA 



\section{- INTRODUCCIÓN}

La Deficiencia de Biotinidasa, conocida también como Deficiencia Múltiple de Carboxilasas de comienzo tardío o juvenil, es un ECM de la Biotina, una vitamina del grupo $B$, que se transmite con un patrón de herencia autosómico recesivo y se presenta con una frecuencia de $1: 40.000$ nacidos vivos $(1,2)$.

El defecto bioquímico específico que da lugar al cuadro clínico es una deficiencia en la enzima Biotinidasa, la cual genera como consecuencia una incapacidad del organismo para recuperar la Biotina a partir de los productos de degradación de cuatro carboxilasas específicas que requieren la incorporación de una molécula de Biotina como grupo prostético para poder pasar desde su forma apoenzima inactiva a su forma holoenzima activa. De esta forma, y en función del mecanismo que se encuentra afectado, la Deficiencia de Biotinidasa es considerada un defecto en el reciclado de la Biotina, cuyo efecto se traduce en una disponibilidad disminuida de la misma para su reutilización en nuevos ciclos de activación de las carboxilasas, causando consecuentemente una deficiencia secundaria de las mismas.

En cuanto a las carboxilasas que se encuentran afectadas, las mismas son la Propionil-CoA Carboxilasa, la 3-Metil-Crotonil-CoA Carboxilasa, la Piruvato Carboxilasa y la Acetil-CoA Carboxilasa. Dadas las rutas metabólicas en las que dichas enzimas se encuentran involucradas, tanto la Biotina como la enzima Biotinidasa resultan indirectamente vinculadas con el metabolismo de Hidratos de Carbono a través de la Gluconeogénesis, con el metabolismo de Proteínas a través del catabolismo de determinados aminoácidos, y con el metabolismo de Lípidos a través de la síntesis de ácidos grasos y la degradación de ácidos grasos de cadena impar $(1,2)$.

Como consecuencia de la disfuncionalidad de estas enzimas, bioquímicamente se va a presentar una hiperamonemia moderada acompañada de la acumulación de una serie de metabolitos como lactato, propionato, 3-OH-propionato, metilcitrato, 3-metilcrotonil-glicina y 3-OH-valerato, los cuales son responsables tanto de la cetoacidosis metabólica observada como del patrón de excreción de ácidos orgánicos urinarios característico de la enfermedad no tratada. 
Clínicamente, y en forma general, se puede decir que la patología se caracteriza por presentar síntomas que pueden ser agrupados en neurológicos, respiratorios y cutáneos. Sin embargo, el hecho de que se expresen todos o solamente un grupo de ellos va a depender de que se esté frente a una Deficiencia Absoluta o Profunda de la enzima, en cuyo caso su actividad va ser menor al $10 \%$; o frente a una Deficiencia Parcial de la misma, en cuyo caso su actividad va estar comprendida entre el 10 y el $30 \%$ y el cuadro clínico se caracterizará exclusivamente por la presencia de síntomas cutáneos (1-3).

De este modo, los individuos afectados por una Deficiencia Profunda de Biotinidasa van a presentar convulsiones, ataxia, hipotonía, sordera, atrofia del nervio óptico, hiperventilación, estridor, apneas, retraso del crecimiento, rash cutáneo, dermatitis seborreica, alopecía, disfunción inmunorregulatoria, conjuntivitis, infecciones micóticas $y$, eventualmente, coma y muerte. Por otra parte, dado que estos síntomas aparecen en promedio a la edad de 3 meses -aunque su aparición puede retrasarse hasta los 2 años de edad- (1-3), las Deficiencias Profundas constituyen el objetivo principal perseguido a través de la PN.

En lo que respecta al tratamiento, el mismo resulta sumamente simple puesto que consiste en la administración oral de Biotina bajo la forma de Biotina libre, en dosis farmacológicas del orden de $5-20 \mathrm{mg} /$ día (3). A través de dicho tratamiento será posible aportar una cantidad apropiada de sustrato para permitir la activación de las carboxilasas, y evitar así la acumulación tanto de ácidos orgánicos como de productos de degradación de estas enzimas como son la Biocitina y los Biotinilpéptidos cortos -todos ellos responsables de la patogenia de la enfermedad-, posibilitando así evitar la instalación del cuadro clínico característico.

Por último, en lo que respecta a la PN y al diagnóstico de la patología, la pesquisa es un procedimiento que se puede realizar de manera muy sencilla llevando a cabo la determinación de la actividad de la enzima Biotinidasa en DBS, resultando necesaria la determinación de dicha actividad enzimática en muestras de suero para la confirmación de la misma (3). Complementariamente, las pruebas confirmatorias incluyen también la determinación de Lactato, ión $\mathrm{NH}_{4}{ }^{+}$y anión Gap, ácidos orgánicos 
urinarios a fin de verificar las características de su patrón de excreción, y la determinación de la actividad de la enzima Biotinidasa en los progenitores. Adicionalmente, en caso de que se disponga de métodos moleculares para la búsqueda de las diferentes mutaciones que pueden estar afectando al gen que codifica para la enzima Biotinidasa, se deben incluir también estos estudios.

\section{Pesquisa Neonatal}

- Período de trabajo evaluado: Diciembre 1997 - Diciembre 2009.

- Métodos: en la Tabla 75 se presentan los diferentes métodos utilizados en la PN de Deficiencia de Biotinidasa y a continuación se describe el fundamento de los mismos:

Tabla 75. Métodos utilizados en la PN de Deficiencia de Biotinidasa

\begin{tabular}{|c|c|}
\hline Período & Método \\
\hline Jul/1997 - Dic/1999 & $\begin{array}{l}\text { Método Colorimétrico - Cuantitativo de desarrollo propio, } \\
\text { basado en el método de Wolf y cols, con calibradores } \\
\text { líquidos. }\end{array}$ \\
\hline Ene/2000 - Dic/2009 & $\begin{array}{l}\text { Método Colorimétrico - Cuantitativo de desarrollo propio, } \\
\text { basado en el método de Wolf y cols, con calibradores en } \\
\text { DBS. }\end{array}$ \\
\hline
\end{tabular}

- Método Colorimétrico - Cuantitativo de desarrollo propio, con calibradores líquidos: El desarrollo y optimización de éste método, basado en la descripción de Heard, Secor McVoy and Wolf (4), fue realizado en el Laboratorio de Detección de Errores Congénitos de la FBA.

Fundamento: La enzima Biotinidasa presente en muestras de sangre entera colectadas en papel de filtro es eluida con una solución del sustrato ácido Biotinil-p-aminobenzoico (Biotinil-PABA), el cual es desdoblado en Biotina y PABA por la actividad de la Biotinidasa. Posteriormente el PABA formado es revelado mediante una reacción de diazotación/copulación con $\mathrm{NaNO}_{2}$, Sulfamato de $\mathrm{NH}_{4}^{+}$y N-1-Naftil-Etilendiamina (NNED) para dar lugar a la formación de un diazocompuesto de color púrpura (Figura 155), cuantificable a 
$\lambda=540 \mathrm{~nm}$ con respecto a una curva de calibración líquida de PABA, cuya intensidad de color es proporcional a la actividad de Biotinidasa presente en la muestra.

$$
\begin{aligned}
& \text { Biotinil-PABA Biotinidasa } \\
& \text { PABA }+\mathrm{NaNO}_{2}+\text { Sulfamato } \mathrm{NH}_{4}^{+}+\mathrm{NNED} \longrightarrow \begin{array}{l}
\text { Diazocompuesto } \\
\text { color púrpura }
\end{array}
\end{aligned}
$$

Figura 155. Fundamento del Método Colorimétrico - Cuantitativo de desarrollo propio para la medida de Biotinidasa.

Para el desarrollo del método se llevó a cabo la preparación y adecuación de todos los reactivos necesarios y la optimización de los diferentes parámetros del ensayo tomando en cuenta además la experiencia de Yamaguchi y cols. (5), habiéndose introducido una modificación en el mismo consistente en el agregado de un detergente no iónico en la preparación del reactivo $\mathrm{NaNO}_{2}$ utilizado en la reacción de diazotación a efectos de minimizar la formación de burbujas sobre el fondo y las paredes de los pocillos, las cuales al interponerse con el haz de luz al momento de la lectura pueden dar lugar a resultados erróneos.

En el Anexo 5, se describe en detalle la preparación de reactivos y el protocolo de ensayo correspondiente al Método Colorimétrico - Cuantitativo de desarrollo propio con calibradores líquidos de PABA.

- Método Colorimétrico - Cuantitativo de desarrollo propio, con calibradores preparados en DBS:

Fundamento: el fundamento de este método es el mismo que el descripto para el método anterior, con la diferencia de que en este caso se introdujo la utilización de calibradores preparados en DBS en lugar de los calibradores líquidos de PABA utilizados en el caso anterior.

En relación a esta modificación se debe destacar que la misma significó un avance de enorme trascendencia tanto para los aspectos operativos como para 
los aspectos analíticos del mismo, puesto que a partir de la implementación de la misma fue posible eliminar el efecto de una serie de variables que ejercen una gran influencia sobre los resultados de los ensayos y que habitualmente no tienen forma de ser controladas cuando la calibración se realiza utilizando calibradores líquidos de PABA. A continuación se presenta una somera descripción de dichas variables:

a) La presencia de un efecto de matriz resultante del hecho de que los calibradores de PABA son preparados en solución acuosa, mientras que las muestras de RN son muestras de sangre entera impregnada en un soporte de papel de filtro, las que obviamente contienen glóbulos rojos y otras células sanguíneas, proteínas y hemoglobina.

b) Que los calibradores líquidos de PABA no son sometidos exactamente al mismo proceso que las muestras de RN debido a que dichos calibradores comienzan a procesarse recién a partir del paso de revelado, es decir a partir de la reacción de diazotación/copulación.

c) Que a consecuencia de lo indicado en el punto b), cualquier situación que pudiera afectar la eficiencia de elución de las muestras del papel de filtro, la temperatura, humedad y tiempo de incubación con el sustrato BiotinilPABA, la eficiencia de precipitación de proteínas con Acido Tricloroacético, la eficiencia de separación de estas proteínas, y/o la transferencia de eluidos, afectará exclusivamente los resultados de las muestras de sangre, sin que la misma influya sobre los resultados obtenidos con los calibradores líquidos.

En cuanto al protocolo utilizado para la preparación de los calibradores de Biotinidasa, debe destacarse que el mismo fue desarrollado íntegramente en el Laboratorio de Detección de Errores Congénitos de la FBA haciendo uso de una de las propiedades de la enzima Biotinidasa de resultar inactivada por calentamiento a $60^{\circ} \mathrm{C}(6)$.

En el Anexo 6, se describe en detalle el procedimiento de ensayo correspondiente al Método Colorimétrico - Cuantitativo de desarrollo propio 
con calibradores preparados en DBS, mientras que en el Anexo 7 se describe el procedimiento de preparación de calibradores de Biotinidasa en DBS.

- Condiciones para la recolección de muestras: a lo largo de todo el período evaluado, las condiciones de recolección de muestras recomendadas para la PN de Deficiencia de Biotinidasa establecían un tiempo mínimo de recolección de muestras a partir de las 24 horas de vida, fijándose el tiempo máximo en 7 días de vida.

- Control de Calidad: El control de calidad de los métodos utilizados en la PN de Deficiencia de Biotinidasa se llevó a cabo mediante la implementación de un estricto Sistema de Control de Calidad Interno y mediante la participación en 2 Programas de Evaluación Externa de Calidad (EEC):

- Control de Calidad Interno: Para la implementación del Sistema de Control de Calidad Interno se utilizaron materiales de control de diferentes procedencias, entre los que se pueden citar los provistos por Programas de EEC como el Newborn Screening Quality Assurance Program - Human Genetic Society for Australasia (NSQAP-HGSA) de Nueva Zelanda, o aquellos preparados en nuestro propio Laboratorio $\left(^{*}\right)$.

NOTA: los materiales de control marcados con (*) son los que se encuentran en uso en la actualidad.

- Evaluación Externa de Calidad: a continuación se listan los Programas de EEC en los cuales se participó en el período evaluado.

- Newborn Screening Quality Assurance Program - Human Genetic Society for Australasia (NSQAP-HGSA). Auckland - New Zealand, desde Noviembre de 1996 hasta Enero de 2003 (programa discontinuado por sus propios organizadores).

- Newborn Screening Quality Assurance Program. Centers for Disease Control and Prevention (NSQAP-CDC). Atlanta - EE.UU., desde Octubre de 1997 hasta la fecha.

- Valores de Corte: en la Tabla 74 se presentan los diferentes VC utilizados en la PN de Deficiencia de Biotinidasa a lo largo del período evaluado, y a continuación se presenta una discusión detallada de los mismos: 
Tabla 74. VC utilizados en la PN de Deficiencia de Biotinidasa

\begin{tabular}{|c|c|c|}
\hline Período & $V C_{1}$ & $V C_{2}$ \\
\hline Dic/1997 - Abr/1998 & $0,200 \mathrm{nmol} / \mathrm{min} \cdot \mathrm{ml}$ & --- \\
\hline May/1998 - Jul/2008 & $0,500 \mathrm{nmol} / \mathrm{min} \cdot \mathrm{ml}$ & $0,200 \mathrm{nmol} / \mathrm{min} \cdot \mathrm{ml}$ \\
\hline Ago/2008 - Dic/2009 & $0,800 \mathrm{nmol} / \mathrm{min} \cdot \mathrm{ml}$ & $0,200 \mathrm{nmol} / \mathrm{min} \cdot \mathrm{ml}$ \\
\hline
\end{tabular}

Con respecto a los VC utilizados se debe mencionar que el VC inicial fue definido en forma preliminar a partir de un estudio de distribución poblacional, habiéndose reevaluado y modificado pocos meses después, una vez que se contó con una cantidad de datos más significativos desde el punto de vista estadístico.

Este primer cambio no sólo implicó incrementar el $V C_{1}$ (tener en cuenta que como se trata de una deficiencia los valores anormales son los valores disminuidos), sino que también se incorporó un segundo $V C\left(V C_{2}\right)$ que permitía definir una categoría de resultados "Dudosos" y otra de resultados "Patológicos", siendo en principio los resultados Patológicos los que presentan mayor probabilidad de que se trate de una Deficiencia Absoluta.

No obstante esto, debe mencionarse que el algoritmo de trabajo definido para esta pesquisa no contempla en ningún caso la derivación de los RN a partir del resultado obtenido en la primera muestra, aún cuando el resultado obtenido se encuentre por debajo del $V C_{2}$, sino que por el contrario, siempre se solicita una segunda muestra en papel.

Finalmente, la última modificación en el VC se introdujo en Agosto del año 2008, a partir de la introducción de una serie de mejoras tanto en la técnica de preparación de los calibradores en DBS como en el procedimiento para la asignación de valores a los mismos, con lo cual el cambio implicó aumentar el $V C_{1}$ a $0,800 \mathrm{nmol} / \mathrm{min} / \mathrm{ml}$ suero.

- Algoritmo de trabajo: En la Figura 156 se describe el algoritmo de trabajo utilizado en la actualidad para la pesquisa de Deficiencia de Biotinidasa en el cual las unidades de Biotinidasa están expresadas en $\mathrm{nmol} / \mathrm{min} / \mathrm{ml}$ suero. 


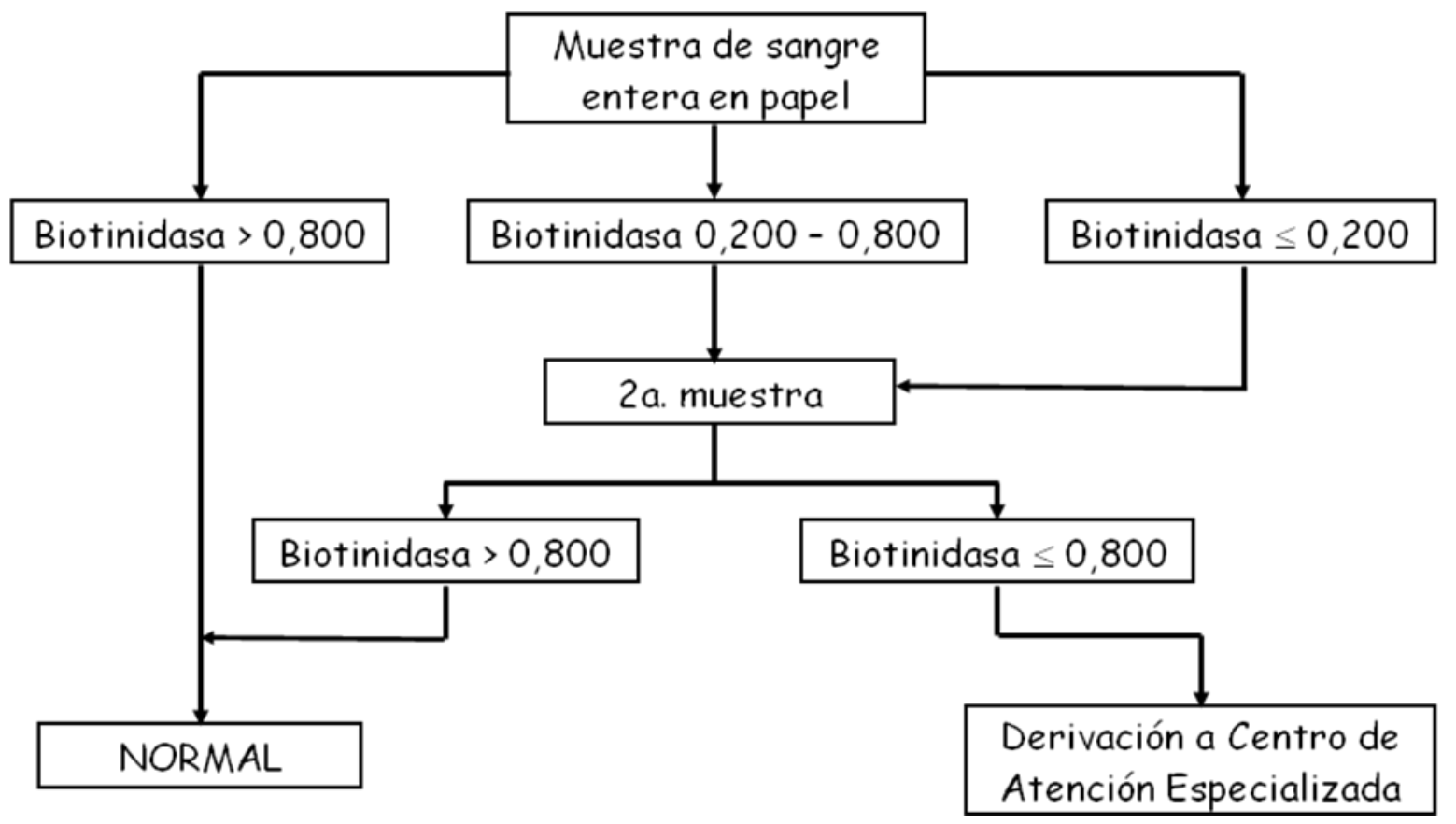

Figura 156. Algoritmo de trabajo para la PN de Deficiencia de Biotinidasa.

- Resultados: La PN de Deficiencia de Biotinidasa se implementó en el Laboratorio de Detección de Errores Congénitos de la Fundación Bioquímica Argentina en Diciembre de 1997 en forma simultánea con la pesquisa de HSC y siguiendo la misma modalidad de trabajo que para aquella, motivo por el cual le caben los mismos comentarios que se realizaron en el Capítulo 12 en cuanto a su ejecución a demanda y también las mismas consideraciones en relación a la Ley Nacional 26279/07 y a la Ley Provincial 13905/08, las cuales en ambos casos contemplan la obligatoriedad de dicha pesquisa. Considerando entonces que para la detección de la Deficiencia de Biotinidasa no se disponía de una estructura real de programa, a fin de cumplimentar las instancias de confirmación, diagnóstico, tratamiento y seguimiento de los casos detectados se contó con el soporte de los Servicios de Neurología y de Laboratorio Central del Hospital de Niños "Sor María Ludovica" de La Plata.

En la Figura 157 se presenta la evolución experimentada en el número de RN pesquisados anualmente para Deficiencia de Biotinidasa a lo largo del período evaluado, mientras que en la Figura 158 se presenta la secuencia general de pesquisa, incluyendo el número total de neonatos pesquisados, el número de RN a 
los cuales se les solicitó una segunda muestra, y el número de casos detectados tanto de Deficiencias Absolutas como de Deficiencias Parciales de Biotinidasa con sus correspondientes incidencias.

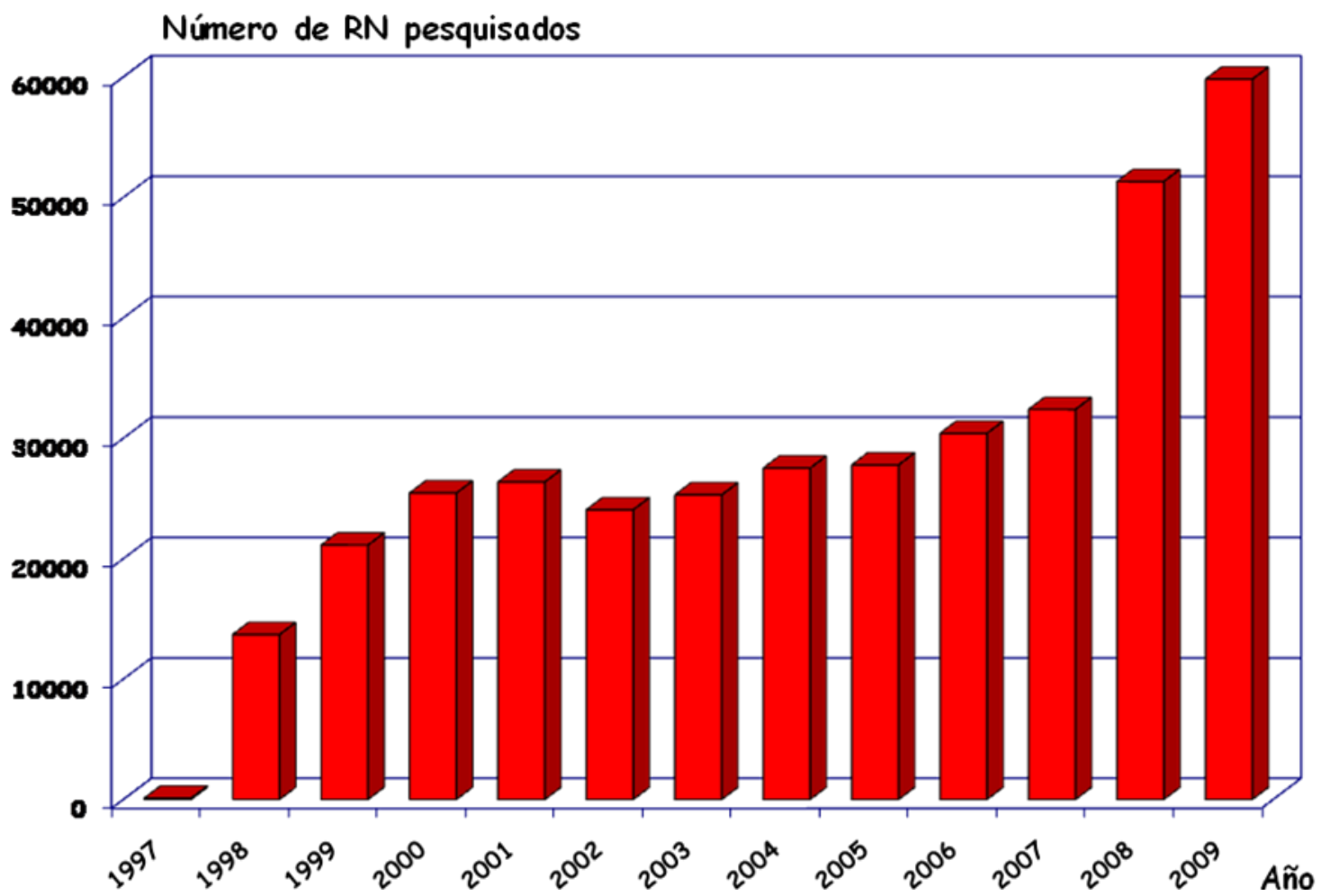

Figura 157. Número de RN pesquisados año a año para Def.de Biotinidasa.

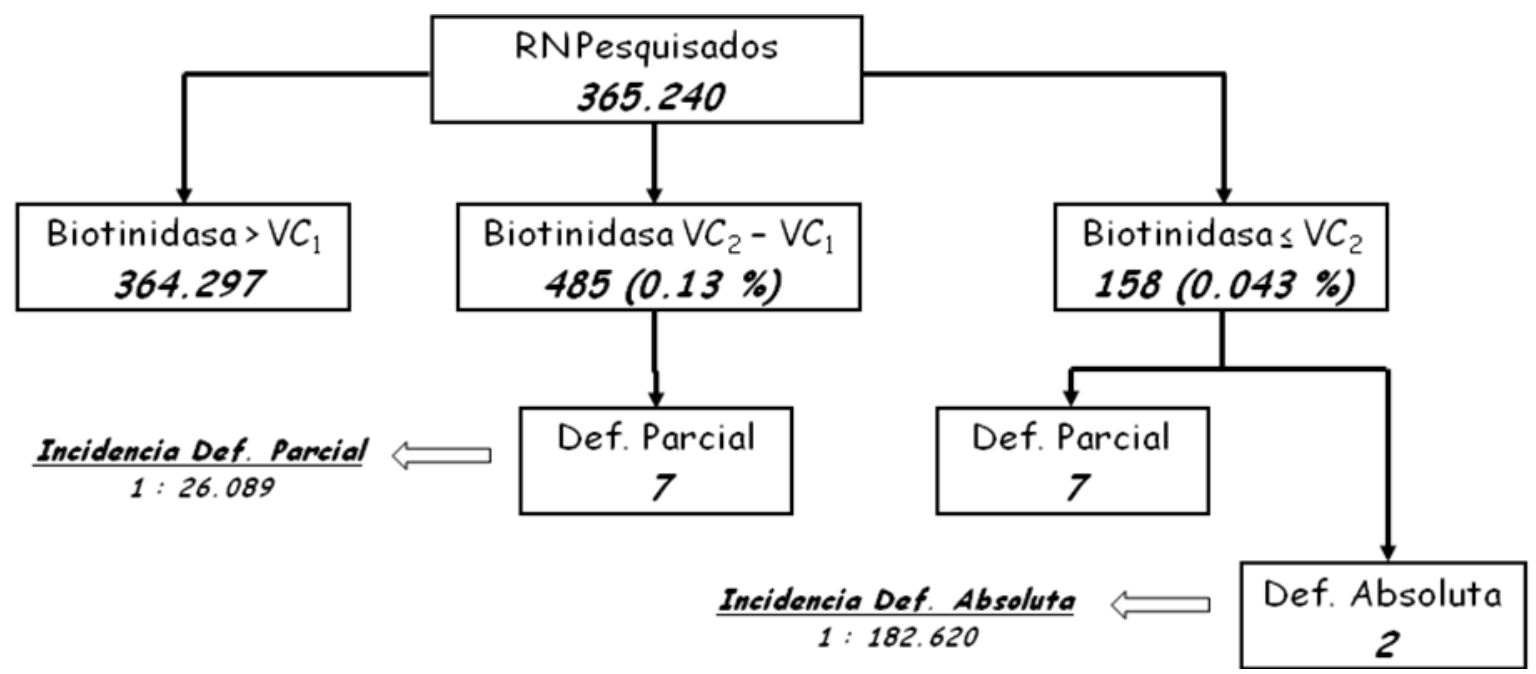

Figura 158. Resultados de la pesquisa de Deficiencia de Biotinidasa.

Con respecto a la evolución en el número anual de RN pesquisados que se presenta en la Figura 157, se puede observar que el patrón de crecimiento experi- 
mentado es cualitativamente similar al ya descripto para HSC pero con un número inferior de RN pesquisados, y con una única diferencia significativa determinada por el hecho de que, en el caso de la Deficiencia de Biotinidasa, la crisis económica de fines de 2001 repercutió directamente en la magnitud en que se solicitaba dicha pesquisa, traduciéndose este efecto en una disminución en el número de RN pesquisados a lo largo del año 2002. Por otra parte, y del mismo modo que ocurrió en el caso de la HSC, la sanción de la Ley Nacional 26279/07 tuvo una muy fuerte influencia en el número de RN pesquisados a lo largo de los años 2008 y 2009. alcanzándose este último año el punto máximo de todo el período evaluado en algo menos de 60.000 RN pesquisados al año.

En cuanto a la secuencia general de pesquisa presentada en la Figura 158, hay varios aspectos para destacar: por un lado, la baja tasa de recitación por resultados anormales $(0,18 \%)$ que se ubica dentro de un rango de valores óptimos, y la llamativamente baja incidencia de la Deficiencia Absoluta de Biotinidasa (1: 182.620) que se encuentra muy por debajo de la descripta bibliográficamente (1), mientras que por el otro, el hecho de que dentro del grupo de RN con resultados de Biotinidasa $\leq 0,200 \mathrm{nmol} / \mathrm{min} / \mathrm{ml}$ suero entre los cuales se confirmaron 7 Deficiencias Parciales, los únicos casos que presentaron una actividad no dosable de la enzima Biotinidasa fueron precisamente aquellos RN diagnosticados finalmente como Deficiencias Absolutas.

Adicionalmente, en la Tabla 75 se presenta la distribución de los casos detectados según la provincia de procedencia, poniendo en evidencia que la gran mayoría de ellos provienen de la Provincia de Buenos Aires.

Tabla 75. Distribución de casos detectados por Provincia

\begin{tabular}{|c|c|c|}
\hline Provincia & Def. Absoluta & Def. Parcial \\
\hline Buenos Aires & 2 & 12 \\
\hline Entre Ríos & -- & 2 \\
\hline Total & 2 & 14 \\
\hline
\end{tabular}

Finalmente, en la Tabla 76 se presentan algunos parámetros estadísticos que caracterizan el desempeño del sistema de detección utilizado. 
Tabla 76. Parámetros estadísticos de la PN de Def. de Biotinidasa

Tasas de recitación

- Por resultados anormales en primera muestra

- Total período evaluado

$0,18 \%$

- Período 2008-2009

$0,07 \%$

- Por recolección inadecuada de muestras

$0,40 \%$

\section{Recuperación de segundas muestras solicitadas}

- Por recolección inadecuada de muestras

- Total período evaluado

$75,6 \%$

- Período 2003-2009

$79,7 \%$

En relación a la información presentada en la Tabla anterior se debe destacar la disminución experimentada en la tasa de recitación por resultados anormales en los 2 últimos años de trabajo, hecho que sin dudas tiene que ver con el ajuste realizado en la técnica de preparación de calibradores en DBS y en el procedimiento utilizado para la asignación de valores a los mismos que ya fuera mencionado anteriormente, por lo cual a pesar de que en Agosto de 2008 se incrementó el $V C_{1}$ de 0,500 a 0,800 $\mathrm{nmol} / \mathrm{min} / \mathrm{ml}$ suero, el conjunto de cambios se tradujo en un incremento en la especificidad del sistema de detección.

En lo que respecta a la tasa de recitación por muestras mal colectadas, la misma tomó valores similares a los ya mencionados para el caso de la PN de Galactosemia, observándose un índice de recuperación de RN para la recolección de segundas muestras solicitadas por este mismo motivo similar al encontrado en el caso de HSC, pero con la salvedad de que al analizar dicho parámetro específicamente para el período 2003-2009, el mencionado índice resulta ser el más alto del grupo de 6 patologías analizadas hasta este momento $(79,7 \%)$.

\section{BIBLIOGRAFIA}

22. Wolf B. "Disorders of Biotin Metabolism" en "The Online Metabolic and Molecular Bases of Inherited Disease". Valle, Beaudet, Vogelstein, Kinzler, Antonarakis, Ballabio Eds. McGraw-Hill. 8th Edition. Chapter 156, 2008.

23. Perez Cerdá C, Merinero Cortés B. "Alteraciones del Metabolismo de la Biotina", en "Diagnóstico y Tratamiento de las Enfermedades Metabólicas 
Hereditarias". Sanjurjo P, Baldellou A Eds. Editorial Ergon - Madrid, $3^{a}$ Edición. Capítulo 78, 1061-69, 2010.

24. American Academy of Pediatrics, Kaye $C$ and the Committee on Genetics. "Newborn Screening Fact Sheets". Pediatr, 118, 934-63, 2006.

25. Heard G, Secor Mc Voy J and Wolf B. "A Screening Method for Biotinidase Deficiency in Newborns". Clin Chem 30, 125-7, 1984.

26. Yamaguchi A, Fukushi M, Arai O, Mizushima Y, Sato Y, Shimizu Y, Tomidokor $K$ and Takasugi N. "A Simple Method for Quantification of Biotinidase Activity in Dried Blood Spots and its Application to Screening of Biotinidase Deficiency". Tohoku J Exp, 152, 339-46, 1987.

27. Ahola $T$, Hemmila I, Raunio $R$ and Lövgren T. "A Time-Resolved Fluorometric Method for the Measurement of Biotinidase Activity" en "Current Trends in Infant Screening". Schmidt B et al Eds. Elsevier Science Publisher. 265-9, 1989.

28. Dove Pettit D, Amador P and Wolf B. "The Quantitation of Biotinidase Activity in Dried Blood Spots Using Microtiter Transfer Plates: Identification of Biotinidase-Deficient and Heterozygous Individuals". Anal Biochem 179, 371-7, 1989. 


\section{ANEXO 5: METODO COLORIMETRICO - CUANTITATIVO PARA LA MEDIDA DE BIOTINIDASA EN DBS DE DESARROLLO PROPIO, EMPLEANDO CALIBRADORES LIQUIDOS.}

\section{- PREPARACION DE REACTIVOS:}

o Acido Tricloroacético (1.84 M): Pesar 60 gramos de Acido Tricloroacético (Merck, Cat. 1.00807) y disolverlos en $200 \mathrm{ml}$ de $\mathrm{H}_{2} \mathrm{O}$ destilada. Conservar en heladera a $4{ }^{\circ} \mathrm{C}$.

o Biotinil-PABA (157 $\mu M$ ) en buffer Fosfato $63 \mathrm{mM}$ y EDTA 5,2 mM: Pesar 730,6 mg de Acido Etilendiaminotetracético (EDTA) (Sigma E-9884) y llevar a disolución total en $128 \mathrm{ml}$ de $\mathrm{K}_{2} \mathrm{PO}_{4} \mathrm{H}$. Pesar 29,0 mg de Biotinil-PABA (Sigma B5768) y agregar a la solución anterior. Ajustar el pH a 6,0 agregando $\mathrm{K}_{2} \mathrm{PO}_{4} \mathrm{H} O$ $\mathrm{KPO}_{4} \mathrm{H}_{2}$ según corresponda. Llevar a volumen final de $480 \mathrm{ml}$ con buffer Fosfato $63 \mathrm{mM}$ de pH 6,0. Conservar en heladera a $4{ }^{\circ} \mathrm{C}$.

o Buffer Fosfato $63 \mathrm{mM}-\mathrm{pH} 6,0$ :

- $\mathrm{KPO}_{4} \mathrm{H}_{2}$ : pesar 2,17 $\mathrm{g}$ de $\mathrm{KPO}_{4} \mathrm{H}_{2}$ (Merck, Art. 4873) y disolver en $250 \mathrm{ml}$ de $\mathrm{H}_{2} \mathrm{O}$ destilada.

- $K_{2} \mathrm{PO}_{4} \mathrm{H}$ : pesar 2,70 g de $\mathrm{K}_{2} \mathrm{PO}_{4} \mathrm{H}$ (Merck, Art. 5104) y disolver en $250 \mathrm{ml}$ de $\mathrm{H}_{2} \mathrm{O}$ destilada.

Para la obtención del Buffer Fosfato $63 \mathrm{mM}$ de $\mathrm{pH}$ 6,0, mezclar las proporciones adecuadas de $\mathrm{KPO}_{4} \mathrm{H}_{2}$ y $\mathrm{K}_{2} \mathrm{PO}_{4} \mathrm{H}$ hasta alcanzar $\mathrm{pH}=6,0$. Conservar en heladera $a 4^{\circ} \mathrm{C}$.

o $\mathrm{NaNO}_{2}(14.5 \mathrm{mM})$ : Fraccionar en frascos de vidrio a razón de $100 \mathrm{mg}$ de $\mathrm{NaNO}_{2}$ (Merck, Art. 1.06549) por frasco. Conservar los frascos en oscuridad a temperatura ambiente. Para su uso, disolver el $\mathrm{NaNO}_{2}$ en $1 \mathrm{ml}$ de $\mathrm{H}_{2} \mathrm{O}$ destilada inmediatamente antes de usar, y diluir 1/100 con $\mathrm{H}_{2} \mathrm{O}$ destilada adicionada de agente tensioactivo. Descartar el excedente.

- $\mathrm{H}_{2} \mathrm{O}$ destilada con agente tensioactivo: agregar $25 \mu$ de detergente NO ION diluido $1 / 20$ en $\mathrm{H}_{2} \mathrm{O}$ destilada, a un volumen de $250 \mathrm{ml}$ de $\mathrm{H}_{2} \mathrm{O}$ destilada. 
o Sulfamato de $\mathrm{NH}_{4}^{+}(43,8 \mathrm{mM})$ : Pesar 1,25 g de Sulfamato de $\mathrm{NH}_{4}^{+}$(Sigma, Cat. 228745) y disolver en $250 \mathrm{ml}$ de $\mathrm{H}_{2} \mathrm{O}$ destilada. Conservar en heladera a $4^{\circ} \mathrm{C}$.

o N-1-Naftiletiléndiamina (3,86 mM): pesar $250 \mathrm{mg}$ de N-1-Naftiletiléndiamina (Sigma, Cat. 222488) y disolver en $250 \mathrm{ml}$ de $\mathrm{H}_{2} \mathrm{O}$ destilada. Conservar en heladera a $4^{\circ} \mathrm{C}$ en frasco color caramelo.

o Solución madre de PABA (2 mM): pesar 68,6 mg de PABA (Sigma, A-1174) y disolver en $250 \mathrm{ml}$ de $\mathrm{H}_{2} \mathrm{O}$ destilada. Almacenar en heladera a $4{ }^{\circ} \mathrm{C}(7)$.

o Soluciones de trabajo de PABA: Para obtener los distintos puntos de la curva de calibración, la Solución madre de PABA se diluye 1/10 en $\mathrm{H}_{2} \mathrm{O}$ destilada. $A$ partir de esta solución se preparan diluciones seriadas al medio de manera tal de obtener concentraciones finales de 0,100;0,050;0,025; 0,0125 y $0,00625 \mathrm{mM}$.

\section{- protocolo de ensayo:}

26. Punchear discos de 1/8" (3,2 mm) de diámetro correspondientes a controles y muestras de RN en microplacas de 96 pocillos fondo en $\mathrm{V}$.

27. Dispensar $60 \mu$ de Biotinil-PABA $157 \mu \mathrm{M}$ en buffer Fosfato $63 \mathrm{mM}$ de $\mathrm{pH}$ 6,0 adicionado de EDTA 5,2 mM, en cada uno de los pocillos. Agitar durante 10 minutos. Observar que los discos queden bien embebidos en la solución.

28. Cubrir las placas con un cubreplacas no adhesivo e incubar durante 16 horas en cámara húmeda a $37^{\circ} \mathrm{C}$.

29. Sacar las placas de la estufa y agregar $60 \mu$ de Acido Tricloroacético 1,84 M. Mezclar por agitación suave y dejar reposar 10 minutos hasta que se formen grumos de proteína precipitada.

30. Centrifugar las microplacas durante 15 minutos a $2000 \mathrm{rpm}$.

31. Transferir $60 \mu$ del sobrenadante de cada pocillo a cada uno de los pocillos correspondientes de una placa transparente de fondo plano.

32. Para la preparación del blanco de reactivos y de la curva de calibración, ambos por duplicado, dispensar $20 \mu$ de Biotinil-PABA en el primer caso y $20 \mu$ de las 
distintas diluciones de PABA recién preparadas. Llevar cada uno de estos pocillos a un volumen de $60 \mu$ dispensando $40 \mu$ de Acido Tricloroacético 1,84 M.

33. Dispensar en cada pocillo $50 \mu$ de solución de $\mathrm{NaNO}_{2} 14,5 \mathrm{mM}$ preparado en el momento. Agitar suavemente e incubar durante 3 minutos a temperatura ambiente.

34. Dispensar en cada pocillo $50 \mu$ de solución de Sulfamato de $\mathrm{NH}_{4}^{+} 43,8 \mathrm{mM}$. Agitar suavemente e incubar 3 minutos a temperatura ambiente.

35.Dispensar en cada pocillo $50 \mu$ de solución de NNED 3,86 mM. Agitar suavemente $e$ incubar 10 minutos a temperatura ambiente hasta que el desarrollo de color se haya completado.

36. Leer en Lector vertical de placas UV-Visible $\lambda=540 \mathrm{~nm} / \lambda_{\text {ref }}=620 \mathrm{~nm}$. EI color es estable al menos por 1 hora.

37. Graficar la absorbancia de cada uno de los calibradores en función de la masa de PABA presente en cada uno de ellos, construir la curva de calibración e interpolar de la misma los nmoles de PABA formados a partir de la Biotinidasa presente en las muestras de RN y controles.

38. Para expresar los resultados en nmoles PABA/min/ml suero, corregir los datos anteriores con un factor de 1,3021 que resulta de aplicar las siguientes correcciones:

- Factor de dilución $=\underline{120 \mu \text { mezcla incubación Biotinil-PABA }}=2$

$$
60 \mu \text { sobrenadante }
$$

- Factor de volumen = $1000 \mu \mathrm{l} / \mathrm{ml}$ $=\frac{1000}{1,6 \mathrm{ml}}$

- Factor de tiempo $=\frac{1}{16 \text { horas }} \times \frac{1 \text { hora }}{60 \mathrm{~min}}=\frac{1}{960 \mathrm{~min}}$ 


\section{ANEXO 6: METODO COLORIMETRICO - CUANTITATIVO PARA LA MEDIDA DE BIOTINIDASA EN DBS DE DESARROLLO PROPIO, EMPLEANDO CALIBRADORES EN DBS.}

\section{- PREPARACION DE REACTIVOS:}

Los reactivos utilizados en esta alternativa son exactamente los mismos que los utilizados en la alternativa descripta en el ANEXO 5, excepto que en este caso no se requiere la preparación de una solución de PABA.

\section{- pRotocolo de eNSAYo:}

1. Punchear discos de $1 / 8 "(3,2 \mathrm{~mm})$ de diámetro correspondientes a calibradores, controles y muestras de RN en microplacas de 96 pocillos fondo en $\mathrm{V}$.

2. Dispensar $60 \mu$ de Biotinil-PABA $157 \mu \mathrm{M}$ en buffer Fosfato $63 \mathrm{mM}$ de $\mathrm{pH}$ 6,0 adicionado de EDTA 5,2 Mm, en cada uno de los pocillos. Agitar durante 10 minutos. Observar que los discos queden bien embebidos en la solución.

3. Cubrir las placas con un cubreplacas no adhesivo e incubar durante 16 horas en cámara húmeda $a 37^{\circ} \mathrm{C}$.

4. Sacar las placas de la estufa y agregar $60 \mu$ de Acido Tricloroacético 1,84 M.

5. Centrifugar las microplacas durante 15 minutos a 2000 rpm.

6. Transferir $60 \mu$ del sobrenadante de cada pocillo a cada uno de los pocillos correspondientes de una placa transparente de fondo plano.

7. Dispensar en cada pocillo $50 \mu$ de solución de $\mathrm{NaNO}_{2} 14,5 \mathrm{mM}$ preparado en el momento. Agitar suavemente $e$ incubar durante 3 minutos a temperatura ambiente.

8. Dispensar en cada pocillo $50 \mu$ de solución de Sulfamato de $\mathrm{NH}_{4}^{+}$43,8 $\mathrm{mM}$. Agitar suavemente e incubar 3 minutos a temperatura ambiente.

9. Dispensar en cada pocillo $50 \mu$ de solución de NNED 3,86 mM. Agitar suavemente $e$ incubar 10 minutos a temperatura ambiente hasta que el desarrollo de color se haya completado.

10. Leer en Lector vertical de placas UV-Visible $\lambda=540 \mathrm{~nm} / \lambda_{\text {ref }}=620 \mathrm{~nm}$. El color 
es estable al menos por 1 hora.

11. Graficar la absorbancia de cada uno de los calibradores en función de la actividad de Biotinidasa expresada en nmoles PABA/min $/ \mathrm{ml}$ suero e interpolar de la misma la actividad de Biotinidasa presente en las muestras de RN y controles. 


\section{ANEXO 7: CALIBRADORES DE BIOTINIDASA EN SANGRE ENTERA, IMPREGNADOS EN PAPEL DE FILTRO.}

\section{- MATERIALES NECESARIOS:}

o Glóbulos rojos:

10.Preparar un pool de glóbulos rojos grupo 0 , factor $\mathrm{Rh}(-)$ a partir del excedente de muestras de sangre entera colectadas con EDTA de 5-10 individuos adultos sanos, donantes de sangre, HIV, HBV y HCV no reactivos, obtenidas para la realización de estudios inmunohematológicos (3-5 $\mathrm{ml}$ de sangre/tubo).

11. Volcar el contenido de todos los tubos en 2 tubos cónicos de $50 \mathrm{ml}$ con tapa a rosca, asegurándose de colocar volúmenes similares en ambos tubos.

12.Centrifugar durante 10 minutos a 3500 rpm. Descartar el plasma y la capa de células formada sobre la superficie del paquete de glóbulos rojos conteniendo plaquetas y glóbulos blancos, aspirando con una pipeta Pasteur descartable.

13.Lavar los glóbulos rojos con solución fisiológica de $\mathrm{NaCl} 9.0 \mathrm{~g} / \mathrm{l}$. Para esto llevar ambos tubos a volumen con la mencionada solución (Vol. final = $45 \mathrm{ml}$ ), homogeneizar por inversión y centrifugar nuevamente por 10 minutos a 3500 rpm. Descartar el líquido de lavado y la capa de células formada sobre la superficie del paquete de glóbulos rojos conteniendo plaquetas y glóbulos blancos, aspirando con una pipeta Pasteur descartable.

14. Repetir el paso 4 dos veces más.

15.Identificar uno de los tubos como $100 \%$ y el otro como $0 \%$.

16.Proceder a realizar un lavado adicional de ambas alícuotas en las mismas condiciones que en el paso 4 pero empleando en lugar de solución fisiológica, el Suero 100 \% para la fracción de glóbulos rojos identificados como $100 \%$ y el Suero con actividad $0 \%$ de Biotinidasa para la fracción de glóbulos rojos identificados como $0 \%$. Descartar el suero del sobrenadante.

17. Homogeneizar por inversión suave. 
18. Medir el hematocrito, el cual deberá estar en el orden del $85 \pm 5 \%$.

19. Almacenar en heladera a $4{ }^{\circ} \mathrm{C}$ hasta el momento de uso.

o Pool de Suero normal:

6. Preparar un pool de sueros de cualquier grupo y factor a partir del excedente del suero proveniente de muestras de sangre colectadas sin anticoagulante de 30-40 individuos adultos sanos, donantes de sangre, HIV, HBV y HCV no reactivos, obtenidos para la realización de estudios inmunoserológicos, asegurándose que los sueros seleccionados sean límpidos y libres de lípidos en todos los casos (3-4 $\mathrm{ml}$ de suero/tubo).

7. Volcar el contenido de todos los tubos en un frasco apropiado con tapa a rosca, con capacidad de 100 a $150 \mathrm{ml}$.

8. Incubar el pool de sueros 30 minutos adicionales a $37^{\circ} \mathrm{C}$ a efectos de asegurar la desfibrinación completa del mismo.

9. Centrifugar el pool de sueros 5 minutos a 3500 rpm a efectos de eliminar cualquier coágulo de fibrina que pudiera estar presente. Si aún así se encontraran microcoágulos o partículas proceder a efectuar un filtrado del mismo.

10. Dividir el pool de sueros en 2 fracciones de volúmenes similares que se identificarán como $100 \%$ y $0 \%$.

11. Colocar la fracción $100 \%$ del pool de sueros en heladera a $4{ }^{\circ} \mathrm{C}$ hasta el momento de uso.

\section{- PROCEDIMIENTO DE PREPARACIÓN}

- Obtención del Suero con actividad 0 \% de Biotinidasa:

1. Distribuir la fracción $0 \%$ obtenida en el paso anterior en los pocillos de dos microplacas de 96 pocillos a razón de $200 \mu$ lpocillo, y llevar a incubar a 60 ${ }^{\circ} \mathrm{C}$ durante 2 horas en incubador Thermomix, a efectos de asegurar un calentamiento homogéneo de todos los pocillos.

2. Una vez concluida dicha incubación colectar el suero de todos los pocillos y volcar en un tubo cónico de $50 \mathrm{ml}$. 
- Preparación de la sangre entera con hematocrito $50 \%$, y actividad de Biotinidasa $0 \%$ y $100 \%$ :

1. Permitir que todos los componentes necesarios para la preparación alcancen temperatura ambiente.

2. Mezclar por un lado, 1 volumen del pool de glóbulos rojos lavados $100 \%$ y $n$ volúmenes del pool de sueros $100 \%$, y por el otro, 1 volumen del pool de glóbulos rojos lavados $0 \%$ y $n$ volúmenes del Suero con actividad $0 \%$ de Biotinidasa, de manera tal de obtener en ambos casos sangre entera con un hematocrito de aproximadamente el $50 \%$.

NOTA: El volumen del pool de sueros a adicionar dependerá del hematocrito alcanzado en el pool de glóbulos rojos lavados con suero. Por ejemplo si el mencionado hematocrito fuera $85 \%$, entonces n será igual a 0.7 .

3. Homogeneizar la sangre por inversión suave.

4. Medir el hematocrito utilizando un contador hematológico, y proceder a quitar o a agregar el volumen apropiado de suero según corresponda, a fin de ajustar el hematocrito al $50 \%$.

- Preparación de la sangre entera con hematocrito $50 \%$, y actividades de Biotinidasa intermedias entre $0 \%$ y $100 \%$ :

1. Definir las fracciones con actividades intermedias de Biotinidasa que se deseen preparar, por ejemplo $10,25,50$ y $75 \%$.

2. Realizar la preparación de dichas fracciones dispensando los volúmenes apropiados de la sangre entera con actividad de Biotinidasa 0 y $100 \%$, conservando una alícuota de actividad $0 \%$ y otra de actividad $100 \%$.

3. Homogeneizar perfectamente cada una de las fracciones.

4. Impregnar cada fracción a razón de $70 \mu$ de sangre por mancha en hojas de papel de filtro Whatman \# 903 previamente rotuladas al efecto de la preparación de los calibradores, de manera tal de poder cortar tiras conteniendo una mancha de cada nivel.

5. Dejar secar a temperatura ambiente durante una noche y fraccionar en bolsas de plástico aluminizado adicionadas de desecantes. 
6. Conservar en freezer $a-20{ }^{\circ} \mathrm{C}$. En estas condiciones los calibradores son estables al menos durante 1 año.

- Asignación de actividades absolutas de Biotinidasa a los calibradores:

La calibración de los estándares se realiza siguiendo las pautas generales para la determinación de actividades enzimáticas.

En este caso en particular, para efectuar la calibración de los estándares preparados en papel de filtro, los mismos deben procesarse como si se tratara de muestras desconocidas siguiendo el protocolo descripto en el ANEXO 5 (Método Colorimétrico - Cuantitativo para la medida de Biotinidasa en DBS de desarrollo propio, empleando calibradores líquidos), utilizando como referencia una curva de calibración líquida de PABA.

Realizar al menos entre 5 y 10 corridas independientes asegurando el control de todas las variables que pueden afectar los resultados de los calibradores preparados en DBS. En caso de que en alguna corrida esto no ocurriera, descartar la misma y proceder a hacer una nueva corrida.

Una vez concluido todo el procedimiento anterior proceder a realizar un análisis estadístico de los datos de manera tal de poder asignar la actividad absoluta de Biotinidasa que le corresponde a cada calibrador expresado en nmoles PABA/min $/ \mathrm{ml}$ suero. 


\section{CAPÍTULO 14}

PESQUISA NEONATAL DE

ENFERMEDAD DE ORINA

$\triangle E$ JARABE DE ARCE 



\section{- INTRODUCCIÓN}

La Enfermedad de Orina de Jarabe de Arce (MSUD) o Leucinosis, es un ECM de los aminoácidos de cadena ramificada (BCAA) Leucina (Leu), Isoleucina (Ile) y Valina ( $\mathrm{Val})$, que se transmite con un patrón de herencia autosómico recesivo y se presenta con una frecuencia de $1: 185.000$ nacidos vivos (1-3).

La patología es causada por una deficiencia a nivel del complejo multienzimático Deshidrogenasa de los $\alpha$-cetoácidos de cadena ramificada (BCKA) de localización intramitocondrial. Como consecuencia de esta deficiencia se produce un incremento en los niveles de BCAA, de sus correspondientes BCKA ( $\alpha$-cetoisocaproico, $\alpha$-ceto- $\beta$ metilvalérico y $\alpha$-cetoisovalérico), y también de Aloisoleucina (Alo-Ile) siendo este un hallazgo patognomónico de la enfermedad (2). Dicho complejo multienzimático consta de 3 componentes catalíticos: E1 o Decarboxilasa el cual está formado por dos subunidades -E1 $\alpha$ y E1 $\beta$ - y es dependiente de tiamina; E2 o Dihidrolipoil Transacilasa; y E3 o Dihidrolipoil Deshidrogenasa, componentes que en todos los casos pueden resultar afectados por diferentes mutaciones dando lugar al cuadro de la MSUD.

Clínicamente la enfermedad se puede agrupar de acuerdo a sus formas de presentación clínica en aquellas de inicio neonatal grave, las de comienzo tardío con sintomatología intermitente, y las formas crónicas progresivas, clasificándose a su vez en 5 formas fenotípicas (1) que son detalladas en la Tabla 77 y descriptas a continuación:

Tabla 77. Clasificación clínica de la MSUD

- Clásica

- Intermedia

- Intermitente

- Sensible a Tiamina

- Deficiencia de Dihidrolipoil Deshidrogenasa (E3)

La forma más severa y frecuente resulta ser la forma Clásica, la cual corresponde al $80 \%$ del total de casos. La misma se presenta sin síntomas al nacer, pero entre el $4^{\circ}$ y el $7^{\circ}$ día de vida puede comenzar a expresar su cuadro clínico, el cual inicialmente se caracteriza por succión débil, rechazo de alimento, letargia e 
hipotonía que se intensifican con el paso del tiempo, bradicardia, bradipnea, movimientos de boxeo o pedaleo, tremulaciones, postura en opistótonos y olor dulzón en la orina, mostrando una evolución posterior hacia la encefalopatía, edema cerebral, coma y muerte. En esta forma la actividad residual de la enzima oscila entre 0 y $2 \%(1-3)$.

La forma Intermedia se puede presentar asintomática por períodos de tiempo variables que van según el caso desde los 5 meses hasta los 7 años de edad, mostrando luego diversos signos neurológicos progresivos como retraso psicomotor, convulsiones, ataxia, retraso mental, desmedro, anorexia y vómitos crónicos. En este caso, y dado que la actividad residual de la enzima oscila entre el 3 y el $30 \%$, la misma manifiesta un aumento de BCAA, BCKA y Alo-Ile, pero de menor magnitud que en la forma Clásica, correspondiéndole una muy baja frecuencia de presentación $(1,2)$.

En cuanto a la Forma Intermitente, la misma se caracteriza por presentar crecimiento y desarrollo psicomotor e intelectual normales, con síntomas que pueden aparecer a cualquier edad pero asociados a factores catabólicos desencadenantes como infecciones, cirugías y quemaduras. En tal caso los signos neurológicos son graves y semejantes a los de la forma Clásica, pudiendo desencadenar crisis letales. En esta forma la actividad de la Deshidrogenasa es del 5-20\%, presentándose niveles de BCAA y BCKA normales en los períodos intercrisis $(1,2)$.

La forma Sensible a Tiamina comprende un grupo heterogéneo de pacientes, con respuesta variable a Tiamina de 10-1000 mg/día. La sintomatología que se presenta es similar a la de la forma Intermedia, con predominio de retraso psicomotor y crisis desencadenadas por situaciones de estrés, sin signos de encefalopatía aguda. La actividad residual de la enzima es del 2-40 \% (1,2).

Por último, la Deficiencia de Dihidrolipoil Deshidrogenasa se trata de una forma muy rara, con edad de comienzo variable, más frecuentemente después del $2^{\circ}$ mes de vida. La misma presenta un deterioro neurológico progresivo, similar al de la forma Intermedia, y una actividad residual de la enzima de 0-25\%. Adicionalmente, esta variante presenta un marcador bioquímico diferencial que es la presencia de una acidosis láctica severa debido a que el componente E3 forma parte también de los complejos enzimáticos de Piruvato y a-cetoglutarato Deshidrogenasa, presentándose 
entonces una deficiencia asociada de estas enzimas $(1,2)$.

Desde el punto de vista de la patogenia de la MSUD, en la misma entran en juego diversos mecanismos, siendo la Leu y el ácido $\alpha$-cetoisocaproico los metabolitos con mayor efecto tóxico (1).

En lo que respecta al tratamiento, el mismo puede dividirse en dos fases (1):

a) Tratamiento de la fase aguda: debe implementarse en forma inmediata y urgente, y tiene por objetivo inicial lograr una rápida normalización de los niveles de BCAA y especialmente de Leu a través de distintas estrategias, las cuales comprenden la administración de una dieta cuidadosa y regulada que provea un aporte de BCAA suficiente para un crecimiento y desarrollo normal pero sin exceder la capacidad degradativa de la enzima; el uso de técnicas extracorpóreas como diálisis peritoneal; la estimulación de la síntesis de proteínas y la disminución del catabolismo. De esta forma se busca evitar el daño neurológico, edema cerebral y muerte propios de esta fase.

b) Tratamiento de mantenimiento: en este caso el objetivo planteado es lograr un crecimiento y desarrollo adecuado de los individuos afectados, y evitar o detectar precozmente las crisis de descompensación, resultando necesario mantener de por vida dicho tratamiento.

Sin lugar a dudas, el éxito terapéutico y el pronóstico de la enfermedad dependen de la edad de diagnóstico, de la agresividad del tratamiento -tanto en la fase inicial como en las crisis de descompensación-, y de la adherencia del paciente a la dieta restringida. Por este motivo, y para dar cumplimiento a la primera condición, la PN juega un rol fundamental en la detección precoz de la MSUD, puesto que esta es la única forma de poder lograr establecer al diagnóstico antes de que se expresen los síntomas e implementar el tratamiento en lo posible dentro de la primera semana de vida.

Dicha pesquisa puede realizarse determinando los niveles de BCAA, para lo cual existen diferentes principios analíticos que brindan la posibilidad de determinar la Leu en forma aislada, como es el caso del método BIA; los 3 BCAA en forma simultánea, como es el caso de los métodos Enzimáticos - Fluorométricos; o el par 
Leu/Ile y Val, como es el caso de la EMT. Esta pesquisa posibilitará la detección de las formas Clásica, Intermedia y de Deficiencia de Dihidrolipoil Deshidrogenasa, pero no la de las formas Intermitentes y Sensibles a Tiamina.

Finalmente, y en lo que respecta a la confirmación del diagnóstico, el mismo requiere el análisis de aminoácidos en plasma empleando por ejemplo Cromatografía de Intercambio Iónico, HPLC o Electroforesis de alto voltaje, y de BCKA por Cromatografía gaseosa/Espectrometría de Masa (1). Eventualmente, y si se dispone de los métodos correspondientes, se puede dosar la actividad de la enzima Deshidrogenasa de los BCKA en fibroblastos cultivados o en linfoblastos del paciente, y también llevar a cabo la búsqueda de mutaciones por técnicas de Biología molecular.

\section{Pesquisa Neonatal}

- Período de trabajo evaluado: Diciembre 2001 - Diciembre 2009.

- Métodos: en la Tabla 78 se presenta el único método que se utilizó en la PN de MSUD a lo largo del período evaluado y a continuación se describe el fundamento del mismo:

Tabla 78. Método utilizado en la PN de MSUD

\begin{tabular}{cl}
\hline Período & \\
& $\begin{array}{l}\text { Método Enzimático - Fluorométrico de desarrollo } \\
\text { propio, basado en el método de Yamaguchi y cols. }\end{array}$ \\
\hline
\end{tabular}

- Método Enzimático - Fluorométrico de desarrollo propio: El desarrollo y optimización de éste método, basado en la descripción de Yamaguchi y colaboradores (4,5), fue realizado en el Laboratorio de Detección de Errores Congénitos de la FBA.

Fundamento: Los BCAA (Leu + Ile + Val) presentes en muestras de sangre entera colectadas en papel de filtro son eluidos con $\mathrm{H}_{2} \mathrm{O}$ destilada, previa fijación de la hemoglobina y de las proteínas al papel con una mezcla Metanol/Acetona/ $\mathrm{H}_{2} \mathrm{O}$. El eluido se hace reaccionar posteriormente con la enzima Leu-Deshidrogenasa que actúa específicamente sobre los BCAA para dar lugar a la formación de sus correspondientes BCKA y NADH, el cual por 
acción de la enzima Diaforasa transforma el sustrato Resazurina en el producto fluorescente Resorufina (Figura 159) que puede ser cuantificado en un Fluorómetro a $\lambda_{E X C / E M}=544 \mathrm{~nm} / 590 \mathrm{~nm}$, siendo su intensidad de fluorescencia proporcional a la concentración de BCAA presentes en la muestra.

$$
\begin{aligned}
& B C A A+N A D^{+} \stackrel{\text { Leu-Deshidrogenasa }}{\longrightarrow} B C K A+N A D H \\
& N A D H+\text { Resazurina } \stackrel{\text { Diaforasa }}{\longrightarrow} \mathrm{NAD}^{+}+\text {Resorufina }
\end{aligned}
$$

Figura 159. Fundamento del Método Enzimático - Fluorométrico de desarrollo propio para la medida de BCAA.

Para el desarrollo del mismo se llevó a cabo la preparación y adecuación de todos los reactivos necesarios, la optimización de los diferentes parámetros de ensayo, y se introdujeron algunas modificaciones a la técnica original de Yamaguchi y colaboradores $(4,5)$ a fin de lograr fundamentalmente, el máximo nivel de automatización posible y la mayor eficiencia del método:

- Utilización de microplacas de transferencia de 96 pocillos MultiScreen Membrane Plate modelo MADVN-65 de Millipore (Figura 52 - Página 153), para automatizar el proceso de transferencia de eluidos empleando el dispositivo Vacuum Manifold de Millipore.

- Preparación y adecuación de los diferentes reactivos de acuerdo a las drogas madre disponibles en nuestro medio.

- Modificación del tiempo y la temperatura de fijación de 30 minutos a $37^{\circ} \mathrm{C}$ a una noche a Temperatura Ambiente, a efectos de poder trabajar con un protocolo "overnight".

En el Anexo 8, se describe en detalle la preparación de reactivos y el protocolo de ensayo correspondiente al Método Enzimático - Fluorométrico de desarrollo propio.

- Condiciones para la recolección de muestras: a lo largo de todo el período evaluado, las condiciones de recolección de muestras recomendadas para la PN de MSUD fueron definidas contemplando un tiempo mínimo de recolección a partir de 
las 24 horas de vida, fijándose el tiempo máximo en 7 días de vida.

- Control de Calidad: El control de calidad de los métodos utilizados en la PN de MSUD se llevó a cabo mediante la implementación de un estricto Sistema de Control de Calidad Interno y mediante la participación en 3 Programas de Evaluación Externa de Calidad (EEC):

- Control de Calidad Interno: Para la implementación del Sistema de Control de Calidad Interno se utilizaron materiales de control provistos por el NSQAPCDC a través de su componente Quality Control.

- Evaluación Externa de Calidad: a continuación se listan los Programas de EEC en los cuales se participó en el período evaluado.

- Newborn Screening Quality Assurance Program. Centers for Disease Control and Prevention (NSQAP-CDC). Atlanta - EE.UU., desde Diciembre de 2001 hasta la fecha.

- Internacional Quality Assurance for Newborn Screening. Geesthacht Alemania, desde Diciembre de 2001 hasta la fecha.

- Newborn Screening Quality Assurance Program - Human Genetic Society for Australasia (NSQAP-HGSA). Auckland - New Zealand, desde Diciembre de 2001 hasta Enero de 2003 (programa discontinuado por sus propios organizadores).

- Valores de Corte: en la Tabla 79 se presentan los diferentes VC utilizados en la PN de MSUD a lo largo del período evaluado, y a continuación se presenta una discusión detallada de los mismos:

Tabla 79. VC utilizados en la PN de MSUD

\begin{tabular}{ccccc}
\hline Período & & $V C_{1}$ & & $V C_{2}$ \\
& & $6,5 \mathrm{mg} / \mathrm{dl}$ & & --- \\
$\mathrm{Dic} / 2001-\mathrm{Nov} / 2002-\mathrm{Dic} / 2009$ & & $8,5 \mathrm{mg} / \mathrm{dl}$ & & $15,0 \mathrm{mg} / \mathrm{dl}$
\end{tabular}

En relación a los $V C$ utilizados en la pesquisa de $M S U D$, el primer $V C$ que se definió fue establecido en un estudio poblacional llevado a cabo en una prueba piloto, pero en vista de la incertidumbre que se planteaba inicialmente en torno a 
los resultados esperables en $R N$ afectados, se decidió definir un VC conservador. Posteriormente, 1 año después de iniciada esta pesquisa, se procedió a modificar el $V C_{1}$ a un valor de $8,5 \mathrm{mg} / \mathrm{dl}$ e incluir un $V C_{2}$ de $15,0 \mathrm{mg} / \mathrm{dl}$ que permitía definir un criterio para aquellos casos en los cuales el RN requería su derivación inmediata al Centro de Atención Especializada a partir del resultado obtenido en la primera muestra.

- Algoritmo de trabajo: En la Figura 160 se describe el algoritmo de trabajo utilizado en la actualidad para la pesquisa de MSUD en el cual las unidades de BCAA están expresadas en $\mathrm{mg} / \mathrm{dl}$.

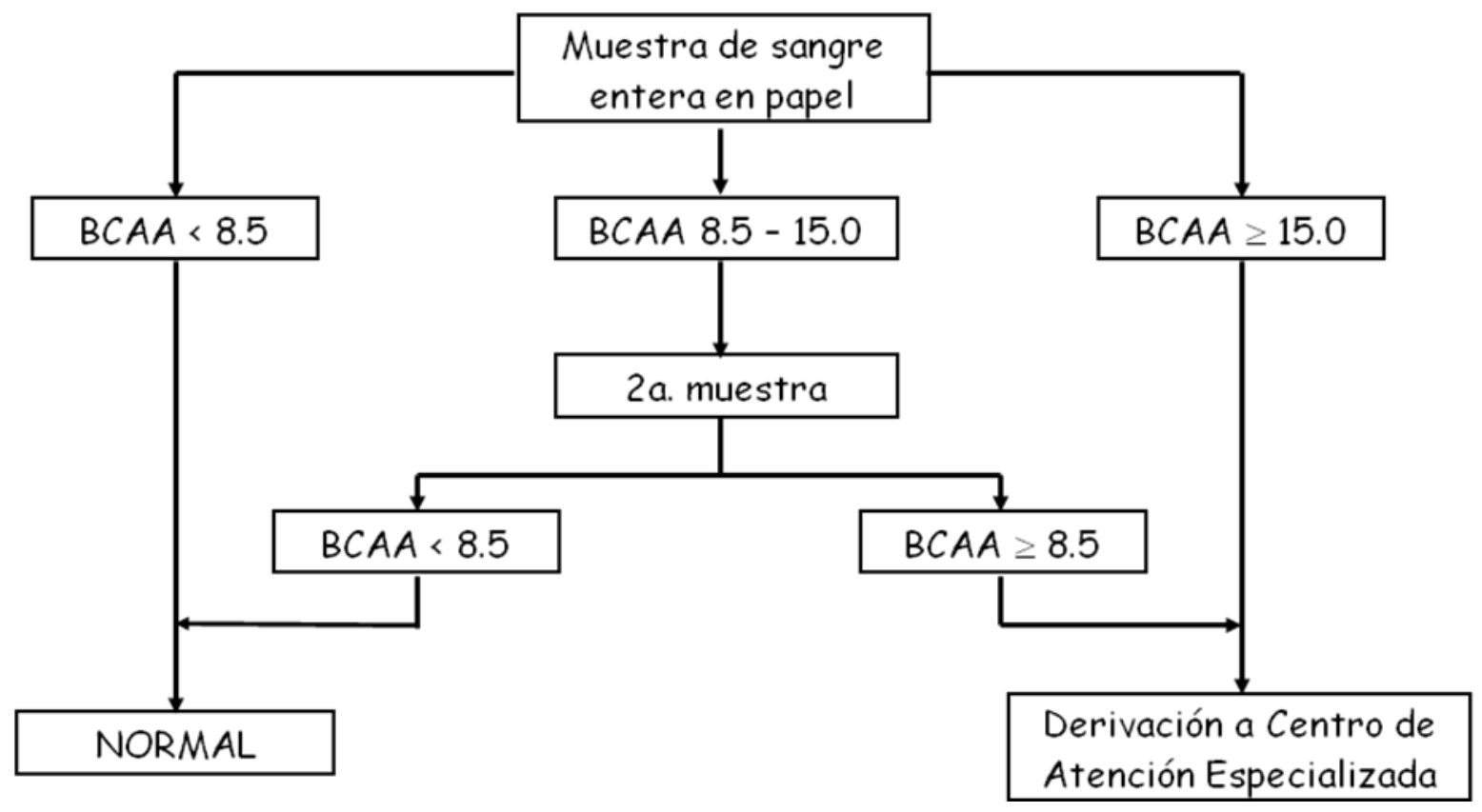

Figura 160. Algoritmo de trabajo para la PN de MSUD.

- Resultados: La PN de MSUD es la pesquisa de implementación más reciente del grupo de 7 patologías que forman parte del panel ofrecido por el Laboratorio de Detección de Errores Congénitos de la Fundación Bioquímica Argentina. La misma fue implementada en Diciembre de 2001, y a diferencia de las 6 enfermedades que fueran discutidas en los Capítulos anteriores, se trata de la única que no contó con una legislación que propiciara su crecimiento puesto que ni la Nación ni la Provincia de Buenos Aires contaban con una ley que contemplara la obligatoriedad 
de realización de su pesquisa. Por este motivo, durante el período de algo más de 8 años de trabajo incluido en este análisis, la misma fue ejecutada a demanda pero con el soporte de los Servicios de Neurología y de Laboratorio Central del Hospital de Niños "Sor María Ludovica" de La Plata para las instancias de confirmación, diagnóstico, tratamiento y seguimiento de los casos detectados. No obstante esto debe mencionarse que la Ley Provincial 13905 sancionada en Diciembre de 2008 incluyó a la MSUD dentro del grupo de enfermedades a pesquisar, siendo ésta hasta la fecha, la única legislación vigente en nuestro país que contempla la obligatoriedad de la misma.

En la Figura 161 se presenta la evolución experimentada en el número de RN pesquisados año a año para MSUD a lo largo del período evaluado, mientras que en la Figura 162 se presenta la secuencia general de pesquisa, incluyendo el número total de neonatos pesquisados, el número de RN a los cuales se les solicitó una segunda muestra, el número de RN derivados y el número de casos detectados con su correspondiente incidencia.

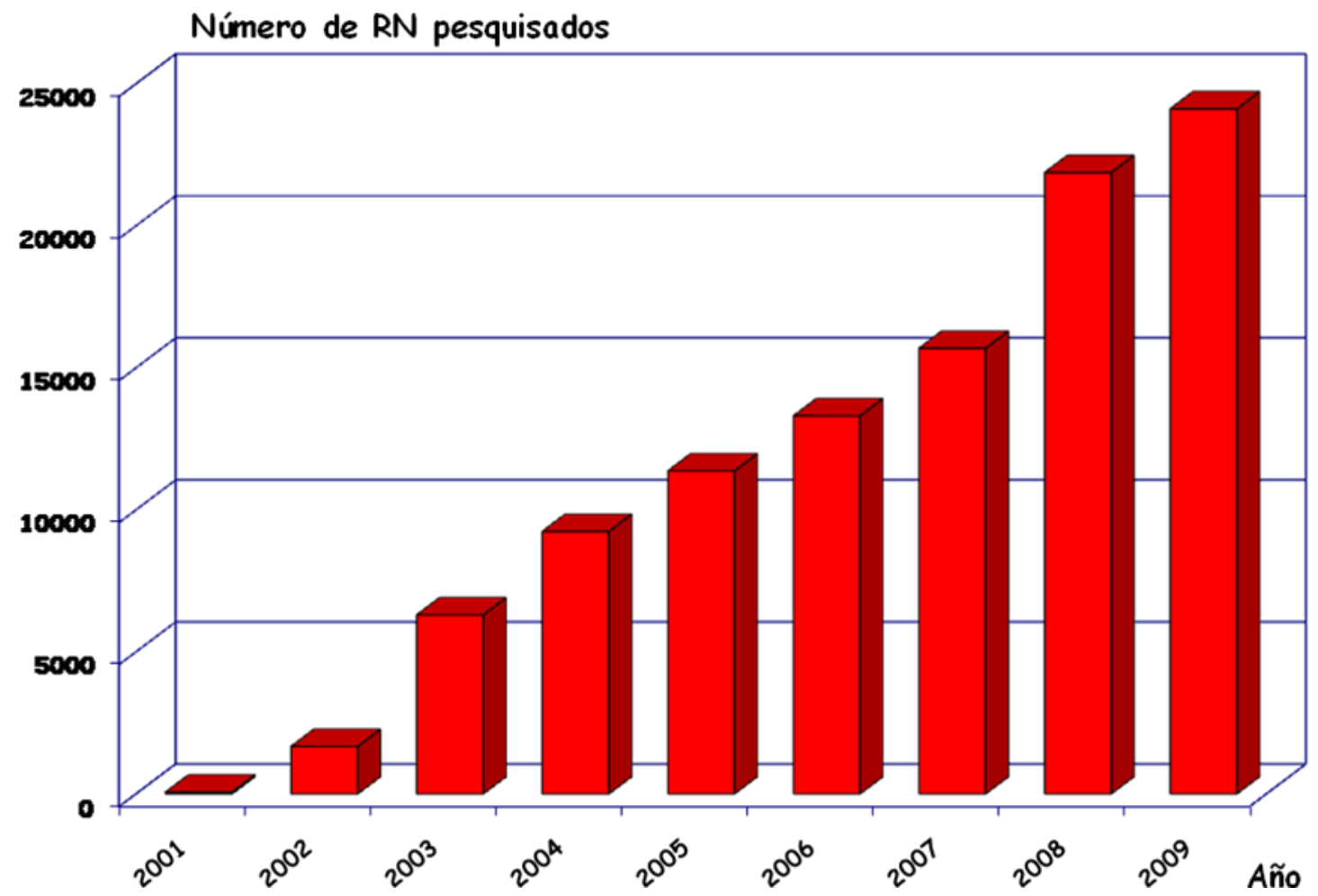

Figura 161. Número de RN pesquisados año a año para MSUD. 


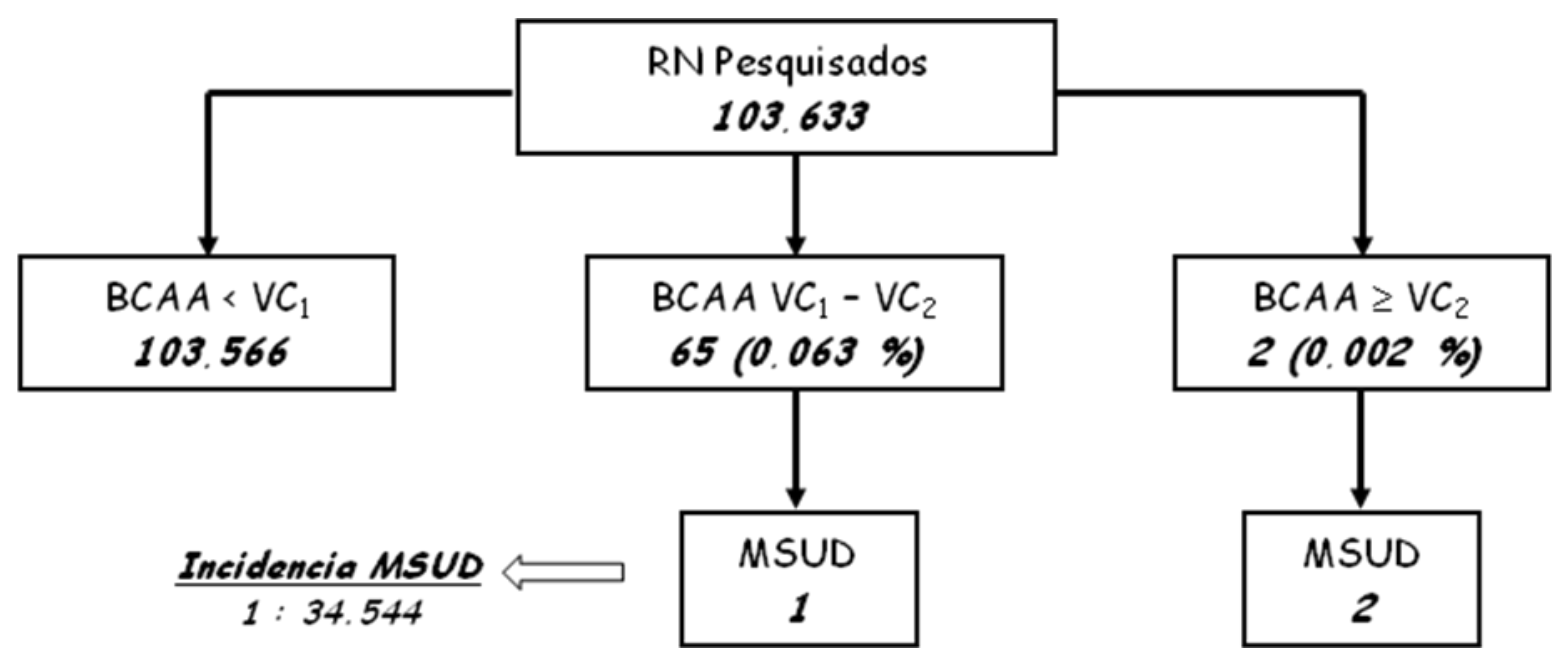

Figura 162. Resultados de la pesquisa de MSUD.

Con respecto a la información presentada en la Figura 161 referente al número anual de RN pesquisados, y a pesar de que su patrón de evolución mostró un crecimiento continuo, se deben mencionar tres situaciones que influyeron directamente en la magnitud que alcanzó el mismo:

a) el escaso crecimiento experimentado a lo largo del año 2002 (1.670 RN pesquisados) a consecuencia de que la implementación de esta pesquisa se concretó apenas 1 mes antes de que se desencadenara la crisis económica de fines de 2001, la cual como es sabido causó un severísimo colapso del sistema de salud,

b) la falta de una legislación que ejerciera un factor de presión adicional para incrementar su demanda, lo cual sumado a la falta de cobertura y reconocimiento de las pruebas por parte de la mayoría de las obras sociales, contribuyó a que el crecimiento experimentado en años posteriores fuera mucho más suave que en el resto de las enfermedades ya discutidas, y

c) el hecho de que después de 8 años de trabajo, en el año 2009 se alcanzara apenas un total de 24.120 RN pesquisados al año, es decir aproximadamente un $12 \%$ de lo pesquisado para PKU e HC, y un $40 \%$ de lo pesquisado para Deficiencia de Biotinidasa que son las patologías que marcan los extremos del rango de RN pesquisados anualmente.

En cuanto a la secuencia general de pesquisa presentada en la Figura 162, se 
debe destacar la baja tasa de recitación por resultados anormales, la cual llega a ser tan sólo del 0,065 \% para todo el período, es decir que resulta necesario localizar a apenas algo más de 6 cada 10.000 RN ya sea tanto para colectar una segunda muestra como para derivar al niño al Centro de Atención Especializada.

Por otra parte, y en relación a los 3 casos detectados se debe mencionar que en uno de ellos el resultado de BCAA obtenido en la primera muestra determinó la necesidad de colectar una segunda muestra llegándose al diagnóstico a los 12 días de vida, mientras que en otro la realización de la prueba de pesquisa para MSUD fue indicada a expensas del cuadro clínico que presentaba el RN, determinando de esta forma que el diagnóstico se confirmara recién a los 35 días de vida, no habiendo sido posible evitar las complicaciones neurológicas y posterior muerte del niño. En este último caso es importante mencionar que complementariamente se rastreó la muestra inicial de pesquisa colectada después de las 48 horas de vida en la cual no se había solicitado la realización de la prueba para detectar la MSUD, quedando demostrando a través de sus resultados que de haberse solicitado la realización de la misma en tiempo y forma, se hubiera podido evitar el desenlace fatal de la enfermedad.

En lo que respecta a la incidencia de la MSUD, se debe mencionar que sin ninguna duda el valor resultante de 1 : 34.544 nacidos vivos es un dato no representativo de la realidad por dos motivos principales: el primero es que la cantidad de RN pesquisados aún no ha alcanzado un valor significativo desde el punto de vista estadístico de manera tal de poder asegurar que dicha incidencia se mantendrá estable en el tiempo aún a pesar de que transcurran períodos de tiempo prolongados sin que se detecte ningún caso o aunque se detecten varios casos en períodos de tiempos cortos; y en segundo lugar porque dicho dato está sesgado por el caso que se confirmó y cuya pesquisa se indicó en base al cuadro clínico del RN.

Adicionalmente, en la Tabla 80 se presenta la distribución de casos detectatados según la provincia de procedencia, en la cual se puede visualizar que solamente 1 de los 3 casos detectados corresponde a la Provincia de Buenos Aires. 
Tabla 80. Distribución de casos detectados por Provincia

\begin{tabular}{lcc}
\hline \multicolumn{1}{c}{ Provincia } & MSUD \\
\cline { 1 - 1 } Buenos Aires & & 1 \\
Santa Fe & & 1 \\
Chubut & & 1 \\
\hline Total & & 3
\end{tabular}

Finalmente, en la Tabla 81 se presentan diferentes parámetros estadísticos que caracterizan el desempeño del sistema de detección para MSUD.

Tabla 81. Parámetros estadísticos de la PN de MSUD

Tasas de recitación

- Por resultados anormales

- Total período evaluado $0,065 \%$

- Año 2002 $1,86 \%$

- Período 2006-2009 $0,020 \%$

- Por recolección inadecuada de muestras $0,49 \%$

- Por muestras < 24 horas $0,12 \%$

\section{Recuperación de segundas muestras solicitadas}

- Por recolección inadecuada de muestras $79,3 \%$

- Por muestras < 24 horas $39,2 \%$

Tal como se puede ver en la Tabla anterior, a pesar de que la tasa de recitación por resultados anormales alcanzó valores óptimos del 0,020 \% en los últimos 4 años de trabajo, en el año 2002 presentó un valor absolutamente inaceptable de $1,86 \%$ a consecuencia de que en la instancia inicial de la pesquisa se había definido un VC altamente conservador tal como ya fue discutido anteriormente.

En cuanto a la tasa de recitación por recolección inadecuada de muestras se pudo determinar, tal como era esperable de acuerdo al criterio de procesamiento establecido en el Laboratorio para aquellas muestras insuficientes que no permiten la realización de todas las pruebas solicitadas y al hecho de que la MSUD es la patología que presenta la incidencia más baja del panel de enfermedades pesquisadas, que dicha tasa de recitación resultó ser la más alta de este grupo de 
enfermedades $(0,49 \%)$, aunque paradójicamente con un excelente porcentaje de recuperación de segundas muestras para todo el período evaluado $(79,3 \%)$.

Por otra parte, en el caso de las muestras colectadas con anterioridad a las 24 horas de vida se observó una tasa de recitación del 0,12 \% con un porcentaje de recuperación de segundas muestras por este motivo de tan sólo el 39,2%, valor muy similar al observado en el caso de PKU para el total del período evaluado.

En definitiva, al tomar en consideración las tasas de recitación de MSUD por muestras con recolección inadecuada, por muestras colectadas antes de las 24 horas de vida y por resultados anormales, y a pesar de que el número de niños que requieren la recolección de una segunda muestra o su derivación al Centro de Atención Especializada por la última de estas 3 causas es extremadamente bajo, resulta que algo más de 6 de cada 100 niños, requiere ser localizado para llevar a cabo la recolección de una segunda muestra.

\section{BIBLIOGRAFIA}

29. Dalmau Serra J, Fernández Sanchez A, Sanchez-Valverde F, Vitoria Milana I. "Enfermedad de Orina de Jarabe de Arce", en "Diagnóstico y Tratamiento de las Enfermedades Metabólicas Hereditarias". Sanjurjo P, Baldellou A Eds. Editorial Ergon - Madrid, 3ª Edición. Capítulo 35, 487-98, 2010.

30. American Academy of Pediatrics, Kaye $C$ and the Committee on Genetics. "Newborn Screening Fact Sheets". Pediatr, 118, 934-63, 2006.

31. Levy H and Albers S. "Genetic Screening of Newborns". Annu Rev Hum Genet $01,139-77,2000$.

32. Yamaguchi A, Mizushima $Y$, Fukushi M, Shimizu $Y$, Kikuchi $Y$ and Takasugi $N$. "Microassay System for Newborn Screening for Phenylketonuria, Maple Syrup Urine Disease, Homocystinuria, Histidinemia and Galactosemia with Use of a Fluorometric Microplate Reader". Screening, 1, 49-62, 1992.

33. Yamaguchi A. "Fluorometric Approach to Screening and Diagnosis Tests for Inborn Errors of Metabolism". Comunicación personal. 1998. 


\section{ANEXO 8: METODO ENZIMATICO - FLUOROMETRICO PARA LA MEDIDA DE BCAA EN DBS, DE DESARROLLO PROPIO.}

\section{- PREPARACION DE REACTIVOS:}

o Solución Fijadora: mezclar Metanol, Acetona y $\mathrm{H}_{2} \mathrm{O}$ destilada en proporciones 70:70:20. Conservar en frasco color caramelo a temperatura ambiente.

o Solución madre de Diaforasa $(500 \mathrm{U} / \mathrm{ml})$ : disolver el contenido de un Frasco de Diaforasa (Worthington, Cat. 4330) en un volumen de buffer Fosfato 0,01 M de $\mathrm{pH} 7,2$ de manera tal de obtener una actividad de $500 \mathrm{U} / \mathrm{ml}$. Fraccionar en frascos de vidrio a razón de $250 \mathrm{U} /$ frasco y almacenar en freezer a $-20^{\circ} \mathrm{C}$.

o Buffer Fosfato 0,01 M - pH 7,2:

- $\mathrm{KPO}_{4} \mathrm{H}_{2}$ : pesar $68 \mathrm{mg}$ de $\mathrm{KPO}_{4} \mathrm{H}_{2}($ Merck, Art. 4873) y disolver en $50 \mathrm{ml}$ de $\mathrm{H}_{2} \mathrm{O}$ destilada.

- $K_{2} P_{4} O_{4}$ : pesar $87 \mathrm{mg}$ de $\mathrm{K}_{2} \mathrm{PO}_{4} \mathrm{H}$ (Merck, Art. 5104) y disolver en $50 \mathrm{ml}$ de $\mathrm{H}_{2} \mathrm{O}$ destilada.

Para la obtención del Buffer Fosfato 0,01 M de pH 7,2, agregar poco a poco el $\mathrm{KPO}_{4} \mathrm{H}_{2}$ sobre los $50 \mathrm{ml}$ de $\mathrm{K}_{2} \mathrm{PO}_{4} \mathrm{H}$ hasta alcanzar el $\mathrm{pH}$ deseado. Conservar en heladera a $4^{\circ} \mathrm{C}$.

o Solución de trabajo de Diaforasa $(3,75 \mathrm{U} / \mathrm{m} /)$ : descongelar un frasco conteniendo $250 \mathrm{U}$ de Solución madre de Diaforasa, y llevar a volumen final de $66,7 \mathrm{ml}$ con $\mathrm{H}_{2} \mathrm{O}$ destilada. Fraccionar en crioviales con tapa a rosca a razón de $2,5 \mathrm{ml}$ por tubo y almacenar en freezer $\mathrm{a}-20^{\circ} \mathrm{C}$.

o Leu-Deshidrogenasa $(1,54 \mathrm{U} / \mathrm{m} /)$ : descongelar un vial conteniendo LeuDeshidrogenasa (Codexis, Cat. 16.11) de actividad específica $85,7 \mathrm{U} / \mathrm{ml}$, medir $1,2 \mathrm{ml}$ de la enzima y llevar a volumen final de $66,7 \mathrm{ml}$ con $\mathrm{H}_{2} \mathrm{O}$ destilada. Fraccionar en crioviales con tapa a rosca a razón de $2,5 \mathrm{ml}$ por tubo y almacenar en freezer $\mathrm{a}-20^{\circ} \mathrm{C}$.

o $\beta$-NAD (15,2 mM): pesar 670,4 mg de $\beta$-NAD (Codexis, Cat. 16.50) y disolver en $66,7 \mathrm{ml}$ de $\mathrm{H}_{2} \mathrm{O}$ destilada. Fraccionar en crioviales con tapa a rosca a razón de $2,5 \mathrm{ml}$ por tubo y almacenar en freezer $\mathrm{a}-20^{\circ} \mathrm{C}$. 
o Solución madre de Resazurina (5 mM): pesar 29,6 mg de Resazurina (Sigma, $\mathrm{R}-2127,85 \%$ pureza) y disolver en $20 \mathrm{ml}$ de $\mathrm{H}_{2} \mathrm{O}$ destilada. Conservar en heladera a $4^{\circ} \mathrm{C}$.

o Glicina/KCl-Resazurina $(0,106 \mathrm{mM})$ : inmediatamente antes de usar, mezclar $10 \mathrm{ml}$ de Buffer Glicina/ $\mathrm{KCl}$ 0,2 M de pH 10,0 y $500 \mu$ de Resazurina 5 mM.

o Buffer Glicina/KCl 0,2 M - pH 10,0:

- Glicina + KCL: pesar 3,75 g de Glicina (Sigma, G-7032), 3,73 g de KCl (Anedra, Art. 7032) y disolver ambas drogas en $250 \mathrm{ml}$ de $\mathrm{H}_{2} \mathrm{O}$ destilada.

- KOH (2 N): pesar 22,4 g de KOH (Anedra, Art. 7051) y disolver en $200 \mathrm{ml}$ de $\mathrm{H}_{2} \mathrm{O}$ destilada.

Para la obtención del Buffer Glicina/ $\mathrm{KCl} 0,2 \mathrm{M}$ de $\mathrm{pH} 10,0$, agregar poco a poco el $\mathrm{KOH}$ sobre los $250 \mathrm{ml}$ de (Glicina $+\mathrm{KCl}$ ) hasta alcanzar el pH deseado. Conservar en heladera a $4{ }^{\circ} \mathrm{C}$.

- Mezcla de Reacción (Leu-Deshidrogenasa, Diaforasa, NAD', Glicina/KClResazurina): Preparar la mezcla enzimática en un volumen acorde a la cantidad de muestras a procesar en las proporciones $245: 245: 245: 200$ de LeuDeshidrogenasa $(1,54 \mathrm{U} / \mathrm{ml})$, Diaforasa $(3,75 \mathrm{U} / \mathrm{ml}), \mathrm{NAD}^{+}(15,2 \mathrm{mM})$ y Glicina/ $\mathrm{KCl}$-Resazurina $(0,106 \mathrm{mM})$.

\section{- protocolo de ensayo:}

39. Punchear discos de 1/8" $(3,2 \mathrm{~mm})$ de diámetro correspondientes a calibradores, controles y muestras de RN en microplacas de transferencia MADVN 65 de Millipore de 96 pocillos, a razón de un disco por pocillo.

40. Dispensar $20 \mu$ de Solución Fijadora, Metanol/Acetona/Agua en cada pocillo.

41. Dejar evaporar la Solución Fijadora durante una noche a temperatura ambiente asegurándose el acceso de una apropiada corriente de aire para aumentar la eficiencia del proceso de evaporación.

NOTA: Para protocolos cortos, es posible evaporar la Solución Fijadora en estufa a $37^{\circ} \mathrm{C}$ durante 1 hora.

42. Dispensar $70 \mu \mathrm{l}$ de $\mathrm{H}_{2} \mathrm{O}$ destilada en cada pocillo. 
43. Agitar durante 15 minutos en shaker DELFIA Plate Shake (Figura 50 - Página 152) para asegurar una completa elución de los BCAA.

44. Transferir cuantitativamente el contenido de cada pocillo a cada uno de los pocillos correspondientes de una placa de fluorometría blanca (Whiteplate, Labsystems Oy), utilizando un sistema Vacuum Manifold (Millipore).

45. Preparar la Mezcla de Reacción y dispensar $50 \mu$ en cada pocillo.

46. Incubar durante 60 minutos a $37^{\circ} \mathrm{C}$.

47. Leer en Fluorómetro a $\lambda_{\text {EXC/EM }}=544 / 590 \mathrm{~nm}$.

48. Graficar la intensidad de fluorescencia de cada uno de los calibradores en función de la concentración de BCAA de cada uno de ellos, construir la curva de calibración e interpolar de la misma los valores de BCAA de controles y de muestras de RN. 
CONCLUSIONES 



\section{- CONCLUSIONES}

La Pesquisa Neonatal (PN) es un sistema preventivo de la Salud Pública a través del cual resulta posible lograr que individuos potencialmente discapacitados o con riesgo de muerte puedan crecer y completar su desarrollo conservando sus capacidades físicas, psíquicas e intelectuales intactas, eliminando el costo social que aquello implica para su familia, y permitiendo además su inserción productiva en la sociedad.

Dadas sus características de aplicación masiva y universal, la PN desempeña un rol social fundamental puesto que contribuye a fortalecer el derecho a la salud de todos los individuos en forma igualitaria, rompiendo las barreras sociales, económicas y culturales que atentan contra la equidad, y ofreciendo, además, la mejor oportunidad para una intervención efectiva.

Cronológicamente, la PN comenzó a dar sus primeros pasos a inicios de la década del '60, pero exclusivamente en países desarrollados. De allí en más la misma experimentó una evolución permanente a lo largo de toda su historia, mostrando también hoy día una tendencia bien definida a continuar evolucionando hacia nuevos horizontes.

Esta evolución plantea un enorme desafío para los Programas de PN, exigiendo que los mismos definan claramente sus alcances en concordancia con las políticas de salud vigentes, el presupuesto y la infraestructura de trabajo disponible.

No obstante estos antecedentes, en países como la Argentina la implementación de la PN se produjo mucho más tardíamente, creando así una necesidad de avanzar a ritmos de crecimiento mucho más acelerados a fin de reducir la brecha existente entre los avances experimentados y la realidad vigente. A pesar de esto, los hechos demuestran que debieron transcurrir muchos años antes de que la PN lograra su integración dentro del sistema de salud pública y su implementación sistemática y continua bajo una estructura de programa.

Las acciones puestas en marcha en la Cátedra de Bioquímica Patológica de la Facultad de Ciencias Exactas de la UNLP, a partir del desarrollo del Método de Inhibición Bacteriana para la medida de Fenilalanina (Phe) para su posterior aplicación 
en la PN de Fenilcetonuria (PKU), sentaron las bases necesarias para concretar el primer paso de este proceso, consistente en la implementación de un Programa Piloto.

En etapas subsiguientes, y dadas las características alentadoras de los resultados obtenidos en esa primera etapa, se montó un primer bosquejo de Laboratorio de PN y se llevó a cabo la puesta en marcha de un Programa de pesquisa de PKU e Hipotiroidismo Congénito $(H C)$ a demanda, hechos que resultaron dos elementos clave y fundamentales para la posterior implementación del Programa de Diagnóstico y Tratamiento de Enfermedades Congénitas - Prodytec ejecutado en forma conjunta entre el Ministerio de Salud de la Provincia de Buenos Aires y la Fundación Bioquímica Argentina, el cual a su vez se constituyó en el primer programa organizado y regionalizado que se implementó en el país.

El crecimiento experimentado en el número de neonatos pesquisados a través del Prodytec, sumado a la incorporación progresiva de nuevas patologías al panel de enfermedades a pesquisar planteó la necesidad de adecuar las características del Laboratorio de Detección de Errores Congénitos de acuerdo al incremento experimentado en la magnitud del volumen diario de trabajo y a la complejización que también progresivamente fueron experimentando los diferentes procesos realizados en el mismo.

De este modo, la organización del Laboratorio se planificó sobre la base de un funcionamiento centralizado y regionalizado en el cual estaban claramente definidos cada uno de los procesos pre-analíticos, analíticos y post-analíticos que debían ejecutarse en el mismo, pero siendo conceptualmente concebido en el marco de una estructura dinámica y versátil capaz de permitir la incorporación de cambios y su adaptación progresiva y permanente según las necesidades que se fueran presentando. Estas características posibilitaron que la capacidad de trabajo del Laboratorio permita procesar actualmente más de 200.000 muestras al año, sin que esto implique un entorpecimiento de los procesos, un cuello de botella en lo que respecta a la dinámica de emisión de resultados, ni tampoco una necesidad de incrementar desmedidamente el plantel de recursos humanos.

Sin lugar a dudas, uno de los elementos clave para poder alcanzar dicha capaci- 
dad de trabajo fue el proceso de Automatización del Laboratorio. Dicho proceso fue abordado principalmente desde el punto de vista de los procesos analíticos, pero sin descuidar los procesos pre- y post-analíticos, habiéndose sustentando el mismo en la creación de un Sistema Informatizado de Gestión de Muestras según las necesidades específicas del Laboratorio; en el uso de un Software creado sobre la base de una idea propia que permitió la automatización del proceso de puncheo de muestras; en la utilización de un Software Multi-Instrumento para el procesamiento de muestras y posterior análisis y validación de los resultados bajo un formato único; en la incorporación de distintos instrumentos modulares automatizados y autoanalizadores para el procesamiento de las muestras de sangre y resolución de las diferentes corridas; y en la unificación del formato de trabajo para cada ensayo en microplacas de 96 pocillos.

Consecuentemente, a través del proceso de automatización antes mencionado fue posible incrementar la eficiencia y el rendimiento del Laboratorio a partir de una simplificación de los procedimientos operativos y reducción de los tiempos de operación, disminución de los errores humanos, incremento de la capacidad operativa, optimización de recursos humanos y procedimientos analíticos, incremento en el rendimiento de reactivos y la consecuente reducción de sus costos.

Los tiempos y condiciones de recolección de muestras, sumados a la calidad de impregnación de las mismas en el papel de filtro fueron de los aspectos pre-analíticos abordados con mayor énfasis y profundidad. Este tratamiento especial se realizó con la finalidad, por un lado, de minimizar la variabilidad biológica y los diferentes factores que podían dar lugar a falsos resultados y fundamentalmente a resultados falsos negativos, mientras que, por el otro, para poder asegurar la obtención de resultados confiables, puesto que como es sabido la calidad de un resultado nunca puede ser superior a la calidad de la muestra a partir de la cual se obtiene el mismo.

Sin embargo, el trabajo de Laboratorio no quedó limitado exclusivamente a su organización y automatización, sino que además se incursionó en el desarrollo de distintos métodos de medida. Este hecho no solamente permitió reducir los costos de los mismos sino también equiparar, y en muchos casos mejorar, la calidad analítica y 
diagnóstica de los resultados con respecto a los métodos disponibles comercialmente, y en algún caso particular como lo es el de la Enfermedad de Orina de Jarabe de Arce (MSUD), suplir la no disponibilidad de reactivos comerciales.

Adicionalmente, se debe destacar que cada uno de estos desarrollos requirió una adecuación y adaptación según los elementos, instrumental y drogas madre disponibles en nuestro medio, hechos que le confieren una mayor relevancia a los desarrollos realizados. A continuación se listan los diferentes métodos de medida desarrollados y optimizados en el Laboratorio de la Fundación Bioquímica Argentina:

- Método de Inhibición Bacteriana para la medida de Phe, para placas de Petri estándar y para placas de $24 \mathrm{~cm} \times 24 \mathrm{~cm}$.

- Método Fluorométrico para la medida de Phe.

- Método Enzimático - Fluorométrico para la medida de Galactosa.

- Método Colorimétrico - Cuantitativo para la medida de Biotinidasa empleando calibradores líquidos.

- Método Colorimétrico - Cuantitativo para la medida de Biotinidasa empleando calibradores preparados en sangre entera e impregnados en papel de filtro (DBS).

- Método Enzimático - Fluorométrico para la medida de Aminoácidos de Cadena Ramificada (BCAA).

Cada uno de estos métodos, al igual que aquellos adquiridos comercialmente, fueron sometidos en todos los casos a exhaustivos procedimientos de Validación, los cuales fueron abordados tanto desde el punto de vista analítico, como diagnóstico, operativo, de diseño y de costos, permitiendo finalmente decidir la aceptación de los mismos y su posterior implementación en la rutina diaria.

Complementariamente, los resultados de cada analito fueron analizados estadísticamente en estudios de distribución poblacional a fin de definir Valores de Corte propios, específicos y representativos de la población estudiada, de manera tal de permitir realizar una interpretación diagnóstica confiable de los resultados. De esta forma fue posible lograr tasas de resultados falsos negativos de cero en todas aquellas patologías en las cuales la variabilidad biológica no desempeña un papel crítico, y 
una tasa de resultados falsos positivos dentro de márgenes óptimos o aceptables.

Por otra parte, se ideó un protocolo original para la preparación de Calibradores de Biotinidasa en DBS, hecho que resultó de fundamental importancia para la optimización del método de medida de esta enzima, dado que no existen calibradores de Biotinidasa disponibles a partir de otra fuente, ya sea comercial o de otro origen.

Los aspectos de Calidad también fueron temas centrales de este trabajo. En este contexto se trabajó específicamente en la implementación de un estricto sistema de control de calidad interno cumplimentando todos y cada uno de los requerimientos exigidos para un Laboratorio de PN, y también en asegurar la participación en al menos 2 Programas de Evaluación Externa de Calidad para cada uno de los analitos evaluados, aspectos que en ambos casos resultan imprescindibles para asegurar el correcto desempeño de los métodos en uso a través del monitoreo continuo de la precisión y la exactitud de los mismos.

Adicionalmente se trabajó también en el diseño de un Sistema Integral de Control de Calidad a través del cual resulta posible monitorear la performance de desempeño del Programa de PN en su conjunto y de cada uno de sus efectores en forma individual, puesto que como es sabido la única forma de lograr una mejora continua en la performance de los efectores de un Programa es a través de la evaluación y monitoreo continuo y permanente del desempeño de cada uno de ellos, y de un proceso educativo de aplicación sistemática.

No obstante esto, los temas de Calidad no quedaron circunscriptos y limitados específicamente a las actividades del propio Laboratorio de Detección de Errores Congénitos, sino que además se llevó a cabo la implementación de un Programa de Evaluación Externa de Calidad dirigido a Laboratorios de toda Latinoamérica, el cual es único por su alcance global en la región y porque además nuclea a más de 180 participantes de 14 países diferentes.

Con respecto a la pesquisa específica de cada una de las patologías que forman parte del panel de enfermedades pesquisadas en el Laboratorio de Detección de Errores Congénitos, la misma fue implementándose en forma progresiva comenzando con PKU en 1991, y siguiendo por HC en 1992, Fibrosis Quística (FQ) y Galactosemia 
en 1995, Hiperplasia Suprarrenal Congénita (HSC) y Deficiencia de Biotinidasa en 1997 y MSUD en 2001. Tal como ya fue discutido en cada uno de los Capítulos correspondientes, cada una de estas patologías presentó sus propias características en cuanto a su modalidad de implementación, alcance y complejidad, resumiéndose en la Tabla 82 los resultados correspondientes al número de neonatos pesquisados, al número de casos confirmados y a las incidencias resultantes para cada patología.

Tabla 82. Neonatos pesquisados, casos detectados $e$ incidencias

\begin{tabular}{|c|c|c|c|c|}
\hline \multirow{3}{*}{$\begin{array}{l}\text { Patología } \\
\text { PKU }\end{array}$} & \multirow{3}{*}{$\begin{array}{c}\begin{array}{c}\text { Neonatos } \\
\text { pesquisados }\end{array} \\
2.632 .968\end{array}$} & \multicolumn{2}{|c|}{ Casos detectados } & \multirow{2}{*}{$\begin{array}{l}\text { Incidencia } \\
1: 26.867\end{array}$} \\
\hline & & PKU & 98 & \\
\hline & & HPA & 117 & $1: 22.504$ \\
\hline$\overline{H C}$ & 2.608 .209 & $\overline{H C}$ & 1146 & $1: 2.276$ \\
\hline$F Q$ & 838.615 & $\overline{F Q}$ & 132 & $1: 6.353$ \\
\hline \multirow[t]{4}{*}{ Galactosemia } & 533.626 & Galactosemia Clásica & 14 & $1: 38.116$ \\
\hline & & Def. Parcial GAL-T & 41 & $1: 13.015$ \\
\hline & & Def. de GAL-K & 3 & $1: 177.875$ \\
\hline & & Def. de GAL-E & 2 & $1: 266.813$ \\
\hline \multirow[t]{3}{*}{$\mathrm{HSC}$} & 411.766 & Perdedora de sal & 50 & $1: 8.236$ \\
\hline & & Virilizante simple & 6 & $1: 68.628$ \\
\hline & & No Clásica & 7 & $1: 58.825$ \\
\hline \multirow[t]{2}{*}{$\overline{\text { Def. de Biotinidasa }}$} & 365.240 & Absoluta & 2 & $1: 182.620$ \\
\hline & & Parcial & 7 & $1: 26.089$ \\
\hline MSUD & 103.633 & MSUD & 3 & $1: 34.544$ \\
\hline Total & & & 635 & $1: 984$ \\
\hline
\end{tabular}

Finalmente, para concluir este trabajo, y para resaltar cuantitativamente la importancia de la PN se debe destacar que el análisis combinado de las incidencias de todas las patologías pesquisadas y sus variantes, permite determinar que aproximadamente 1 de cada 1.000 recién nacidos vivos $(1: 984)$ ha de ser detectado con alguna de dichas enfermedades, permitiendo de este modo implementar las acciones terapéuticas necesarias que han de eliminar o disminuir la morbi-mortalidad y/o discapacidad asociadas a cada una de ellas. 

